Memorias

\title{
III CONGRESO INTERNACIONAL DE REGULACIÓN Y CONSUMO
}

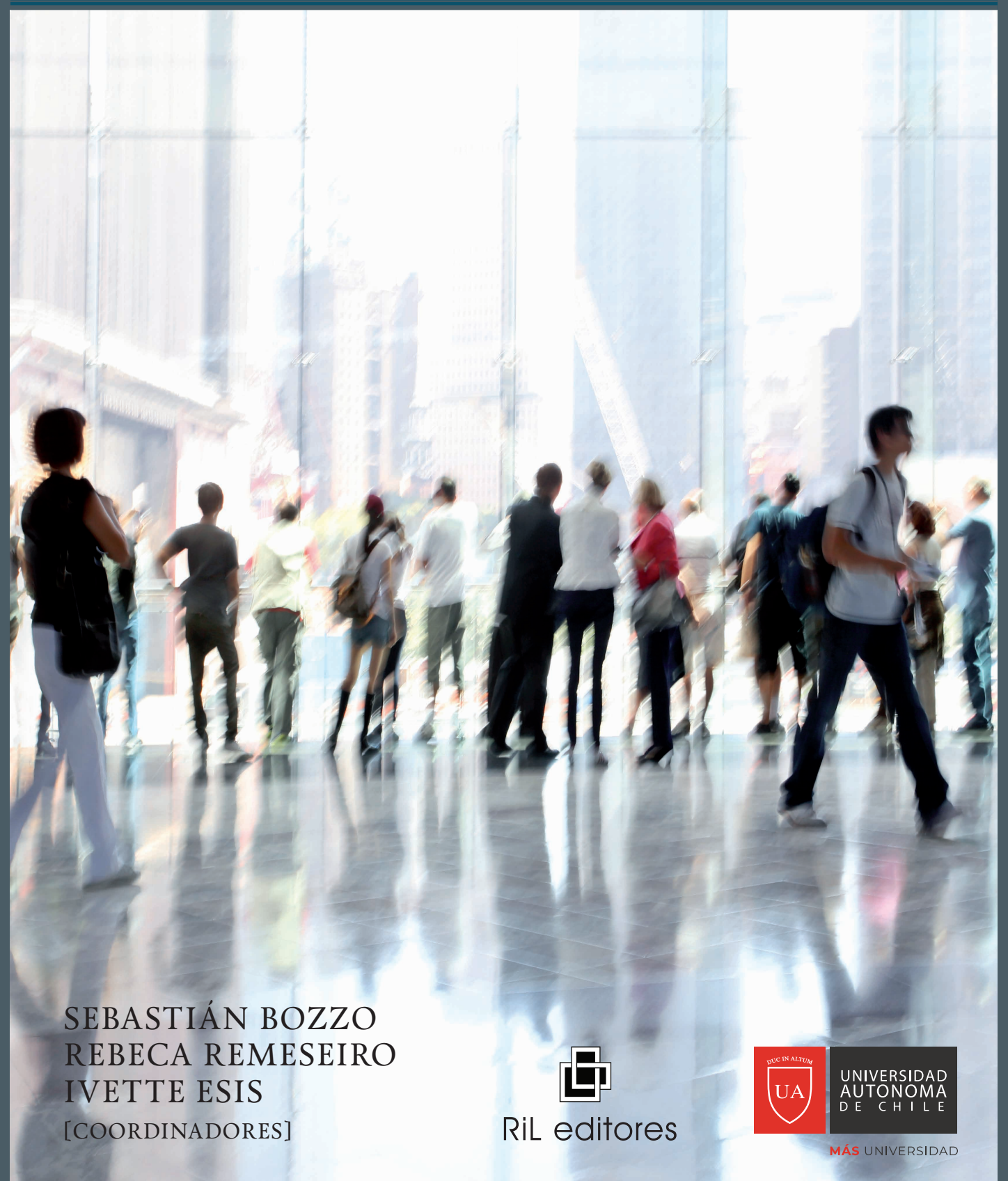




Memorias III Congreso InTERnacional de Regulación y Consumo

Diciembre, 2018

Centro de Regulación y consumo

Universidad Autónoma de Chile 

Sebastián Bozzo

Rebeca Remeseiro

IVETTE EsIS

(COORDINADORES)

\section{MeMORIAS \\ III Congreso \\ INTERNACIONAL \\ De Regulación y Consumo}


38I.34 Bozzo, Sebastián

B Memorias III Congreso Internacional de Regulación y Consumo / Sebastián Bozzo, Rebeca Remeseiro, Ivette Esis, coordinadores. - - Santiago : Universidad Autónoma de Chile

- RIL editores, 2020.

446 p. $; 23 \mathrm{~cm}$.

ISBN: 978-956-OI-0722-O

1 PROTECCIÓN DEL CONSUMIDOR. 2 CONSUMIDORES

Memorias II Congreso Internacional

de Regulación y Consumo

Primera edición: marzo de 2020

(C) Sebastián Bozzo, Rebeca Remeseiro, Ivette Esis, 2020

Registro de Propiedad Intelectual $\mathrm{N}^{\circ} 3$ I 0.995

(C) RIL® editores, 2020

Sede Santiago:

Los Leones 2258

CP 75 I 1055 Providencia

Santiago de Chile

(d) (56) 222238100

ril@rileditores.com・www.rileditores.com

Sede Valparaíso:

Cochrane 639, of. 92

CP 236I80I Valparaíso

(j) (56) 322746203

valparaiso@rileditores.com

Sede España:

europa@rileditores.com・Barcelona

(C) Centro de Comunicación de las Ciencias, 2020

Universidad Autónoma de Chile

https://ciencias.uautonoma.cl I ciencias@uautonoma.cl

ISBN Universidad Autónoma de Chile 978-956-8454-6I-6

Composición, diseño de portada e impresión: RIL® editores

Impreso en Chile $\bullet$ Printed in Chile

ISBN 978-956-OI-0722-O

Derechos reservados. 


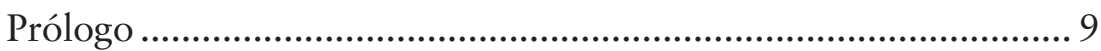

\section{Parte. Derecho del consumo}

Los límites constitucionales en la atribución de competencias al Servicio Nacional del Consumidor. Análisis de la sentencia del Tribunal Constitucional bajo el rol n 4012-17 Alexander Espinoza y Jhenny Rivas Alberti.

Una aproximación a la arbitrariedad como cláusula abusiva: análisis a la cláusula del no-show Diego Aguilar Vildoso 45

Acerca de la responsabilidad por productos sanitarios defectuosos: reflexiones sobre la prescripción extintiva Erika Isler Soto.

No todo lo que brilla es oro: análisis del impacto del nuevo etiquetado nutricional de alimentos (Ley 20.606) Jaime Lorenzini B.

Sharing economy, prosumer y derecho del consumidor: su aplicación en la Ley sobre protección de los derechos de los consumidores Francisca Barrientos Camus 107

El Ombudsman Sectorial: en el consumo en general y en los servicios básicos en particular Juan Pablo Díaz Fuenzalida

Nuevo modelo de distribución de la carga de la prueba en el procedimiento de policía local del consumo Andrés Eduardo Celedón Baeza . 
Cosa juzgada e insuficiencia de pruebas en los procesos colectivos de consumidores y usuarios

Maite Aguirrezabal Grünstein

La protección del consumidor de crédito inmobiliario en el contexto europeo Adela Serra Rodríguez

Algunas consideraciones desde el Derecho civil sobre el Derecho del consumo y las acciones colectivas indemnizatorias Mario E. Clemente Meoro.

Avanços em matéria de Direito do Consumidor no Brasil:

Panorama a partir dos 30 anos da Constituição Federal de 1988 e do Código de Defesa do Consumidor Gabriel Oliveira de Aguiar y Thiago Gonçalves Paluma

\section{Parte. Derecho Regulatorio}

Entre la neutralidad técnica y el paternalismo libertario: reflexiones sobre la regulación económica desde la teoría evolutiva de las instituciones

Luis Alfonso Herrera Orellana.

Las concentraciones mediáticas en Chile y el principio del pluralismo informativo Alexander Espinoza y Jhenny Rivas Alberti....

Regulación ambiental y financiera de la minería en los suelos y subsuelos marinos, la Zona

Patricio Masbernat y Gloria Ramos-Fuentes

Consulta indígena y centrales de generación hidroeléctrica de menos de 3MW: desregulación riesgosa, a la luz del derecho fundamental a la identidad cultural de los pueblos indígenas Juan Jorge Faundes Peñafiel.

La regulación de la educación en el Estado garante Pablo Nuevo López

Ventajas y desventajas de la multa como sanción penal para personas jurídicas Patricia Faraldo Cabana. 


\section{Prólogo}

El régimen jurídico del consumo ha adquirido una importante relevancia en pro de la protección de los intereses de los consumidores y, también, de los proveedores en pro de un mercado cada vez más equilibrado entre ambos sectores. Esta disciplina jurídica es muy amplia y abarca desde la promulgación y puesta en práctica de leyes especiales y normativas de carácter administrativo en la materia, el análisis de las decisiones judiciales dictadas por los órganos jurisdiccionales, así como la regulación de contratos y asuntos relativos a la responsabilidad contractual y no contractual que pudieren surgir. El derecho regulatorio, a su vez, tiene un amplio alcance que comprende las áreas en las cuales interviene el derecho público y el derecho administrativo.

Conscientes de esta realidad, el pasado 6 de diciembre de 2018 fue celebrado el III Congreso Internacional de Regulación y Consumo, organizado por el Centro de Regulación y Consumo, el Instituto de Investigaciones en Derecho y la Facultad de Derecho de la Universidad Autónoma de Chile. Este evento, en su tercera edición consecutiva, reunió a treinta y tres destacados académicos y expertos, nacionales y extranjeros, de diferentes áreas del Derecho del Consumo y el Derecho Regulatorio.

La obra que a continuación presentamos recoge diecisiete artículos resultantes de las ponencias de los expositores, los cuales fueron revisados por un par ciego evaluador. Con el propósito de 
facilitar su lectura, el libro se divide en dos partes: la primera, sobre Derecho del Consumo; y, la segunda, sobre Derecho Regulatorio.

Así, en la primera parte, el lector podrá conocer los trabajos intitulados «Los límites constitucionales en la atribución de competencias al Servicio Nacional del Consumidor. Análisis de la sentencia del Tribunal Constitucional bajo el Rol N. 4012-17» de Alexander Espinoza y Jhenny Rivas Alberti; «Una aproximación a la arbitrariedad como cláusula abusiva: análisis a la cláusula del no-show», de Diego Aguilar Vinoso; «Acerca de la responsabilidad por productos sanitarios defectuosos: reflexiones sobre la prescripción extintiva", de Erika Isler Soto; "No todo lo que brilla es oro: análisis del impacto del nuevo etiquetado nutricional de alimentos (Ley 20.606)» de Jaime Lorenzini B.; «Sharing economy, prosumer y derecho del consumidor: su aplicación en la Ley sobre protección de los derechos de los consumidores» de Francisca Barrientos Camus; "El Ombudsman Sectorial: en el consumo en general y en los servicios básicos en particular», de Juan Pablo Díaz Fuenzalida; «Nuevo rol de la carga de la prueba en el procedimiento de policía local del consumo», de Andrés Celedón Baeza y «Cosa juzgada e insuficiencia de pruebas en los procesos colectivos de consumidores y usuarios» de Maite Aguirrezabal Grünstein. Asimismo, esta parte del libro contiene la participación de destacados exponentes extranjeros referidos a «La protección del consumidor de crédito inmobiliario en el contexto europeo», de Adela Serra Rodríguez; «Algunas consideraciones desde el Derecho civil sobre el Derecho del consumo y las acciones colectivas indemnizatorias», de Mario Clemente Meoro; y, «Avanços em matéria de Direito do Consumidor no Brasil: panorama a partir dos 30 anos da Constituição Federal de 1988 e do Código de Defesa do Consumidor», de Thiago Paluma y Gabriel Oliveira de Aguiar Borges.

En la segunda parte de la obra, se exponen los trabajos realizados por autores chilenos y extranjeros sobre los siguientes temas: «Entre la neutralidad técnica y el paternalismo libertario: reflexiones sobre la regulación económica desde la teoría evolutiva de las instituciones», de Luis Alfonso Herrera Orellana; «Las concentraciones mediáticas en Chile y el pluralismo informativo", de Alexander Espinoza y Jhenny Rivas Alberti; «Regulación ambiental y financiera de la 
minería en los suelos y subsuelos marinos», de Patricio Masbernat y Gloria Ramos-Fuentes; "Consulta indígena y centrales de generación hidroeléctrica de menos de 3MW: desregulación riesgosa, a la luz del derecho fundamental a la identidad cultural de los pueblos indígenas», de Juan Jorge Faundes Peñafiel; «La regulación de la educación en el Estado garante», de Pablo Nuevo López y «Ventajas y desventajas de la multa como sanción penal para personas jurídicas», de Patricia Faraldo Cabana.

Esperamos que esta obra sea de gran utilidad teórico-práctica para los estudiantes, académicos y profesionales del Derecho, así como a los interesados en esta dinámica materia.

Santiago, julio de 2019. 



\section{PARTE}

\section{DeRecho Del CONSUMO}





\title{
LOS LÍMITES CONSTITUCIONALES EN LA ATRIBUCIÓN DE COMPETENCIAS al Servicio Nacional del Consumidor. ANÁlisis DE LA SENTENCIA DEL TRIBUNAL CONSTITUCIONAL BAJO EL ROL N ${ }^{\circ}$ 4OI2-I 7
}

\author{
THE CONSTITUTIONAL LIMITS \\ IN THE ATTRIBUTION OF COMPETENCES \\ to the National Consumer Service. \\ ANALYSIS OF THE JUDGMENT \\ of the Constitutional Tribunal \\ UNDER THE ROLE $\mathrm{N}^{\circ}$ 4OI 2-I 7
}

Alexander Espinoza ${ }^{1}$
Jhenny Rivas Alberti

1 Doctor iuris Universität Passau, Alemania. Docente de la Universidad Autónoma de Chile (Sede Talca). E-mail: alexander.espinoza@uautonoma.cl.

2 Doctora en Derecho por la Universidad de Zaragoza, España. Docente de la Universidad Autónoma de Chile (Sede Talca).E-mail: jhenny.rivas@uautonoma.cl. 
Resumen. El presente trabajo procura establecer si el legislador puede atribuir al Servicio Nacional del Consumidor la resolución de las contiendas entre proveedores y consumidores o si tales facultades pertenecen exclusivamente a los tribunales, de acuerdo con lo dispuesto en el artículo 76 de la Constitución, a la luz del principio de separación de poderes.

Palabras Clave: funciones administrativas, jurisdicción, separación de poderes.

Aвstract. The present work tries to establish if the legislator can attribute to the National Consumer Service the resolution of the disputes between suppliers and consumers or if such faculties belong exclusively to the courts, in accordance with the provisions of article 76 of the Constitution, in light of the principle of separation of powers.

KEYWORDS: separation of powers; jurisdiction; Administrative functions.

SumARIo 1.Introducción. 2. La separación de funciones y el monopolio de la jurisdicción. 2.1. La opinión disidente; 2.2. Evolución histórica del principio de separación de funciones; 2.3. La separación de funciones en el Estado moderno; 2.4. Conclusiones parciales. 3. El principio de independencia del Poder Judicial: 3.1. El significado del artículo 76 de la Constitución; 3.2. Evolución jurisprudencial; 3.3. Conclusiones parciales; 3.4. Los órganos que requieren jurisdicción; 3.5. El significado del artículo $19 \mathrm{~N}^{\mathrm{o}} 3$ inciso $6^{\circ}$ de la Constitución; 3.6. Conclusiones parciales; 3.7. El artículo 76 , inciso primero y la separación de funciones; 3.8. El principio de separación de funciones en Alemania; 3.9. El principio de separación de funciones en Latinoamérica. 4. Conclusiones finales. 5. Bibliografía.

\section{INTRODUCCIÓN}

Mediante sentencia del 18 de enero de 2018 el Tribunal Constitucional se pronunció acerca del proyecto de ley, que modifica la Ley $\mathrm{N}^{\circ}$ 19.496, sobre Protección de los Derechos de los Consumidores. El Tribunal analizó la atribución de facultades al Servicio Nacional del Consumidor, para imponer sanciones de multa a los proveedores, 
constituirse en instancia de mediación, así como para ordenar el cese de las conductas infractoras, la restitución de los cobros que le parezcan improcedentes, además de adoptar indeterminadas medidas para evitar supuestas infracciones futuras.

Las normas mencionadas fueron objeto de control de constitucionalidad, a la luz de lo dispuesto en los artículos $19, \mathrm{~N}^{\circ} 3$, inciso sexto, y 76, inciso primero, de la Carta Fundamental, desde el punto de vista del régimen de separación de funciones ${ }^{3}$, así como, en base a la garantía de un proceso justo y racional, prevista en el artículo $19, \mathrm{~N}^{\circ} 3^{\circ}$, inciso sexto, de la Constitución, en cuanto a la separación orgánica de la investigación y la sanción ${ }^{4}$. Finalmente, el Tribunal revisó si se encontraban dadas las condiciones que garantizaran la independencia e imparcialidad, como componentes de todo proceso justo y racional ${ }^{5}$.

En cuanto al régimen de separación de funciones, observó el Tribunal que se trataba del ejercicio de «jurisdicción», entendida como aquella actividad tendente a la solución de un conflicto u oposición de relevancia jurídica entre partes interesadas, la cual según lo prescrito en el artículo 76, inciso primero, de la Carta Fundamental, pertenece exclusivamente única y solamente a los tribunales establecidos por la ley, sin que el presidente de la República, ni tampoco alguno de los servicios públicos que son sus colaboradores, puedan «ejercer funciones judiciales» como esas ${ }^{6}$.

En el presente estudio analizaremos el significado y alcance del principio de separación de funciones, con el objeto de determinar cuáles son los límites constitucionales en la atribución de competencias señaladas en el proyecto de ley, que modifica la Ley $N^{\circ}$ 19.496, sobre Protección de los Derechos de los Consumidores. Sin embargo, no forma parte del presente trabajo el análisis de los criterios que pueden ser aplicados para delimitar entre las funciones administrativas y jurisdiccionales, así como los requisitos de imparcialidad e independencia que serían requeridos, en caso de que

TC Rol N 4012-17-CPR de 18 de enero de 2018, $33^{\circ}$.

4 TC Rol N 4012-17-CPR de 18 de enero de 2018, $33^{\circ}$.

5 TC Rol No 4012-17-CPR de 18 de enero de 2018, $38^{\circ}$.

6 TC Rol No 4012-17-CPR de 18 de enero de 2018, $36^{\circ}$. 
se estime constitucionalmente admisible el ejercicio de funciones jurisdiccionales por órganos administrativos.

\section{LA SEPARACIÓN DE FUNCIONES Y EL MONOPOLIO DE LA JURISDICCIÓN}

La sentencia del 18 de enero de 2018, mediante la cual el Tribunal Constitucional se pronunció acerca del proyecto de ley que modifica la Ley $\mathrm{N}^{\circ}$ 19.496, sobre Protección de los Derechos de los Consumidores, estableció que algunas de las normas del proyecto de ley habrían sustituido el actual régimen de separación de funciones por uno nuevo en que se unen las funciones administrativas y jurisdiccionales, y agregó que tales normas no pueden residir en un organismo meramente administrativo, en virtud de un principio básico del derecho público universal, el cual es el de separación de funciones ${ }^{7}$.

El Tribunal Constitucional ha reiterado en sentencia reciente que el principio de separación de funciones constituye una base esencial de nuestra institucionalidad republicana y democrática (artículo $4^{\circ}$ de la Constitución), señalando que tal principio impide que exista una confusión entre las funciones administrativas y judiciales ${ }^{8}$.

\subsection{La opinión disidente}

El fallo cuenta con el voto en contra de los ministros señores Carlos Carmona Santander, Gonzalo García Pino y Nelson Pozo Silva, quienes estimaron que debía establecerse el contenido del principio de «separación de funciones» a partir del texto constitucional y no de un principio no escrito. Advirtieron que, doctrinariamente, este es un concepto más politológico que jurídico y en su configuración como principio organizador, resulta de más plausible aplicación a los regímenes presidencialistas. Sostuvieron que en la expresión aparentemente simple de «separación de poderes» se da un racimo de ideas superpuestas (por ejemplo, «distribución», «diferenciación», «aislamiento»

TC Rol No 4012-17-CPR de 18 de enero de 2018, 33․

8 TC Rol No 2865 de 30 de diciembre de 2015, 35% Rol No 3594-17 de 31 de mayo de $2018,33^{\circ}$. 
y «confrontación»), pero no todos estos términos son sinónimos y las implicaciones de alguno de ellos son recíprocamente incongruentes.

Los ministros observaron en su voto salvado que la Constitución Política de la República contiene múltiples mecanismos de cooperación entre el Poder Ejecutivo y el Poder Judicial en el régimen de nombramientos, de sanción y de remoción de jueces (artículos 32, numerales $12^{\circ}$ y $13^{\circ}$ ). En actos con incidencia sobre actos jurisdiccionales (artículo 32, numeral $14^{\circ}$ ) y el artículo 76 delimita el sentido negativo de esas cooperaciones en orden a que «ni el Presidente de la República ni el Congreso pueden, en caso alguno, ejercer funciones judiciales, avocarse causas pendientes, revisar los fundamentos o contenido de las resoluciones o hacer revivir procesos fenecidos». Por ende, no basta con reseñar un principio global de separación de funciones, sino que se ha de probar que el legislador le impuso a un servicio público un ejercicio de una función judicial.

Concluyeron que lo esencial es la secuencia formulada genéricamente en el artículo 38 de la Constitución. Esto significa que siempre existan procedimientos que permitan garantizar la separación de los poderes y el control jurisdiccional de los actos administrativos. La Constitución lo dispone en ese orden y no afecta la alternatividad en un conjunto amplísimo de asuntos.

\subsection{Evolución histórica del principio de separación de funciones}

Entre los principios más destacados que se establecieron para prevenir todo ejercicio arbitrario de poder, se encuentra la teoría de la división de poderes de Montesquieu: «para que no se pueda abusar del poder, es necesario que, por la disposición de las cosas, el poder detenga al poder». ${ }^{9}$ Tal es, esencialmente, el esquema primigenio del principio político de la división de poderes, hoy «modelo racional de validez universal». ${ }^{10}$

La evolución del postulado de separación de poderes se remonta a Aristóteles, quien distinguía entre tres ámbitos funcionales del

\footnotetext{
9 Bartlett Díaz (2016) 48; Fuentes (2011) 53; Hayek (1980) 15.

10 Armienta Calderón (2016) 25.
} 
cuerpo político: en primer lugar, la función de deliberativa y resolutiva, relativa a la emisión de leyes, las relaciones internacionales y la responsabilidad de magistrados; en segundo lugar, la función de emitir órdenes y la jurisdicción. Sin embargo, la estabilidad política no dependía de una organización formal sino del equilibrio social. La mayoría de los ciudadanos debería tener un patrimonio mediano y suficiente, para que ni los ricos ni los pobres ni otros particulares pudieran ejercer un dominio del conjunto. ${ }^{11}$

En el esquema de control y moderación del poder expuesto por Platón y Polybios, el aspecto organizatorio tiene una mayor relevancia. Se propone una forma de gobierno mixta, con el fin de dividir el poder y limitarlo. Según Polybios, cada uno de los factores de poder debían ser ponderados entre sí, de tal forma que «ninguno reciba una posición de supremacía determinante, sino que se mantengan en equilibrio, como en una balanza, que las fuerzas en conflicto se contengan entre sí y que con ello el orden constitucional se mantenga estable de forma permanente». En términos similares, Cicero prefería una forma del estado equilibrada y moderada. Maquiavello esperaba una mayor estabilidad del Estado, a través de la vigilancia recíproca de "príncipes, nobles y representantes del pueblo, reunidos en el mismo estado». Althusious propuso una «observación recíproca, vigilancia y supervisión, entre los titulares del gobierno y un órgano destinado a la protección de la constitución». Harrington proponía separar el poder social y político, no solo a través de un equilibrio entre las relaciones poder económico, sino una distribución de las competencias del Estado: una cámara debía proponer las leyes, el pueblo debía aprobarlas y un magistrado debía ejecutarlas. ${ }^{12}$

Locke desconfiaba del poder legislativo y exigía la separación con el poder ejecutivo: «Ante la debilidad de la naturaleza humana, que siempre está dispuesta a tomar el poder, sería una gran tentación para aquellos que detentan el poder legislativo, tener también el poder de ejecutar las leyes. Con ello podrían liberarse a sí mismos del deber de obedecer las leyes y adecuar la configuración y la ejecución en provecho propio y perseguir intereses distintos del resto de la sociedad y del gobierno». La regla general contra la concentración

11 Zippelius (2007) 242.

12 Zippelius (2007) 242. 
del poder era descrita así: «balancing the power of government by placing several parts of it in different hands». ${ }^{13}$

En la propuesta de Montesquieu, el balance de poderes puede ser alcanzado si el poder legislativo, ejecutivo y judicial es colocado en órganos distintos. ${ }^{14}$ En su teoría de la separación de los poderes del Estado, Montesquieu sostiene que la distribución jurídica de funciones solo podrá limitar el uso arbitrario del poder y salvaguardar la libertad y los derechos de los ciudadanos, si se combina con otro principio basado en su distribución social. Por esta razón, describe un modelo institucional en el que se distribuye el poder entre los tres estamentos relevantes de la sociedad inglesa, integrándolos a los órganos jurídicos: el Poder Ejecutivo es atribuido al monarca que tendrá suficientes mecanismos para oponerse a las tentativas del Legislativo de arrogarse todo el poder. El Poder Legislativo, en tanto, estará constituido por representantes de clases sociales distintas: nobles y pueblo. Esto impedirá que el Poder Legislativo dicte leyes que desconozcan las aspiraciones de los grupos relevantes de la sociedad. Por último, la distribución del Poder Judicial sigue el principio de que los hombres deben ser juzgados por sus iguales, asignando las causas entre miembros del pueblo a los tribunales ordinarios, y las causas que involucran a los nobles a la Cámara de los Lores. ${ }^{15}$

El principio de separación de poderes quedó plasmado en la Declaración de los Derechos de Virginia del 12 de junio de 1776, la cual estableció en el artículo V: "Que los poderes Legislativo, Ejecutivo y Judicial deben ser separados y distintos...». Por su parte, la Declaración de los Derechos del Hombre y del Ciudadano, del 26 de agosto de 1789, estableció en el artículo 16 que: «Toda sociedad en la cual la garantía de los derechos no esté asegurada, ni la separación de poderes determinada, no tiene Constitución». De tal forma, la tesis de Montesquieu fue reconocida como un elemento esencial constitutivo del moderno estadoestado de derecho. ${ }^{16}$

\footnotetext{
Zippelius (2007) 243.

Zippelius (2007) 244.

Fuentes (2011) 48.

Armienta (2016) 26.
} 


\subsection{La separación de funciones en el Estado moderno}

El principio clásico de separación de poderes constituye un modelo elaborado hace tres siglos con referencia a arreglos institucionales incomparablemente más simples que los de las actuales democracias constitucionales. En ese entonces las funciones del Estado eran poco más que la función penal y el mantenimiento del orden público al interior y la defensa militar al exterior. ${ }^{17}$ Respecto a estos arreglos la función principal de la división de poderes era la de diferenciar a los poderes del Estado de tal manera que uno fuera el freno y el límite del otro; en particular, se trataba de garantizar la separación e independencia del poder monárquico de otra forma absoluto, de la función legislativa y de la función judicial. ${ }^{18}$

El sistema jurídico distribuye el poder del Estado en tres órganos: el Legislativo, representante de la voluntad general del pueblo que expresa a través de las leyes; el Ejecutivo, encargado de dar cumplimiento a dicha voluntad, y el Judicial, que juzga los delitos y las diferencias entre particulares. Pero, además, el sistema comprende una serie de facultades y procedimientos que permiten que estos órganos participen de otro poder sin confundirse con él. ${ }^{19}$

En el derecho contemporáneo el principio clásico de separación de poderes debe adecuarse a las condiciones que impone el Estado moderno. La limitación del poder no solo se encuentra referida a los temas clásicos del balance de los poderes del Estado, sino que debe tomar en consideración el equilibrio de los poderes sociales, especialmente el de los partidos, sindicatos y medios de comunicación masivos, así como las hegemonías internacionales. ${ }^{20}$

Encontraremos que, si bien la limitación del poder, como fundamento del principio de separación de poderes tuvo en su origen una función de protección de la libertad del individuo, sin embargo, en la actualidad ha perdido este importante punto de referencia pues ha sido objetivizado.

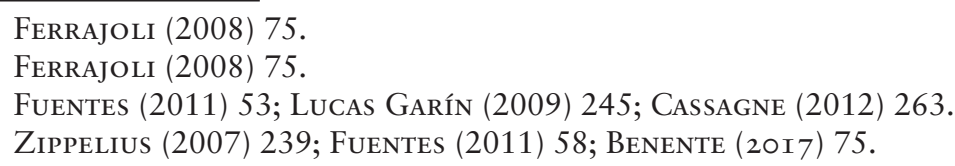


Otro elemento que debemos tomar en consideración se refiere a la influencia que ejercen otros factores, tales como la especialización, la estructura y los procedimientos del órgano, en la distribución de competencias entre los órganos del Estado. Por ello, el principio clásico de separación de funciones ha recibido innumerables cambios en el diseño de las constituciones modernas. La diversidad de las funciones del Estado ha traído consigo una equivalente diversidad estructural.

\subsection{Conclusiones parciales}

Hemos visto que un adecuado tratamiento del principio de separación de funciones requiere de una visión clara de la relación entre la teoría política y el derecho constitucional. En el caso del principio de separación de poderes, se trata de un principio suprapositivo reconocido constitucionalmente, el que puede tener una aplicación práctica como principio orientador de la interpretación de la ratio de las normas constitucionales expresas que establezcan, o bien, la separación del ejercicio de funciones legislativas, ejecutivas o judiciales por distintos órganos distintos (separación de poderes), o un sistema de controles y limitaciones (balance de poderes).

Sin embargo, compartimos el criterio expuesto por Konrad Hesse, en el sentido que el principio de separación de poderes no es un dogma de derecho natural, sino un principio histórico, que en su formulación pretendía establecer un orden que asegurara los efectos en la libertad de una situación real de fuerzas políticas. Tampoco en la actualidad podría ser desvinculado de un orden estatal determinado y de sus consecuencias. ${ }^{21}$

En efecto, la interpretación de la Constitución debe tomar en consideración que el significado de sus disposiciones resulta modificado, en virtud del principio de unidad de la Constitución, por un sistema armónico de valores, principios y normas ${ }^{22}$, que incluso pueden guiar al intérprete en direcciones distintas.

De tal forma, la separación de funciones y el balance de poderes son elementos que deben ser utilizados en el proceso de interpretación

21 Hesse (I997) 187.

22 TC Rol 567-06 de 03 de junio de 2010, $27^{\circ}$. 
de las normas de la Constitución, no como una regla de valor absoluto, sino como un principio orientador de la finalidad de la norma que tome además en consideración la realidad histórica.

\section{El PRincipio de independencia del Poder Judicial}

Recordemos que la sentencia del 18 de enero de 2018, mediante la cual el Tribunal Constitucional se pronunció acerca del proyecto de ley, que modifica la Ley N 19.496 sobre Protección de los Derechos de los Consumidores, estableció que la resolución de las contiendas entre proveedores y consumidores «pertenece exclusivamente a los tribunales establecidos por la ley», según lo prescrito en el artículo 76 de la Constitución Política ${ }^{23}$. De acuerdo con lo expuesto, analizaremos las disposiciones constitucionales aplicables, a la luz del principio de separación de funciones.

En efecto, según la sentencia del 18 de enero de 2018, la expresión "pertenece exclusivamente a los tribunales establecidos por la ley», contenida en el artículo 76, inciso primero, de la Carta Fundamental debe ser interpretada, siguiendo el Diccionario de la Lengua Española, que les corresponde única y solamente a ellos, de manera privativa o excluyente, sin que el presidente de la República ni tampoco alguno de los servicios públicos que son sus colaboradores (artículo $1^{\circ}$ de la Ley $\mathrm{N}^{\circ} 18.575$ ) puedan «ejercer funciones judiciales» como esas ${ }^{24}$.

Observó el Tribunal que se trataba del ejercicio de «jurisdicción», entendido como aquella actividad tendente a la solución de un conflicto u oposición de relevancia jurídica entre partes interesadas ${ }^{25}$.

\subsection{El significado del artículo 76 de la Constitución}

El artículo 76 de la Constitución dispone que «ni el presidente de la República ni el Congreso pueden, en caso alguno, ejercer funciones judiciales (...)». En cuanto a la prohibición dirigida al presidente de

23 TC Rol N 4012-17-CPR de 18 de enero de 2018, $37^{\circ}$.

24 TC Rol N 4012-17-CPR de 18 de enero de 2018, 37.

25 TC Rol N 4012-17-CPR de 18 de enero de 2018, $36^{\circ}$. 
la República y al Congreso, de ejercer funciones judiciales, se mantuvo la redacción contenida ya en el artículo 80 de la Constitución de 1925. La actual redacción ha permanecido inalterada desde la Constitución Política de $1833^{26}$, la cual recoge el texto de la Constitución Política de la monarquía española, promulgada en Cádiz en $1812^{27}$. Se trata de una disposición que encontramos además en buen número de constituciones latinoamericanas, tales como la de Argentina (art. 109); del Ecuador (art. 168); de Nicaragua (art. 159) de Paraguay (art. 248) y de Perú (art. 139).

En la Comisión de Estudios de la Nueva Constitución (CENC) se descartaron redacciones más amplias, tales como «ninguna otra autoridad puede en caso alguno ejercer funciones judiciales, abocarse a causas pendientes o hacer revivir procesos fenecidos", o «ninguno de los otros poderes del Estado», debido a la existencia de tribunales especiales que ejercen jurisdicción, tales como el Director de Impuestos Internos, el Superintendente de Aduanas, la Junta de Aduanas, el Tribunal de Marcas, el Tribunal de Comercio, o la Comisión Antimonopolios ${ }^{28}$.

En la doctrina se afirma que la mencionada prohibición se establece taxativamente para el Presidente de la República y para el Congreso Nacional, pero no para sus subordinados o ramas. Es decir, ni el Presidente de la República ni el Congreso Nacional pueden ejercer jurisdicción, pero sí lo podrían hacer un ministro de Estado o un director o jefe de servicio o bien el Senado o la Cámara de Diputados. ${ }^{29}$

26 «Art. 108. La facultad de juzgar las causas civiles i criminales pertenece esclusivamente a los Tribunales establecidos por la lei. Ni el Congreso, ni el presidente de la República pueden en ningún caso ejercer funciones judiciales, o avocarse causas pendientes, o hacer revivir procesos fenecidos».

27 «Art. 243. Ni las Cortes ni el Rey podrán ejercer en ningún caso las funciones judiciales, avocar causas pendientes, ni mandar abrir los juicios fenecidos.»

28 Sesión 281a, celebrada en jueves 31 de marzo de 1977.

29 Bordalí (2008) 209. 


\subsection{Evolución jurisprudencial}

En sentencia de 22 de noviembre de 1993, el Tribunal Constitucional sostuvo el criterio de que el ejercicio de funciones jurisdiccionales era un elemento determinante de la calificación como «tribunal» del órgano que lo ejerce. Señaló que dentro del concepto «causas civiles» a que se refería el inciso primero del entonces artículo 73 de la Constitución, se deben incluir todas aquellas controversias jurídico-administrativas que se pueden suscitar, y que deben resolver autoridades, que si bien no están insertas dentro de los tribunales que regula el Código Orgánico de Tribunales, están ejerciendo jurisdicción y resolviendo cuestiones que afectan los derechos de las personas ${ }^{30}$. Advirtió que, al otorgarse facultades jurisdiccionales a un funcionario administrativo, este actúa como un tribunal de primera instancia ${ }^{31}$.

Entre tanto, como veremos más adelante, la calificación de los órganos que ejercen funciones jurisdiccionales como tribunales ha evolucionado en la jurisprudencia del Tribunal Constitucional, en el sentido de admitir que tales funciones son ejercidas por órganos administrativos.

A partir de 2006, el Tribunal Constitucional se ha pronunciado en torno a las competencias atribuidas por el Código Tributario de 1960, a la Dirección Regional del Servicio de Impuestos Internos, en materia de reclamaciones de los contribuyentes. En criterio del Tribunal se trataba del ejercicio de funciones de carácter jurisdiccional entendida la jurisdicción, como «el poder deber que tienen los tribunales para conocer y resolver, por medio del proceso y con efecto de cosa juzgada, los conflictos de intereses de relevancia jurídica que se promuevan en el orden temporal, dentro del territorio de la República y en cuya solución les corresponda intervenir» ${ }^{32}$.

El fallo cuenta con el voto en contra de los ministros señores Jorge Correa Sutil y Francisco Fernández Fredes, quienes advirtieron que no se presentaban los elementos que configuran una controversia

$30 \quad$ TC ROL N ${ }^{\circ} 176$ de de 22 de noviembre de $1993,6^{\circ}$.

31 TC ROL N 176 de de 22 de noviembre de 1993, $7^{\circ}$.

32 TC Rol No 606-2006 de 20 de marzo de $20069^{\circ}$. Rol No 595-2006 de 20 de marzo de 2007; Rol N 574-2006 de 13 de marzo de 2007; Rol N 613-2006 de 9 de marzo de 2007; Rol No 642-2006 8 de marzo de 2007; Rol No 54720062 de enero de 2007. 
jurisdiccional. En cambio, el análisis de los intervinientes, de la resolución y, parcialmente, de las formas procesales muestra que estas son las propias del reclamo administrativo denominado recurso jerárquico. En tales condiciones, debía concluirse que no estamos en presencia de funciones jurisdiccionales.

En sentencias posteriores, el Tribunal Constitucional ha afirmado que la facultad de los directores regionales del Servicio de Impuestos Internos de aplicar, rebajar o condonar sanciones administrativas, se enmarca dentro de sus potestades administrativas sancionatorias, que no suponen ejercicio de jurisdicción ${ }^{33}$.

Este criterio ha sido acogido por la doctrina, en el sentido que corresponde al legislador determinar la política represiva y establecer que conductas serán sancionadas por la vía penal o por la vía administrativa.$^{34}$ El problema sería propio de un tema de discusión política, relacionado con motivos históricos, o relacionados con la naturaleza de menor importancia de los ilícitos; la cantidad de trabajo y esfuerzo que puede superar la capacidad de los tribunales y la buena marcha de administración de justicia; o la especialidad de la Administración en razón del interés y materia que comprenden. ${ }^{35}$

\subsection{Conclusiones parciales}

La sentencia del 18 de enero de 2018 deja de lado el tenor literal de la expresión «ni el Presidente de la República ni el Congreso» en la interpretación del artículo 76, inciso primero, de la Constitución Política, para atribuirle a la prohibición un sentido más amplio, que también comprende a los servicios públicos que son los colaboradores del Presidente de la República ${ }^{36}$.

Con ello, contraría el Tribunal el sentido que tenía la disposición, según la historia fidedigna de su establecimiento, dado que en la Comisión de Estudios de la Nueva Constitución (CENC) se admitió

33 TC Rol No $725-2007$ de 26 de junio de $200812^{\circ}$. Criterio reiterado en TC Rol $\mathrm{N}^{\mathrm{o}} 766-200726$ de junio de 2008, C-12 y 13. Reiterado además en TC Rol N 3106-16-CPR de 12 de julio de 2016, $17^{\circ}$.

34 Cordero y Aldunate (2012) 359.

35 Cordero y Aldunate (2012) 340.

36 TC Rol N 4012-17-CPR de 18 de enero de 2018, $37^{\circ}$. 
la existencia de tribunales especiales que ejercían jurisdicción, tales como el Director de Impuestos Internos, el Superintendente de Aduanas, la Junta de Aduanas, el Tribunal de Marcas, el Tribunal de Comercio, o la Comisión Antimonopolios ${ }^{37}$.

En realidad, el Tribunal Constitucional no se encuentra impedido de realizar una interpretación que descarte el sentido originario de la norma constitucional. El Tribunal ha advertido recientemente que es particularmente complejo recurrir exclusivamente a un criterio originalista de interpretación constitucional, debido a que el originalismo se traduce en el uso de las actas de la Comisión de Estudios de la Nueva Constitución o las actas del Consejo de Estado. Por lo mismo, según el Tribunal, el uso de este tipo de criterios interpretativos debiera ser auxiliar, no central ni decisivo. También en casos muy justificados y nunca para rigidizar el sentido del texto ${ }^{38}$.

Se trata entonces de una interpretación teleológica del artículo 76, inciso primero, de la Constitución Política, orientada por el principio de separación de funciones, para concluir que ni presidente de la República, ni tampoco alguno de los servicios públicos, pueden «ejercer funciones judiciales» ${ }^{39}$. Sin embargo, tal significado de la norma, podría en nuestro criterio resultar contrario al sentido del artículo $19 \mathrm{~N}^{\mathrm{o}} 3$ inciso $6^{\circ}$ de la Constitución, tal como veremos en seguida.

\subsection{Los órganos que ejercen jurisdicción}

La sentencia del 18 de enero de 2018, mediante la cual el Tribunal Constitucional se pronunció acerca del proyecto de ley, que modifica la Ley $\mathrm{N}^{\circ} 19.496$ sobre Protección de los Derechos de los Consumidores, solo acude al contenido del artículo $19 \mathrm{~N}^{\circ} 3$ inciso $6^{\circ}$ de la Constitución, al analizar «las garantías de un procedimiento y una investigación racionales y justos». Sin embargo, parece omitir toda referencia a la expresión "órgano que ejerza jurisdicción» contenida al inicio de la norma. Analizaremos si, y en qué medida,

37 Sesión 281a, celebrada en jueves 31 de marzo de 1977.

38 TC Rol No $3729-17$ de 28 de agosto de 2017, $30^{\circ}$.

39 TC Rol N 4012-17-CPR de 18 de enero de 2018, $37^{\circ}$. 
el contenido de esta norma es relevante para la interpretación del artículo 76, inciso primero.

\subsection{El significado del artículo $19 \mathrm{~N}^{\circ} 3$ inciso $6^{\circ}$ de la Constitución}

El artículo $19 \mathrm{~N}^{\circ} 3$ inciso $6^{\circ}$ dispone que: «Toda sentencia de un órgano que ejerza jurisdicción debe fundarse en un proceso previo legalmente tramitado. Corresponderá al legislador establecer siempre las garantías de un procedimiento y una investigación racionales y justos». La norma citada alude expresamente al ejercicio de funciones jurisdiccionales por parte de un órgano que emite una sentencia.

La interpretación basada en la historia fidedigna de la norma remite a los debates de la Comisión de Estudios de la Nueva Constitución (CENC) en su sesión $\mathrm{N}^{\circ} 103$, en la cual la observación del señor Diez, según la cual habría que aclarar que por «órgano que ejerce jurisdicción» se entiende a los tribunales administrativos, fiscales, Impuestos Internos, Contraloría General de la República, tribunales arbitrales, etcétera. Es decir, todo órgano que tenga facultad para dictar una resolución o fallo, llámese como se llame, que afecte a la situación de una persona», fue acogida por el señor Evans, quien acotó que «ello significa establecer que la norma se aplicará en toda controversia que se suscite en el orden temporal».

Por tal motivo, el señor Ortuzar propuso la redacción que quedó aprobada, «con el objeto de que abarque todos los casos que se han señalado ${ }^{40}$. El criterio sostenido durante los debates de la Comisión de Estudios de la Nueva Constitución (CENC), según el cual la expresión «órgano que ejerce jurisdicción» contenida en el artículo $19 \mathrm{~N}^{\circ} 3$ inciso $5^{\circ}$, debe ser interpretado como todo órgano que tenga facultad para dictar una resolución o fallo, incluyendo a los órganos de la administración pública, también ha sido reiterado por el Tribunal Constitucional. Este ha señalado que de la simple lectura del inciso quinto del numeral $3^{\circ}$ del artículo 19 constitucional, se desprende que la garantía consagrada en él ha sido contemplada

40 Segunda Parte de la Sesion 83a, Celebrada en jueves 31 de octubre de 1974; Bordalí (2008) 209. 
por el constituyente respecto de los órganos que ejercen jurisdicción, concepto que es más amplio que el de tribunales judiciales y comprende, por tanto, a órganos administrativos en la medida en que efectivamente actúen ejerciendo funciones jurisdiccionales ${ }^{41}$.

\subsection{Conclusiones parciales}

Aún cuando pareciera que el desarrollo del discurso nos lleva a un análisis circular, sin embargo, la circunstancia que la sentencia del 18 de enero de 2018 hubiera considerado aplicable «las garantías de un procedimiento y una investigación racionales y justos» a un órgano administrativo, como lo es el Servicio Nacional del Consumidor, constituye una admisión implícita de que se trata de un órgano que puede ejercer funciones jurisdiccionales. De lo contrario, tal órgano hubiera quedado fuera del ámbito de aplicación del artículo $19 \mathrm{~N}^{\circ} 3$ inciso $5^{\circ}$.

Como hemos visto, la interpretación extensiva del artículo 76, inciso primero, de la Constitución Política, para concluir que ni Presidente de la República, ni tampoco alguno de los servicios públicos, pueden "ejercer funciones judiciales», realizada por el fallo bajo análisis ${ }^{42}$, constituiría una mutación de su sentido originario, así como del significado del artículo $19 \mathrm{~N}^{\mathrm{o}} 3$ inciso $6^{\circ}$ de la Constitución. Un cambio de significado de la norma no puede basarse solo en el principio de separación de funciones, sino que hubiera requerido de una justificación adicional.

Estimamos, entonces, que la prohibición absoluta contenida en el artículo 76, inciso primero, de la Constitución Política, no debe ser objeto de interpretación extensiva, en cuanto a los órganos allí señalados, esto es, el Presidente de la República y el Congreso. Esto no significa sin embargo, que la norma citada quede despojada de otro significado desde el punto de vista de la separación de poderes, como veremos a continuación.

41 TC Rol No 513-06 de 02 de enero de 2007, $11^{\circ}$.

42 TC Rol N 4012-17-CPR de 18 de enero de 2018, $37^{\circ}$. 


\subsection{El artículo 76, inciso primero y la separación de funciones}

Ciertamente, el artículo 76 de la Constitución es considerado una clara consagración de la doctrina de la separación de poderes y de la independencia del poder judicial. ${ }^{43}$ Tal como lo ha establecido el Tribunal Constitucional, el citado artículo 76 se encuentra referido al principio del monopolio de la jurisdicción -de las causas civiles y criminales- al poder judicial ${ }^{44}$. El artículo 76 tiene por finalidad el resguardo del principio de independencia judicial. El artículo 12 del Código Orgánico de Tribunales dispone en tal sentido que «el Poder Judicial es independiente de toda otra autoridad en el ejercicio de sus funciones». Este precepto consagra la separación de funciones ${ }^{45}$. También ha señalado el Tribunal Constitucional que la potestad jurisdiccional les permite a los tribunales conocer, resolver y hacer cumplir lo juzgado, excluyendo en el área de los conflictos sometidos a su poder cualquier injerencia de autoridad alguna, nacional o internacional.

Debemos preguntarnos si el contenido de protección de la independencia del poder judicial es consecuente con nuestra afirmación anterior, en el sentido que ciertos órganos administrativos pueden ejercer funciones jurisdiccionales. Observaremos el tratamiento del problema en el derecho comparado.

\subsection{El principio de separación de funciones en Alemania}

El Tribunal Federal Constitucional de Alemania ha reconocido que la división de poderes es un principio estructural de organización y funcionamiento de la Ley Fundamental ${ }^{46}$. La Ley Fundamental procura la distribución del poder, la interrelación de los tres poderes

\footnotetext{
Bordalí (2008) 209.

TC Rol No 2690 de 6 de agosto de 2015, $10^{\circ}$.

45 Voto salvado del ministro señor Cristián Letelier Aguilar, en la sentencia TC Rol No 2897-15 de 4 de Julio de 2017.

46 BVerfGE 34, 52 / 59; BVerfGE 3, 225 - Gleichberechtigung; BVerfGE 34, 52 Hessisches Richtergesetz; BVerfG, Beschluss des Zweiten Senats vom 30. Juni 2015 - 2 BvR 1282/11 - Rn. (1-13), Rn. 126.
} 
y la moderación que de allí resulta de la dirección del Estado ${ }^{47}$. La distribución del poder permite el control y limitación recíproca de los órganos de los poderes legislativo, ejecutivo y judicial, cumple la función de asegurar la protección de la libertad del individuo ${ }^{48} \mathrm{y}$ la sujeción al derecho del poder del Estado ${ }^{49}$.

Otro de los fines de la división de poderes es garantizar que las decisiones de los órganos del Estado sean asumidas por los órganos que, de acuerdo con su organización, composición, funcionamiento y procedimientos, disponen de las mejores condiciones para asumir las decisiones más adecuadas a la materia ${ }^{50}$.

Sin embargo, el principio de división de poderes no se encuentra establecido en una forma pura para el ámbito de la Federación. Se establecen numerosas limitaciones y balances de los poderes. De la estructura constitucional establecida en la Ley Fundamental no se desprende una separación absoluta, sino de controles recíprocos, frenos y moderaciones de los poderes ${ }^{51}$.

Aún cuando del sentido de la división de poderes no pueda derivarse una separación estricta de las funciones del poder del Estado, sin embargo, por otra parte, debe respetarse la distribución de fuerzas entre los poderes prevista en la Ley Fundamental. Ningún poder puede atribuirse una supremacía sobre otro poder que no esté prevista en la Constitución ${ }^{52}$.

Un ejemplo de esto es la reserva funcional de decisiones que derivan del proceso de aplicación de normas a un caso concreto, a la Administración Pública, la cual posee la estructura y los

47 BVerfGE 34, 52 / 59; BVerfG, Urteil des Zweiten Senats vom 07. November 2017 - 2 BvE 2/11 - Rn. (1-372), Rn. 228.

48 BVerfGE 22, 106 - Steuerausschüsse; BVerfGE 3, 225 - Gleichberechtigung; BVerfGE 34, 52 - Hessisches Richtergesetz; BVerfG, Beschluss des Zweiten Senats vom 30. Juni 2015 - 2 BvR 1282/11, Rn. 126; BVerfGE 95, 1/17.

49 BVerfG, Urteil des Zweiten Senats vom 07. November 2017 - 2 BvE 2/11, Rn. 228.

50 BVerfG, Beschluss des Zweiten Senats vom 30. Juni 2015 - 2 BvR 1282/11, Rn. 126; BVerfGE 68, 1/86 - Atomwaffenstationierung; Papier (2012) 43.

51 BVerfGE 34, 52 / 59; BVerfGE 3, 225/247 - Gleichberechtigung; BVerfGE 34, 52 - Hessisches Richtergesetz.

52 BVerfGE 34, 52 / 59; BVerfG, Beschluss des Zweiten Senats vom 30. Juni 2015 - 2 BvR 1282/11, Rn. 126; BVerfGE 22, 106 - Steuerausschüsse; BVerfGE 34, 52 - Hessisches Richtergesetz; BVerfG, Urteil des Zweiten Senats vom 07. November 2017 - 2 BvE 2/11, Rn. 228. 
conocimientos especializados para ello. El Parlamento puede asumir tal actividad administrativa solo cuando en el caso concreto existan suficientes motivos materiales para ello ${ }^{53}$.

Ningún poder puede ser despojado de las competencias necesarias para el ejercicio de sus funciones constitucionales. El núcleo de los distintos poderes es inalterable, con ello debe ser excluido que uno de los poderes abandone alguna de las funciones típicas que le atribuye la Constitución ${ }^{54}$.

Para la relación entre el legislativo y el ejecutivo esto significa que corresponde al Parlamento la tarea constitucional de regulación normativa. Solo el Parlamento posee la legitimación democrática para asumir las decisiones esenciales. Aún cuando la Constitución permite una potestad normativa «derivada» del ejecutivo, sin embargo, esta solo puede desarrollarse en el marco previamente señalado por el legislador. Una atribución global del poder normativo al ejecutivo sería incompatible con el principio de división de poderes ${ }^{55}$.

Por otra parte, no toda intervención del parlamento en la administración constituye una infracción de la división de poderes. Incluso una cierta transferencia de fuerzas a costa del ejecutivo y a favor del parlamento sería incuestionable en la democracia parlamentaria. Solo cuando en favor del parlamento se produzca una irrupción en el ámbito medular del ejecutivo, habría sido infringido el principio de división de poderes ${ }^{56}$.

Esta limitación de la eficacia del principio de división de poderes, solo referido a la protección del ámbito medular de un poder del Estado, restringe las consecuencias de la infracción de este principio a casos estrechamente delimitados, mientras que adquiere mayor importancia práctica, en cuanto a su eficacia en la interpretación de otras disposiciones constitucionales ${ }^{57}$.

Un ejemplo de ello es la estricta limitación de las facultades del parlamento en materia de relaciones internacionales. El art. 59

\footnotetext{
53 BVerfG, Beschluss des Zweiten Senats vom 30. Juni 2015 - 2 BvR 1282/11, Rn. 127.

54 BVerfGE 34, 52 / 59; BVerfG, Beschluss des Zweiten Senats vom 30. Juni 2015 - 2 BvR 1282/11, Rn. 125; BVerfGE 34, 52 - Hessisches Richtergesetz.

55 BVerfGE 34, 52/59 - Hessisches Richtergesetz.

56 BVerfGE 9, 268/280 - Bremer Personalvertretung.

57 SACHS, M. (2007) 93; WitTRECK (2009) 5.
} 
aparte 2 frase 1 GG debe ser interpretado a la luz del principio de separación de poderes establecido en el art. 20 aparte 2 GG. La concentración de poder político que residiría en atribuir al Parlamento competencias adicionales a las establecidas en la Ley Fundamental que constituyen facultades medulares de naturaleza ejecutiva, sería contrario al sistema de distribución de poder, responsabilidad y controles, previsto en la Constitución ${ }^{58}$.

\subsection{El principio de separación de funciones en Latinoamérica}

Como veremos, la solución intermedia asumida por la jurisprudencia alemana es similar al mecanismo aplicado en algunos países latinoamericanos, para conciliar entre la división de poderes y la flexibilidad y complejidad organizativa del Estado moderno.

La Constitución de Colombia de 1991 se pronuncia expresamente acerca de la atribución de funciones jurisdiccionales a autoridades administrativas. En su artículo 116 inciso III, dispone que: «Excepcionalmente la ley podrá atribuir función jurisdiccional en materias precisas a determinadas autoridades administrativas (...)». La Corte Constitucional ha señalado que si bien el legislador tiene la facultad de conferir facultades jurisdiccionales a la administración debe, entre otros requisitos, respetar un principio de excepcionalidad, asociado a (i) la reserva de ley en la definición de funciones (incluidos los decretos con fuerza de ley), (ii) la precisión en la regulación o definición de tales competencias; y (iii) el principio de interpretación restringida o restrictivita de esas excepciones ${ }^{59}$.

La regla de atribución precisa exige que se delimiten adecuadamente las materias respecto de las cuales podrán ser ejercidas funciones jurisdiccionales y que se indiquen claramente las autoridades administrativas que serán titulares de la competencia para ello ${ }^{60}$. Además, la excepcionalidad por un mecanismo de residualidad, presupone que todos los asuntos sobre los que no exista una excepción taxativamente consagrada en la Constitución o la Ley serán

\footnotetext{
58 BVerfGE 68, 1/86 - Atomwaffenstationierung.

59 C-156/13.

60 C-436/13; C-156/13.
} 
de competencia de los jueces. Siempre que el legislador prevea una atribución de competencias en materia jurisdiccional en cabeza de autoridades administrativas, se puede suponer que, residualmente, se mantendrá un conjunto muy amplio de materias de competencia exclusiva de los jueces ${ }^{61}$. Con todo, la atribución de demasiadas funciones jurisdiccionales a la administración debilitaría la administración de justicia, de manera que podría dar lugar a una sospecha de inconstitucionalidad ${ }^{62}$.

Si bien la Constitución Política de los Estados Unidos Mexicanos no estatuye un sistema rígido de división de poderes, sin embargo prohíbe la unificación de dos o más poderes en uno. ${ }^{63}$ Para que sea válido, desde el punto de vista constitucional, que uno de los poderes ejerza funciones propias de otro poder, es necesario, que así lo consigne expresamente la carta magna o que la función respectiva sea estrictamente necesaria para hacer efectivas las facultades que le son exclusivas, y que la función se ejerza únicamente en los casos expresamente autorizados o indispensables para hacer efectiva una facultad propia. ${ }^{64}$

La jurisprudencia de Argentina ha considerado que el principio del monopolio de la jurisdicción quedaría a salvo siempre y cuando los organismos de la administración dotados de jurisdicción para resolver conflictos entre particulares hayan sido creados por ley, su independencia e imparcialidad estén aseguradas, el objetivo económico y político tenido en cuenta por el legislador para crearlos haya sido razonable y, además, sus decisiones estén sujetas a control judicial amplio y suficiente. ${ }^{65}$

Finalmente, debemos referirnos al criterio establecido por la Corte Interamericana de Derechos Humanos, en el sentido que si bien de conformidad con la separación de los poderes públicos, la función jurisdiccional compete eminentemente al Poder Judicial, otros órganos o autoridades públicas pueden ejercer funciones del mismo tipo.

\footnotetext{
61 C-156/13.

62 C-156/13.

63 Carmona (2007) 183.

64 CARMona (2007) 185.

65 «Angel Estrada y Cía. SA c/ Resolución 71/96 Secretaría de Energía y Puertos», de fecha 05/04/2005, $12^{\circ}$; Gordillo (2005) 307-311; Cassagne (2012) 11; Barbará (2006) 22.
} 
Por tal razón, cualquier órgano del Estado que ejerza funciones de carácter materialmente jurisdiccional, tiene la obligación de adoptar resoluciones apegadas a las garantías del debido proceso legal en los términos del artículo 8 de la Convención Americana ${ }^{66}$.

\section{Conclusiones finales}

En la interpretación del artículo 76, inciso primero, de la Constitución Política, debe mantenerse el tenor literal de la expresión «ni el presidente de la República ni el Congreso», para atribuirle a la prohibición de ejercer funciones judiciales un sentido restringido, que no comprende a los servicios públicos. Tal interpretación, no solo deriva de la historia fidedigna de su establecimiento, sino también de su relación sistemática con lo dispuesto en el artículo 19 No 3 inciso $5^{\circ}$. Una interpretación finalista, orientada por el principio de separación de funciones, podría servir, en todo caso, para fijar ciertos límites que impidan dejar sin contenido las competencias esenciales del poder judicial y exigir una justificación racional para la atribución de funciones judiciales a los órganos del Poder Ejecutivo.

Recordemos que la finalidad del principio de separación de poderes es la de limitar al poder, para impedir su ejercicio arbitrario, con lo cual se establece una garantía de protección a la libertad individual. A pesar de la evolución de la sociedad y de la estructura del Estado moderno, la limitación del poder no ha perdido su utilidad y su vigencia prácticas.

Como se observa, el principio de separación de poderes no constituye un principio de rango superior a la Constitución Política, ni puede tener un efecto normativo externo como parámetro de control de constitucionalidad. Sin embargo, puede tener una aplicación práctica como principio orientador de la interpretación teleológica de normas constitucionales expresas que establezcan, o bien la separación orgánica de funciones, o un sistema de controles y limitaciones. De esta forma, puede producir efectos internos en

66 Corte IDH Caso del Tribunal Constitucional Vs. Perú Sentencia de 31 de enero de 2001, párr. 71; Corte IDH Caso Vélez Loor vs. Panamá, Sentencia de 23 de noviembre de 2010, párr. 142; Alarcón (2009) 323; RuOCCo (2015) 859-868; Delgado (2011) 305-329. 
la determinación del alcance de las disposiciones constitucionales, con el fin de impedir la supremacía indebida de uno de los poderes o bien la afectación de un núcleo inalterable conformado por las competencias esenciales de cada uno de los poderes públicos.

Pero, una vez determinado que no sería contrario al principio de división de poderes, la atribución de funciones jurisdiccionales a un órgano del poder ejecutivo, siempre que no suponga un debilitamiento del Poder Judicial, sin embargo, ese análisis no conduce necesariamente a una postura definitivcon respecto a la atribución de facultades al SERNAC de la resolución de contiendas entre proveedores y consumidores.

En primer lugar, sería necesario determinar si tal decisión forma parte del ámbito de evaluación del Legislador, tal como ha sido afirmado por abundamente jurisprudencia constitucional ${ }^{67}$. En principio el Legislador es libre de crear los órganos que estime necesarios para el cumplimiento de la Constitución Política de la República mientras estos ciertamente no modifiquen el diseño que ella contiene ${ }^{68}$.

Una vez establecida la facultad del Legislador de configuración de la estructura organizativa que considera más adecuada, podríamos desarrollar los elementos que deben ser tomados en consideración. Encontraremos elementos de variada naturaleza que intervienen en el diseño de un mecanismo de protección eficaz de los intereses de los consumidores. Tal es el caso de los factores que determinan el acceso de los consumidores y usuarios, tales como la distribución geográfica del funcionario competente; la suficiente capacidad para dar respuesta, de acuerdo con el número de solicitudes; el grado

67 Véase, con respecto a la facultad de señalar el órgano jurisdiccional que debe resolver las diversas controversias que se suscitan entre la autoridad administrativa, en uso de sus facultades fiscalizadoras, y los particulares afectados, TC Rol No 616-06 de 06 de septiembre de 2007, 30ª la configuración del sistema de acciones y recursos respecto de las decisiones judiciales, TC Rol No 1448 09 de 07 de septiembre de $2010,42^{\circ}$; la regulación del derecho a la actividad económica, TC Rol No 480-06 de 27 de junio de 2006, 11º ; la definición de los bienes jurídicos protegidos a través de la potestad punitiva, TC Rol N² 2402-13 de 26 de noviembre de $2013,23^{\circ}$; la configuración de la potestad sancionatoria, TC Rol No 725-2007 de 26 de junio de 2008, 28º; TC Rol No 2897-15 de 4 de Julio de 2017, 45 ${ }^{\circ}$; Cordero (2013) 128.

68 TC Rol No $1732-10$ de 21 de junio de $2011,19^{\circ}$. 
de especialidad, según la complejidad de la materia ${ }^{69}$; principios de procedimiento, tales como la informalidad, la gratuidad, la celeridad, etc. Es relevante además para la decisión del legislador, aspectos económicos, tales como el costo presupuestario de la estructura orgánica, o políticos, tales como la responsabilidad del Gobierno frente a los ciudadanos ${ }^{70}$.

Finalmente, quedaría por determinar cuáles son los requisitos de imparcialidad e independencia exigibles a un órgano administrativo, en ejercicio de facultades jurisdiccionales.

\section{Bibliografía}

\section{a) Doctrina:}

Alarcón, R. B. (2009). «El caso del Tribunal Constitucional, a propósito de la sentencia de la Corte Interamericana de Derechos Humanos», Revista Española de Relaciones Internacionales, (1), pp. 86-137. https://dialnet.unirioja.es/descarga/articulo/4844041.pdf.

Armienta Calderón, Gonzalo M. (2016): «La relación entre los poderes legislativo y ejecutivo en el constitucionalismo mexicano". En: Mora Donatto, Cecilia Judith (Coordinadora). Relaciones entre gobierno y Congreso. México: UNAM, Instituto de Investigaciones Jurídicas. Disponible en: https://archivos.juridicas.unam.mx/www/ bjv/libros/1/346/4.pdf [Fecha de consulta: 22 de febrero de 2018]

BARBARÁ, J. E. (2006). «El control judicial de entes reguladores y de control: luces y sombras en la evaluación de los entes», p. 22, disponible en: http://siare.clad.org/fulltext/0055732.pdf.

BARTLETt Díaz, Manuel (2016): «El equilibrio de poderes y la función de control». En: Mora DonatTo, Cecilia Judith (Coordinadora). Relaciones entre gobierno y Congreso. México: UNAM, Instituto de Investigaciones Jurídicas. Disponible en: https://archivos.juridicas.unam.mx/ www/bjv/libros/1/346/5 [Fecha de consulta: 22 de febrero de 2018]

Benente, Mauro (20I7): «Presidencialismo y poder económico en la reforma constitucional Argentina de 1994», Revista de Derecho, Universidad del Norte, 47: 73-104 Disponible en: http://www. scielo.org.co/pdf/dere/n47/0121-8697-dere-47-00073.pdf. [Fecha de consulta: 22 de febrero de 2018]

69 TC Rol No 3130 de 9 de agosto de 2016, $18^{\circ}$.

70 En este sentido, la jurisprudencia alemana, BVerfGE 9, 268 - Sindicatos de funcionarios públicos de Bremen. 
Bordalí Salamanca, A. (2008): «La doctrina de la separación de poderes y el poder judicial chileno», Revista de derecho (Valparaíso), (30), pp. 185-219.

CARMona Tinoco, Jorge Ulises (2007): «La división de poderes y la función jurisdiccional», Revista Latinoamericana de Derecho, (7), 7, p. 183

CASAgne, Juan Carlos (2012): «El Sistema Judicialjudicialista y la Llamada Judicialjudicialización de la Actividad de la Administración Pública", Derecho y sociedad. No 29. Disponible en: http://revistas.pucp. edu.pe/index.php/derechoysociedad/article/viewFile/17284/17571. [Fecha de consulta: 22 de febrero de 2018]

Cassagne, J. C. (2012). «Las facultades jurisdiccionales de los entes reguladores de servicios públicos. El caso "Angel Estrada», en: Administración y justicia: un análisis jurisprudencial: liber amicorum Tomás-Ramón Fernández, (Madrid, Civitas) pp. 3897-3910. Disponible en: http://www.cassagne.com.ar/publicaciones/Las_facultades_jurisdiccionales_de_los_entes_reguladores_.pdf

Comisión de Estudio de la Nueva Constitución Política de la RePÚBLICA (I977): Actas Oficiales. Sesion 281a, celebrada en jueves 31 de marzo de 1977. Disponible en: https://www.leychile.cl/Navegar/ scripts/obtienearchivo?id=recursoslegales/10221.3/3768/2/Tomo_IX_ Comision_Ortuzar.pdf. [Fecha de consulta: 22 de febrero de 2018]

Cordero Quinzacara, E. (2013): «Sanciones administrativas y mercados regulados», Revista de derecho (Valdivia), 26(1), pp. 119-144. Disponible en: http://mingaonline.uach.cl/scielo.php?script=sci_ arttext\&pid=S0718-09502013000100006\&lng=es\&nrm=iso [Fecha de consulta: 22 de febrero de 2018]

Cordero Quinzacara, Eduardo y Aldunate Lizana, Eduardo (2012): «Las bases constitucionales de la potestad sancionadora de la Administración», Revista de Derecho de la Pontificia Universidad Católica de Valparaíso XXXIX (Valparaíso, Chile, 2do Semestre), pp. 337 - 361. Disponible en: https://scielo.conicyt.cl/pdf/rdpucv/ n39/a13.pdf. [Fecha de consulta: 22 de febrero de 2018]

Delgado Ávila, Daniel (2011): «El derecho fundamental al juez independiente en la jurisprudencia de la Corte Interamericana de Derechos Humanos", Anuario mexicano de derecho internacional, 11, pp. 305-329. Disponible en: http://www.scielo.org.mx/scielo. php?script=sci_arttext\&pid=S1870-46542011000100010\&lng=es \&tlng=es. [Fecha de consulta: 09 de enero de 2019].

Ferrajoli, Luigi (2008): «La esfera de lo indecidible y la división de poderes», en: Estudios Constitucionales, Centro de Estudios Constitucionales de Chile, Universidad de Talca, Año 6, No 1, 2008, pp. 337-343. 
Fuentes, Claudia (2011): «Montesquieu: Teoría de la distribución social del poder», Revista de Ciencia Política [en linea] 2011, 31 (Sin mes): Disponible en: http://www.redalyc.org/articulo.oa?id=32419207003 [Fecha de consulta: 22 de febrero de 2018]

Gordillo, A. (2005) «Ángel Estrada» en Res Publica, Revista de la Asociación Iberoamericana de Derecho Administrativo, año I, $\mathrm{n}^{\circ}$ 2, México, pp. 307-311, http://gordillo.com/articulos/art49.pdf [Fecha de consulta: 22 de febrero de 2018]

Hayek, Friedrich A. (1980): El Ideal Democrático y la Contención del Poder. Estudios públicos, $\mathrm{N}^{\circ}$. 1, pp 12-75. Disponible en: https://cepchile. cl/cep/site/artic/20160303/asocfile/20160303183439/rev01_hayek1. pdf. [Fecha de consulta: 22 de febrero de 2018]

Hesse, Konrad (I997): «Grundzüge des Verfassungsrechts der Bundesrepublik Deutschland «. 17. Auflage. C.F.Müller Juristischer Verlag. Heildelberg [Traducción nuestra].

Lucas Garín, Andrea (2009): «Nuevas dimensiones del principio de división de poderes en un mundo globalizado", Centro de Estudios Constitucionales de Chile, Universidad de Talca. Año 7, $\mathrm{N}^{\circ}$ 2, pp. 241-253. Disponible en: https://scielo.conicyt.cl/pdf/estconst/v7n2/ art09.pdf [Fecha de consulta: 22 de febrero de 2018].

Pinilla Rodríguez, Francisco (2007): «Las denominadas funciones jurisdiccionales de los órganos de la administración del Estado: Apreciaciones a partir de la STC de 26 de marzo de 2007», Revista Ius et Praxis, año $14-\mathrm{n}^{\circ} 1$, pp. $363-389$. Disponible en: https:// scielo.conicyt.cl/pdf/iusetp/v14n1/art15.pdf [Fecha de consulta: 22 de febrero de 2018].

Ruocco, Graciela (2015). «El principio del «debido proceso» en vía administrativa", La justicia uruguaya: Revista Jurídica, (152), pp. 859868. http://revistaeletronicardfd.unibrasil.com.br/index.php/rdfd/ article/download/408/317 [Fecha de consulta: 22 de febrero de 2018]

SACHs, M. (2007). Art. 20. En M. Sachs, Grundgesetz (München: Verlag C.H.Beck) pp. 766-823.

Zippelius Reinhold (2007): Allgemeine Staatslehre. Politikwissenschaft. 15 Auflage. Verlag C.H. Beck [Traducción nuestra].

\section{b) Jurisprudencia}

«Angel Estrada y Cía. SA c/ Resolución 71/96 Secretaría de Energía y Puertos», de fecha 05/04/2005, $12^{\circ}$. Disponible en: https:// sjconsulta.csjn.gov.ar/sjconsulta/documentos/verDocumentoById. html?idDocumento=5804061 [Fecha de consulta: 22 de febrero de 2018] 
Beschluss des Zweiten Senats vom 30. Juni 2015 - 2 BvR 1282/11 - Rn. (1-13), Fundstelle(n): BVerfGE 139, 321 - 378. Disponible en: http:// www.bverfg.de/e/rs20150630_2bvr128211.html [Fecha de consulta: 22 de febrero de 2018]

Bundesverwaltungsgericht Urt. v. 27.10.1966, Az.: BVerwG II C 103.63. Fundstellen: BVerwGE 25, 210 - 221. Disponible en: https://www. jurion.de/urteile/bverwg/1966-10-27/bverwg-ii-c-10363/. [Fecha de consulta: 22 de febrero de 2018]

BVerfG, Beschluss des Zweiten Senats vom 30. Juni 2015 - 2 BvR 1282/11 - Rn. (1-13), Fundstelle(n): BVerfGE 139, 321 - 378. Disponible en: http://www.bverfg.de/e/rs20150630_2bvr128211.html [Fecha de consulta: 22 de febrero de 2018]

BVerfG, Urteil des Zweiten Senats vom 07. November 2017 - 2 BvE 2/11 - Rn. (1-372). Fundstelle(n) BverfGE 147, 50 - 184. Disponible en: http://www.bverfg.de/e/es20171107_2bve000211.html. [Fecha de consulta: 22 de febrero de 2018]

BVerfGE 21, 139 - Freiwillige Gerichtsbarkeit. Disponible en: http://www. servat.unibe.ch/dfr/bv021139.html [Fecha de consulta: 22 de febrero de 2018]

BVerfGE 22, 106 - Steuerausschüsse. Disponible en: http://www.servat.unibe.ch/dfr/bv022106.html [Fecha de consulta: 22 de febrero de 2018] BVerfGE 3, 225 - Gleichberechtigung. Disponible en: http://www.servat.unibe.ch/dfr/bv003225.html [Fecha de consulta: 22 de febrero de 2018] BVerfGE 34, 52 - Hessisches Richtergesetz. Disponible en: http://www. servat.unibe.ch/dfr/bv034052.html [Fecha de consulta: 22 de febrero de 2018]

BVerfGE 4, 331/346 - Soforthilfegesetz. Disponible en: http://www.servat.unibe.ch/dfr/bv004331.html [Fecha de consulta: 22 de febrero de 2018]

BVerfGE 68, 1 - Atomwaffenstationierung. Disponible en: http://www. servat.unibe.ch/dfr/bv068001.html [Fecha de consulta: 22 de febrero de 2018]

BVerfGE 8,197 - Bußgeldverfahren. Disponible en: http://www.servat.unibe.ch/dfr/bv008197.html [Fecha de consulta: 22 de febrero de 2018]

BVerfGE 9, 268/280 - Bremer Personalvertretung. Disponible en: http:// www.servat.unibe.ch/dfr/bv009268.html [Fecha de consulta: 22 de febrero de 2018]

BVerfGE 95, 1 - Südumfahrung Stendal. Disponible en: http://www.servat. unibe.ch/dfr/bv095001.html [Fecha de consulta: 22 de febrero de 2018]

Corte Constitucional de Colombia, C-156/13. Disponible en: http://www. corteconstitucional.gov.co/relatoria/2013/C-156-13.htm. [Fecha de consulta: 22 de febrero de 2018] 
Corte Constitucional de Colombia, C-436/13. Disponible en: http://www. corteconstitucional.gov.co/relatoria/2013/C-436-13.htm [Fecha de consulta: 22 de febrero de 2018]

Corte Interamericana de Derechos Humanos, Caso del Tribunal Constitucional Vs. Perú Sentencia de 31 de enero de 2001 (Fondo, Reparaciones y Costas). Disponible en: http://www.corteidh.or.cr/docs/ casos/articulos/seriec_71_esp.pdf [Fecha de consulta: 22 de febrero de 2018].

Corte Interamericana de Derechos Humanos Caso Vélez Loor vs. Panamá Sentencia de 23 de noviembre de 2010 (Excepciones Preliminares, Fondo, Reparaciones y Costas. Disponible en: http://www.corteidh. or.cr/docs/casos/articulos/seriec_218_esp2.pdf [Fecha de consulta: 22 de febrero de 2018]

TC Rol 567-06 de 03 de junio de 2010. Disponible en: https://www.tribunalconstitucional.cl/ver2.php?id=1386 [Fecha de consulta: $22 \mathrm{de}$ febrero de 2018]

TC Rol N²402-13 de 26 de noviembre de 2013. Disponible en: https:/ www.tribunalconstitucional.cl/ver2.php?id=2865 [Fecha de consulta: 22 de febrero de 2018]

TC Rol No 3106-16-CPR de 12 de julio de 2016. Disponible en: http:// www.tribunalconstitucional.cl/ver.php?id=3292 [Fecha de consulta: 22 de febrero de 2018]

TC Rol N 4012-17-CPR de 18 de enero de 2018. Disponible en: http:// www.tribunalconstitucional.cl/wp/ver.php?id=3621 [Fecha de consulta: 22 de febrero de 2018]

TC Rol No 1448-09 de 07 de septiembre de 2010. Disponible en: https:// www.tribunalconstitucional.cl/ver2.php?id=1522 [Fecha de consulta: 22 de febrero de 2018]

TC ROL N ${ }^{\circ} 176$ de de 22 de noviembre de 1993. Disponible en: https:// www.tribunalconstitucional.cl/ver2.php?id=440 [Fecha de consulta: 22 de febrero de 2018]

TC Rol No 251 de 27 de enero de 1997. ID vLex: 58942804. Disponible en: http://jurisprudencia.vlex.cl/vid/-58942804 [Fecha de consulta: 22 de febrero de 2018]

TC Rol No 2690 de 6 de agosto de 2015, ID vLex: 580043022. Disponible en: http://jurisprudencia.vlex.cl/vid/580043022 [Fecha de consulta: 22 de febrero de 2018]

TC Rol No 2865 de 30 de diciembre de 2015, ID vLex: 591076914. Disponible en: http://jurisprudencia.vlex.cl/vid/591076914 [Fecha de consulta: 22 de febrero de 2018]

TC Rol No 2897-15 de 4 de julio de 2017. Disponible en: https://www. tribunalconstitucional.cl/ver2.php?id=3447 [Fecha de consulta: 22 de febrero de 2018] 
TC Rol No 2897-15 de 4 de julio de 2017. ID vLex: 685329045. Disponible en: http://jurisprudencia.vlex.cl/vid/685329045 [Fecha de consulta: 22 de febrero de 2018]

TC Rol No 3130 de 9 de agosto de 2016. ID vLex: 647104033. Disponible en: http://jurisprudencia.vlex.cl/vid/647104033 [Fecha de consulta: 22 de febrero de 2018]

TC Rol No 3594-17 de 31 de mayo de 2018, ID vLex: 727329889. Disponible en: http://jurisprudencia.vlex.cl/vid/727329889 [Fecha de consulta: 22 de febrero de 2018]

TC Rol No 3729-17 de 28 de agosto de 2017. Disponible en: http://jurisprudencia.vlex.cl/vid/692332513 [Fecha de consulta: 22 de febrero de 2018]

TC Rol No 480-06 de 27 de junio de 2006. Disponible en: https://www. tribunalconstitucional.cl/ver2.php?id=616 [Fecha de consulta: 22 de febrero de 2018]

TC Rol No 513-06 de 02 de enero de 2007. Disponible en: https://www. tribunalconstitucional.cl/ver2.php?id=142 [Fecha de consulta: 22 de febrero de 2018]

TC Rol No 547-2006 2 de enero de 2007. Disponible en: http://www. tribunalconstitucional.cl/ver.php?id=126 [Fecha de consulta: $22 \mathrm{de}$ febrero de 2018]

TC Rol No 574-2006 de 13 de marzo de 2007. Disponible en: http://www. tribunalconstitucional.cl/ver.php?id=113 [Fecha de consulta: 22 de febrero de 2018]

TC Rol No 595-2006 de 20 de marzo de 2007. Disponible en: http://www. tribunalconstitucional.cl/ver.php?id=107. [Fecha de consulta: $22 \mathrm{de}$ febrero de 2018]

TC Rol N $604-2006$ de 20 de marzo de 2007. Disponible en: http://www. tribunalconstitucional.cl/ver.php?id=99 [Fecha de consulta: $22 \mathrm{de}$ febrero de 2018]

TC Rol No 606-2006 de 20 de marzo de 2006. Disponible en: http://www. tribunalconstitucional.cl/ver.php?id=97 [Fecha de consulta: 22 de febrero de 2018]

TC Rol No 613-2006 de 9 de marzo de 2007. Disponible en: http://www. tribunalconstitucional.cl/ver.php?id=95 [Fecha de consulta: 22 de febrero de 2018]

TC Rol No 616-06 de 06 de septiembre de 2007, Disponible en: https:// www.tribunalconstitucional.cl/ver2.php?id=93 [Fecha de consulta: 22 de febrero de 2018]

TC Rol No 642-2006 8 de marzo de 2007. Disponible en: http://www. tribunalconstitucional.cl/ver.php?id=95 [Fecha de consulta: 22 de febrero de 2018] 
TC Rol No 694 de 5 de julio de 2007. ID vLex: 58942394 . Disponible en: http://jurisprudencia.vlex.cl/vid/-58942394 [Fecha de consulta: 22 de febrero de 2018]

TC Rol No 695 de 5 de julio de 2007. ID vLex: 58942394 . Disponible en: http://jurisprudencia.vlex.cl/vid/-58942394 [Fecha de consulta: 22 de febrero de 2018]

TC Rol N $725-2007$ de 26 de junio de 2008. Disponible en: https://www. tribunalconstitucional.cl/ver2.php?id=962 [Fecha de consulta: 22 de febrero de 2018]

TC Rol No 725-2007 de 26 de junio de 2008. Disponible en: http://www. tribunalconstitucional.cl/ver.php?id=962. [Fecha de consulta: $22 \mathrm{de}$ febrero de 2018]

TC Rol No 766-2007 26 de junio de junio de 2008, C-12 y 13. Disponible en: http://www.tribunalconstitucional.cl/ver.php?id=963 [Fecha de consulta: 22 de febrero de 2018]

TC Rol no 980 de 13 de mayo de 2008. ID vLex: 58941736. Disponible en: http://jurisprudencia.vlex.cl/vid/-58941736 [Fecha de consulta: 22 de febrero de 2018] 


\title{
UNA APROXIMACIÓN A LA ARBITRARIEDAD COMO CLÁUSULA ABUSIVA: ANÁLISIS A LA CLÁUSUla DEL NO-SHOW
}

\author{
AN APPROACH TO ARBITRARINESS \\ AS AN ABUSIVE CLAUSE: AN ANALYSIS \\ OF THE «NO-SHOW» CLAUSE
}

Diego Aguilar Vildoso ${ }^{1}$

RESUMEN. En la legislación chilena el concepto de arbitrariedad es utilizado, a través del artículo 16 letra a) de la Ley 19.496, como una causal para determinar la abusividad de una cláusula en un contrato de adhesión, sin embargo, no se define qué se entiende por tal. Este artículo aborda la noción de cláusulas abusivas y, en específico, el concepto de arbitrariedad, utilizando un caso del mercado de servicios

\footnotetext{
Abogado. Licenciado en Ciencias Jurídicas y Sociales (Universidad Alberto Hurtado). Magíster (c) en Ciencia Política (Universidad de Chile). E-mail: daguilarv@gmail.com Este trabajo fue presentado con fecha 6 de diciembre de 2018 en el III Congreso Internacional de Regulación y Consumo, organizado por el Centro de Regulación y Consumo de la Universidad Autónoma de Chile. Agradezco al Servicio Nacional del Consumidor (SERNAC), institución de la que formé parte entre mayo de 2016 y febrero de 2019, por su valioso aporte al desarrollo del derecho del consumidor en Chile.
} 
de transporte aéreo de pasajeros como ejemplo, con el objetivo de prestar sustento a la invocación que se realiza de dicha norma.

A partir de un análisis comparado para entender el tratamiento que distintas legislaciones latinoamericanas realizan sobre las cláusulas abusivas y la arbitrariedad como causal, se indagarán los criterios que el Servicio Nacional del Consumidor (SERNAC) ha utilizado en Chile para imputarla; procediéndose a exponer algunos de los criterios jurisprudenciales que se han elaborado para sancionar su vulneración.

Finalmente, luego de examinar la cláusula del no show se reflexiona que, aun cuando la norma chilena no provee de una definición para el concepto de arbitrariedad, es posible concluir, a partir de la jurisprudencia, que esta se refiere a toda cláusula contractual donde sea posible observar una posición de abuso exorbitante con correlativo riesgo de detrimento y subordinación de la contraparte débil y que no cuente con una justificación alguna que la explique.

PAlABRAS ClAVE: arbitrariedad, cláusula abusiva, contrato de adhesión.

Aвstract. In Chilean law the concept of arbitrariness is used, through article 16 letter a) of Law 19.496, as a cause to determine the abusiveness of a clause in an adhesion contract, however, what is meant by that is not defined.

This article addresses the notion of abusive clauses and, specifically, the concept of arbitrariness, using a case of the air travel market as an example, with the aim of lending support to the invocation that is made of said rule.

Based on a comparative analysis to understand the treatment that different Latin American legislations make about abusive clauses and arbitrariness as a causal, the criteria that the National Consumer Service (SERNAC) has used in Chile to impute it will be investigated; proceeding to expose some of the jurisprudential criteria that have been developed to sanction their violation.

Finally, after examining the "no show» clause, it is thought that, even though the Chilean law does not provide a definition for the concept of arbitrariness, it is possible to conclude, from the jurisprudence, that this refers to any contractual clause where it is possible to observe a position of exorbitant abuse with correlative 
risk of detriment and subordination of the weak counterparty and that does not have a justification that explains it.

KEYWORDS: adhesion contract, abusive clause, arbitrariness.

SuMARIO. I. Introducción. 2. Las cláusulas abusivas. 2.1.¿Qué se entiende por «abusividad»?: a) Uruguay; b) Perú; c) Bolivia; d) Colombia. 2.2. Características de una cláusula abusiva. 3. Las cláusulas abusivas en Chile. 3.1 El concepto de arbitrariedad. 3.2. Criterios jurisprudenciales para identificar la abusividad de una cláusula en Chile. 4. Un caso particular de arbitrariedad: La cláusula del noshow. 5. Conclusiones. 6. Bibliografía.

\section{INTRODUCCIÓN}

La primera de las causales del artículo 16 letra a) de la Ley 19.496, que establece normas sobre protección de los derechos de los consumidores, se refiere a la arbitrariedad, sin embargo, la norma no repara mayormente en el concepto remitiéndose solo a enunciarlo sin describir su significado. ${ }^{2}$

Según la Real Academia Española (RAE), lo arbitrario es aquello «sujeto a la libre voluntad o al capricho antes que a la ley o a la razón». La jurisprudencia de la Excma. Corte Suprema, en tanto, expresada en Sáez Marín (2001), resuelve un recurso de inaplicabilidad señalando que «un acto o proceder es arbitrario cuando es contrario a la justicia, la razón o las leyes, y dictado por la sola voluntad o capricho».

En una sentencia reciente, Vargas con Banco Estado de Chile (2018), el máximo tribunal confirma que una conducta es arbitraria cuando «no está respaldada por alguna explicación que pueda razonablemente justificarla».

Como se aprecia, lo que se entienda por arbitrario es trascendente para dirimir distintas contiendas judiciales. En el ámbito de los derechos del consumidor, por ejemplo, si la arbitrariedad se detecta en un contrato por adhesión, implica que las cláusulas correspondientes sean abusivas, y que el juez pueda declarar de oficio la nulidad absoluta.

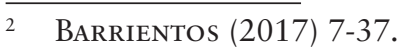


La procedencia de este tipo de nulidad se explica por el interés público que irrogan los contratos por adhesión ${ }^{3}$ : al ser utilizados para abarcar de manera eficiente el fenómeno de la contratación masiva, es fundamental contar con la regulación de normas de equidad en su cumplimiento.

Entender qué es lo arbitrario, entonces, es de suma relevancia, no solamente por los efectos pecuniarios y por la prescripción de diez años que observa la nulidad absoluta, sino también por su significancia: el juez puede (y debe) declararla de oficio. Del mismo modo, dicha circunstancia explica que la abusividad no pueda sanearse por la ratificación de las partes y que pueda ser alegada por todo aquel que tenga interés en ello.

Resulta necesario, entonces, abordar el concepto de arbitrariedad, con el objeto de colaborar en la utilización que se le da a la norma expresada en el artículo 16 letra a) de la Ley 19.496.

En atención a lo anterior, este trabajo se estructura de la siguiente manera: en un primer momento, se realiza un análisis comparado de las cláusulas abusivas en América Latina, distinguiendo entre aquellas legislaciones que ofrecen una definición del concepto y aquellas que extienden un catálogo de cláusulas que se sancionan por abusivas, dentro de las cuales se encuentran las arbitrarias. Luego, se describe el caso chileno al respecto - manifestado en la Ley 19.496-, exponiendo algunos criterios jurisprudenciales para identificar a las cláusulas abusivas, particularmente, aquellas que se han determinado como arbitrarias. Finalmente, aplicando los elementos ya desarrollados, se examina una cláusula contractual comúnmente utilizada en el mercado de servicio de transporte aéreo de pasajeros, con el propósito de determinar si es posible considerarla abusiva por arbitrariedad.

\section{LAS ClÁUSUlas ABUSIVAS}

La autonomía privada entendida, de acuerdo a Barcía, como «el poder o facultad de los individuos para crear actos jurídicos o someterse a un estatuto legal o particular, si lo desean de esta forma,

3 Campos (2018) 11-36. 
y regular los efectos del acto jurídico o someterse a un estatuto preexistente» ${ }^{4}$, se constituye por los siguientes elementos:

i. La libertad para contratar, es decir, la libertad para sentarse a negociar; $y$,

ii. La libertad contractual.

Sobre esta última es que se cimienta la negociación de un determinado acto jurídico o el sometimiento a un estatuto jurídico ya existente como lo serían los contratos de adhesión ${ }^{5}$.

Una primera aproximación sobre estos contratos, la encontramos en la Ley 19.496, específicamente, en su artículo $1^{\circ} \mathrm{N}^{\circ} 6$ que los identifica como «aquel cuyas cláusulas han sido propuestas unilateralmente por el proveedor sin que el consumidor, para celebrarlo, pueda alterar su contenido».

Aquella definición, sin embargo, a juicio de gran parte de la doctrina, es poco feliz, por cuanto no coloca el énfasis en la técnica o forma de contratar — utiliza por el proveedor de bienes y/o servicios para imponer sus términos al otro contratante- sino en el tipo de contrato, cuestión que no sería comprensiva del fenómeno de contratación masiva finalidad para la cual fueron concebidos los contratos por adhesión ${ }^{6}$.

Precisamente, en nombre de ese propósito es que se han observado prácticas que afectan los derechos del consumidor, originadas por: (i) la posición ventajosa en que se encuentran las empresas que proveen los viene o servicios; (ii) las asimetrías de información que los favorecen; y (iii) las grandes diferencias en el poder negociador entre las partes.

Estas circunstancias son abordadas por el legislador con el objeto de equilibrar la relación contractual y prevenir faltas a los derechos del consumidor. Analizados los distintos cuerpos normativos de América Latina relativos a esta materia, se aprecia que la abusividad de una cláusula contractual se determina de dos maneras (que pueden ser conjuntas): definiendo legalmente lo que se entiende

\footnotetext{
BARCIA (2006) 72.

Barcia (2006).

6 Perez y Pizarro (2013) 55.
} 
por cláusula abusiva o extendiendo una pauta donde se expresan las características de las cláusulas que serían abusivas, sin aportar un concepto.

A continuación, se revisarán estos dos modelos para normar las cláusulas abusivas. En un primer momento, el enfoque estará puesto en aquellas legislaciones que entregan una definición legal; posteriormente, se estudiarán los cuerpos normativos que confieren causales para que sean los propios actores los que determinen la procedencia de una cláusula abusiva.

\section{1. ¿Qué se entiende por "abusividad»?}

De las legislaciones estudiadas destacan los conceptos de abusividad prescritos en las legislaciones de los siguientes países:

\section{a) Uruguay}

A través del artículo 30 de la Ley 17.250 ( «Ley de Relaciones de Consumo») se indica que una cláusula es abusiva "por su contenido o por su forma toda cláusula que determine claros e injustificados desequilibrios entre los derechos y obligaciones de los contratantes en perjuicio de los consumidores, así como toda aquella que viole la obligación de actuar de buena fe. La apreciación de carácter abusivo de las cláusulas no referirá al producto o servicio ni al precio o contraprestación del contrato, siempre que dichas cláusulas se redacten de manera clara y comprensible».

Luego, adicionalmente, por medio del artículo 31, se dispone un catálogo de cláusulas abusivas, entre las cuales se encuentra la letra c), que sin hacer alusión expresa al concepto de arbitrariedad, señala que serán abusivas: «las cláusulas que autoricen al proveedor a modificar los términos del contrato».

\section{b) Perú}

Mediante el artículo 49 de la Ley 29.571 («Código de Protección y Defensa del Consumidor») este marco normativo prescribe que «en los contratos por adhesión y en las cláusulas generales de 
contratación no aprobadas administrativamente, se consideran abusivas y, por tanto, inexigibles todas aquellas estipulaciones no negociadas individualmente que, en contra de las exigencias de la buena fe, coloquen al consumidor, en su perjuicio, en una situación de desventaja o desigualdad o anulen sus derechos».

Posteriormente se dispone de un catálogo de cláusulas abusivas, estableciendo en el artículo 50 aquellas «cláusulas abusivas de ineficacia absoluta» y en el artículo 51 las «cláusulas abusivas de ineficacia relativa». En este último grupo, en la letra b) específicamente, se hallan aquellas cláusulas que "permitan al proveedor modificar unilateralmente las condiciones y término de un contrato de duración continuada, en perjuicio del consumidor, salvo que obedezca a motivos expresados en él y el consumidor goce del derecho a desvincularse del mismo sin penalización alguna».

A modo complementario, en el mismo cuerpo legal, es dable destacar el artículo 56, norma que en su letra c) confiere a todo consumidor un derecho contra «métodos comerciales coercitivos», disposición que origina que los proveedores no puedan «modificar, sin el consentimiento expreso del consumidor, las condiciones y términos en los que adquirió un producto o contrató un servicio, inclusive si el proveedor considera que la modificación podría ser beneficiosa para el consumidor. No se puede presumir el silencio del consumidor como aceptación, salvo que él así lo haya autorizado expresamente y con anterioridad».

\section{c) Bolivia}

Por medio del artículo 22 de la Ley 453 («Ley General de los derechos de los usuarias y usuarios y de las consumidoras y consumidores») se define a las cláusulas abusivas como «aquellas que dejan a las usuarias y usuarios, a las consumidoras y los consumidores en estado de total desventaja y desigualdad frente a los proveedores de productos o servicios».

Asimismo, en el punto II de la referida norma, se indican seis causales que originan la abusividad de una cláusula, dentro de la que se encuentra el establecer «a favor del proveedor, la facultad 
unilateral de modificar los términos del contrato de consumo o servicio, previamente suscrito».

\section{d) Colombia}

Finalmente, la legislación colombiana, en el artículo 42 de la Ley 1.480 («Estatuto del Consumidor») manifiesta que «son cláusulas abusivas aquellas que producen un desequilibrio injustificado en perjuicio del consumidor y las que, en las mismas condiciones, afecten el tiempo, modo o lugar en que el consumidor puede ejercer sus derechos. Para establecer la naturaleza y magnitud del desequilibrio, serán relevantes todas las condiciones particulares de la transacción particular que se analiza. Los productores y proveedores no podrán incluir cláusulas abusivas en los contratos celebrados con los consumidores. En caso de ser incluidas serán ineficaces de pleno derecho».

Del mismo modo, y atendiendo al interés de este trabajo, es menester atender a lo señalado por el artículo 38 que se refiere a las cláusulas prohibidas: «En los contratos de adhesión, no se podrán incluir cláusulas que permitan al productor y/o proveedor modificar unilateralmente el contrato o sustraerse de sus obligaciones».

\subsection{Características de una cláusula abusiva}

En oposición al grupo anterior, las legislaciones de los países que siguen, si bien no desarrollan el concepto de "arbitrariedad", configuran catálogos de cláusulas abusivas constituidos por diferentes causales entre las cuales se hallan aquellas estipulaciones que extiendan a favor del proveedor, y en detrimento del consumidor, la atribución de modificar unilateralmente el precio o las condiciones del contrato.

A modo de ilustración, el siguiente cuadro especifica aquellas cláusulas, sancionadas por abusivas, donde se entienden subsumidas las denominadas «arbitrarias»: 


\begin{tabular}{|c|c|c|}
\hline País & Ley & Norma \\
\hline Argentina & $\begin{array}{c}\text { Art. } 37 \text { Ley } \\
24.240\end{array}$ & $\begin{array}{l}\text { «Interpretación. Sin perjuicio de la validez del contrato, se } \\
\text { tendrán por no convenidas: (...) b) Las cláusulas que importen } \\
\text { renuncia o restricción de los derechos del consumidor o amplíen } \\
\text { los derechos de la otra parte». }\end{array}$ \\
\hline Ecuador & $\begin{array}{l}\text { Art. } 43 \text { Ley } \\
\text { Orgánica de } \\
\text { Defensa del } \\
\text { Consumidor }\end{array}$ & $\begin{array}{l}\text { "Cláusulas Prohibidas. Son nulas de pleno derecho y no producirán } \\
\text { efecto alguno las cláusulas o estipulaciones contractuales que: } \\
\text { (...) 5. Permitan al proveedor la variación unilateral del precio o } \\
\text { de cualquier condición del contrato; } 6 \text {. Autoricen exclusivamente } \\
\text { al proveedor a resolver unilateralmente el contrato, suspender } \\
\text { su ejecución o revocar cualquier derecho del consumidor nacido } \\
\text { del contrato, excepto cuando tal resolución o modificación esté } \\
\text { condicionada al incumplimiento imputable al consumidor». }\end{array}$ \\
\hline Paraguay & $\begin{array}{c}\text { Art. } 28 \text { Ley } \\
1.334\end{array}$ & $\begin{array}{l}\text { «Se considera abusivas y con llevan la nulidad de pleno derecho y, } \\
\text { por lo tanto, sin que se puedan oponer al consumidor las cláusulas } \\
\text { o estipulaciones que: (...) e) permitan al proveedor la variación } \\
\text { unilateral del precio o de otras condiciones de contrato }(\ldots) \text { h) } \\
\text { impongan condiciones injustas de contratación, exageradamente } \\
\text { gravosas para el consumidor, o causen su indefensión». }\end{array}$ \\
\hline Venezuela & $\begin{array}{l}\text { Art. } 87 \\
\text { Ley de } \\
\text { Protección al } \\
\text { Consumidor } \\
\text { y Usuario } \\
\end{array}$ & $\begin{array}{l}\text { "Se consideran nulas de pleno derechos las cláusulas o } \\
\text { estipulaciones establecidas en el contrato de adhesión: (...) 5) } \\
\text { Permitan al proveedor la variación unilateral del precio o de } \\
\text { otras condiciones del contrato». }\end{array}$ \\
\hline Brasil & $\begin{array}{l}\text { Art. } 51 \\
\text { Código } \\
\text { Defensa del } \\
\text { Consumidor }\end{array}$ & $\begin{array}{l}\text { «Son nulas de pleno derecho, entre otras, las cláusulas } \\
\text { contractuales relativas a la provisión de productos y servicios } \\
\text { que: (...) IV. Establezcan obligaciones consideradas inequitativas, } \\
\text { abusivas, que coloquen al consumidor en desventaja exagerada, o } \\
\text { sean incompatibles con la buena fe o la equidad». }\end{array}$ \\
\hline Costa Rica & $\begin{array}{l}\text { Art. } 42 \\
\text { Ley de } \\
\text { Promoción } \\
\text { de la } \\
\text { Competencia } \\
\text { y Defensa } \\
\text { Efectiva del } \\
\text { Consumidor }\end{array}$ & $\begin{array}{l}\text { «En los contratos de adhesión, sus modificaciones, anexos o } \\
\text { adenda, la eficacia de las condiciones generales está sujeta al } \\
\text { conocimiento efectivo de ellas por parte del adherente o a la } \\
\text { posibilidad cierta de haberlas conocido mediante una diligencia } \\
\text { ordinaria Son abusivas y absolutamente nulas las condiciones } \\
\text { generales de los contratos de adhesión, civiles y mercantiles, que: } \\
\text { (...) e) Faculten al predisponente para rescindir unilateralmente } \\
\text { el contrato, modificar sus condiciones, suspender su ejecución, } \\
\text { revocar o limitar cualquier derecho del adherente, nacido del } \\
\text { contrato, excepto cuando tal rescisión, modificación, suspensión, } \\
\text { revocación o limitación esté condicionada al incumplimiento } \\
\text { imputable al último». }\end{array}$ \\
\hline $\begin{array}{c}\text { República } \\
\text { Dominicana }\end{array}$ & $\begin{array}{c}\text { Art. } 38 \text { Ley } \\
\text { 358-05 }\end{array}$ & $\begin{array}{l}\text { «Son nulas y no producirán efectos algunos las cláusulas o } \\
\text { estipulaciones contractuales que: (...) e) Permitan al proveedor } \\
\text { la modificación sin previo aviso de los términos y condiciones } \\
\text { del contrato lo que, en ningún caso, podrá hacerse en forma } \\
\text { discriminatoria y sin criterios objetivos para los consumidores } \\
\text { o usuarios; f) Impongan condiciones injustas o discriminatorias, } \\
\text { exageradamente gravosas o causen desprotección al consumidor } \\
\text { o usuario». }\end{array}$ \\
\hline
\end{tabular}




\begin{tabular}{|c|c|l|}
\hline México & $\begin{array}{c}\text { Art. 90 Ley } \\
\text { Federal de } \\
\text { Protección al } \\
\text { Consumidor }\end{array}$ & $\begin{array}{l}\text { «No serán válidas y se tendrán por no puestas las siguientes } \\
\text { cláusulas de los contratos de adhesión ni se inscribirán en el registro } \\
\text { cuando: I. Permitan al proveedor modificar unilateralmente } \\
\text { el contenido del contrato, o sustraerse unilateralmente de sus } \\
\text { obligaciones». }\end{array}$ \\
\hline Panamá & $\begin{array}{l}\text { «Nulidad absoluta de cláusulas abusivas en los contratos de } \\
\text { adhesión. Son abusivas y absolutamente nulas las condiciones } \\
\text { generales de los contratos de adhesión que: (...) 2. Limiten o } \\
\text { extingan la obligación a cargo del otorgante o proveedor. 3. } \\
\text { Favorezcan excesiva o desproporcionadamente la posición } \\
\text { contractual de la parte otorgante o proveedor, importen renuncia } \\
\text { orestricción de los derechos del adherente o consumidor (...) 5. } \\
\text { Faculten al otorgante o proveedor para rescindir unilateralmente } \\
\text { el contrato, modificar sus condiciones, suspender su ejecución, } \\
\text { revocar o limitar cualquier derecho del adherente o consumidor, } \\
\text { nacido del contrato, excepto cuando la rescisión, modificación, } \\
\text { suspensión, revocación o limitación esté condicionada a a } \\
\text { incumplimiento imputable al consumidor». }\end{array}$ \\
\hline
\end{tabular}

\section{Las cláusulas abusivas en Chile}

En el Título II, Párrafo $4^{\circ}$ denominado «normas de equidad en las estipulaciones y en el cumplimiento de los contratos de adhesión", de la Ley 19.496, el Legislador-al igual que los cuerpos normativos de Argentina, Ecuador, Paraguay, Venezuela, Brasil, Costa Rica, República Dominicana, México y Panamá- escrituró las características para identificar a una cláusula abusiva.

Así, en el caso chileno, son abusivas aquellas cláusulas que:

a. Otorguen a una de las partes la facultad de dejar sin efecto o modificar a su solo arbitrio el contrato o de suspender unilateralmente su ejecución, (...) y sin perjuicio de las excepciones que las leyes contemplen;

b. Establezcan incrementos de precio por servicios, accesorios, financiamiento o recargos, salvo que dichos incrementos correspondan a prestaciones adicionales que sean susceptibles de ser aceptadas o rechazadas en cada caso y estén consignadas por separado en forma específica;

c. Pongan de cargo del consumidor los efectos de deficiencias, omisiones o errores administrativos, cuando ellos no le sean imputables:

d. Inviertan la carga de la prueba en perjuicio del consumidor; 
e. Contengan limitaciones absolutas de responsabilidad frente al consumidor que puedan privar a éste de su derecho a resarcimiento frente a deficiencias que afecten la utilidad o finalidad esencial del producto o servicio;

f. Incluyan espacios en blanco, que no hayan sido llenado o inutilizados antes de que suscriba el contrato, y

g. Vayan en contra de las exigencias de la buena fe, atendiendo para estos efectos a parámetros objetivos, causen en perjuicio del consumidor, un desequilibrio importante en los derechos y obligaciones que para las partes de deriven del contrato. Para ello se atenderá a la finalidad del contrato y a las disposiciones especiales o generales que lo rigen (...).

La Excma. Corte Suprema, refiriéndose a este catálogo de cláusulas abusivas, en SERNAC con BBVA (2018), manifiesta que estos son $«(. .$.$) eventos indiscutidos de cláusulas abusivas, por lo cual no$ pueden producir efectos en la relación proveedor-consumidor al no observar las limitaciones impuestas en razón del orden público económico y de los principios que deben presidir la contratación masiva entre proveedores y consumidores a fin de que ella cumpla la función económica de realizar, en algún grado, la equivalencia de las prestaciones, los beneficios mutuos y la conmutatividad. El contrato de adhesión también debe significar un acuerdo de voluntades verdaderamente concurrentes que procuran una relación que realice la garantía de reciprocidad y equivalencia de las prestaciones».

Aunque la Ley del consumidor no prescribe que se entiende por arbitrariedad si se pronuncia sobre la consecuencia que tendrá las estipulaciones que concedan a una de las partes la facultad de modificar a su arbitrio el vínculo contractual: no producirán efecto alguno.

Si revisamos la jurisprudencia, encontraremos diferentes casos en los que se ha aplicado el artículo 16 letra a) de la Ley 19.496, en muchos de ellos el Servicio Nacional del Consumidor (SERNAC) ha sido el actor que ha impulsado la sanción de conductas arbitrarias en las relaciones de consumo.

En consideración a estos elementos se estudiará la aplicación que ha observado el concepto de arbitrariedad en sede judicial a raíz de distintas demandas colectivas interpuestas por el SERNAC. 


\subsection{El concepto de arbitrariedad}

Realizando un análisis a distintas demandas colectivas presentadas por el SERNAC, en las que se pide sancionar la arbitrariedad que se observa en el actuar de distintos proveedores de bienes y/o servicios, se logra determinar que esta agencia de protección al consumidor imputa la arbitrariedad en dos ocasiones, cuando:

a. La empresa pretende arrogarse la posibilidad de abstraerse del fiel cumplimiento del contrato convenido, de modo que prescinde totalmente del consentimiento del consumidor, verificándose una desigualdad evidente entre las prerrogativas e imposiciones que para cada una de las partes significa la celebración del contrato, por ejemplo:

- En el caso de la prestación de servicios educacionales, una determinada Institución de Educación Superior se atribuía la posibilidad de modificar el servicio contratado, al habilitarse para prestar sus servicios de docencia en cualquiera de sus sedes, sin establecer limitaciones razonables o parámetros objetivos que faculten este cambio $^{7}$;

- Refiriéndose a la cláusula de «comisiones» en un contrato bancario, se argumenta que el Banco, al reservarse la posibilidad de modificar las comisiones durante la vigencia de los contratos, reviste de abusividad al convenio, por cuanto se otorga la facultad de modificar a su solo arbitrio el contrato ${ }^{8}$.

- Sobre una productora, se sostiene que atribuirse la facultad de modificar el programa, precios y ubicaciones de un determinado evento, vulnera lo prescrito en el artículo 16 letra a), de la Ley 19.496, al alterar los términos y condiciones que se informaron, ofrecieron y perfeccionaron con los consumidores, generando en estos últimos una sensación se incertidumbre que, en

7 Demanda colectiva presentada por SERNAC contra Corporación Educacional Universidad del Mar, con fecha 04-09-2014, en el $3^{\circ}$ S.J.L. Civil de Viña del Mar.

8 Demanda colectiva interpuesta por SERNAC contra BBVA, con fecha 21-082012, en el $30^{\circ}$ S.J.L. Civil de Santiago. 
definitiva, vulnera el principio de certeza jurídica que todo proveedor de bienes y servicios debe mantener'.

b. La empresa atribuye al solo hecho de guardar silencio una actitud positiva por parte del consumidor, en relación a las modificaciones realizadas por el proveedor:

- Atendiendo, nuevamente, a la cláusula de «comisiones» en un contrato bancario, se argumenta que el Banco, al imputar una consecuencia al silencio del consumidor o cliente, reviste de abusividad al convenio por cuanto aceptar dicha facultad significaría que el proveedor pueda dejar sin efecto o suspender unilateralmente la ejecución del contrato ${ }^{10}$.

- Considerando una cláusula utilizada por una empresa del retail, en la que se expresa que la actuación del consumidor, luego de modificado el sistema de crédito pretéritamente convenido entre ambas partes, significará aceptar las nuevas condiciones de uso, el SERNAC imputa la abusividad de la estipulación, en el sentido del artículo 16 letra a): la empresa se auto confiere una autorización para modificar unilateralmente y a su solo arbitrio, prescindiendo de la voluntad de la otra parte, las condiciones de uso del sistema de crédito ${ }^{11}$.

Sobre estas actuaciones, distintos tribunales de justicia recogen los argumentos utilizados por la agencia de protección al consumidor chilena. De la revisión jurisprudencial realizada, dos sentencias ilustran el debate sobre el carácter abusivo de cláusulas en un contrato de adhesión, señalando que un vínculo contractual adolece de aquel cuando:

9 Demanda colectiva interpuesta por SERNAC contra Ticket Fácil, 19-12-2011, en el $30^{\circ}$ S.J.L. Civil de Santiago.

10 Demanda colectiva interpuesta por SERNAC contra BBVA, con fecha 21-082012, en el $30^{\circ}$ S.J.L. Civil de Santiago.

11 Demanda colectiva interpuesta por SERNAC contra La Elegante, con fecha 29-11-2011, en el $3^{\circ}$ S.J.L. Civil de Coquimbo. 
c. Se afecta el interés difuso de los consumidores. Este concepto es debidamente analizado por la Corte de Apelaciones de Valparaíso con fecha 4 de octubre de 2007, en el fallo causa rol número 874-2007.

En dicha sentencia se indica que la cláusula abusiva «en doctrina es aquella que confiere derechos exorbitantes en favor del proponente del contrato de adhesión, le atribuyen la facultad de fijar o modificar sus elementos, su régimen jurídico, como cambiar el tipo de producto o servicio, modificar los precios, ceder el contrato sin el consentimiento del adherente, la atribución de la facultad exclusiva de interpretación del contenido contractual, la sumisión de la ejecución de las presentaciones a condiciones de carácter potestativo, cuya realización dependa únicamente de la voluntad del proponente, la atribución del derecho de la libre rescisión del contrato al mismo proponente y, en general, cualquier reforma al contenido del contrato ${ }^{12}$.

d. Se modifica unilateralmente el contrato. Esta acción proscrita por el artículo 16 letra a) se constituye, a juicio de la Excma. Corte Suprema, como una «alteración unilateral a los contratos cualquier modificación que se haga a los clientes, si, como consecuencia de ella, se procede a modificar los términos del mismo, dejándoles la opción de aceptar la modificación o de poner término al contrato, desconociendo así el derecho que les asiste a mantener la convención en los términos inicialmente pactados sin la modificación propuesta».

Una estipulación de esta índole significaría «dar legitimación a la empresa para modificar la convención unilateralmente, desde el momento que niega al consumidor su derecho a mantener la operación del contrato, tal cual se había inicialmente pactado». Es insuficiente aquella justificación que se apoya en que el proveedor no impuso al cliente la modificación, pues, de hecho, en el caso que se acepte una cláusula de este talante, el cliente jamás podría manifestar su oposición,

12 SERNAC com Ticket Fácil (2015). 
siendo la alternativa que se ponga término al contrato firmado. Basta para vulnerar al artículo 16 letra a) que el cliente no pueda continuar con el contrato en los términos inicialmente pactados. Por este solo hecho existe contravención a artículo 16 letra a) y la cláusula debe considerarse abusiva» ${ }^{13}$.

\subsection{Criterios jurisprudenciales para identificar la abusividad de una cláusula en Chile}

El carácter abusivo de las estipulaciones contractuales señala la Excma. Corte Suprema, en SERNAC con Ticketmaster (2018), «está determinado por el desequilibrio notable e injustificado en las prestaciones que la estipulación impone, en perjuicio del adherente consumidor y en beneficio del predisponente proveedor». En la misma sentencia, el máximo tribunal determina que aquel desequilibrio puede ser concretado en diferentes ámbitos del convenio, cuestión que queda en evidencia si atendemos al diverso contenido con el que finalizan, adoptando prácticas tales como:

a. Conferir derechos exorbitantes al proponente, como se aprecia en estipulaciones a través de las cuales la empresa proveedora del bien y/o servicio se otorga facultades para fijar o modificar elementos del contrato (cambiar el precio, el tipo de producto o servicio o su régimen jurídico);

b. Excluir o restringir derechos de los consumidores, como se verifica en aquellas cláusulas que disponen de renuncias al ejercicio de acciones judiciales (reducen los medios de prueba, alteran la carga de prueba);

c. Reducir las obligaciones del predisponente, como se identifica en la exoneración o restricción de la responsabilidad que le cabe a la empresa proveedora del bien y/o servicio ante el incumplimiento o cumplimiento defectuoso;

d. Imponen al consumidor cargas desproporcionadas, constituyendo un ejemplo de esta práctica el pago gravoso de

13 SERNAC con BBVA (2018). 
indemnizaciones o el establecimiento de plazos excesivamente breves para ejercer el derecho a reclamo.

En efecto, como también expresa la máxima magistratura en SERNAC con BBVA (2018) «la normativa del consumo se establece bajo un supuesto de asimetría contractual donde es descollante la posición dominante del proveedor, generalmente una empresa poderosa y predisponente habitual del contrato de adhesión, que contrasta con la del consumidor anónimo colocado en la disyuntiva de aceptar el contrato o simplemente no proveerse del servicio o del bien que requiere. A este consumidor profano y anónimo se le protege, haciendo irrenunciables anticipadamente los derechos que la ley en su favor consagra. Conforme a los actuales conceptos jurídicos, el contrato de adhesión se estima normalmente válido, aunque reconocidamente da cuenta de una situación contractual claramente desigual que puede devenir fácilmente en instrumento de abuso».

Recapitulando, el proveedor al diseñar un contrato de adhesión hace manifiesto el desequilibrio que existe en la relación contractual, el que se torna en injustificado al momento de estipular cláusulas que solo ceden en perjuicio del consumidor.

Con el objeto de prevenir la configuración de contratos que adolezcan de exorbitantes atribuciones en favor del proveedor, sin causa lógica y razonable que las expliquen, diferentes legislaciones han prescrito que estas serán abusivas. Una de las razones que explican esa sanción es la causal de arbitrariedad, cuya aplicación se identificará por medio de una disposición contractual presente en el mercado de servicio de transporte aéreo de pasajeros.

\section{UN CASO PARTICULAR DE ARBITRARIEDAD: LA CLÁUSULA DEL NO-SHOW}

Tomando en consideración lo expuesto y a la luz de lo preceptuado en el artículo 16 letra a) de la Ley 19.496, toca analizar aquella cláusula utilizada en el mercado de servicio de transporte aéreo de pasajeros, en virtud de la cual líneas aéreas impiden a los consumidores utilizar el tramo de vuelta en los casos que no hayan hecho uso del tramo de ida. 
Un ejemplo de este tipo de cláusulas es el siguiente:

«USO DEL PASAJE: Los vuelos o tramos que componen el itinerario deberán volarse en el orden consecutivo indicado. El Transportista, sujeto a las condiciones revistas en la legislación aplicable, podrá negar el embarque a un pasajero que no cumpla con el orden del itinerario antes referido o si el pasajero no ha volado alguno de los tramos indicados en su pasaje. Si no se vuela alguno de los tramos indicados en el itinerario, este se cancelará en su totalidad, sin previo aviso, no procediendo ningún tipo de reembolso salvo que las condiciones de la tarifa de tu pasaje lo permitan. A modo de ejemplo y sin que esta condición se limite a este caso en específico, si el pasajero no vuelta el primer tramo que se especifica en el itinerario (entendiéndose como ida), este no podrá volar ningún otro (entendiéndose como vuelo de escala o de vuelta). El pasaje que compraste es intransferible».

Esta cláusula es abusiva pues, además de vulnerar el artículo 16 letra g) de la Ley 19.496 que dice relación con la buena fe con las que se deben ejecutar los contratos, implica un desequilibrio importante en detrimento del consumidor, quien ve limitado su derecho a utilizar de forma libre - y de la manera que estime conveniente- el derecho patrimonial o bien adquirido, al mismo tiempo que la empresa proveedora del servicio contratado, de manera arbitraria, se reserva la facultad de efectuar modificaciones al vínculo contractual, negando la provisión del servicio al consumidor sin proporcionar una justificación económica o comercial y ni siquiera extendiendo reembolso o aviso al consumidor.

La jurisprudencia, en este sentido, ha sido tajante, y argumentando en razón de la causal de arbitrariedad dispuesta en el artículo 16 letra a) de la Ley 19.496 ha fallado en favor de los consumidores en distintas ocasiones. En Ramírez con LATAM Airlines Group (2017), por ejemplo, la Corte de Apelaciones de Antofagasta, teniendo a la vista, precisamente, la cláusula anteriormente transcrita, resuelve:

El consumidor paga un pasaje que comprende dos tramos e impedirle tomar alguno de los tramos si por alguna razón no toma el tramo inicial, constituye, de cara a la contraprestación 
a favor de la aerolínea, un grave desequilibrio y se traduce en una cláusula abusiva evidente (...). ${ }^{14}$

Se sostiene esta conclusión en tres fundamentos de los cuales nos interesa aquel que se refiere al concepto de arbitrariedad y que señala que:

(...) no hay justificación alguna económica ni comercial a la luz de lo expuesto para que se pierda el pasaje de vuelta, ni siquiera desde el punto de vista financiero para presionar al pasajero, sino es un aprovechamiento irracional y abusivo de situaciones personales de los pasajeros favoreciéndose discrecionalmente por la línea área. ${ }^{15}$

Sobre el argumento precedente, Barrientos analizando la sentencia en Jarpa con Lan, controversia originada por la utilización de la cláusula citada, concluye - aun cuando el fallo no se refiere explícitamente a la modificación unilateral y arbitraria — que «la ratio decidendi de esta sentencia es que el empresario no puede limitar los derechos adquiridos por el consumidor que compra pasajes de ida y de vuelta. En efecto, el tribunal entendió que el dinero pagado por los dos tramos aéreos había ingresado al patrimonio de la empresa, por lo que no puede negarse el cumplimiento de la prestación». ${ }^{16}$

En la misma línea que los tribunales chilenos se pronunció el Tribunal Supremo de España en su sentencia 631/2018, desentrañando la siguiente cláusula establecida en los contratos de Iberia Líneas Aéreas de España S.A.:

Dependiendo del tipo de tarifa, clase de servicio, estancia en destino, etc., puede realizar su reserva para vuelos de ida o ida o vuelta. Independientemente de la tarifa aplicada, si alguno de los trayectos comprados no se usa, automáticamente se

14 Ramírez con LATAM Airlines Group (2017).

15 Ramírez con LATAM Airlines Group (2017).

16 BARRIENTOS (2017). 
cancelarán los trayectos restantes comprendidos en el mismo billete. (Organización de Consumidores y Usuarios. ${ }^{17}$

La máxima magistratura española indica que esa condición «no supone que exista una obligación del viajero de utilizar todos y cada uno de los tramos contratos, de tal forma que tal obligación constituya una "prestación esencial» del contrato y convierta lo que es un derecho otorgado al viajero por el contrato en una obligación del viajero; ni que la utilización parcial de la prestación por parte del cliente modifique el objeto principal del contrato". ${ }^{18}$

Luego, refiriéndose al argumento de la empresa, que explica que la cláusula es un elemento fundamental de la política de precios de la compañía-cuestión que pudo, eventualmente, haberse acogido como una causa razonable para desestimar la abusividad de la cláusula-, el Tribunal Supremo de España resuelve: «la decisión de abaratar los precios para el caso de la venta conjunta de varios tramos es una opción legítima de la compañía aérea. Pero no supone que, una vez que la compañía ha comercializado un billete que incluye varios tramos a un precio inferior al que habría supuesto comercializarlos separadamente, la utilización por el cliente de alguno de esos tramos (por ejemplo, en un billete de ida y vuelta, la no utilización de la ida y sí solamente de la vuelta) cause un perjuicio a la compañía aérea, que ha cobrado el precio íntegro del billete que sacó a la venta, sin que la ausencia de un pasajero en el avión incremente sus costes, pues en todo caso sucedería lo contrario». ${ }^{19}$

\section{Conclusiones}

La legislación chilena, sin embargo, no define lo que entiende por abusividad de una cláusula contractual, optando por extender las causales y características a partir de las cuales se les puede identificar,

17 Organización de consumidores y usuarios (OCU) con Iberia Líneas Aéreas de España S.A. (2018).

18 Organización de consumidores y usuarios (OCU) con Iberia Líneas Aéreas de España S.A. (2018).

19 Organización de consumidores y usuarios (OCU) con Iberia Líneas Aéreas de España S.A. (2018). 
un modelo que también ha sido adoptado por otras legislaciones de América Latina.

En SERNAC con BBVA (2018), la Excma. Corte Suprema, desarrollando el concepto de abusividad sostiene que «(...) la consideración del carácter abusivo de una cláusula contractual es una cuestión que importa una apreciación sobre el contenido de la estipulación en cuanto a la extensión de las prerrogativas que confiere a una de las partes y posición en que coloca o puede colocar a la contraparte. Esa evaluación no requiere necesariamente la prueba de una situación de abuso real y concreto, bastando para el juzgamiento la posibilidad de que la articulación valide una posición de abuso exorbitante con correlativo riesgo de detrimento y subordinación de la contraparte débil. Por ello, cada cláusula cuestionada es examinada en su contenido, evaluándose el espacio o ámbito de acción que entrega a las partes — que puede ser razonable y plausible atendidas las características de la relación- o, por el contrario, exorbitante y desmedido, generando el consiguiente riesgo de desmedro injusto de los derechos de la contraparte».

Dentro del catálogo de causales desde el cual se colige la abusividad de una cláusula, se encuentran aquellas que otorgan a una de las partes las facultad de dejar sin efecto o modificar a su solo arbitrio el contrato o de suspender unilateralmente su ejecución. Sin embargo, la arbitrariedad no se define legalmente. Ante esto, se realizó un ejercicio de relevamiento doctrinal y jurisprudencial que nos permite entenderla para luego aplicarla.

La doctrina, aunque no precisamente del ámbito del derecho del consumidor, se refiere a lo arbitrario como aquello que es «abusivo, caprichoso o no razonable» ${ }^{20}$. De una manera más específica, desentrañando la potestad reglamentaria, Cazor y Pfeffer indican que arbitrariedad significa: «apreciación falsa de los hechos, ruptura del principio de igualdad, falta de proporcionalidad, desviación del poder, vulneración de los derechos fundamentales, irrazonabilidad». ${ }^{21}$

Atendiendo al derecho del consumidor, en tanto, es posible encontrar referencias jurisprudenciales que permiten identificar aquella causal de abusividad, a partir de las cuales se observa una posición

20 Valenzuela (1990) 175-198.

21 Cazor y Pfeffer (2009) 191-227. 
de abuso exorbitante con correlativo riesgo de detrimento y subordinación de la contraparte débil y que no cuentan con justificación alguna que las explique.

En Ramírez con LATAM Airlines Group (2017), por ejemplo, la Corte de Apelaciones de Antofagasta, resuelve que no existen fundamentos económicos ni comerciales para que un pasajero pierda el pasaje de vuelta por el hecho de no haber utilizado el de ida. Lo que, si existe, a juicio de dicha Corte, es un aprovechamiento irracional y abusivo de situaciones personales de los pasajeros, que discrecionalmente solo favorece a la aerolínea.

En un mismo orden de ideas, sobre casos similares, el Tribunal Supremo de España se pronunció desmenuzando las argumentaciones que una empresa ofreció para explicar la decisión de negar el embarque a pasajeros que se presentan solamente al vuelo de vuelta, expresando que, bajo ninguna circunstancia, la ausencia de un pasajero incrementa los costos de la empresa, pues, de hecho, sucedería lo contrario. ¿Dónde se hallan, entonces, las razones que explican el negar un servicio por el que diligentemente el consumidor ya enteró el pago convenido?

En diferentes contiendas judiciales, se ha resuelto que basta para vulnerar el artículo 16 letra a) que el cliente no pueda continuar con el contrato en los términos inicialmente pactados. Esto es precisamente lo que ocurre con la cláusula del no show: aún cuando se disponga en el contrato por adhesión, la cláusula otorga a la aerolínea la facultad de dejar sin efecto el convenio - acto prohibido por la Ley 19.496 - sin indicar causa racional, objetiva y lógica que explique la acción, cuestión que, como hemos visto en un análisis comparado; en la jurisprudencia chilena y española; y en la doctrina, es derechamente arbitraria. 


\section{BibliografíA}

\section{a) Doctrina:}

BARCíA, R. (2006): «La autonomía privada como principio sustentador de la teoría del contrato y su aplicación en Chile», Cuadernos de Análisis Jurídico, Colección de Derecho Privado, №3: pp. 159-185. BARRIENTOS, F. (2017): «El concepto de arbitrariedad del artículo 16 a) de la Ley de consumo: Análisis de los criterios judiciales que examina la cláusula de modificación unilateral», Revista de Derecho, Universidad de Concepción, Revista N²42, año LXXXV: pp. 7-37.

CAmpos, S. (2018): «Sobre el poder-deber de declarar de oficio la nulidad de cláusulas manifiestamente abusivas y su aplicabilidad en Chile», Revista de Derecho y Consumo, Universidad Diego Portales, $\mathrm{N}^{\circ} 1$ (enero): pp. $11-36$.

Cazor, K.; Pfeffer, E. (2009). «La búsqueda de criterios orientadores en la configuración de las potestades normativas en Chile», Revista Ius et Praxis, $\mathrm{N}^{\circ} 15$ (1): pp. 191-227.

Valenzuela, R. (1990). «El recurso constitucional de protección sobre materia ambiental en Chile», Revista de Derecho, Universidad Católica de Valparaíso, Nº XIII (1989-1990): pp. 175-198.

\section{b) Jurisprudencia:}

Jarpa con LAN. (2009): Segundo Juzgado de Policía Local, Rol Nº 73.6455-2009.

Organización de Consumidores y Usuarios (OCU) con Iberia Líneas Aéreas de España S.A. (2018): Tribunal Supremo de España, 12 de noviembre de 2018 (recurso de casación). Disponible en: http://www.abc. es/gestordocumental/uploads/economia/sentencia-clausulas-iberia. pdf [Fecha de consulta: 20 de diciembre de 2018].

Ramírez con LATAM Airlines Group S.A. (2017): Corte de Apelaciones de Antofagasta, 16 de octubre de 2017 (recurso de apelación). Disponible en: http://corte.poderjudicial.cl/SITCORTEPORWEB/ DownloadFile.do?TIP_Documento=3\&TIP_Archivo=3\&COD_ Opcion=1\&COD_Corte $=15 \& C R R \_I d T r a m i t e=20138123 \&$ CRR_ IdDocumento=18038111 [Fecha de consulta: 20 de agosto de 2018]. Sáez Marín (2001): Corte Suprema, 21 de junio de 2011 (recurso de inaplicabilidad), Revista de Derecho y Jurisprudencia, tomo 98 (2001), sección $5^{\text {a }}$, p. 105. 
Servicio Nacional del Consumidor con BBVA Banco Bilbao Vizcaya Argentaria Chile (2018): Corte Suprema, 29 de noviembre de 2018 (recurso de casación en el fondo). Disponible en: https://suprema.pjud.cl/ SITSUPPORWEB/DownloadFile.do?TIP_Documento=3\&TIP_ Archivo $=3 \&$ COD_Opcion $=1 \&$ COD_Corte $=1 \&$ CRR_ IdTramite $=3368570 \&$ CRR_IdDocumento $=2871455 \&$ Cod_Descarga $=11$ [Fecha de consulta: 30 de noviembre de 2018].

Servicio Nacional del Consumidor con Ticketmaster S.A. (2009): Corte Suprema, 09 de abril de 2018 (recurso de casación en el fondo). Disponible en: https://suprema.pjud.cl/SITSUPPORWEB/ DownloadFile.do?TIP_Documento=3\&TIP_Archivo=3\&COD_ Opcion=1\&COD_Corte $=1 \& C R R \_I d T r a m i t e=3194389 \& C R R \_$ IdDocumento=2703293\&Cod_Descarga $=11$ [Fecha de consulta: 20 de agosto de 2018].

Servicio Nacional del Consumidor con Ticket Fácil S.A. (2015): 30 S.J.L. Civil de Santiago. Disponible en: https://civil.pjud.cl/CIVILPORWEB/ DownloadFile.do?TIP_Documento=3\&TIP_Archivo=3\&COD_ Opcion=1\&COD_Tribunal=288\&CRR_IdTramite=67509694\&CRR_ IdDocumento=60184555 [Fecha de consulta: 22 de enero de 2019].

Vargas con Banco Estado de Chile (2018): Corte Suprema, 20 de agosto de 2018 (recurso de apelación). Disponible en: https://suprema.pjud. cl/SITSUPPORWEB/DownloadFile.do?TIP_Documento=3\&TIP_ Archivo $=3 \&$ COD_Opcion $=1 \& C O D \_C o r t e=1 \& C R R$ IdTramite $=3293768 \&$ CRR_IdDocumento=2799095\&Cod_Descarga $=11$ [Fecha de consulta: 23 de agosto de 2018].

\section{c) Normativa}

Ley (chilena) $\mathrm{N}^{\circ} 19.496$ que establece normas sobre protección de los derechos de los consumidores

Ley (uruguaya) $\mathrm{N}^{\circ} 17.250$ de relaciones de consumo.

Ley (peruana) N²9.571 que establece el Código de Protección y Defensa del Consumidor.

Ley (argentina) $\mathrm{N}^{\circ} 24.240$ que establece normas de protección y defensa de los consumidores.

Ley (colombiana) $\mathrm{N}^{\circ} 1.480$ por medio de la cual se expide el Estatuto del Consumidor y se dictan otras disposiciones.

Ley (ecuatoriana) $\mathrm{N}^{\circ} 21$ Orgánica de Defensa del Consumidor.

Ley (paraguaya) $\mathrm{N}^{\circ} 1.334$ de Defensa del Consumidor y del Usuario.

Ley (venezolana) de Protección al Consumidor y Usuario.

Código (brasileño) de Defensa del Consumidor. 


\section{Diego Aguilar Vildoso}

Ley (costarricense) de Promoción de la Competencia y Defensa Efectiva del Consumidor.

Ley (mexicana) Federal de Protección al Consumidor.

Ley (panameña) $\mathrm{N}^{\circ} 45$ que dicta Normas sobre Protección al Consumidor y Defensa de la Competencia. 


\title{
ACERCA DE LA RESPONSABILIDAD POR PRODUCTOS SANITARIOS DEFECTUOSOS: REFLEXIONES SOBRE LA PRESCRIPCIÓN EXTINTIVA ${ }^{\mathrm{I}}$
}

\author{
About THE DEFECTIVE SANITARY \\ PRODUCTS LIABILITY: REFLECTIONS \\ ON THE EXTINCTIVE PRESCRIPTION
}

\section{Erika Isler Soto ${ }^{2}$}

Resumen. El trabajo se refiere a la prescripción extintiva de la acción indemnizatoria correspondiente a la responsabilidad por productos sanitarios defectuosos en el ordenamiento jurídico chileno. Para tal efecto, se aborda en primer lugar su regla general, esto es, de cinco años contados desde la aparición de los daños. Luego, en

1 Este trabajo forma parte del Proyecto FONDECYT de Iniciación nº 11190230 : «Los medios de tutela del consumidor ante el producto defectuoso, en la ley 19.496» del que la autora es investigadora responsable.

2 Profesora de Derecho Civil (Universidad de Talca); Abogada; Licenciada en Ciencias Jurídicas y Sociales (Universidad Austral de Chile); Magíster en Derecho, mención Derecho Privado (Universidad de Chile); Magíster en Ciencia Jurídica (Pontificia Universidad Católica de Chile); Doctora en Derecho (Pontificia Universidad Católica de Chile).E-mail: eisler@utalca.cl 
segundo lugar, se examina la posible vigencia de un plazo máximo de caducidad de inicio objetivo. Con posterioridad se revisan dos excepciones a la regla señalada: los ensayos clínicos y las patologías del régimen de garantías en salud.

PAlABRAS Clave: consumidor, prescripción extintiva, producto sanitario, responsabilidad por productos.

Aвstract. The document refers to the statute of limitation of the medicament product liability in the Chilean legal system. At first the paper refers to the general rule: 5 years from the appearance of the damages. Then, it is analyzed a possible maximum expiration term. Finally, two exceptions rules are reviewed: clinical experiments and pathologies of the health guarantee law.

KEYWORDS: medicament, product liability, consumer, statute of limitation.

SUMARIO. Introducción. 1. La regla general. 1.1. El plazo propiamente tal.1.2. El dies a quo.1.2.1. La manifestación del daño. 1.2.2. La vigencia de un plazo máximo de caducidad. 2. Las excepciones. 2.1. Los ensayos clínicos. 2.2. El régimen de garantías en salud (Ley 19.966). 3. Conclusiones. 4. Bibliografía.

\section{INTRODUCCIÓN}

Aunque nuestro ordenamiento jurídico no cuenta con un régimen general que aborde la responsabilidad por productos - por cierto es un importante desafío pendiente-, dicha omisión es parcialmente resuelta por el Código Sanitario, en el sentido de que la Ley 20.850 sobre protección financiera para diagnósticos y tratamientos de alto costo (más conocida como Ley Ricarte Soto) le introdujo un estatuto de responsabilidad que busca hacerse cargo de ello en particular cuando el producto tenga el carácter de sanitario (farmacéutico, alimenticio, cosmético, de higiene, de odorización personal y artículos de uso médico).

Ahora bien, dicha normativa se refiere expresamente a la prescripción extintiva, mediante la regulación del plazo como uno de sus elementos, instaurando una regla general, seguida de dos casos a los cuales prefirió otorgarles plazos particulares. Desde luego, la 
explicitación del régimen aplicable a esta institución resulta un acierto, si consideramos que precisamente el establecimiento de plazos extintivos incide directamente en el campo de eficacia que puede tener una acción —esta vez en razón del tiempo-y, por lo tanto, no solo por ella se asignan derechos, sino que también constituirá uno de los criterios que presumiblemente tomará en cuenta el individuo, a quien se puede reclamar la indemnización, para decidir si se atiene o no a ciertos estándares de cuidado.

No obstante, la redacción de las disposiciones que se refieren a ella puede dar lugar a una serie de dudas interpretativas, de cuya respuesta dependerá si la pretensión del actor se verá o no satisfecha. El propósito de este trabajo, por lo tanto, consiste en examinar y analizar dichas reglas, dando cuenta de los posibles desafíos que han quedado pendientes para el Legislador, y proponiendo también algunas vías de interpretación.

Cabe señalar que aunque la prescripción se compone de dos elementos - transcurso del tiempo y silencio de la relación jurídica- el texto se referirá, por razones de extensión, únicamente al primero de ellos, que es precisamente el que ha sido regulado por el C. San. Queda así para otra ocasión el análisis de los supuestos de interrupción y suspensión que pueden resultar procedentes y cuya regulación el Legislador también ha omitido.

Por otra parte, se previene que se analizará en primer lugar el plazo común contemplado en el estatuto de responsabilidad por productos sanitarios, para luego revisarse los dos casos de excepción, mencionados en él mismo, referentes a los ensayos clínicos y el régimen de garantías en salud (GES).

\section{LA REGLA GENERAL}

Tal como se indicó con anterioridad, el Código Sanitario otorga a quien ha sufrido daños a causa de un producto sanitario defectuoso, un plazo de cinco años contados desde la manifestación del daño ya 
sea por el defecto del producto o por el daño que dicho defecto le ocasionó (Art. 111 L C. San.) ${ }^{3}$, para poder reclamar su resarcimiento.

Ahora bien, antes de entrar al análisis de dicha regla, debemos recordar que el transcurso del tiempo como elemento de un plazo extintivo se compone a su vez de dos aspectos que presentan igual relevancia: el plazo propiamente tal (inicial) y el momento a partir del cual este comienza a correr (dies a quo). A continuación, se revisarán ambos presupuestos de manera separada.

\subsection{El plazo propiamente tal}

Como se adelantó, el C. San. establece un plazo de prescripción de cinco años, el que se cuenta desde la manifestación del daño. Se puede apreciar entonces que no coincide con el término establecido en el C.C. para la responsabilidad extracontractual, fijado en cuatro años desde la perpetración del acto (Art. 2332 CC. $\left.{ }^{4}\right)$. Tampoco se identifica con aquel término consagrado para la contractual, puesto que si bien son coherentes en lo que dice relación con el plazo inicial - cinco años para las acciones ordinarias - no ocurre lo mismo con el dies a quo (Art. 2515 CC $^{5}$ ). Lo anterior nos recuerda una vez más la anacronía de la mantención de reglas diferenciadas, únicamente en razón de la fuente en la cual tiene origen, para explicar la acción indemnizatoria por productos defectuosos ${ }^{6}$.

Artículo $111 \mathrm{~L}$ : «La acción de reparación de los daños y perjuicios previstos en este Título prescribirá a los cinco años contados desde la manifestación del daño, ya sea por el defecto del producto o por el daño que dicho defecto le ocasionó. La acción de repetición del que hubiese satisfecho la indemnización contra todos los demás responsables del daño prescribirá en el plazo de dos años contado desde el día de su pago. La acción para el resarcimiento de los daños producidos con ocasión de un ensayo clínico prescribirá en el plazo establecido en el artículo $111 \mathrm{E}$ ».

4 Art. 2332 CC: «Las acciones que concede este título por daño o dolo, prescriben en cuatro años contados desde la perpetración del acto».

5 Art. 2515 CC: «Este tiempo es en general de tres años para las acciones ejecutivas y de cinco para las ordinarias. La acción ejecutiva se convierte en ordinaria por el lapso de tres años, y convertida en ordinaria durará solamente otros dos».

6 Sobre este punto se puede revisar: Della Maggiora y Zárate (2003) 8; IsLer Soto (2018) 599-609; Momberg Uribe (2017) 145. 
Con todo, el mayor despliegue en el tiempo de la acción civil, tanto si lo ponderamos con la responsabilidad extracontractual (cinco años) como con la contractual (manifestación de los daños), podría insinuarnos que el legislador esta vez ha considerado que la lesión puede referirse a aspectos más sensibles que en otros casos. Ello puede obedecer a que las consecuencias de la presencia de un defecto en un producto sanitario - pensemos, por ejemplo, en los medicamentos- muy probablemente se situarán en el ámbito extrapatrimonial - la vida o la integridad del consumidor-, por lo que aumentan las posibilidades de que se afecten bienes jurídicos no disponibles. Ello es una manifestación de que la regulación de la prescripción extintiva dependerá de las valoraciones y ponderaciones que el Estado - y con ello la conciencia social — tenga acerca de la eventual prevalencia o equilibrio entre la justicia y la certeza jurídica.

Ahora bien, esta técnica por la cual se contemplan plazos más extensos para reclamar ciertas prerrogativas en razón de sus especiales características, la encontramos en derecho comparado, incluso de manera más patente. Así, por ejemplo, en el régimen general del BGB alemán, se exceptúa de la prescripción ordinaria (regelmässige Verjährungsfrist) de tres años contados desde el establecimiento de la pretensión $(\mathbb{S} 195 \mathrm{BGB})^{7}$, la prescripción de treinta años (Dreissigjährige Verjährung), que procede respecto de acciones que tienen por objeto obtener el resarcimiento de daños a la vida, cuerpo, salud, libertad u opciones sexuales, entre otras ${ }^{8}$.

\195 BGB: «Regelmäßige Verjährungsfrist. Die regelmäßige Verjährungsfrist beträgt drei Jahre».

8 \197 BGB: "Dreißigjährige Verjährungsfrist. (1) In 30 Jahren verjähren, soweit nicht ein anderes bestimmt ist, 1 . Schadensersatzansprüche, die auf der vorsätzlichen Verletzung des Lebens, des Körpers, der Gesundheit, der Freiheit oder der sexuellen Selbstbestimmung beruhen, 2. Herausgabeansprüche aus Eigentum, anderen dinglichen Rechten, den SS 2018, 2130 und 2362 sowie die Ansprüche, die der Geltendmachung der Herausgabeansprüche dienen, 3. rechtskräftig festgestellte Ansprüche, 4. Ansprüche aus vollstreckbaren Vergleichen oder vollstreckbaren Urkunden, 5. Ansprüche, die durch die im Insolvenzverfahren erfolgte Feststellung vollstreckbar geworden sind, und 6. Ansprüche auf Erstattung der Kosten der Zwangsvollstreckung. (2) Soweit Ansprüche nach Absatz $1 \mathrm{Nr} .3$ bis 5 künftig fällig werdende regelmäßig wiederkehrende Leistungen zum Inhalt haben, tritt an die Stelle der Verjährungsfrist von 30 Jabren die regelmäßige Verjährungsfrist». 


\subsection{El dies a quo}

El dies a quo de un plazo extintivo corresponde al momento a partir del cual este comienza a correr. Ahora bien, el Código Sanitario esta vez, y a diferencia de lo que ocurre a propósito del GES, explicita el hecho que determina el inicio de la prescripción, situándolo en específico en la «manifestación del daño, ya sea por el defecto del producto o por el daño que dicho defecto le ocasionó» (Art. $111 \mathrm{~L}$ ).

\subsubsection{La manifestación del daño}

Se puede advertir que el Legislador rechaza la utilización de un criterio meramente objetivo para el cual es indiferente si el legitimado activo conoce o no la disponibilidad de la acción, como podría ser, por ejemplo, la compra, la entrega e incluso la ingesta del producto de que se trate.

Se opta así por un sistema que, alejándose de la certeza jurídica, se acerca más a la justicia. Una solución en contrario implicaría negar la tutela a aquel sujeto que efectivamente no ha accionado, pero no por desidia, sino que simplemente en atención a que no conocía el perjuicio. Como explica Lanata Fuenzalida, la prescripción «descansa sobre el presupuesto de que el titular del crédito conoce a cabalidad su existencia y que su abandono obedece a un acto de voluntariedad, es decir está en plena condición de haberlo podido ejercer» ${ }^{9}$. Ello resulta especialmente relevante en el caso de los productos sanitarios, puesto que muy frecuentemente el daño a la salud o a la vida de un individuo solo se advertirá mucho tiempo después de su utilización o disfrute.

Por tal razón, nuestros tribunales de justicia ya se habían pronunciado, en el mismo sentido, precisamente respecto de bienes que caben bajo la denominación de «sanitarios», en sede de protección de los derechos de los consumidores, cuando aún no entraba en vigencia la Ley 20.850 y, por lo tanto, tal era el estatuto que solía invocarse. En efecto, los pronunciamientos judiciales, al interpretar el Art. 26 LPDC, que en aquel entonces establecía un plazo de "seis meses, contado desde que se haya incurrido en la infracción respectiva», de

9 Lanata Fuenzalida (2010) 245. 
manera mayoritaria comprendieron que solo podía principiar con la advertencia de los daños. Así ocurrió, por ejemplo, a propósito de suplementos alimenticios nocivos ${ }^{10}$, o chocolates contaminados con Salmonella ${ }^{11}$.

Ahora bien, siendo claro que el término no comenzará a correr sino cuando se manifieste el daño, la norma a continuación menciona dos posibilidades en que ello puede suceder: la advertencia del defecto o bien del daño propiamente tal. Sobre este punto, Corral Talciani ya, en los años 2015 y 2016 había acusado la ambigüedad de dicha expresión, desde que no se puede vislumbrar claramente en qué casos, podría advertirse el daño, únicamente mediante la constatación del defecto ${ }^{12}$. Se trata de una prevención acertada, en el sentido de que la propia disposición (Art. 111 L) indica que ambos hechos - la revelación del daño y del defecto - constituyen modalidades de la aparición del daño, de lo que se desprende que está reiterando, al menos una de dichas exigencias.

Por otra parte, cabe mencionar que si bien el rechazo a la utilización de un sistema objetivo estricto resulta correcta, hubiese sido deseable que el Legislador precisara el sujeto relevante al momento de la determinación de la manifestación del daño. Aunque la lógica indica que debiese tratarse de la propia víctima, en un eventual juicio se pueden plantear otras posibilidades, como podría ser, por ejemplo, el médico.

Lo anterior se entronca con otra cuestión igualmente importante, y que dice relación con aquellos casos en los cuales, apareciendo los síntomas, no sea posible aún asociárselos a la presencia del defecto que causó la enfermedad. Ello puede verificarse en la práctica, en atención a que recién luego de la realización de un estudio, más o menos extenso según el supuesto particular, y fundamentado en el análisis de exámenes médicos, es probable que se tenga conocimiento de la relación de causalidad entre la anomalía y el perjuicio.

En estos casos, el plazo de prescripción únicamente comenzará a correr cuando ello efectivamente ocurra, puesto que una acción interpuesta con anterioridad podría incluso considerarse como

\footnotetext{
10 SERNAC con Brawn Medical S.A. (2010).

11 SERANC con Falabella SACI (2008).

12 Corral Talciani (2015); Corral Talciani (2016) 899-908.
} 
irresponsable o abusiva. Recordemos, asimismo, lo señalado acerca de la naturaleza excepcional de la prescripción — de haber duda debe preferirse la vigencia del derecho-, así como de su carácter sancionatorio, por el cual no podría reprocharse la inactividad del sujeto, si no ha podido salir de él, lícita y responsablemente.

Cabe agregar que el Art. 111 J C. San. establece como presupuesto de la responsabilidad civil, la acreditación de la relación de causalidad entre el daño y el defecto, por lo que mal podría comenzar a correr la prescripción con anterioridad a que ello ocurra, puesto que si fuere así la acción podría nacer prescrita.

Con todo, en este mismo sentido se falló en su oportunidad en la causa Sernac con Braun Medical S.A. (2010), al rechazarse que la prescripción se contara a partir de la sola manifestación de los síntomas (bipokalemia). Por el contrario, solo podía principiar desde que ellos, pudieron ser asociados a la ingesta del producto (ADN) fabricado con un menor porcentaje de potasio al que correspondía y que constaba en el rotulado ${ }^{13}$.

\subsubsection{La vigencia de un plazo máximo de caducidad}

En aquellos supuestos en los cuales el momento de inicio se fija conforme a un criterio subjetivo - la advertencia de los daños, el conocimiento del legitimado pasivo, la disponibilidad de la acción, etc. - la técnica jurídica suele exigir su asociación a un plazo máximo de caducidad, el cual sí debe principiar de manera objetiva. La fundamentación de una regla en tal sentido radica en la tutela de la certeza jurídica, dentro de un esquema en que previamente había sido desplazada por la justicia ${ }^{14}$. Así explica Cañizares Laso: «un sistema subjetivo, único y genuino, podría conducir a que las pretensiones nunca prescribirían si el titular de la pretensión no tiene conocimiento o posibilidad de conocimiento, en los términos vistos» ${ }^{15}$.

En nuestro ordenamiento jurídico encontramos algunos ejemplos de ello. Así, por ejemplo, el Art. 36 del DL 3557 de 1980 sobre

13 SERNAC con Brawn Medical S.A. (2010).

14 Ver Barros Bourie (2007) 767; Ferrada Walker (2012) 53; LAMARCA I Marquès (2002) 4.

15 Cañizares Laso (2002) 421. 
Protección Agrícola (Ministerio de Agricultura) señala que: «Si al aplicar plaguicidas se causaren daños a terceros, ya sea en forma accidental o como consecuencia inevitable de la aplicación, estos podrán demandar judicialmente la indemnización de perjuicios correspondiente dentro del plazo de un año contado desde que se detecten los daños. En todo caso, no podrán ejercerse estas acciones una vez que hayan transcurrido cuatro años desde la aplicación del plaguicida».

Asimismo, el Art. 146 inc. $5^{\circ}$ de la Ley de Navegación (DL 2222) establece que: «Los derechos a indemnizaciones y las obligaciones que nazcan de lo preceptuado en este párrafo, prescribirán en tres años, contados desde la fecha en que se produjo el daño o se realizaron los actos que dan acción de reembolso. Sin embargo, no podrá interponerse acción alguna después de seis años contados desde la fecha del siniestro. Cuando el siniestro consista en una serie de acontecimientos, el plazo de seis años se computará desde la fecha inicial del más antiguo».

No obstante, el Código Sanitario ha silenciado este punto, por lo que no existe claridad acerca de la procedencia de un eventual plazo máximo, sobre lo cual en su momento se pronunciarán nuestros tribunales de justicia. No obstante, en la respuesta que se otorgue tendrá especial incidencia, la determinación del régimen supletorio aplicable al estatuto de responsabilidad contenido en el C. San., lo cual tampoco es resuelto por esta normativa.

Así, de defenderse la naturaleza extracontractual de la acción, así como el carácter subjetivo del inicio de su prescripción (Art. $2332 \mathrm{CC})^{16}$, podría invocarse la tesis de la vigencia implícita de un término de caducidad de diez años, por ser este el plazo máximo de consolidación de las relaciones jurídicas en nuestro ordenamiento (nulidad absoluta, prescripción adquisitiva ordinaria) ${ }^{17}$.

16 Barcia Lehmann (2013) 610; Barros Bourie (2007) 924; Barros Bourie (2011) 28; Corral Talciani (2013) 938; Domínguez Águila (2004) 376; Elorriaga de Bonis (2011a) 39-61; Elorriaga De Bonis (2011b) 272.

17 Barros Bourie (2007) 767 y 924; Elorriaga De Bonis (2011b) 289. 


\section{LAS EXCEPCIONES}

Finalmente, cabe mencionar que el propio C. San. establece dos excepciones a la regla general anteriormente expuesta y que pasan a explicarse a continuación.

\subsection{Los ensayos clínicos}

En primer lugar, se regula de manera particular la situación de los ensayos clínicos, prescribiendo la acción civil que surgiere a propósito de ellos, en diez años contados desde la manifestación del daño (Art. 111 E C.San. ${ }^{18}$. Naturalmente salta a la vista que el Legislador esta vez ha gravado más intensamente la responsabilidad del legitimado pasivo, aumentando al doble el término extintivo.

La razón que puede encontrarse detrás de ello, podría decir relación con la circunstancia de que en este tipo de prestaciones el desconocimiento acerca de las consecuencias dañosas que se pueden producir, suele ser aún mayor que aquellas otras que provienen de un producto sanitario ya elaborado y comercializado. Tal también podría ser el fundamento de la presunción de la relación de causalidad entre el daño y la investigación, con que la que el legislador pretende aliviar la carga probatoria de la víctima (Art. 111 E C. San.).

Por otra parte, esta vez, el plazo legal coincide con aquel que se considera como máximo de consolidación de las relaciones jurídicas, por lo que se acrecienta la duda acerca de la eventual vigencia de este último, particularmente si consideramos que los períodos máximos de caducidad suelen principiar de manera objetiva, a diferencia de lo que ocurre con el criterio utilizado por el Art. 111 E C. San.

18 Art.111 E C. San.: «Los titulares de las autorizaciones para uso provisional con fines de investigación serán responsables por los daños que causen con ocasión de la investigación, aunque estos se deriven de hechos o circunstancias que no se hubieren podido prever o evitar según el estado de los conocimientos de la ciencia o de la técnica, existentes en el momento de producirse los daños. Asimismo, acreditado el daño, se presumirá que este se ha producido con ocasión de la investigación. La acción para perseguir esta responsabilidad prescribirá en el plazo de diez años, contado desde la manifestación del daño». 


\subsection{El régimen de garantías en salud (Ley 19.966)}

La segunda regla particular se contempla para la prescripción de la acción indemnizatoria que se puede ejercer en contra de la Central de Abastecimiento del Sistema Nacional de Servicios de Salud (CENABAST), conforme a la Ley 19.966. En esta ocasión, el Art. 111 I inc. final C. San., concede a quien ha sufrido el daño, un plazo de cinco años ${ }^{19}$.

Se puede apreciar entonces que, en una primera lectura, no existiría diferencia alguna con la regla general respecto del plazo propiamente tal (inicial), por lo que cabe preguntarse cuál ha sido la motivación para realizar una mención expresa en tal sentido.

Conforme a una primera respuesta, se podría considerar que la excepción se referiría al dies a quo, el cual, habiéndose silenciado por la norma, y en oposición a la regla del Art. 111 L C. San., debería determinarse por lo tanto conforme a un mecanismo objetivo. No obstante, no pareciera ser tal la solución correcta, en el sentido de que, como se dijo, la excepcionalidad de la prescripción importa que deba estarse a aquella posible interpretación que más favorezca a la víctima. Por otra parte, si recordamos que las reglas de esta institución se aplican igualmente a favor y en contra del Estado (Art. 2497 CC $)^{20}$, y siendo la CENABAST una institución pública frente a la falta de una regla expresa que lo beneficie, deberá ser tratado de igual forma que un particular.

Así las cosas, la mención de los cinco años esta vez tiene como objetivo reiterar la vigencia de dicho plazo, respecto de vínculos jurídicos que, por encontrarse regidos por la Ley 19.966, pudiere aparecer la duda.

19 Art. 111 I inc. final C. San: «La Central de Abastecimiento del Sistema Nacional de Servicios de Salud, en su calidad de órgano de la Administración del Estado, responderá en su caso, conforme a las reglas establecidas en el Título III de la ley $\mathrm{N}^{\circ} 19.966$, que establece un régimen de garantías en salud, pudiendo siempre repetir contra las personas señaladas en el inciso anterior. El plazo de prescripción para ejercer esta acción será de cinco años».

20 Art. 2497 CC: «Las reglas relativas a la prescripción se aplican igualmente a favor y en contra del Estado, de las iglesias, de las municipalidades, de los establecimientos y corporaciones nacionales, y de los individuos particulares que tienen la libre administración de lo suyo». 


\section{Conclusiones}

De lo anteriormente expuesto, es posible colegir que la acción indemnizatoria propia de la responsabilidad por productos sanitarios defectuosos prescribe en el plazo de cinco años contados desde la manifestación del daño. Sin perjuicio de lo anterior, no basta con la mera aparición de los síntomas de una enfermedad para que príncipe a correr el término extintivo, sino que se requiere además que se los pueda asociar al defecto del producto.

Por otra parte, subiste la duda referente a la vigencia de un plazo máximo de caducidad, de inicio objetivo el cual, no obstante, podría asociarse a una eventual naturaleza extracontractual de la acción.

El estatuto indemnizatorio asimismo contempla dos excepciones a la regla señalada, cada una de las cuales da origen también a desafíos interpretativos. Si bien en ambas se sigue silenciando la procedencia del mencionado plazo máximo, la incertidumbre se acrecienta en el caso de los ensayos clínicos, puesto que su término de prescripción coincide con aquel que el régimen común contempla para la consolidación de las instituciones jurídicas. Asimismo, respecto de las patologías propias del régimen de garantías en salud, tampoco se indica el dies a quo de la propia prescripción.

\section{Bibliografía}

\section{a) Doctrina:}

Barcia Lehmann, Rodrigo (2013): «Artículo 26 LPDC», en: De la Maza, Iñigo y Pizarro Wilson, Carlos (edit.): La protección de los derechos de los consumidores (Santiago, Editorial Thomson Reuters), pp. 607-648.

BARros Bourie, Enrique (2007): Tratado de responsabilidad extracontractual (Santiago, Editorial Jurídica de Chile).

Barros Bourie, Enrique (2011): "Conceptualismo y vulgarismo en el Derecho Civil Patrimonial», en Figueroa Yañez, Gonzalo; Barros Bourie, Enrique; Tapia Rodríguez, Mauricio (Coord.): Estudios de Derecho Civil VI (Santiago, Abeledo Perrot), pp. 21-36. 
CaÑizares Laso, Ana (2002): «La prescripción en el BGB después de la reforma del Derecho de Obligaciones», en Estudios Jurídicos en homenaje al profesor Luis Díez-Picazo. Tomo 1 (Madrid, Editorial Thomson Civitas) pp. 409-431.

Corral Talciani, Hernán (2013): «Artículo 47 LPDC» en: De la Maza, Iñigo y Pizarro Wilson, Carlos (edit.): La protección de los derechos de los consumidores (Santiago, Editorial Thomson Reuters) pp. 933-938.

Corral Talciani, Hernán (2015): «Ley Ricarte Soto» y nuevo régimen de responsabilidad civil, El Mercurio Legal 18.06.2015, disponible en http://www.elmercurio.com/legal/movil/detalle. aspx? Id=904000\&Path=/0D/CB/, [Fecha de consulta: 23 de mayo de 2018].

Corral Talciani, Hernán (2016): «El primer régimen legal chileno de responsabilidad por productos: daños por defectos de los productos sanitarios», en Barría Paredes, Manuel (ed.): Estudios de Derecho Civil XI (Santiago, Thomson Reuters), pp. 897-911.

Della Maggiora, Atilio V.; Zárate, José Martín (2003): «La prescripción en la relación de consumo", en Cartapacio de Derecho: Revista Virtual de la Facultad de Derecho, $\mathrm{N}^{\circ} 5$, disponible en http://www. cartapacio.edu.ar/ojs/index.php/ctp/article/viewFile/49/29, [Fecha de consulta: 23 de mayo de 2018].

Domínguez Águila, Ramón (2004): La prescripción extintiva. Doctrina y Jurisprudencia (Santiago, Editorial Jurídica de Chile).

Elorriaga De Bonis, Fabián (2011) (A): «Del día de inicio del plazo de prescripción de una acción indemnizatoria cuando el perjuicio se ha manifestado con posterioridad al hecho que lo origina", en Prescripción extintiva: Estudios sobre su procedencia y funcionamiento en Derecho Público y Privado. Cuadernos de Extensión Jurídica $N^{\circ}$ 21 (Santiago, Universidad de los Andes), pp. 39-61.

Elorriaga De Bonis, Fabián (2011) (B): «El día de inicio de plazo de prescripción de una acción indemnizatoria cuando el perjuicio se ha manifestado con posterioridad al hecho que lo origina», en VARAS Braun, Juan Andrés; Turner Saelzer, Susan; Corral Talciani, Hernán; y otros (Coord.): Estudios de Derecho Civil. Jornadas de Derecho Civil 2005-2009. Tomo IV (Santiago, Thomson Reuters), pp. 271-289.

FERRADA WALKeR, Luis Valentín (2012): «La interpretatio per aliam legem como regla para definir el sentido del artículo 2332 del Código Civil, sobre prescripción de la acción de responsabilidad extracontractual», Revista de Derecho Escuela de Postgrado, Universidad de Chile, $\mathrm{N}^{\circ}$ 2, pp. 35-60. 
IsLER Soto, Erika (2018): «La responsabilidad por productos y su incidencia en la unificación de la responsabilidad civil de consumo", en Llamas Pombo, Eugenio (Coord.): Congreso Internacional de Derecho Civil Octavo Centenario de la Universidad de Salamanca (Valencia, Tirant lo Blanch), pp. 599-609.

LAMARCA I MARQuès, Albert (2002): «Entra en vigor la ley de modernización del derecho alemán de obligaciones», en InDret (Barcelona). Disponible en http://www.indret.com/pdf/078_es.pdf [Fecha de consulta: 14 de enero de 2019].

Lanata Fuenzalida, Gabriela (2010): «Prescripción y caducidad en el Derecho del Trabajo", Revista de Derecho Universidad de Concepción, $\mathrm{N}^{\circ}$ 227-228, Año LXXVIII, Enero-Diciembre 2010, Concepción, pp. 239- 272 .

Momberg Uribe, Rodrigo (2017): «Responsabilidad por productos defectuosos: ¿Estatuto contractual, extracontractual o especial?», en Barría Díaz, Rodrigo; Ferrante, Alfredo; San Martín Neira, Lilian (Ed.): Presente y futuro de la responsabilidad civil (Santiago, Thomson Reuters), pp. 129-146.

\section{b) Jurisprudencia:}

Sernac con Braun Medical S.A. (2010): JPL San Bernardo, Rol 3422-4-2008, 18.01.2010, confirmada por la C. Ap. San Miguel, Ing. 187-2010, 17.05.2010.

Sernac con Falabella SACI (2008): 2 JPL Las Condes, Rol 29.517-10-2007, 04.09.2008.

\section{c) Normativa nacional:}

Código Civil.

Código Sanitario.

Ley 19.496, Que establece normas sobre protección de los derechos de los consumidores. Diario Oficial, 7 de marzo de 1997.

Ley 20.850 sobre protección financiera para diagnósticos y tratamientos de alto costo y rinde homenaje póstumo a don Luis Ricarte Soto Gallegos, D.O. 06.06.2015.

\section{Normativa comparada:}

Bürgerliches Gesetzbuch, 18.08.1896, Alemania. 


\title{
No TODO LO QUE BRILLA ES ORO: ANÁLISIS DEL IMPACTO DEL NUEVO ETIQUETADO NUTRICIONAL DE ALIMENTOS (LEY 20.606)
}

\author{
All THAT GLITTERS IS NOT GOLD: \\ ANALYSIS OF THE IMPACT OF THE NEW FOOD \\ NUTRITION LABELING (LAW 20.606)
}

Jaime Lorenzini B. ${ }^{1}$

Resumen. El presente trabajo aborda el impacto que ha tenido la Ley 20.606 sobre Composición Nutricional de los Alimentos y su Publicidad a dos años de su entrada en vigencia, considerando sus objetivos iniciales en contraste con los datos empíricos que han arrojado las últimas investigaciones y encuestas nacionales, realizando un análisis crítico de la normativa e identificando algunas de sus falencias.

Palabras clave: deberes de información, economía conductual, etiquetado nutricional de alimentos.

ABSTRACT. This paper deals with the impact of Law 20,606 on the Nutritional Composition of Food and its Advertising two years

1 Doctor en Derecho (c) por la Universidad de Chile. Socio de Lorenzini, Twyman, Castillo y Pohl Abogados. Email: jlorenzini@lnz.cl 
after its entry into force, considering its initial objectives in contrast to the empirical data that the latest research and national surveys has produced, performing a critical analysis of the regulations and identifying some of its shortcomings.

KEYWORDS: duties of information, food nutrition labeling, behavioral economics.

Sumario. 1. Contexto y objetivos de la nueva regulación. 2. Importancia del estudio del comportamiento de los consumidores previo a la generación de una regulación. 3. Nuevo etiquetado nutricional de alimentos (Ley 20.606). 4. Análisis crítico de la normativa. 4.1. Los objetivos de la Ley de Etiquetados. 4.2. La Ley de Etiquetado no considera la existencia de sesgos cognitivos de los consumidores. 4.3. Los sellos de advertencia no consideran medidas de consumo habitual. 5. El comportamiento de los consumidores. 6. Conclusiones. 7. Bibliografía.

\section{Contexto y objetivos de la nUeVa Regulación}

La Ley $\mathrm{N}^{\circ} 20.606$ sobre Composición Nutricional de los Alimentos y su Publicidad, conocida también como Ley de Etiquetado entra en vigencia el 27 de junio de 2016, estableciendo, en términos generales, un marco regulatorio especial para regular la información nutricional de alimentos altos en grasas saturadas, sodio, azúcares y calorías, prohibiendo la venta de alimentos altos en dichos estándares en establecimientos educacionales y regulando la publicidad de estos productos dirigida a menores de catorce años. Para efectos de este trabajo, solo se abordará el impacto relativo a los sellos de advertencia y no serán objeto de análisis la normativa referente a publicidad ni tampoco las prohibiciones de venta de ciertos alimentos en establecimientos educacionales.

Los objetivos de esta ley se construyeron sobre la idea general de modificar la conducta de las personas en un área específica del consumo de cierto tipo de alimentos.

Desde el punto de vista de la historia de la ley, su fundamento descansa en los problemas identificados por diversos estudios e investigaciones que señalan que, en Chile, durante los últimos quince 
años, se ha evidenciado un importante aumento del sobrepeso y la obesidad, así como otras enfermedades similares que están relacionadas con la nutrición y alimentación desde etapas precoces de la vida ${ }^{2}$. Muy relacionado con lo anterior, destaca también el auge de la «comida rápida» acompañada de una fuerte publicidad y de grandes campañas promocionales, especialmente dirigida a niños.

Efectivamente constituye un delicado problema de política pública la obesidad y sobrepeso de un porcentaje muy importante de la población chilena. Las cifras dan cuenta que una de cada once muertes se atribuyen al exceso de peso de las personas. ${ }^{3}$ Existe una masiva malnutrición por exceso de la población, lo cual representa un grave problema de salud pública.

Frente a este tipo de diagnóstico, la Organización Mundial de la Salud (OMS) desarrolló ciertas directrices que deben desarrollar los gobiernos en sus políticas públicas. Dichas recomendaciones fueron recogidas con el fin de plantear un marco regulatorio especial sobre seguridad alimentaria y alimentación saludable que recogiera los principios y orientaciones internacionales, para guiar al consumidor hacia patrones de conducta saludables, advirtiéndole sobre los riesgos de alimentos nocivos para su salud. Estas recomendaciones se tradujeron finalmente en establecer reglas mínimas de información clara sobre la calidad y cantidad de lo que está consumiendo y con el fin de reducir los factores de riesgo de salud. ${ }^{4}$

\section{IMPORTANCIA DEL ESTUDIO DEL COMPORTAMIENTO DE LOS CONSUMIDORES PREVIO A LA GENERACIÓN DE UNA REGULACIÓN}

La Organización para la Cooperación y el Desarrollo Económico $(\mathrm{OECD})^{5}$ ha llamado la atención sobre la importancia de efectuar tanto un análisis ex ante como ex post de las regulaciones. La evaluación ex ante analiza un proyecto de ley previo a su entrada en

\footnotetext{
AAVV (2012) 6.

3 Olivares y Quiroga (2018) 4. La obesidad tiene una directa correspondencia con los altos índices en patologías relacionadas tales como diabetes, hipertensión, infartos cardíacos, ataques cerebrales y algunos tipos de cáncer.

4 AAVV (2012) 5-7.

5 OECD (2014)
} 
vigencia y su propósito es analizar precisamente qué efectos (costos y beneficios) y externalidades podría generar una eventual aplicación de ley. Por su parte, la evaluación ex post es un paso crucial y esencial del ciclo político-regulatorio, y su objetivo es confirmar si se han cumplido los objetivos deseados por la regulación. Este análisis previo se justifica por cuanto funcionamos en un entorno de escasez, y por consiguiente deben tomarse decisiones de política pública para asegurar una eficiencia regulatoria.

Los estudios y monitoreo de la información suministrada, una vez implementadas las respectivas regulaciones informacionales, resultan necesarios teniendo presente que incluso con pruebas eficaces antes de la implementación en muchos casos puede ser difícil predecir las reacciones de los consumidores a la información.

El foco de atención de los estudios de comportamiento de los consumidores debe considerar, a lo menos, aspectos relacionados con los aportes que ha suministrado la Economía Conductual, incluyendo sesgos cognitivos de los consumidores, problemas de comprensión lectora y comportamiento intuitivo de las personas.

Resulta indispensable que la autoridad considere la utilidad de estudios de comportamiento de consumidor cuando considera apropiado establecer regulaciones que imponen deberes de información en favor de los consumidores, tanto antes de la generación de normas que establezcan deberes de información a los proveedores, así como para medir el impacto efectivo de la información proporcionada en términos de medir las reacciones de los consumidores posteriores a la implementación de las normas que establecen obligaciones informacionales. Dado que funcionamos en un entorno de escasez, deben tomarse decisiones de política pública para asegurar eficiencia regulatoria.

Respecto de estudios previos a la implementación de normas que hacen obligatorio el suministro de información, es posible anticipar que la inversión de tiempo y recursos para garantizar que la información funcione correctamente en el mercado es muy baja en comparación con el costo de estos requisitos informacionales en la economía.

La ausencia de adecuados estudios previos por parte de la autoridad (especialmente los órganos de gobierno a cargo de la formulación de proyectos de ley) antes de dictar una regulación puede conllevar elevados costos a la población, por cuanto tras muchos 
años puede llegar a identificarse la ineficacia de las soluciones que fueron previstas como exitosas, desaprovechando los aportes de disciplinas científicas y habiéndose malgastado tiempo valioso y retrasarse injustamente el logro de los objetivos para una parte muy importante de los habitantes del país.

\section{Nuevo Etiquetado Nutricional de Alimentos (LEY 20.606)}

El etiquetado nutricional constituye la herramienta práctica que facilita la elección de los alimentos de manera adecuada, de acuerdo a los lineamientos que proporcionan las guías alimentarias y, de esta forma, es un mecanismo que puede contribuir en la mejora de la calidad de vida de la población. ${ }^{6}$

El etiquetado nutricional que contienen los alimentos envasados constituye una información técnica, que no es de fácil comprensión para el consumidor no familiarizado de los conceptos y nociones relacionadas con aspectos alimenticios, lo cual lo convierte en una información compleja para la mayoría de la población.

En el año 2016 se dictó la Ley No 20.606 sobre composición nutricional de los alimentos y su publicidad. Esta regulación entró en vigencia en junio de ese mismo año. El objetivo principal de este cuerpo legal es proteger la salud de los chilenos, en especial de los niños y niñas. Con este propósito se implementó un sistema de sellos de advertencia que destaca la presencia de un alto porcentaje de aquellos nutrientes críticos: azúcares, grasas saturadas, sodio y calorías. El sello de advertencia escogido por la autoridad fue «ALTO EN». La lógica y justificación de este nuevo etiquetado nutricional contenido en la nueva regulación sería el facilitar la distinción de aquellos productos alimenticios envasados que serían menos saludables (precisamente por contener altos porcentajes de nutrientes críticos) y de esta forma contribuir a que los consumidores puedan preferir los alimentos sin sellos de advertencia, o bien aquellos con la menor cantidad de sellos.

6 Olivares y Quiroga (2018) 4. 
La regulación se enmarcó en el trabajo por parte de la autoridad (Ministerio de Salud), encaminado a levantar información relevante para procurar identificar el mejor sistema para mejorar la elección de alimentos por parte de la población a partir de ciertos signos o etiquetas en los propios alimentos envasados. Uno de estos estudios fue encargado a la consultora Feedback por el Ministerio de Salud y SERNAC en junio de $2009^{7}$ cuyo objetivo fue evaluar la compresión, aceptación, funcionalidad y uso de seis modelos de información nutricional diseñados para orientar a consumidores en relación a la información nutricional crítica para la decisión de compra de productos de alimentación. Se trata de un estudio cualitativo, y el propio informe aclara que "la técnica cualitativa se constituye en la más adecuada para dar cuenta de perspectivas, sentidos y aspecto sutiles de la comunicación. Además, se presenta como la principal técnica de investigación social para dar cuenta del «saber» sobre aspectos de la práctica social».$^{8} \mathrm{El}$ momento de este estudio era precisamente el adecuado para conocer en forma previa y antes de la generación de una regulación en la materia la comprensión y utilidad práctica en la población que tendría un nuevo etiquetado nutricional.

De acuerdo a un informe preparado por IPSOS Chile para el Ministerio de Salud en el año $2017^{9}$, se indicó que el objetivo principal de la esta ley fue proteger la salud de nuestra población, en especial de los niños y niñas, incorporando un marco regulatorio que permitiese: 1) entregar información más clara y comprensible al consumidor por medio del símbolo de advertencia «ALTO EN»; 2) asegurar una oferta saludable de alimentos al interior de los establecimientos educaciones de prebásica, básica y media, por medio de la prohibición de la venta, promoción y entrega gratuita de aquellos alimentos cuya composición nutricional supere los límites establecidos por el Ministerio de Salud, y 3) proteger a los menores de catorce años de la sobreexposición a la publicidad, prohibiéndola en aquellos alimentos que superan los límites establecidos por el Ministerio de Salud.

\footnotetext{
Ministerio de Salud de Chile-Feedback (2009).

Ministerio de Salud de Chile-Feedback (2009) 11.

IPSOS CHILE (2017) 5.
} 
El año 2012, la autoridad de salud le solicitó a un grupo de académicos del Instituto de Nutrición y Tecnología de los Alimentos (INTA) de la Universidad de Chile un estudio de evaluación de mensajes de advertencia en el rotulado alimentario. Este estudio ya se desarrolló cuando ya había sido dictada y publicada la Ley 20.606. La metodología de este estudio consideró tanto una fase cualitativa y cuantitativa. Entre las recomendaciones de este informe a la autoridad en lo relativo a la eficacia de nuevos sellos de advertencia en el etiquetado nutricional, se llamó la atención sobre la importancia de «rotar las consecuencias negativas asociadas al consumo excesivo de nutrientes críticos de modo de evitar el «desgaste» del mensaje» ${ }^{10}$. Este informe concluyó que «la evidencia en relación a la efectividad de la aplicación de este tipo de mensajes en el rotulado alimentario es prácticamente inexistente. Teóricamente se sugiere que los beneficios serían importantes y podrían provenir de la reformulación de productos de parte de la industria, de la mejora en el consumo alimentario de la población y de la mayor educación y alerta poblacional en temas nutricionales y de salud». ${ }^{11}$

Respecto a las nuevas modificaciones a la regulación del etiquetado nutricional, la ley establece la obligación de incorporar mensajes de advertencia en la parte frontal de los envases de alimentos. Este nuevo mensaje está representado por un sello octagonal negro «ALTO EN» calorías, azúcares, sodio y grasas saturadas. En forma complementaria, la nueva regulación establece límites para el contenido de estos nutrientes críticos, y se establece que los productos alimenticios envasados que excedan dichos límites deberán llevar este sello de advertencia.

\section{ANÁlisis CRítico de la NORMATIVA}

Se identifican las siguientes falencias a la normativa relacionada con el nuevo etiquetado nutricional de alimentos:

10 Instituto de Nutrición y Tecnología de los Alimentos (2012) 8.

11 Instituto de Nutrición y Tecnología de los Alimentos (2012) 11. 


\subsection{Los objetivos de la Ley de Etiquetados}

Los objetivos que considera la Ley de Etiquetados solucionan un problema exclusivamente para una parte de la población o para un cierto tipo de actos de consumo, ya que solo se aplica a actos de consumo de productos alimenticios que se adquieren en supermercados o establecimientos afines, donde el suministro de información nutricional está disponible y visible para todo el público. No tenemos conocimiento de algún estudio que se haga cargo del porcentaje de la población que consume productos alimenticios en otros establecimientos donde la información nutricional no está a la vista del público, como restaurantes, casinos, hospitales, entre otros. De acuerdo a fuentes de la industria, un importante porcentaje de la población no come en su casa, por lo tanto, no tienen a la vista la información nutricional de los sellos, tornándose estos últimos en un despropósito.

En otras palabras, la solución que busca dar la Ley de Etiquetados en este ámbito se aplicaría para un universo acotado de consumidores que se alimentan diariamente solo con productos comprados en supermercados o establecimientos similares.

De acuerdo a un estudio realizado por Estudio Jumbo GFK $^{12}$ aplicado a un grupo objetivo de hombres y mujeres mayores de veinticinco años, residentes de todo el país, con hijos menores de dieciocho años, señala que entre los alimentos que son más consumidos y que forman parte de una colación están las frutas, yogures, cereales, jugos, pan con agregado, entre otros. Tomando como ejemplo el pan con agregado, el consumidor promedio difícilmente lo preparó realizando un cálculo mental de las grasas y calorías que contiene, a partir de la información nutricional que pudo haber observado al momento de comprar cada uno de los ingredientes por separado en un supermercado o establecimiento a fin. Dicho cálculo, en cambio, podría razonablemente realizarlo bajo el supuesto que compró el pan con agregado como un producto final en un supermercado. En este sentido, también es relevante considerar que, de acuerdo a otro estudio realizado también por Jumbo GFK Adimark, señala que un

12 GFK Adimark (2018). 
$63 \%$ de un grupo objetivo de hombres y mujeres mayores de veinticinco años, de los estratos económicos ABC1, C2 y C3D de todo Chile decide lo que se comerá en su casa.

\subsection{La Ley de Etiquetado no considera la existencia de sesgos cognitivos de los consumidores}

La normativa del citado cuerpo legal parte de la base de que las personas actúan siempre racionalmente y como un homo economicus a la hora de tomar decisiones y no considera que la mayor parte de los consumidores tiene sesgos. En otras palabras, y de acuerdo lo que señala la Economía Conductual, los consumidores no siempre responden a la información proporcionada de forma tan racional como los modelos económicos tradicionales asumen. ${ }^{13}$

De acuerdo a una encuesta realizada por el Instituto de Comunicación e Imagen de la Universidad de Chile, a diciembre 2016, en 1.067 adultos de distintos niveles socioeconómicos, solo un 39,2\% del total declaró que la presencia de sellos influye en su compra. En consecuencia, a un 60,8 \% la presencia de estos sellos no le influye en su compra. En el mismo sentido, y complementando la idea anterior, en una encuesta realizada por "Cliodinámica» en diciembre de 2017, a un grupo de 1.505 adultos de distintos niveles socioeconómicos, mostró un análisis interesante, ya que si bien señala consumidores que comparan la presencia de sellos a la hora de comprar (que son un $48,1 \%$ ), dentro de este grupo un $79,1 \%$ indica que influyen sobre su compra. En estos términos, solo una baja proporción del universo de consumidores declara que los sellos de advertencia influyen en su compra.

En definitiva, podemos afirmar que en la toma de decisiones ${ }^{14}$ intervienen diversos sesgos que se deben tener en cuenta, de lo contrario pueden resultar en ineficacias como consecuencias de una regulación basada meramente en suministro de información a los consumidores. Algunos de los sesgos son los siguientes:

13 Howells (2005)

14 Cortada de Kohan (2008) 
a. Sesgos de percepción, ya sea en cualquiera de los cinco sentidos y que influyan en la comprensión de una persona en relación a una toma de decisión de consumo. La autoridad no logró advertir ni anticipar las serias dificultades que tendrán los consumidores cuando, por la aplicación progresiva de la nueva regulación en el tiempo, en un futuro próximo la mayoría de los productos contarán con sellos de advertencia, los consumidores no puedan ya distinguir ni tener alternativas de elección (dado que la gran mayoría de los productos tendrá sellos de advertencia).

b. Sesgos de status quo, hay una tendencia mayoritaria de que las personas al momento de tener que elegir entre quedarse en el estado actual o cambiarse a otra alternativa, sea mejor o peor, prefieren mantenerse, y así se estaría evitando tomar una elección. ${ }^{15}$ Este sesgo se ilustra en un estudio realizado por la consultora Visión Humana «Chilescopio 2016», respecto a la actitud de compra de consumidores chilenos, al señalar que un $69 \%$ de las personas de una determinada muestra declaró que prefiere comprar marcas que conoce bien y que me han dado un buen resultado en el pasado. ${ }^{16}$

c. Comportamiento intuitivo de los consumidores: en las relaciones de consumo cotidianas, como ir a un supermercado, las personas en general desarrollan conductas mecánicas que son resultado de pensamientos asociativos realizados sin esfuerzo. ${ }^{17}$ Una propiedad que caracteriza al pensamiento intuitivo es que se nos viene a la mente de forma espontánea. En las habituales y cotidianas decisiones de consumo que enfrentan las personas a diario operan mecanismos y procesos mentales rápidos, automáticos, sin esfuerzo, asociativos. Con frecuencia además estas operaciones mentales tienen una carga emocional y la costumbre o el hábito previo tiene una fuerte influencia. Todo lo anterior permite concluir que esta forma de pensar es difícil de controlar o modificar. Esto caracteriza el sistema cognitivo en base a la intuición, y que se

15 Kahneman, Knetsch y Thaler (1991).

16 Visión Humana (2016).

17 Kahneman (2003) 184. 
diferencia del sistema cognitivo de razonamiento que presenta como características relevantes el ser un proceso mental lento, controlado, que exige un esfuerzo, y que no está influido por las emociones (sino que es neutral en este sentido). El supuesto que tiene el regulador detrás del establecimiento de deberes de suministro de información impuestos a los proveedores en materia de alimentos (sellos de advertencia) es la conducta racional de los destinatarios de aquella información. Se trata de un supuesto especialmente poco realista considerar al consumidor (destinatario de la información) como un agente racional que efectúa sus elecciones en un contexto de exhaustivo análisis basado en la información disponible, incorporando en su proceso de toma de decisión todos los detalles relevantes que aporta el suministro de información.

d. Cuentas mentales por parte de los consumidores: sus efectos en el comportamiento de las personas se relacionan con la teoría del empujón o nudges (Thaler y Sunstein) ${ }^{18}$, y que en síntesis se basa en una premisa muy simple: entre dos opciones, las personas escogen a menudo la que es más fácil sobre la que es más adecuada. Los hallazgos de la contabilidad mental permiten comprender y explicar cómo los resultados de un evento son percibidos y experimentados por los consumidores, y cómo las decisiones son tomadas y evaluadas posteriormente. Esto se advierte con claridad en las decisiones de consumo de las personas frente a una tentadora oferta, limitada en el tiempo, en el precio de un bien (por ejemplo un producto alimenticio adquirido en un supermercado), de forma tal que el consumidor promedio tiende a percibir el beneficio de ahorrarse un parte significativa del precio normal del producto con lo cual en su contabilidad mental ello le ha significado un excelente resultado en sus finanzas, sin atender a si acaso necesitaba realmente el bien o este cumplía con sus expectativas y reales necesidades (o bien era satisfactorio para sus salud en términos de un cuidadoso análisis de las

18 Thaler (1985). 
propiedades nutricionales del alimento, examinando los sellos de advertencia).

Una mayor cantidad de información puesta a disposición de los consumidores no constituye per se una solución eficiente que asegure enfrentar correctamente el problema de asimetría de información.

La evidencia de estudios de comportamiento de consumidores en nuestro país demuestra que, en lo relativo a la eficacia de los sellos de advertencia en el etiquetado de alimentos en los consumidores, el mayor impacto fue al inicio (durante los primeros seis meses de vigencia de la nueva regulación), y un año después es posible observar un efecto rebote y que incluso ciertas categorías están volviendo a sus ventas históricas. Según una investigación de la Universidad de Chile, las categorías de alimentos rotulados con sellos tales como los chocolates, dulces y galletas no muestran una variación significativa en las preferencias de compra. ${ }^{19}$

\subsection{Los sellos de advertencia no consideran medidas de consumo habitual}

En relación a la rotulación nutricional, en el Decreto $\mathrm{N}^{\circ} 13$ que corresponde al reglamento de la Ley $\mathrm{N}^{\circ} 20.606$, existen cuatro nutrientes que se deben declarar por cada $100 \mathrm{gr}$ o $\mathrm{ml}$ del producto. El enfoque de los parámetros técnicos en base a $100 \mathrm{~g} / \mathrm{ml}$ no representa

19 En este estudio se evaluó el impacto del etiquetado en los productos de las categorías yogurts, postres, cereales, galletas, chocolates-golosinas, snacks, bebidas y jugos a través de las compras de una importante cadena de supermercados, de manera de comparar el comportamiento de compra con los meses equivalentes del año anterior a la implementación de los sellos de advertencia. De acuerdo a las conclusiones de esta investigación, pese a que se observaron disminuciones en el consumo de snacks y bebidas, se requiere de mayores estudios para confirmar si efectivamente el efecto encontrado se debe exclusivamente a la presencia de los ellos de advertencia u otros factores. Una limitación que se constata en este propio estudio dice relación con el hecho de que la muestra de individuos que compra en los supermercados objeto del estudio tiene ciertas características sociodemográficas que no necesariamente representan a toda la población de Chile. Lo anterior, teniendo especialmente en cuenta que se consideran individuos que registran su identificación de socio al momento de la compra, lo que restringe el grupo de individuos analizados. 
el consumo habitual de los alimentos, dado que la porción habitual de consumo generalmente es muchísimo menor a $100 \mathrm{~g} / \mathrm{ml}$. La apreciación de los productos en base a $100 \mathrm{~g}$ o $100 \mathrm{ml}$ crea una falsa «impresión», tanto de los productos que tienen tamaños de porción pequeños (muy por debajo de los $100 \mathrm{~g} / 100 \mathrm{ml}$ ), como de aquellos que tienen tamaños de porción elevados ${ }^{20}$. Esto último no permite al consumidor comparar dentro de una misma categoría. Por ejemplo, la información nutricional respecto 100 gramos de mantequilla, en otras palabras, está dirigida a un público que consume quince tostadas al día, lo cual es altamente poco probable.

Siguiendo esta idea, la base de cálculo por 100 g. perjudica el análisis, particularmente en un gran número de alimentos que se consume por debajo de los 50 gramos, lo cual no permite al consumidor comparar dentro de una misma categoría, como por ejemplo mantequilla con sal, manteca, margarina o estándar, margarina light, entre otros. De acuerdo a un estudio realizado por la industria, la forma correcta de hacer la medición es por porción de consumo.

Adicionalmente, y relacionado con lo anterior, tampoco es claro el concepto de adición versus ingrediente: el ingrediente como tal no tiene «sello» de ningún tipo, sin embargo, si se adiciona el ingrediente, en una baja cantidad, el alimento lleva «sello». Por ejemplo, un kilo de sal normal y un pote de miel no tienen sellos, y un cereal con miel lleva sello de azúcares, por lo tanto, el consumidor puede entender que estos productos al no tener sellos pueden ser utilizados o consumidos de manera libre. Quedan eximidos de la obligación de incorporar el rótulo de advertencia aquellos alimentos que no tenga adición de azúcar sodio o grasa saturada (tales como el azúcar, la miel, el yogur natural con fruta, la sal, el aceite, la leche natural, los mix naturales de frutos secos, entre otros alimentos). ${ }^{21}$

Por lo tanto, se hace necesario al menos debatir o plantear la necesidad de implementar una estandarización de porciones vinculantes y establecer límites de nutrientes por porciones y categorías ${ }^{22}$.

20 Fuentes de la industria confirman esta aproximación, entre otras en intervenciones en Seminario CEP, octubre 2018.

21 Olivares y Quiroga (2018) 25.

22 En opinión de Olivares y Quiroga (2018) sobre este aspecto se aclara que la autoridad chilena ha establecido sus límites críticos en 100 gramos para los productos sólidos y $100 \mathrm{ml}$ para los productos líquidos. En su visión «El 


\section{El COMportamiento de los CONSUmidores}

Tradicionalmente la base de las políticas económicas y gubernamentales ha sido considerar al ser humano como un individuo racional, es decir, que en su proceso de tomas de decisiones las personas recurren a un proceso de optimización de la utilidad que le reportan tales decisiones. Sin embargo, la evidencia ${ }^{23}$ demuestra que los seres humanos no somos racionales en todas las decisiones que tomamos, y que no siempre recurrimos a un proceso de optimización de utilidad para tomar decisiones. Las personas se suelen dejar llevar por muchos factores que la economía tradicional no ha considerado. La Economía Conductual ha recogido el estudio y descripción de estos otros muchos factores que afectan nuestra toma de decisiones, combinando la Economía y la Psicología de manera de poder comprender el comportamiento del ser humano.

A medida que se indaga en la efectividad de la información suministrada por parte de los proveedores en favor de los consumidores (como ocurre precisamente en el caso de los sellos de advertencia del nuevo etiquetado nutricional), es posible observar una importante cantidad de conocimiento e investigaciones a partir de lo cual han ido surgiendo algunos datos contradictorios sobre las ventajas de la información per se. La visión tradicional (mayor cantidad de información suministrada a los consumidores es siempre positiva) merece ser cuidadosamente analizada para identificar ciertos errores y paradigmas en esta aproximación.

En este contexto, resulta importante abordar el análisis de los aspectos relacionados con la Economía Conductual de los propios

cuestionamiento es entonces, el por qué la decisión de establecer los límites críticos en gramos/mililitros y no en porciones de alimentos. La respuesta a esta interrogante es que inicialmente la propuesta era establecer los límites críticos por porción de consumo habitual de un alimento, ya que el Reglamento Sanitario de los Alimentos establece que los mensajes nutricionales deben ser expresados de esta manera. Sin embargo, los 100 gramos o $100 \mathrm{ml}$ permiten estandarizar el gramaje de los alimentos que se comercializan, ya que en la industria alimentaria cada producto, según la empresa o tipo de alimento, tiene una porción de consumo habitual específica, lo que complicaría establecer de forma genérica los límites críticos de los nutrientes contenidos en los alimentos del mercado». Olivares y Quiroga (2018) 24.

23 Véanse los estudios sobre comportamiento de las personas referidos más adelante. 
consumidores para considerar la efectiva utilidad o no de la información suministrada a partir de mandatos informativos. El foco de atención de los estudios de comportamiento de los consumidores incluye aspectos relacionados, entre otros, con sesgos cognitivos de los consumidores, problemas de comprensión lectora y comportamiento intuitivo de las personas ${ }^{24}$.

Pese a los esfuerzos de la autoridad por procurar generar estándares obligatorios de suministros de información para que los consumidores estén adecuadamente informados y en base a esa información disponible tomen mejores decisiones de consumo y cambien hábitos de consumo ${ }^{25}$, se advierte y constata que en el mercado existe un ambiente de notoria desinformación de los consumidores ${ }^{26}$. Esta desinformación es un fenómeno que es consecuencia de una serie de circunstancias, deliberadas o no, en las cuales la capacidad de comprensión de las personas no funciona adecuadamente. Lo anterior conlleva una situación en la que el acto de informar pareciera que en la práctica se niega a sí mismo y puede producir efectos contra intuitivos e indeseados, ya que la mayor información puesta a dispo-

24 La evidencia que arroja la experiencia y estudios sobre el comportamiento del consumidor aclara que el supuesto de la utilidad per se de toda información puesta a disposición del consumidor es ficticio, irreal, y no se da en la práctica en las relaciones de consumo. Pretender por la autoridad que la sola entrega de información valiosa y útil para los consumidores será utilizada efectivamente por estos no es sino un espejismo (tal como lo demuestran los estudios de comportamiento del consumidor referenciados más adelante).

25 La autoridad sanitaria ha procurado un cambio de conducta alimentaria por parte de los consumidores a partir de exhortaciones explícitas. La Subsecretaría de Salud ha efectuado un llamado a la población a informarse y «escoger aquellos alimentos que no tienen sellos o que dentro de sus alternativas tienen menor cantidad de advertencias, para ir produciendo un cambio de conducta alimentaria». Así se indica en la información disponible de la propia página web del Ministerio de Salud, noticia destacada del 24 de mayo de 2016. Disponible en: https://www.minsal.cl/subsecretario-de-salud-publica-y-entrada-en-vigenciade-etiquetado-de-alimentos-hay-personas-que-insisten-en-crear-clima-de-temorrespecto-de-esta-politica/

26 «Los chilenos no saben leer las tablas nutricionales que traen los envases", BARROS y ZACARÍAS (2018) 13. Isabel Zacarías es nutricionista de la Universidad de Chile y fundadora de varios programas en el Instituto de Nutrición y Tecnología de los Alimentos (INTA), Isabel Zacarías. Para esta especialista rotular y colocar sellos a los alimentos según la composición nutricional en 100 gr y $100 \mathrm{ml}$ puede llegar a generar confusión y desinformación a los consumidores. Barros y ZaCARías (2018) 13. 
sición de los consumidores no constituye per se una solución eficiente que asegure enfrentar correctamente el problema de asimetría de información. Se requiere de un cuidadoso estudio y observación de los factores que afectan la comprensión de la información por parte de los consumidores en las relaciones de consumo.

La práctica cotidiana demuestra que los consumidores de productos alimenticios pueden no tener mayor disposición a cambiar hábitos alimenticios. Por su parte, y por una serie de razones que explican este comportamiento (incluyendo campañas de marketing y publicidad, y el sesgo de status quo) existen en los consumidores importantes lealtades que exhiben hacia ciertas marcas o productos.

Los aspectos técnicos y tecnológicos asociados a las reformulaciones de ciertos alimentos para procurar disminuir los nutrientes críticos (sodio, azúcar, grasas) encarecen los respectivos productos alimenticios que han sido modificados. Esto por sí solo es una razón que no puede minimizarse en el contexto de los hábitos de consumo de la población ${ }^{27}$, teniendo presente que por razones económicos las personas -incluso pretendiendo acceder a una alimentación más saludable en términos de elegir productos sin sellos de advertenciavan a continuar prefiriendo productos con estos sellos, ya que sus recursos económicos no le permiten acceder a estos otros productos reformulados pero que son más caros en el mercado.

La sola existencia de un nuevo esquema de rotulación de alimentos no produce los efectos deseados si no se efectúa un trabajo de educación a largo plazo, con la intensidad adecuada y permanencia en el tiempo. Las campañas puntuales que ha efectuado la autoridad (Ministerio de Salud), principalmente en los primeros meses de vigencia de la nueva regulación, no tienen la aptitud de generar nuevos hábitos de consumo: para ello se requiere realizar esfuerzos consistentes en el desarrollo e implementación políticas públicas de educación en torno a la alimentación, junto con el refuerzo de hábitos saludables por los consumidores consistentes en actividad física en forma periódica.

27 De acuerdo a una investigación realizada en tres comunas populares de Santiago, las principales razones que expresaron las personas a cargo de la selección sus alimentos fueron los factores económicos como predominantes (70\%). ArAYA y Atalah (2002). 
Una reciente investigación desarrollada en el ámbito académico se propuso entender la percepción de los consumidores de los alimentos de acuerdo con distintos factores nutricionales (en particular, la percepción de saludable, la percepción de perder o ganar peso y la estimación de calorías), según la presencia de dos importantes estímulos: la publicidad de los alimentos y los sellos de advertencia del etiquetado nutricional. El objetivo relacionado con el análisis del estímulo de los sellos de advertencia estudió los posibles cambios en las percepciones nutricionales que provocan estos sellos del etiquetado de los alimentos envasados, haciendo una importante comparación con la situación previa a la implementación de los respectivos sellos en los productos alimenticios. Las conclusiones de esta investigación dan cuenta de los siguientes resultados: la reciente regulación que establece el nuevo etiquetado de sellos de advertencia merecería mejorarse por un sistema de información nutricional que sea más clara que el actual, para que en lugar de establecer la regulación límites dicotómicos (tener o no tener sellos), se pueda desarrollar un sistema que permita matices. ${ }^{28}$

De acuerdo con los informes de la autoridad de salud en Chile, ${ }^{29}$ se advierten las percepciones y actitudes de la población sobre la importancia práctica de los sellos de advertencia en sus decisiones de compra. Algunos resultados de este estudio explican que los encuestados manifestaron que tras comparar la cantidad de sellos de advertencia presentes en un alimento eligen productos alimenticios con menos sellos de advertencia $(58,4 \%)$, no compran alimentos con sellos $(40,9 \%)$, compran menos cantidad de lo que hubieran comprado si el alimento no tuviera sellos $(55,2 \%)$, o les es indiferente si un alimento tiene sellos de advertencia $(40,2 \%)$. Estos resultados parecerían alentadores y podría llegar a concluirse que está siendo exitosa la política pública basada en la obligación de incorporar sellos de advertencia en los alimentos envasados para generar cambios de hábitos en los consumidores en Chile. Pero no todo lo que brilla es oro: merece tenerse en consideración las inferencias y sesgos que sufren las personas frente aciertos estímulos.

28 Mora y SantibáÑ̃z (2016) 65.

29 AAVV (2018). 
Al momento de valorar distintos estímulos (tales como los sellos de advertencia en los alimentos) se producen ciertos errores y se observan contradicciones entre el desarrollo del razonamiento y la conducta efectiva. Las personas suelen tener una mejor valoración de sí mismos. La evidencia científica sobre el comportamiento de las personas ha advertido la distorsión de la percepción propia, comprobada en casos en los que las personas declaraban como se comportarían respecto de cierto estímulo, y se constató que su conducta difería ostensiblemente de lo que habían asegurado en una encuesta ${ }^{30}$.

A partir de los estudios disponibles, es posible considerar que las personas cometen errores al determinar su propio comportamiento porque se basan mayoritaria y únicamente en la información basada en el caso que tienen sobre sí mismos. Por ejemplo, basan sus predicciones en su personalidad y no en cómo han actuado en el pasado. Es decir, interfieren las fuerzas emocionales que no están presentes al momento de aproximarse en forma teórica a una cierta decisión, pero que sí se manifiestan en las personas una vez que se encuentran en el momento de la decisión misma. Interesantes

30 Epley y Dunning (2000) 861-875. Uno de los estudios considerados (Daffodil Days) tiene como contexto un evento universitario consistente en la venta de flores a beneficio de la Sociedad Americana del Cáncer. El estudio se basó en una encuesta, según la cual los alumnos debían prever si, tanto ellos mismos como sus compañeros, comprarían dichas flores de caridad. Una vez terminado el evento, se volvió a preguntar a los mismos si efectivamente compraron las flores. Los resultados demostraron que, por regla general, los estudiantes cometieron errores en su propio comportamiento, pues compraron menos flores de las que habían asegurado en la primera encuesta. Por el contrario, fueron más acertados al predecir el comportamiento de sus compañeros, pues estimaron que estos no comprarían tantas flores, y así sucedió. Otro estudio referido por los autores citados ( ¿Can You Spare a Dime?) consiste en la realización de una encuesta junto con un pago de cinco dólares y se desarrolla con tres condiciones distintas. Aquellos en la condición de comportamiento real debían decidir si dar parte de su paga a una caridad, al mismo momento de recibirla. En la condición cercana, a los participantes se les aclaraba que la situación de donar el dinero era meramente hipotética, y debían prever cuanto donarían sus compañeros y ellos mismos. En la condición distante, a los participantes solo se les da la descripción del experimento realizado en las otras dos condiciones, y deben determinar cuánto ellos mismos hubieran donado y la cantidad que sus compañeros lo hubieran hecho. Se advierten desviaciones entre lo declarado en las encuestas y la conducta efectiva. 
estudios desarrollados en torno a las percepciones de las personas en ciertos ambientes dan cuenta que merece atenderse el contexto de los conflictos intrapersonales de los individuos, y que uno de ellos es la tensión entre lo que la persona quiere frente a lo que debe hacer. ${ }^{31}$ Las respuestas (formales, racionales) frente a ciertos estímulos se basan fundamentalmente en lo que la persona debe hacer (por razones objetivas, de beneficio físico, económico, social, etc.), pero al momento de analizar el comportamiento efectivo, el individuo se mueve fundamentalmente por lo que quiere hacer, no por lo que debe hacer. Lo anterior da lugar al comportamiento inconsistente, y se demuestra que existe una diferencia entre lo que las personas predicen que elegirán en el futuro, frente a lo que realmente prefieren llegado el momento. ${ }^{32}$

Por consiguiente, los resultados de los estudios de la autoridad de salud en Chile basados en respuestas hipotéticas no pueden ser considerados para concluir que efectivamente los consumidores estén cambiando sus hábitos de consumo ${ }^{33}$, y no resulta válido en consecuencia considerar que la política pública basada en el nuevo etiquetado nutricional (sellos de advertencia) ha sido exitosa en Chile.

Bazerman, Tenbrunsel y Wade-Bensony (1998) 225-241.

Milkman, Rogers y Bazerman (2009) 1047-1059.

33 La experiencia de los especialistas en estudios de comportamiento del consumidor recomienda que siempre es necesario basarse no solo en estudios de metodología cualitativa (como fue el caso del primer estudio del Ministerio de Salud el año 2009, encargado a la consultora Feedback) sino también en estudios cuantitativos. Generalmente se recomienda hacer un estudio cualitativo en una primera etapa y luego en base a los resultados hacer un estudio cuantitativo. Los estudios cualitativos son exploratorios y no son extrapolables a la población; sus conclusiones son solo tentativas e incluyen generalizaciones especulativas. Su objetivo no es predecir el comportamiento de las personas, y una limitación de los métodos cualitativos es su dificultad para generalizar. En cambio, los estudios cuantitativos son determinantes y extrapolables a la población, y su propósito es predecir y/o controlar los fenómenos del comportamiento de los individuos De Pelekais (2000). 


\section{Conclusiones}

La sola existencia de regulaciones que imponen deberes de información en favor de los consumidores no logra generar cambios en las conductas de los sujetos destinatarios de la regulación (los consumidores), por cuanto intervienen una serie de factores relacionados con sesgos y hábitos que contrarrestan los objetivos iniciales de la autoridad al momento regular un área del mercado. Pese a que pueda existir una opinión favorable por parte de la autoridad -en base a ciertos estudios relacionados con las percepciones y grado de conocimiento de los consumidores- de la herramienta consistente en sellos de advertencia obligatoria en los alimentos, la evidencia científica disponible da cuenta que los consumidores tienen comportamientos contradictorios a sus preferencias y declaraciones.

Existen, por otra parte, razones que pueden afectar significativamente el logro de los objetivos buscados por el legislador al implementar la obligación del nuevo etiquetado nutricional, y que se relacionan con el limitado alcance de la regulación (ya que los sellos de advertencia no se aplican en los numerosos casos cotidianos en que se consumen productos alimenticios en establecimientos donde la información nutricional no está a la vista del público), la falta de anticipación por parte de la autoridad legislativa y sanitaria de la conducta esperable de las personas frente a un nuevo etiquetado y que son explicadas por la Economía del Comportamiento (sesgos de status quo y comportamiento intuitivo de los consumidores, entre otros), y la circunstancia que los sellos de advertencia no consideran medidas de consumo habitual.

Para anticipar y evitar políticas públicas regulatoriamente ineficaces, resulta de primera importancia prestar atención antes de la dictación de una regulación al estudio del comportamiento de los consumidores. Lo anterior, por cuanto es una ingenuidad alejada de la realidad pretender que la sola regulación generará cambios de conducta, sin abordar los impactos que tienen los factores internos en el racional de las personas. 


\section{Bibliografía}

a) Doctrina:

AAVV (2012): Historia de la Ley 20.606, Proyecto de Ley sobre regulación de alimentos poco saludables (Santiago, Biblioteca del Congreso Nacional de Chile).

AAVV (2018): Informe de Evaluación de la Implementación de la Ley sobre Composición Nutricional de los Alimentos y su Publicidad (Santiago, Ministerio de Salud). Disponible en: https://www.minsal. cl/wp-content/uploads/2018/05/Informe-Implementaci\%C3\%B3nLey-20606-febrero-18-1.pdf

Araya Aburto, S. (20I7): Efectos del etiquetado de alimentos en el comportamiento de los consumidores. Disponible en http://repositorio. uchile.cl/handle/2250/146296

Araya, Marcela y Atalah, Eduardo (2002): «Factores que determinan la selección de alimentos en familias de sectores populares», Revista Chilena de Nutrición. Vol. 29, N³, Diciembre.

Barros, Cristian y Zacarías, Nicolás (2018): «Ley de Etiquetado: ¿Sin sellos es más sano?», Facultad de Comunicaciones (Santiago, Universidad del Desarrollo), p. 13. Disponible en: http://comunicaciones. udd.cl/periodismo/ [Fecha de consulta: 10 de octubre de 2018]

Bazerman, Max, Tenbrunsel, Ann y Wade-Bensony, Kimberly (1998): «Negotiating with yourself and losing: Making decisions with competing internal preferences", Academy of Management Review, Vol. 23, No. 2, pp. 225-241.2

Cortada de Kohan, Nuria (2008): «Los Sesgos Cognitivos en la Toma de Decisiones", International Journal of Psychological Research, Vol. 1, No. 1.

De Pelekais, Cira (2000): "Métodos cuantitativos y cualitativos: diferencias y tendencias", Telos, Vol. 2. Disponible en: https://www. researchgate.net/publication/275651756_Metodos_cuantitativos_y_ cualitativos_diferencias_y_tendencias_Qualitative_and_Quantitative_Methods_Diferences_and_Tendencies

Epley, Nicholas y Dunning, David. Feeling (2000): «Holier Than Thou»: Are Self-Serving Assessments Produced by Errors in Self- or Social Prediction? Journal of Personality and Social Psychology, Vol. 79, No. 6.

GFK Adimark (2018): Chile Come Sano, V ${ }^{\circ}$ 2, Enero. Disponible en: https://www.adimark.cl/es/estudios/documentos/Estudio_Colaciones_Come_Sano_22-02-2018.pdf 
Howells, Geraint (2005): «The Potential and Limits of Consumer Empowerment by Information", Journal of Law and Society. Volume $32, \mathrm{~N}^{\circ} 3$.

Instituto de Nutrición y Tecnología de los Alimentos (2012): Estudio sobre evaluación de mensajes de advertencia de nutrientes críticos en el rotulado de alimentos. Informe Final (Santiago, Universidad de Chile). Disponible en: https://ciperchile.cl/pdfs/2014/11/ alimentos/INFORME-FINAL-MENSAJES-INTA.pdf

Ipsos Chile (2017): Estudio de Percepción de Consumidores sobre Descriptores Nutricionales Presentes en la Publicidad y Etiquetado de Alimentos Sobre la Rotulación de Alimentos Que Presentan el Símbolo «Alto en» en Coexistencia con otros Mensajes presentes en el Rótulo» (Santiago, Ministerio de Salud), p. 5. Disponible en https:// ciperchile.cl/wp-content/uploads/Informe-Ipsos.pdf

Kahneman, Daniel (2003): «Mapas de Racionalidad Limitada: Psicología para una Economía Conductual». Revista Asturiana de Economía - RAE, $\mathrm{N}^{\circ} 28$.

Kahneman, Daniel, Knetsch, Jack L. y Thaler, Richard H. (1991): "Anomalies: The Endowment Effect, Loss Aversion, and Status Quo Bias», The Journal of Economic Perspectives, $\mathrm{N}^{\circ} 5$.

Milkman, Katherine, Rogers, Todd y Bazerman, Max. Highbrow Films Gather Dust (2009): "Time-Inconsistent Preferences and Online DVD Rentals», Management Science, Vol. 55, No. 6, June.

Ministerio de Salud de Chile-Feedback (2009). Informe de investigación cualitativo: Evaluación de etiquetados nutricionales (Santiago, Ministerio de Salud).

Mora, Camilo y Santibáñez, Catalina (2016): «Efectos de misleading en publicidad y de la nueva Ley de Etiquetados sobre la percepción nutricional de los alimentos». Seminario para optar al título de Ingeniero Comercial, Escuela de Economía y Administración, Facultad de Economía y Negocios (Santiago: Universidad de Chile).

OECD (2014), La Evaluación de las Leyes en Chile. Resumen Ejecutivo. Disponible en: https://www.oecd.org/about/50194073.pdf

Olivares, Catalina y Quiroga, Javiera (2018): Ley No 20.606: Efecto en la Modificación de Consumo de Alimentos en Chile. Tesina presentada a la Facultad de Medicina de la Universidad Finis Terrae. (Santiago, Universidad Finis Terrae. Facultad de Medicina. Escuela de Nutrición y Dietética).

Thaler, Richard (1985): «Mental Accounting and Consumer Choice», Marketing Science, Vol. 4, No. 3. 
No todo LO QUE BRILLA ES ORO: ANÁLISIS DEL IMPACTO DEL NUEVO ETIQUETADO...

Visión Humana (2016): «Chilescopio 2016», Nueva versión del estudio Chilescopio. Estilo de vida, consumo y relación con los medios de los chilenos». Disponible en: https://issuu.com/visionhumana/docs/ informe_publico_chilescopio_2016_vi

\section{b) Normativa:}

Ley 20.606 (13/11/2015) sobre composición nutricional de alimentos y su publicidad.

Decreto 13/2015. Reglamento Ley 20.606 sobre composición nutricional de alimentos y su publicidad. 



\title{
SHARING ECONOMY, PROSUMER Y DERECHO DEL CONSUMIDOR: SU APLICACIÓN EN LA LEY SO- BRE PROTECCIÓN DE LOS DERECHOS DE LOS CONSUMIDORES
}

\author{
SHARING ECONOMY, PROSUMER \\ AND CONSUMER LAW: ITS APPLICATION \\ IN THE CONSUMER'S PROTECTION LAW
}

\section{Francisca Barrientos Camus $^{1}$}

Resumen. Este artículo explora la posibilidad de que el prosumer; esto es, el sujeto que es a la vez proveedor y consumidor pueda ser considerado como proveedor, según la definición del artículo 1 $\mathrm{N}^{\mathrm{o}}$ 2, de la Ley sobre protección de los derechos de los consumidores, $\mathrm{N}^{\circ} 19.496$.

1 Doctora en Derecho (Universidad de Los Andes); Profesora Adjunta Facultad de Derecho (Universidad Adolfo Ibáñez). E-mail: francisca.barrientos@edu. uai.cl. Parte de estas ideas fueron expuestas en la Conferencia Inaugural del III Congreso internacional de consumo organizada por la Universidad Autónoma de Chile, con fecha 6 de diciembre de 2018 y «Sharing economy e tutela del consumatore in America Latina», Seminario Harmonization of European and Latin-American Consumer Law, celebrado los días 12 y 13 de abril de 2018, en la Università «Magna Graecia» de Catanzaro, Italia. 
Palabras Clave: consumidor, economía compartida, prosumer.

Abstract. This paper explores the possibility that the prosumer, that is, the person who at the same time is a provider and consumer, can be considered as a provider, according to the definition of article 1 $\mathrm{N}^{\circ}$ 2, of the Law on the protection of consumer rights, Law $\mathrm{N}^{\circ} 19.496$.

KEYWORDS: sharing economy, prosumer, consumer.

Sumario:1. Introducción. 2. La mirada a la LPDC. 2.1. Los administradores de las plataformas colaborativas. 2.2. El prosumer. a. El prosumer que tiene orientación comercial. b. El prosumer que tiene no orientación comercial. 2.3. El consumidor colaborativo. 3. Conclusiones. 4. Bibliografía.

\section{INTRODUCCIÓN}

Sundararajan expresaba: «Donde había una fábrica ahora hay una plataforma. Donde había trabajadores ahora hay usuarios productores. Donde había jefes ahora hay algoritmos y mecanismos de reputación entre usuarios. Donde había salarios ahora hay ingresos fluctuantes $»^{2}$. Esto marca la importancia de la sharing economy o economía colaborativa, pues este autor refiere al funcionamiento de las plataformas de uso común en contraste con los antiguos métodos de producción de cosas de consumo, las fábricas.

Otra aproximación la presenta Albert Cañigueral, referente de habla hispana sobre economía colaborativa, quien nos dice que «el consumo colaborativo supone compartir los bienes frente a poseerlos, y focalizarse en poner en circulación todo aquello que ya existe. Pasar de entender el consumo como propiedad a entender el consumo como acceso y uso» ${ }^{3}$. Es decir, se trata de los usos de las plataformas, en el sentido propuesto por Sundararajan y colaborativa de Cañigueral. Ahora se comparten los bienes que las fábrican manufacturan y esto circula a través de las plataformas colaborativas.

Para simplificarlo, se ha dicho que la economía colaborativa supone «... la posibilidad de que 'mis cosas' puedan ser 'tus cosas' por 'un precio', no es necesariamente un nuevo fenómeno, pero, sin

SundaraRAJAN (2016) 25.

CAÑigueral (2014) 25. 
duda, es un hecho que se ha potenciado con la democratización del acceso a internet» ${ }^{4}$. Por eso, con la posibilidad que ofrece internet, el mundo vuelve a tener relaciones $\mathrm{P} 2 \mathrm{P}$ peer to peer, con el agregado que los consumidores contratan con influencias éticas, medioambientales, sociológicas y culturales importantes, que están más allá del simple consumo.

Así las cosas, este fenómeno que podríamos llamar «consumo colaborativo» abre espacios $\mathrm{P} 2 \mathrm{P}$ para comprar, arrendar, intercambiar y compartir bienes y servicios de consumo masivo, con monedas tradicionales o criptomonedas, celebrando compraventas o permutas o incluso sin costes monetarios. ${ }^{5}$ No se trata de economías gratuitas que se basan en el mero intercambio de bienes, porque ya se conocen una serie "plataformas de intermediación» que pueden prestar servicios onerosos tipo market places. Estas relaciones se llaman $\mathrm{B} 2 \mathrm{P}$, business to peer, que grafican al proveedor o profesional con una persona natural.

Lo curioso de este fenómeno es que las empresas de intermediación no tienen propiedad sobre los bienes o servicios que venden, como Uber que no tiene dominio sobre los automóviles que utiliza para transportar las personas; o, como AliExpress que no tiene bienes, solo pone en contacto vendedores con compradores cobrando una comisión.

En las siguientes lineas, se examinará la calificación jurídica de estas plataformas colaborativas, los prosumer y consumidores colaborativos, bajo las reglas de la Ley $\mathrm{N}^{\mathrm{o}} 19.496$ sobre protección de los derechos de los consumidores (en lo adelante, ley o LPDC).

\section{LA MIRADA A LA LPDC}

Siguiendo a Jarne ${ }^{6}$, en general, se propone distinguir entre una modalidad de consumo colaborativo puro o propio, que se manifiesta en las personas que pueden actuar con fines gratuitos o no

\footnotetext{
Arroyo (2016) 34.

FERnÁNdeZ (2016) 38.

JARNE (2016) 70.
} 
comerciales, de aquellas en que existe un ánimo de lucro y cierta orientación profesional ${ }^{7}$.

Sobre estas personas se encuentran los administradores de «plataformas colaborativas». Comenzaré el análisis de estas últimas, toda vez que sería más fácil su calificación de "proveedor» según los términos de la LPDC.

\subsection{Los administradores de las plataformas colaborativas}

El modelo comercial colaborativo desarrollado por las plataformas profesionales lucrativas es la intermediación. Un ejemplo de ellas es Uber ${ }^{8}$.

En nuestro país se ha cuestionado, por ejemplo, que no paguen impuestos, también la calificación jurídica de trabajadores de sus conductores y la falta de seguridad de los pasajeros. Por las fuertes presiones que ha ejercido el gremio de los taxis, al infringir las leyes que regulan la competencia ${ }^{9}$, se ha decidido enviar un proyecto de ley al Congreso ${ }^{10}$ para regular esta plataforma colaborativa. Lo

7 García (2016) 108.

8 En Chile, la participación de Uber es importante. La prensa informa que hay 1,8 millones de usuarios y 46 mil conductores, solo en las ciudades más importantes del país, http://www2.latercera.com/noticia/choferes-uber-crecen-84-10-mesesusuarios-suman-18-millones-chile/

9 Entre tantas noticias, ver http://www.24horas.cl/nacional/la-lucha-de-lostaxistas-contra-uber-1833945, https:/www.efe.com/efe/america/economia/ masiva-protesta-de-taxistas-chilenos-contra-las-aplicaciones-uber-y-cabify/20000011-3321777, http://www2.latercera.com/noticia/taxistas-protagonizan-nueva-jornada-movilizacion-uber-cabify/

10 En efecto, se está tramitando un proyecto de ley en el Congreso denominado «Proyecto de ley que moderniza la legislación sobre transporte remunerado de pasajeros» Boletín No 10.937-15, ingresado el día 25 de octubre de 2016. Este proyecto intenta implementar un registro y condiciones de funcionamiento de plataformas intermediadoras del transporte privado de personas y velar por la seguridad de los pasajeros. Se permite el transporte privado y colectivo de personas de forma remunerada (artículo 2). Los servicios privados que no sean taxis no pueden aceptar dinero en efectivo (artículo 4). Llama la atención que se haya proyectado una destinación especial para el pago de impuestos, por ejemplo, que los dineros recaudados se dirigirían a un «fondo que busca financiar proyectos que permitan la incorporación de tecnologías en los vehículos de transporte remunerado de pasajeros facilitando su modernización». Uno de esos proyectos se relaciona con el «renovar vehículos que presten servicios de 
importante es que este proyecto hace una remisión expresa a la ley de consumo ${ }^{11}$. Esto implica el reconocimiento de estas plataformas como proveedoras ${ }^{12}$; y que, por lo tanto, están obligadas a respetar los derechos de los pasajeros consumidores.

Entonces, como es posible inferir se considera que los administradores de estas páginas webs colaborativas son empresas ${ }^{13}$ proveedoras en los términos de las LPDC. Existen, una serie de razones que apoyan esta conclusión.

Primero, en la LPDC se reconoce que los proveedores pueden ser personas naturales o jurídicas, fundamentalmente sociedades ${ }^{14}$. La regla general es que los administradores se constituyan como personas jurídicas con fines de lucro, incluso muchas de ellas tienen presencia internacional, pero no tienen una agencia en el país para

transporte de taxis». Esto último ha sido criticado, ya que se cree que se está intentando fomentar a los taxis (Libertad y Desarrollo, 2016, p. 39).

11 En el texto se establece que «los actos y contratos que celebren los pasajeros mediante las plataformas tecnológicas, se regirán por lo dispuesto en la Ley $\mathrm{N}^{\circ}$ 19.496, que Establece normas sobre protección de los derechos de los consumidores» (artículo 17).

12 El proyecto chileno les reconoce la calidad de proveedoras a las administradoras de estas plataformas relacionadas con el transporte privado de personas, pero nada se dice sobre la calidad jurídica del conductor.

13 Broseta (1965) define a las empresas como una organización de capital y de trabajo destinada a la producción o mediación de bienes y servicios para el mercado, Broseta (1965) 274; Uría (2001) sostiene que el empresario es una persona física o jurídica que por sí o por medio de delegados ejercita y desarrolla en nombre propio una actividad en el mercado constitutiva de empresa adquiriendo la titularidad de las obligaciones y derechos nacidos de esa actividad, Uría (2001) 31; Sánchez-Calero (2004) define al empresario como la persona física o jurídica que profesionalmente y en nombre propio ejercita la actividad de organizar los medios precisos para la producción o cambio de bienes o servicios para el mercado., en SÁnCHEZ-CALERo (2004) 102.

14 En nuestro sistema hay personas jurídicas de Derecho privado con y sin fines de lucro. Las personas jurídicas sin fines de lucro son las corporaciones y las fundaciones. La corporación se distingue por la importancia de los miembros y la fundación por el patrimonio. Para Alessandri y Somarriva (1998) la corporación en sentido estricto era la unión estable de una pluralidad de personas que persigue fines ideales o no lucrativos, Alessandri y Somarriva (1998) 504. Se llaman también asociaciones (Ley No 20.500 de 2011). Incluso existen las personas jurídicas mixtas. La fundación es una organización que no consiste en una alianza de personas para la realización de determinados fines, AlESSANDRI y SOMARRIVA (1998) 504. Y las personas jurídicas de Derecho privado con fines de lucro son las sociedades. 
desarrollar sus operaciones. Esto es importante para el derecho tributario y ha sido objeto de grandes críticas ${ }^{15}$.

Segundo, la ley de manera amplia realiza una descripción de las actividades que los proveedores realizan ${ }^{16}$, por lo que cabría este fenómeno dentro de la comercialización de los servicios. Por eso, estas plataformas quedan plenamente integradas a la legislación de consumo. Incluso, se puede analizar desde la perspectiva de la intermediación. Respecto de ella, hay una norma particular consagrada en el artículo 43 de la ley, que se ha explicado como una hipótesis de responsabilidad directa objetiva ${ }^{17}$, y se ha aplicado mucho, por ejemplo, para las agencias de viajes ${ }^{18}$. Con ello, habría un acercamiento al modelo Airbnb.

Tercero, ejercen su negocio de forma habitual, requisito exigido por la legislación nacional. En efecto, en la LPDC el proveedor es el que habitualmente desarrolla una serie de actividades ${ }^{19}$. Por esta razón, Sandoval ${ }^{20}$ considera que el ocasional no es proveedor para los efectos del consumo ${ }^{21}$. La habitualidad es un requisito mercantil pensado para que los comerciantes o empresarios desarrollen su actividad con cierta repetición, de forma constante o profesional. Se opone a este concepto el sujeto que realiza actividades esporádicas, que supone la repetición de actos de manera constante por

15 Vid por ejemplo http://www.economiaynegocios.cl/noticias/noticias.asp?id=460061

16 «La ley incluye las actividades de producción, fabricación, importación, construcción, distribución o comercialización de bienes o de prestación de servicios a consumidores, por las que se cobre precio o tarifa» (artículo $1 \mathrm{~N}^{\circ} 2$ ). Con ello, nuestra legislación nacional ha puesto el acento en diversas actividades, siendo la más importante la comercialización que es propia del vendedor, que además cobra un precio o tarifa.

17 Ver Rodríguez (2014) 810; Contardo (2013) 910.

18 Vid Contardo (2010).

19 El artículo $1 \mathrm{~N}^{\circ} 2$ señala que el proveedor habitualmente desarrolla actividades de producción, fabricación, importación, construcción, distribución o comercialización de bienes o de prestación de servicios a consumidores. Pero, puede realizar otras que no están explicitadas en la definición de proveedor, como la gestión de la publicidad por parte del anunciante (artículo 28) o la rotulación (artículo 29).

20 SANDOVAl (2004) 49.

21 En Eheremberg con Multitienda Hites S.A. (2007), el tribunal estimó que el actor no tenía la calidad de consumidor final, al pretender la compra de 840 balones de fútbol para uso personal. El juez lo tuvo por comerciante, lo que parece discutible por la habitualidad que requiere el ejercicio del comercio. Al parecer, se trataba de un proveedor ocasional. 
parte de los comerciantes ${ }^{22}$. Palma ${ }^{23}$ señaló que debe tratarse de la "profesión habitual», sin que sea necesario demostrarlo de manera pública y notoria, principal o accesoria. Por su parte, Olavarría ${ }^{24}$, consideraba, más bien, que este requisito apuntaba a una idea de un «espíritu» que existiría entre los profesionales.

Entonces, para concluir este acápite no quedan dudas que los administradores de plataformas colaborativas son proveedores, en los términos de la LPDC, por las razones expuestas. Dicho eso, ahora corresponde examinar la calificación jurídica del prosumer.

\subsection{El prosumer}

En términos amplios, se considera que los prosumer son los proveedores y consumidores a la vez. Este es el desafío que presenta la sharing economy para el derecho del consumidor, toda vez que cuesta calificar al conductor del vehículo de Uber o al sujeto que arrienda su casa en Airbnb, porque la mayoría de estos sujetos no son empresarios de taxis o pertenecientes a la industria hotelera.

Como es un concepto económico en evolución resulta difícil y un tanto apresurado ofrecer una definición concreta. Por eso, mas bien, se construirá su fisonomía a través de las diversas tipologías de estos sujetos, según si tienen o no ánimo de lucro.

Desde esta perspectiva, puede sostenerse que los prosumer son personas que tienen ánimo de lucro y cierta orientación comercial, como también aquellas personas que no lo tienen, es decir, que interactúan de forma gratuita sólo con fines colaborativos; tema que se analizará a continuación.

22 Por ello, el artículo 8 del Código de Comercio expresa: «No es comerciante el que ejecuta accidentalmente un acto de comercio». De este modo, el comerciante que no es habitual pierde su carácter de tal».

23 Palma (1935) 84 y 88.

24 Olavarría (1954) 131. 


\section{a. El prosumer que tiene orientación comercial}

El sujeto que vende ciertas cosas con cierta orientación comercial presenta ciertas dificultades en su calificación. Precisamente, por esta razón, se creó el concepto de prosumer.

Como no es habitual ${ }^{25}$, podría fácilmente descartarse como proveedor, ya que la ley lo exige ${ }^{26}$. Ahora bien, si los vendedores o prestadores del servicio son habituales, calificarían como proveedores. Y, si se añade la intermediación, se obtiene un régimen de corresponsabilidad, en el cual dos agentes proveedores que deben velar por la tutela del consumidor.

En Chile, se excluye de la definición de proveedor a los profesionales liberales ${ }^{27}{ }^{28}$. El hecho que se excluya a los profesionales liberales de la definición de proveedor representa un problema para la calificación del prosumer que no está constituido como empresa, pero que cobra precios por los bienes que vende, pues según las reglas nacionales no sería proveedor, pero queda la duda respecto de su calidad de consumidor.

25 Un extraño ejemplo de no habitualidad en la compra de un camión es Automotora Bilbao con Muñoz (2013), fallo en el que se demostró que la demandante compró un camión nuevo (cero kilómetros) para transportar bienes. Para la Corte el hecho de comprar el camión dedicado a transportar bienes, en caso alguno lo tranforma en proveedora «... toda vez que ella no se dedica al arriendo de camiones, ni a otra actividad que tenga relación directa con la adquisición del vehículo» (énfasis agregado, considerando $5^{\circ}$ ). Pese a que su giro era el transporte, se entendió que no fue habitual en la compra. No se comparte la decisión de este fallo, quizás la demandante calificaba como pequeña empresaria, aunque no se ventiló esta cuestión en el juicio.

26 Supra 2.1.

27 El texto señala expresamente que: «No se considerará proveedores a las personas que posean un título profesional en forma independiente». Esto quiere decir que se excluye a los profesionales liberales». Los profesionales liberales se caracterizan por desarrollar actividades intelectuales propias de su profesión, que ejercen sus actividades de forma individual (liberal), sin que tengan subordinación o dependencia.

28 Respecto de esta exclusión, tiempo atrás sostuve que «En la actualidad, no parece adecuado mantenerles un privilegio de exclusión creado hace muchos siglos atrás. Por las características de los mercados altamente especializados, la fabricación de los productos en serie, su comercialización masiva, la influencia de la publicidad, todos los cuales conllevan a la despersonalización de las relaciones obligatorias, ya no sería posible asimilar la distinción entre profano y profesional liberal que justificaba el derecho de clases», BARRIENTOS (2016) 71 y 72. 


\section{b. El prosumer que tiene no orientación comercial}

El prosumer que no tiene vocación de comerciante, sino que desarrolla actividades colaborativas sin ánimo de lucro, no debería ser calificado como proveedor. Aunque el tema puede ser discutible ${ }^{29}$. Por eso, más bien, pienso que lo determinante es que no se cobre un cobre un precio o tarifa, tal como lo exige la ley.

Es decir, la ley de consumidor exige el cobro de un precio o la celebración de un acto jurídico oneroso ${ }^{30}$, esto es de la esencia de la relación de consumo, la intervención del lucro. Con ello, se pretende graficar es que, en palabras simples, para estar dentro de relación de consumo alguien tiene que vender un producto $u$ ofrecer un servicio y otro, cualquiera, tiene que pagar un precio oneroso por eso.

Entonces, se debe estar frente a actos o negocios jurídicos gratuitos que no estén amparados bajo la LPDC, como podrían ser las ofertas y promociones, que se ven como elementos determinantes para la formación del consentimiento, porque contienen deberes de precontractuales de información para el consumidor ${ }^{31}$. Para terminar, tan solo resta examinar la situación del consumidor colaborativo.

\subsection{El consumidor colaborativo}

Los consumidores colaborativos son, para todos los efectos, consumidores. Así, por interactuar con administradores de plataformas o prosumers, ellos no pierden los beneficios tutelares de la LPDC, porque se asume que el consumidor tiene como contraparte a un sujeto

29 En España se ha dicho que «Existen razones que militan en contra de incluir a las personas jurídicas como consumidores: suelen o pueden contar con recursos técnicos, de organización y de defensa superiores a los de cualquier persona física; su poder de negociación (v. gr., ciertas fundaciones) puede ser incluso superior al de algunos empresarios», Cámara (2010) 99.

30 En otra oportunidad defendía que de lege lata la noción de «destinación final» debería resaltar frente a otras partes de la definición legal de consumidor, especialmente frente a la expresión «cualquier acto jurídico oneroso» y la «adquisición» de los bienes o servicios, porque se presentaba un problema en la praxis judicial que entendía que el consumidor era sólo el sujeto que compraba o que pagaba por el bien o servicio. BARRIENTOS (2015) 333 y ss.

31 LAGOs (2013) 783 y 784. 
que tiene orientacion comercial y cumple con los requisitos para ser calificado como proveedor. Con ello, surge la relación de consumo.

Esto implica pensar las relaciones colaborativas desde la perspectiva pro-consumidor, haciéndoles exigibles todos los deberes de información, seguridad, con reglas de interpretación contra proferentem, aplicando la buena fe y el desequilibrio en las prestaciones del contrato como los criterios orientadores de las cláusulas que en ellos se contengan, etc.

Por eso, de lege ferendae se requiere la presencia estatal o supranacional $^{32}$, para que regule las exigencias mínimas que deben contener las páginas web en los cuales se celebran estos contratos $^{33}$. En este sentido, se planteado, por ejemplo, la organización de un régimen de seguros ${ }^{34}$. También se valoran los esfuerzos de autorregulación ${ }^{35}$ o los controles que la misma sociedad impone a

32 La Comisión Europea recomienda que las plataformas informen al consumidor colaborativo si es que está actuando con un profesional o con otro particular, para que sepan si se aplica la ley de consumo.

33 Barocelli y Estevarena (2018) lo plantean desde la vulnerabilidad a propósito del consumidor electrónico en términos que: «Pensar en el consumidor bajo un estándar de un 'consumidor medio', como lo concibe la jurisprudencia comunitaria europea, esto es, normalmente informado, razonablemente atento y eficaz, diligente, con cierta experiencia y aptitud para interpretar la información que se le facilita sobre los productos y servicios las condiciones en las que estos se comercializan, razonablemente observador y prudente y que percibe y conocer las marcas, es, a nuestro modo de ver, una versión 2.0 del 'buen padre de familia', que desnaturaliza el concepto de consumidor, requiriendo la prueba de vulnerabilidades in concreto, que pretende invisibilizar las diferencias, particularidades y situaciones de muchas personas bajo una idea totalizante, propia del derecho decimonónico, perjudicando especialmente a las más vulnerables, desventajosas y desfavorecidas de la sociedad, obligándolos a demostrar esa situación en todos los casos y dejar muchas veces en el camino a otros, según el ojo del juzgador. Por el contrario, si entendemos a la vulnerabilidad como nota presente en todas las relaciones de consumo, de carácter sociológico y sistémico, establecemos un marco de protección integrador, que se acentúa en especial frente a los más desaventajados» BARocelli y Estevarena (2018). Asimismo, comparto la opinión de García, «Las medidas tendientes a aumentar la confianza de los consumidores y su protección no deben, sin embargo, dificultar la actividad de aquellos particulares que ocasionalmente presten servicios en el marco de un sistema de economía colaborativa, de forma que se les exijan obligaciones de información desproporcionadas u otras cargas administrativas», García (2016) 109.

34 JARNE (2016) 74.

35 LÓPEz (2016) 174-208. 
través de asociaciones de consumidores. Por ejemplo, cabe destacar el trabajo que desarrolló una asociación de consumidores con una universidad española que apunta a ese objetivo ${ }^{36}$, para alertar a cuidar la seguridad de estas páginas webs colaborativas.

De otra forma, el consumo colaborativo no comercial, prescinde del sujeto profesional en su actividad, permitiendo y fomentando cierta autosuficiencia de los particulares en relación a la satisfacción de sus necesidades ${ }^{37}$.

En estos casos, se habla de contratos P2P (peer to peer), que grafican la idea del «ciudadano productor», para contraponerlo a la empresa o empresario. De alguna forma, con este modelo de desarrollo se volvería a aplicar las reglas civiles de la contratación, pero que en esta época no pueden aplicarse tabula rasa, porque la mayoría de las reglas civiles se construyeron durante la primera y los inicios de la segunda revolución industrial. En efecto, nuestro Código Civil es de 1855, cuyo modelo era de las personas libres e iguales ${ }^{38}$, plenamente informadas o castigadas si no lo estaban (nemo auditor). Ellas sufrían el riesgo de las cosas, caveat emptor, con plena vigencia del principio de la fuerza obligatoria del contrato o pacta sunt servanda.

Entonces, en los casos en que el consumidor colaborativo actué con fines particulares que no tienen vocación de lucro, en general, no se aplica la legislación de consumo.

\section{Conclusiones}

Para finalizar, es posible arribar a las siguientes conclusiones. Primero, los administradores de plataformas colaborativas son empresas proveedoras en los términos definidos en la ley de consumo. Ellos tienen por objeto la prestación o comercialización de servicios, de manera habitual, ejerciendo — desde una perspectiva— labores de intermediación.

36 Organización de Consumidores y Usuarios, en colaboración con la Universidad Complutense de Madrid. Información obtenida a través de JARnE (2016) 70. JARNE (2016) 64.

38 Vid. BARAONA (2014) 
Segundo, respecto de la calificación del prosumer será necesario distinguir si tiene o no orientación profesional. En el primer supuesto, podría considerarse como un proveedor siempre y cuando sea habitual. Si no lo es, díficilmente calificará como proveedor, menos si se trata de un profesional liberal, porque nuestra ley lo excluye de forma expresa. En el segundo caso, esto es, el prosumer que no tiene vocación profesional habrá que verificar si cobra un precio o tarifa aun cuando no tenga ànimo de lucro. Si lo hace con habitualidad será considerado como proveedor.

Y, tercero, los consumidores colaborativos siempre serán consumidores sin distinción de ninguna clase para todos los efectos de la LPDC.

\section{4.- Bibliografía}

\section{a) Doctrina:}

Alessandri, Arturo y Somarriva, Manuel en el texto de Vodanovic, Antonio (2015): Tratado de Derecho Civil. Partes preliminar y general (Santiago, Ediciones Jurídicas de Santiago) T. I.

Arroyo, Juan Carlos (2016): «La Economía Colaborativa en FinTech, una oportunidad de reinvención...», en: Informe economías colaborativas en América Latina, Banco Interamericano de Desarrollo e Instituto de Empresa de Madrid.

Barocelli, Sebastián y Estevarena, Esteban (2018): «La protección de los consumidores en plataformas de comercio electrónico", $L a$ Ley, 30 de mayo de 2018, $\mathrm{N}^{\circ} 6$ Fallo comentado: CNCom., sala D-22/03/2018-Kosten, E, cita on line: AR/DOC/870/2018.

BARAONA, Jorge (2014): «La regulación contenida en la ley 19.496 sobre protección de los derechos de los consumidores y las reglas del código civil y comercial sobre contratos: un marco comparativo", Revista Chilena de Derecho vol.41, n.2, pp. 381-408.

Barrientos, Francisca (2015): «La evolución judicial del concepto de consumidor. La importancia de la destinación final y la clasificación de los consumidores materiales y jurídicos», en Álvaro Vidal, Gonzalo Severín, Claudia Mejías (edits). Estudios de Derecho Civil X. (Santiago, Thomson Reuters), pp. 333-350.

BARRIENTOS, Francisca (2016): La garantía legal (Santiago, Thomson Reuters). Broseta Pont, Manuel (1965): La empresa, la unificación del derecho de obligaciones y el derecho mercantil (Madrid, Editorial Tecnos). 
CÁmara, Sergio (2010): «El concepto legal de «consumidor» en el derecho privado europeo y en el derecho español: aspectos controvertidos o no resueltos», Cuadernos de Derecho Transnacional, vol. 3 No 1 , pp. 84-117.

CAÑIgueral, Albert (2014): Vivir mejor con menos (Barcelona, Conecta) https://www.slideshare.net/acanyi/1er-cap-vivir-mejor-con-menos/1

Contardo, Juan Ignacio (2010): Responsabilidad civil contractual de las agencias de viajes (Santiago, Editorial AbeledoPerrot Legal Publishing).

Contardo, Juan Ignacio (2013): "Artículo 43», Íñigo de la Maza y Carlos Pizarro [dres.] Francisca Barrientos [cood.]. La protección de los derechos de los consumidores (Santiago, Editorial Thomson Reuters), pp. 899-918.

Fernández, Nuria (2016): «Problemática jurídica derivada de la economía colaborativa, Aspectos Jurídicos y Tributarios», https:// www.mincotur.gob.es/Publicaciones/Publicacionesperiodicas/ EconomiaIndustrial/RevistaEconomiaIndustrial/402/NURIA \%20 FERN\%C3\%81NDEZ\%20P\%C3\%89REZ.pdf

GARCÍA, Lourdes (2016): "Agenda europea para la economía colaborativa», Revista CESCO de Derecho de Consumo, No 18/2016, pp. 107-112 https://www.revista.uclm.es/index.php/cesco/article/view/1108/928

Jarne, Pablo (2016): «El consumo colaborativo en España: experiencias relevantes y retos de futuro", Revista Cesco de Derecho de Consumo, No17/2016, pp. 62-75 https://www.revista.uclm.es/index.php/cesco/ article/view/998/869

LAgos, Osvaldo (2013): «Artículo 35», Íñigo de la Maza y Carlos Pizarro [dres.] Francisca Barrientos [cood.]. La protección de los derechos de los consumidores (Santiago, Editorial Thomson Reuters), pp. 779-801.

Libertad y Desarrollo (2016): «Regulación de plataformas tecnológicas para el transporte privado», Temas Público No 1279-9, 4 de noviembre de 2016, https://lyd.org/wp-content/uploads/2016/11/ TP-1279-REGULACION-DE-PLATAFORMAS-TECNOLOGICASPARA-EL-TRANSPORTE-PRIVADO04-11-2016.pdf

Lopéz, David (2016): «La autorregulación del comercio electrónico en Chile», Revista Boliviana de Derecho 2016, No 21 pp. 174-208. <http:// www.scielo.org.bo/scielo.php?script=sci_arttext\&pid=S207081572016000100009\&lng=es\&nrm=iso>. ISSN 2070-8157.

Olavarría Ávila, Julio (1969): Manual de Derecho Comercial (Barcelona, Imprenta Clarasó) 3era [ed.].

Palma Rogers, Gabriel (1935): Derecho Comercial. Apuntes de clases redactados por H. Guerra, E. Covacevich y G. Gaete (Santiago, Talleres gráficos Artuffo). 
RodRíguez, María Sara (2014): «Responsabilidad por incumplimiento de contratos de servicios. La protección del consumidor y del cliente por prestaciones defectuosas", Revista Chilena de Derecho, vol.41, n.3, pp.791-823.

SÁnchez-Calero, Fernando (2004): Instituciones de Derecho mercantil (Madrid, Editorial Mc Graw Hill).

Sandoval López, Ricardo (2004): Derecho del consumidor (Santiago, Editorial Jurídica de Chile)

Sundararajan, Arun (2016): The Sharing Economy. The End of Employment and the Rise of Crowd-Based Capitalism (The MIT Press).

Uría, Rodrigo (2001): Derecho mercantil (Barcelona, Editorial Marcial Pons).

\section{b) Jurisprudencia:}

Eheremberg con Multitienda Hites S.A. (2007): Cuarto Juzgado de Policía Local de Santiago, 23 de noviembre de 2007 (denuncia infraccional y demanda civil) Rol No 12.806-2006.

Automotora Bilbao con Muñoz (2013): Corte de Apelaciones de Santiago, 28 de marzo de 2013 (demanda civil) Rol No 434-2012.

\section{c) Normativa:}

Proyecto de ley que moderniza la legislación sobre transporte remunerado de pasajeros» Boletín $\mathrm{N}^{\circ} 10.937-15$, ingresado el día 25 de octubre de 2016.

Ley 19496 (07/03/1997) sobre protección de los derechos de los consumidores 


\title{
El Ombudsman Sectorial: EN EL CONSUMO EN GENERAL Y EN LOS SERVICIOS BÁSICOS EN PARTICULAR
}

\author{
The Sectorial Ombudsman: \\ IN THE CONSUMER IN GENERAL \\ AND THE BASIC SERVICES IN DETAIL
}

Juan Pablo Díaz Fuenzalida ${ }^{1}$

Resumen. El artículo trata sobre el Ombudsman Sectorial en el consumo en general y en los servicios básicos en particular. La figura jurídica del Ombudsman, que desde sus orígenes comenzó siendo un Alto Comisionado del Parlamento para denunciar las irregularidades de la Administración Pública, fue insertándose en distintas latitudes y en variadas materias del Derecho llegando inclusive al

\footnotetext{
Doctor en Derecho y Máster en Gobernanza y Derechos Humanos (Universidad Autónoma de Madrid); Magíster en Docencia Universitaria, Licenciado en Ciencias Jurídicas y Sociales (Universidad Autónoma de Chile, sede Santiago); Abogado, título otorgado por la Excelentísima Corte Suprema de Chile. Profesor de Derecho Constitucional, adscrito al Instituto de Investigación en Derecho de la Universidad Autónoma de Chile. Editor Alterno de la Revista Justicia y Derecho de la Universidad Autónoma de Chile, disponible en: www.revistajusticiayderecho. com E-mail: juanpablo.diaz@uautonoma.cl / jpdiazfuenzalida@gmail.com
} 
mundo privado. Es así como hoy en día existe la institución del «ombudsman sectorial», realidad que se evidencia con el presente artículo analizando al ombudsman del consumidor, de la libertad económica, de la prensa (de los lectores), de los bancos e instituciones financieras, de los seguros y de los servicios básicos.

Palabras Clave: Ombudsman sectorial, consumo en general, servicios básicos.

Aвstract. The text deals with the "Sectorial Ombudsman» in the consumer and in the basic services. The legal construct of the ombudsman from its origins began as a High Commissioner of the Parliament for reporting evidence of serious wrongdoing to the Public Administration. But, is that over time, the institution was inserted in different latitudes, in the several areas of law and in private sector. The work is about the various sectorial ombudsman, in detail in the consumer law, of the economic freedom, of the press (of the reading), of the bank and financial institutions, of the insurance and of the basic services.

KEYwORDs: Sectoral Ombudsman, consumer in general, basic services

Sumario. 1.Introducción. 2. Ombudsman del consumidor. 3. Ombudsman de la libertad económica. 4. Ombudsman de la Prensa (de los lectores). 5. Ombudsman de los bancos e instituciones financieras. 6. Ombudsman de los Seguros. 7. Ombudsman de los Servicios Básicos. 8. Conclusiones. 9. Bibliografía

\section{INTRODUCCIÓN}

Cuando se instauró por primera vez el Ombudsman en la Constitución Sueca de 1809, donde también se perfecciona la institución ${ }^{2}$, quizás nadie pensaba el impacto que iba a tener en el mundo. Es una figura jurídica que no solo se ha expandido a la mayoría de los países $^{3}$, sino que también la institución ha mutado para integrarse

ROVIRA ViÑAs (2002) 37 - 38.

3 Sólo por nombrar algunos: En Europa en casi todos los países, como el Defensor del Pueblo en España, el Proveedor de Justicia en Portugal, el Defensor de Derechos en Francia, el Comisionado Parlamentario para la Administración en Reino Unido, los diversos Defensores Cívicos en Italia (que conforman un red 
a diversas materias del derecho en los ordenamientos jurídicos también diversos.

La palabra «Ombudsman» dice relación con una persona que actúa como vocero o representante. La versión original se dedicaba a recibir e investigar las quejas ciudadanas contra actos injustos de la Administración del Estado. Para ello debe tener las herramientas jurídicas y fácticas, con el objeto de denunciar los actos lesivos, pero, sin poder de revocarlos ${ }^{4}$. De ahí la idea que el Ombudsman no tiene potestad, sino que solo auctoritas. Era en su constructo primigenio una institución elegida por el Parlamento que, de ahí que es en esencia un Alto Comisionado del Parlamento que recibe quejas ciudadanas respecto del mal funcionamiento de la Administración para denunciar sus irregularidades en su actuar.

Sin embargo, como se venía anticipando, la figura del Ombudsman fue mutando, aunque conservando su esencia, que es recibir quejas denunciando irregularidades y mal servicio para solucionarlas con auctoritas pero sin potestas, intentando convencer, pero sin vencer al controlado. De ahí que surge el «Ombudsman Sectorial» que, como ya evidencia su nombre, se preocupa solo de una o varias materias perteneciendo entonces su actuar áreas o sectores específicos. Uno de los primeros casos lo encontramos en el Ombudsman militar en Noruega en 1952, pero ahora estas instituciones son cada vez más recurrentes, llegando a materias difíciles de imaginar, como el Defensor de las Funerarias en Reino Unido y en Países Bajos 5 .

Ya contextualizado el tema de investigación, no queda otra alternativa que definir el objetivo general y los objetivos particulares del presente trabajo: el objetivo general es evidenciar la inserción de la figura jurídica del Ombudsman en materias distintas a su versión original (que era la de controlar sólo a la Administración del Estado).

de ombudsman regionales), la Comisión de Peticiones en Alemania, entre otros; en Latinoamérica (todos excepto Chile): El Defensor del Pueblo en Argentina, las Defensorías del Pueblo en Bolivia, Colombia, Perú, entre otros; en África: El Protector Público de Sudáfrica, el Mediador de Marruecos, el Ombudsman de Gambia, entre otros; en Asia, en Israel el Knesset, en Paquistán Wafaqi Mohtasib, entre otros; en Oceanía: en Australia el Commonwealth Ombudsman, el Ombudsman de Nueva Zelanda, entre otros.

4 Rovira Viñas (2002) 38.

5 Maiorano (2010). 
Los objetivos particulares dicen relación con constatar aquello a través del análisis de casos de ombudsman en materias de regulación y consumo, en concreto, el Ombudsman de los consumidores libertad económica, de la prensa (de los lectores), en bancos e instituciones financieras, en los servicios básicos. Con ello se podrá dilucidar si la figura jurídica se ha encaminado en materias del derecho de la regulación y el consumo, y, si su estructura orgánica es ciertamente un Ombudsman.

\section{OMBUDSMAN DEL CONSUMIDOR}

El Ombudsman de los consumidores en Suecia, que es adicional al Ombudsman general, surge en el año 1971, el que es elegido para un mandato de tres años por el Gobierno. Según palabras de su primer titular, Sven Heurgren, su principal misión es transformar al consumidor-objeto a un consumidor-ciudadano. Además de su normativa orgánica y funcional, se apoya en la regulación del marketing, la que tiene por objeto proteger al público contra las publicidades abusivas y engañosas. Asimismo, se hacía de la normativa sobre condiciones de contratación, la que tiene por objeto hacer que desaparezcan cláusulas abusivas en desmedro de los consumidores ${ }^{6}$.

Su trabajo actualmente versa sobre los siguientes tópicos ${ }^{7}$ :

- Supervisión de empresas

- Acuerdos con la industria

- Seguridad de los bienes y servicios.

- Orientación independiente a los consumidores.

- Temas de finanzas privadas.

- Educación y apoyo en la orientación al consumidor y el asesoramiento presupuestario y de la deuda de los municipios.

- Fortalecer a los jóvenes para que sean consumidores conscientes.

- Mapear y analizar la situación y condiciones de los consumidores en diferentes mercados.

6 Gil-Robles y Gil-Delgado (1981) 54.

7 Sitio electrónico del Om Konsumentverket de Suecia. Disponible en https://www. konsumentverket.se/om-konsumentverket/vart-arbete/ [Fecha de consulta: 14 de junio de 2019]. 
En cuanto a sus actividades destaca lo que el mismo Sven Heurgren comentó de la institución que ejercía ${ }^{8}$ :

«Hemos hecho desaparecer de los periódicos un anuncio que prometía un curso de adelgazamiento (diez kilos por mes). Contra la suma de 25 coronas, el anunciante remitía a sus engañados, en hoja multicopiada, algunos consejos en materia de nutrición y un menú milagro.

Hemos puesto igualmente fin a las campañas que promocionaban auténtica charlatanería, como, por ejemplo, un brazalete biomagnético soberano contra insomnios y reumatismos. Disponemos además de expertos, análisis y tests. De esta forma hemos hecho modificar la presentación de un postre a base de gelatina y de perfume sintético. Cada paquete de este producto estaba decorado con frutas frescas. El fabricante ha aceptado nuestra decisión: ni una fruta más en el exterior de los paquetes».

Se denota entonces que su principal misión es la defensa de los consumidores, inclusive dejando en evidencia malas prácticas de vendedores y productores de bienes y servicios. Suma que toma una posición clara, no es mediador o sujeto neutral entre el ciudadano y el productor, sino que su trabajo es en defensa de los consumidores inclusive intentando coartar otros derechos como lo puede ser la libertad de expresión o emprendimiento, si esta llegase a vulnerar los derechos de los consumidores.

\section{OMbudsman de la libertad ECONÓMiCa}

Uno de los países característicos es Suecia, donde se instaura en el año 1954 el Ombudsman de la Libertad Económica, con motivo a sostener las reglas básicas de una economía capitalista, donde la oferta y demanda sean libres. Es designado por el rey en Consejo, actúa de oficio o a solicitud de parte, y, vigila el buen juego en el libre mercado. Su actuación es más de negociador con la parte infractora de las reglas de libre competencia, para hacerle comprender

8 Gil-Robles y Gil-Delgado (1981) 55. 
de su actitud inadmisible, y de no cambiar su actitud, tendrá que tomar otras medidas más gravosas, llevando el caso a tribunales si fuese necesario. Dos actos son especialmente prohibidos, los precios impuestos y las alianzas de precios, a no ser que estas últimas sean beneficiosas para el consumidor? .

Puede haber mejores o peores sistemas económicos, con pros y contras. Sin embargo, para que funcionen, no puede haber deficiencias o quiebres de las reglas básicas. Es así como es fundamental para el sistema capitalista, el libre mercado, que no haya colusiones porque así no hay competencia, siendo desmejorados los consumidores en precio y calidad de los productos y servicios. De ahí la relevancia del Ombudsman de la libertad económica.

\section{Ombudsman de la Prensa (de los lectores)}

Esta figura ha sido adoptada en varios países, el objetivo es mejorar el periodismo escrito, de forma tal que el lector pueda reclamar ante una entidad cuando considere que sus derechos como lector han sido vulnerados por algún periodista o por una información en particular. ${ }^{10}$ En general, esta estrategia de control ha sido generada por la pérdida de credibilidad que enfrentan los periódicos, incluso en algunos casos escándalos por falta de objetividad, como también en aspectos formales como error en uso del lenguaje, traducciones, entre otras fallas ${ }^{11}$. En ese sentido, es difícil decidirse si es en realidad un Ombudsman de la prensa o en bien de los lectores.

Hay antecedentes de este tipo de institución al menos desde la segunda década en Estados Unidos. En efecto, en 1913, Joseph Pulitzer creó una oficina para atender e investigar las quejas de los lectores del periódico New York World. En general, las reclamaciones se referían al deterioro de contenidos, falta de contraste en los contenidos, como también la frivolidad de estos y la ausencia de impunidad. Asimismo, en Kentucky, en la década de los setenta, se dice que fue creado a imagen y semejanza que el mismísimo

9 Gil-Robles y Gil-Delgado (1981) 56.

10 SÁNCHEZ PiÑa (1999).

11 Yepes Bustamante (2008) 12. 
Ombudsman sueco ${ }^{12}$. Por otro lado, el periódico japonés Yomiuri Shimbun ha sostenido que desde el año 1938 desarrolló una figura jurídica semejante ${ }^{13}$.

El caso de Suecia nos da a conocer esta particular institución, porque este tipo de defensor es nombrado libremente por las organizaciones de prensa, ergo no de autoridades gubernamentales o parlamentarias. Curiosamente es una especie de Ombudsman privado, de grupo o sector, precisamente de la prensa. Tampoco es el único caso, ocurre, por ejemplo, en Estados Unidos con el grupo Xerox. En efecto, su misión principal es controlar la deontología del periodismo, investigando las violaciones de las reglas de la moralidad profesional y la no intrusión en la vida privada de las personas ${ }^{14}$.

Uno de los Ombudsman de la prensa en Suecia, Lennart Groll, en cierta forma explica la institución con las siguientes palabras:

«Existe una comisión llamada de los buenos usos de la prensa, que se compone de seis miembros de los cuales dos representan a los lectores (el gran público). Los periódicos se han comprometido a publicar las resoluciones de esta comisión en casos de amonestación. Yo mismo soy un intermediario entre el lector y el editor.

Toda queja me es comunicada y yo intervengo cerca de los redactores en jefe a fin de obtener una rectificación. Recibo aproximadamente cuatrocientas por año. Puedo incluso enviar una advertencia al periódico. Lo he hecho recientemente contra L'Expressen. Este diario trataba la muerte de una prostituta suiza. Publicaba muchas fotografías de la víctima que no tenían nada que ver con los hechos, y que constituían una intrusión en su vida privada y en la de su familia.

El periódico ha sido obligado a publicar mi carta y a pagar una indemnización de tres mil coronas ${ }^{15}$.

Por otro lado, en 1980 se crea en Estados Unidos la Organization of news Ombudsman, que agrupa a sus congéneres de diferentes

\footnotetext{
Yepes Bustamante (2008) 11 - 12.

VÁsQuez Ríos (2002) 106.

Gil-Robles y Gil-Delgado (1981) 56.

15 Le Figaro, 30 de septiembre de 1974.
} 
naciones. Su objeto es extender la figura en donde no exista la institución, precisar sus funciones y métodos de trabajo, como también generar un foro de intercambio de experiencias ${ }^{16}$. Actualmente tiene representación a través de miembros regulares asociados de los siguiente siguientes países: Alemania, Argentina, Australia, Bélgica, Brasil, Canadá, Colombia, Dinamarca, España, Estados Unidos, Estonia, Finlandia, Holanda, India, Israel, Japón, Kenia, Portugal, Reino Unido, Sudáfrica, Suecia, Suiza, Turquía y Zimbabue ${ }^{17}$.

En Latinoamérica el Ombudsman de la prensa aparece inicialmente en Brasil, aunque su fuerza es más de control interno de los periódicos que externa desde la sociedad. Así, encontramos la figura en Bolivia, Brasil, Colombia, México, Panamá, Puerto Rico y Venezuela. Cada uno de ellos con similitudes, pero también diferencias ${ }^{18}$. $\mathrm{Al}$ respecto, son muy pedagógicas las palabras de Javier Restrepo, defensor del periódico El Colombiano, de Medellín:

No hay un modelo único de defensor, no puede haberlo. Entre los cerca de 50 defensores de todo el mundo que nos reunimos en San Diego, convocados por la Organization of News Ombudsman, había el Ombudsman pedagogo, el ombudsman magistrado, el investigador e incluso el ombudsman reportero. Pongo esas variedades junto con las descripciones del Ombudsman que se han dado a lo largo de sus historia y me pregunto si hay un hilo conductor, una viga maestra que permita definir la gran razón de ser de esta figura, no tanto por regodeo intelectual sino como clave para abrir el futuro de esta institución; y es cuando uno encuentra, detrás de todas esas definiciones y modelos, que el Ombudsman ha puesto en marcha una pedagogía del derecho a la información y que sus tareas hacen parte de un mecanismo que impulsa la aplicación y vigencia de ese derecho ${ }^{19}$.

\footnotetext{
16 Herrera Damas (2005).

17 Sitio electrónico del Organization of News Ombudsman. Disponible en https:// www.newsombudsmen.org/regular-members/ [Fecha de consulta: 14 de junio de 2019].

18 Yepes Bustamante (2008) 14.

19 Restrepo (2003)
} 
Un caso que es relevante revisar es en Colombia, pues la creación de un ombudsman de la prensa en algunos diarios, como en «El Tiempo», generó posiciones encontradas. En general, se pensaba a favor, pues se consideraba que era un elemento de control que debía aplicarse, pero también hubo otros que estimaban que la figura le restaba independencia al periódico, opinión por cierto de José Salgar de otro diario, «El Espectador». Algunos incluso fueron más críticos, consideraban que era un mal necesario para mejorar la credibilidad en los medios ${ }^{20}$.

\section{OMBUDSMAN DE LOS BANCOS \\ E INSTITUCIONES FINANCIERAS}

Este tipo de institución sectorial, al que también se la ha denominado Ombudsman financiero, es un intermediario, defensor o mediador, según se explicará, entre las intuiciones financieras, bancos u otras, con sus clientes. Es una figura de conciliación o supervisión para que no haya necesidad de tomar acciones legales en tribunales de justicia. Hay experiencias de este tipo de naturaleza jurídica pública, como lo podría ser una entidad estatal, y privada, creados por las mismas instituciones financieras ${ }^{21}$. En ese sentido, cambia bastante su visión, pues, como podrá deducirse, si son privados serán más conciliadores mientras que si son públicos, al menos en teoría, tendrán un rol más de supervisión e incluso de defensor de los clientes financieros.

Un ejemplo de Ombudsman bancario estatal lo encontramos en México, al que se le denomina Comisión Nacional para la Protección y Defensa de los Usuarios de Servicios Financieros. En efecto, es un organismo público descentralizado de la Administración Pública Federal, con autonomía técnica y jurídica para dictar resoluciones y dictámenes, tiene facultad para imponer sanciones ${ }^{22}$, entre otras ${ }^{23}$.

\footnotetext{
20 Yepes Bustamante (2008) 16.

21 JimÉnEZ (2014).

22 Estatuto Orgánico de la Comisión Nacional para la protección de defensa de los usuarios de servicios financieros, (México).

23 Ley de Protección y Defensa al Usuario de Servicios Financieros, de 18 de enero de 1999, última reforma 10 de enero de 2014, (México).
} 
La razón de ser de esta institución promover y difundir la educación y la transparencia financiera para que los usuarios tomen decisiones informadas sobre los beneficios, costos y riesgos de los productos y servicios ofertados en el sistema financiero mexicano. Asimismo, proteger los intereses de los de los usuarios mediante la supervisión y regulación a las instituciones financieras y proporcionarles servicios que los asesoren y apoyen en la defensa de sus derechos ${ }^{24}$.

La Comisión Nacional para la Protección y Defensa de los Usuarios de Servicios Financieros realiza una serie de actividades. Ha sido la supervisión de créditos, haciendo análisis comparativos, incluyendo el Crédito Personal, Crédito de Nómina y Crédito de Auto $^{25}$, presentado sus resultados a los usuarios vía comunicados que sintetizan lo esencial ${ }^{26}$. Así como también realiza educación financiera, como con su comunicado que buscaba evitar defraudaciones, las que intentaban sorprender al público solicitando datos personales, como cuando se pedía datos de tarjetas de crédito para «blindarlas», pero la Comisión advirtió que ninguna de las compañías dueñas de esas tarjetas (como, por ejemplo, MasterCard, Visa, entre otras) van a llamar pidiendo dicha información, pues éstas ya tienen esa información ${ }^{27}$.

Sin embargo, algunas de las actuaciones de la Comisión Nacional para la Protección y Defensa de los Usuarios de Servicios Financieros al menos son discutibles, porque parecen, en ocasiones, más una publicidad para las entidades bancarias que asesoramiento financiero, como cuando fomentaba un buen uso de la tarjeta de crédito en vacaciones ${ }^{28}$, (en vez de promover no usarla para no estar pagando durante el año, por ejemplo viajando a lugares más accesibles presupuestariamente o promoviendo el ahorro para el siguiente

24 Sitio electrónico de la Comisión Nacional para la Protección y Defensa de los Usuarios de Servicios Financieros. Disponible en https:/www.gob.mx/condusef/ que-hacemos [Fecha de consulta: 14 de junio de 2019].

25 Comisión Nacional para la Protección y Defensa de los Usuarios de Servicios Financieros (2016a).

26 Comisión Nacional para la Protección y Defensa de los Usuarios de Servicios Financieros (2016b).

27 Comisión Nacional para la Protección y Defensa de los Usuarios de Servicios Financieros (2011).

28 Comisión Nacional para la Protección y Defensa de los Usuarios de Servicios Financieros (2016c). 
año, de manera de no estar obligado a instituciones financieras por créditos de consumo, que es sabido que tienen, en general, intereses más altos que otro tipo de préstamos).

Además, esta es una institución que en ciertos casos tiene potestas y no solo auctoritas, lo que la diferencia o hace variar al Ombudsman. Ello es un fenómeno propio en Latinoamérica, en que poco a poco se ha ido modificando o añadiendo funciones adicionales a la institución original ${ }^{29}$. Como ya se había anticipado, en virtud de la Ley de Protección y Defensa al Usuario de Servicios Financieros ${ }^{30}$, la Comisión puede: aplicar medidas de apremio ${ }^{31}$; imponer sanciones administrativas en el ámbito de su competencia por infracciones a las leyes que regulan las actividades e Instituciones Financieras, sujetas a su supervisión, así como a las disposiciones que emanen de ellas ${ }^{32}$; conocer y resolver sobre el recurso de revisión que se interponga en contra de las sanciones aplicadas, así como condonar total o parcialmente las multas impuestas ${ }^{33}$. Es más, hay un Título y Capítulo completo de la normativa desarrollado exclusivamente para determinar las sanciones y del recurso administrativo que se interponer ante la misma Comisión ${ }^{34}$. Es decir, además de ente sancionador administrativo, ejercer facultades similares a las jurisdiccionales, siendo una especie de juez y parte en dichos casos.

Por otro lado, hay ombudsman bancarios de naturaleza privada. Uno de los ejemplos más representativos es el caso de Suiza, con el Swiss Banking Ombudsman, institución que comenzó sus funciones en el año 1993 atendiendo alrededor de 2000 consultas al año. A pesar de ser una figura privada, tiene un cierto grado de independencia dura en el cargo cinco años, con posibilidad de reelección ${ }^{35}$. Se preocupa de

29 Maiorano (2001) 191-198.

30 Ley de Protección y Defensa al Usuario de Servicios Financieros, de 18 de enero de 1999, última reforma 10 de enero de 2014, (México). Disponible en http://www.condusef.gob.mx/PDF-s/marco_juridico/ley_condusef.pdf [Fecha de consulta: 14 de junio de 2019].

31 Artículo 11. XXII, Fracción reformada por el DOF 05-01-2000.

32 Artículo 11. XXXVIII, Fracción adicionada por el DOF 25-06-2009.

33 Artículo 11. XXXIX, Fracción adicionada por el DOF 25-06-2009.

34 Artículos 93-108, Fracciones adicionadas y adicionadas por: DOF 05-01-2000, 12-05-2005, 07-07-2005, 06-06-2006, 15-06-2007, 25-06-2009, 10-01-2014.

35 Foundation Charter of the Swiss Banking Ombudsman Foundation, (Suiza), artículo 10. 
las quejas que se dan en la materia contra bancos con sede en Suiza. Aunque sea una entidad privada, el servicio es gratuito y confidencial. Es un ente mediador más que defensor propiamente tal, pero tampoco tiene rol de tribunal ${ }^{36}$. Podría decirse que es una especie de mediación, «neutral», no vinculante previa a jurisdicción arbitral.

Además, existe la Swiss Banking Ombudsman Foundation, que apoya al Swiss Banking Ombudsman, la que se regula por estatutos privados desde el año $1993^{37}$. Como entidad privada, es creada por estatutos. Su capital inicial fue de 800.000 francos suizos, ha sido establecida por un periodo indefinido ${ }^{38}$. El Consejo de dicha fundación es quien elige al Swiss Banking Ombudsman, permitiéndole reelegirlo. También tiene la facultad de realizar las normas de procedimiento, reglamentos y resoluciones por las que debe actuar el Ombudsman. Aprueba las cuotas de funcionamiento para que aporten en cotizaciones los bancos suizos ${ }^{39}$. Por dar un ejemplo, las actuales reglas de procedimiento del Ombudsman fueron aprobadas por un acta de Consejo ${ }^{40}$.

Como los demás ombudsman también hace informes anuales. En 2016, se refirió, entre otras cosas, a la interrupción de la tasa de cambio mínimo entre el franco suizo frente al euro. En efecto, el Banco Nacional Suizo suspendió aquella transacción lo que originó numerosas quejas, sobre todo porque estaban pendientes las operaciones de cambio de divisas en esas monedas, así como en dólares estadounidenses y libras esterlinas, afectado no solo a los usuarios, sino que también en diferentes productos bancarios y al procesamiento de las transacciones respectivas. Asimismo, hizo alusión a las tasas de interés negativas. Así, en conjunción con la interrupción de la tasa de cambio mínimo del franco suizo frente al euro, el Banco Nacional

36 Sitio electrónico del Swiss Banking Ombudsman. Disponible en http://www. bankingombudsman.ch/en/office-of-the-ombudsman/ [Fecha de consulta: 14 de junio de 2019].

37 Foundation Charter of the Swiss Banking Ombudsman Foundation, (Suiza).

38 Foundation Charter of the Swiss Banking Ombudsman Foundation, (Suiza), artículo 5 .

39 Foundation Charter of the Swiss Banking Ombudsman Foundation, (Suiza), artículo 10.

40 Rules of Procedure for the Swiss Banking Ombudsman, aprobadas por el Consejo de la Swiss Banking Ombudsman Foundation el 7 de diciembre de 2012, para que entraran a regir el 1 de julio de 2013 (Suiza). 
de Suiza también ha decidió introducir una tasa de interés negativa para los bancos sobre los depósitos por encima de un determinado umbral de exención. También a materias sobre hipotecas de tasa fija, asesoramiento de inversión y gestión de activos, usos indebidos y fraudes, cargos y asuntos de identificación que dicen relación con la confidencialidad de las actuaciones del ombudsman ${ }^{41}$.

Otro caso muy particular, que podríamos decir que es un sistema mixto, pues, aunque sean instituciones privadas se regulan por normas obligatorias estatales, corresponde a los Defensores del Cliente en España. En efecto, todas las entidades supervisadas por el Banco de España están obligadas a tener un Servicio de Atención al Cliente y, opcionalmente, un Defensor del Cliente, conforme a lo dispuesto en la Orden ECO/734/2004, de 11 de marzo ${ }^{42}$.

Las entidades financieras están obligadas a atender y resolver las quejas y reclamaciones que sus clientes les presenten, relacionadas con sus intereses y derechos legalmente reconocidos ${ }^{43}$. El Defensor del Cliente es elegido por la entidad financiera ${ }^{44}$. Asimismo, cada entidad o grupo aprobará el Reglamento para del Defensor ${ }^{45}$, aunque con ciertas exigencias mínimas de contenido, relativas lo siguiente: a) Duración del mandato, en su caso, y posibilidad de renovación; b) Causas de incompatibilidad, inelegibilidad y cese; c) Relación clara y precisa de asuntos cuyo conocimiento, por razón del fondo, la cuantía o cualquier otro criterio, se atribuye al defensor del cliente, en su caso, con indicación expresa de que aquellos que no le correspondan serán competencia del departamento o servicio de atención al cliente; si ambas instancias tuvieran atribuido el conocimiento del mismo tipo de reclamación se deberá especificar si tras la decisión del departamento o servicio de atención al cliente el reclamante puede acudir al defensor del cliente como segunda instancia, sin

\footnotetext{
41 Swiss Banking Ombudsman (2015).

42 Sitio electrónico del Banco de España. Disponible en http://www.bde.es/ bde/es/secciones/servicios/Particulares_y_e/Servicio_de_Ate/Servicios_de_ At_6d9079a9970c631.html [Fecha de consulta: 14 de junio de 2019].

43 Orden ECO/734/2004 (España), artículo 3.

44 Orden ECO/734/2004 (España), artículo 4.2.

45 Orden ECO/734/2004 (España), artículo 8.1.
} 
perjuicio del plazo de dos meses para dictar una decisión definitiva para el reclamante ${ }^{46}$.

También contribuye a características de ombudsman la celeridad de los procedimientos de este tipo de procurador. En efecto, Los defensores del cliente, disponen de un plazo de dos meses, a contar desde la presentación ante ellos de la queja o reclamación, para dictar un pronunciamiento ${ }^{47}$. Lo mismo ocurre con el poder/ deber de presentar un informe anual explicativo del desarrollo de sus función, que tenga: a) resumen estadístico de las quejas y reclamaciones atendidas, con información sobre su número, admisión a trámite y razones de inadmisión, motivos y cuestiones planteadas en las quejas y reclamaciones, y cuantías e importes afectados; b) resumen de las decisiones dictadas, con indicación del carácter favorable o desfavorable para el reclamante; c) criterios generales contenidos en las decisiones; d) recomendaciones o sugerencias derivadas de su experiencia, con vistas a una mejor consecución de los fines que informan su actuación ${ }^{48}$.

En España, varios son varios los bancos e instituciones financieras que han optado a tener defensor de clientes. Un caso es el del Banco Santander, donde el Defensor del Cliente es elegido conjuntamente y por unanimidad del grupo, debiendo ser ajeno de las entidades de las que presta servicio. Durará tres años en el cargo con posibilidad de reelección cuantas veces se considere oportuno. El desempeño del cargo será incompatible con cualquier cargo o profesión que pueda impedir o menoscabar el cumplimiento de sus funciones o comprometer la imparcialidad e independencia. En cuanto a sus funciones, están la tutela y protección de los derechos e intereses de los usuarios y clientes de servicios financieros, derivados de sus relaciones con las entidades, así como procurar que tales relaciones se desarrollen en todo momento conforme a los principios de buena fe, equidad y confianza recíproca ${ }^{49}$.

En cuanto a las materias que trata, conoce, estudia y resuelve las quejas y reclamaciones que los usuarios o clientes le planteen,

46 Orden ECO/734/2004 (España), artículo 8.3.

47 Orden ECO/734/2004 (España), artículo 10.3.

48 Orden ECO/734/2004 (España), artículo 17.

49 Reglamento del Defensor del Cliente (Banco Santander de España). 
siempre que las quejas se refieran a operaciones o servicios bancarios y financieros, siempre que se refieran a tardanzas, desatenciones o defectos en el funcionamiento de dichos servicios financieros y, que las reclamaciones a la pretensión de obtener restitución de sus intereses y derechos legalmente reconocidos, ya deriven de los contratos, de la normativa de transparencia y protección de la clientela o de las buenas prácticas y usos financieros y en particular del principio de equidad. También le corresponde conocer, estudiar resolver cuestiones encomendadas por el Banco en materias que haya relación con este y sus clientes o usuarios, donde el Defensor podrá actuar como mediador con el objeto de llegar a un arreglo amistoso entre las partes ${ }^{50}$. Estas son al fin y al cabo elegido por la entidad financiera, pudiendo en cualquier momento cambiar su reglamentación, a su arbitrio, agregando o suprimiendo materias de revisión por el Defensor. Asimismo, el Banco puede excluir materias de competencia del Defensor ${ }^{51}$.

\section{Ombudsman de los Seguros}

Otro ombudsman sectorial lo encontramos en los seguros. Este tipo de figura lo encontramos en una serie de países. En España, el Grupo Winterthur instituyó el Defensor del Cliente; en Australia, el Ombudsman del Seguro; en Irlanda, Ombudsman del Asegurado; en Singapur, Nueva Zelanda y Finlandia, Bureau del Ombudsman del Seguro; en Estados Unidos de Norteamérica, Ombudsman para los Reclamos de Seguros de New Jersey; en India: Guru-cibernético-de Seguros; en Gran Bretaña, el Insurance Ombudsman Bureau de más doscientas empresas aseguradoras, entre otras. Uno de los ejemplos recientes y significativos en la materia sucede en Estados Unidos con su nueva Ley de Sanidad, de la segunda década del siglo XXI, donde, entre otras obligaciones, impone a las aseguradoras crear un defensor del asegurado para recibir reclamaciones del nuevo régimen ${ }^{52}$.

Para precisar la institución, es significativo el caso de Argentina, donde es posible citar el caso de la Asociación Argentina de

50 Reglamento del Defensor del Cliente (Banco Santander de España).

51 Reglamento del Defensor del Cliente (Banco Santander de España), artículo 8.

52 Maiorano (2014) 22. 
Compañías de Seguros, que ha incorporado un ombudsman corporativo, primer instituto sectorial de dicha república ${ }^{53}$. Como diría uno de los defensores del asegurado y ex Defensor del Pueblo de Argentina, don Jorge Luis Maiorano ${ }^{54}$, "el objetivo fue generar un espacio para la solución de conflictos entre los asegurados y sus Compañias propendiendo así a la desjudicialización de esos conflictos y a la autorregulación aspirando siempre a la mejora del servicio hacia sus clientes ${ }^{55}$. En efecto, el Defensor del Asegurado es una figura de carácter privado creada en el ámbito de la Asociación Argentina de Compañías de Seguros ${ }^{56}$, orientada a la protección de los derechos de los asegurados y/o beneficiarios, mediante la intervención en los conflictos que se suscitaren entre la persona física o jurídica que tuviera contratado un seguro y un asegurador debidamente autorizado para operar, siempre y cuando este último haya previamente adherido al sistema del defensor de la asociación mencionada ${ }^{57}$.

Es una figura privada. El Defensor del Asegurado es designado por la Junta Directiva de la Asociación Argentina de Compañías de Seguros, sobre una terna propuesta por el Comité Ejecutivo. Durará tres años en el cargo con posibilidad de reelección cuantas veces se estime oportunas ${ }^{58}$, y su informe anual será presentado a dicha asociación ${ }^{59}$. El presidente de la Asociación Argentina de Compañías de Seguros formulará un informe anual respecto de la actuación del Defensor del Asegurado en el que incluirá las recomendaciones que

53 Maiorano (2011) 11.

54 Es interesante además señalar que Jorge Luis Maiorano había conocido el cargo de Ombudsman precisamente como tal, pues fue Defensor del Pueblo, designado por Resolución DP 270/94 de los Presidentes de ambas Cámaras del Congreso y con el acuerdo de las mismas, desde el 17 de octubre de 1994 por el período 1994 -1999 (Argentina), concluyendo por vencimiento del mandato el 17 de octubre de 1999.

55 Maiorano (2014) 22.

56 Ver más sobre la asociación en el sitio electrónico de la Asociación Argentina de Compañías de Seguros. Disponible en http://www.aacs.org.ar/nosotros.html [Fecha de consulta: 14 de junio de 2019].

57 Sitio electrónico del Defensor del Asegurado de Argentina. Disponible en http:// www.defensorasegurado.org.ar/defensor.html [Fecha de consulta: 14 de junio de 2019].

58 Estatuto del Defensor del Asegurado (Argentina), artículo 4.

59 Estatuto del Defensor del Asegurado (Argentina), artículo 2. 
este considere necesario efectuar y la descripción de las materias que pudieran afectar la credibilidad en materia de seguros ${ }^{60}$.

Como una figura privada, no hay injerencia del Estado que conforma un sistema de libre adhesión para las aseguradoras. En efecto, pueden optar a incorporar la institución o no, pero una vez adheridas, la resolución que dicte la defensoría del asegurado es obligatoria siempre y cuando el asegurado acepte. Tanto es así que en caso de que el asegurador no diere cumplimiento a lo resuelto por el Defensor del Asegurado, el recurrente tendrá derecho a reclamar judicialmente la ejecución de la Resolución ${ }^{61}$. En ese sentido, actúa más como un árbitro que como un ente meramente mediador.

Otras características del Defensor del Asegurado en Argentina, entre las que destaca son que: actúa en casos de personas naturales I físicas o jurídicas, aunque tiene límites ante ciertas cuantías, no sea inferior a 2.000 (dos mil pesos) ni superior a 161.000 (ciento sesenta y un mil pesos); las compañías aseguradoras adheridas al régimen y los mismos asegurados tienen la obligación de colaborar con sus requerimientos y proporcionarle toda la información que les sea solicitada; el procedimiento es informal y gratuito para el asegurado, no se exige patrocinio de abogado; en todo caso, rige el principio de subsidiariedad por el cual debe agotarse previamente la vía administrativa interna ante la propia aseguradora antes de acudir el Defensor del Asegurado. El reclamo no procede cuando el asegurado haya acudido con anterioridad a la vía administrativa, judicial, arbitral o de mediación previa a la vía judicial, salvo que desista en estas vías en forma expresa; la presentación de un reclamo ante el defensor del asegurado no limita el derecho del asegurado de acudir posteriormente ante tribunales de justicia ni de desistir en cualquier momento del procedimiento; la celeridad es relevante, el Defensor del Asegurado cuenta con veinte días hábiles para dictar su pronunciamiento; la informalidad también es importante, el reclamo puede iniciarse personalmente o por correo electrónico ${ }^{62}$.

Una peculiaridad del Defensor del Asegurado en Argentina es que de acuerdo con nueva legislación de 2010 y a prácticas judiciales,

60 Estatuto del Defensor del Asegurado (Argentina), artículo 12.

61 Maiorano (2014) 22.

62 Maiorano (2014) 22. 
se ha convertido en un ombudsman privado, sin embargo, revestido con un a cierta potestad pública, para mediar entre las partes de forma obligatoria, antes o durante juicios. En efecto, la Ley 26.589 de 2010, establece en una serie de procedimientos la mediación obligatoria $^{63}$. Es así como desde el 2011 que jueces en materia comercial derivan los casos a los respectivos al Defensor del Asegurado si la compañía demandada por el asegurado está adherida al sistema que instauró la Asociación Argentina de Compañías de Seguros. En consecuencia, los Magistrados invisten al Defensor del Asegurado como un mediador extrajudicial, dentro de un proceso ya promovido ${ }^{64}$.

El magistrado don Máximo Astorga, titular del Juzgado Comercial número 15 , como tantos otros ${ }^{65}$, en una de las providencias de las derivaciones expresó ${ }^{66}$ :

La Ley 26.589 permite reeditar - para las aseguradoras adheridas al sistema presidido por el Defensor del Asegurado - la mediación en tanto el Juez apreciara útil tal renovación de las negociaciones. Ello así y sin perjuicio del estado procesal de las presentes actuaciones, considero conveniente aplicar tal regulación a este juicio, teniendo en cuenta que tal especialista asegura un alto grado de conocimiento y una gran posibilidad de transacción en casos como el presente. No obstante ello, habría que resaltar que sería preferible y más económica una transacción que continuar con las etapas procesales oportunas a fin de llevar adelante el presente proceso. Por ello hácese saber a las partes, que deberán ajustar su proceder a las reglas impuestas por la Ley 26.589 a los efectos de sustanciar el conflicto ante el Defensor del Asegurado, estatuto que aparece difundido en www.defensorasegurado.org.ar.

Con ello, el Ombudsman del asegurado ya no sólo genera consecuencias entre la aseguradora con su cliente, sino que ha llegado a considerarse en el poder judicial.

63 Ley 26.589, de 3 de mayo de 2010, Establécese con carácter obligatorio la mediación previa a procesos judiciales, (Argentina).

64 Maiorano (2011) 11.

65 Como también el Magistrado, Héctor Osvaldo Chomer, en Maiorano (2011) 11.

66 Maiorano (2014) 22. 


\section{Ombudsman de los Servicios Básicos}

Con el avanzar de la sociedad, los servicios básicos se vuelven cada vez más indispensables. Inclusive hay autores, como el doctor en políticas públicas e integrante del Ombudsman de la Energía en México, don Paul Sánchez Campos, que consideran particularmente a la energía como incluida a los Derechos Humanos, puesto que sin ella, se afecta una serie de derechos, como la vivienda digna, la salud, la educación e incluso la alimentación ${ }^{67}$. Por ello, hay países que han estimado no solo en la implementación y progresión de las energías, (y también otros servicios básicos), con la supervisión de dicha industria, instaurando al ombudsman para otorgar un mejor servicio al respecto. No es menor señalar, como recuerda Sánchez que en estos mercados usualmente hay monopolios naturales o de pocos productores donde los mayores afectados son los grupos vulnerables ${ }^{68}$, por lo que la necesidad de crear una institución que los proteja se hace imprescindible.

En efecto, uno de los casos de ombudsman sectoriales de servicios básicos lo encontramos en Australia. En efecto, en el Estado de Australia del Sur se creó en el año 2000 la Electricity Industry Ombudsman (SA) Limited, institución privada respecto de materias de electricidad. Luego, en el año 2003 se incorporó competencias en materia de gas, cambiando su nombre a Energy Industry Ombudsman (SA) Limited. Y, posteriormente, a finales del año 2011, se le incorpora los servicios de agua, llamándose ahora Energy and Water Ombudsman (SA) Limited, quedando entonces sumergida en el contexto de la energía (electricidad y gas) y del agua. Dicha figura se encarga de investigar y resolver conflictos entre los distribuidores de dichos servicios básicos con sus clientes. En efecto, de su nombre, se evidencia que es una entidad privada, es decir, no tiene carácter

67 Sánchez Campos (2015).

68 Sánchez Campos (2015). 
gubernamental o público. Por ello, se rige por la respectiva acta de constitución ${ }^{69}$ y sus estatutos ${ }^{70}$ de índole privada ${ }^{71}$.

Lo mismo ocurre en el Estado de Western Australia. En el año 2004 se crea el Gas Industry Ombudsman, y en 2005 el Electricity Ombudsman, fusionándose en ese mismo año ambas instituciones. Posteriormente en el año en enero de 2014 la figura jurídica asume competencias sobre agua, por lo que se convierte en la actual Energy and Water Ombudsman ${ }^{72}$.

Las materias que investiga son, y, evidentemente siempre que estén relacionadas con el suministro de energía (electricidad o gas) y agua, entre otras, las siguientes ${ }^{73}$ :

- Suministro de electricidad, gas o agua;

- Facturación;

- Créditos y pagos;

- Recuperación de deudas.

- Desconexión,

- Pagos ordinarios de los servicios;

- Comercialización de los servicios;

- El uso poderes legales en relación con terrenos.

- Daños o pérdidas derivadas del suministro de los servicios;

- Servicios de agua que afecten a una persona, se o no cliente.

En todo caso, este ombudsman sectorial puede rechazar una queja si no hay interés suficiente de parte reclamante sobre el asunto,

69 The Corporation Act. Constitution of energy and wáter ombudsman (SA) limited (ACN 089791 604), enmendada al 25 de junio de 2014, (Australia).

70 Charter of Energy and Wáter Ombudsman (SA) limited (ACN 089791 604), enmendada al 19 de junio de 2013, (Australia).

71 Sitio electrónico del Energy and Water Ombudsman (SA) Limited. Disponible en http://www.ewosa.com.au/index.php/about/about-us [Fecha de consulta: 14 de junio de 2019].

72 Sitio electrónico del Energy and Water Ombudsman Western Australia. Disponible en http://www.ombudsman.wa.gov.au/ewowa/about_us/history.htm [Fecha de consulta: 14 de junio de 2019].

73 Sitio electrónico del Energy and Water Ombudsman Western Australia, Community languages. Disponible en http://www.ombudsman.wa.gov.au/ewowa/ documents/Translations/Spanish-EWOWA-Information-Sheet.pdf [Fecha de consulta: 14 de junio de 2019]. 
si es necesario investigar, o si existe otro organismo que pueda encargarse de la queja ${ }^{74}$. Es decir, se aplica el principio de subsidiariedad. Sin embargo, el ombudsman no investiga sobre ${ }^{75}$ :

- El establecimiento de precios o tarifas o el establecimiento de las estructuras de los precios.

- El contenido de las políticas gubernamentales.

- Actividades comerciales no cubiertas por la licencia del servicio de electricidad, gas o agua del proveedor.

- Las quejas que están siendo consideradas por un juzgado o tribunal o que el ombudsman considere que deberían ser tratadas por un tribunal.

Por otro lado, además de que en Australia exista el ombudsman para la energía y el agua, también se provee para las telecomunicaciones (telefonía e internet). Así, en el año 1993 se crea la Telecommunications Industry Ombudsman Limited, que es independiente de la industria, el Gobierno y las organizaciones de consumidores. Es una institución de índole privada, se rige por su Acta de Constitución ${ }^{76}$ y sus reglamentos. Es administrada por un Consejo que elige a un ombudsman unipersonal y un Adjunto. Resuelve reclamos sobre quejas de servicios de telefonía e internet, estando las empresas asociadas a cumplir sus resoluciones hasta 50.000 dólares y a sugerir recomendaciones de hasta 100.000 dólares $^{77}$.

Al Telecommunications Industry Ombudsman Limited llegan quejas respecto a contratos, servicio al cliente, internet defectuoso,

74 Sitio electrónico del Energy and Water Ombudsman Western Australia, Community languages. Disponible en http://www.ombudsman.wa.gov.au/ewowa/ documents/Translations/Spanish-EWOWA-Information-Sheet.pdf [Fecha de consulta: 14 de junio de 2019].

75 Sitio electrónico del Energy and Water Ombudsman Western Australia, Community languages. Disponible en http://www.ombudsman.wa.gov.au/ewowa/ documents/Translations/Spanish-EWOWA-Information-Sheet.pdf [Fecha de consulta: 14 de junio de 2019].

76 Constitution of Telecommunications Industry Ombudsman Limited (ACN 057 634 787), (Australia).

77 Sitio electrónico del Telecommunications Industry Ombudsman Limited de Australia. Disponible en https://www.tio.com.au/about-us [Fecha de consulta: 14 de junio de 2019]. 
conexión terrestre, teléfonos fijos defectuosos, exceso de uso de datos (cobros excesivos), entre otros. Es interesante un caso de publicado en el año 2011, que sirve para entender la labor de la institución. En efecto, la propietaria de una pequeña farmacia había recibido una factura por internet banda ancha de más de ocho mil dólares, con motivo a estar por el límite de uso de internet. El Ombudsman investigó y notó que, independiente de que, si se había ocupado o no el servicio de internet por todo lo que indicaba la factura, el proveedor de servicios no había advertido a la clienta cuando su uso de internet estaba cerca de sobrepasar el límite mensual, de manera que se consideró que el proveedor contribuyó a generar la alta factura. En consecuencia, una vez contactado con proveedor, este redujo la cantidad de la factura a la que hubiera correspondido si es que hubiera avisado a la clienta en el momento debido ${ }^{78}$.

\section{Conclusiones}

A través del presente artículo, como se pretendió con el objetivo general, ha quedado en evidencia que la figura del «Ombudsman» se ha insertado en materias distintas a su versión original, que era controlar a la Administración del Estado. En efecto, se ha desarrollado la institución controlando en materias donde actúa el sector privado, en concreto en asuntos sobre derecho del consumo (con el Ombudsman del Consumidor), en derecho económico (con el Ombudsman de la Libertad Económica), en derecho de la prensa (con el Ombudsman de los Lectores), en derecho comercial (con el Ombudsman de los Bancos e Instituciones Financieras, y el de los Seguros) y, en derecho regulatorio (con el Ombudsman de los Servicios Básicos).

En general, la mayoría de las versiones de ombudsman sectoriales siguen la esencia de la figura jurídica original, que es controlar con auctoritas pero sin potestas. Es así como la institución pretende convencer y no vencer a quien denuncie. Asimismo, todos reciben quejas ciudadanas sectoriales, que en la mayoría de los casos son

78 Sitio electrónico del Telecommunications Industry Ombudsman Limited de Australia, Excess data usage. Disponible en https:/www.tio.com.au/publications/case-studies/case-study-5 [Fecha de consulta: 17 de agosto de 2016]. 
derechamente clientes, como lo es quien compre un producto, quien contrata un seguro, quien tiene una cuenta corriente bancaria, quien reciba un servicio básico de suministro de luz, agua o electricidad. Y, todos, en miras a una mejora permanente y proceso de evaluación, elaboran informes anuales sobre su gestión y de lo que es posible perfeccionar en el controlado, sugiriendo, por ejemplo, erradicar malas prácticas en el servicio.

Sin embargo, siempre hay excepciones. En efecto, la Comisión Nacional para la Protección y Defensa de los Usuarios de Servicios Financieros en México, tiene más de 30 atribuciones, y, entre ellas se encuentras algunas que son sin lugar a dudas de potestas y no de auctoritas. Es así que puede imponer sanciones, determinar apremios e incluso actuar como órgano administrativo (pero con características jurisdiccionales como tribunal) al resolver recursos en contra de sus resoluciones sancionatorias. Ello, no ha sido en la creación de la figura jurídica, sino que ha devenido con el tiempo a través de cambios en su orgánica, producto de modificaciones normativas desde el año 2000 al 2014 a lo menos. Así, se ha adicionado cada vez mayor poder sancionador con potestas a la institución, lo que desnaturaliza a la Comisión de la esencia de lo que es un ombudsman. Ya no convencerá, sino que obligará coercitivamente a modificar conductas.

No obstante, la complejidad está en la efectiva independencia de la que están provistos este tipo de ombudsman. En efecto, si es una institución pública que controla a un privado, al menos en teoría existe independencia. Sin embargo, si en los casos en que el mismo privado sea quien elija directa o indirectamente al ombudsman, como ocurre en general en las denominadas defensorías bancarias, hay mucho de que dudar. En otras palabras, si el controlado decide quien lo controle, el ombudsman se convierte en una oficina de reclamación y autocontrol (que también pueden ser un aporte) más que en un defensor del ciudadano sectorial. No es que se esté en desacuerdo con el ombudsman del sector privado, sino que en la forma de elección y aspectos que depriman su independencia (como que sea dependiente su presupuesto de a quien controle). Ocurre lo mismo con algunas defensorías públicas que controlan a la Administración, siendo elegidas por el Poder Ejecutivo. 


\section{9.- Bibliografía}

\section{a) Doctrina}

Gil-Robles y Gil-Delgado, Álvaro (1981): El control parlamentario de la Administración (El Ombudsman), segunda edición, (Madrid, Editorial Instituto Nacional de Administración Pública).

Herrera Damas, Susana (2005): «Situación del ombudsman en el mundo», en: Sala de prensa, año VI, vol. 3, N 76, febrero.

Jiménez, Gabriela (2014): "Qué es el Ombudsman Bancario», en Ombudsman Social. Disponible en http://ombudsman.social/2014/03/ que-es-el-ombudsman-bancario/ [Fecha de consulta: 11 de agosto de 2016].

Maiorano, Jorge Luis (2001): «El Defensor del Pueblo en América Latina. Necesidad de Fortalecerlo", Revista de Derecho, Valdivia, Chile, v. 12. pp. 191-198.

Maiorano, Jorge Luis (2010): «El Defensor del Asegurado: hacia una superación de los conflictos entre las compañías de seguros y sus asegurados», Revista El Derecho, Derecho de Seguros, Buenos Aires.

Maiorano, Jorge Luis (2011): «Una novedosa decisión judicial sobre solución extrajudicial de conflictos», nota a fallo, publicada en La Ley, 10 de agosto de 2011, p. 11.

Maiorano, Jorge Luis (2014): «Del siglo XIX al siglo XXI: el Defensor del Asegurado", Revista Novedades, publicación de la Asociación Argentina de Compañías de Seguros, año 14, N 60, octubre, Buenos Aires.

Restrepo, Javier Dario (2003): «En defensa del derecho a la información», Sala de prensa, año V, v. 2, $\mathrm{N}^{\circ} 53$, marzo.

Rovira Viñas, Antonio (2002): Comentarios a la Ley Orgánica del Defensor del Pueblo, (Navarra, Editorial Aranzadi).

Sánchez Campos, Paul (2015): «Acceso a la energía y derechos humanos tras la reforma", Diario El Universal, artículo de 12 de octubre de 2015. Disponible en http://www.eluniversal.com.mx/articulo/ cartera/2015/10/12/acceso-la-energia-y-derechos-humanos-tras-lareforma [Fecha de consulta: 17 de agosto de 2016].

SÁnChez Piña, Zaira Elena (1999): La figura del defensor del lector en el diario colombino. El Tiempo y el diario venezolano El Nacional, (Caracas, Editorial Universidad Católica Andrés Bello).

VÁsquez Ríos, Aldo (2002): El defensor del público, un Ombudsman en materia de comunicación social, (Lima, Editorial San Martín de Porres).

Yepes Bustamante, Luis Alfonso (2008): Defensoría del lector en tres periódicos colombianos, 1992-2007, (Medellín, Editorial Universidad de Antioquia). 


\section{b) Normativa}

Charter of Energy and Wáter Ombudsman (SA) limited (ACN 089791 604), enmendada al 19 de junio de 2013, (Australia).

Constitution of Telecommunications Industry Ombudsman Limited (ACN 057634 787), (Australia).

Estatuto del Defensor del Asegurado, (Argentina).

Estatuto Orgánico de la Comisión Nacional para la protección de defensa de los usuarios de servicios financieros, (México). Disponible en http://www.condusef.gob.mx/PDF-s/marco_juridico/estatuto.pdf [Fecha de consulta: 11 de agosto de 2016].

Foundation Charter of the Swiss Banking Ombudsman Foundation, (Suiza). Ley 26.589, de 3 de mayo de 2010, Establécese con carácter obligatorio la mediación previa a procesos judiciales, (Argentina). Disponible en http://servicios.infoleg.gob.ar/infolegInternet/anexos/165000-169999/166999/norma.htm [Fecha de consulta: 16 de agosto de 2016].

Ley de Protección y Defensa al Usuario de Servicios Financieros, de 18 de enero de 1999, última reforma 10 de enero de 2014, (México). Disponible en http://www.condusef.gob.mx/PDF-s/marco_juridico/ ley_condusef.pdf [Fecha de consulta: 14 de junio de 2019].

Orden ECO/734/2004, (España).

Reglamento del Defensor del Cliente, (Banco Santander de España).

Rules of Procedure for the Swiss Banking Ombudsman, aprobadas por el Consejo de la Swiss Banking Ombudsman Foundation el 7 de diciembre de 2012, para que entraran a regir el 1 de julio de 2013, (Suiza).

The Corporation Act. Constitution of energy and wáter ombudsman (SA) limited (ACN 089791 604), enmendada al 25 de junio de 2014, (Australia).

\section{c) Comunicados e informes defensoriales}

Comisión Nacional para la Protección y Defensa de los Usuarios de Servicios Financieros (2016a): «Supervisión del crédito al consumo». Disponible en http://www.condusef.gob.mx/PDF-s/Comunicados/2016/ presentacioncom65.pdf [Fecha de consulta: 11 de agosto de 2016]. Comisión Nacional para la Protección y Defensa de los Usuarios de Servicios Financieros (2016b): «Presenta Condusef resultados de la supervisión de crédito al consumo». Disponible en http://www.condusef.gob. mx/index.php/prensa/comunicados-2016/1351-presenta-condusefresultados-de-la-supervision-de-credito-al-consumo [Fecha de consulta: 11 de agosto de 2016]. 
Comisión Nacional para la Protección y Defensa de los Usuarios de Servicios Financieros (2011): «Evita ser defraudado». Disponible en http:// www.condusef.gob.mx/index.php/prensa/comunicados-2011/223evita-ser-defraudado [Fecha de consulta: 11 de agosto de 2016].

Comisión Nacional para la Protección y Defensa de los Usuarios de Servicios Financieros (2016c): «Haz de la tarjeta de crédito tu aliada en estas vacaciones». Disponible en http://www.condusef.gob.mx/index. php/prensa/comunicados-2016/1350-haz-de-la-tarjeta-de-credito-tualiada-en-estas-vacaciones [Fecha de consulta: 11 de agosto de 2016].

Swiss Banking Ombudsman (2015): "Annual Report 2015». Disponible en http://www.bankingombudsman.ch/wp-content/ uploads/2016/06/2015_in_Kuerze_30.6.2016_EN.pdf [Fecha de consulta: 11 de agosto de 2016].

\section{d) Medios electrónicos}

Sitio electrónico de la Asociación Argentina de Compañías de Seguros. Disponible en http://www.aacs.org.ar/nosotros.html [Fecha de consulta: 14 de junio de 2019].

Sitio electrónico de la Comisión Nacional para la Protección y Defensa de los Usuarios de Servicios Financieros. Disponible en https://www.gob. $\mathrm{mx} /$ condusef/que-hacemos [Fecha de consulta: 14 de junio de 2019].

Sitio electrónico del Banco de España. Disponible en http://www.bde.es/ bde/es/secciones/servicios/Particulares_y_e/Servicio_de_Ate/Servicios_de_At_6d9079a9970c631.html [Fecha de consulta: 14 de junio de 2019].

Sitio electrónico del Defensor del Asegurado de Argentina. Disponible en http://www.defensorasegurado.org.ar/defensor.html [Fecha de consulta: 14 de junio de 2019].

Sitio electrónico del Energy and Water Ombudsman (SA) Limited. Disponible en http://www.ewosa.com.au/index.php/about/about-us [Fecha de consulta: 14 de junio de 2019].

Sitio electrónico del Energy and Water Ombudsman Western Australia. Disponible en http://www.ombudsman.wa.gov.au/ewowa/about_us/ history.htm [Fecha de consulta: 14 de junio de 2019].

Sitio electrónico del Energy and Water Ombudsman Western Australia, Community languages. Disponible en http://www.ombudsman. wa.gov.au/ewowa/documents/Translations/Spanish-EWOWAInformation-Sheet.pdf [Fecha de consulta: 14 de junio de 2019].

Sitio electrónico del Om Konsumentverket de Suecia. Disponible en https:// www.konsumentverket.se/om-konsumentverket/vart-arbete/ [Fecha de consulta: 14 de junio de 2019]. 
Sitio electrónico del Organization of news Ombudsman. Disponible en https://www.newsombudsmen.org/regular-members/ [Fecha de consulta: 14 de junio de 2019].

Sitio electrónico del Swiss Banking Ombudsman. Disponible en http:// www.bankingombudsman.ch/en/office-of-the-ombudsman/ [Fecha de consulta: 14 de junio de 2019].

Sitio electrónico del Telecommunications Industry Ombudsman Limited de Australia, Excess data usage. Disponible en https://www.tio.com. au/publications/case-studies/case-study-5 [Fecha de consulta: 17 de agosto de 2016].

Sitio electrónico del Telecommunications Industry Ombudsman Limited de Australia. Disponible en https://www.tio.com.au/about-us [Fecha de consulta: 14 de junio de 2019]. 



\section{NueVo MODELO DE DisTRIBUCiÓN \\ DE LA CARGA DE LA PRUEBA \\ EN EL PROCEDIMIENTO DE POLICÍA \\ LOCAL DEL CONSUMO}

\section{New Distribution CHARge of THE PROOF MODEL IN THE CONSUMERISM OF LOCAL POLICE PROCEDURES}

\section{Andrés Eduardo Celedón Baeza ${ }^{1}$}

Resumen. La facilidad o disponibilidad probatoria surge frente a reglas rígidas de distribución de las cargas probatorias del derecho común, las cuales resultan muchas veces insuficientes para casos concretos, los mayores problemas radican en la insuficiencia

1 Abogado. Licenciado en Ciencias Jurídicas y Sociales (Universidad de Concepción). Docente de Derecho Procesal Civil y Derecho de Policía Local (Universidad Autónoma de Chile, sede Temuco). Magíster en Derecho Universidad Degli Studi di Génova (Italia) - Universidad Católica de Temuco (Chile), Mención Derecho Procesal Civil. Master en Economía y Derecho del Consumo (Universidad Castilla La Mancha - España); y Post Graduado en Metodología en la Enseñanza del Derecho (Universidad Católica de Temuco) y Responsabilidad Contractual y Extracontractual (Universidad Castilla La Mancha - España). Miembro del Centro de Regulación y Consumo, Universidad Autónoma de Chile. E-mail: andres.celedon@uautonoma.cl, aceledonb@clpabogados.cl 
probatoria del consumidor en situaciones especiales, los cuales hasta el momento se han suplido con reglas implícitas, no muchas veces certeras, como las facultades de oficio del juzgador o con el sistema de presunciones, sin embargo, poco acuerdo existe en relación a la dosis probatoria necesaria en un proceso del consumo con la finalidad de suplir dicha deficiencia. Entiende el autor que el legislador ha establecido la regla de la facilidad o disponibilidad probatoria, de clara influencia en el derecho comparado, para suplir dichas deficiencias y superar las asimetrías procesales del procedimiento individual del consumo.

Palabras clave: Carga de la prueba - Flexibilidad probatoria - Disponibilidad Facilidad Probatoria - Procedimiento Infraccional.

AвSTRACT. The probatory ease or availability arise from the strict rules of the probatory charge distribution of common law, which most of the time happen to be insufficient to specific cases. The biggest issues lie in the probatory insufficiency of the consumer in special situations, which until now have been supplied by implicit rules, not always accurate, such as the judge mandatory actions, or by a system of presumptions. Nevertheless, there is little agreement in relation to the probatory fix needed in a consumerism procedure to supply such shortcoming. The author, understands that the legislator has stablished the rule of probatory facility or availability, clearly influenced in the compared law, to supply such deficiencies and overcome the processual asymmetries of the individual procedure of consume.

Keywords: Proof charge - Probatory flexibility - Probatory ease - Infractionary procedure

Sumario. Introducción. 1. La prueba en el proceso del consumo. 2. La nueva regulación de la flexibilización probatoria en la ley 21.081. 3. ¿Cómo impactará la nueva regla en el procedimiento de policía local? 4. Conclusiones. 5. Bibliografía.

\section{INTRODUCCIÓN.}

El Congreso Internacional de Regulación y Consumo se convierte en la instancia precisa para que todos los actores se reúnan a 
debatir como se ha comportado el sistema, el procedimiento y las normas en aras de la protección de los derechos del consumidor.

Bastante se ha avanzado en regular sub-áreas del derecho del consumo, especialmente en las leyes de fondo, las cuales deberán estar acompañadas de una normativa procesal que logre articular de buena forma dicha finalidad. En este sentido, uno de los aspectos más relevantes son los temas referidos a la prueba, pues la gran mayoría de la doctrina parte de la base que estamos frente a una relación asimétrica, derivada de la deficiente información del consumidor frente al proveedor.

Frente a este escenario y las largas líneas que se han escrito, la institucionalidad ya ha comenzado a trabajar sobre las Directrices de las Naciones Unidas para la protección del consumidor, la cual dispone que deben efectivizarse los medios de solución de controversias y de compensación, reafirmando en la letra F.38 - de las directrices- que «los Estados Miembros deben alentar a todas las empresas a solucionar las controversias con los consumidores de forma rápida, justa, transparente, poco costosa, accesible y exenta de formalidades y a crear mecanismos voluntarios, como servicios de asesoramiento y procedimientos extraoficiales para presentar reclamaciones, que puedan servir de ayuda a los consumidores».

Se abre el debate si el derecho común es suficiente para satisfacer las pretensiones de los consumidores o será necesario recurrir a instituciones más avanzadas y propias del sistema consumidorista en aras de ir estructurando una sólida institucionalidad para esta especial área del derecho, en constante evolución, y que otorgue soluciones prácticas y efectivas a las más variadas necesidades de los consumidores.

Sin embargo, uno de los mayores problemas que enfrenta la disciplina son las cuestiones probatorias, que surgen desde el acceso a la jurisdicción, los grados de especialización de las materias y la variada casuística, lo que termina generando un serio problema de dispersión de instituciones.

Lo relevante en materia probatoria radica, por tanto, en que la aplicación de la norma debe reducirse a determinar si los medios de prueba son suficientes y si los hechos alegados han sido debidamente acreditados, sobre todo en un sistema que se desarrolla en una sola 
audiencia y no tiene fijación de hechos a probar por parte del juez, a lo menos en la práctica uniforme de los tribunales de policía local.

En consecuencia, el presente trabajo tiene por objeto efectuar una revisión de temas probatorios en materia de derecho del consumo en sede de policía local, desde una revisión de la flexibilización probatoria y como impactará en sede de policía local, combinando la actual ley de tramitación ante los Juzgados de Policía Local, ley 18.287 (en adelante LTJPL) y la reciente modificación introducida por la Ley 21.081, publicada en el Diario Oficial de 13 de septiembre de 2018 a la Ley 19.496 sobre Protección de los Derechos del Consumidor (en adelante LPDC).

\section{LA PRUEBA EN EL PROCESO DEL CONSUMO}

Los procedimientos del consumo presentan variadas particularidades, en especial aquel que combina las acciones infraccionales y las que tienen por objeto obtener la reparación e indemnización adecuada y oportuna, cubriendo la ley de procedimiento, en sede de policía local, la acción infraccional y/o la reparatoria² (con la modificación introducida por la Ley 21.081, en los artículos 50, 50 A y $50 \mathrm{H}$ ). Junto a ello, cobra gran relevancia el papel del tribunal, tanto en su fase infraccional como en su fase civil (reparatoria o de cumplimiento de la prestación), y la actividad de las partes en la búsqueda e incorporación de la prueba, discutiéndose si el juez competente para conocer de las acciones del consumo (Juzgado de Policía Local) debe asumir en su fase infraccional un rol activo y en la fase indemnizatoria y/o reparatoria una actitud pasiva derivado del principio dispositivo del proceso civil.

2 El artículo 50 de la LPDC (modificado) se refería específicamente a que el incumplimiento de las normas contenidas en la ley dará lugar a las acciones destinadas a sancionar al proveedor que incurra en infracción y a obtener, producto del hecho infraccional, la debida indemnización de perjuicios o la reparación que corresponda, o de cumplimiento de la prestación, entre otras finalidades. Pero dicho artículo es modificado por artículo 1 Nro., 22 quedando que «las denuncias y acciones que deriven de esta ley se ejercerán frente a actos, omisiones o conductas que afecten el ejercicio de cualquiera de los derechos de los consumidores» lo que dará lugar a las denuncias y acciones individuales correspondientes. 
En nuestra opinión, dicha diferenciación es, además de carente de sentido, confusa en cuanto a su planteamiento y errónea a los fines del proceso del consumo. Sin embargo, no pretendemos en las siguientes líneas aclarar este punto, pero si dejarlo planteado para futuras conversaciones.

El proceso del consumo, al igual que el resto de los procedimientos, se configura por una fase de conocimiento y juzgamiento, la primera en dos etapas, discusión y prueba, que se reducen a la presentación, en la práctica, de una denuncia y/o querella infraccional, o de una querella infraccional y demanda civil (dejamos de lado acá la discusión si es factible el ejercicio de la acción civil sin acción infraccional previa ${ }^{3}$ ) y la fase de prueba a una audiencia única denominada de contestación, conciliación y prueba ${ }^{4}$.

Es en la fase de prueba donde se presentan los mayores problemas en torno al derecho a probar de los consumidores, pues muchas veces se tratan de compras cotidianas ${ }^{5}$, que en la mayoría de las ocasiones el consumidor no tiene el cuidado de pre-constituir sus pruebas mediante el resguardo de los medios necesarios para el posible ejercicio de una acción. A la vez, que el proceso del consumo se transforma de suyo complejo para el consumidor debido a la gran casuística en la materia, pues no solo encontramos procedimientos derivados del robo de vehículos en estacionamientos, sobreventa de vuelos, defecto en la calidad de productos eléctricos y otros, en los cuales ya existe cierto consenso en la literatura jurídica, pero especialmente en la jurisprudencia, sino una serie de cuestiones más que merecen la preocupación de esta especial rama del derecho.

3 Ello conforme a lo dispuesto en el artículo 50 B de la LPDC en relación al artículo 9 de la LPJPL. Al respecto revisar: Celedón BAEza (2015) 200 y Celedón (2018) 1. Teniendo presente que la normativa reformada seguirá ofreciendo la discusión por la redacción de las normas citadas (artículo 50 A, 50 H y 50 I).

4 Artículo 7 de la LPJPL.

5 Las decisiones de los consumidores implican una serie de graduaciones que permiten diseñar modelos de tomas de decisiones, por ejemplo, procesos con alta implicación y alto nivel de conocimiento (la compra de un automóvil), procesos de alta implicación y bajo nivel de conocimiento (por ejemplo, la compra de un automóvil por una persona sin mayores experiencias en el rubro), influenciado sólo por la publicidad o las opiniones, procesos de baja implicación y alto conocimiento (por ejemplo, la compra de un secador de pelo), o procesos de baja implicación y de poca información (por ejemplo, la compra diaria del pan). 
Este proceso del consumo tiene dos particularidades relevantes: a) estamos frente a una relación asimétrica, tal como lo ha reconocido la doctrina mayoritaria que se manifiesta en una evidente desigualdad de los intervinientes del proceso, especialmente, en materia de información; y b) nos encontramos, al igual que en el resto de los procedimientos judiciales, frente a la afirmación incontrovertible que los hechos alegados por el accionante deben ser acreditados para lograr la convicción del juzgador en torno a la existencia del hecho infraccional y, a su vez, resolver la probanza de la existencia del daño y su quantum indemnizable.

Lo que se extraña en este procedimiento, en sede local, es una audiencia previa que permita ofrecer, depurar y determinar la prueba que se llevará adelante para acreditar las pretensiones deducidas, así como la casi nula utilización de la facultad del juez de decretar de oficio prueba tendiente a arribar a una convicción ajustada a la realidad de los hechos planteados ${ }^{6}$, fuera de las tradicionales medidas para mejor resolver.

Así las cosas, la practica jurisprudencial no documentada hasta el momento, en sede de Policía Local, es la que rige en los procesos civiles derivados de la norma del artículo 1698 del Código Civil, es decir, se hace recaer la prueba en el querellante-demandante civil pues no existe, en la normativa protectora del consumo, disposiciones tales como el artículo 6 de la Ley brasileña ${ }^{7}$, que establece en el numeral VIII la facilitación de la defensa de sus derechos (como derecho básico del consumidor), al permitir «inclusive con la inversión de la carga probatoria en su favor en el proceso civil, cuando a criterio del juez la alegación es verosímil o cuando fuera hiposuficiente, según las reglas ordinarias de experiencia». O como el artículo 472 de la Ley colombiana ${ }^{8}$ (norma aplicable a los derechos del consumidor) que en su artículo 30 dispone que «la carga de la prueba corresponderá al demandante. Sin embargo, si por razones de orden económico o técnico, si dicha carga no pudiere ser cumplida,

\footnotetext{
$6 \quad$ Ello pese a existir el artículo 16 inciso 1, LPJPL.

7 Ley 8.078, 11 de septiembre de 1990, que dispone sobre la Protección del consumidor y dicta otras providencias.

8 Ley 474, 06 de agosto de 1998, por la cual se desarrolla el artículo 88 de la Constitución Política en relación al ejercicio de las acciones populares y de grupo y se dictan otras disposiciones.
} 
el juez impartirá las ordenes necesarias para suplir la deficiencia y obtener los elementos probatorios indispensables para proferir un fallo de mérito, solicitando dichos experticios probatorios a la entidad pública cuyo objeto esté referido al tema materia de debate y con cargo a ella». O como lo señala el Código Modelo de Procesos Colectivos para Iberoamérica, que en su artículo 12.2 dispone que "durante la fase de instrucción, si surgieren modificaciones de hecho o derecho relevantes para el juzgamiento de la causa, el juez podrá rever, en decisión fundada, la distribución de la carga de la prueba, y conceder a la parte a quién le fue atribuida un plazo razonable para la producción de la prueba, respetando las garantías del contradictorio en relación a la parte contraria».

En la práctica diaria de los tribunales locales, la regla general, es la carga estática de la prueba y no la dinámica, en virtud de la cual el onus probandi debería recaer en aquel que tenga la mejor posibilidad de probar en base a la relación de asimetría que generan las relaciones del consumo.

Por tanto, estamos ante uno de los mayores problemas del derecho del consumo, la carga de la prueba, ya que, por un lado, permitirá dar satisfacción a las pretensiones del accionante y una adecuada defensa del accionado y, por otro, permitirá que el juez pueda continuar en forma normal con su itinerario procesal de dar solución al litigio, evitando la fórmula del non liquet, es decir, no está claro, que hoy se manifiesta en distintas actividades contrarias a los fines el proceso.

Con la claridad del establecimiento de las reglas sobre carga probatoria podemos cumplir con el principio constitucional de un justo procedimiento o lo que el derecho comparado reconoce como tutela judicial efectiva, que permite conocer en forma anticipada las reglas que serán aplicables a las partes en la resolución del caso concreto.

La dinámica del procedimiento en sede de Policía Local permite, incluso, que el juez pueda fallar con los antecedentes aportados por las partes, cuando hay conformidad en cuanto a los hechos y solo discrepancia jurídica, anticipando la tutela definitiva, por lo que resultaría relevante aportar al juez, en forma previa, todo el material necesario para una mejor resolución del asunto, independiente de quién lo aporte, ello en una propuesta de lege ferenda en relación a la 
normativa actual. Sin embargo, por desidia de las partes, estrategias mal comprendidas o simplemente por imposibilidad física, resulta difícil aportar al juez todos los elementos para un adecuado juicio decisorio de lo planteado, permitiendo que, en muchas ocasiones, el juez se encuentre en un limbo probatorio, aun teniendo certeza de lo que debe resolver (con solo las presentaciones de las partes), por lo que enfrentado al principio de la inexcusabilidad y del non liquit debe cumplir, pese a dichos inconvenientes, con la resolución del caso, y recurrir a estas fórmulas solo frente a casos de no subsanación de defectos en etapas previas o en la etapa de la sentencia atribuyendo efectos negativos frente a la falta del material probatorio?.

En esta etapa de incertidumbre probatoria, nos encontramos frente a las llamadas cargas estáticas de la prueba, en que las reglas de distribución probatoria se encuentran establecidas con anterioridad. Así, tanto las partes como el órgano jurisdiccional, saben de antemano cuáles serán las reglas a aplicar, sin embargo, en la casuística del procedimiento individual del consumo nos damos cuenta de que dichas reglas rígidas son insuficientes a los fines del procedimiento, por lo que en ciertos casos resulta más útil trasladar la carga probatoria a la parte contraria o distribuirla mediante los postulados de la regla dinámica ${ }^{10} \mathrm{o}$ de flexibilidad probatoria.

Frente al concepto de carga de la prueba ${ }^{11}$ surgen verdaderas interrogantes, ya que que en el ámbito nacional, dicha norma se ubica a propósito de las obligaciones en nuestro Código Civil (de clara influencia romana), debiendo ser una carga procesal, en los

9 Así lo ha reconocido una sentencia del Tribunal Supremo español, de fecha 9 de mayo de 2013, núm. 241/2013, N Rec. 485/2012 al indicar que «la carga de la prueba o, dicho de otra forma, los efectos negativos de la falta de la prueba nada más entra en juego cuando no hay prueba sobre determinados extremos de hecho, por lo que su infracción únicamente tiene lugar en aquellos casos en los que, teniéndose por no probado un determinado hecho relevante para la resolución de la controversia, el tribunal atribuye los efectos negativos de tal vacío probatorio a la parte a la que no corresponde soportarlos».

10 Al respecto debe indicarse que el creador del concepto es Peyrano (2004), en su obra Cargas probatorias dinámicas, el que las conceptualiza como el «desplazamiento de la carga a quién está en mejores condiciones técnicas profesionales o fácticas para producir las pruebas».

11 Al respecto revisar el concepto de aportación de la prueba (Onus Probandi) en Peñallillo (I993). 
términos reseñados por la doctrina alemana, de tal forma que si nos inclinamos por esta última teoría, como lo indica Escaler Bascompte ${ }^{12}$ al expresar que la regla de la carga de la prueba «sirve de ayuda al juez para dar respuesta a aquellos casos en que tiene dudas sobre la existencia de hechos con relevancia jurídica para la resolución del caso concreto. También está consolidado que el fundamento de ello se encuentra en la clásica probibición de non liquet», deberíamos concluir que en el actual procedimiento es una carga procesal y no una regla de juicio, como ocurre en el sistema español, por ejemplo.

Las reglas de carga estática de la prueba son fijadas de antemano, así su aplicación resulta bastante sencilla y no deriva de la posición procesal que ocupen las partes, sino que dependen de su posición frente al caso concreto, en que el juez no tiene mayor incidencia en la búsqueda de la verdad, sin embargo, en materia del consumo en ocasiones dicha regla es insuficiente y, en otras, ineficiente frente a la dinámica del procedimiento, por lo que sería más oportuno transformarla en una regla de juicio para dar solución al caso concreto frente a la falta de material probatorio derivado de la regla de la carga probatoria.

Por último, las reglas de la sana crítica ${ }^{13}$ imperante en este sistema procesal obligan a incorporar un principio no reconocido en nuestra legislación, cual es, el de la adquisición procesal ${ }^{14}$, en virtud del cual se obliga al juez a valorar todas las pruebas y antecedentes presentados ${ }^{15}$, ya sea en favor o en contra de las partes, incluso con independencia de la parte que la presentó, así lo ha resuelto, por ejemplo, la Audiencia Provincial de Barcelona 183/2011, de 14 de abril, al resolver que «los resultados de la actividad procesal son comunes para las partes y se consiguen para el proceso, por lo que las pruebas practicadas son del proceso y están destinadas al juez (que puede utilizarlas, prescindiendo de quién las haya producido o aportado), pudiendo valerse de ellas cualquiera de las partes, y ha-

\footnotetext{
ESCALER (2017) 23.

Artículo 14 inciso 2 de la LPJPL.

14 También llamado principio de incorporación, comunidad de pruebas, comunidad de medios de pruebas, aportación indiferenciada.

15 Indica la norma del artículo 14 citado, en su parte pertinente que «en general, tomará en especial consideración la multiplicidad, gravedad, precisión, concordancia y conexión de las pruebas y antecedentes del proceso que utilice».
} 
bilitando al juez para fundar su decisión en la actividad probatoria desenvuelta en su conjunto", en consecuencia, la actividad procesal de las partes implican una actuación común en pro del proceso, razón por la cual las pruebas se destinan a la actividad resolutiva del juez, el cual debe utilizarlas en su proceso de razonamiento, con prescindencia de quién las aportó y en aras de una solución conjunta y concreta al caso específico, cuestión distinta son las argumentaciones de las partes.

Volviendo a nuestro punto de inicio, será en esta etapa en la cual el juez sin regla previa, podrá determinar si la prueba ofrecida y rendida por las partes resulta adecuada para probar los hechos planteados, determinando la suficiencia probatoria del material ofrecido e incluso rendido, el que muchas veces resulta insuficiente o hasta improcedente o poco pertinente, por lo que frente a dicha situación surgen las reglas de flexibilización probatoria, como novedad en nuestro sistema procesal del consumo.

Un ejemplo ilustrará el problema: hasta antes de la Ley 20.96716, la jurisprudencia prácticamente uniforme de los tribunales sentaba la doctrina de responsabilidad del proveedor frente al robo o daños producidos en un vehículo en el estacionamiento proporcionado por el proveedor, en razón de la obligación de seguridad que en el recae, pues la prestación de servicio que otorga el proveedor es integral o global y se extiende también a dichos servicios anexos, por lo que comprendía no solo la custodia sino también la prevención de cualquier daño que podrían sufrir los vehículos (recayendo la prueba en el proveedor). Sustentar la tesis contraria, es decir, que el deber de probar recayera en el consumidor - tanto de haber ingresado al establecimiento comercial y que el vehículo fue dejado en el estacionamiento - resultaba lesivo a sus derechos y de una prueba imposible, por lo que la jurisprudencia tendió a establecer que la probanza del deber de seguridad debía recaer en el proveedor. Otro tanto ocurre en materia de espectáculos públicos ${ }^{17}$ en que se

16 Ley 20.967, DO., 17 de noviembre de 2016, que regula el cobro de servicios de estacionamiento.

17 Acá surge igualmente la discrepancia ¿Quién debe acreditar la infracción? Por un lado, se sostiene que proveedor debe acreditar que vendió lo ofrecido y, por otro, que el consumidor debe acreditar que el proveedor ha puesto a la venta más localidades de las posibles. Algunos casos jurisprudenciales citados por Guerrero 
discutió por la jurisprudencia en quién recaía el peso de la prueba por sobreventa de tickets.

\section{LA NUEVA REGULACIÓN DE LA FLEXIBILIZACIÓN PROBATORIA EN LA LEY 2I.O8I}

Así indica el inciso quinto del artículo $50 \mathrm{H}$, agregado por la Ley 21.081: "El tribunal podrá distribuir la carga de la prueba conforme a la disponibilidad y facilidad probatoria que posea cada una de las partes en el litigio, lo que comunicará a ellas para que asuman las consecuencias que les pueda generar la ausencia o insuficiencia del material probatorio que hayan debido aportar o el no rendir la prueba correspondiente de que dispongan en su poder».

Contra la regla estática, fruto de nuestra tradición civilista, surge esta regla dinámica inserta en un artículo variopinto, transformándose en una de las reformas procesales más innovadoras de los últimos tiempos en materia del consumo, adelantándose sin mayores discusiones al anhelado sistema procesal civil en discusión desde ya hace varios años en el Congreso Nacional.

La regulación histórica de la carga de la prueba en nuestros variados sistemas procesales se reduce a la rígida formula contemplada en el artículo 1698 del Código Civil, la cual se ha mantenido

Becar ilustran el problema: Martínez con Puerto Montt. Rol 6885-2005 JPL Puerto Montt, Sernac con Anfp, Rol 128.811-2 JPL de Peñalolen, en que desechó la demanda por falta de pruebas y Viveros con Plus Eventos y Entel Chile, Rol 1582-2005 Corte de Apelaciones de Concepción, que dejó establecido que «los razonamientos precedentes revelan que al no resultar demostrado el ilícito en que se basaría la demanda deducida ... tal libelo no puede prosperar». Como se ve estos casos transforman la prueba en casi imposible para el consumidor, en «la protección de los derechos de los consumidores». GUERrero BeCAR (2013) 582. Tambien en un interesante fallo Corte de Apelaciones de Temuco, Rol 10-2011 resolvió que «es importante destacar que la ley aludida en materia de onus probandi tiene otra dimensión, que es la tendencia actual en el derecho civil o en el derecho de daños, esto es, no es efectivo que deba darse aplicación al artículo 1698 del Código Civil, sino como se trata de reparar a la víctima lo que corresponde que haga el querellante y demandante civil es, .... Ahora bien, y esto es lo interesante, como parte débil y por la carga dinámica de la prueba quien debe derribar la afirmación del demandante es el proveedor, es decir, debe acreditar-porque es el que tiene mayor información sobre el producto, mayor capacidad económica...». 
inalterable en el tiempo y se reduce a la necesidad de las partes de probar los hechos que constituyen la parte fáctica de la discusión, bajo el riesgo de obtener una sentencia desfavorable a sus pretensiones o defensas.

En definitiva, el material probatorio va a ser esencial para el juez en su labor de conectar los hechos a la norma jurídica aplicable como regla de conducta imperante hasta ahora, en que a las partes les asiste la responsabilidad de acreditar los hechos que le sirven de sustento a sus afirmaciones, dependiendo de su planteamiento procesal.

Pero lo que ha sido tradicional, hasta el momento, deja paso a la novedad del año, cual es que el Juez de Policía Local pasa a tener un rol trascendental en la distribución de la carga probatoria, transformando el procedimiento individual del consumo (con clara influencia en el proceso infraccional de la Ley 18.287) hacia una raíz más publicista del proceso, es decir, orientado en la búsqueda de la solución efectiva del conflicto, dotando a este juez de más facultades que le permitan reconstruir los hechos a fin de establecer la real verdad procesal.

Lo anterior obedece no solo a un capricho del legislador o al mero hecho de innovar, sino que a una verdadera conjunción de los principios del derecho del consumidor y las normas procesales aplicables a la solución efectiva de las controversias del consumo, para producir una adecuación entre ellas en aras de soluciones reales.

La disponibilidad y facilidad probatoria son una más de las varias reglas, dentro de la teoría de las llamadas cargas probatorias dinámicas, para aquellos casos en que se justifique la dificultad o facilidad probatoria para una de las partes. Esta teoría que tiene su punto de partida en el país vecino en dos sendos Congresos, el primero, el año 1992, en las V Jornadas Bonaerenses de Derecho Civil, Comercial, Procesal e Informático, en la ciudad de Junín, donde una de sus conclusiones fue que «las reglas vigentes acerca de la distribución de la carga de la prueba, que no obstan a la iniciativa probatoria del tribunal, deben ser preservadas como viga maestra en la materia, sin perjuicio de su prudente flexibilización para mejor adaptarlas a las circunstancias del caso. .... La llamada doctrina de las cargas probatorias dinámicas puede y debe ser utilizada por los estrados judiciales en determinadas situaciones en las cuales no 
funcionan adecuada y valiosamente las previsiones legales que, como norma, reparten los esfuerzos probatorios. La misma importa un desplazamiento del onus probandi, según fueran las circunstancias del caso, en cuyo mérito aquél puede recaer, v.gr., en cabeza de quien esté en mejores condiciones técnicas, profesionales o fácticas para producirlas, más allá del emplazamiento como actor o demandado o de tratarse de hechos constitutivos, impeditivos, modificativos o extintivos» y, el segundo, en mayo de 1993 en Termas de Río Hondo (Provincia de Santiago del Estero) el XVII Congreso Nacional de Derecho Procesal donde se explicita que «la temática del desplazamiento de la carga de la prueba reconoce hoy como capitulo más actual y susceptible de consecuencias prácticas a la denominada doctrina de las cargas probatorias dinámicas, también conocida como principio de solidaridad o de efectiva colaboración de las partes con el órgano jurisdiccional en el acopio del material de convicción. La misma importa un apartamiento excepcional de las normas legales sobre la distribución de la carga de la prueba, a la que resulta procedente recurrir sólo cuando la aplicación de aquélla arroja consecuencias manifiestamente disvaliosas. Dicho apartamiento se traduce en nuevas reglas de reparto de la imposición probatoria ceñida a las circunstancias del caso y renuentes a enfoques apriorísticos (tipo de hecho a probar, rol de actor o demandado, etc.). Entre las referidas nuevas reglas se destaca aquélla consistente en hacer recaer el onus probandi sobre la parte que está en mejores condiciones profesionales, técnicas o fácticas para producir la prueba respectiva».

Así surge una verdadera corriente inspiradora de las cargas dinámicas de la prueba a partir de los escritos previos de Peyrano, Chiappini y Morello, las cuales pertenecen a los llamados desplazamientos de las cargas probatorias.

Aclarado el origen de los conceptos, intentaremos conceptualizarlos: i) Por facilidad probatoria vamos a entender no solo para quién resulta más fácil incorporar el material probatorio, sino que, en los términos de Muñoz Sabaté «aquellos en que la prueba resulte más económica, más rápida, más fiable o más segura de poder practicarse», y por disponibilidad probatoria, para el mismo autor, se hace referencia "a una situación de cercanía, acceso o contacto 
del litigante con el medio o la fuente de prueba, lo cual permite su traslado al proceso sin obstáculos» ${ }^{18}$.

En sistemas comparados estas reglas de desplazamientos probatorios constituyen una excepción a la regla general de distribución legal del onus probandi, tal como ocurre en el sistema español, el artículo 217.6 de la Ley de Enjuiciamiento Civil, que permite aquella regla de alteración al momento de dictar sentencia siempre que considerase dudoso los hechos relevantes para la decisión, transformándola en una regla de juicio.

Stürner nos señala que, dentro del esclarecimiento procesal, en el sistema procesal alemán, encontramos el deber de información o aviso y aporte probatorio de parte, ya que en aquellos casos de falta de ofrecimiento de prueba de una parte el tribunal de oficio puede instar a esa prueba o indicar la falta de la misma, pero advertida que sea la parte, si permanece pasiva, el tribunal no tiene ningún deber de suplir esa falta de actividad probatoria.

La doctrina de las cargas dinámicas, ampliamente reconocida en la doctrina y legislación comparada, distribuye las cargas probatorias para aquella de las partes que está en mejor disposición de aportarlas al tribunal, haciendo aplicable los principios de colaboración y solidaridad entre las partes.

Pero ¿quién está en mejor posición de aportar el material probatorio? Simplemente aquel interviniente que tenga en su poder el medio probatorio o la mejor facilidad de aportar la prueba o los elementos necesarios para su configuración, ahora bien, ello no implica aliviar la carga probatoria o eximirle a quién realmente debe probar, sino que implica colaborar y facilitar su rendición.

Para Escaler Bascompte «se entiende que la facilidad probatoria es inherente a la posición dominante de un sujeto en la relación juridica» pudiendo "extraer la conclusión de que la facilidad probatoria apreciada a partir de la posición dominante de alguna de las partes opera como criterio preferente ante cualquier otra interpretación de las reglas de carga de prueba». ${ }^{19}$

En consecuencia, al sujeto que se le asigna la carga probatoria se encuentra en una situación de ventaja con relación al material

18 Muñoz Sabaté (2001) 181.

19 EsCALER (2017) 139. 
probatorio y la parte contraria, pues tiene en su poder el elemento generador de la controversia y se encuentra en mejor posición para lograr el establecimiento de la verdad, asistiéndole el deber de cooperación probatoria, a su vez, la tenencia de dicho elemento se transforma en el factor clave, toda vez que estará en su poder principalmente por razones profesionales, técnicas, jurídicas, económicas, de mercado o publicitaria, piénsese, por ejemplo, en un instructivo especializado de un automóvil que no es entregado al cliente por su grado de complejidad, el cual puede ser requerido por el tribunal como carga probatoria y explicitado a través de un informe pericial, sin embargo, la norma es tanto o más relevante en cuanto a las consecuencias que le pueda generar la ausencia o insuficiencia del material probatorio.

Entonces, ¿debe probarse la debilidad probatoria de la parte? Como ya hemos expresado en el capítulo anterior, la dificultad y variedad de procesos del consumo dificulta la producción de prueba de parte del consumidor, de tal forma que resulta indiferente quién aporte el material probatorio, pues mediante el principio de la adquisición procesal más la inversión probatoria derivada de la facilidad o disponibilidad probatoria, no requiere de prueba la debilidad probatoria, lo que permitiría generar un incidente dilatorio en el procedimiento, innecesario al fin del proceso del consumo que debe ser un procedimiento rápido y expedito por esencia.

Ahora, atendida la ubicación de la norma, su aplicación se reduce a la audiencia que se ha fijado para tal efecto, y a la cual nos referiremos en el siguiente capítulo, pero su ubicación tampoco nos ayuda a determinar un nuevo concepto, cual es, el de la dosis o suficiencia probatoria, que sería una medida judicial subjetiva del juez al ponderar los medios de prueba tendientes a acreditar un hecho, lo que se acerca al concepto de estándar, que en términos generales se ha conceptualizado como la certeza o probabilidad que los medios de prueba producen convicción en el juzgador. ${ }^{20}$

20 Así Abel Lunch, citando a A. Keane y P. McKeown, indica que «el término estándar de prueba debe relacionarse con el de la carga de la prueba, que en el sistema anglosajón, tiene una doble comprensión: por una parte, la carga de la persuasión (persuasive burden o legal burden), entendida como la obligación impuesta a una parte por una disposición legal de probar un hecho controvertido; y, por otra parte, la carga de la evidencia (evidental burden), entendida como la 
Por último, no existe en nuestro sistema una regla de conducta en materia infraccional sobre la suficiencia o dosis probatoria, como ocurre en materia penal con la regla de una condena más allá de toda duda razonable, o en materia procesal civil con el sistema reglado de valoración probatoria, lo que se suple en materia de policía local con una adecuada motivación de la decisión.

\section{4. ¿Cómo IMPaCtará la NUEVA REgLa EN EL PROCEDIMIENTO DE POLICÍA LOCAL?}

En nuestro sistema de justicia local, que no corresponde a un sistema procesal civil ni penal, sino a un sistema procesal infraccional con caracteres propios, pero en el cual se tramitan en forma conjunta o paralela dos tipos de acción, la regla de desplazamiento quedará en la esfera del juzgador en el comparendo al cual se cite para rendir el material probatorio (recordando que en el procedimiento individual del consumo todo el material probatorio se ofrece, presenta y rinde en una única audiencia conforme al artículo 8 de la Ley 18.287 LPJPL), por lo que en dicha audiencia el juez, verificando en forma previa dicho material, deberá proceder a examinarlo y cotejarlo con las pretensiones y defensas de las partes y determinar si dicho material es suficiente para establecer la verdad de lo ocurrido, si ello no es así procederá a comunicar dicha circunstancia a los intervinientes, dictando una resolución al respecto y distribuyendo la carga de la prueba conforme a los criterios indicados.

La práctica obligará a los tribunales a disponer de un mayor tiempo para efectuar la determinación de la dinamización probatoria pues, en la mencionada audiencia, además de proceder a contestar la querella infraccional y demanda civil (si la hubiere) el juez deberá revisar el material probatorio ofrecido por las partes y recibirlo para, acto seguido, cotejarlo con las alegaciones de las partes y dictar una resolución en la cual distribuya la carga de la prueba, conforme a la disponibilidad o facilidad probatoria de cada parte, indicando en la misma resolución las consecuencias de la ausencia o insuficiencia

obligación de una parte de aportar prueba suficiente de un hecho controvertido ante del tribunal de los hechos» y para una análisis más amplio de este tema en Abel Lluch (2012) 173-200. 
del material probatorio que hayan debido aportar o el no rendir la prueba que esté en su poder, para luego, entendemos por ordenación procesal y mejor conocimiento de las pruebas, proceder a la formulación de acuerdos en la fase conciliatoria, pues uno de los mayores beneficios de esta institución es el resultado de la calidad de acuerdos que se puedan alcanzar entre las partes, aunque debemos decir que procesalmente mayores incentivos no existen, como en materia penal (acuerdos reparatorios, por ejemplo) de termino anticipado del procedimiento.

Ya hemos indicado que si bien esta es una regla dirigida al juez, nada impide que sea el propio demandante quién pueda formular el requerimiento en su demanda, indicando las razones por las cuales no aporta la prueba sobre un determinado hecho, por lo que resulta adecuado que sea el propio demandante que en su libelo indique la conveniencia de desplazar la carga probatoria a la parte contraria en razón de la facilidad y/o disponibilidad probatoria, justificando dicha circunstancia.

Tal como lo hemos indicado en el procedimiento de policía local la regla fijada por el artículo citado chocará con tres grandes problemas: 1) Que, el procedimiento se desarrolla con una audiencia única; 2) Que, en dicha audiencia se contesta la demanda y querella infraccional, si la hubiere; y 3) Que, no existe en la práctica jurisprudencial de los tribunales de policía local la fijación de hechos que permita depurar los mismos y que sea orientador de lo que deben o no probar las partes y sobre lo cual discurra la aplicación de la regla de desplazamiento probatorio.

De tal forma que, en la práctica, el procedimiento individual del consumo debería transformarse en un proceso por audiencias y con fijación de los hechos a probar, lo que deviene en una mayor certeza de la regla de la carga probatoria dado que, en caso contrario, la prueba a rendir puede salir de los cauces normales transformándose en sobreabundante y con poca claridad en cuanto al desplazamiento probatorio.

No obstante lo anterior, aún quedan herramientas procesales para acreditar los hechos, la facultad contemplada en el artículo 16 de LPJPL que permite al juez decretar durante el transcurso del procedimiento las diligencias probatorias que estime pertinente, sin embargo, bajo este nuevo crisol de reglas probatorias si la parte 
respectiva, no obstante, que el tribunal desplazó la carga de prueba y nada hizo, siendo debidamente advertida, la regla del artículo 16 no podría ser utilizada por el juez para reparar la situación de falta de prueba o esclarecimiento de algún hecho, en consecuencia, esta dinamización probatoria ¿ puede entenderse para aquellos casos en que no existe prueba suficiente para acreditar los hechos planteados al juzgador? Creemos que la respuesta debe ser negativa, pues la facilidad / disponibilidad probatoria dice relación con la actividad previa de las partes tendiente a acreditar los hechos de la causa y no a avalar la decidía o inactividad de la parte para acreditar sus aseveraciones, puesto que en caso contrario podría vulnerarse el principio de imparcialidad, al disponer una diligencia que la propia parte debidamente advertida no realizó, máxime si es advertida de su inactividad procesal.

Volvamos al inicio, antes de referirnos a la parte final del procedimiento, esto es la denuncia, querella y/o demanda civil de indemnización de perjuicios, para responder la pregunta ¿podrá el accionante formular una carga procesal de falta de disponibilidad probatoria? Estimamos que puede perfectamente indicarlo con la fundamentación debida, es decir, indicar las razones precisas y determinadas por la cuales carece del medio probatorio y resulta más adecuado distribuir la carga a la parte contraria en relación a los hechos fundantes de la pretensión, pero claro será el juez el que determinará la distribución probatoria en la etapa fijada por la norma y en no en etapas preliminares del procedimiento.

Finalmente, llegamos al periodo de la sentencia y ya hemos indicado que la regla de dinamización probatoria es una regla de carga y no una regla de juicio, puesto que no se ubica, como en la Ley de enjuiciamiento civil española, en los requisitos de la sentencia (artículo 217), sino que en el procedimiento mismo en la fase de conocimiento.

En razón de lo anterior, en un acápite de la sentencia, debe quedar claramente establecido cuales fueron los hechos controvertidos (pese a no fijarse, como indicamos), pues estos requerirán de una debida motivación y fundamentación, para dar o no por probados los mismos. Sin embargo, en caso de duda respecto de la acreditación de un hecho controvertido, el tribunal tendrá que dar la suficiente razón para explicitar cual es la regla probatoria aplicable, si lo fuera 
la regla estática deberá razonar en base a ello, pero si fuera la regla de flexibilidad, deberá indicar si su aplicación derivo de una solicitud de la parte o bien de una decisión del tribunal, de tal forma que en esta parte la sentencia debe cumplir estrictamente con las reglas de motivación, pero sobre todo congruencia, pues debe hacer aplicable el apercibimiento fijado a la parte respecto del medio de prueba no incorporado en virtud de la flexibilización probatoria.

En resumen y para claridad de las ideas, el procedimiento en el cual se haga uso de esta facultad de reduce a lo siguiente:

1. Presentación de la querella infraccional y demanda civil (si de deduce);

2. El tribunal cita a una audiencia única de contestación, conciliación y prueba;

3. En la realización del comparendo el querellado y demandando civil, procederá a contestar la querella y demanda civil;

4. Acto seguido las partes conforme a la regla general ofrecerán y rendirán sus medios de prueba.

El juez conforme a la nueva facultad podrá distribuir la carga de la prueba conforme a la disponibilidad y facilidad probatoria, comunicando a las partes mediante una resolución las consecuencias de la ausencia o insuficiencia de un medio de prueba decretado conforme a esta facultad y citará a una nueva audiencia para cumplir con la citada resolución.

Tal como lo hemos expuesto pareciera ser que, en la práctica de los tribunales, se transformará en un procedimiento complejo frente a lo variopinto de las materias que son de su competencia, sin embargo, enfocado desde una perspectiva del derecho procesal del consumo termina siendo una norma garantizadora de los derechos del consumidor en aras de lograr un equilibrio procesal efectivo, pero también garante de los derechos del proveedor, pues se amplía el abanico de posibilidades para el juez y las partes, que serán reales conocedoras de los efectos de su decidía procesal probatoria.

Nos resta por referirnos brevemente a los recursos que proceden en sede de policía local contra la sentencia definitiva, recordemos que no procede el recurso de casación, por lo que no habría infracción de 
ley, pero si apelación pues puede ocurrir que el agravio denunciado sea la errónea aplicación de la regla de flexibilización lo que podría redundar en una supuesta indefensión de la parte contra la cual se produjo la prueba, sin embargo, consideramos que dicho agravio no puede ser tal sino se reclamó en forma oportuna de la resolución que flexibilizó la carga probatoria y que, además, no rindió la prueba teniendo claro conocimiento del apercibimiento fijado por el tribunal.

\section{Conclusiones}

Finalmente podemos concluir que: 1) Las reglas sobre carga de la prueba siguen destinadas a las partes pero, ahora con la institución procesal comentada, al juez para alcanzar la verdad del caso planteado; 2) Las reglas sobre dinamización de la carga de la prueba son de aplicación subsidiaria de la regla general en materia de prueba y en caso alguno pueden venir a reemplazar la decidía procesal de las partes; 3) La finalidad esencial de esta institución es poner a resguardo el carácter público del proceso, pero por sobre todo el igualitario acceso a la justicia y una tutela judicial verdaderamente efectiva; 4) Disponibilidad y facilidad no son términos sinónimos pues cada uno busca una finalidad distinta; y 5) Finalmente, estas nuevas reglas buscan que el juez dicte una sentencia ajustada a la realidad de los hechos y conforme a los principios inspiradores del derecho del consumo.

No podemos dejar de mencionar que esta novedad procesal debe ir acompañada en un futuro cercano de una modernización de la justicia local que permita la real concreción de los principios del derecho del consumo y normas procesales como las comentadas, caso contrario quedarán en un mero intento legislativo sin una concreción práctica debido a la realidad imperante. 


\section{BibLIOGRAFÍA}

a) Doctrina:

Abel Lluch, Xavier (2012): «Doxa», Cuadernos de Filosofía del Derecho, pp. 173-200. Disponible en: file:///C:/Users/Compaq/Downloads/ladosis-de-prueba-entre-el-common-law-y-el-civil-law.pdf

Celedón Baeza, Andrés (2015): «Tutela Jurisdiccional del Consumidor. Legitimidad para Accionar. Reforma al sistema tutelar del consumo en Chile. Desde lo jurisdiccional a lo administrativo», en: Actas del XXVIII Congreso Nacional de Derecho Procesal. Jujuy 2015. Disponible en: http://www.procesal2015.org.ar/images/ Tutela_jurisdiccional_del_consumidor._Legitimidad_para_accionar.-_Versi\%C3\%B3n_10_carillas.pdf

Celedón, Andrés (2018). «Un problema menos o un problema más: un comentario a propósito de las competencias de los Juzgados de Policía Local en materia de protección a los derechos del consumidor», en: El Mercurio Legal, [online] p.1. Available at: http://www.elmercurio. com/legal/noticias/opinion/2018/01/29/un-problema-menos-o-unproblema-mas-un-comentario-a-proposito-de-las-competencias-delos-juzgados-de-policia-local-en-materia-de-proteccion-a-los-derechos-del-consumidor.aspx [Fecha revisión: 7 Sep. 2018].

Escaler B, Ramón (2017): La carga de la Prueba, $1^{\circ}$ ed. (Barcelona, Editorial Atelier).

Guerrero Becar, José Luis (2013): «Artículo 23 Inciso 2․ Multa sobreventa de espectáculos Públicos. Comentario», en: Pizarro Wilson, Carlos; Barrientos Camus, Francisca; De la Maza Gazmuri, Iñigo, C. La protección de los derechos de los consumidores (Santiago: Editorial Thomson Reuters).

Muñoz Sabaté, L. (2001): «Fundamentos de prueba judicial civil», en: LEC 1/2000 (Barcelona, Ed. Bosch).

Peyrano, J.W. (2004): Cargas probatorias dinámicas (Buenos Aires, Rubizal Culzoni Editores).

Peñailillo A, Daniel (I993): La prueba en materia sustantiva civil. Parte General. $1^{\circ}$ ed. (Santiago, Editorial Jurídica).

\section{b) Jurisprudencia:}

Sentencia del Tribunal Supremo de España, de fecha 9 de Mayo de 2013, núm. 241/2013, $\mathrm{N}^{\circ}$ Rec. 485/2012.

Sentencia Juzgado de Policía Local de Peñalolen, Rol 128.811. 
Sentencia Juzgado de Policía Local de Peñalolen, Rol 1582-2005. Viveros con Plus Eventos.

Sentencia Juzgado de Policía Local de Puerto Montt. Rol 6885-2005. Sernac con Anfp.

Corte de Apelaciones de Temuco, Rol 10-2011. Jaime Enrique Guerra Diaz Con Nipon Autos Motor Ltda.

c) Normativa:

Ley 19.496 (07/02/1997). Establece normas sobre protección de los derechos de los consumidores.

Ley 20.967 (17/11/2016). Que regula el cobro de servicios de estacionamiento.

Ley 21.081 (13/09/2018). Modifica ley n 19.496, sobre protección de los derechos de los consumidores.

Ley 8.078 (11/09/1990). Brasil. Que dispone sobre la Protección del consumidor y dicta otras providencias.

Ley 474 (06/08/1998). Colombia. Por la cual se desarrolla el artículo 88 de la Constitución Política en relación al ejercicio de las acciones populares y de grupo y se dictan otras disposiciones. 


\title{
CoSA JUZGADA E INSUFICIENCIA DE PRUEBAS EN LOS PROCESOS COLECTIVOS DE CONSUMIDORES Y USUARIOS
}

\author{
RES IUDICATA AND INSUFFICIENCY \\ OF EVIDENCE IN THE CONSUMERS \\ CLASS ACTION
}

\section{Maite Aguirrezabal Grünstein ${ }^{1}$}

Resumen. El presente trabajo tiene por objeto analizar la eficacia que produce la cosa juzgada en un proceso colectivo en que la pretensión ha sido rechazada por insuficiencia probatoria y los requisitos para iniciar un nuevo procedimiento en el caso de encontrarnos ante este supuesto.

Palabras clave: cosa juzgada, eficacia, prueba

Abstract. The purpose of this paper is to analyze the effectiveness of the res judicata in a class action in which the claim has been rejected due to insufficiency of evidence and the requirements to initiate a new procedure.

KEYWORDS: res iudicata, effectiveness, evidence

1 Profesora Investigadora (Facultad de Derecho, Universidad de los Andes). Email: maguirrezabal@uandes.cl 
Sumario. 1.Planteamiento del problema. 2.La cosa juzgada en el proceso colectivo: 2.1. Cosa juzgada e interés supraindividual; 2.2. Sistemas desarrollados en relación con la extensión de los efectos de la cosa juzgada en el procedimiento colectivo y el derecho de los miembros ausentes; 2.2.1. La eficacia erga omnes de la sentencia; 2.2.2. Eficacia «secundum eventum litis». 3. Cosa juzgada e insuficiencia de pruebas. 4. Una posible solución: Las facultades del juez. 5. Conclusiones. 6. Bibliografía

\section{Planteamiento Del PROBlema}

Comparado con los distintos problemas jurídicos tradicionales, el de la protección jurídica de los intereses supraindividuales, especialmente en lo relativo a la protección de los consumidores y usuarios, tiene una historia relativamente corta ${ }^{2}$. Hasta finales del siglo pasado, la figura del consumidor no tenía importancia en el orden económico y social, puesto que se pensaba que los mecanismos del mercado, dentro de un sistema de equilibrios económicos, eran capaces por sí mismos de asegurar su protección. Esta situación se vio pronto superada como consecuencia del desarrollo y desenvolvimiento económico que generó una tendencia monopolística dentro del mercado. El Estado surge entonces como representación de un poder institucionalizado y encomendado a la protección de la libertad de los sujetos en cuanto a sus relaciones económicas.

Lo anterior se manifiesta principalmente en el fenómeno de la contratación en masa, que uniforma las cláusulas contractuales y establece condiciones generales en la contratación como respuesta a la necesidad de distribuir productos o servicios homogéneos ${ }^{3}$.

2 Solamente en los años sesenta se multiplican las declaraciones y normativas tendientes a la protección del consumidor. Estados Unidos fue el pionero en plasmar la defensa de los consumidores, y siguiendo el ejemplo norteamericano los países industrializados han reaccionado de forma paralela. Fue a partir del mensaje al Congreso que diera el día 19 de marzo de 1962 el presidente John F. Kennedy sobre la protección de los intereses de los consumidores con el que se inició el movimiento de protección y defensa de estos, y que se extendió con mucha rapidez, creándose asociaciones, doctrina y leyes especiales para esta materia. En Inglaterra destaca la Consumer Protection Act, de 1961.

3 Cfr. Rodríguez López (2010) 402. En este mismo sentido Bonet (1989), quien señala que «aquí opera una paradoja que, considerada en su estructura, 
Esta etapa se caracteriza también por la politización de los derechos sociales, económicos y culturales, y se desarrollan dos fenómenos que son indisociables: la emergencia de nuevos grupos sociales de particulares condiciones y la identificación y categorización de intereses que si bien se pueden determinar de pertenencia individual, en razón de su importancia colectiva se establecen como propios de esos grupos o categorías sociales y que han sido denominados por la doctrina intereses supraindividuales o transindividuales ${ }^{4}$.

Ellos se enmarcan en lo que se ha conocido como derechos de tercera generación o derechos humanos de la solidaridad, que encuentran su origen científico en la teoría de Vasak, sobre la dimensión internacional de los derechos del hombre. Junto a la reconocida distinción entre derechos civiles, políticos, económicos y culturales, habla de estos nuevos derechos, que son aquellos que proceden de una cierta concepción de la vida en comunidad, y solo se pueden realizar por la conjunción de los esfuerzos de todos los que participan en la vida social ${ }^{5}$.

La sociedad contemporánea ha sido calificada como una sociedad de masas, en la que las relaciones son cada vez más complejas: hay agrupaciones de diversos tipos (partidos políticos, sindicatos, asociaciones, etc.) o simplemente individuos afectados por infracciones del ordenamiento jurídico que tiene relevancia colectiva.

Desde la perspectiva del Derecho Comparado, se constata un amplio movimiento internacional de acceso a la justicia de los intereses supraindividuales y de los entes que los representan. Este movimiento tiene su origen en cambios jurídicos y sociales.

Junto con el movimiento en pro de la protección de los intereses medio ambientales, han surgido también los «movimientos pro

puede explicar, bien que parcialmente, los efectos del fenómeno del consumo. Mientras que el producto se acerca al consumidor por una publicidad que se le ofrece rompiendo la frontera de la intimidad privada del ciudadano, el productor responsable del producto se aleja del consumidor, bien físicamente por el establecimiento lejano del centro de producción, bien jurídicamente por la interposición de intermediarios, lo que crea trabas en orden a la exigencia de la calidad y del cumplimiento de lo que impone la buena fe contractual». BonET Navarro (1989) 20.

4 Para un estudio en extenso de la noción de interés supraindividual, vid. AGUIRREZABAL GRÜNSTEIN (2006) 69-91.

5 Cfr. VASAK (I982) 3-10. 
consumatore», que comienza a cobrar fuerza a partir del mensaje del presidente Kennedy de fecha 15 de marzo de 1962, comenzaron a divulgarse diversas leyes de protección del consumidor y, a nivel de la Comunidad Europea, se inicia una importante labor tanto a nivel normativo como a nivel de búsqueda de soluciones.

El fenómeno de la masificación ha repercutido en el ámbito jurídico produciendo nuevas relaciones entre el individuo y la sociedad. Se caracteriza por el reconocimiento y la legitimación de organizaciones intermedias que encuentran su fundamento en la solidaridad, y que rompen con las respuestas ofrecidas por un Derecho basado en el carácter individual de las situaciones jurídicas. Lo anterior ha provocado que la tutela procesal ya no pueda limitarse a los intereses individuales, lo que a su vez supone vencer una serie de condicionantes internos.

Para Cappelletti, el problema básico que presentan los intereses supraindividuales es que a nadie le corresponde el derecho de remediar el daño que sufre ese interés o bien el interés de cada uno es demasiado pequeño para accionar, lo que hace recomendable la acumulación de reclamaciones. Pero esta acumulación también presenta problemas, porque, aunque a los interesados se les permita organizarse y demandar colectivamente, estos pueden hallarse dispersos, carecer de la información suficiente o faltar el acuerdo en cuanto a la estrategia común que seguirán.

Por ello, aunque la regla general es que la protección de estos intereses requiere de una acción de grupo, estos movimientos serán de escasos resultados si no existe además una política de gobierno que actúe en bien de ese grupo ${ }^{6}$.

La heterogeneidad, característica propia de esta clase de intereses, afecta también a los mecanismos para su protección, de modo que las dificultades para su acceso a la jurisdicción les afectan de modo distinto. Además, presentan el problema añadido de su escasa aprehensibilidad y su difícil atribución a los ciudadanos individualmente considerados, lo que choca con el carácter individualista de las normas procesales y de las exigencias en materia de legitimación.

6 Cfr. Cappelleti y Garth (1978) 20-21. 
El que un derecho o interés sea supraindividual significa que trasciende la esfera de lo meramente individual, está marcado por la impersonalidad y rompe con el concepto clásico de derecho subjetivo. Estos derechos «no pertenecen a una persona física o jurídica determinada, sino a una comunidad amorfa, fluida y flexible, con identidad social, pero sin personalidad jurídica» ${ }^{7}$.

Para llegar a obtener una noción de interés supraindividual debe partirse del concepto general de interés y de interés jurídico, analizando qué es lo que se añade a esta noción general para que el interés pueda ser calificado como interés supraindividual. La doctrina $^{8}$ ha elaborado varios criterios para definir el concepto, según cuál es elemento destacado y en que se fundamenta la noción general de interés, atribuyéndoles un carácter nuevo, pudiendo así distinguir, en general, entre un criterio subjetivo, un criterio objetivo $y$ un criterio normativo.

Existen también definiciones que emplean otros criterios. Almagro, por ejemplo, distingue tres planos: un plano subjetivo, referido a colectivos poco precisos en su composición, generalmente anónimos e indeterminados, aunque con dificultades determinables; un plano objetivo, en que el contenido del objeto se difumina, sea porque los mínimos no están fijados legislativamente, sea porque los obligados son múltiples y cada uno tiene que poner algo para el cumplimiento o realización del derecho y un plano formal de accionabilidad o justiciabilidad imprecisa, puesto que este último problema abre a la doctrina el problema de nuevas formas de acceso a la justicia, porque al ser un grupo el afectado en determinada materia, desborda los esquemas clásicos del Derecho procesal ${ }^{9}$.

Se ha destacado también de este tipo de intereses su naturaleza conflictual, puesto que se trata normalmente de intereses incompatibles o contradictorios entre los que debe llevarse a cabo una función política de mediación y de coordinación, y un cierto grado de indeterminación, que implica una dificultad para circunscribir

GIDI (2004) 32.

8 El concepto todavía es incierto y equívoco y se presta a bastantes confusiones. Delimitar qué se entiende por interés supraindividual implica hacer una puntualización no sólo terminológica, sino también sustancial, para preparar el terreno y las condiciones del acceso a la justicia de tales intereses.

9 Cfr. Almagro Nosete (1983) 638 y ss. 
su difusión, puesto que se repiten y extienden a todos los miembros de una colectividad.

Las acciones para su protección han sido concebidas para la defensa de los siguientes tipos de intereses: 1) los intereses difusos, que son aquellos intereses supraindividuales de naturaleza indivisible de los que son titulares sujetos indeterminados unidos por circunstancias de hecho; 2) los intereses colectivos, que también son de naturaleza supraindividual e indivisible, pero entre los titulares de esos intereses existe algún tipo de vinculación jurídica y 3) los intereses individuales homogéneos, que son aquellos de naturaleza individual y de titularidad exclusiva pero con un origen fáctico común.

Esta triple clasificación tiene su origen en los sistemas jurídicos anglosajones y ha sido principalmente desarrollada por el Derecho brasileño ${ }^{10}$. Así, el Código de Defensa del Consumidor define en su artículo 81 estos dos tipos de intereses, y señala que son difusos los intereses «transindividuales, de naturaleza indivisible, de los que sean titulares personas indeterminadas y ligadas por circunstancias de hecho» (fracción I) y que son colectivos los intereses «transindividuales, de naturaleza indivisible, de los que sea titular un grupo, una categoría o una clase de personas ligadas entre sí o con la parte contraria por una relación jurídica base» (fracción II).

De las definiciones, podemos concluir que estas categorías de intereses presentan dos características comunes: su supraindividualidad y su naturaleza indivisible ${ }^{11}$, que de acuerdo con Barbosa, significa que "los interesados se hallan siempre en una especie de comunión tipificada por el hecho de que la satisfacción de uno solo implica necesariamente la satisfacción de todos, así como la lesión de

10 En este sentido Pellegrini (1984) 30-31, distingue los intereses colectivos y difusos, y afirma que se consideran colectivos los intereses comunes a una colectividad de personas entre las que debe existir un vínculo jurídico, y difusos los intereses que sin existir un vínculo jurídico de por medio se basan en factores de origen fáctico y accidentales, como el habitar en una misma zona o consumir un mismo producto. Pellegrini Grinover (1984) 30-31.

11 Algunos autores señalan que en el caso de los intereses supraindividuales puede distinguirse una indivisibilidad en dos grados. La indivisibilidad que se refiere al derecho difuso es absoluta en función de la propia indeterminación de las personas que componen la comunidad titular del derecho o interés, mientras que en el caso de los intereses colectivos la indivisibilidad es relativa porque los miembros de la colectividad titular del derecho son determinados o fácilmente determinables. 
uno solo constituye, ipso facto, la lesión de la entera comunidad» ${ }^{12}$. Presuponen también que la solución a los conflictos que pudieran generarse debe ser la misma para todos los integrantes del grupo.

Frente a estos intereses supraindividuales el Código Brasileño de Consumo se encarga también de definir los intereses individuales homogéneos, como aquellos que, siendo de carácter individual tienen un origen común (fracción III) y que pueden ejercerse colectivamente para obtener una reparación individual de los daños sufridos por los consumidores ${ }^{13}$.

En el estudio de los intereses supraindividuales la labor más profunda fue desarrollada, en su origen, por la doctrina ${ }^{14}$, y en la actualidad, de forma cada vez más decidida, por la jurisprudencia. El trabajo gira en torno a la elaboración de los conceptos de interés difuso $^{15}$ e interés colectivo, y a los criterios de reconocimiento y

12 Barbosa Moreira (1992) 235.

13 Ello porque cada miembro del grupo es titular de un derecho individual de naturaleza divisible.

14 En cuanto al tratamiento de este tema, la doctrina italiana ha sido muy prolífica. Una obra muy completa es la de Vigoriti (1979).

15 El centro de la discusión en cuanto a la definición de «interés difuso» radica necesariamente en qué debe entenderse por «difuso». El Diccionario de la Lengua Española define «difuso» como ancho, dilatado, con lo que no aporta demasiado a la discusión, y el Diccionario de Uso Español lo define como «aquello que hace referencia a algo que es extenso y poco preciso». Para Acosta (1982) 45, el concepto vendrá determinado "por dos notas o criterios diferenciadores, a saber: su pertenencia a un grupo carente de organización y el carácter anónimo del mismo. Así, tomando como base ambos rasgos -organizativo y subjetivoentendemos por interés difuso el interés propio, jurídicamente reconocido, de un grupo social o colectividad indeterminada de sujetos, desprovista de una organización que los tome para sí enteramente y tenga capacidad para su defensa, cuya tutela jurisdiccional responde a eventuales iniciativas meramente individuales». El autor extrae de las posiciones de Giannini y Vigoriti los criterios diferenciadores de intereses difusos y colectivos, esto es, los criterios organizativo y subjetivo. Sánchez (1980), considera que el interés difuso «es el interés jurídicamente reconocido de una pluralidad indeterminada o indeterminable de sujetos que, en potencia, pueden ser incluso todos los que integran la comunidad general de referencia, el ordenamiento general cuya normativa protege tal tipo de intereses». SánChez Morón (1980) 118. Para LozanoHiguero (1983), el interés difuso es «el interés de un sujeto jurídico en cuanto compartido - expandido-compartible-expandible- por una universalidad, grupo, categoría, clase, o género de los mismos; cuyo disfrute, ostentación y ejercicio son esencialmente homogéneos y fungibles, y que adolece de estabilidad u coherencia en su vinculación subjetiva, así como de concreción normativa 
tutela de estos intereses, plasmándose en posiciones diversas que, pese a las diferencias, se orientan mayoritariamente, a que no constituyen un tertium genus respecto de las figuras tradicionales del interés legítimo y del derecho subjetivo.

Barbosa distingue tres grupos de situaciones de relevancia supraindividual: aquellas en las que hay más de un titular activo o pasivo de la relación jurídica material, pero cuyos problemas de tutela procesal pueden resolverse mediante instituciones clásicas (litisconsorcio, intervención de terceros); aquellos casos en que un grupo más o menos amplio de personas se encuentran unidas por un vínculo jurídico; y por último, los intereses comunes a una colectividad de personas que no necesariamente se encuentran jurídicamente vinculadas, sino que, más bien, el interés que se trata de tutelar se basa en datos de hecho, siendo muy difícil la delimitación de los componentes del grupo precisamente por la inexistencia de este vínculo jurídico ${ }^{16}$.

El primer grupo se ajusta a las estructuras clásicas del derecho y por lo tanto escapa a esa nueva forma de considerar las situaciones jurídico-subjetivas de ventaja a través de la característica de la relevancia supraindividual. La trascendencia social es importante en el caso del segundo y tercer grupo, en los que se apunta la distinción entre intereses difusos y colectivos.

Respecto de estas categorías de intereses puede decirse que comparten los mismos problemas jurídicos y que ambas se refieren a bienes de carácter indivisible ${ }^{17}$, pero con una distinción fundamen-

orgánica en sus tutelas material y procesal». Puede entonces concluirse, que el término "difuso" alude a una "escasa precisión jurídica» en relación con el vocablo «interés». Esta difusión o falta de precisión se manifiesta en el plano subjetivo, objetivo y formal del modo que sigue: subjetivamente, la difusión se manifiesta en un doble aspecto, ya que se trata de intereses referidos a colectivos poco precisos en su composición, generalmente anónimos e indeterminados o determinables con dificultades, y en la medida en que estos intereses se densifican en derechos constitucionalmente reconocidos, la titularidad de estos derechos que aunque individuales tienen su proyección y desarrollo en el grupo social, motivan cuestiones de filosofía jurídica todavía abiertas entre individualismo social y socialismo. LozANo-Higuero y Pinto (1983) 149-150.

16 Cfr. Barbosa Moreira (1979) 2674-2677.

17 En este sentido, señala Ferrer (2004), que la distinción entre situaciones difusas y colectivas no siempre es clara puesto que ambas obedecen al mismo fenómeno. Por la circunstancia de ser la indivisibilidad una nota esencial de estos intereses, 
tal: los intereses difusos se refieren al sujeto no como individuo sino como miembro de un grupo que puede ser más o menos amplio, pero indeterminado o de muy difícil determinación, mientras que los intereses colectivos atañen a grupos delimitados en que los miembros se encuentran determinados o son fácilmente determinables.

Son varios los criterios que se han propuesto para diferenciar los intereses difusos y los colectivos, destacando aquellos que atienden a si los miembros del grupo están vinculados por circunstancias de hecho o bien ligados por una relación jurídica o aquellos que consideran que los intereses difusos presentan una nota de mayor «extraneidad» que los intereses colectivos, y por lo tanto los primeros resultan más neutrales que los segundos ${ }^{18}$.

El Derecho brasileño desarrolla otro criterio, referido a la vinculación jurídica, siendo colectivos «aquellos intereses comunes a una colectividad de personas y solamente a ellas, cuando existe un vínculo jurídico entre los integrantes del grupo: la sociedad mercantil, el condominio, la familia, los entes profesionales, el mismo sindicato, dan margen a que surjan intereses comunes, nacidos en función de una relación base que une a los miembros de las respectivas comunidades y que, no confundiéndose con los intereses estrictamente individuales de cada sujeto, permiten su identificación", y difusos «aquellos que, no fundándose en un vínculo jurídico, se basan en datos de hecho genéricos y contingentes, accidentales y mudables: como habitar en la misma región, consumir los mismos productos, vivir en determinadas circunstancias socioeconómicas, someterse a particulares empresas» ${ }^{19}$.

Gutiérrez de Cabiedes destaca varios aspectos: los intereses colectivos y difusos no presentan diferencias esenciales, puesto que hacen referencia a un mismo fenómeno jurídico y a situaciones

no pueden ser considerados como una suma de intereses individuales porque pertenecen a una colectividad. Ferrer Mac-Gregor (2004) 13

18 Este criterio ha sido adoptado en España por Almagro (1983) 96, que señala que «lo típico de estos intereses sociales o colectivos que se denominan difusos es su acotación por grupos o clases o sectores de manera más o menos extensa». Y debido a esta distribución de los intereses en clases o grupos «surgen conflictos a veces entre la satisfacción de los intereses de un grupo respecto de otros, lo que lleva a poner de relieve otra nota que acompaña al concepto de intereses difusos la conflictualidad».

19 Pellegrini Grinover (1998) 707. 
jurídicas con una misma naturaleza y estructura, y que comportan similares problemas procesales. Sin perjuicio de lo señalado, considera que los factores determinantes al momento de diferenciarlos son la extensión y la determinación de los sujetos interesados, al que puede agregarse el de la vinculación entre los miembros del grupo o de la colectividad interesada. "Así, cuando el grupo de personas que se encuentran de forma común y simultánea en una misma situación jurídica con respecto a un bien que todos ellos disfrutan sea determinado o determinable en su composición, en sus miembros, puede hablarse de interés colectivo. Cuando, por el contrario, se trate de una comunidad de sujetos amplia e indeterminada o muy difícilmente determinable puede hablarse de interés difuso» ${ }^{20}$.

En lo que respecta a los derechos individuales homogéneos o plurisubjetivos, corresponden a una categoría de intereses que ha sido elaborada en los países del Common Law y por la legislación brasileña, que como hemos señalado, la introduce en el Código del Consumidor de 1990. Son derechos individuales que por efectos prácticos se hacen "accidentalmente colectivos» ${ }^{21}$, y que han sido definidos como «una compilación de derechos subjetivos individuales, marcados por la nota de divisibilidad, del cual es titular una comunidad de personas indeterminadas más determinables, cuyo origen está en alegaciones de cuestiones comunes de hecho o de derecho» ${ }^{22}$.

Estos intereses se distinguen de los difusos y colectivos en que aquéllos son verdaderos derechos individuales, privativos e indisponibles por terceros, pero que pueden existir en número plural y tener un origen fáctico común y un contenido sustantivo homogéneo ${ }^{23}$.

20 Gutiérrez de Cabiedes (1998) 109.

21 Cfr. Barbosa, J. (1979), cit. n 15, 195-196. Los distingue así de los supraindividuales, a los que califica como «esencialmente colectivos», citado por Watanabe (2004). Este mismo autor los califica como «ontológicamente individuales, pero que son tutelados colectivamente, por razones de estrategia de tratamiento de conflictos». Watanabe (2004) 3.

22 Gidi (2004) 35.

23 Gutiérrez de Cabiedes (1998) 441. El autor señala que, por ejemplo, la difusión de una publicidad engañosa o la comercialización de un producto defectuoso dan lugar a un interés difuso, mientras que la falta de higiene o seguridad en una fábrica dará lugar a un interés colectivo. Serán derechos 
Presentan dos características esenciales para su tratamiento colectivo: su homogeneidad, que le viene dada por su origen común ${ }^{24}$ y su divisibilidad, puesto que nos encontramos ante derechos que pueden ejercerse individualmente, pero respecto de los cuales resulta más conveniente su defensa colectiva.

Agrega Pellegrini que la distinción fundamental se manifiesta en que en los intereses supraindividuales la solución del litigio es la misma para todos, debido a la indivisibilidad del objeto del proceso y en los segundos, en cambio, la solución no es la misma para todos, precisamente porque el objeto del proceso es divisible ${ }^{25}$.

La diferencia entre los intereses supraindividuales y los plurisubjetivos tiene mucha importancia desde el punto de vista práctico puesto que su tratamiento procesal es distinto por tratarse los segundos de derechos subjetivos clásicos, lo que implica que en lo que respecta a la legitimación, los límites subjetivos de eficacia de la sentencia y la indemnización de los perjuicios dependerán de las circunstancias personales del titular del derecho ${ }^{26}$.

Frente a esta realidad, surge entonces la necesidad de crear un procedimiento especial para la defensa de estos intereses de masas, que rompe con los esquemas procesales tradicionales, y que destaca

individuales plurales aquellos de que son titulares quienes han adquirido un bien que no responde a las cualidades anunciadas o contratadas.

24 No es requisito que entre las personas titulares de este tipo de derechos exista una relación jurídica anterior, puesto que el vínculo con la parte contraria nacerá precisamente de la lesión, relación que además es individual y que afectará de modo distinto la esfera jurídica de cada uno de ellos. El origen común en todo caso puede ser más o menos remoto. Mientras más remoto menos homogéneos serán estos derechos. Tampoco este origen común implica necesariamente una unidad de hecho temporal, lo que significa que no es necesario que el hecho creador de los derechos sea el único o el mismo en todos los derechos. Lo esencial será que nos encontremos ante situaciones jurídicamente iguales, aunque los hechos sean diferentes.

25 Cfr. Pellegrini Grinover (1994) 106-114. En sentido contrario Gutiérrez de Cabiedes (1998) 443, quien considera que la distinción no debe basarse en el criterio de la divisibilidad, sino en la existencia o inexistencia de monopolio en la disposición material y procesal de la situación jurídica que se tutela.

26 Hay que estar también a la forma en que se formula la solicitud de tutela jurisdiccional y los fundamentos de la demanda colectiva, para saber si nos encontramos ante una verdadera demanda para la tutela de intereses supraindividuales o si bien se trata de tutela intereses individuales homogéneos. 
por una serie de principios o reglas que deben tenerse en cuenta al momento de legislar sobre la materia.

Frente a incumplimientos que provengan de actos de consumo masivos, más allá de los elementos accidentales relativos a la fecha, al lugar y cantidad del producto o servicio, resulta lógico que se pueda configurar un proceso orientado a proteger a una pluralidad de sujetos, siempre que las acciones tengan elementos de conexión que así lo justifiquen.

$\mathrm{Al}$ encontrarse los consumidores en situaciones idénticas, no es deseable que se dicten resoluciones contradictorias, ya que ello compromete la garantía de igualdad ante la ley, al dar los tribunales un tratamiento diverso a situaciones idénticas.

Por cierto, esta novísima tendencia en ningún caso pretende la supresión de los derechos individuales de los consumidores para caer en un colectivismo asfixiante. Por lo mismo, el mecanismo procesal para la protección colectiva de los derechos es una institución de excepción. Se debe recurrir a ella solo cuando los instrumentos clásicos no permitan amparar una situación jurídica colectiva y considerando que se trata por su naturaleza, de una tutela procesal diferenciada.

En este sentido, el proceso colectivo presenta una serie de características particulares que lo apartan del proceso tradicional individualista, y que lo convierten en una clase de tutela procesal diferenciada. Estas características dicen relación especialmente con tres figuras: la legitimación, la cosa juzgada y el rol del juez en el procedimiento ${ }^{27}$.

\section{LA COSA JUZGADA EN EL PROCESO COLECTIVO \\ 2.1. Cosa juzgada e interés supraindividual}

Es un principio generalmente aceptado que, en consideración de la seguridad jurídica, la sentencia que pone fin a una situación controvertida ha de alcanzar un grado de firmeza que la haga inamovible. La cosa juzgada tradicional tiene límites objetivos y subjetivos. Los primeros se refieren al thema decidendum, en cuanto a que su fuerza se extiende a las cuestiones litigiosas amparadas por la cosa

27 Sobre el particular, cfr. AguirRezabal GrünStein (2011) 573-618; AguirReZABAL (2006) 143-173 y 69-91. 
juzgada, tanto en los fundamentos de la sentencia como en su parte dispositiva. En cuanto a los límites subjetivos afecta solamente a quienes fueron partes en el proceso, y no puede favorecer ni perjudicar.

En esta línea de pensamiento, un proceso que tenga por objeto la tutela de intereses individuales no presenta problemas respecto a la cosa juzgada: sea cual sea el resultado, si la sentencia alcanza la autoridad de cosa juzgada, afectara a las partes que participaron, quienes no podrán discutir nuevamente el caso.

Sin embargo, en los procesos colectivos la situación difiere, por cuanto una acción es colectiva si resuelve los intereses de los miembros ausentes de un grupo, y la sentencia que se pronuncia sobre una acción de esta naturaleza debe tener efectos más allá de las partes e intervinientes.

Por ello, uno de los mayores problemas que suscita la tutela jurisdiccional de los intereses supraindividuales es determinar la extensión de los efectos de la sentencia que resuelva las pretensiones de tutela de los mismos. La doctrina se ha pronunciado en diversos sentidos, siendo el denominador común del problema resolver cómo se afectan los derechos de los miembros de la clase que no han comparecido al proceso para ejercer su derecho de defensa.

La premisa inicial es que el legitimado activo actúa en el proceso colectivo con la calidad de adecuado representante de la clase, es decir, ejerciendo una defensa vigorosa de todos los intereses de sus miembros, tal y como si ellos mismos hubieran estado presentes o asumiendo que, de haber ejercido directamente la defensa, no podrían haberlo hecho de mejor modo.

Ese extremo, deberá ser evaluado con anterioridad, en la etapa de admisibilidad de la acción colectiva y durante todo su devenir, ya que el ejercicio de una pretensión representativa conducirá, necesariamente, a que en los procesos colectivos se modifiquen algunas pautas que son operativas en los sistemas individuales tradicionales para que el tratamiento de un conflicto de esas características sea posible.

En el proceso colectivo, por lo tanto, solo será posible una decisión que se extienda a los miembros de la clase -que no han puesto de manifiesto su voluntad de quedar excluidos del proceso-, si previamente se ejerció el control de la representación adecuada del legitimado activo. Además será necesario, por ejemplo, publicitar 
debidamente la existencia de una pretensión colectiva e informar sobre las consecuencias que la decisión reportará a todas las personas que podrán resultar interesadas en ese litigio.

Sin ese tipo de recaudos, la cosa juzgada que se extendiera a los miembros ausentes del proceso debería ser calificada como una decisión arbitraria que violentaría las más delicadas garantías constitucionales. El desafío, en el marco de los procesos colectivos, es garantizar que la discusión representativa contenga verdaderamente los posibles postulados del grupo involucrado.

\subsection{Sistemas desarrollados en relación con la extensión de los efectos de la cosa juzgada en el procedimiento colectivo y el derecho de los miembros ausentes}

\subsubsection{La eficacia erga omnes de la sentencia}

Como ya hemos señalado, las acciones colectivas fueron concebidas para la tutela de derechos de un grupo numeroso de personas. La doctrina venía considerando necesario extender la eficacia de la sentencia respecto de toda la colectividad interesada, aunque algunos de los individuos afectados hubieran estado apartados del proceso en que se dictó la sentencia que se pronuncia sobre el interés supraindividual.

Para que los ausentes en el proceso puedan ser legítimamente vinculados por la cosa juzgada de la sentencia colectiva emanada en un procedimiento en el cual no participaron se ha creado la ficción de considerarlos presentes en el juicio, representados adecuadamente por uno de los miembros del grupo. Pero al momento de determinar los efectos de esta sentencia se dividía, ya que por una parte, se señalaba que el principio de defensa de los individuos que no habían intervenido en el proceso induce a excluirlos de los efectos de la sentencia que rechaza la pretensión, mientras que la sentencia que acoja la demanda valdrá para todos los miembros de la colectividad.

Sobre este aspecto los criterios propuestos abarcan a quienes sostenían la eficacia ultra partes de la sentencia ${ }^{28}$, a los que proponían

28 Cfr. Gómez De Liaño (1986), quien considera que la legitimación colectiva derivada de este artículo «origina asimismo una eficacia «ultra partes de la 
atender a los límites subjetivos normales de eficacia interpartes ${ }^{29}$, o los que propugnaban la producción de cosa juzgada secundum eventum litis o secundum eventum probationem ${ }^{30}$, que ha sido generalmente entendida por la doctrina en el sentido de que si la sentencia es favorable a las pretensiones deducidas esta debe expandir sus efectos al resto de la colectividad, y si es desfavorable debe solo producir efectos interpartes, por lo que los legitimados podrían demandar nuevamente fundando el libelo en los mismos hechos ${ }^{31}$.

sentencia» que afecta a quienes no han sido partes en sentido formal, pero son titulares como integrantes del grupo afectado de una misma relación. Y se verán sujetos por la ejecución de la sentencia». Gómez De Liaño (1986) 576. En el mismo sentido, Cordón (1989), quien señala que «no se resentirían las estructuras procesales civiles por el hecho de que la sentencia de condena desplegase una eficacia ultra partes, siempre que, por respeto al principio de libre disposición de los derechos, se dejase a la parte individual la iniciativa en la ejecución...», agregando luego que la doctrina del Tribunal Constitucional sostiene que puede existir indefensión formal sin que necesariamente se produzca una indefensión de carácter material. El fundamento de la eficacia ultrapartes lo encontramos en el principio de economía procesal y en el evitar las decisiones contradictorias, impidiendo así un derroche de actividad jurisdiccional y asegurando la igualdad de tratamiento de los sujetos dependientes de una única situación sustancial objeto de pronunciamiento jurisdiccional Cordón Moreno (1989) 130. En este mismo sentido Pellegrini (2004), quien siguiendo a Liebman (1939) 6, distingue entre la eficacia y la autoridad de la sentencia y es con base en esa distinción que «Liebman resuelve el problema de la eficacia de la sentencia con relación a terceros: la limitación subjetiva de la cosa juzgada a las partes y sus sucesores (posteriores a la demanda judicial) es una cosa; pero ella no excluye la extensión subjetiva de la eficacia de la sentencia a terceros», y agrega luego que la sentencia se encuentra firme, es inmutable para las partes, pero no así para los terceros, quienes pueden sublevarse contra esta eficacia natural de la sentencia. Pellegrini Grinover (2004) 256.

29 Cfr. De La Oliva (1989) quien afirma que en la doctrina «...anida una confusión lo suficientemente grande como para que se dude del principio res iudicata inter partes, por el que en virtud del intangible principio de audiencia («nadie debe ser condenado sin ser oído y vencido en juicio»), los efectos vinculantes de la sentencia que recaen en un proceso entre A y B no pueden afectar a C, por más que la situación jurídica constitutiva de la res in indicio deducta sea común a A, B y C». De La Oliva (i 989 ) 161. En este mismo sentido, cfr. Bordalí (2004) 308; Gutiérrez de Cabiedes (1998) 432 y ss.; Punzi (2002) 275 y ss.

30 Cfr. Almagro (1983) 86 y Acosta (1982) 137.

31 Esta solución ha sido recogida por el Derecho brasileño en la tutela de intereses supraindividuales. Así, la cosa juzgada producirá efectos erga omnes salvo en el caso en que la demanda sea rechazada por insuficiencia de pruebas, caso en el produce efectos secundum eventum litis. Cfr. en este sentido Pellegrini GRINOver (1992) 13-24. En sentido contrario, GIDI (2004b), quien señala que 
Por lo tanto, se establece la eficacia de la sentencia dependiendo del resultado de la misma, lo que parece poco ortodoxo, puesto que impondría una carga excesiva sobre la contraparte al no ser oponible a terceros la sentencia desestimatoria, porque tendría que defenderse en juicio un número ilimitado de veces, siempre por lo mismo y sin poder oponer nunca la eficacia de la sentencia en los procesos que se inicien ${ }^{32}$.

En el Derecho Comparado, la posibilidad de extender los efectos «secundum eventum litis» ha sido rechazada por la doctrina que promueve la existencia de un «ideological plaintiff», es decir, un representante adecuado que lucha de forma correcta y tenaz por los intereses del grupo $^{33}$. Así, en la mayoría de las legislaciones se propugna el efecto «erga omnes» ${ }^{34}$ de la sentencia pronunciada en un procedimiento colectivo, siempre que se hayan defendido adecuadamente los derechos e intereses de aquellos que no han sido parte en

estos efectos secundum eventum litis se forman precisamente cuando la sentencia es favorable a la pretensión deducida, y no cuando es desfavorable, como suele señalar la doctrina. La sentencia tendrá una extensión de sus efectos de cosa juzgada de acuerdo a esta fórmula cuando la acción colectiva es acogida por el tribunal, de modo tal que dicha sentencia hará cosa juzgada erga omnes o ultra partes para tutelar el bien colectivo, vinculando a la comunidad o al colectivo titular del derecho supraindividual, y vinculando también, positivamente y en su esfera individual, a los titulares de derechos individuales homogéneos que pertenecen a esa comunidad o colectivo. Ese sería el sentido, a juicio de este autor, de la extensión de los efectos de cosa juzgada secundum eventum litis. GIDI (2004b) 273-274.

32 Cfr. Tapia Fernández (2000) 807-808. En este mismo sentido, Garnica (2000), considera que la extensión ultra partes de los efectos del proceso es censurable y a la que se puede reprochar a la vista del principio de audiencia y del 24.1 $\mathrm{CE}$, pero cree que era la opción más razonable porque es la que menos cuestiones suscita y también la más justa desde la perspectiva del demandado. El legislador opta por un sistema cerrado en el que el ejercicio de la acción del grupo cierra el paso a cualquier otra acción posterior, tanto individual como de grupo. Garnica Martín (2000) 857.

33 Cfr. en este sentido, CAppelletti (1976) 192.

34 Sistema adoptado por la legislación chilena del consumidor, Ley $\mathrm{N}^{\circ}$ 19.496, modificada por la Ley $\mathrm{N}^{\circ} 19.955$, que en su artículo 54 dispone que La sentencia ejecutoriada que declare la responsabilidad del o los demandados producirá efecto erga omnes, con excepción de aquellos procesos que no hayan podido acumularse conforme al número 2) del inciso final del artículo 53, y de los casos en que se efectúe la reserva de derechos que admite el mismo artículo. 
el proceso ${ }^{35}$. Pero existe naturalmente el riesgo de que un miembro del grupo, que ni siquiera tiene conocimiento de la existencia de la acción colectiva, sea afectado por la cosa juzgada y tenga su derecho declarado inexistente en juicio ${ }^{36}$.

Por lo mismo, para considerar presentes en el juicio a los miembros ausentes se han previsto tres sistemas: el de la presencia obligatoria; el del opt in y el del opt out. A través de la técnica de la presencia obligatoria, «todos los miembros del grupo serán considerados presentes en juicio, sin la posibilidad de excluirse del grupo y evitar ser afectados por la cosa juzgada producida en la acción colectiva ${ }^{37}$.

Mediante la técnica del opt in, «será considerado presente en juicio (y vinculado por la sentencia colectiva) solamente aquel miembro del grupo que solicite expresamente su inclusión en el proceso colectivo» ${ }^{38}$. Por el contrario, a través de la técnica de $o p t$ out, se presume que los miembros del grupo desean formar parte

35 A juicio de Gidi (2004c) «constituye un error generalizado definir la acción colectiva como aquella que se ejercita sin el consentimiento de los miembros del grupo, puesto que el legislador debe establecer mecanismos de publicidad suficientes que permitan a los miembros del grupo manifestar su voluntad. Para ello es que se han establecido mecanismos de opt in y opt out a los que nos referimos, y sin perjuicio de que la acción nunca pierde su carácter de colectiva». GiDi (2004c) 19 y ss.

36 Gidi (2004d) agregando que en los casos donde el valor de la pretensión individual es reducido, la presunción de que el miembro del grupo perjudicado tiene interés en participar de la acción colectiva es mucho más realista, y que por otro lado, en los casos donde las pretensiones individuales tienen valor muy alto, que justifiquen financieramente la proposición de acciones individuales, muy probablemente el miembro será informado de la existencia de la acción colectiva y podrá ejercer el derecho de autoexclusión o habrá ya propuesto su acción individual. GIDI (2004d) 21.

37 GIDI (2004d) 20. Agrega el autor que: «Resulta muy relevante en los casos donde la pretensión del grupo es de naturaleza indivisible y en los casos de insolvencia del demandado. Sin embargo, ella puede ser extremadamente perjudicial para los miembros del grupo en las situaciones donde las pretensiones colectivas sean divisibles y los miembros del grupo tengan interés en proponer acciones individuales».

38 GIDI (2004d) 20. Considera también que tienen la ventaja de incluir en el grupo solamente aquellos miembros realmente interesados en participar en el litigio colectivo, excluyéndose a aquellos que consideren inadecuada la representación, a los que prefieren tutelar personalmente sus intereses y a los que simplemente no deseen solicitar la tutela jurisdiccional, pero que se corre el riesgo de excluir de los beneficios ofrecidos por la tutela colectiva a un gran número de miembros. 
del litigio y se condiciona su exclusión a una manifestación expresa en ese sentido.

Si el grupo fue efectivamente perjudicado por el demandado, es de su interés que todos los miembros sean beneficiados. Si es el demandado quien tiene la razón, estará interesado en que la sentencia de improcedencia de la acción colectiva vincule el mayor número posible de personas, cerrando definitivamente la controversia ${ }^{39}$.

Siguiendo la línea doctrinal ya explicada en la materia, la legislación chilena, en el artículo 54 de la LPC se ha encargado de regular los efectos de la sentencia definitiva dictada en un proceso de este tipo que «la sentencia ejecutoriada que declare la responsabilidad del o los demandados producirá efectos erga omnes...», lo que implica que nuestro legislador ha optado por extender los efectos de la sentencia a todo el grupo de consumidores afectados, hayan o no intervenido en el proceso ${ }^{40} \mathrm{y}$ sin perjuicio de las oportunidades que la ley le fija para intervenir y efectuar reserva de derechos mediante el sistema del opting out.

\subsubsection{Eficacia «secundum eventum litis»}

La eficacia de la cosa juzgada secundum eventum litis establece que los efectos de la cosa juzgada se extienden a quienes no han sido parte del proceso únicamente si la sentencia acoge la pretensión, es decir, la sentencia tendrá efectos erga omnes si se declara fundada la demanda. Esta teoría es también conocida en el sistema anglosajón como preclusión unilateral o one way preclusion, en que se busca favorecer a la parte demandante.

Por el contrario, si la sentencia declara infundada la pretensión, aquellos que no fueron parte del proceso tendrán el derecho de iniciar

39 Entre los países que adoptan el sistema de opt in o equivalente, están Francia, con la action en représentation conjointe, Japón, con el appointed party system previsto en el art. 30 del Código de Proceso Civil japonés y Suecia. Un análisis comparativo mejor desarrollado se encuentra en GiDi (2004e).

40 Nos parece que la principal motivación para que una sentencia pueda producir efectos erga omnes es la de evitar la repetición constante de juicios posteriores al proceso colectivo, y cuya fundamentación última la constituye la economía procesal. Ya señalaba la Ley en el artículo $51 \mathrm{~N}^{\circ} 2$ que el juez determinará las correspondientes indemnizaciones conforme al mérito del proceso y que no procedería la reserva prevista en el artículo 173 del Código de Procedimiento Civil. 
nuevos procesos sobre la misma controversia ${ }^{41}$. La sentencia por lo tanto vinculará a los miembros de la clase únicamente en caso que se logre un resultado favorable, es decir, de ser desfavorable, no será vinculante.

Como una derivación del postulado anterior, la teoría secundum eventum probationem propone que la cosa juzgada no siempre ponga fin al proceso, sino que se puede reabrir con una posterior demanda si se presenta una situación de insuficiencia de pruebas o de nueva prueba y ello haya impedido un resultado favorable.

Por lo tanto, se establece la eficacia de la sentencia dependiendo del resultado de la misma, lo que, a juicio de parte de la doctrina, no parece muy ortodoxo, ya que impondría una carga excesiva para la contraparte al no ser oponible a terceros la sentencia desestimatoria, porque tendría que defenderse en juicio un número ilimitado de veces, siempre por lo mismo y sin poder oponer nunca la eficacia de la sentencia en los procesos que se inicien.

A lo anterior, la legislación brasileña agrega la posibilidad de extender los efectos «secundum eventum litis» si la pretensión ha sido rechazada por una representación inadecuada del «ideological plaintiff», es decir, un representante adecuado que no lucha de forma correcta y tenaz por los intereses del grupo ${ }^{42}$.

\section{Cosa Juzgada e insuficiencia de pruebas}

La posibilidad de revisar la cosa juzgada ante una situación de insuficiencia probatoria se encuentra recogida por el artículo 33 del Código Modelo de Procesos Colectivos para Iberoamérica y

41 En el entendido que permite el inicio de nuevas demandas colectivas, puesto que siguiendo la normativa del Código Modelo y del Código de Defensa del Consumidor de Brasil, la cosa juzgada colectiva no perjudica los intereses individuales ni las acciones indemnizatorias que luego pudieran interponer los consumidores afectados.

42 Se presume por la ley brasileña que la representación ha sido inadecuada si puede iniciarse un nuevo procedimiento colectivo fundado en nueva prueba. Tal como señala Gidi (2004e) 105, el control de la legitimación en el Derecho Brasileño es mucho más fuerte que en el sistema estadounidense. No se incluye en esta presunción la incorrecta estrategia en la defensa o no se encuentra adecuadamente fundamentada. 
encuentra su origen en los artículos 103 y 104 del Código de Defensa del consumidor del Brasil ${ }^{43}$.

La codificación modelo para Iberoamérica elaborada por el Instituto Iberoamericano de Derecho Procesal, ha optado por regular separadamente la cosa juzgada a propósito de intereses supraindividuales y la cosa juzgada respecto de intereses individuales homogéneos ${ }^{44}$. Para los intereses o derechos difusos o colectivos, el régimen de la cosa juzgada es siempre la eficacia de la sentencia erga omnes, salvo cuando el rechazo de la demanda se deba a una insuficiencia de pruebas, hipótesis en que la demanda colectiva podrá volver a ser entablada en un plazo de dos años contado desde el conocimiento de la prueba nueva sobreviniente y valiéndose de ella.

Con relación a los intereses o derechos individuales homogéneos, la opción de la legislación brasileña, mantenida en el Código, es de la cosa juzgada secundum eventum litis o sea, la cosa juzgada positiva actúa erga omnes, beneficiando a todos los miembros del grupo; pero la cosa juzgada negativa sólo alcanza a lo colectivo, pudiendo cada individuo, perjudicado por la sentencia, oponerse a la cosa juzgada, promoviendo su acción individual, en el ámbito personal.

43 Dispone el artículo 103 que «En las acciones colectivas de que trata este Código, la sentencia hará cosa juzgada: I. Erga omnes, excepto si la pretensión fue juzgada improcedente por insuficiencia de pruebas, hipótesis en la que cualquier legitimado podrá intentar otra acción, con idéntico fundamento, valiéndose de nuevas pruebas, en la hipótesis del artículo 81, inciso I. II. Ultra partes, más limitadamente al grupo, categoría o clase, salvo improcedencia por insuficiencia de pruebas en los términos del inciso anterior, cuando se tratara de la hipótesis prevista en el artículo 81, inciso II. III. Erga omnes, sólo en el caso de procedencia de la acción, para beneficiar a las víctimas y a sus sucesores, en la hipótesis del artículo 81, inciso III. Pr. 1. Los efectos de la cosa juzgada previstos en los incisos I y II no perjudicarán intereses y derechos individuales de los integrantes de la colectividad, grupo, categoría o clase. Pr. 2. En la hipótesis prevista en el inciso III, en caso de la pretensión, los interesados que no hubieran intervenido en el proceso como litisconsortes podrán proponer acción de indemnización a título individual. Pr. 3. Los efectos de la cosa juzgada a que se refieren los artículos 13 y 16 de la Ley número 7.347 de 24 de julio de 1985, no perjudicarán las acciones de indemnización por daños personalmente sufridos, propuestas individualmente o en la forma prevista en este Código pero, si es procedente la pretensión, beneficiarán a las víctimas y a sus sucesores, que podrán proceder a la liquidación y a la ejecución, en los términos de los artículos 96 a 99».

44 Como ya se señaló, la distinción se debe a sus diferencias en cuanto a su naturaleza indivisible. 
Algunos países latinoamericanos como Argentina y Chile también han adoptado el sistema antes descrito. De esta manera, el art. 33 de la Ley General del Ambiente argentina, se establece que «la sentencia hará cosa juzgada y tendrá efecto erga omnes, a excepción de que la acción sea rechazada, aunque sea parcialmente, por cuestiones probatorias». En el caso de Chile, nuestra ley de protección del consumidor en su artículo 54 expresa que «la sentencia ejecutoriada que declare la responsabilidad del o los demandados producirá efectos erga omnes», lo que implica que se ha optado por extender los efectos de la sentencia a todo el grupo de consumidores afectados, hayan o no intervenido en el proceso y sin perjuicio de las oportunidades en que la ley permite hacer reserva de derechos ${ }^{45}$.

El artículo 54 inciso final, se refiere a la posibilidad de que se niegue lugar a la demanda y dispone que en ese caso «cualquier legitimado activo podrá interponer, dentro del plazo de prescripción de la acción, ante el mismo tribunal y valiéndose de nuevas circunstancias una nueva acción, entendiéndose suspendida la prescripción a su favor por todo el plazo que duró el juicio colectivo. El tribunal declarará encontrarse frente a estas nuevas circunstancias junto con la declaración de admisibilidad de la acción dispuesta en el artículo 52». La disposición debe concordarse con lo dispuesto por el artículo 52 inciso $7^{\circ}$ en que también el legislador ha previsto la posibilidad de renovar la acción colectiva fundada en nuevos antecedentes, si ésta es declarada inadmisible.

Esta norma parece encontrar su antecedente inmediato en el Derecho brasileño, en el que la única posibilidad de iniciar un nuevo proceso colectivo se produce si la sentencia que niega lugar a la demanda se funda en la insuficiencia de pruebas, derivada de la mala instrucción del proceso, pudiendo cualquier legitimado proponer la misma acción presentando en el nuevo juicio nuevo material probatorio, debiendo convencer al magistrado de que la prueba es efectivamente nueva ${ }^{46}$.

\footnotetext{
45 Optando por lo tanto nuestro legislador por la técnica ya descrita del opting out.

46 Cfr. Gidi (2004b) 280 y ss. Señala el autor que: «Si la 'nueva prueba' se limita a reafirmar lo que ya se sabe y no añada nada a la convicción del magistrado, no debe ser considerada como 'nueva prueba'. El criterio que debe implementar el aplicador del derecho debe ser sustancial y no meramente formal. La nueva prueba debe ser sustancialmente innovadora y no apenas formalmente nueva».
} 
Nótese también que para la etapa de admisibilidad la ley dispone la necesidad de «nuevos antecedentes», mientras que para el caso de la sentencia definitiva, exige la ocurrencia de "nuevas circunstancias» ${ }^{47}$.

El criterio adoptado por nuestro legislador no parece seguir la orientación de las legislaciones comparadas ya reseñadas, en que sí se menciona específicamente la necesidad de contar con nuevo material probatorio para proceder a la revisión de la cosa juzgada colectiva. Ello podría plantear eventuales conflictos al momento de determinar el alcance de la expresión «nuevas circunstancias» o la de «nuevos antecedentes», ya que no existen pautas que nos permitan calificar el hecho de encontrarnos efectivamente ante estas nuevas circunstancias.

Creemos en todo caso que el legislador debió haber optado por un criterio concreto en torno a la exigencia de material probatorio específico. Por lo tanto, podemos concluir que, a pesar de la redacción imprecisa de la normativa chilena, nos encontramos frente a un sistema que gira alrededor del elemento de la prueba como causa para poder determinar si los efectos de la cosa juzgada cierran las puertas o no a los demás miembros que forman parte de la acción colectiva para iniciar un nuevo proceso.

Para proceder a la revisión de la cosa juzgada ante una situación de insuficiencia probatoria y ante la casi inexistente jurisprudencia que pueda orientar en este sentido, ha sido la doctrina la encargada de fijar algunas pautas que orientan las posibilidades de efectuar esta solicitud y su procedimiento. Siguiendo a $\mathrm{Gidi}^{48}$, podemos formular las siguientes precisiones:

Como primera observación, podemos señalar que cualquier legitimado puede volver a intentar la acción colectiva para proteger el mismo derecho transindividual en el caso de que presente nuevas pruebas, ya que el hecho de que el representante no haya podido presentar todas las pruebas por su negligencia o por motivos ajenos a su voluntad significa que representó inadecuadamente los intereses del grupo ante el tribunal. Así, la legislación brasileña presume

47 No resulta comprensible el cambio en la terminología y tampoco hay antecedentes en la historia de la ley que justifiquen la redacción en uno y otro caso. Entendemos que ambas se refieren a la necesidad de justificar la nueva demanda en material probatorio.

48 Cfr. Gidi (2004b) 280 y ss. 
la inadecuación de la representación en la acción colectiva previa si son presentadas nuevas pruebas en la segunda acción colectiva, encontrándonos ante una situación de insuficiencia probatoria ${ }^{49}$.

Segundo, la sentencia que rechaza la acción colectiva es una sentencia de fondo con eficacia de cosa juzgada. No es un pronunciamiento de non liquet porque decide la controversia negando lugar a la demanda por falta de pruebas.

Tercero, de acuerdo con la mayoría de los juristas brasileños, para que esta excepción sea aplicable y para que la sentencia colectiva no produzca cosa juzgada, es imperativo que el juez expresamente reconozca en su razonamiento que la sentencia estuvo basada en una falta de pruebas ${ }^{50}$. En consecuencia, si en cualquier tiempo después de la sentencia se descubre que nuevas pruebas podrían cambiar el resultado del procedimiento, la acción colectiva que protege al mismo derecho del grupo podrá volver a ser propuesta.

Cuarto, el demandante en el segundo juicio debe ofrecer la producción de la nueva prueba en su demanda, y este nuevo material debe ser suficiente por sí solo de revertir el resultado del proceso anterior en que se rechace la pretensión ${ }^{51}$. Por ello, un material probatorio que se limita a reafirmar lo que ya se sabe y no añada nada a la convicción del magistrado, no debe ser considerado como «nueva prueba», porque el criterio que debe implementarse debe ser sustancial y no meramente formal, es decir, debe ajustarse «a la realidad de los hechos» ${ }^{52}$ y que permitiera justificar una solución diferente para el conflicto ya resuelto.

En lo que respecta a la naturaleza de los medios probatorios, creemos que no necesariamente debe tratarse de prueba documental sino de cualquier medio que no se haya producido en el primer juicio y que cumpla con las condiciones ya reseñadas.

Coincide la doctrina en que la simple presentación de la nueva prueba es suficiente e incluso puede llegar a disposición de la parte

49 Artículos 103 y 104 del Código de Defensa del Consumidor de Brasil.

50 Si así no lo hiciera no será posible, en opinión de GIDI (2004b) 281, volver a iniciar una acción colectiva, pudiendo solamente reabrirse.

51 Lo que en palabras de la doctrina se ha denominado "cosa juzgada secundum eventum probationis», y que revela el objetivo de anteponer el valor de la justicia al valor de la seguridad jurídica. Vid. en este sentido, BArbosa (1979) 122.

52 GIDI (2004b) 282. 
años después de la primera sentencia colectiva. De ahí que algunas legislaciones comparadas han optado por establecer límites temporales para el inicio del nuevo procedimiento ${ }^{53}$.

\section{UNA POSIBLE SOLUCIÓN: LAS FACULTADES DEL JUEZ}

Luego de haber realizado un análisis de la teoría secundum eventum probationem y haber concluido que resulta un sistema que sitúa al demandado en una posición de incertidumbre jurídica al abrir las puertas a un nuevo proceso con el conocimiento de nuevas pruebas, una interrogante que automáticamente surge es qué sucede entonces con aquel afectado que se ha visto perjudicado por una mala estrategia procesal al presentarse material probatorio insuficiente o al no haberse presentado las nuevas pruebas que el afectado sabe pueden cambiar el resultado del proceso.

El Código Modelo de Procesos Civiles para Iberoamérica acogió expresamente la solución de entregar iniciativa probatoria al órgano jurisdiccional. Tal como señala en su Exposición de Motivos, «el aumento de las facultades del Tribunal se proyecta, dentro del nuevo proceso por audiencia, con un Juez director del proceso, el cual conoce después de su iniciación para actuar en la audiencia como protagonista, junto a las partes».

Ciertamente, al enumerar las facultades del Tribunal, el artículo $33.4^{\circ}$ establece la de «ordenar las diligencias necesarias para esclarecer la verdad de los hechos controvertidos, respetando el derecho de defensa de las partes». Por su parte, complementando este precepto, el artículo 34.2 impone al Tribunal el empleo de las facultades y poderes que le concede el Código para la dirección del proceso y la averiguación de la verdad de los hechos alegados por las partes.

En lo que respecta al Código Modelo de procesos colectivos, añade todavía algunas disposiciones más que nos interesan para terminar de delimitar la posición del Juez en cuanto a su actividad probatoria en esta clase de procedimientos. Se trata de varias disposiciones dirigidas a la regulación de la carga probatoria de

53 Como ya se señaló a propósito del Código Iberoamericano, que fija un plazo máximo de 2 años para iniciar un nuevo procedimiento. 
una manera muy flexible. En primer lugar, el apartado cuarto del parágrafo $5^{\circ}$ del artículo 11 establece la exigencia de que el Juez, en la misma audiencia previa, «esclarecerá a las partes en cuanto a la distribución de la carga de la prueba».

Luego, el artículo 12.1 del Código Modelo determina que la carga de la prueba incumbe a la parte que posea conocimientos técnicos o informaciones específicas sobre los hechos, o mayor facilidad para su demostración. Se dispone que, si por razones de orden económico o técnico, la regla inicial no puede ser cumplida, el juez impartirá las órdenes necesarias para suplir la deficiencia y obtener los elementos probatorios indispensables para proferir un fallo sobre el fondo.

Para ello se permite requerir pericias a entidades públicas, condenando al demandado vencido al pago de los correspondientes emolumentos. Aun cuando por esta vía no sea posible aportar la prueba que el juez estime necesaria, podrá ordenar su práctica con cargo al Fondo de los Derechos Difusos e Individuales Homogéneos, al que se refiere el artículo 8 del Código Modelo.

Una última idea importante que conviene destacar de la regulación del artículo 12 se refiere a la provisionalidad de la decisión del Juez respecto a la carga de la prueba, pues las modificaciones de hecho o de derecho relevantes para el juzgamiento de la causa, podrán justificar en ocasiones una revisión de la distribución inicialmente prevista de la carga de la prueba, concediendo un plazo razonable para su producción y respetando la posibilidad de contradicción de la contraparte.

\section{Conclusiones}

a) El sistema de Derecho Procesal debe responder al desarrollo y evolución de nuestra sociedad y sus exigencias; la concepción clásica del proceso debe adaptarse a las nuevas necesidades sociales.

b) La aparición de intereses propios de una colectividad social ha generado la necesidad de revisar la regulación clásica de algunas estructuras procesales, cuyo diseño inicial respondió a la tutela de intereses individuales. 
c) La cosa juzgada es una garantía inherente a la tutela jurisdiccional efectiva y en los procesos colectivos presupone la modificación de su eficacia interpartes por un concepto ultra parte o erga omnes.

d) La teoría secundum eventum probationem propone que la cosa juzgada no siempre ponga fin al proceso; se puede reabrir con una posterior demanda si se presenta una situación de insuficiencia de pruebas o nueva prueba. Consideramos que si bien permite iniciar un nuevo proceso a quienes no tuvieron acceso a suficientes pruebas, se afecta el derecho a la seguridad jurídica de los demandados.

e) En atención a la situación de incertidumbre que se genera a la parte demandada, el otorgamiento de facultades al órgano jurisdiccional podría ser una posible solución para suplir los efectos de rechazar la teoría secundum eventum probationis.

\section{BibliografíA}

\section{a) Doctrina:}

Acosta Estevez, José (1982): Tutela procesal de los consumidores, (Barcelona, Bosch).

AguirReZAbAl GrünsteIn, Maite (2006): «Algunas precisiones en torno a los intereses supraindividuales (colectivos y difusos)», Revista chilena de derecho, 33.

AguirreZabal Grünstein, Maite (2011): «Los principios procesales que informan los procedimientos colectivos", Principios Procesales, ed. por Jorge Peyrano (Buenos Aires, Rubinzal-Culzoni).

Aguirrezabal Grünstein, Maite (2006): «El procedimiento para la defensa de intereses colectivos y difusos de consumidores y usuarios en la Ley 19.946», Cuadernos de Extensión Jurídica, (Santiago, Universidad de los Andes).

Almagro Nosete, José (1983): «La protección procesal de los intereses difusos en España", Justicia 83.

Barbosa Moreira, José (1992): «La iniciativa en la defensa judicial de los intereses difusos y colectivos (un aspecto de la experiencia brasileña)», Revista Uruguaya de Derecho Procesal 3.

Barbosa Moreira, José (1979): "A açao popular do Direito brasileiro como intrumento de tutela jurisdiccional dos chamados «intereses difusos»", Studi in onore de Enrico Tullio Liebman (Milano, Giuffré).

Bonet Navarro, Angel (1989): «Protección eficaz y acceso a la justicia de los consumidores», Estudios sobre Consumo 16. 
Bordalí Salamanca, Andrés (2003): Tutela jurisdiccional del medio ambiente, (Santiago, Editorial Fallos del Mes).

Cappelleti, Mauro; Garth, Bryant (1978): El acceso a la justicia. La tendencia en el movimiento mundial para hacer efectivos los derechos (México, Fondo de Cultura Económica).

CAPPELletti, Mauro (1976): «Appunti sulla tutela giurisdizionale di interessi collettivi o diffusi», AA.VV.: Le azioni a tutela di interessi colletivi. Atti del convegno di studio, Pavia, 11-12 giugno, Cedam, Padova.

Cordón Moreno, Faustino (1989): «El acceso a la justicia civil de los derechos de los consumidores", Estudios sobre Consumo n 16.

De La Oliva, Andrés (1989): «Sobre la protección jurisdiccional de los consumidores y usuarios», Estudios sobre Consumo, núm. 16.

Ferrer Mac-Gregor, Eduardo (2004): Juicio de amparo e interés colectivo: la tutela de los derechos difusos y colectivos (México, Porrúa).

Garnica Martín, Juan (2000): «Artículo 221. Sentencias dictadas en procesos promovidos por asociaciones de consumidores y usuarios", Comentarios a la nueva Ley de Enjuiciamiento Civil (coord. Fernández-Ballesteros, M.; Rifá Soler, J.; y Valls Gombau, J.) (Barcelona, Iurgium).

GIDI, Antonio (2004a): «Cosa juzgada en acciones colectivas», en: La tutela de los derechos difusos, colectivos e individuales homogéneos. Hacia un Código Modelo para Iberoamérica, (coord. Gidi, A.; y FerRer Mac Gregor, E.) (México, Porrúa).

Gidi, Antonio (2004b): «Derechos difusos, colectivos e individuales homogéneos», en: La tutela de los derechos difusos, colectivos e individuales homogéneos. Hacia un Código Modelo para Iberoamérica, (coord. Gidi, A.; y Ferrer Mac Gregor, E.) (México, Porrúa).

GIDI, Antonio (2004c): «El concepto de acción colectiva», en: La tutela de los derechos difusos, colectivos e individuales homogéneos. Hacia un Código Modelo para Iberoamérica, (coord. GIDI, A.; y FerRer Mac Gregor, E.) (México, Porrúa).

GIDI, Antonio (2004d): «Las acciones colectivas en los Estados Unidos», Procesos Colectivos. La tutela de los derechos difusos, colectivos $e$ individuales en una perspectiva comparada, (coord. GIDI, A.; y Ferrer MaC Gregor, E.).

Gidi, Antonio (2004e): "Class actions in Brazil. A model for civil law countries", American Journal of Comparative Law, vol. 51.

Gómez De Liaño GonZÁlez, Fernando (1986): «La legitimación colectiva y el artículo 7 de la Ley Orgánica del Poder Judicial», Justicia 86, n 3. Gutiérrez de Cabiedes, Pablo (1998): La tutela jurisdiccional de los intereses supraindividuales: colectivos y difusos (Pamplona, Aranzadi).

Liebman, Enrico (1939): Eficacia y autoridad de la sentencia (Traducción de Santiago Sentís Melendo) (Buenos Aires, Ediar Editores). 
Lozano-Higuero y Pinto, Manuel (1983): La Protección de los intereses difusos: intereses de los consumidores, ecológicos, urbanísticos, el acceso a la R.T.V (Madrid, García Blanco).

Rodríguez LóPEz, Ricardo (2010): «Tutela jurisdiccional de los derechos de los consumidores y usuarios», Actualidad Civil 56.

Pellegrini Grinover, Ada (1984): "A problemática dos interesses difusos", A tutela dos interesses difusos (Sao Paulo, Saraiva).

Pellegrini Grinover, Ada (1998): «Acciones colectivas para la defensa del ambiente y de los consumidores, en La ley brasileña núm. 7347 de 24 de julio de 1985)», Revista de Derecho Procesal n 3.

Pellegrini Grinover, Ada (1994): «I processi collettivi del consumatore nella prassi brasiliana", Rivista di Diritto Processuale.

Pellegrini Grinover, Ada (2004): «Eficacia y autoridad de la sentencia: el Código Modelo para Iberoamérica y la teoría de Liebman», $L a$ tutela de los derechos difusos, colectivos e individuales homogéneos. Hacia un Código Modelo para Iberoamérica, (coord. GidI, A.; y Ferrer Mac Gregor, E.), Porrúa, México.

Pellegrini Grinover, Ada (1992): «El nuevo proceso brasileño del consumidor", Estudios sobre Consumo, núm. 25.

Sánchez Morón, Miguel (1980): La participación del ciudadano en la administración pública (Madrid, Centro de estudios políticos y constitucionales).

Tapia Fernández, Isabel (2000): «Artículo 221. Sentencias dictadas en procesos promovidos por asociaciones de consumidores y usuarios», Comentarios a la Ley de Enjuiciamiento Civil (coord. Cordón Moreno, F.; et. al.), Aranzadi, Navarra.

VIgoRITI, Vincenzo (1979): Interessi colletivi e processo. La legitimazione ad gire, (Milán Giuffrè Editore).

VASAK, Karel (1982): «Human rights: as a legal reality», The international dimensions of human rights (Connecticut, Greenwood Press).

Watanabe, Kasuo (2004): «Acciones colectivas: cuidados necesarios para la correcta fijación del objeto litigioso del proceso", La tutela de los derechos difusos, colectivos e individuales homogéneos. Hacia un Código Modelo para Iberoamérica, (Coord. Gidi, A.; Y Ferrer Mac Gregor, E.), Porrúa, México.

\section{b) Normativa:}

Ley N ${ }^{\circ} 19.496$ (3/1997) que establece Normas sobre Protección de los Derechos de los Consumidores. 


\title{
LA PROTECCIÓN DEL CONSUMIDOR DE CRÉDITO INMOBILIARIO EN EL CONTEXTO EUROPEO
}

\author{
Consumer Protection of CRedit \\ AGREEMENTS RELATING IMMOVABLE \\ PROPERTY IN THE EUROPEAN CONTEXT
}

Adela Serra Rodríguez ${ }^{1}$

RESUMEN. El presente trabajo analiza algunos de los aspectos más relevantes de la Directiva 2014/17/UE en relación con la tutela del consumidor de crédito inmobiliario, contrastándolo con la normativa vigente en España y la proyectada ley que la incorpora.

PAlABRAS Clave: protección del consumidor, crédito inmobiliario, deudor, fiador, garante, información, transparencia.

AвsтRACт. The paper analyzes some of the most relevant aspects of the Directive 2014/17 on credit agreements for consumers relating to residential immovable property, comparing it with the current Spanish regulations and the proposed transposition rule.

1 Adela Serra Rodríguez. Catedrática de Derecho civil. Universidad de Valencia (España). Email: Adela.Serra@uv.es 
KeYwORDs: consumer protection, real estate credit, debtor, guarantor, duty of information.

Sumario. 1. Planteamiento. 2. Finalidad de la Directiva de contratos de crédito inmobiliario: armonización máxima vs. armonización mínima. 3. Ámbito subjetivo y objetivo de aplicación de la Directiva y del Proyecto de ley español. 4. Medidas de protección del deudor: el reforzamiento del deber de transparencia material. 5. Conclusiones. 6. Bibliografía.

\section{i. Planteamiento}

Este trabajo pretende analizar algunos de los aspectos más relevantes de tutela del consumidor previstas en la Directiva 2014/17/CE, del Parlamento y del Consejo, de 4 de febrero, sobre los contratos de crédito celebrados con los consumidores para bienes inmuebles de uso residencial ${ }^{2}$, apuntando, al mismo tiempo, algunas novedades o medidas adicionales que ha plasmado el regulador español. Para ello nos detendremos en la finalidad perseguida por la norma comunitaria y su ámbito de aplicación, delimitando los sujetos merecedores de protección y los contratos que comprende.

Esta Directiva debería haber sido transpuesta por el legislador español antes del 21 de marzo de 2016, retraso que ha provocado que la Comisión, después de abrir un expediente sancionador, haya llevado a España (junto con, entre otros, Chipre, Croacia, Grecia y Portugal) ante el TJUE según lo dispuesto en el art. 258 TFUE. ${ }^{3}$

El 17 de noviembre de 2017 se publicó en el Boletín de las Cortes Generales el Proyecto de Ley reguladora de los contratos de crédito inmobiliario ${ }^{4}$, que fue precedido de dos anteproyectos del Ministerio de Economía y competitividad, uno hecho público en marzo de 2017 que fue precedido, a su vez, de otro de julio de 2016. Actualmente, la tramitación legislativa del Proyecto de ley está bastante avanzada,

DOUE 28.2.2015, L 60/34.

3 Disponible en: https://ec.europa.eu/info/publications/mortgage-credit-directive-transposition-status_en. Este retraso se ha justificado, entre otras razones, en la situación política española desde finales del año 2017, la prolongación de la situación del Gobierno en funciones que impidió que se llevara a cabo la labor legislativa exigida.

4 BOCG, Congreso de los Diputados, Serie A, 17.11.2017, núm. 12-1. 
al haberse aprobado el pasado diciembre en el Congreso el Informe de la ponencia, el Dictamen de la Comisión de Economía y Empresa sobre el proyecto de ley con la introducción de algunas enmiendas, y definitivamente por el Pleno el día 20 de diciembre, encontrándose actualmente en tramitación en el Senado 5 .

En España esta situación contrasta con la existencia de dos leyes autonómicas que, con base en las competencias sobre protección de los consumidores asumidas estatutariamente, la han incorporado, siquiera parcialmente. Se trata de la Ley 20/2014, de 29 de noviembre, de modificación de la Ley 22/2010, del Código de consumo de Cataluña, para la mejora de la protección de las personas consumidoras en materia de créditos y préstamos hipotecarios, vulnerabilidad económica y relaciones de consumo - algunos de cuyos preceptos han sido recurridos ante el Tribunal Constitucional y declarados inconstitucionales por invadir competencias estatales-, y la Ley 3/2016, de 9 de junio, de la Comunidad Autónoma de Andalucía, para la protección de los derechos de las personas consumidoras y usuarias en la contratación de préstamos y créditos hipotecarios sobre la vivienda.

\section{Finalidad de la Directiva de contratos DE CRÉDITO INMOBILIARIO: ARMONIZACIÓN MÁXIMA VS. ARMONIZACIÓN MÍNIMA}

Tras la crisis económica y financiera mundial que estalló en el año 2008 y que en España se dejó con especial virulencia para un importante sector de la población, el legislador comunitario ha variado ligeramente su enfoque, en tanto que su prioridad ya no es tanto el fomento de la libre prestación de servicios en el ámbito del crédito hipotecario, incentivando la competencia y buscando mayor disponibilidad de productos y, con ello, la ampliación del número de

\footnotetext{
El Informe de la Ponencia está publicado en el BOCG 11.12.2018, núm. 12-4; el Dictamen emitido por la Comisión de Economía y Empresa sobre el Proyecto de ley, así como los escritos de mantenimiento de enmiendas para su defensa ante el Pleno en BOCG 19.12.2018, núm. 12-5; y la aprobación por el Pleno del Congreso en el BOCG 8.1.2019, núm. 12-6.
} 
prestatarios $^{6}$, sino el restablecimiento de la confianza de los consumidores en el sector financiero. A ello, respondía la Comunicación de la Comisión de 4 de marzo de 2009 titulada «Gestionar la recuperación europea ${ }^{7}$, en la que se proponen una serie de medidas en relación con los contratos de crédito para bienes inmuebles de uso residencial —entre ellas un marco creíble de intermediación crediticia-, con vistas a implantar, de cara al futuro, mercados responsables y fiables y «restablecer la confianza de los consumidores».

La Comisión reafirmó su compromiso con un mercado interior eficiente y competitivo en su Comunicación al Parlamento Europeo, al Consejo, al Comité Económico y Social Europeo y al Comité de las Regiones del 13 de abril de 2011, titulada «Acta del Mercado Único: Las doce prioridades para estimular el crecimiento y reforzar la confianza. «Juntos por un nuevo crecimiento»» ${ }^{8}$. En esta Comunicación el Consejo ya advierte de la estrategia adoptada desde la Unión Europea —Europa 2020 - en que se fijan ambiciosos objetivos para una nueva trayectoria de «crecimiento inteligente, sostenible e inclusivo ${ }^{9}$. Entre las doce prioridades, y respecto de lo que aquí interesa, se incluye la relativa a "los consumidores como actores del mercado único», destacándose de que proseguirá el trabajo que se está realizando sobre la protección de los consumidores de productos financieros minoristas, "prestándose especial atención a la transparencia de los gastos bancarios y a la mayor protección de quienes contraen un préstamo en el mercado de los créditos hipotecarios».

6 En tal sentido, se manifestaba el Libro verde de la Comisión sobre «El crédito hipotecario en la UE [Bruselas, 19.7.2005 (COM (2005) 327 final]. En la misma línea, el Libro Blanco de la Comisión sobre la integración de los mercados de crédito hipotecario de la Unión de 18 de diciembre de 2007, anunciaba la intención de examinar distintas opciones de actuación orientadas a mejorar la accesibilidad, comparabilidad y exhaustividad de la información crediticias.

7 Bruselas, 4.3.2009 [COM (2009) 114 final]. En la Comunicación se pone en evidencia la preocupación de la Comisión, tras la estabilización de los mercados financieros, por la contracción del crédito, teniendo que continuar las reformas del sector financiero, para conseguir que los préstamos lleguen de nuevo a las empresas y a los hogares.

8 Bruselas, 13.4.2011 [COM (2011) 206 final].

9 COM (2010) 2020. Los empleos de tales términos parecen sugerir que hasta la crisis de 2007/2008 el crecimiento no podía calificarse así. 
Con esta finalidad y teniendo en cuenta los problemas que han sufrido los mercados hipotecarios de los Estados miembros de la Unión Europea en relación con la irresponsabilidad en la concesión y contratación de préstamos, se propone la Comisión establecer un marco jurídico adecuadamente armonizado en una serie de ámbitos, que coadyuve a garantizar que los consumidores que busquen celebrar contratos de crédito para bienes inmuebles puedan hacerlo con la confianza de que las entidades con las que se relacionen se comporten de manera profesional y responsable.

La Directiva 2014/17/CE tiene por finalidad establecer un régimen más transparente, eficiente y competitivo en la Unión Europea en el otorgamiento de crédito hipotecario a consumidores, elevando el nivel de protección hasta ahora existente que, como hemos visto, en el caso español ha resultado insuficiente. Junto a ello, se presenta como un instrumento para contribuir a la estabilidad financiera, con vistas a implantar un mercado crediticio europeo fiable y responsable, restableciendo la confianza de los consumidores tras la crisis financiera de los pasados años. Se pretende, ante todo, un mercado europeo más transparente y tuitivo del consumidor en la concesión de créditos hipotecarios, garantizando, al mismo tiempo, el funcionamiento responsable del mercado europeo del crédito hipotecario ${ }^{10}$. A este objetivo se refiere también el Preámbulo del Proyecto de ley español, que insiste en la contribución de esta norma en la implantación de un mercado único europeo más transparente, competitivo y homogéneo.

Con tal propósito la Directiva distingue normas que son objeto de la máxima armonización, como sucede con el suministro de información precontractual en el formato de ficha europea de información normalizada (en adelante, FEIN) y el cálculo de la tasa anual equivalente (en adelante, TAE). Respecto de estas disposiciones la Directiva es de máximos, no pudiendo los Estados miembros establecer otras disposiciones, aunque fueran más estrictas. Sin embargo, respecto de otros aspectos o ámbitos — que no son de máxima armonización - se permite que los Estados miembros mantengan o adopten disposiciones más rigurosas, siempre que sean compatibles con las

10 Una exhaustiva exposición de los precedentes de esta Directiva puede verse en Arroyo Amayuelas (2017) 5-12; Lauroba Lacasa (2012) 117-132. 
obligaciones que el Derecho de la Unión impone a los Estados (art. 2 y Cdo. 7), como, por ejemplo, en relación con los requisitos en materia de conocimientos y competencia del personal, que persiguen que consigan un alto nivel de profesionalidad del que se beneficie el consumidor $^{11}$. Por eso, frente al pretendido objetivo de conseguir un mejor funcionamiento del mercado interno europeo de créditos hipotecarios, lo cierto es que, al ser en su mayoría, las normas de la Directiva de armonización mínima, subsistirán las diferencias entre las regulaciones de los Estados miembros ${ }^{12}$.

Otros aspectos, como, por ejemplo, la validez de los contratos de crédito, el derecho de propiedad, el registro de la propiedad, la información contractual o las cuestiones poscontractuales quedan fuera del ámbito cubierto por la Directiva, por lo que los Estados miembros tienen libertad de mantener o adoptar disposiciones nacionales en el ámbito del Derecho contractual. Lo mismo ocurre con las reglas sobre elección de tasador o empresa de tasación o notarios, en que se permite a los Estados miembros establecer que las partes puedan elegirlos de común acuerdo.

Como ha sido puesto de manifiesto por la doctrina ${ }^{13}$, a pesar del objetivo declarado, lo que caracteriza a esta Directiva es el de prever una serie de normas de conducta más bien dirigidas a las entidades financieras concedentes del crédito que a la estricta protección de los consumidores. Según el propio Preámbulo de la Directiva (Considerando 83) «los Estados miembros pueden decidir que ciertos aspectos contemplados en la presente Directiva, como la evaluación de la solvencia del consumidor, se transpongan al Derecho

11 En efecto, se trata de una Directiva de mínimos en su mayoría, lo que, unido al carácter programático de algunas normas, su deliberada inconcreción y las numerosas exclusiones y posibilidades de opt-out facilitó su aprobación por el Consejo, como expone Arroyo (2017) 12.

12 Así lo advierten Díaz Alabart y Álvarez Moreno (2015) 22 y Díaz AlaBART (2OI5) 287-288. Ahora bien, como apunta la autora, la previsión de una cláusula de revisión (art. 44), tres años después de que finalice el plazo de incorporación, que verificará la eficacia y adecuación de las disposiciones de la Directiva en relación con los consumidores y el mercado interior, así como la presentación en dicha fecha del Informe previsto en el art. 45 por la Comisión, pueden conducir a que en dicho momento se replantee el nivel de armonización y se opte por una nueva Directiva que acerque más las legislaciones nacionales.

13 Albiez Dorhmann (2015) 1. En el mismo sentido, Casado Navarro (2015) 15. 
nacional, mediante normativa prudencial, mientras que otros, como la obligación de los prestatarios de actuar de manera responsable, se transpongan por medio del Derecho civil o del Derecho penal» ${ }^{14}$. En efecto, la Directiva 2014/17/UE hace referencia a normas y requisitos prudenciales [cfr. Considerandos 8 y 83, art. 1], con lo que parece invocar a que determinados aspectos se incorporen a través normas de conducta dirigidas a entidades financieras, de carácter preventivo y con marcado acento disciplinario (y, por tanto, de naturaleza administrativa), cuyo cumplimiento sería supervisado por un organismo competente, con base en una norma previa. Lo novedoso de la Directiva 2014/17/UE es que permite a los Estados miembros introducir estas normas prudenciales de supervisión en aras a controlar la conducta de las entidades concedentes de crédito respecto de los consumidores prestatarios ${ }^{15}$.

\section{3. Ámbito SUbJETIVo y OBJETIVO DE APLICACIÓN De la Directiva y Del Proyecto de ley español}

La Directiva 2014/17/CE se aplica, según su art. 3, a los contratos de crédito al consumo garantizados «por una hipoteca o por otra garantía comparable comúnmente utilizada en un Estado miembro sobre bienes inmuebles de uso residencial, o garantizados por un derecho relativo a un bien inmueble de uso residencial». También se aplica a los «contratos de crédito cuya finalidad sea adquirir o conservar derechos de propiedad sobre fincas o edificios construidos o por construir».

Luego, la norma trata de favorecer y proteger, al que obtiene crédito inmobiliario, no necesariamente hipotecario, aunque en la

14 Para Zunzunegui (2017) es esta frase la clave para interpretar los preceptos de la Directiva, en lo que respecta a la evaluación de la solvencia, como trataremos más adelante, en tanto que la considera una «norma híbrida, prudencial y de conducta». Zunzunegui Pastor (2017).

15 Albiez (2015) 5-ss. Como expone este autor las normas prudenciales no tienen normalmente como objetivo la protección del consumidor, ya que en su mayoría están dirigidas a los bancos y a las entidades financieras que operan en el mercado crediticio. En ellas suele preverse un organismo de supervisión que vigila que las entidades cumplan con dicha regulación, con lo que es inevitable que directa o indirectamente se beneficie a los clientes. 
mayoría de los supuestos sea esta la figura a la que se acuda para garantizar la satisfacción de aquel ${ }^{16}$. Es, además, coherente con la Directiva 2008/48/UE, de 23 de abril, relativa a los contratos de crédito al consumo y por la que se deroga la Directiva 87/102/CEE, de 26 de diciembre, en materia de crédito al consumo ${ }^{17}$, que excluía de su ámbito de aplicación «a) los contratos de crédito garantizado por una hipoteca o por otra garantía comparable comúnmente utilizada en un Estado miembro sobre bienes de uso residencial, o garantizados por un derecho relativo a un bien inmueble de uso residencial», b) «los contratos de crédito cuya finalidad sea adquirir o conservar derechos de propiedad sobre fincas o edificios construidos o por construir» $(\text { art. } 2)^{18}$.

Así, la Directiva se aplica a los contratos de crédito garantizados con hipoteca o con otra garantía o derecho real sobre bien inmueble de uso residencial, con independencia de su finalidad, si bien en tanto que se aplica a contratos con consumidores quedaría fuera el préstamo hipotecario constituido sobre un inmueble de uso residencial para financiar la actividad empresarial o profesional del prestatario, a diferencia de lo que ocurre en el Proyecto de Ley de contratos de crédito inmobiliario español. En cambio, cuando tal garantía no existe sí es relevante la finalidad del crédito, que ha de ser la de «adquirir o conservar derechos de propiedad sobre fincas o edificios construidos o por construir». Aunque no lo diga el art. 3.1.b), una interpretación sistemática de la norma lleva a concluir que también en este supuesto los inmuebles han de tener una finalidad de uso residencial ${ }^{19}$.

No define expresamente, sin embargo, qué ha de entenderse por «bien inmueble de carácter residencial», por lo que surgen dudas si

16 La Directiva 2014/17/UE deja fuera, sin embargo, de su ámbito de aplicación algunos contratos (art. 3.2), mientras que otros pueden ser excluidos a elección de los Estados miembros -opt out-(art. 3.3).

17 DOUE 22.5.2008, L 133/66.

18 La conveniencia de la coexistencia de dos Directivas (la 2008/48/UE, limitada al crédito al consumo; y la 2014/17/UE, reservada al crédito inmobiliario) ha sido cuestionada por Arroyo (2017) 13, teniendo en cuenta que «las técnicas de comercialización de ambos contratos son las mismas»y, por tanto, «las medidas preventivas y de protección adoptadas no son muy distintas»

19 Por una interpretación amplia se inclinan Arroyo (2017) 17-18 y ANDERson (2016) 52. 
cabe identificarlo con la expresión «vivienda habitual» que utiliza el legislador español, al introducir una serie de especialidades en la ejecución hipotecaria (cfr. arts. 671 y 693.III Ley de Enjuiciamiento Civil; art. 114.III Ley Hipotecaria). De su Considerando 13 y art. 3.3 b) puede concluirse que inmueble de uso residencial no solo es el destinado a vivienda habitual o permanente, ni se identifica con residencia principal, sino también el que constituye la segunda residencia ${ }^{20}$.

En cuanto a los elementos subjetivos, la Directiva se aplica con independencia de que el prestamista o intermediario del crédito sea persona física o jurídica, si bien no impide que los Estados miembros limiten esta condición únicamente a las personas jurídicas o a determinadas formas de personas jurídicas. En su definición de prestamista se remite a la contenida en el art. 3 Directiva 2008/48/ CE, de 23 de abril, relativa a los contratos de crédito al consumo, esto es, es la persona física o jurídica que concede o se compromete a conceder crédito incluido «en el ejercicio de su actividad comercial o profesional».

Pueden, por tanto, trasladarse aquí las dudas que suscita aquel precepto, sobre si incluir en el ámbito de la Directiva 2014/17/UE a las personas que ocasionalmente concedan crédito, sin ser entidades de crédito, siempre que se conceda en el ejercicio de la actividad propia del empresario ${ }^{21}$. Cierto es que en el ámbito de la Directiva 2014/17/UE la hipótesis aquí planteada será bastante infrecuente.

La Directiva se aplica a los contratos de crédito inmobiliario cuando el prestatario o acreditado tenga la condición de consumidor, entendiendo por tal, en virtud de la remisión que el art. 4 hace al art. 3 a) de la Directiva 2008/48/CE, la "persona física que actúa con fines que están al margen de su actividad comercial o profesional». Ha sido criticado, acertadamente, que la Directiva deje fuera de su ámbito de aplicación a los empresarios, sobre todo a las empresas familiares o pequeños empresarios, lo que se considera un error teniendo en cuenta los numerosos empresarios que han garantizado

20 Arroyo (2017) 17; MuñIz Espada (2016) 9. También, respecto de la Ley 20/2014, de 29 de diciembre, de modificación de la Ley 22/2010, de 20 de julio, del Código de Consumo de Cataluña, Esquirol (2015) 177.

21 Así, por la aplicación de la Directiva 2008/48/CE a estos sujetos, v. ORDÁs (2008) 12. 
las deudas derivadas del ejercicio de su actividad empresarial o profesional con la propia vivienda habitual ${ }^{22}$. Esta omisión solo resulta paliada en parte, ya que, según dispone el Considerando 12 de la Directiva, en caso de contratos con doble finalidad (mixta), cuando el contrato se celebra con un objeto en parte relacionado y en parte no relacionado con las actividades comerciales, empresariales o con la profesión de la persona en cuestión, y cuando dichas actividades comerciales, empresariales o dicha profesión son tan limitadas que no predominan en el contexto general del contrato, dicha persona debe ser considerada consumidor.

Se aparta, además, el legislador comunitario en este punto de la jurisprudencia del TJUE que ha ido avanzando en la ampliación de la noción de consumidor, no exigiendo la ausencia de ánimo de lucro al contratar [SSTJUE de 25 de octubre de 2005 (asunto C $350 / 03)^{23}$ y 10 de abril de 2008 (asunto C 412/06) ${ }^{24}$ ], e incluso considerando consumidor al abogado que celebra con un banco «un contrato de crédito, sin que en él se precise el destino del crédito ... cuando dicho contrato no esté vinculado a la actividad profesional del referido abogado", sin que sea pertinente que «esté garantizado mediante una hipoteca contratada por dicha persona en su condición de representante de su bufete de abogados, la cual grava bienes destinados al ejercicio de la actividad profesional de esa persona, como un inmueble perteneciente al citado bufete» [STJUE de 3 de septiembre de 2015 (asunto C-110/14, Caso Ovidiu Costea)].

Al igual que la Directiva 2008/48/CE, y la Ley española de Crédito al Consumo, se excluye del ámbito de aplicación de la Directiva 2014/17/UE, los contratos de crédito garantizados celebrados con consumidores personas jurídicas que, sin embargo, sí están comprendidos en el concepto de consumidor que ofrece el art. 3 TRLGDCU.

Suscita también dudas si cae dentro del ámbito de aplicación de la Directiva 2014/17/UE el hipotecante no deudor y el fiador. Respecto del primero, por su negativa se puede argumentar que

22 Arroyo (2017) 15 y Gallego Sánchez (2014) 213, quien sostiene que materialmente los microempresarios están necesitados de una protección similar a las de las personas físicas.

23 ECLI:EU:C (2005) 637.

24 ECLI:EU:C (2008) 215. 
literalmente la norma se refiere a los "contratos de crédito", siendo que el hipotecante no es concesionario del crédito, ni interviene en la relación garantizada. Respecto del segundo, al no ser el contrato de fianza un contrato de crédito habría que concluir que tampoco queda comprendido en la norma. Sin embargo, se ha apelado en la doctrina a su condición de deudor (subsidiario) para considerarle consumidor si cuando avala lo hace en esa condición ${ }^{25}$. En ambos casos, no habría problema en que los Estados miembros ampliaran el ámbito de aplicación.

En relación con el ámbito de aplicación el Proyecto de Ley español se separa de la Directiva, lo que puede hacer, porque en este aspecto es de mínimos. El Proyecto de ley no es una norma de protección de los consumidores, sino que se aplica a personas físicas, que sean deudores, fiadores o garantes, de préstamos garantizados con hipoteca sobre bien inmueble de uso residencial o cuya finalidad sea la adquisición o conservación de derechos de propiedad sobre terrenos o inmuebles construidos o por construir. Así, se contempla expresamente en su Exposición de Motivos, al aludir a la ampliación de ámbito subjetivo de protección frente a la Directiva, extendiéndolo a colectivos como «trabajadores autónomos».

El proyecto de ley, al igual que la Directiva, se aplica a prestamistas, personas físicas o jurídicas, que realizan dicha «actividad de manera profesional», pareciendo excluir, por ejemplo, al promotor inmobiliario que conceda crédito ocasionalmente a los adquirentes de inmuebles. Sin embargo, tanto en el texto del Informe de la Ponencia como del Dictamen de la Comisión de Economía y Empresa, fruto de la enmienda transaccional núm. 6 , se ha precisado en el art. 2, que la actividad de concesión de préstamos hipotecarios se desarrolla con carácter profesional no solo cuando el prestamista interviene en el mercado de servicios financieros con carácter empresarial, sino también cuando lo hace «de forma ocasional, con una finalidad

25 Arroyo (2017) 16, que cita del Auto del TJUE de 19 de noviembre de 2015 que considera, a efectos de la aplicación de la Directiva 93/13/CE, consumidor al fiador (persona física) que garantiza las obligaciones asumidas por una sociedad mercantil en el marco de un contrato de crédito, cuando esa persona actúe con un propósito ajeno a su actividad profesional y carezca de vínculos funcionales con dicha sociedad. 
exclusivamente inversora", y así ha quedado plasmado en el texto aprobado por el Pleno del Congreso ${ }^{26}$.

Objetivamente el Proyecto de ley se aplica a contratos de crédito (préstamo) garantizados con hipoteca «u otro derecho real de garantía sobre un inmueble de uso residencial», con independencia de su finalidad ${ }^{27}$. También comprende a los contratos de préstamo — sin garantía real- cuando su finalidad, que aquí si es relevante, sea la de adquirir o conservar derechos de propiedad sobre terrenos o inmuebles construidos o por construir, siempre que el «prestatario, el fiador o garante sea un consumidor» [art. 2.1 b)].

En relación con este último supuesto, se suscita la duda de si basta con que cualquiera de los tres sujetos que enumera tenga la condición de consumidor para aplicar la ley, lo que significaría que se aplicara a un garante que actuara al margen de su actividad profesional aun cuando el prestatario (garantizado) no tuviera la condición de consumidor. $\mathrm{O}$ al revés, si teniéndola este último, se aplica al garante profesional. La doctrina del TJUE, en los Autos de 19 de noviembre de 2015 (Caso Dumitru) y de 14 de septiembre de 2016 (Caso Dumitras) ${ }^{28}$, permite deslindar en estos supuestos el préstamo y el contrato de garantía, de manera que si el garante actúa con un propósito ajeno a su actividad profesional y no tiene vínculos funcionales con la deudora (sociedad mercantil), aquél podrá ser considerado consumidor a los efectos de la aplicación de la Directiva 93/13 sobre cláusulas abusivas. Por ello, considero que la ley proyectada se aplicará a garantes no profesionales (consumidores), aunque el préstamo no sea de consumo.

26 El Proyecto ha optado por mantener, si bien con modificaciones, la Ley 2/2009, de 31 de marzo, por la que se regula la contratación con los consumidores de préstamos o créditos hipotecarios concedidos por empresas que no son entidades de crédito. Ahora bien, solo se aplicará a contratos distintos de los previstos en el art. 2.1 de la Ley de contratos de crédito inmobiliario. Se ignora con ello el dictamen del Consejo de Estado que reiteraba la conveniencia de elaborar una única disposición legal, con derogación de esta Ley. V. Arroyo (2017) 32.

27 Resulta llamativo que si bien el título del Proyecto es «ley reguladora de contratos de crédito inmobiliario» en el texto articulado solo se refiere al contrato de préstamo, aunque según el art. 2.3 se debe entender indistintamente a créditos y préstamos.

28 Autos del TJUE de 19 de noviembre de 2015 (asunto C-74/15, ECLI:EU:2015:772) y de 14 de septiembre de 2016 (asunto C-534/15, ECLI: EU: C: 2016: 700). 
Tampoco es suficientemente clara la norma, al emplear la disyuntiva en su art. 1 ( "personas físicas que sean deudores, fiadores $o$ garantes»), si exige que el prestatario tenga siempre la condición de persona física o es suficiente que concurra esta condición en una de las tres posiciones que enuncia "prestatario, fiador o garante», lo que permitiría aplicar esta normativa cuando el avalista fuera persona física, pero el deudor (hipotecante o no) fuera persona jurídica, e incluso una sociedad ${ }^{29}$. Con base en el art. 4.1, que define al prestatario como toda persona física hay que concluir que este siempre ha de serlo ${ }^{30}$.

Cuando el préstamo está asegurado con garantía real la finalidad que debe darse al inmueble sobre el que se ha constituido la garantía, atendiendo al art. 1 y 2.1 a) del Proyecto, en el mismo sentido que la Directiva, ha de ser de «uso residencial». Sin embargo, ni el Proyecto de Ley, ni el art. 4 de la Directiva, que recoge 28 definiciones, especifican qué ha de entenderse por bien inmueble de uso residencial. Para despejar tal duda el Informe de la Ponencia y el Dictamen de la Comisión de Economía y Empresa han introducido en el texto aprobado en el Pleno un inciso en el art. 2.1 a), según el cual «[A] estos efectos, también se entenderán como inmuebles para uso residencial aquellos elementos como trasteros, garajes, y cualesquiera otros que sin constituir vivienda como tal cumplen función doméstica». Quedaría excluido, por tanto, el préstamo con hipoteca sobre local de negocio, siendo dudoso el caso del despacho profesional hipotecado, ya que si atendemos a un concepto objetivo y no finalista también tendría dicho uso ${ }^{31}$. Al no pronunciarse explícitamente el Proyecto de ley queda incluido el bien inmueble de uso residencial adquirido como inversión para alquilar (buy to let).

Por último, el término "conservar derechos de propiedad», que ha de ser la finalidad del préstamo para que quede incluido en el ámbito del Proyecto de Ley, puede ser entendido en un sentido material (rehabilitar o renovar el inmueble) o jurídico, como préstamo

Cabanas (2017) 4.

30 En el Informe de la Ponencia y el Dictamen de la Comisión de Economía y Empresa este art. 2.2 ha pasado a un nuevo art. 3 bis que contiene un elenco de definiciones, entre ellas, el de prestatario que se reconduce solo a persona física.

31 Cabanas (2017) 4. 
para refinanciación de la adquisición ya producida (por ejemplo, evitar una ejecución del inmueble).

\section{MEdidAS DE PROTECCIÓN DEL DEUdOR: EL REFORZAMIENTO DEL DEBER DE TRANSPARENCIA MATERIAL}

En cuanto al contenido de la Directiva y del Proyecto del Ley, ambas normas articulan dos grupos de medidas: unas, dirigidas a disciplinar la conducta de los prestamistas, intermediarios de crédito y representantes designados en relación con la oferta, concesión e intermediación de contratos de crédito, exigiendo un nivel adecuado de conocimientos y competencias de su personal, así como una política de remuneraciones que no impida la obligación de tener en cuenta los intereses del consumidor, evitando las malas prácticas de venta que se han producido en los últimos años, motivadas, en parte, por las entidades que incentivaban a su personal a celebrar un determinado número o tipo de contratos u ofrecer al consumidor ciertos servicios accesorios sin tener en cuenta sus intereses.

Otras medidas están destinadas específicamente a incrementar la protección del prestatario, imponiendo, por ejemplo, nuevos deberes de transparencia e información precontractual o la obligación de evaluar la solvencia del consumidor. Llegados a este punto, me centraré en el contenido y alcance del deber de transparencia material y el reforzamiento de las funciones asesoras de los notarios que se prevé en la proyectada norma española, que ha ido más allá de la estricta transposición de la Directiva.

En efecto, el proyecto de ley — texto aprobado en Pleno del Congreso- regula de manera detallada el deber de transparencia material en dos preceptos (arts. 14 y 15). Su finalidad es conseguir que el prestatario —el garante o fiador ex art. 2.2 2 — esté adecuadamente informado del significado y alcance del contenido del contrato,

32 El art. 2.2 del Proyecto de ley originario, que extiende la obligación de comparecencia del art. 13 y demás normas de protección del prestatario a «toda persona física que sea fiadora o garante del préstamo», ha pasado en el Informe de la Ponencia y el Dictamen de la Comisión de Economía y Empresa, a estar incluido en el art. 15.4, que es el que regula el deber de comparecer ante notario, su finalidad y contenido. 
de su carga económica y jurídica, específicamente de algunas de las cláusulas que mayor litigiosidad han provocado en los últimos años.

En la línea de lo previsto en el art. 14 de la Directiva, conforme al art. 12 del Proyecto de ley este deber de transparencia se traduce en la exigencia de entrega al deudor por el «prestamista, intermediario o su representante designado», con antelación mínima de siete días respecto de la firma del contrato (ampliados a diez días en el Informe de la Ponencia y en el Dictamen de la Comisión de Economía y Empresa), de una serie de documentación, a saber:

a. La Ficha Europea de Información Normalizada (FEIN), facilitada según formato recogido en el Anexo I, que tendrá la consideración de oferta vinculante durante el plazo pactado hasta la firma del contrato, que deberá ser al menos de siete días (ampliado a diez, según apuntamos), con lo que el legislador español ha optado por configurarlo como un período de reflexión y no como derecho de desistimiento, lo que le permitía hacer el art. 14.6 de la Directiva.

b. Una Ficha de Advertencias Especializadas (FiAE), en la que se informará al prestatario de la existencia de cláusulas especialmente sensibles, como límites mínimos en el tipo de interés aplicable como consecuencia de bajada de índices, cláusulas de vencimiento anticipado, o distribución de gastos asociados a la concesión del préstamo.

c. Junto a esta deberá entregarse otra adicional: si el préstamo es a interés variable, un documento separado con referencia especial a las cuotas periódicas a satisfacer por el prestatario en diferentes escenarios de evolución de tipos de interés;

d. Una copia del proyecto de contrato, que incluya de forma desglosada, la totalidad de los gastos asociados a la firma del contrato, especificando los que corresponden al arancel notarial, a los derechos registrales, al Impuesto de Transmisiones Patrimoniales y Actos Jurídicos Documentados y los costes de gestoría.

Como resultado de modificación introducida en el texto del proyecto de ley por el Informe de la Ponencia, este 
apartado ha sido objeto de una nueva redacción (nuevo apartado e), mucho más detallada, exigiendo una «información clara y veraz de los gastos que corresponden al prestamista y al prestatario», y especificando su distribución. Esta nueva redacción pretende zanjar la polémica generada en los últimos meses del año 2018 por pronunciamientos judiciales dispares en torno a quién debía soportar el pago del Impuesto de Transmisiones Patrimoniales y Actos Jurídicos Documentados (ITPyAJD) y que se pretendió poner fin con la aprobación del Real Decreto-ley 17/2018, de 8 de noviembre, por el que se modifica el art. 29 del Texto Refundido de la Ley reguladora de tal impuesto considerando sujeto pasivo del impuesto, en caso de escrituras de préstamo hipotecario, al prestamista ${ }^{33}$.

Han sido numerosas las sentencias que han declarado la abusividad de las cláusulas que imponen todos los gastos generados por la compraventa y el préstamo hipotecario contraído para financiarlo al consumidor, a partir de la STS 23 de diciembre de $2015^{34}$.

Con la nueva redacción de este precepto los gastos de tasación del inmueble corresponderán al prestatario y al

33 Me refiero a la polémica generada por las SSTS (Sala $3^{\mathrm{a}}$ ) de 16, 22 y 23 de octubre de 2018 (RJ 2018/4082, RJ 2018/4599 y RJ 2018/4618, respectivamente), que anularon el precepto reglamentario que establecía que el prestatario era el sujeto pasivo de dicho impuesto y a la STS de Pleno de la Sala $3^{\text {a de }} 27$ de noviembre de 2018 (RJ 2018/5198), que contradijo las anteriores al sostener que el sujeto pasivo era el prestatario.

34 Roj: STS 5618/2015. Esta sentencia declaró nula por abusiva la cláusula que imponía en un préstamo hipotecario al consumidor prestatario de forma exclusiva «todos los tributos, comisiones y gastos ocasionados por la preparación, formalización, subsanación y tramitación de escrituras, modificación —incluyendo división, segregación o cualquier cambio que suponga alteración de la garantía- y ejecución de este contrato, y por los reintegros derivados del mismo, así como por la constitución, conservación y cancelación de su garantía, siendo igualmente a su cargo las primas y demás gastos correspondientes al seguro de daños, que la parte prestataria se obliga a tener vigente en las condiciones expresadas en la cláusula $11^{\mathrm{a}}{ }$. El Tribunal Supremo fundamentó su decisión, entre otros preceptos, en el art. 89.3 TRLGDCU que califica como abusivas en la compraventa de viviendas «la imposición al consumidor de los gastos de documentación o de gestión que por ley corresponda al empresario", considerando que la «financiación es una faceta o fase de dicha adquisición» y por no permitir una mínima reciprocidad en la distribución de los gastos producidos. 
prestamista los de gestoría, el coste de los aranceles notariales de la escritura de préstamo hipotecario, así como los de inscripción de las garantías en el Registro, remitiéndose para el pago del ITPyAJD a la legislación tributaria.

e. Si se exige la suscripción de un seguro en garantía del cumplimiento de las obligaciones del contrato de préstamo (de amortización), de un seguro de daños respecto del inmueble u otros, se deberá entregar por escrito las condiciones del contrato.

Por último, si el préstamo ha de formalizarse en escritura pública, se incluirá la advertencia de la obligación de recibir asesoramiento personalizado y gratuito del notario que elija el prestatario sobre el contenido y las consecuencias de la información contenida en la documentación.

En realidad, lo que debe asegurarse no es tanto la entrega de toda la información anterior, como que esta venga acompañada de unas explicaciones adecuadas. Además, hay que tener en cuenta que la Orden EHA/2899/2011, de 28 de octubre, sobre transparencia y protección del cliente de servicios bancarios, ya prevé una FIPER, con mención obligatoria de determinados riesgos y advertencias, cuya cumplimentación no ha permitido salvar la falta de transparencia de las cláusulas suelo. Esta Orden convivirá con la futura Ley, en tanto esta última no sea desarrollada reglamentariamente, siempre que no resulten incompatibles, lo que puede plantear problemas en tanto que su ámbito de aplicación no plenamente es coincidente.

Como novedad significativa destacaría el reforzamiento de las funciones de los notarios como garantes de la transparencia, que se materializa en la práctica de un acta previa a la escritura pública.

Como hemos visto, ya el art. art. 14.1 g) Proyecto de ley prevé que si el préstamo se formaliza en escritura pública debe advertirse al prestatario de la obligación de recibir asesoramiento personalizado y gratuito del notario que elija el prestatario para la autorización de 
la escritura, sobre el contenido y las consecuencias de la información contenida en la documentación que se le entrega.

Este asesoramiento es algo distinto tanto del deber de ofrecer explicaciones adecuadas que incumbe al prestatario o intermediario de crédito, como de la actividad de asesoramiento, a la que se refiere el art. 19, que es un servicio distinto de la mera actividad crediticia, y normalmente retribuido, consistente en la recomendación personalizada que el prestamista, el intermediario o el representante designado puede hacer al prestatario.

Toda la documentación anterior debe remitirse «a través de la interconexión de las plataformas de los prestamistas y del Consejo General del Notariado", según el art.12.1 in fine del Proyecto originario. El Informe de la Ponencia, que ha tenido reflejo en el texto aprobado en el Pleno, se limita a prever que la remisión se realizará por medios telemáticos seguros, que se determinará reglamentariamente y que deberán contar con unas exigencias mínimas, entre las que destaca que no suponga coste alguno para el prestatario (art. 14.1 in fine).

El art. 15, que lleva por rúbrica «Comprobación del cumplimiento del principio de transparencia material», contempla el deber del prestatario de comparecer ante el Notario para obtener su asesoramiento presencial, durante el plazo mínimo de siete días anterior a la firma del contrato (ampliado a diez en el Informe de la Ponencia). Como tarde, el prestatario deberá comparecer ante el notario el día anterior a la autorización. Tal como está configurado en el Proyecto, no se trata de una facultad del prestatario, que puede ejercitar o no (como hacía el Anteproyecto de ley), sino de un deber o, mejor dicho, de una carga. Aunque no se diga literalmente, durante dicho plazo es exigible que el prestatario tenga en su poder ya la documentación a los efectos de obtener información y asesoramiento del notario.

Incumbe al notario comprobar que toda la documentación cumple los requisitos previstos en el art. $14.1 \mathrm{y}$, en caso afirmativo, 
deberá extender acta notarial previa a la formalización del préstamo en que haga constar:

a. el cumplimiento de los plazos legalmente previstos de puesta a disposición del prestatario de los documentos descritos en el artículo 14.1;

b. las cuestiones planteadas por el prestatario y el asesoramiento del notario, recogiéndose las pruebas de entendimiento realizadas al prestatario de diversos ejemplos de aplicación práctica de las cláusulas financieras, en diversos escenarios de coyuntura económica, en especial las relativas a tipos de interés y en su caso los instrumentos de cobertura de riesgos financieros suscritos con ocasión del préstamo;

c. que se ha asesorado al prestatario sobre las cláusulas específicas recogidas en la FEIN y en la FIAE, de manera individualizada y con referencia expresa a cada una de ellas, sin que sea suficiente una referencia genérica. En presencia del notario, el prestatario responderá a un test que tendrá por objeto concretar la documentación entregada y la información suministrada (novedad del Proyecto, respecto del Anteproyecto).

d. En el texto originario del Proyecto de ley el art. 13 exigía la manifestación firmada y manuscrita del prestatario en que declarara que había recibido la documentación del art. 12.1, con una antelación mínima de siete días, la comprendía y aceptaba su contenido y entiende los riesgos jurídicos y económicos de la operación.

En este punto también el texto del Proyecto de Ley ha sufrido alguna modificación, tras el Informe de la Ponencia. Así, ha desaparecido, acertadamente, la obligación de realizar unas pruebas de entendimiento al prestatario del apartado c), así como constar la manifestación firmada y manuscrita del prestatario del apartado d), que ya venía prevista en el art. 6 de la Ley 1/2013, de 14 de mayo, para medidas para reforzar la protección de deudores hipotecarios, reestructuración de deuda y alquiler social, y que no evitó los pronunciamientos judiciales sobre la nulidad de las cláusulas suelo. 
Si no se puede acreditar documentalmente el cumplimiento en tiempo y forma de las obligaciones de información y documentación o si no comparece el prestatario el Notario no extenderá el acta y, por tanto, no se autorizará la escritura pública. En el Anteproyecto el acta notarial podía extenderse el mismo día de la formalización de la escritura del préstamo; ahora la comparecencia y la extensión del acta debe celebrarse, como mínimo, un día antes.

Ha desaparecido también del Proyecto de Ley la previsión del Anteproyecto que establecía la presunción iuris tantum de que el principio de transparencia material se había cumplido con el otorgamiento del acta notarial. Esta norma, como advirtió el Consejo General del Poder Judicial, al invertir la carga de la prueba no favorecía especialmente al consumidor, a pesar de lo que decía la Exposición de Motivos - prueba constituida en beneficio de ambas partes-, llegando el CGPJ a decir que suponía la consagración normativa de la prohibición de alterar en perjuicio del consumidor las normas sobre la carga de la prueba [art. 82.4 c) TRLGDCU] ${ }^{35}$. Por ello, se propuso como más adecuado y coherente remitirse, en cuanto a los efectos del acta, a la legislación notarial que los detalla. Y así se hace en el art. 15.6 del Proyecto: «Conforme al art. 17 bis 2 b) Ley del Notariado y el art. 319 LEC el contenido del acta se presumirá veraz e íntegro, y hará prueba del asesoramiento prestado por el notario y de la manifestación de que el prestatario comprende y acepta el contenido de los documentos descritos, a efectos de cumplir con el principio de transparencia en su vertiente material».

De otra parte, cabe subrayar que el acta donde conste la entrega de toda la documentación y el asesoramiento imparcial al prestatario no generará coste arancelario alguno, y se incorporará una reseña identificativa del acta en la escritura pública. El Proyecto de Ley ha disipado las dudas sobre si la práctica del acta había de ser o no gratuita, ya que lo que preveía el Anteproyecto es que el acta «no

35 El informe de 5 de mayo de 2017 puede consultarse en http://www.poderjudicial. es/cgpj/es/Poder-Judicial/Consejo-General-del-Poder-Judicial/Actividad-delCGPJ/Informes/Informe-sobre-el-Anteproyecto-de-Ley-Reguladora-de-losContratos-de-Credito-Inmobiliario. 
generará coste para el prestatario», por lo que, para algunos, debía ser el profesional el que asumiera los que puedan producirse ${ }^{36}$.

Ha desaparecido también del Proyecto de Ley la norma del Anteproyecto (art. 13.4), según la cual los registradores no inscribirán ninguna escritura si no se acredita el cumplimiento no solo de la norma sobre el control de los notarios del principio de transparencia, a través del acta previa, sino también la norma relativa información precontractual y entrega de documentación, con lo que parecía que se establecía un ulterior control de transparencia material por parte de los Registradores, lo que podría provocar conflictos en caso de que se alcanzara un juicio distinto al del notario. Ahora, según el art. 20.2 los registradores no inscribirán ninguna escritura relativa a los préstamos a los que se refiere la norma «en la que no conste la reseña del acta conforme al art. 13.6», limitándose, por tanto, a un control formal de la práctica del acta notarial, pero no al cumplimiento efectivo del principio de transparencia.

Por último, la DA $8^{\mathrm{a}}$ del Proyecto de Ley recoge la obligación del notario autorizante de la escritura de préstamo de entregar o remitir telemáticamente al prestatario sin coste alguno copia simple de aquella, a la que acompañará la nota de despacho practicada por el registrador en la copia autorizada. Los registradores de la propiedad también remitirán gratuitamente y de forma telemática al interesado nota simple literal de la inscripción y de la nota de despacho y calificación, indicando las cláusulas no inscritas con la motivación de la suspensión o denegación.

\section{Conclusiones}

Teniendo en cuenta todo lo anterior, a modo de conclusión cabe formular algunas reflexiones:

En primer lugar, el legislador español debería haber ordenado sistemáticamente la vigente regulación del contrato de crédito inmobiliario celebrado con consumidores y con no consumidores y que encontramos dispersa en varias normas, cuyo ámbito de aplicación

36 En todo caso, la memoria económica del Proyecto de ley cuantifica en 8.750.000 $€$ el coste de la práctica de esta acta previa (calculado para 250.000 préstamos hipotecarios que se formalizaron en el año 2016, $35 €$ coste unitario). 
puede ser parcialmente concurrente (Ley 2/2011, de 4 de marzo, de Economía Sostenible; Orden EHA 2899/2011, sobre transparencia y protección del cliente bancario; Circular del Banco de España 5/2012, de 5 de junio, que desarrolla la anterior, sobre transparencia de los servicios bancarios y responsabilidad en la concesión de préstamos; Ley 2/2009 de 31 de marzo, por la que se regula la contratación con consumidores de préstamos o créditos hipotecarios y de servicios de intermediación para la celebración de contratos de préstamo o crédito).

En segundo lugar, falta definir con claridad suficiente el alcance objetivo y subjetivo del texto proyectado que incorpora finalmente la Directiva 2014/17/UE. Al ampliar su ámbito de aplicación respecto de la Directiva, debería precisar quiénes y en qué casos son los destinatarios del régimen de protección que dispensa la norma. Es cierto que tras la aprobación del Informe de la Ponencia sobre el Proyecto de Ley algunas de las dudas se han aclarado, pero subsisten otras ya mencionadas anteriormente en relación con la condición o no de consumidor del garante o del fiador o la posible aplicación de la norma a garantes que no sean personas físicas.

En tercer lugar, el cumplimiento de los requisitos de los arts. 14 y 15 llevará consigo que, entre otras cláusulas, la cláusula suelo (o de limitación a la baja del tipo de interés aplicable en los préstamos a interés variable), que forma parte del precio o del objeto del contrato, supere el control de transparencia material, en los términos que fijó la famosa STS (Pleno de Sala 1ª 9 de mayo de $2013^{37}$. El prestatario tendrá muy complicado acreditar que, pese a que el prestamista y el notario han cumplido las exigencias informativas contenidas en estos preceptos, no conocía el alcance de la carga económica y jurídica de la cláusula suelo. En todo caso, el juez deberá cercionarse de que, en efecto, recibió información suficiente y adecuada. No obstante, este control de transparencia no evitará que otras cláusulas del contrato, no negociadas, relativas a elementos accidentales del mismo, puedan ser declaradas abusivas por suponer un desequilibrio importante entre los derechos y obligaciones de las partes, en perjuicio del consumidor y en contra de las exigencias de la buena fe (v. art. 82.1 TRLGDCU).

$37 \quad$ RJ 2013/3088. 
Se erige al notario en una pieza fundamental en la comprobación del principio de transparencia material, pero no debería trasladarse a estos los deberes de información precontractual y contractual y de ofrecer explicaciones adecuadas que incumben, en primer lugar, y como contenido esencial de su posición contractual, a los prestamistas e intermediarios de crédito.

La nueva regulación pretende poner fin a las controversias suscitadas en relación con la cláusula que impone todos los gastos de formalización del préstamo hipotecario al prestatario y su carácter abusivo. Una cláusula que los distribuya de manera diversa sería nula, ya no por abusiva, sino por contravenir norma imperativa (art. 14), incluso aunque fuera pactada entre deudores personas físicas no consumidoras.

\section{BibliogRAFÍA}

\section{a) Doctrina:}

Albiez Dorhmann, Klaus Jochen (2015): «Una invitación a los Estados miembros de la UE: normas prudenciales a favor del consumidor en los préstamos para la adquisición de bienes inmuebles de uso residencial (a propósito de la Directiva 2014/17/UE, de 4 de noviembre de 2014)», Revista de Derecho civil, vol. II, núm. 2: pp. 1-30. Disponible en: http://www.nreg.es/ojs/index.php/RDC/article/view/126 [Fecha de consulta: 01 de diciembre de 2018]

Arroyo Amayuelas, Esther (2017): «La directiva 2014/17/UE sobre contratos de crédito con consumidores para bienes inmuebles de uso residencial», Indret, 2/2017: pp. 1-44. Disponible en http://www.indret.com/pdf/1304.pdf [Fecha de consulta: 01 de diciembre de 2018]

CABanas, Ricardo (2017): «Anotaciones de un notario perplejo al Anteproyecto de Ley Reguladora de los Contratos de Crédito Inmobiliario", Diario La Ley, no 9047, versión electrónica LA LEY 11795/2017.

CASAdo Navarro, Antonio (2015): «La normativa española sobre transparencia de préstamos hipotecarios ante la Directiva 2014/17/UE reguladora de los contratos de crédito para bienes inmuebles de uso residencial celebrados con consumidores", Diario La Ley, $\mathrm{n}^{\circ}$ 8636, Ref. D-403. 


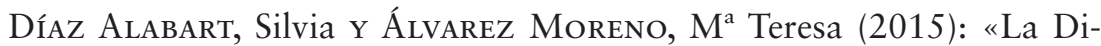
rectiva 2014/17, de 4 de febrero de 2014, sobre los contratos de crédito celebrados con consumidores para bienes inmuebles de uso residencial», en Díaz Alabart, Silvia (directora), Represa Polo, $\mathrm{M}^{\mathrm{a}}$ Patricia (coordinadora), La protección del consumidor en los créditos hipotecarios (Directiva 2014/17/UE) (Madrid, Reus): pp. 13-52.

Díaz Alabart, Silvia (2015): «Contratación de créditos hipotecarios y protección del consumidor (Directiva 2014/17, de 4 de febrero)», en Pereña Vicente, Montserrat y Delgado Martín, Palmira (directoras), Nuevas orientaciones del Derecho civil en Europa, (Cizur Menor, Thomson Reuters Aranzadi-Fundación cultural del Notariado): pp. 287- 288.

Esquirol Jiménez, Víctor (2015): «La nueva regulación de los créditos y préstamos hipotecarios en el Código de consumo de Cataluña", Revista Jurídica de Cataluña, núm. 3: pp. 743-762.

Gallego SÁnchez, Esperanza (2014): «La obligación de evaluar la solvencia del deudor. Consecuencias derivadas de su incumplimiento», en Prats Albentosa, Lorenzo y Cuena Casas, Matilde (coordinadores), Préstamo responsable y Ficheros de Solvencia, (coordinadores) L. (Cizur Menor, Thomson Reuters Aranzadi): pp. 207-242.

Lauroba Lacasa, Elena (2012): «La propuesta de Directiva del Parlamento Europeo y del Consejo sobre los contratos de crédito relativos a los bienes inmuebles de uso residencial», en Lauroba Lacasa, Elena (directora), Garantías reales en escenarios de crisis: presente y prospectiva, (Barcelona, Marcial Pons): pp. 117-132.

MuÑIz EspadA, Esther (2016): El deterioro del mercado hipotecario y la necesidad de su reconstrucción. Aportaciones desde el Derecho europeo (Madrid, Civitas Thomson Reuters).

Ordás Alonso, Marta (2008): «El ámbito de aplicación de la Directiva 2008/48/CE del Parlamento europeo y del Consejo, de 23 de abril de 2008, relativa a los contratos de crédito al consumo y por la que se deroga la Directiva 87/102/CEE del Consejo", Revista Doctrinal Aranzadi Civil-Mercantil, núm. 16, BIB 2008/2866: pp. 1-40.

Zunzunegui Pastor, Fernando (2017): «Efectos contractuales del deber de evaluación de la solvencia (STJUE 9/11/2016)», Blog Hay Derecho, Disponible en https://hayderecho.com/2017/01/24/efectos-contractuales-del-deber-de-evaluacion-de-la-solvencia-stjue-9112016/. [Fecha de consulta: 24 de enero de 2017] 


\section{b) Jurisprudencia:}

STS (Pleno de Sala 1 ${ }^{\text {a }}$ ) de 9 de mayo de 2015 (RJ 2013/3088).

STS (Sala $1^{\text {a }}$ ) de 23 de diciembre de 2015 (Roj: STS 5618/2015).

STS (Sala 3 ${ }^{\mathrm{a}}$ ) de 16 de octubre de 2018 (RJ 2018/4082).

STS (Sala 3 ${ }^{\mathrm{a}}$ ) de 22 de octubre de 2018 (RJ 2018/4599).

STS (Sala 3 ${ }^{\mathrm{a}}$ ) de 23 de octubre de 2018 (RJ 2018/4618).

STS (Pleno de Sala 3a) de 27 de noviembre de 2018 (RJ 2018/5198).

Auto TJUE de 19 de noviembre de 2015. (asunto C-74/15,ECLI:EU:C:2015:772. Caso Dumitru).

Auto TJUE de 14 de septiembre de 2016 (asunto C-534/15,ECLI:EU:C:2016:700. Caso Dumitras).

STJUE de 25 de octubre de 2005 (asunto C 350/03, ECLI:EU:C:2005:637, Caso Schulte).

STJUE de 10 de abril de 2008 (asunto C 412/06, ECLI:EU:C:2008:215, Caso Annelore Hamilton).

STJUE de 3 de septiembre de 2015 (asunto C-110/14, ECLI:EU:C:2015:538, Caso Ovidiu Costea).

\section{c) Normativa:}

Directiva 2008/48/CE, de 23 de abril, del Parlamento y del Consejo, relativa a los contratos de crédito al consumo y por la que se deroga la Directiva 87/102/CEE, del Consejo (DOUE 22.5.2008, L 133/66).

Directiva 2014/17/CE, del Parlamento y del Consejo, de 4 de febrero, sobre los contratos de crédito celebrados con los consumidores para bienes inmuebles de uso residencial (DOUE 28.2.2015, L 60/34).

Real Decreto Legislativo 1/2007, de 16 de noviembre, por el que se aprueba el Texto Refundido de la Ley General para la Defensa de los Consumidores y Usuarios y otras leyes complementarias (BOE núm. 287, de 30 de noviembre de 2007).

Ley $2 / 2009$ de 31 de marzo, por la que se regula la contratación con consumidores de préstamos o créditos hipotecarios y de servicios de intermediación para la celebración de contratos de préstamo o crédito (BOE núm. 79, de 1 de abril de 2009).

Ley 2/2011, de 4 de marzo, de Economía Sostenible (BOE núm. 55, de 6 de marzo de 2011).

Ley $1 / 2013$, de 14 de mayo, medidas para reforzar la protección a los deudores hipotecarios, de reestructuración de deuda y alquiler social (BOE núm. 116, de 15 de mayo de 2013). 
Ley 20/2014, de 29 de noviembre, de modificación de la Ley 22/2010, del Código de consumo de Cataluña, para la mejora de la protección de las personas consumidoras en materia de créditos y préstamos hipotecarios, vulnerabilidad económica y relaciones de consumo (BOE núm. 18, de 21 de enero de 2015).

Ley 3/2016, de 9 de junio, de la Comunidad Autónoma de Andalucía, para la protección de los derechos de las personas consumidoras y usuarias en la contratación de préstamos y créditos hipotecarios sobre la vivienda (BOE núm. 157, de 30 de junio de 2016).

Real Decreto-ley 17/2018, de 8 de noviembre, por el que se modifica el Texto refundido de la Ley del Impuesto de Transmisiones Patrimoniales y Actos Jurídicos Documentados, aprobado por Real Decreto legislativo 1/1993, de 24 de septiembre (BOE núm. 271, de 9 de noviembre de 2018).

Orden EHA/2899/2011, de 28 de octubre, de transparencia y protección del cliente de servicios bancarios (BOE núm. 261, de 29 de octubre de 2011).

Circular del Banco de España 5/2012, de 5 de junio, a entidades de crédito y proveedores de servicios de pago, sobre transparencia de los servicios bancarios y responsabilidad en la concesión de préstamos (BOE núm. 161, de 6 de julio de 2012).

Proyecto de Ley reguladora de los contratos de crédito inmobiliario (BOCG núm. 12-1, de 17 de noviembre de 2017).

Informe de la Ponencia del Proyecto de Ley reguladora de los contratos de crédito inmobiliario (BOCG núm- 12-4, de 11 de diciembre de 2018).

Dictamen emitido por la Comisión de Economía y Empresa sobre el Proyecto de ley, así como los escritos de mantenimiento de enmiendas para su defensa ante el Pleno (BOCG 19.12.2018, núm. 12-5).

Proyecto de ley reguladora de contratos de crédito inmobiliario aprobado por el Pleno del Congreso (BOCG 8.1.2019, núm. 12-6). 


\section{Algunas consideraciones desde el Derecho CiVil sobre el Derecho DEL CONSUMO Y LAS ACCIONES COLECTIVAS INDEMNIZATORIAS}

\section{SOME CONSIDERATIONS FROM THE CIVIL LAW ON CONSUMER LAW AND COMPENSATORY CLASS ACTIONS}

Mario E. Clemente Meoro ${ }^{1}$

Resumen. La legitimación colectiva para el ejercicio de acciones, tanto inhibitorias como indemnizatorias, a efectos de proteger a los consumidores en el Derecho español tiene una serie de presupuestos y consecuencias de naturaleza civil, que son los que se estudian en este trabajo.

Palabras clave: Derecho civil, Derecho del consumo, legitimación colectiva, acciones colectivas, contratos.

AвsтRACT. The collective legitimation for the exercise of actions, both inhibitory and compensatory, in order to protect consumers

1 Catedrático de Derecho Civil. Universidad de Valencia (España). E-mail: Mario. Clemente@uv.es 
in Spanish law has a series of budgets and consequences of a civil nature, which are those studied in this work.

KeY wORDs: Civil law, consumer law, collective legitimation, class actions, contracts.

Sumario. 1.Introducción. 2. Evolución del concepto de contrato. 3. Consecuencias de la evolución del Derecho de la contratación. 4. Otros factores. 5. Desajuste entre los principios codiciales y extracodiciales del Derecho de contratos. 6. Jurisprudencia sobre control de contenido de los contratos con consumidores. 7. Qué hacer en relación con los desajustes legales y jurisprudenciales. 8 . La administrativización del contrato. 9. Acciones colectivas indemnizatorias: 9.1. Constitución de la parte demandante: principio opt-in; 9.2. Principio «quien pierde, paga»; 9.3. Honorarios de los abogados y financiación de las acciones colectivas de indemnización; 9.4. Reparación integral sin función punitiva. 10. Consideraciones finales. 11. Bibliografía.

\section{INTRODUCCIÓN}

Tal y como resulta de su título, este trabajo solo pretende abordar algunas de las muchas cuestiones relativas a la protección de los consumidores y las acciones colectivas. Por tanto, sin pretensión de exhaustividad. Y aunque el tema es en parte procesal, se trata a continuación desde la perspectiva del Derecho civil. A tal efecto, se expone la situación actual del Derecho de la contratación, sus desajustes legales y jurisprudenciales en relación con la protección de los consumidores, para terminar con ciertos aspectos de las acciones colectivas indemnizatorias desde el Derecho sustantivo.

\section{Evolución DEL CONCEPTO DE CONTRATO}

En Roma había un númerus clausus de contratos, de manera que las demás convenciones no tenían fuerza para vincular jurídicamente (acaso, solo socialmente). Originariamente, eran necesarios unos determinados actos solemnes y rituales (nexum, sponsio, stipulatio). 
Más tarde también se admite que la entrega de una cosa (datio rei), en determinados casos, generará la obligación de restituirla. Y más adelante, se estimó por el Derecho pretorio que ciertas obligaciones pudieran crearse por acuerdo entre las partes, pero con carácter excepcional y limitado a ciertos tipos: compraventa, arrendamiento, mandato y sociedad. A lo más que se llegó, también en el ámbito del Derecho pretorio, fue a la consideración de las convenciones de intercambio (do ut des; do ut facias; facio ut des; facio ut facias) como contratos, al concederse acción para obtener el cumplimiento de la promesa y no solo la restitución de lo entregado (condictio causa data, causa non secuta).

El pacto desnudo (nudum pactum) —esto es, el que no tenía carácter formal o típico- no obligaba (ex nudo pacto actio non nacsitur; nuda pactio obligationem non parit). Solo cabía defensa por vía de excepción (exceptio pacti), aunque algunos pactos fueron más tarde dotados de acción. Es el caso de los pacta adiecta o pactos añadidos a un contrato como complemento de éste, de los pactos tipificados por el Pretor (v. gr., el de hipoteca); y los pacta legitima, a los que los emperadores concedieron acción especial. En cualquier caso, en Derecho romano no se conoce el contrato como categoría general; solo había algunos acuerdos de voluntades a los que se consideraba contratos por vincular obligatoriamente a las partes: los nominados (formales, reales, literales y consensuales) y los innominados.

En la Edad Media, el concepto de contrato evoluciona como consecuencia de la introducción mediante el Derecho canónico de la idea de fidelidad a la palabra dada y del deber de veracidad. Estas premisas de carácter ético y religioso llevan a la consideración de que toda promesa produce acción, ya que mentir es contrario a la ley de Dios. En los tribunales eclesiásticos cabe reclamar por el pecado cometido al incumplir lo prometido, y esa doctrina penetra también en los tribunales civiles. Asimismo, el Derecho canónico establece que debe cumplirse el juramento añadido al acto de contraer una obligación, aunque no esté reconocido por el Derecho civil, si es libre y veraz, con discernimiento y justa causa. De otra parte, el desarrollo del tráfico mercantil impulsa prescindir de trabas formales a la contratación. 
Todo ello lleva a que las legislaciones nacionales vengan a establecer, más pronto o más tarde, el principio de libertad formal en la contratación, que en el caso del Derecho castellano se materializa en fecha temprana en la ley única del Título XVI del Ordenamiento de Alcalá (1340): «Sea valedera la obligación o el contrato que fueron hechos, en cualquier manera que parezca que alguno se quiso obligar a otro e facer contrato con él». Ya no hay un númerus clausus de contratos, sino tantos tipos como las partes convengan, en cuanto sus estipulaciones sean lícitas.

El paso siguiente lo dan la Escuela del Derecho natural racionalista (siglos XVII y XVIII) y la Ilustración, que hacen hincapié en la idea de voluntad individual. Conforme a la ley natural, es la voluntad de las partes la que fundamenta la obligatoriedad de los contratos (solus cosensus obligat). Se formula, a partir de ahí, una concepción unitaria del contrato, la doctrina del contrato como categoría general.

La Codificación recoge, a través de Domat y Pothier, estos planteamientos. No solo se legisla sobre los distintos tipos de contrato, sino también sobre el contrato en general, estableciendo unas «disposiciones generales», esto es, lo que viene a ser una teoría general del contrato; y esa teoría general se funda además en dos postulados: la igualdad de las partes y la plena libertad de ellas. Los Códigos suprimen las diferencias sociales de orden estamental, contemplan un único sujeto de derecho como persona física, el ciudadano, y conceden personalidad jurídica a ciertos entes, pero siempre sobre la base de su igualdad para actuar en el tráfico. Asimismo, se considera que estos sujetos actúan con plena libertad para pactar, conforme al principio de autonomía privada o de la voluntad. Cada ciudadano está en disposición de defender sus intereses en condiciones de libertad e igualdad, decidiendo en cada caso si quiere obligarse y cómo. La autorregulación o autotutela es el mejor mecanismo de protección del individuo, sin que haga falta que los poderes públicos interfieran. La regulación de los contratos es, consecuentemente, dispositiva; solo muy excepcionalmente, imperativa.

Sin embargo, estos postulados se formulan en relación con una forma de contratación que los progresos técnicos y el cambio de los 
modelos económicos ha convertido en poco frecuente: la contratación por negociación ${ }^{2}$.

Los códigos decimonónicos operan sobre una economía básicamente agraria y sólo incipientemente industrial, en que las relaciones contractuales tenían un carácter personal. Antes de llegar a un acuerdo, había tratos preliminares, ofertas y contraofertas, discusiones. Pero este modo de concluir contratos se limita actualmente a los que tienen gran relevancia para la economía de alguna de las partes, o de ambas. Cuando los bienes o servicios se producen $\mathrm{u}$ ofertan masivamente, que es lo más frecuente, no hay negociación. Los prestadores no solo reducen gastos mediante la producción en masa, también mediante la estandarización de la contratación de sus bienes y servicios. No es económicamente eficiente negociar con cada uno de los clientes, sino ofrecer junto con el producto o servicio un clausulado contractual estándar, al que el interesado ha de adherirse. La mayoría de los contratos están predispuestos por el proveedor de los bienes o servicios (comerciante, empresario, profesional), conformando lo que se conoce como "condiciones generales de la contratación». Se trata de contratos tipo en que se sustituye el Derecho dispositivo de los códigos y leyes civiles y mercantiles, establecido de manera imparcial y con el propósito de mantener el equilibrio de intereses entre las partes, por reglas convenientemente formuladas en interés del predisponente. También se advierte que las cláusulas no negociadas pueden determinar un desequilibrio injustificado entre las prestaciones de las partes.

\section{Consecuencias de la evolución del Derecho DE LA CONTRATACIÓN}

Abundando en estas circunstancias, se ha señalado por MARTíNEZ DE AGUirre que sus consecuencias no son nada desdeñables ${ }^{3}$. Expongo a continuación sus consideraciones:

En primer lugar, se ha producido la inversión de la relación existente entre la producción y el mercado. La gran empresa capitalista

\footnotetext{
2 Díez-Picazo (2007) 157.

3 Martínez de Aguirre (1994) 36 y ss.
} 
no permite que la producción se adapte al mercado, sino que debe ser al revés. En la sociedad de consumo es el mercado quien tiene que adaptarse a las exigencias de la producción a través de la captación de los consumidores. La producción en masa obliga a dar salida en el mercado a los bienes así producidos, cuya adquisición es impuesta al consumidor a través de técnicas muy diversas: marketing, diversificación artificiosa de los productos, reducción deliberada de su vida útil, generalización de nuevos mecanismos de financiación...

En segundo lugar, las nuevas técnicas de producción, comercialización y distribución provocan un mayor distanciamiento entre el productor y el consumidor, separados económicamente por una cadena de intermediarios, y físicamente por la lejanía entre el centro de producción y el lugar de consumo: lejanía que repercute mucha veces, por otro lado, en un creciente desconocimiento de las características reales de los productos puestos en el mercado por el distribuidor o comerciante más cercano al consumidor final, que es con quien éste se relaciona directamente. Asimismo, debe destacarse la creciente complejidad y sofisticación de los productos, y la rapidez con que se producen cambios e innovaciones, a veces puramente cosméticos. Todo ello repercute en la opacidad del mercado frente al consumidor, que carece de fuentes de información fiables y de conocimientos propios suficientes para tomar decisiones razonables.

En tercer lugar, se han de resaltar los mayores riesgos personales y patrimoniales que supone la producción y distribución en masa: la posibilidad de que se produzcan daños como consecuencia de la adquisición o empleo de bienes defectuosos es cualitativa y cuantitativamente muy superior en este nuevo panorama socioeconómico. Esto quiere decir tanto que los daños pueden afectar a un número muy importante de personas (intoxicaciones masivas, defectos de diseño que afectan a todos los productos fabricados conforme al mismo, etc.), como que la intensidad de esos daños puede alcanzar niveles hasta hace poco tiempo desconocidos (los ejemplos de la talidomida o de la intoxicación masiva por consumo de aceite de colza desnaturalizado son tristemente célebres). De estos daños, los más importantes, que han actuado como motor de la adopción de sistemas específicos de protección, son los personales - relativos a 
la salud y seguridad de las personas-, pero no puede desdeñarse la importancia de los puramente patrimoniales.

Desde luego, la contratación estandariza mediante condiciones generales de la contratación tiene, como señala $\mathrm{ALFARO}^{4}$ a quien sigue Martínez de AguirRes ${ }^{5}$, ciertos efectos ventajosos: las condiciones generales provocan una reducción de los costes de celebración y regulación de los contratos; favorecen la división de tareas entre los miembros de la organización empresarial; facilitan la coordinación entre estos y hacen posible el cálculo anticipado del coste de producción de bienes y servicios que ofrece la empresa. Pero lo más trascendente es que ha determinado que el contrato mediante negociación previa haya dejado de ser el paradigma y que haya hecho falta replantearse el papel de la autonomía de la voluntad en el Derecho de contratos.

\section{Otros FACTORES}

A las anteriores consideraciones, cabe añadir ahora otros factores que incrementan la necesidad de reformular el Derecho de la contratación. Es el caso de la globalización, la multiplicación de los mercados —incluyendo el digital—y de las relaciones transfronterizas, además de la existencia de estructuras supranacionales que han impulsado el nacimiento de cuerpos de Derecho que se ocupan de esta materia sirviéndose de nuevos puntos de vista y de nuevos criterios (cfr. apartado III de la Exposición de Motivos de la Propuesta de Modernización del Código Civil en materia de Obligaciones y Contratos elaborada por la Comisión General de Codificación, Sección de Derecho Civil).

\section{Desajuste ENTRE los PRinCipios CODiCiales Y EXTRACODICIALES DEL DERECHO DE CONTRATOS}

Nos encontramos en el ordenamiento jurídico español con un Código Civil que parte de un modelo de contrato asentado en los

Alfaro (1991) 28.

Martínez de Aguirre (1994) 38. 
principios de autonomía privada (art. 1255) y libertad formal (art. 1278) y con una legislación relativamente reciente en que la protección de los consumidores determina limitaciones de tales principios. Es el caso, básicamente, de la Ley 7/1998, de 13 de abril, sobre condiciones generales de la contratación (LCGC) y del Texto Refundido de la Ley General para la Defensa de los Consumidores y Usuarios (TRLGDCU), aprobado por Real Decreto Legislativo 1/2007, de 16 de noviembre; textos legales a los que añadir otros muchos relativos a publicidad, crédito al consumo, ordenación del comercio minorista, venta a plazos de bienes muebles, aprovechamiento por turno de bienes inmuebles de uso turístico, servicios de la sociedad de la información, comercialización a distancia de servicios financieros.

Gran parte de esta normativa tiene su origen en el Derecho comunitario, en el que existen asimismo otras normas aplicables a contratos con consumidores, ya aprobadas o en tramitación, como la Propuesta de Reglamento relativo a una normativa común de compraventa europea ${ }^{6}$, la Propuesta de Directiva relativa a determinados aspectos de los contratos de suministro de contenidos digitales ${ }^{7}$ y la Propuesta de Directiva relativa a determinados aspectos de los contratos de compraventa en línea y otras ventas a distancia ${ }^{8}$.

\section{JURISPRUDENCIA SOBRE CONTROL DE CONTENIDO DE LOS CONTRATOS CON CONSUMIDORES}

Como ha señalado CARrasco9 , ya antes de la promulgación de los textos legales que limitan los principios de autonomía privada y libertad formal la jurisprudencia comenzó a ejercer un control de contenido de los contratos por dos vías, la de la integración y la de la interpretación contractual.

La primera vía acude a las previsiones del art. 1258 CC, en que se establece que los contratos obligan no sólo al cumplimiento de lo expresamente pactado, sino también a todas las consecuencias que, según su naturaleza, sean conformes a la buena fe, al uso y a la

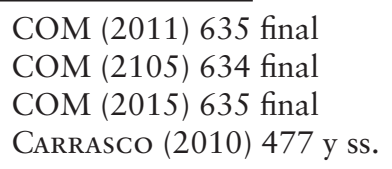


ley. Se trata de una norma de integración contractual que impone deberes implícitos de buena fe. Pero «sólo hay un paso desde interpretar el art. $1258 \mathrm{CC}$ como regla de competencia, que permite al juez imponer ex bona fide obligaciones contractuales a una parte, más allá de lo expresamente pactado, a hacerla funcionar como regla de control de validez, por la que se declaran inválidos por medio de una exceptio doli determinados contenidos contractuales pactados, que son contrarios a las exigencias de la buena fe.

El procedimiento para este tránsito puede reconstruirse teóricamente de dos formas, aunque de hecho el juicio aplicado por el operador será materialmente el mismo, y ni seguramente él mismo podrá discriminar si ha practicado una u otra aventura argumentativa. Pues, en efecto, cabe proceder integrando previamente el contrato en cuestión con una regla exigida por la buena fe, y suprimiendo a continuación el pacto contractual que es contrario a este contenido así integrado, o cabe proceder confrontando directamente el pacto cuestionado con las exigencias de la buena fe, y luego, eventualmente integrar con la buena fe la laguna producida por la nulidad ${ }^{10}$. Las poco matizadas (y muchas veces innecesarias) declaraciones de la jurisprudencia de casación confirman al intérprete que la protección específica de la normativa de consumidores es un «desarrollo» del art. 1258 CC y que este precepto contiene una norma de control de validez de los pactos contrarios a la buena fe» ${ }^{11}$.

La segunda vía recurre al «uso invalidante de la regla de interpretación contra proferentem» del art. 1288 CC. La jurisprudencia no se limita a interpretar términos contractuales oscuros de la forma más favorable para el adherente, sino que simula la existencia de problemas interpretativos donde está claro el término en cuestión, y anula el término discutido por el procedimiento indirecto de hacerlo deliberadamente oscuro, y luego interpretarlo en contra del predisponente.

10 SSTS (Sala 1. ${ }^{\text {a) }} 27$ enero 1977 (RJ 1977, 121) y 26 mayo 1986 (RJ 1986, 2823).

11 SSTS (Sala 1. ${ }^{\text {) }} 19$ noviembre 1994 (RJ 1994, 8539) y 14 febrero 2000 (RJ 2000, 1236). 


\section{QuÉ HACER EN RELACIÓN CON LOS DESAJUSTES LEGALES Y JURISPRUDENCIALES}

Según se ha expuesto, tenemos en el ordenamiento español y cuerpo legal que vertebra el Derecho de obligaciones y contratos - y los demás sectores del Derecho privado-, el Código Civil, y un conjunto normativo extracodicial, tanto nacional como comunitario, que no se ajusta a los principios de aquel; y también se dan pronunciamientos jurisprudenciales que en algún que otro caso aportan soluciones que se separan de la interpretación sistemática de las normas aplicables.

Como ha señalado Delgado Echeverría ${ }^{\mathrm{I} 2}$, las normas aplicadas por los Tribunales, decisivas para atender los conflictos más frecuentemente exteriorizados en el campo del Derecho del tráfico, no son las del Código Civil. En muchos casos porque las normas proceden de abundantes disposiciones extracodiciales muy difíciles de cohonestar con las del Código o directamente contrarias a sus principios, como buena parte del llamado Derecho del consumo. Y, lo que es más importante, porque las doctrinas con que los Tribunales motivan sus fallos citando artículos del Código no son aplicación de este, sino el producto de una evolución interpretativa de las disposiciones del mismo que solo razonamientos artificiosos pueden derivar de aquellas disposiciones, cuando no son fruto del puro y peligroso decisionismo judicial.

\section{¿Qué hacer en estas circunstancias?}

La primera opción es confiar en el buen juicio de los Tribunales a la hora de enjuiciar los asuntos que le ocupan en relación con el Derecho de los contratos, tanto si afecta a los consumidores como si no.

Mas esta opción significa inclinarse por un Derecho del caso, de corte anglosajón, que no es el nuestro, un Derecho judicial que no asegura los principios constitucionales de legalidad y seguridad ${ }^{13}$.

Si partimos de que la legislación del Derecho contractual español se caracteriza por su dispersión, por bascular entre principios no

12 Delgado Echeverría (2010) 16.

13 Delgado Echeverría (2010) 17. 
coincidentes y, en muchos casos contradictorios, por su aplicación conforme a criterios que no se corresponden con su literalidad ni con la voluntad del legislador, por su limitada eficacia social, parece indispensable una modificación legislativa. $\mathrm{Y}$ a este respecto cabe considerar, básicamente, dos posibilidades: a) un único texto legal que regule la teoría general del contrato con reglas especiales para los contratos con consumidores; b) un texto legal —o varios— con distinta regulación para los contratos entre particulares $(\mathrm{P} 2 \mathrm{P})$, entre profesionales y consumidores (B2C) y entre empresarios (B2B); incluso para los que se celebren entre grandes y medianas o pequeñas empresas.

La primera solución supone continuar con el planteamiento codificador. El texto legal que regule la teoría general del contrato viene a ser un Código, con su carácter vertebrador. Las reglas de protección de los consumidores tendrían carácter especial, esto es, el de normas ad hoc por razones de orden subjetivo - contrata un consumidor con un empresario-, con principios propios, aunque no necesariamente opuestos a los del Derecho contractual común.

La segunda solución supone compartimentar el Derecho contractual. No habría un Derecho de contratos común sino reglas distintas en función de los sujetos intervinientes. Pero esto conduce a la dispersión normativa, con los inevitables problemas de coordinación, lagunas e incluso antinomias.

La primera solución es la que se propugnó por la Sección de Derecho Civil de la Comisión General de Codificación en su Propuesta de Modernización del Código Civil en materia de Obligaciones y Contratos (PMDOC, 2009), y la que propugna la Asociación de Profesores de Derecho Civil en su Propuesta de Código Civil (PCC, 2015).

La Exposición de Motivos de la primera de estas propuestas se refiere al tema en los siguientes términos:

Singulares dificultades han producido, en la concepción y redacción del presente borrador de anteproyecto de ley, la relación del moderno Derecho de obligaciones y contratos con las incesantes normas aparecidas en los últimos veinte o veinticinco años en la materia que hoy se conoce como Derecho de Consumo y, en particular, con el régimen jurídico de los contratos con consumidores. No puede desconocerse que estas regulaciones modernas significan un cambio en los 
puntos de vista de valoración de determinadas circunstancias que alteran en profundidad el Derecho tradicional. Ante ello puede el legislador adoptar dos posibles posturas. De acuerdo con la primera, todas las normas relativas al Derecho de Consumo, cualquiera que sea su procedencia, y cualquiera que fuera su trascendencia, como pertenecientes a un Derecho especial, deben subsistir en leyes especiales y el Código civil todo lo más que puede hacer es realizar una somera remisión a tales normas, del tipo de las que los codificadores de 1889 realizaron a tantas leyes especiales. No puede ocultarse que este tipo de solución sería preferida por los especialistas en la materia que profesan lo que algún autor llamó la «especialización científica» y considerada como una intrusión en un cuerpo de leyes, por más que estos últimos tengan vocación de universalidad y penetren en la materia que desean monopolizar. La segunda posibilidad es recoger por lo menos el núcleo sustancial de la mayor parte de las reglas especiales, que tienen su origen en directivas europeas y que han sido luego incorporadas a leyes españolas, realizando la remisión solo a aquellos puntos en que el casuismo de las normas pueda resultar mayor. En este punto, como en otros, el anteproyecto se alinea con la ley alemana de modernización del Derecho de obligaciones y como ella ha preferido recoger el conjunto de normas sustanciales reguladoras de la susodicha materia.

En el sentido indicado, la PMDOC incluye la regulación de las condiciones generales de la contratación (arts. 1261-1264), los contratos celebrados fuera de los establecimientos mercantiles (arts. 1265-1266), la protección de los consumidores en los contratos a distancia (art. 1267) y la contratación electrónica (art. 1268).

Por su parte, la PCC incluye reglas sobre exigencias formales en la contratación con consumidores (art. 523-4), condiciones generales de la contratación (arts. 525-5 a 525-9), contratos con consumidores (arts. 528-1 a 528-10) y compraventa de bienes de consumo (arts. 541-1 a 541-17). En su Exposición de Motivos se señala que la regulación contenida en el Libro V de la PCC («De las obligaciones y contratos») comprende todo tipo de contratos privados; también la contratación de consumo, de manera que ya no es necesario optar por una hipotética naturaleza civil o mercantil de los contratos mixtos. Sólo se excluyen aquellos contratos que disfrutan ya de 
una regulación unitaria en leyes especiales, como es el caso, entre otros, de los arrendamientos urbanos, del contrato de seguro, de los contratos publicitarios, de los contratos de transporte. Tampoco se incorporan aquellos contratos de consumo cuya regulación por el Derecho de la Unión Europea resulta excesivamente reglamentista y cambiante para su codificación. También se indica en la Exposición de Motivos de la PCC que el último Capítulo del Título II se dedica a los contratos de consumo, pero que a lo largo de todo el Título se han ido insertando referencias a los consumidores, que también se encuentran en el Título I. A esto se añade la siguiente consideración:

Cabe pensar que, existiendo un Capítulo dedicado específicamente a los contratos de consumo, toda regla relativa a los consumidores debería encontrarse en el mismo. Tal proceder, sin embargo, acaso daría una imagen falsa de la realidad, pues llevaría a pensar que la contratación entre consumidores y empresarios no es sino una excepción al régimen general.

Por el contrario, la idea que se ha incorporado a la Propuesta es la de que las reglas generales incluyen, cuando es oportuno, este ámbito de la contratación. No se trata, por ejemplo, de que la regla sea la de que se presume la solidaridad en caso de pluralidad de sujetos, pero que hay una excepción para el caso de contratos de consumo. Se trata más bien de que la regla general incluye la presunción de solidaridad y la de mancomunidad, según los casos (artículo 513-2.b). Desde este punto de vista, el Capítulo VIII se limita a recoger determinadas definiciones, prohibiciones y deberes del profesional o empresario, procedentes en su mayor parte del Texto Refundido de la Ley General de Defensa de los Consumidores y Usuarios y otras leyes complementarias. Se persigue, de este modo, que el Código Civil establezca el marco general de normas tuitivas del consumidor, pero en absoluto se agota la materia, sin perjuicio de incorporar en algunos de los Títulos dedicados a los contratos en particular la regulación que el mencionado Texto Refundido dedica a determinados contratos específicos de consumo.

Esta solución, la de incorporar a un texto de Derecho contractual general disposiciones relativas a la protección de los consumidores, es 
la del Proyecto de Marco Común de Referencia (Draft of Common Frame of Reference; DCFR), pero no el de la Propuesta de Código Mercantil de la Sección de Derecho Mercantil de la Comisión General de Codificación (PCM, 2013), que en su Exposición de Motivos declara lo siguiente:

Derecho mercantil y protección de los consumidores.

I-30. Importa destacar que se ha tomado como criterio general el de no incorporar a este Código mercantil las normas de protección de los consumidores, que se consideran vigentes y respetando su imperatividad, se ha considerado, en efecto, que habiéndose promulgado el texto refundido de la Ley General para la Defensa de los Consumidores y Usuarios, en fecha muy reciente, y tratándose de un texto legal equiparable a un Código sobre la materia, parecía poco adecuado alterar ese planteamiento legislativo, de manera que se respeta la diferencia de las normas de protección de los consumidores como ajenas a la regulación del Código mercantil.

\section{LA ADMINISTRATIVIZACIÓN DEL CONTRATO}

Hasta el momento hemos señalado cómo la estandarización y producción de contratos en masa ha determinado ciertas limitaciones del principio de autonomía privada para la protección de los consumidores. Pero además de tales limitaciones, cabe hacer alguna alusión al intervencionismo administrativo en material contractual.

Se ha señalado que las reglas sobre el contrato y la responsabilidad, expedientes indispensables para la defensa de los consumidores, no bastan ${ }^{14}$. De un lado, su utilidad limitada a un círculo restringido de sujetos, por la eficacia relativa del contrato y de las sentencias; y de otro, porque actúan a posteriori, cuando el incumplimiento y el daño ya se han producido, lo que no resulta satisfactorio para los consumidores, que prefieren prevención a reparación. Además, contrato y responsabilidad exigen el recurso a los tribunales, lo que puede ser un obstáculo insalvable, sobre todo por los costes desproporcionados de las pequeñas reclamaciones.

14 Casas Vallés (I99i) 79. 
Ciertamente, una de las vías para reducir las dificultades que encuentra el consumidor para acudir a la vía judicial ha consistido en el reconocimiento de la legitimación a las asociaciones de consumidores, a las que se otorga el beneficio de la justicia gratuita [art. 37 d) TRLGDCU]; también el derecho a una compensación sobre la cuantía de la indemnización durante el tiempo que transcurra desde la declaración de responsabilidad hasta su pago efectivo (art. 134 TRLGDCU). Sin embargo, estas medidas son de eficacia limitada; y la propia LGDCU no oculta su preferencia por el arbitraje (cfr. arts. 57 y 58 TRLGDCU), que pese a ser un medio de resolución de conflictos de carácter privado, está fuertemente administrativizado.

Dotar a los consumidores de una sólida posición contractual puede servir de muy poco si luego ha de ser el propio afectado quien asuma la carga de su defensa poniendo en marcha el aparato judicial. Así es que para satisfacer la defensa de los consumidores se ha recurrido a intensificar el fenómeno del intervencionismo administrativo. No solo por la vía de someter a las empresas a un cúmulo de exigencias y requisitos para el desarrollo de su actividad (algo ya habitual), sino dando un paso más, atribuyendo a la Administración la facultad de controlar el correcto cumplimiento de las normas imperativas destinadas a mejorar la posición contractual —esto es, jurídico-privada- de los consumidores.

De este modo, la intervención se proyecta también sobre el contrato, alcanzando a su perfeccionamiento, contenido obligatorio y ejecución. A la relación entre empresa y consumidor viene a superponerse así otra entre aquélla y la Administración, de tal forma que muchas de las obligaciones privadas resultantes del contrato adquieren, al propio tiempo, una proyección jurídico-pública. El empresario queda doble e independientemente sujeto: frente al consumidor en virtud del contrato y frente a la Administración en virtud de las facultades de control que ésta tiene atribuidas, con la consecuencia de que un mismo acto puede ser, a la vez, ilícito civil y administrativo. Ello hace posible una actuación inmediata y de oficio de la Administración, que acaba asumiendo como propios los intereses contractuales del consumidor y actuando de hecho-aun sin serlo- como parte de la relación. 
Como ejemplo de esta realidad puede citarse la legislación relativa a las garantías por la percepción de cantidades anticipadas en la compraventa de viviendas (Ley 57/1968, de 27 de julio; ahora en la Disposición Adicional Primera de la Ley 38/1999, de 5 de noviembre, de Ordenación de la Edificación (LOE). Conforme a esta normativa, el promotor ha de garantizar la restitución de tales cantidades con aval o seguro de caución. Durante muchos años esta garantía no solía prestarse. Los promotores, en un mercado al alza, no tenían inconveniente en restituir las cantidades anticipadas y volver a vender la vivienda a mayor precio. En los últimos tiempos, con un mercado a la baja, los consumidores han comenzado a exigir la prestación de la garantía; y en muchos casos los promotores se mostraron reacios, sabedores de que para el consumidor resultaba desproporcionado acudir a los tribunales para que se otorgara la garantía. En tales circunstancias, resulta muy efectivo hacer saber al promotor que puede ser sancionado por la Administración si incumple con su obligación de garantizar; y no solo por una vivienda sino por toda la promoción inmobiliaria.

En cualquier caso, la actuación de la Administración para el consumidor no sólo tiene ventajas en términos de coste y eficacia, sino también inconvenientes y riesgo. En primer lugar, porque la facultad de imponer sanciones está sometida a exigencias de tipicidad y culpabilidad; en segundo lugar, porque puede producirse cierta confusión en cuanto a los medios disponibles y, en su caso, la jurisdicción competente, abriéndose además paso al riesgo de decisiones contradictorias.

\section{ACCIONES COLECTIVAS INDEMNIZATORIAS}

El art. 20.1 de la Ley 26/1984, de 19 de julio, General para la Defensa de los Consumidores y Usuarios (LGDCU) supuso la superación de los problemas derivados de la legitimación estrictamente individual para el ejercicio de acciones inhibitorias o de cesación, al contemplar que pudieran interponerlas las asociaciones de consumidores y usuarios, aunque no estuvieran expresamente tipificadas o contempladas por alguna otra norma. En el mismo sentido, se 
pronunciaron el art. 25.1 Ley 34/1988, de 11 de noviembre, General de Publicidad (LGP), respecto de la publicidad ilícita, el art. 19.2 a) de la Ley 3/1991, de 10 de enero, de Competencia Desleal (LCD), en relación con los actos de competencia desleal, y el art. 16.3 de la Ley 7/1998, de 13 de abril, de Condiciones Generales de la Contratación (LCGC), en cuanto a cláusulas abusivas.

El caso es que no se reconocía legitimación a las asociaciones de consumidores y usuarios para el ejercicio de acciones colectivas indemnizatorias, ni en la LGDCU ni en el art. 7.3 Ley Orgánica 6/1985, de 6 de julio, Orgánica del Poder Judicial (LOPJ), sin perjuicio de que el art. 12.2 LCGC permitiera a las asociaciones de consumidores y usuarios, una vez declarada nula una condición general, solicitar indemnización por los daños y perjuicios causados; y de que la STS (Sala 2. $\left.{ }^{a}\right) 26$ septiembre 1997 (RJ 1997, 6366), relativa a al envenenamiento masivo por consumo de aceite de colza desnaturalizado, acogiendo el recurso formulado por la Organización de Consumidores y Usuarios (OCU), que intervino en el proceso como representante de un gran número de consumidores afectados, reconociera indemnización a los perjudicados identificados en el proceso, «aunque no estén amparados por la postulación, es decir, aunque no aparezcan directamente representados en el proceso».

El reconocimiento de las acciones colectivas indemnizatorias se produce con la LEC (Ley 1/2000, de 7 de enero), conforme a los arts. 6.1.7 $7^{\circ}, 7.7,11,13.1,15,76.2 .1 .^{\circ}, 78.4,221,222.3,256.1 .6^{\circ}$ y 519.

Esta legitimación para el ejercicio de las acciones colectivas indemnizatorias plantea una serie de cuestiones procesales, como las relativas a su ámbito de aplicación; a los niveles de legitimación para su ejercicio según se trate de grupos de afectados, asociaciones de consumidores y usuarios o entidades legalmente constituidas para la defensa de estos; a la concurrencia de legitimaciones (intervención individual de consumidores y acumulación de acciones y de procesos); al llamamiento a los perjudicados y comunicación previa a la demanda; y al contenido, eficacia y ejecución de la sentencia. Todas estas cuestiones han sido objeto de tratamiento por ilustres juristas. Especialmente por los procesalistas, y también por algunos civilistas. Pero no me detendré a tratar tales cuestiones, que pertenecen a una parcela de la ciencia jurídica que me es ajena. 
En lugar de ello, me referiré sucintamente a ciertos aspectos de la Recomendación de la Comisión Europea de 11 de junio de 2013 sobre los principios comunes aplicables a los mecanismos de recurso colectivo [en inglés, collective redress, que vienen a ser lo que nosotros conocemos como acciones colectivas y los norteamericanos como class actions] de cesación o de indemnización en los Estados miembros en caso de violación de derechos reconocidos por el Derecho de la Unión (2013/396/UE), centrándome en las acciones colectivas de indemnización, en cuanto tienen cierta trascendencia sustantiva.

\subsection{Constitución de la parte demandante: principio opt-in}

La Comisión se decanta por la constitución de la parte demandante conforme al principio de la participación voluntaria (opt-in), esto es, con el consentimiento expreso de las personas físicas o jurídicas que afirmen haber sufrido daños (apartado 21). Como regla, es necesaria la declaración de voluntad expresa de los sujetos afectados para que le alcance la eficacia de la resolución. Por tanto, la sentencia solo será vinculante para los adheridos; los demás perjudicados mantienen la facultad de incoar demandas por daños y perjuicios a título individual.

No obstante, se deja abierta la puerta al principio opt-out, — sentencia vinculante para pertenecientes al grupo de afectados, salvo los que explícitamente se hayan separado de él一, en cuanto se establece que cabe en virtud de disposiciones legales o de resoluciones judiciales que lo justifiquen debidamente por razones de buena administración judicial. Pero este principio opt-out resulta problemático, en especial en asuntos transfronterizos, pues las partes con domicilio en otros países distintos de aquel en que se ha ejercitado la acción colectiva pueden desconocer la existencia del litigio en curso y, en consecuencia, participar en él sin su consentimiento. En el ordenamiento jurídico español rige el principio opt-in, tal y como resulta de los arículos 13.1 y 15 LEC.

El principio opt-in determina la facultad de desistimiento de todo miembro de la parte demandante, que puede retirarse de esta parte en cualquier momento antes de que se dicte la resolución definitiva 
o de que el asunto se resuelva válidamente de otra manera, siempre que se cumplan las mismas condiciones que se aplican a la retirada en las acciones individuales, y sin que se les prive de la posibilidad de proseguir con su demanda de otra forma, si ello no perjudica a la buena administración de la justicia (apartado 22).

Del mismo modo, las personas físicas o jurídicas que aleguen haber sufrido daños en el asunto que se enjuicia, pueden adherirse a la parte demandante en cualquier momento antes de que se dicte resolución definitiva o de que se resuelva válidamente de otra manera, si ello no perjudica a la buena administración de la justicia (apartado 23).

La Comisión considera que el sistema de participación voluntaria preserva la autonomía de las partes para decidir si se persona o no en el litigio y permite determinar con mayor facilidad la cuantía de la demanda colectiva, que consiste en la suma de todas las demandas individuales. Y en este sentido, resulta especialmente relevante la facilitación de información sobre el ejercicio de las acciones colectivas, para garantizar a os perjudicados la oportunidad de participar en ellas. Esta cuestión también es objeto de tratamiento en la Recomendación de la Comisión, que en su apartado 10 dispone que «los Estados miembros deberán garantizar que la entidad representante o el grupo de demandantes puedan difundir información sobre la presunta violación de derechos reconocidos por el Derecho de la Unión y su intención de interponer una acción de cesación, así como sobre un caso de daños masivos y su intención de interponer una acción por daños y perjuicios en forma de recurso colectivo".

Esta recomendación relativa a la información previa a la interposición de la demanda se encuentra recogida en el artículo 256.1.6. ${ }^{\circ}$ LEC, que prevé como diligencia preliminar la de quien pretenda iniciar un proceso para la defensa de los intereses colectivos de consumidores y usuarios al objeto de concretar a los integrantes del grupo de afectados cuando, no estando determinados, sean fácilmente determinables. A tal efecto el tribunal adoptará las medidas oportunas para la averiguación de los integrantes del grupo, de acuerdo a las circunstancias del caso y conforme a los datos suministrados por el solicitante, incluyendo el requerimiento al demandado para que colabore en dicha determinación. 
Por su parte, el artículo 15.2 LEC establece que en los procesos en el que estén determinados o sean fácilmente determinables los perjudicados por el hecho dañoso, el demandante o demandantes deberán haber comunicado previamente su propósito de presentación de la demanda a todos los interesados; y en este caso, tras el llamamiento, el consumidor o usuario podrá intervenir en el proceso en cualquier momento, pero solo podrá realizar los actos procesales que no hubieran precluido.

Y en relación con la información relativa a acciones colectivas ya ejercitadas, al que también se refiere el apartado 10 de la Recomendación de la Comisión, el art. 15.1 LEC dispone que en los procesos promovidos por asociaciones o entidades constituidas para la protección de los derechos e intereses de los consumidores y usuarios, o por los grupos de afectados, se llamará al proceso a quienes tengan la condición de perjudicados por haber sido consumidores del producto o usuarios del servicio que dio origen al proceso, para que hagan valer su derecho o interés individual. Este llamamiento se hará por el secretario judicial publicando la admisión de la demanda en medios de comunicación con difusión en el ámbito territorial en el que se haya manifestado la lesión de aquellos derechos o intereses. Y el art. 15.3 LEC regula el supuesto de que el proceso tenga que ver con un hecho dañoso que perjudique a una pluralidad de personas indeterminadas o de difícil determinación: el llamamiento suspenderá el curso del proceso por un plazo que no excederá de dos meses y que el secretario judicial determinará en cada caso atendiendo a las circunstancias o complejidad del hecho y a las dificultades de determinación y localización de los perjudicados. El proceso se reanudará con la intervención de todos aquellos consumidores que hayan acudido al llamamiento, no admitiéndose la personación individual de consumidores o usuarios en un momento posterior, sin perjuicio de que estos puedan hacer valer sus derechos o intereses conforme a lo dispuesto en los artículos 221 y 519 LEC.

Téngase en cuenta que estos medios de publicidad de acciones colectivas en curso no se aplican al ejercicio de una acción de cesación para la defensa de los intereses colectivos y de los intereses difusos de los consumidores y usuarios (art. 15.4. LEC). 


\subsection{Principio «quien pierde, paga»}

La Comisión recomienda que los Estados miembros se aseguren de que la parte perdedora en una acción colectiva reembolse las costas judiciales necesarias soportadas por la parte ganadora (principio "quien pierde, paga»), siempre que se cumplan las condiciones previstas en la legislación nacional aplicable (apartado 13). Con este principio se trata, por un lado, de disuadir a los demandantes de interponer demandas temerarias; y por otro, de fomentar la interposición de demandas colectivas motivadas ${ }^{15}$.

En el ordenamiento jurídico español este principio no se formula con carácter específico para las acciones colectivas, sino con carácter general para todo tipo de procesos. Es el principio del vencimiento, según el cual, las costas de la primera instancia se imponen a la parte que haya visto rechazadas todas sus pretensiones, salvo que el tribunal aprecie, y así lo razone, que el caso presentaba serias dudas de hecho o de derecho, teniendo en cuenta la jurisprudencia recaída en casos similares (cfr. art. 394.1 LEC). Pero si la estimación o desestimación de las pretensiones fuera parcial, cada parte abonará las costas causadas a su instancia, y las comunes por mitad, salvo que haya méritos para imponerlas a una de ellas por haber litigado con temeridad (cfr. art. 394.2 LEC). Se establece también un límite cuantitativo cuanto se impongan las costas al litigante vencido: solo estará obligado a pagar, de la parte que corresponda a los abogados y demás profesionales que no estén sujetos a tarifa o arancel, una cantidad total que no exceda de la tercera parte de la cuantía del proceso, por cada uno de los litigantes que hubieren obtenido tal pronunciamiento. A estos solos efectos, las pretensiones inestimables se valorarán en 18.000 euros, salvo que, en razón de la complejidad del asunto, el tribunal disponga otra cosa. Pero estos límites cuantitativos no se aplican si se aprecia temeridad (art. 394.3 LEC).

15 cfr. Informe de la Comisión al Parlamento Europeo, al Consejo y al Comité Económico y Social Europeo sobre la aplicación de la Recomendación de la Comisión, de 11 de junio de 2013; 25 de enero de 2018, COM (2018) 40 final. 


\subsection{Honorarios de los abogados y financiación de las acciones colectivas de indemnización}

La Comisión Europea recomienda que los Estados miembros garanticen que los honorarios de los abogados y su método de cálculo no creen ningún incentivo para emprender acciones judiciales que sean innecesarias desde el punto de vista de los intereses de las partes. En tal sentido, considera que no deben permitir los honorarios condicionales, esto es, el pacto de quota litis (apartados 29 y 30); y asimismo se recomienda que los Estados miembros prohíban calcular la remuneración o los intereses que percibirá quien financie los recursos colectivos a partir del informe fijado en el acuerdo alcanzado o la indemnización concedida (apartado 32). Se trata de limitar los honorarios profesionales de los abogados y la remuneración de financiadores de las acciones colectivas, por considerar que pueden determinar la interposición de demandas innecesarias. Sin embargo, tanto en relación con los honorarios profesionales como con relación a la remuneración de los financiadores, se admiten excepciones. En cuanto a los primeros, si hay una normativa nacional adecuada en casos de recursos colectivos; en relación con la segunda, si hay regulación (¿supervisión?) por una autoridad pública para garantizar los intereses de las partes.

En el ordenamiento español, el pacto de quota litis estuvo históricamente prohibido, sobre la base de considerarlo lesivo de los intereses de los abogados, que podían llegar a no recibir ninguna retribución alguna por sus servicios profesionales si se perdía el pleito. Hoy está admitido, desde la STS (Sala 3. ${ }^{\mathrm{a}}$ ) 4 noviembre 2008 (RJ 2009, 338). En la Recomendación de la Comisión, al margen de su ambigüedad — se insta a prohibir los honorarios y remuneraciones condicionales, pero se formulan excepciones no suficientemente definidas-, el planteamiento es otro. No es la defensa de los intereses de los abogados sino de la Administración de Justicia. Se trata de evitar que, sobre la base de que solo van a tener que pagar si algo obtienen, se interpongan demandas «innecesarias»; esto es, infundadas.

En relación con la financiación, la Recomendación de la Comisión apunta varias reglas. 
En primer lugar, que la parte demandante debería declarar al órgano jurisdiccional, al iniciarse el procedimiento, el origen de los fondos que va a utilizar para sufragar el ejercicio de la acción (Considerando 14).

En segundo lugar, que el órgano jurisdiccional debería suspender el procedimiento cuando, en caso de que se utilicen recursos financieros de tercero: a) exista un conflicto de intereses entre el tercero y la parte demandante y sus miembros; b) el tercero no disponga de recursos suficientes para cumplir sus compromisos financieros con la parte demandante que ha incoado el procedimiento de recurso colectivo; c) la parte demandante no disponga de recursos suficientes para hacer frente a los costes de la parte contraria en caso de que el procedimiento de recurso colectivo no prospere (Considerando 15).

Y, en tercer lugar, que los Estados miembros deberían garantizar que, cuando una acción de recurso colectivo esté financiada por un tercero privado, este tendrá prohibido: a) intentar influir en las decisiones procesales de la parte demandante, incluidas las transacciones; b) financiar una acción colectiva contra un demandado que sea un competidor del proveedor de fondos o contra un demandado del que dependa el proveedor de fondos; c) exigir intereses excesivos sobre los fondos prestados.

Como cabe apreciar, se trata de evitar que las condiciones de la financiación por terceros de las acciones colectivas incentiven el ejercicio de acciones colectivas abusivas o que den lugar a conflictos de intereses. Sin embargo, no hay vestigio en el ordenamiento jurídico español, ni en el de los demás Estados miembros de la Unión Europea, de reglas relativas a la financiación por terceros de acciones colectivas, pese a que, efectivamente, haya habido casos en que se ha dado.

\subsection{Reparación integral sin función punitiva}

La Comisión recomienda que la indemnización que se conceda a las víctimas de los daños masivos no sea superior a la que habrían obtenido si hubieran ejercitado una acción individual. Se rechaza, expresamente, que se concedan indemnizaciones punitivas, que son 
las que conceden a la parte demandante una indemnización superior al daño sufrido, ajenas a las tradiciones jurídicas de gran parte de los Estados miembros (cfr. Considerando 16 de la Recomendación), pues solo en el Reino Unido (Inglaterra y Gales), Irlanda y Grecia existen algunos supuestos, excepcionales, de indemnizaciones punitivas. La reparación, en consecuencia, ha de ser integral, reparadora de todo el daño efectivamente sufrido por el perjudicado, pero sin función punitiva o disuasoria.

\section{io. Consideraciones finales}

Aunque nuestros Códigos Civiles conservan muchas de las reglas contractuales heredadas del Derecho Romano, el Derecho de contratos ha sufrido una evidente evolución. Así, ha pasado de un carácter formal y limitado al consensual y abierto, con base en los principios de igualdad y libertad de las partes. Pero los progresos técnicos y de orden económico han abocado a un sistema de contratación en que predomina la predisposición del clausulado contractual. Se ha invertido la relación entre la producción y el mercado, se han distanciado, económica y físicamente, los productores y los consumidores, y se han incrementado los riesgos personales y patrimoniales de los consumidores; lo que ha dado lugar a la contratación estandarizada o con condiciones generales. A lo anterior se suma el fenómeno de la globalización.

Para dar solución a la nueva realidad contractual, se han formulado reglas especiales para los contratos con condiciones generales, o con consumidores, y se ha recurrido a un control del contenido de los contratos con base en precepto inicialmente formulados en otro contexto. Todo ello ha suscitado la cuestión de qué hacer para solventar los desajustes entre las normas aplicables y las soluciones dadas por los Tribunales. Cabría pensar en confiar en el buen juicio de los Tribunales. Pero esta no es nuestra tradición jurídica. Por el contrario, y en el ámbito de esta nuestra tradición, caben dos posibilidades: a) un único texto legal, tanto para la teoría general de los contratos como para las especialidades de los que se celebren con consumidores; b) diversos textos legales, según se trata de contratos 
entre particulares, entre profesionales y consumidores o entre empresarios, incluso distinguiendo entre grandes y medianas o pequeñas empresas. A nuestro juicio, resulta preferible la primera posibilidad.

Desde otra perspectiva, no hay que perder de vista la influencia del Derecho administrativo en relación con la protección de los consumidores; en especial, a través de reglas sancionadoras de los derechos de estos. Pues bien, en este contexto legal, jurisprudencial y doctrinal, también merecen atención los intentos de superar los problemas derivados de la legitimación estrictamente individual para el ejercicio de acciones para la protección de los consumidores, mediante la configuración de acciones colectivas, tanto de cesación como de indemnización. Este mecanismo está todavía en vía de construcción, tal y como resulta de la Recomendación de la Comisión Europea de 11 de junio de 2013 sobre los principios comunes aplicables a los mecanismos de recurso colectivo de cesación o de indemnización en los Estados miembros en caso de violación de los derechos reconocidos por el Derecho de la Unión (2013/396/UE), así como del correspondiente Informe de la Comisión ${ }^{16}$.

En tal Recomendación se apuntan algunas cuestiones con trascendencia sustantiva (principio de participación voluntaria, principio «quien pierde, paga», honorarios de abogados, financiación por terceros, reparación integral), que ponen de manifiesto la vigencia y alcance de algunas de las tradicionales reglas del Derecho contractual. Así, el principio de participación voluntaria (opt-in) supone la aplicación del principio de autonomía privada, pero también se contempla la posibilidad excepcional del principio opt-out. Y se establecen reglas que no atienden al interés de las partes, sino de la Administración de Justicia, como las relativas a las costas («quien pierde, paga») y los honorarios de los abogados, que pretenden, básicamente, evitar demandas infundadas. En el mismo sentido, las recomendaciones sobre financiación por tercero de las acciones colectiva tienen por objeto evitar abusos y conflictos de intereses. Finalmente, el rechazo de la indemnización punitiva supone una clara preferencia por el principio compensatorio del Derecho de daños, en la tradición jurídica continental.

16 COM (2018) 40 final 


\section{I.BIBLIOGRAFÍA}

\section{a) Doctrina}

Alfaro Águila-Real, Jesús (1991): Las condiciones generales de la contratación (Madrid, Civitas).

Carrasco Perera, Ángel (2010): Derecho de Contratos (Cizur Menor, Thomson Reuters).

Casas Vallés, Ramón (1991): «Defensa de los consumidores y Derecho Civil», Revista Jurídica de Catalunya, vol. 91, pp. 79-120.

Delgado Echeverría, Jesús (2010): «Retos de la dogmática civil española en el primer tercio del siglo XXI». Disponible en http://www. codigo-civil.net/nulidad/lodel/docannexe.php?id=816 [Fecha de consulta: $1 / 12 / 2018]$.

Díez-Picazo y Ponce de León, Luis (2007): Fundamentos del Derecho Civil Patrimonial, vol. I., Introducción. Teoría del Contrato, $6 .{ }^{2}$ edición (Cizur Menor, Civitas).

Martínez de Aguirre y Aldaz, Carlos (I994): «Trascendencia del principio de protección a los consumidores en el Derecho de obligaciones», Anuario de Derecho Civil, vol. 47, No. 1: pp. 31-90.

\section{b) Normativa:}

Código Civil español, actualizado a 05.08.2018.

Ley Orgánica 6/1985, de 6 de julio, Orgánica del Poder Judicial (LOPJ).

Ley 34/1988, de 11 de noviembre, General de Publicidad (LGP), Texto

Refundido de la Ley 7/1998, de 13 de abril, sobre condiciones generales de la contratación (LCGC).

Ley 38/1999, de 5 de noviembre, de Ordenación de la Edificación (LOE). Ley 3/1991, de 10 de enero, de Competencia Desleal (LCD).

Ley $1 / 2000$, de 7 de enero (LEC).

Ley General para la Defensa de los Consumidores y Usuarios (TRLGDCU), aprobado por Real Decreto Legislativo 1/2007, de 16 de noviembre.

Propuesta de Reglamento relativo a una normativa común de compraventa europea [COM(2011) 635 final].

Propuesta de Directiva relativa a determinados aspectos de los contratos de compraventa en línea y otras ventas a distancia [COM(2015) 635 final]. 
Recomendación de la Comisión Europea de 11 de junio de 2013 sobre los principios comunes aplicables a los mecanismos de recurso colectivo de cesación o de indemnización en los Estados miembros en caso de violación de los derechos reconocidos por el Derecho de al Unión (2013/396/UE).

Informe de la Comisión al Parlamento Europeo, al Consejo y al Comité Económico y Social Europeo sobre la aplicación de la Recomendación de la Comisión, de 11 de junio de 2013, sobre los principios comunes aplicables a los mecanismos de recurso colectivo de cesación o de indemnización en los Estados miembros en caso de violación de los derechos reconocidos por el Derecho de al Unión (2013/396/ UE) [COM(2018) 40 final].

\section{c)Jurisprudencia citada ${ }^{17}$ :}

STS (Sala 1. ${ }^{\text {a })} 27$ enero 1977 (RJ 1977, 121).

STS (Sala 1. $\left.{ }^{a}\right) 26$ mayo 1986 (RJ 1986, 2823).

STS (Sala 1.a) 19 noviembre 1994 (RJ 1994, 8539).

STS (Sala 1.a) 14 febrero 2000 (RJ 2000, 1236).

STS (Sala 1. $\left.{ }^{a}\right) 4$ noviembre 2008

STS (Sala 2. $\left.{ }^{a}\right) 26$ septiembre 1997 (RJ 1997, 6366).

STS (Sala 3. $\left.{ }^{a}\right) 4$ noviembre 2008 (RJ 2009, 338).

17 STS: Sentencia del Tribunal Supremo (español); RJ: Repertorio de Jurisprudencia (Aranzadi). 



\title{
Avanços EM MATÉria de Direito DO CONSUMIDOR NO BRASIL: PANORAMA A PARTIR DOS 30 ANOS DA CONSTITUIÇÃO Federal de I988 e do Código de Defesa DO CONSUMIDOR
}

\author{
Developments in Consumers' Rights \\ IN BRAZIL: A PANORAMA OF THE THIRTY \\ YEARS OF THE FEDERAL CONSTITUTION \\ OF I988 AND BRAZILIAN CONSUMER \\ Defense Code
}

Gabriel Oliveira de Aguiar Borges ${ }^{1}$ Thiago Gonçalves Paluma Rocha ${ }^{2}$

Mestre em Direito pela Universidade Federal de Uberlândia (UFU). Professor da Faculdade Santa Rita de Cássia. Advogado. E-mail: gabrieloab@outlook.com

2 Doutor em Direito pela Universitat de València. Professor e Diretor de Inovação da Universidade Federal de Uberlândia (UFU). Coordenador da Rede Internacional de Processo Civil Internacional. Membro da Academia Brasileira de Direito Internacional (ABDI).E-mail: thiago.paluma@ufu.br 
Resumo. Relações de consumo são marcadas pela desigualdade, vez que o consumidor se encontra, via de regra, em posição de vulnerabilidade frente ao fornecedor, que detém suficiência técnica, econômica, jurídica, informacional, etc. Tendo isso em vista, a Constituição Federal de 1988, conhecida como «constituição cidadã», dada a ampla gama de direitos e garantias fundamentais tutelados, trouxe a proteção ao consumidor como direito fundamental e princípio da ordem econômica. Desde então, muitos têm sido os avanços em matéria de Direito do Consumidor no Brasil. No entanto, ainda há muito a ser desenvolvido. O objetivo do presente trabalho é analisar os desafios e perspectivas do Direito do Consumidor no Brasil.

Palavras-CHAve: Direito do Consumidor; Constituição de 1988; Proteção ao Consumidor no Brasil.

Abstract. Consumers relations are often unequal, given that the consumer is usually in a vulnerable position, as the provider is technically, economically, juridically and informationally self-sufficient. In order to fix it, the Federal Constitution of 1988, known as the "Civic Constitution» due to its wide range of fundamental rights and guarantees, has brought up consumers' protection as a fundamental right and a principle of the economic order. Since then, there have been many developments regarding Consumers' Rights in Brazil. However, there is still much to be developed. This work aims to analyse the challenges and perspectives of Consumers' Rights in Brazil.

KeYwords: Consumers' Rights; Constitution of 1988; Consumers' Protection in Brazil.

SUMARIO. Introdução. 1. Da proteção constitucional do consumidor. 2. O modelo híbrido do direito privado brasileiro: um código para iguais e outro para diferentes. 3. Da necessidade de atualização do Código de Defesa do Consumidor: 3.1 Do superendividamento; 3.2. Do comércio eletrônico; 3.3 Da resolução de conflitos. 4. Considerações finais. 5. Bibliografia. 


\section{INTRODUÇÃO}

Algumas relações jurídicas são marcadas por um desequilíbrio, uma verdadeira desigualdade entre as partes, as quais podem aparecer de várias maneiras, seja pela desproporção econômica, falta de compreensão de informações por uma das partes, dentre outras situações ensejadoras de vulnerabilidade de um dos sujeitos.

No direito privado, existia, em outros tempos, um padrão individualista $^{3}$, o qual acaba cedendo espaço a outros interesses, levando à necessidade de uma intervenção estatal em favor do vulnerável, com vistas a trazer, de volta, a igualdade jurídica, corrigindo elementos de desigualdade, cabendo ao Estado proteger a parte mais fraca ${ }^{4}$.

O reconhecimento de diferentes direitos subjetivos se deu em etapas diferentes, começando por algumas situações específicas, como o direito do trabalhador, que passa a ser tratado por disciplina jurídica específica, e culminando na concepção de direitos coletivos e difusos, onde se atribui a titularidade do direito a toda uma coletividade. A partir do momento em que coletividades de consumidores se organizam, surgem movimentos sociais que culminam com o surgimento do consumidor, em um tempo em que também apareciam os ambientalistas almejando à consolidação de um Direito Ambiental, dentre outros movimentos urbanos ${ }^{5}$.

O marco histórico da preocupação com direitos consumeristas é atribuído ao discurso realizado pelo ex-presidente estadunidense John Kennedy no Congresso dos Estados Unidos, em 1962, pregando a necessidade de proteção de alguns direitos básicos do consumidor, como a segurança, a informação, o direito de escolha e o direito de ser ouvido. A partir daí, inúmeras leis foram criadas naquele país, com normas de proteção aos consumidores ${ }^{6}$.

Em 1972, em Estocolmo, na Suécia, ocorre a Conferência Mundial do Consumidor e, no ano seguinte, a Comissão das Nações Unidas sobre os Direitos do Homem veio a deliberar que a pessoa consumidora deve gozar de quatro direitos fundamentais, que são

\footnotetext{
WALINE (1945) 19 et seq.

RIPERT (1937) 133.

RAMSAY (2001) 45-65.

Miragem (2014) 38.
} 
os mesmos quatro citados por Kennedy em seu discurso (segurança, informação sobre produtos, serviços e condições de contratação, escolha de bens alternativos de qualidade satisfatória e preços aceitáveis e o direito de ser ouvido nos processos decisórios em matéria consumerista). Também em 1973, a Assembleia Consultiva da Comunidade Europeia veio a aprovar a Resolução 543, originando a Carta Europeia de Proteção ao Consumidor ${ }^{7}$.

Em 1985, a Organização de Nações Unidas (ONU) edita a Resolução 39/248, estabelecendo, além da necessidade de proteção dos consumidores - considerando sua posição de vulnerabilidade -, uma regulação extensa da matéria, garantindo alguns objetivos, e.g., proteção da saúde e segurança do consumidor, promoção de interesses econômicos dos consumidores, acesso à informação adequada, permitindo-lhes escolher adequadamente os produtos e serviços conforme seus desejos e necessidades ${ }^{8}$.

No Brasil, promulga-se o Código de Defensa do Consumidor (CDC) no começo da década de 1990, devido à determinação constitucional do art. 48 do Ato das Disposições Constitucionais Transitórias da Constituição da República Federativa do Brasil (ADCT), estabelecendo normas de ordem pública, conforme art. $1^{\circ}$ do próprio CDC, com efetividade por intermédio da atribuição de competência jurisdicional tanto de ordem civil quanto penal e administrativa a vários órgãos estatais, reconhecendo, também, papel de destaque à sociedade civil organizada, através de associações de consumidores, dentre outras entidades de defesa consumerista.

No direito privado clássico, tínhamos um ordenamento jurídico privado girando em torno do Código Civil, a ponto de só se entender como direito o que se expressava no códex de natureza cível. Dentre os principais princípios do Direito Civil moderno, temos a autonomia da vontade, cujos principais expoentes se encontram no contrato e na propriedade, configurados pela liberdade de manifestação da vontade, com a correspondente vinculação ao pacto, por meio do princípio do pacta sunt servanda.

No início do século XX, ocorre sensível modificação no pacta sunt servanda e no princípio da autonomia da vontade. Em

STiglitz (1988) 54 et seq.

8 Miragem (2014) 39. 
consequência da impossibilidade de cumprimento das prestações pelas partes devido às guerras e crises econômicas, a jurisprudência francesa traz a chamada teoria da imprevisão, que teve, como leading case, o Caso da Compagnie General d'Éclairage de Bordeaux, em que áreas produtoras de carvão foram ocupadas em razão da guerra, aumentando o preço da matéria prima e, por conseguinte, o custo da prestação da concessionária de serviço público, com a necessidade, portanto, de revisão do contrato devido à guerra e suas consequências imprevisíveis? .

A partir da nova teoria, ressurge a cláusula rebus sic stantibus, ou «enquanto as coisas permanecerem as mesmas», corrigindo o desequilíbrio dos contratos devido à alteração das circunstâncias.

Após o término da Segunda Grande Guerra, os países capitalistas sofrem grande modificação em suas estruturas econômicas e modelos de negócio, massificando-se o crédito e a atividade publicitária, devido à crescente indústria de bens de consumo de massa.

Nesse contexto, o contrato, antes visto como acordo pessoal entre dois sujeitos, é profundamente alterado ${ }^{10}$, em um fenômeno conhecido como «despersonalização do contrato», considerando a ausência de contato direto entre os contratantes, de maneira tal a não existir mais negociação dos termos do ajuste, surgindo, assim, as chamadas «condições gerais dos contratos», bem como os «contratos de adesão» ${ }^{11}$.

A partir daí, a liberdade de contratar e a autonomia da vontade se tornam insuficiente para assegurar justiça e equilíbrio das relações contratuais, vez que só garantem a chamada «igualdade formal», sendo necessário, considerando a situação de vulnerabilidade dos consumidores frente aos fornecedores de produtos e serviços, recuperar a antiga noção de igualdade, que vinha da filosofia aristotélica, em que se admite o reconhecimento de diferenças, possibilitando um tratamento desigual para os desiguais: é a chamada «igualdade material» ${ }^{12}$.

No que diz respeito à responsabilidade, ao passo que, no direito privado clássico, a responsabilidade civil era subjetiva, ou

\footnotetext{
LONG (2007) 189-197.

10 Gomes (1983) 101-109.

11 Marques (2002) 52 et seq.

12 Miragem (2014) 42.
} 
seja, impresciência de culpa, mas, com o advento de novos riscos e a dificuldade de demonstrar a culpa da parte mais forte em várias situações, esse "filtro» perde sua utilidade como critério de solução de situações de danos, surgindo a responsabilidade objetiva, em que o risco entra como critério, ao invés da culpa ${ }^{13}$.

Em todo esse panorama, o direito do consumidor aparece como uma forma de microssistema, superando-se a época de grandes códigos que previam a universalidade de condutas jurígenas, passando-se a um período de atomização das normas e consequente decodificação ${ }^{14}$. No Brasil, esse microssistema surge a partir da promulgação do CDC. O leitmotiv do presente trabalho é estudar a evolução do Direito do Consumidor no Brasil, desde a Constituição de 1988, até os tempos atuais, comparando a proteção consumerista no Brasil a alguns outros sistemas.

\section{DA PROTEÇÃO CONSTITUCIONAL DO CONSUMIDOR}

No Brasil, o poder constituinte originário não se limitou a garantir a defesa do consumidor como direito fundamental, como determinou, também a elaboração de um código para garantir tal proteção, conforme art. 48 do ADCT. O CDC vem, então, consagrar um novo microssistema de direitos e deveres específicos para as relações de consumo, aproximando, de maneira mais efetiva, suas proposições normativas dos fatos por ele regulados.

Quando se consagra direitos fundamentais para sujeitos de relações privadas, como as relações de consumo, aceita-se uma nova concepção acerca do sentido e da própria função da Constituição, que tem a dignidade da pessoa humana como fundamento da liberdade, da justiça e da paz.

Em face deste novo significado de Constituição, que regulam a estrutura estatal, direitos e garantias fundamentais e elementos de estabilização constitucional ${ }^{15}$ reaproxima o direito público do direito privado, elevando-se, ao nível constitucional, inúmeras matérias outrora reguladas por normas ordinárias, de forma que a Constituição

13 Miragem (2014) 42-43.

14 IRTI (1989).

15 Silva (2001) 44-45. 
passa a tratar das categorias fundantes do direito privado: pessoa, família, propriedade e contrato ${ }^{16}$.

Nesse contexto, destaca-se que a proteção do consumidor aparece em nossa ordem constitucional como direito fundamental (art. $5^{\circ}$, XXXII, da Constituição) e como princípio da ordem econômica (art. 170, V, da Constituição). Passemos ao estudo desses artigos.

Os direitos fundamentais são a base lógica e axiológica sobre a qual o ordenamento se funda ${ }^{17}$ e é exatamente por isso que são superiores aos demais preceitos do ordenamento. Não obstante, eles não possuem a mesma potencialidade para realização ou produção de efeitos, vez que a eficácia dos direitos fundamentais se encontra vinculada à norma constitucional que determinou seu status, dependendo, pois, desta, para produzir efeitos ${ }^{18}$.

$\mathrm{O}$ direito do consumidor aparece como direito à proteção ${ }^{19}$ estatal contra a intervenção de terceiros, atribuindo ao consumidor alguns direitos que, via de regra, são oponíveis contra entes privados e até mesmo ao próprio Estado (com relação a determinados serviços públicos).

Tal proteção é, ao mesmo tempo que um direito fundamental, também, um dever do estado de promover esse direito (note-se que o art. $5^{\circ}$, XXXII, preconiza que o Estado promoverá, na forma da lei, a defesa do consumidor).

Quando se estabelece proteções e distinções fundadas em algumas qualidades individuais do sujeito que as aproveita leva à questão da igualdade: até que ponto a pessoa destinatária de proteção jurídica não vai desrespeitar ou contradizer o direito à igualdade, que também possui status constitucional?

Argumenta-se que, ao se estabelecer proteção específica ao consumidor, promove-se a equalização de uma relação que, faticamente, é desigual, vez que é ilusória a ideia de que uma relação fática de igualdade em fenômenos nos quais existe grande discrepância de poder econômico e domínio técnico entre as partes $^{20}$.

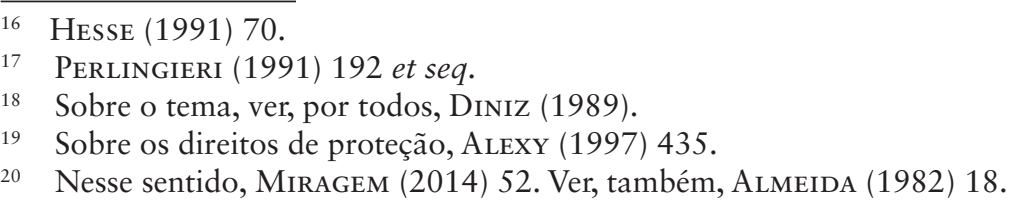


Cumpre, aliás, mencionar a distinção entre igualdade jurídica e igualdade fática, cerne da justificação dos chamados direitos de proteção. Conforme indica Alexy, o BVerfG possui interpretação ambígua, mas que traz que o legislador, a princípio, não pode aceitar diferenças fáticas entre as pessoas quando estas forem incompatíveis com os ideais de justiça, devendo eliminá-las quando houver incompatibilidade ${ }^{21}$. No caso das relações consumeristas, cabe ao direito do consumidor eliminar as diferenças entre fornecedor e consumidor.

Ora, todas as pessoas, em algum momento, são consumidoras. Por isso, reconhece-se o direito do consumidor como direito humano, aceitando-se a necessidade humana essencial de consumo. Deve-se determinar um vínculo entre necessidades humanas e direitos por meio dos conceitos de autonomia e liberdade individual, bem como tomada de decisões normativas de caráter público ${ }^{22}$.

Questão relevante é a de se considerar ou não a pessoa jurídica como titular de direitos fundamentais, vez que o art. $2^{\circ}$ do CDC entende que consumidor é «toda a pessoa física ou jurídica que adquire produto ou serviço como destinatário final». A resposta está no fato de que toda pessoa jurídica é composta por pessoas naturais, de forma que a eficácia de proteção abrange, também, direitos e interesses dos sócios e administradores e da própria pessoa jurídica, na qualidade de projeção dessas pessoas ${ }^{23}$.

Sobre isso, relevante o exemplo de Bruno Miragem: «imagine-se, por exemplo, a proteção do sigilo bancário de uma pessoa jurídica, largamente reconhecida em nosso direito. É hipótese de proteção de direitos fundamentais a partir da garantia de sigilo de informações de pessoa jurídica que, tipicamente, serve de instrumento à realização de atividade econômica por parte de seus sócios, administradores e empregados. A proteção do consumidor, neste sentido, visa à proteção de um bem jurídico supraindividual» ${ }^{24}$.

Além do art. $5^{\circ}$, XXXII, que consagra a proteção ao direito do consumidor como direito fundamental, verifica-se, também, a elevação da defesa do consumidor como princípio fundamental da

\footnotetext{
Alexy (1997) 407.

AÑon RoIG (1994) 23.

Ver Gómez Montoro (2002) 49-105.

Gómez Montoro (2002) 55.
} 
ordem econômica, conforme art. 170, V, não só como conteúdo proibitivo ou limitador da autonomia privada, mas com caráter interventivo-promocional, efetivando-se preceitos constitucionais que o estabelecem como direito e como princípio, assumindo, assim, caráter conformador da ordem econômica ${ }^{25}$.

Ora, a aferição da legitimidade dos fins da ordem econômica haverá de respeitar o princípio da dignidade humana. Assim, vinculando-se princípios conformadores da ordem constitucional econômica à dignidade da pessoa humana, por certo que o conteúdo da ordem econômica é informado pela realização de necessidades da pessoa, conforme serão consagradas ou reconhecidas pela carta magna.

Dessa maneira, o exame in concreto da proteção e defesa do consumidor indica a preferência desta outros princípios constitucionais, como a livre iniciativa, não podendo, porém, preceder o direito à vida, saúde ou segurança, razão de ser da necessidade humana de consumo.

\section{O MODELO HÍBRIDO DO DIREITO PRIVADO BRASILEIRO: UM CÓDIGO PARA IGUAIS E OUTRO PARA DIFERENTES}

Em 2003, entrou em vigor, no Brasil, o Código Civil Brasileiro (CCB). Esse código teve o mérito de unificar as obrigações civis e empresariais, segundo a teoria italiana da empresa. Não obstante, deixou de regular as relações entre fornecedores e consumidores, vez que essas já se encontravam reguladas pelo CDC.

Isso tem extrema relevância, vez que o modelo brasileiro de direito privado acabou sendo diferente dos principais modelos de direito privado, quais sejam, o francês, o italiano e o alemão, ainda que o direito brasileiro, assim como aqueles, é pertencente à chamada família romana de direitos ${ }^{26}$.

No regime francês, optou-se por manter o Code Civil do tempo napoleônico intacto, bem como o Code de Commerce, intactos, trazendo normas relativas às relações de consumo em forma de consolidação, no chamado Code de la Consommation.

25 Grau (1997) 260.

26 Zweigert, Kötz (1996) 114. 
Dessa maneira, conforme lição de Cláudia Lima Marques, «sem modificar seu Direito Privado, em 1993, a França preferiu organizar um Código de Consumo (Code de la Consommation), consolidando todas as suas leis internas e as Diretivas especiais de defesa do consumidor. Como se observa, o tema do novo Código de consumo não é o consumidor, mas o consumo mesmo e o mercado de consumo, com todas suas implicações. Em outras palavras, o tema 'consumo' é transversal e transpassa várias disciplinas, direito civil, direito comercial, econômicos, administrativo, penal e processual. Em uma figura de linguagem, o sistema francês é composto de vários pilares (ou disciplinas, que continuam intactas) e um novo Código, tema ou disciplina, que transpassa a todos, como uma ponte sustentada por vários pilares de naturezas diferentes ${ }^{27}$.

No modelo italiano, o direito do consumidor ficou em legislações esparsas, sendo que, no Codice Civile, foi incluído, após a Diretiva 93/13/CEE sobre cláusulas abusivas, um capítulo de nome Dei contratti del consumatore. De toda forma, o códex privado acaba regulando apenas o controle do conteúdo dos contratos de consumo, mas não toda a matéria envolvendo relações jurídicas de consumo ${ }^{28}$.

Na metáfora de Cláudia Lima Marques, «o modelo italiano possui um círculo maior, que é o Código Civil de 1942, e dentro do qual se encontram algumas normas especiais para consumidores, mas uma série de outras normas esparsas e especiais de defesa dos consumidores, em forte descodificação. A especificidade em relação ao francês é incluir, no Código Civil, a figura do contrato com consumidores e manter leis especiais, diferentemente do modelo francês, que optou por duas codificações em separado» ${ }^{29}$.

Por sua vez, a Alemanha incluiu, na parte geral do Bürgerliches Gesetzbuch (BGB), as figuras do consumidor e do fornecedor como sujeitos de direito, trazendo, para dentro do códex privado, a proteção e defesa do consumidor.

Dessa maneira, no modelo alemão, o Direito Civil se manteve no centro do direito privado, abraçando, inclusive, a proteção dos

\footnotetext{
Marques (2004) 42.

28 Alpa (2002) 10 et seq.

29 Marques (2004) 43.
} 
vulneráveis, inclusive os consumidores, de forma que as relações de consumo se viram reguladas pelo próprio $\mathrm{BGB}^{30}$.

Assim, o que o legislador alemão fez "pode ser comparado (permitam-me a figura de linguagem) a um grande círculo geral, que seria o direito civil novo do BGB-Reformado, com um núcleo duro, composto pelas normas especiais (sociais) para a proteção dos consumidores, nos novos parágrafos incorporados das antigas leis especiais, assim como suas cláusulas gerais privilegiadoras» ${ }^{31}$.

No caso do Brasil, quando da elaboração do Código Civil Brasileiro de 2002 (CC/02 ou CCB), buscou-se superar o individualismo que impregnava o antigo Código Civil de 1916 (CC/16), unificandose, inclusive, as obrigações civis e comerciais sob um mesmo diploma normativo, sem, contudo, deixar de respeitar as leis extravagantes, de forma que o Direito Privado no Brasil tem, por lei básica, o CC/02, que, contudo, não se mostra como única norma privatista.

De fato, o CDC se apresenta como contraponto em relação à amplitude da aplicabilidade do CC/02, vez que é um código que traz o tratamento especial que se espera que o Estado dê aos vulneráveis na relação de consumo. É dizer, temos, no nosso direito privado, um código para relações jurídicas entre partes iguais (o CC/02, regulando relações civis) e um código para relações jurídicas entre partes diferentes (o CDC, que regula relações de consumo).

$\mathrm{Na}$ metáfora trazida por Cláudia Lima Marques, «o direito privado brasileiro reconstruído pela Constituição de 1988 seria semelhante a um edifício. O Código Civil de 2002 é a base geral e central, é o próprio edifício, em que todos usam o corredor, o elevador, os jardins, é a entrada comum a civis, a empresários e consumidores em suas relações obrigacionais. Já o CDC é um local especial, só para privilegiados, é como o apartamento de cobertura: lá existem privilégios materiais e processuais para os diferentes, que passam por sua porta e usufruem de seu interior, com piscina, churrasqueira, vista para o rio ou o mar e outras facilidades especiais. Na porta da cobertura só entram os convidados: os consumidores, os diferentes, em suas relações mistas com fornecedores. Sustentando conceitualmente o privilégio ou como base do CDC, está o CC/2002, com seus

\footnotetext{
30 Marques (2004) 47.

31 Marques (2004) 47.
} 
princípios convergentes (boa-fé, combate ao abuso, à lesão enorme, à onerosidade excessiva etc.), sempre prontos a atuar subsidiariamente» ${ }^{32}$. E completa: «a diferença de paradigma é, porém, substancial: a proteção do desigual concedida pelo CDC é mais forte do que a boa-fé normal das relações entre iguais» ${ }^{33}$.

De toda forma, pode haver, entre o CDC e o CC/02, antinomias que, dada a complexidade da situação, não conseguem ser resolvidas por critérios tradicionais, de forma que se há que recorrer ao chamado «diálogo das fontes», em que «há influências recíprocas, [...] aplicação conjunta das duas normas ao mesmo tempo e ao mesmo caso, seja complementarmente, seja subsidiariamente, seja permitindo a opção voluntária das partes sobre a fonte prevalente (especialmente em matéria de convenções internacionais e leis-modelos), ou mesmo permitindo uma opção por uma das leis em conflito abstrato. Uma solução flexível e aberta, de interpenetração, ou mesmo a solução mais favorável ao mais fraco da relação (tratamento diferente dos diferentes) ${ }^{34}$.

Três são as maneiras em que esse diálogo pode acontecer:

Primeiramente, «na aplicação simultânea das duas leis, uma lei pode servir de base conceitual para a outra (diálogo sistemático de coerência), especialmente se uma lei é geral e a outra especial; se uma é a lei central do sistema e a outra um micro-sistema específico, incompleto materialmente, apenas com completude subjetiva de uma tutela de um grupo da sociedade ${ }^{35}$.

$\mathrm{Na}$ segunda maneira, o diálogo ocorre quando, «na aplicação coordenada das duas leis, uma lei pode complementar a aplicação da outra, dependendo de seu campo de aplicação no caso concreto (diálogo sistemático de complementariedade e subsidiariedade em antinomias aparentes ou reais), e, ainda, indicando a aplicação complementar tanto de suas normas, quanto de seus princípios, no que couber, no que for necessário ou subsidiariamente» ${ }^{36}$.

Por fim, «há, ainda, o diálogo das influências recíprocas sistemáticas, como no caso de uma possível redefinição do campo de

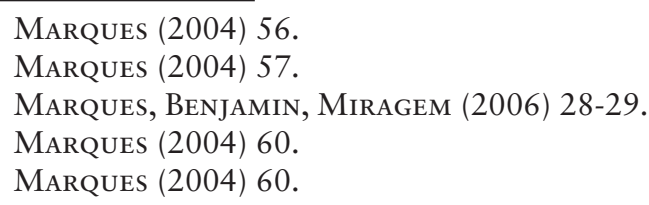


aplicação de uma lei [...] ou como no caso da possível transposição das conquistas do Richterrecht (Direito dos Juízes), alcançadas em uma lei para a outra. É a influência do sistema especial no geral e do geral no especial, um diálogo de double sens (diálogo de coordenação e adaptação sistemática) ${ }^{37}$.

\section{Da neCessidade de atualizaÇão do Código DE Defesa do Consumidor}

De toda forma, em que pesem os avanços legislativos na proteção dos consumidores, não se pode olvidar que se trata de um código da década de 1990, que já se tornou defasado em alguns aspectos.

Nesse ínterim, em 2010, o Senado Federal nomeou uma comissão de juristas para fornecer subsídios ao Poder Legislativo, com vistas a um projeto de lei que levasse à modernização do códex.

Os anteprojetos de lei que acabaram apresentados tratam de três temas: crédito e superendividamento; comércio eletrônico e parte geral; resolução de $\operatorname{conflitos}^{38}$.

\subsection{Do superendividamento}

Nos tempos hodiernos, "Os convites empolgantes aos empréstimos, bem como as facilidades prometidas aos setores assalariados, desnudaram dois sujeitos interessantes: o banqueiro descentralizado (representado por financeiras e correspondentes, espalhados para além das agências bancárias) defensor da 'popularização ou democracia do crédito'; e o consumidor hipervulnerável que, ao lado da família, compromete parte da renda mensal e do mínimo existencial, falindo pessoalmente» ${ }^{39}$.

Tem evoluído a doutrina no que diz respeito a classificar o superendividamento, enquanto acúmulo de débitos decorrente de fatos inesperados que acabam levando a situação do devedor a uma onerosidade excessiva, em virtude de desemprego, morte,

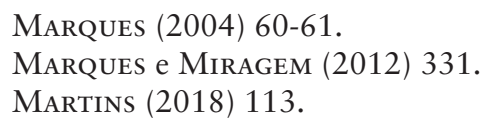


divórcio, doença e situações afins (acumulação passiva de débitos), ou, ainda, em decorrência de abusos do próprio consumidor que, conscientemente, ou inconscientemente (iludido pelo marketing) acaba contratando débitos de forma reiterada (acumulação ativa de débitos). A partir daí, vem a classificação do superendividamento em passivo e ativo ${ }^{40}$.

Ora, «havia razões suficientes para que a egrégia comissão adotasse técnicas substanciais de prevenção ao superendividamento, bem como instrumentos de repactuação dos débitos para restabelecimento da dignidade do devedor. O que, em termos de ciência jurídica (teoria gral [sic] do direito), prontamente permite a constatação dos princípios da boa-fé (através dos deveres de cooperação, cuidado e informação), da solidariedade (função social do crédito na inclusão dos consumidores) e dignidade da pessoa humana (na proteção do mínimo existencial ou reste à vivre)» ${ }^{41}$.

\subsection{Do comércio eletrônico}

Segundo a justificativa do anteprojeto de lei para amodernar o CDC, temos que é «imprescindível a introdução de uma seção específica sobre a proteção dos consumidores no âmbito do comércio eletrônico, em razão de sua expressiva utilização. Se, à época da promulgação do Código de Defesa do Consumidor, o comércio eletrônico nem sequer existia, atualmente é o meio de fornecimento a distância mais utilizado, alcançando sucessivos recordes de faturamento. Porém, ao mesmo tempo ocorre o aumento exponencial do número de demandas dos consumidores. As normas projetadas atualizam a lei de proteção do consumidor a essa nova realidade, reforçando, a exemplo do que já foi feito na Europa e nos Estados Unidos, os direitos de informação, transparência, lealdade, autodeterminação, cooperação e segurança nas relações de consumo estabelecidas através do comércio eletrônico. Busca-se ainda a proteção do consumidor em relação às

\footnotetext{
40 Martins (2018) 117.

41 Martins (2018) 119-120.
} 
mensagens eletrônicas não solicitadas (spams), além de exercitar o exercício de direito de arrependimento ${ }^{42}$.

Ora, com relação ao direito de arrependimento, cobranças, segurança nos dados e no pagamento, os arts. 49, 42, 43 e 52, do CDC já trazem algumas normas claras e impositivas. De toda forma, existe o desafio de trazer tal proteção para o $e$-commerce ${ }^{43}$.

Ora, «o modelo do paraíso democrático baseado no livre acesso e intercâmbio de opiniões pode ser uma situação meramente transitória e fugaz. Rapidamente surgem portais e sítios que canalizam a maioria das mensagens num crescente processo de concentração, viabilizado pela concessão de direitos de propriedade intelectual sobre inúmeros bens imateriais. O funcionamento da Internet não é uma questão meramente privada; é uma forma externa da globalização, com efeitos políticos e sociais que envolvem a ordem pública e a necessidade de regulação. Não se trata de patrocinar intervenções distorcidas, mas sim intervenções institucionais, com o escopo de resguardar a privacidade, o consumo, a moral, o tratamento igualitário e não discriminatório ${ }^{44}$.

$\mathrm{E}$, de fato, hoje, temos uma regulação do $e$-commerce no Brasil por intermédio do Decreto $n^{\circ} 7962 / 2013$, mas cabe mencionar que «referido decreto não cuida com precisão da extensão da responsabilidade civil nas compras pela internet, cujo tema está pautado fundamentalmente pelo Código Civil, arts. 927 e 931, e pelo Código de Defesa do Consumidor (CDC, especialmente os arts. 12 e 13. De qualquer forma, a doutrina é uniforme quanto à admissibilidade da aplicação do ordenamento jurídico brasileiro às relações estabelecidas no comércio eletrônico» ${ }^{45}$.

\subsection{Da resolução de conflitos}

O CDC é muito vanguardista no que diz respeito à tutela processual do consumidor, inclusive dando amplos poderes ao Ministério

\footnotetext{
Marques e Miragem (2012) 340.

Marques (2004) 241.

LORENZETTI (2004) 75.

TeIXeIRA (2015) 83.
} 
Público para esse mister e, ainda, possibilitando a tutela coletiva, por meio da ação civil pública.

De toda forma, o que se almeja é «desjudicializar os conflitos entre consumidor e fornecedor, reforçando a utilização de outras vias e, no plano do processo, implementando os meios consensuais de solução de controvérsias» ${ }^{46}$.

De fato, há que se «relembrar que se no campo do direito individual se dizia da fuga do juiz, agora noutro perfil deve ressurgir, absolutamente quando necessário, o Poder Judiciário pelas portas da conciliação num cariz resolutivo e dialógico para solução das demandas de massa. Insiste-se na obrigatoriedade de conciliação e no aumento de instrumentos para correta cognição pelo Judiciário dos fatos sociais ensejadores do conflito (dentre eles a audiência pública), distanciando-se por completo do formalismo excessivo ${ }^{47}$.

\section{CONSIDERAÇÕES FINAIS}

À giza de conclusão, cabe relembrar que a Constituição de 1988 se preocupou com a proteção dos vulneráveis e um dos sujeitos constitucionalmente identificados enquanto tal foi justamente o consumidor. Por isso, além de ter a proteção ao consumidor como princípio da ordem econômica, conforme art. 170, V, o art. $5^{\circ}$, XXXII, trouxe, ainda, como direito fundamental, a proteção do consumidor «na forma da lei», razão pela qual o ADCT trouxe a obrigatoriedade de se editar um Código para esse mister, o qual foi promulgado no início dos anos 1990: o CDC.

Depois da promulgação do CDC, ainda veio o novel CC/02, inserindo o Brasil em uma categoria sui generis de direito privado, em que se tem um código regulando relações civis e comerciais e outro regulando relações consumeristas. Tais códigos se influenciam entre si, por meio do chamado diálogo de fontes.

Contudo, não sem motivo, veio a premente necessidade de atualizar o CDC, vez que já faz algumas décadas desde sua promulgação. Por isso, em 2010, foi instituída uma comissão no Senado,

\footnotetext{
46 Marques e Miragem (2012) 356.

47 Martins (2018) 124.
} 
com vistas à sua modernização, especialmente no que diz respeito ao superendividamento, ao comércio eletrônico e à resolução de conflitos entre consumidor e fornecedor.

De fato, o Brasil é um país de vanguarda na proteção do consumidor, tendo um excelente código, fora a proteção constitucional a essa figura, mas a proteção carece, ainda de alguma atualização. De toda forma, essa desatualização não pode deixar a entender que nosso direito consumidor é ruim, ou ultrapassado, vez que o Direito positivo demora muito mais a se atualizar do que a tecnologia, razão pela qual arriscamos dizer que o Direito sempre estará desatualizado.

\section{Bibliografía}

\section{a) Doutrina:}

Alexy, Robert (1997): Teoría de los derechos fundamentales (Madrid, Centro de Estudios Constitucionales).

Alpa, Guido (2002): Il diritto dei consumatori (Roma, Laterza).

Almeida, Carlos Ferreira (1982): Os direitos dos consumidores (Coimbra, Almedina).

AÑon roig, María José (1994): Necesidades y derechos. Un ensayo de fundamentación. (Madrid, Centro de Estudios Constitucionales).

Diniz, Maria Helena (1989): Norma constitucional e seus efeitos (São Paulo, Saraiva).

Gomes, Orlando (1983): «A função do contrato», in: Novos temas de direito civil (Rio de Janeiro, Forense).

Gómez Montoro, Ángel J. (2002): «La titularidad de derechos fundamentales por personas jurídicas: un intento de fundamentación», Revista española de derecho constitucional, n. 65. Madrid, 2002, p. 49-105.

Grau, Eros Roberto (1997): A ordem econômica na Constituição de 1988. Interpretação e crítica. 3. ed. (São Paulo, Malheiros).

Hesse, Konrad (1991): Derecho constitucional y derecho privado (Madrid, Civitas).

IRTI, Natalino (1989): L'etat della decodificazione. 3. ed. (Milano, Giuffrè) Long, M. et ali (2007): Les grands arrêts de la jurisprudence administrative. 16. ed. (Paris, Dalloz).

Lorenzetti, Ricardo Luís (2004): Comércio eletrônico. Trad. Fabiano Menke (São Paulo, RT). 
Marques, Cláudia Lima (2004): Confiança no comércio eletrônico e a proteção do consumidor: um estudo dos negócios jurídicos de consumo no comércio eletrônico (São Paulo, RT).

Marques, Claudia Lima (2002): Contratos no Código de Defesa do Consumidor. 4. ed. (São Paulo, RT).

MARQues, Claudia Lima (2004): «Superação de antinomias pelo diálogo de fontes: o modelo de coexistência entre o CDC e o CCB/02», Revista de direito do consumidor. Vol. 51. São Paulo: RT, 2004, pp. 41-64.

Marques, Claudia Lima; Benjamin, Antonio Herman; Miragem, Bruno (2006): Comentários ao Código de Defesa do Consumidor. 2. ed. (São Paulo, RT).

Marques, Claudia Lima; Miragem, Bruno (2012): «Anteprojetos de lei de atualização do Código de Defesa do Consumidor», Revista de direito do consumidor. Vol. 82. São Paulo: RT, 2012.

Martins, Fernando Rodrigues (2018): «A contingente atualização do Código de Defesa do Consumidor: Novas Fontes, Metodologia e Devolução de Conceitos», in: Direito Privado e Policontexturalidade (Rio de Janeiro: Lumen Juris).

Miragem, Bruno (2014): Curso de direito do consumidor. 5. ed. (São Paulo, RT).

Perlingieri, Pietro (1991): Il diritto civile nella legalitá constituzionale. 2. ed. (Napoli: Edizioni Scientifiche Italiane).

RAMSAY, Iain (2001): "Consumer protection in the era of informational capitalism», in: Wilhemsson, Thomas; Tuominem, Salla; TuomoLA, Heli, Consumer law in the information Society (Hague, Kluwer Law International).

RIPERT, Georges (1937): O regime democrático e o direito civil moderno (São Paulo, Saraiva).

Silva, José Afonso da (2001): Curso de direito constitucional positivo. 19. ed. (São Paulo, Malheiros).

Stiglitz, Gabriel (1988): Protección jurídica del consumidor. 2. ed. (Buenos Aires, De Palma).

TeIXeIRA, Tarcísio (2015): Comércio eletrônico: conforme o Marco Civil da Internet e a regulamentação do e-commerce no Brasil (São Paulo, Saraiva).

Waline, Marcel (1945): L'individualisme et le Droit (Paris: Éditions Domat Montchrestien).

ZweIgert, Konrad; Kötz, Hein (1996): Einführung in die Rechtsvergleichung auf dem Gebiete des Privatrechts. 3. Aufl (Tübingen, Mohr). 
Avanços em matéria de Direito do Consumidor no Brasil: Panorama...

\section{b) Normativa:}

Ato das disposições constitucionais transitórias da Constituição da República Federativa do Brasil (1988)

Código Civil Brasileiro

Código de Defensa do Consumidor 



\section{PARTe}

\section{Derecho Regulatorio}





\section{ENTRE LA NEUTRALIDAD TÉCNICA Y EL PATERNALISMO LIBERTARIO: REFLEXIONES SOBRE LA REGULACIÓN ECONÓMICA DESDE LA TEORÍA EVOLUTIVA DE LAS INSTITUCIONES}

BETWEEN TECHNICAL NEUTRALITY AND LIBERAL PATERNALISM: REFLECTIONS ON ECONOMIC REGULATION FROM THE EVOLUTIONARY THEORY OF INSTITUTIONS

Luis Alfonso Herrera Orellana ${ }^{1}$

Licenciado en Filosofía. Abogado summa cum laude. Especialista en Derecho Administrativo. Profesor de Derecho Administrativo (Universidad Central de Venezuela). Magister en Derecho Constitucional. Profesor de Derecho Procesal Constitucional y Contencioso-Administrativo (Universidad Católica Andrés Bello). Profesor de Derecho Político, Teoría Constitucional y Derecho Económico (Universidad Autónoma de Chile, Sede Santiago).E-mail: Luis.herrera@uautonoma.cl 
Resumen. Expone las nociones básicas de la regulación económica y sus concepciones predominantes, sus debilidades y riesgos, así como las consecuencias de aquellas, y explora una posible concepción alternativa derivada de la teoría evolutiva de las instituciones.

Palabras Clave: regulación económica, concepción neutral, concepción paternalista, teoría evolutiva de las instituciones.

AвSTRACT. It exposes the basic notions of economic regulation and its predominant conceptions, its weaknesses and risks, as well as the consequences of them, and explores a possible alternative conception derived from the evolutionary theory of institutions.

KEYWORDS: economic regulation, neutral conception, paternalistic conception, evolutionary theory of institutions.

Sumario. Introducción. 1. Acerca de las concepciones predominantes de la regulación económica en el Derecho Contemporáneo. 2. Debilidades y riesgos de las concepciones predominantes de la regulación. 3. Consecuencias de las debilidades y riesgos identificados. 4. ¿Hay alguna alternativa a las concepciones dominantes sobre la regulación?: La concepción evolutiva de la regulación. 5. Aportes de la concepción evolutiva a la teoría de la regulación económica. 6. Bibliografía

\section{INTRODUCCIÓN}

Al menos desde la segunda postguerra, existe un consenso general acerca de la necesidad de producir y aplicar regulación económica en las sociedades en que operan economías de libre mercado, así como respecto a los principios generales y los fines que dicha regulación debe observar para servir como un instrumento útil para las autoridades y los individuos a los que se le aplican sus preceptos, al momento de tomar sus decisiones económicas.

No necesariamente existe el mismo acuerdo, en cambio, respecto de la estructura y tipo de normas que debe contener la regulación económica. Existen estándares y requisitos para la producción de regulación con calidad y eficiencia. Pero no existe, o no se ha desarrollado de forma explícita, una metateoría acerca de cómo deben la Administración del Estado tradicional y las agencias administrativas 
o autoridades independientes, desarrollar la legislación al ejercer la potestad normativa, a fin de, más allá de la eficiencia e impacto, no incurrir en invasiones a la reserva legal ni tampoco afectar los derechos fundamentales de los particulares.

Se puede decirse que son dos, en la actualidad, las concepciones de regulación económica que ofrecen a las autoridades administrativas orientaciones, pautas y conceptos para desarrollar su labor del modo más eficaz, institucional y eficiente posible, a saber, la concepción que llamaremos neutral, por su pretensión de no tomar partido a favor de políticas económicas que reflejen valores concretos, y la concepción que llamaremos paternalista, por su preocupación central en colaborar con los consumidores para que realicen las mejores elecciones al adquirir bienes y servicios.

Ahora bien, ¿aportan la concepción neutral o la concepción paternalista de la regulación económica bases teóricas suficientes para que la estructura normativa de esta última respete y garantice los principios y derechos asegurados por un orden público económico constitucional como el vigente en Chile, o es necesario tener en cuenta, en el Derecho Administrativo, alguna otra concepción de la regulación que aporte bases teóricas para lograr esos cometidos?

\section{ACERCA DE LAS CONCEPCIONES PREDOMINANTES DE LA REGULACIÓN ECONÓMICA EN EL DERECHO CONTEMPORÁNEO}

Un sector de la doctrina, que asume una concepción neutral de la regulación, se limita a indicar que esta no debe favorecer a ningún sujeto o sector en particular sino garantizar el orden público económico constitucional, y que los principios técnicos que la rigen son, en sí mismos, garantía suficiente de que no adoptará contenidos que afecten las materias antes mencionadas. Esta es la concepción más extendida en la tradición jurídica europeo-continental legislada, predomina en el derecho comunitario europeo y en los derechos internos de los países que integran esa Unión, en la cual se asume a los fallos del mercado y la asimetría de información entre proveedores y consumidores, como las principales razones de su existencia. 
De acuerdo con Joaquín Cano: «...el nuevo concepto de regulación (...) consiste en la 'supervisión continua de una determinada actividad, ordenándola y encauzándola tanto mediante decisiones de valor normativo como de otras de carácter ejecutivo que se refieren a la verificación o el control del cumplimiento de los requisitos previamente establecidos en las normas. Regular en este contexto no es solo dictar normas, sino una actividad continua de seguimiento o control de una actividad que se manifiesta en poderes normativos, de ordenación del funcionamiento del mercado, de vigilancia y supervisión del mismo, de resolución de controversias, de poderes sancionadores, etc.» ${ }^{2}$

Por su parte, Gaspar Ariño explica que la regulación de postguerra consistió en algo más que solo cambiar la titularidad de bienes y actividades: «...frente a la planificación estatal, se argumentó que la única forma de saber lo que satisface las necesidades de los ciudadanos es permitir que éstos ejerzan su libertad, devolverles la capacidad de elegir (...) Las actividades de interés económico general siguen siendo 'esenciales' para el individuo y la sociedad, siguen presentando las mismas características que tenían (tendencias monopolistas, infraestructuras de red, barreras de entrada, etc.) y justamente por ello son y seguirán siendo siempre 'actividades reguladas'. Pero la regulación, ahora, no viene a sustituir al mercado, sino a hacerlo posible, a recrearlo. Es una 'regulación para la competencia'» ${ }^{3}$.

No obstante, esta concepción neutral, al no establecer otro límite más preciso a la regulación que la obligación de «recrear» el mercado, permite excesos manifiestos como este: «...finalmente tenemos la regulación económica stricto sensu. Es aquella que penetra y configura determinadas actividades que tienen particular relevancia o trascendencia en la vida social. En todos los países, la legislación ha separado un conjunto de actividades que, con el nombre de servicios públicos, actividades reglamentadas, actividades de interés general u otra calificación similar, se hallan especialmente disciplinadas y sometidas al poder público, cuando no nacionalizadas y gestionadas por el propio Estado. Son empresas y actividades sujetas a detalladas regulaciones, no solo en su marco externo, como

Cano Campos (2009) 34.

Ariño Ortiz (2005) 12 y 15. 
las anteriores, sino en_la propia vida interna de la empresa, cuyos aspectos técnicos, financieros, comerciales o contables, el quantum y el modo de su actividad están también sometidos a normas y a directrices especiales (dimensión y recursos mínimos, volumen de producción, zonas de mercado, precios, calidades, constitución de stocks de garantía, etc.) que la Administración dicta para ellas. En estos casos la regulación no solo limita o condiciona externamente el ejercicio de la actividad, sino que configura internamente a ésta» ${ }^{4}$.

Lo que Gaspar Ariño llama regulación económica stricto sensu, a su juicio puede contener no solo mandatos consistentes en obligaciones jurídicas de hacer o de dar cuyo cumplimiento está a cargo del patrimonio del operador económico de la actividad de interés general (una suerte de impuesto, podría considerarse), sino también mandatos dirigidos a definir «la propia vida interna de la empresa», por lo que acepta incluso que «en estos casos la regulación no solo limita o condiciona externamente el ejercicio de la actividad, sino que configura internamente a esta». En este caso, la estructura normativa de la regulación le debe permitir a la autoridad, con la excusa de «recrear» el mercado, intervenir y dirigir las decisiones y las elecciones de proveedores y consumidores, en especial de los primeros, cuando consideren que ello es necesario para mantener «ordenado» un sector determinado.

En cambio, otro sector de la doctrina, que asume más bien una concepción paternalista de la regulación, estima que esta, con apoyo en la economía conductual, debe tener una postura más protectora de los consumidores, debido a los sesgos cognitivos que éstos tienen, los cuales les impiden ser siempre racionales en sus elecciones acerca de qué es lo mejor para sí. Por tanto, la estructura normativa de la regulación le debe permitir ser "paternalista», esto es, ayudar a los particulares a realizar «mejores elecciones» al adquirir bienes y servicios en el mercado. Es la postura dominante en la tendencia normativa estadounidense y británica que da base al llamado administrative state, la cual sostiene que los particulares requieren un «empujón» al momento de elegir lo que más les conviene.

4 Ariño Ortiz (2005) 17. 
Valga indicar que «...el término Nudge se puede traducir como «pequeño empujoncito» y se enmarca en una corriente de pensamiento que sus creadores, Thaler y Sunstein, denominaron 'paternalismo libertario'. En el paternalismo libertario, los nudges son el vehículo a través del cual se comunican las intenciones u objetivos 'paternalistas' del regulador, mientras al mismo tiempo se preserva la libertad de elección de los sujetos regulados»" .

Cass Sunstein, máximo exponente de esta concepción, lo explica así: «....anteriormente me he referido al uso de nudges como un mecanismo de regulación. Durante muchos años he trabajado sobre este tema con (...) Richard Thaler. Los nudges consisten en impulsos que no fuerzan a nadie a hacer nada y que no afectan a la libertad de elección, pero que tienen la capacidad de generar gente más sana, más rica y más feliz (...) Muchas veces los nudges constituyen el punto álgido de la simplicidad. Thaler incluso tiene un mantra: hazlo fácil. Aquellos que están a favor de los nudges son conscientes de la importancia que tiene la libertad de elección. Son respetuosos con el libre mercado y con la libertad individual, y permiten a la gente hacer las cosas a su manera. Al mismo tiempo, ponen el acento en que la gente se puede equivocar y consideran que a casi todos nos puede venir bien un poco de ayuda alguna vez. Insisten en que las decisiones se toman ante una situación que nos viene dada por las instituciones públicas y privadas. Los nudges están en todas partes, aunque no los veamos» ${ }^{6}$.

El mismo autor explica que el «paternalismo» en la regulación económica cuestiona en forma directa el «Principio del daño» de John Stuart Mill: «...a menos que exista daño a otros, el gobierno no puede usar el poder político sobre el pueblo [sostiene ese principio]. La idea del 'consumidor soberano' central en la economía moderna y en gran parte del debate político, es prima cercana del Principio del daño (...) el Principio del daño genera muchas dudas acerca de muchas leyes y regulaciones, incluidas aquellas que exigen a la gente tener una receta médica antes de adquirir ciertas medicinas, prohibir a los empleados trabajar en lugares inseguros (...) y promover la seguridad alimentaria. En todos estos casos, el poder es ejercido

Boulin y Cadenas (2018) 68.

SunSTEIN (2014) 20 y 21. 
sobre la gente, en gran medida para promover su propio bien (...) Mi meta (...) es desafiar el Principio del daño sobre la base de que en ciertos contextos la gente es propensa al error y las intervenciones paternalistas harían que su vida fuera mejor ${ }^{7}$.

\section{DebiliddADES Y RIESGOS DE LAS CONCEPCIONES PREDOMINANTES DE LA REGULACIÓN}

Debido a las premisas de las que parten, ambas concepciones son susceptibles de afectar en no pocos casos tanto el contenido esencial de derechos fundamentales económicos, como del orden público constitucional, al menos en sociedades en que este apunte al funcionamiento de una economía basada en el mercado.

En el caso de la concepción neutral de la regulación, no asume de forma explícita que la generación de riqueza, esto es, de bienes y servicios para satisfacer necesidades humanas y generadas por la vida en sociedad, requiere asegurar la mayor libertad individual posible $^{8}$. En efecto, la mayoría de la doctrina tributaria de este enfoque solo resguardan la libertad individual tanto del oferente como del demandante de forma indirecta, en términos formales, a partir de la protección y promoción de la competencia, lo que deriva de la insistencia en adoptar un enfoque racionalista instrumental, no vinculado a valores sustantivos, ante un tema sustantivo, antropológico, como es la acción humana ${ }^{9}$.

Al carecer de una epistemología y antropología sólidas, no es eficaz para impedir que se impongan mandatos directos o indirectos a través de la regulación económica tanto a proveedores como a consumidores, ya que apela en no pocos casos a principios generales para definir el marco de ejercicio de la potestad normativa, así como para evaluar qué contenidos pueden incluirse o no en cada regulación, siendo que dichos principios, dada su indeterminación sustantiva, pueden ser «ajustados» mediante la argumentación para justificar decisiones regulatorias que terminen por restringir y hasta

\footnotetext{
SunSTEIN (2017) 6.

RALLO (2018).

Mises (2018).
} 
vulnerar derechos fundamentales tanto de los proveedores como de los consumidores.

En otros casos, apela a conceptos jurídicos indeterminados, como el interés general, el bien común, la utilidad pública o la función social de algún derecho individual, que en lugar de restringir el alcance de la regulación a fijar prohibiciones, condiciones o sanciones en caso de incumplimiento, permite que ésta imponga conductas y fines de obligatoria observancia para los particulares, y atribuya potestades ilimitadas al regulador para investigar y adoptar medidas administrativas, por ejemplo.

Por último, tampoco suele, la concepción neutral, considerar el análisis de costos y beneficios de la regulación económica, al menos no desde el Derecho Administrativo, al concebirla más como una decisión técnica que como una medida dialógica y performativa, adoptada desde el intercambio con los directos destinatarios de su contenido, así como del conocimiento de los previsibles efectos que tendrá sobre las dinámicas económicas a las que se aplicará.

La concepción paternalista, por su parte, evita la neutralidad de la otra concepción, es más pragmática y realista, y de forma explícita se compromete con un valor central en materia económica, como es la libertad de elegir de los consumidores. También plantea que es tarea del regulador, y por tanto del Derecho Administrativo, evaluar costos y beneficios, emplear métodos para medir un impacto, propender a su reducción, su simplicidad y mejor manejo, etc.

El gran problema de la concepción paternalista, si bien parte de una base epistemológica y antropológica consistente, como es la economía conductual o del comportamiento ${ }^{10}$, es que justifica de forma retórica la aplicación directa de mandatos a los proveedores, e indirecta, aunque lo niegue, a los consumidores, lo que hace que, a partir de una premisa cierta -la del sujeto postsoberano-, arribe a una conclusión al menos refutable -el Gobierno debe ser paternalista con el sujeto postsoberano-.

En efecto, la regulación económica, según esta concepción, debe más que atender fallas, equilibrar asimetrías o potenciar la competencia, debe ayudar a las personas a elegir mejor, y ello a través de

10 Sunstein y Thaler (2006) 161 y ss. 
precisos y justificados «empujoncitos», esto es, llevar o acercar a los consumidores a las elecciones que son mejores para ellos, en cuanto a salud, placer, costos, calidad de vida, etc., y alejarlos de las que son menos beneficiosas, cuando no abiertamente perjudiciales, sin llegar en general a prohibir algunas elecciones.

¿Quién decide qué elecciones son mejores y qué elecciones peores? Pues otras personas, solo que unas muy concretas, los funcionarios reguladores que, investidos de potestades que les otorga el Derecho Administrativo -normativas, sancionatorias, de autotutela-, estarían según esta concepción en mejor posición que el resto de las personas, debido a su conocimiento, experiencia, etc., para dominar sus propios sesgos cognitivos derivados de afectos y preferencias, y definir en sus decisiones regulatorias las elecciones para sí y para otros más favorables y beneficiosas.

De este modo, desvinculándose en un grado considerable de los límites que a través de la Constitución el Estado de Derecho impone a la acción de la autoridad sobre la conducta de los particulares, y asumiendo que la burocracia, el Estado administrativo, es quien mejor puede determinar qué necesita o es mejor para las personas en situaciones en que deciden mal o pueden hacerlo, la concepción paternalista propicia condiciones para la proliferación de normas de organización, en especial sobre los proveedores de bienes y servicios.

Propicia, de forma inevitable, el intervencionismo económico en contra del orden espontáneo del mercado, lo que no solo ocurre, por cierto, por la sobreabundancia o desboque, en palabras de Eduardo García de Enterría, de legislación y regulación. Aunque por otras causas, la concepción paternalista también termina por apoyarse en un racionalismo instrumental, que sostiene que hay personas capaces de controlar o anular sus emociones mediante el uso de la razón utilitaria, de medios con arreglo a fines, etc., para proteger a otras menos capaces de ello, a fin de que no elijan en contra de sí mismas.

Más allá de lo anterior, el paternalismo libertario en la regulación, enfocado en empujar hacia lo mejor a los consumidores, puede perder de vista que ese énfasis puede tornar a la regulación económica en un obstáculo para garantizar condiciones que, mediante el ensayo y el error, vía orden espontáneo o no deliberado de las relaciones de cooperación económica, pueda la función empresarial desarrollar 
nuevas y mejores formas de satisfacer necesidades humanas, al tener que ajustar sus decisiones internas como proveedor, a las exigencias paternalistas de la regulación vigente.

\section{Consecuencias de las Debilidades Y RIESGOS IDENTIFICADOS}

El problema, como lo muestran los casos de EEUU e Inglaterra con tradiciones constitucionales basadas en el rule of law pero con predominio de regulaciones paternalistas a la fecha, es que si desde el Derecho Administrativo, más allá del Derecho Constitucional, no se adoptan una teoría y una concepción conforme a la Constitución de la regulación, la Administración del Estado y las agencias terminarán por dejar sin relevancia en muchos casos, lo que establezca la norma suprema.

Ante ese riesgo, una vez examinado el contenido del orden público económico constitucional de Chile ${ }^{11}$, por ejemplo, es inevitable preguntarse si aquélla sería compatible con este último, que no permite, en general, a los reguladores inducir las elecciones de los consumidores.

De acuerdo con Lara Arroyo: «...la actividad económica en Chile no se encuentra sujeta a una regulación especial sino afecta a aquella aplicable a todo actuar individual, subordinándose al estatuto general aplicable a los particulares, estructurado sobre la base de la autonomía de la voluntad, la buena fe negocial y las normas jurídicas de general aplicación, salvo tratándose de aquellos casos que el legislador estimó necesario disciplinar, en atención, entre otros, al interés público comprometido (...) En consecuencia, la estructura regulatoria se desprende del rol subsidiario del Estado, emanado de la propia CPR, en cuanto impone como deber del Estado fomentar y promover la libre iniciativa individual, respetando las normas que la regulen en cuanto éstas se encuentren expresamente establecidas. Lo anterior, en atención a que nuestro sistema constitucional establece las bases de protección de toda actividad económica tanto por vía formal como sustancial, esto es, al imponer un límite al actuar de los

11 Zavala Morales y Morales (2009)113 a 120; Fermandois (2011) 151 y ss. 
órganos administrativos y por otra parte al consagrar un verdadero estatuto tutelar del emprendimiento económico en Chile» ${ }^{12}$.

Por tanto, sostiene el mismo autor: «...podemos señalar que el sistema chileno no establece per se una regulación de la actividad y emprendimiento económico, sino que por el contrario fomenta la actividad mercantil, estableciendo los debidos resguardos, por cierto, pero que deben interpretarse estrictamente y en la medida que el legislador los haya impuesto, como en la especie sucede con las actividades reguladas en nuestro país» ${ }^{13}$.

Cuando no existe una teoría jurídica del orden público económico y una metateoría de la regulación que de él ha de derivar, en la forma antes planteada, es factible que ocurra lo sucedido en Venezuela desde antes de la instauración de la planificación centralizada hoy dominante, donde la doctrina más reconocida adscribía, sobre la regulación económica, tesis como la siguiente: «como no existe un sentido unívoco de regulación (...) el alcance de la regulación administrativa o social se ve claramente influenciado por la cláusula del Estado social, que moldea y da contenido a este tipo de regulación. Cláusula del Estado social que, como se indicara, impone emplazamientos positivos en cabeza de los Poderes Públicos quienes deberán intervenir a fin de asegurar la efectiva protección de esos bienes jurídicos lesionados por el ejercicio de la iniciativa económica (...) El Estado interviene para configurar el ejercicio de la iniciativa económica, ante los fallos de mercado existentes dentro de un determinado sector (...) La regulación económica se caracteriza, en cuanto a su forma de manifestación, por dos elementos. Así, (i) ante todo, se trata de una regulación externa, o sea, que opera desde fuera de la empresa. Además (ii) es una intervención que, operando desde un ámbito interno, penetra en el desarrollo de la propia empresa, condicionando las decisiones que podrá adoptar el empresario, cuya autonomía es, pues, claramente limitada» ${ }^{14}$.

Tal perspectiva, que criticamos en trabajo anterior dedicado a este mismo tema ${ }^{15}$, convierte a la regulación económica en instru-

\footnotetext{
Lara Arroyo (2011) 164 y 165.

LARA (2OI I) 167 a 169.

Hernández (2006) 149 y 153.

15 Herrera Orellana (2013) 333 y ss.
} 
mento para que desde la Administración del Estado se configure, planifique e incluso dirija de forma coactiva la actividad económica abierta a la libre iniciativa privada, esto es, no reservada al Estado, pero sí declarada de interés general.

Tal perspectiva hace posible posturas como esta: «...en el ámbito de la Administración económica, la regulación atiende a las medidas de ordenación y limitación de determinado sector económico, adoptadas externamente con la finalidad de restringir y, en ciertos casos, dirigir el ejercicio de actividades económicas, pero siempre con subordinación plena a la Ley (...) La regulaciones, entonces, el conjunto de medidas de ordenación y limitación adoptadas por la Administración, y mediante las cuales condiciona externamente el ejercicio de la libertad económica en determinado sector (...) Bajo esta noción, y desde el plano de la Administración económica (...) el énfasis del concepto de regulación se coloca en dos notas: (i) dado su carácter externo y sustitutivo de la libre iniciativa privada, y (ii) sus fundamentos económicos» ${ }^{16}$.

Expuesto lo anterior, preguntamos ¿existe otra concepción que analice o permita analizar la regulación económica que pueda considerarse una alternativa a las concepciones neutral y paternalista antes expuestas de forma resumida?

\section{4. ¿HAY Alguna Alternativa a las CONCEPCIONES DOMINANTES SOBRE LA REGULACIÓN?: LA CONCEPCIÓN EVOLUTIVA DE LA REGULACIÓN}

Ante estas dos tendencias, cabe preguntarse, desde el Derecho Administrativo, lo siguiente: ¿̇será en verdad suficiente afirmar la neutralidad de la regulación para lograr que ésta, en efecto, no desborde los límites que le imponen la legislación y los derechos fundamentales?, ¿bastará con proclamar que la regulación debe proteger más a los particulares en sus decisiones por sus sesgos cognitivos, pero sin imponerles ninguna elección, para que los límites antes mencionados, sean respetados en cada caso?

16 Hernández (2006) 155 a 157. 
El gran riesgo que corren las economías de libre mercado, basadas en la propiedad privada y la libertad económica, es que la Administración tradicional o las agencias administrativas, a través de la regulación, les impongan mandatos a los particulares que en ellas interactúan que no solo limiten de forma excesiva y arbitraria su libertad de elegir y contratar, sino incluso que la eliminen en algunos casos.

Ese riesgo quizá es mayor en el caso de una regulación «paternalista», por no tener presente que a los particulares carentes de potestades públicas mal se puede aplicar aquel tipo de normas, en lugar de reglas en el sentido estricto que a éstas atribuye la llamada teoría evolutiva de las instituciones sociales, que tiene en Carl Menger a uno de sus más destacados precursores.

De acuerdo con dicha teoría es indispensable distinguir entre normas de conducta o leyes en sentido estricto, derivadas de un orden espontáneo o no deliberado, que proveen información para la toma de decisiones sin establecer fines específicos, y las normas de organización o mandatos, creadas de forma intencional o deliberada para el logro de fines concretos ${ }^{17}$.

Sobre el primer tipo de normas explica Martínez Meseguer que: «...las normas gracias a las cuales se forma el orden espontáneo que da lugar al nacimiento de la sociedad humana, a las que en adelante denominaremos leyes, tienen unas características muy diferentes a aquellas otras reglas que dan lugar a una organización y que denominaremos mandatos, u órdenes específicas y determinadas. Las normas que regulan un orden espontáneo no necesitan (...) que su contenido sea expresamente conocido por los individuos, basta con que éstos actúen observando determinadas regularidades. La ley, por tanto, se limita a proporcionar al individuo que actúa una información fundamental (...) que deberá ser tenida en cuenta para adoptar una determinada decisión (...) Aunque, eso sí, jamás establecerá el desarrollo de una forma de actuar determinada» ${ }^{18}$.

En cambio, la norma de organización o mandato tiene una estructura distinta, en la cual tanto la elección como los fines están razonablemente limitados o incluso predeterminados, siendo lo

17 Hayek (20I4), Capítulos V y VI.

18 Martínez (2009) 207. 
usual o práctico que estos se apliquen en forma casi regular y casi sin excepciones a organizaciones sujetas al principio de legalidad como es el caso de la Administración Pública, pero en general, a toda la organización del Estado.

Según el citado Martínez Meseguer, lo explica así: «el mandato, por su parte, determina la acción concreta que debe ser desarrollada, no dejando que los que deban obedecerlo tengan la posibilidad de tomar una decisión al respecto según sus preferencias particulares y su conocimiento subjetivo del contexto donde se desarrolla la acción. Un ejemplo típico de este tipo de normas sería aquél que establece que un semáforo rojo indica que el automovilista deberá detenerse, mientras que en fase verde permite que se reinicie la marcha o que ésta continúe. No dejando margen a la voluntad individual en este tipo concreto de decisión (afortunadamente para la circulación y la seguridad de conductores y peatones) ${ }^{19}$.

Ahora bien, mientras las normas de mera conducta o leyes han surgido y siguen surgiendo (el comercio electrónico en el marco del Derecho Comercial mundial es una prueba actual de ello) de forma espontánea y no deliberada, vía ensayo y error, las normas de organización o mandatos, por lo general, derivan en cambio de actos de voluntad, de una planificación, de un cálculo, ya sea de privados o del Estado, conforme al cual para el logro de ciertos fines u objetivos de interés social, se adoptan y establecen en normativas ciertos pasos, específicas organizaciones y se distribuyen de cierto modo diferentes tareas, con miras a cumplir esos fines, de modo que mientras la libertad de las personas es mejor asegurada y promovida por leyes, la acción institucional del Estado, y de la Administración en particular, es mejor establecida por mandatos.

Pero, dado que a las personas, si se pretende respetar y garantizar su libertad y dignidad, no se les puede imponer por normativas conductas o fines específicos en contra de su voluntad, solo se les puede, eso sí, prohibir ciertas conductas o buscar determinados fines debido al perjuicio que generan a otras personas o a bienes o intereses públicos (es lo que hacen las normas de orden público en el Derecho Privado, y las que tipifican ilícitos en el Derecho Penal

19 Martínez (2009) 208. 
y el Derecho Sancionatorio en general). Es así como la distinción entre leyes y mandatos es vital a la hora de establecer las normas de actuación tanto de los particulares como de la Administración, de modo tal que sean las leyes las que rijan la mayor parte de las actuaciones privadas de los particulares, cosa que no parece puedan garantizar ni la concepción neutral ni la concepción paternalista de la regulación económica.

Será a partir de una metateoría desarrollada a partir de la concepción evolutiva, permitiría comprender y asegurar que ninguna regulación económica llegue a impedir ese orden no deliberado en la economía, que hace posible el emprendimiento, la innovación y la creación de riqueza, y a tener claros los supuestos en que mediante la regulación económica se puedan aplicar normas de organización a los particulares.

Ante el temor de no incurrir en una postura «ideológica» o «no científica» al regular, propio de la concepción neutral, y frente a la apuesta optimista de la concepción paternalista, la concepción evolutiva de la regulación plantea renunciar al miedo y al optimismo regulatorio, y confiar en el individualismo metodológico, la acción humana, la función empresarial y el orden cooperativo espontáneo ${ }^{20}$ para ir desde la regulación dando respuesta, mediante prudentes prohibiciones, condiciones y limitaciones, a aquellas conductas, elecciones u opciones que generen perjuicios y no beneficios, según sus resultados más que de acuerdo a preferencias subjetivas a priori, a las personas, pero de forma progresiva y sin optar por la dirección administrativa de los procesos de intercambio económico.

\section{Aportes de la CONCEPCión EVOlutiva a la teOría DE LA REGULACIÓN ECONÓMICA}

¿Qué aporta la distinción entre normas de conducta y normas de organización de la teoría evolutiva al estudio de la regulación económica? Básicamente la posibilidad de desarrollar una concepción evolutiva de la regulación económica, gracias a las bases en que ésta se apoyaría.

20 Infantino (2001) 104 y ss. 
Esas bases son, en primer lugar, una epistemológica, adecuada para la toma de decisiones regulatorias, basada en el individualismo metodológico y en la ciencia de la acción humana, que refuerza los fines de la concepción neutral al exigir al regulador medidas que garanticen la libertad y autonomía de los agentes económicos no solo porque formalmente así lo exigen la Constitución y otras fuentes jurídicas estatales -eventualmente modificables- sino porque solo otorgando esa garantía resulta posible lograr condiciones de intercambio que hagan posible la satisfacción de necesidades de bienes y servicios en la sociedad.

Y en segundo lugar, una antropológica, que permite la generación de una metateoría de la regulación en cuanto a su estructura normativa, completando y al mismo tiempo corrigiendo lo propuesto por el paternalismo libertario, pues junto a las exigencias de costosbeneficios, eficiencia, simplicidad, mínima extensión, etc., añade la orden al regulador de aplicar en este ámbito de forma mayoritaria normas de conducta a los particulares, que siempre le permitan elegir sin coacción o inducción desde la autoridad, y solo de forma extraordinaria, respecto de su conducta externa, mandatos o normas de organización, con fines exigibles por razones de utilidad pública o bien común.

A partir del desarrollo de estas bases epistemológica y antropológica, y de la metateoría a desarrollar, cuyo análisis y exposición en extenso corresponde a otro lugar, se puede argumentar, por ejemplo, por qué a través de la regulación económica se podría, sin vulnerar un orden público económico constitucional como el vigente en Chile -que reconoce y tutela, de forma implícita la acción humana y la función empresarial ${ }^{21}$-, contemplar la aplicación de mandatos en casos tales como:

i. Cuando los particulares entren en relación directa con la Administración del Estado mediante procedimientos administrativos con objeto y finalidad definidos por ley;

ii. Cuando usen algún bien público gerenciado por la Administración del Estado, como parques, avenidas, autopistas, etc.;

21 Navarro Beltrán (2016) 58 y ss. 
iii. Cuando actúan en lugar de la Administración del Estado, y asume potestades, o;

iv. Cuando eligen realizar una actividad calificada por ley como de interés público, y acepta que se le apliquen mandatos externos, esto es, limitativos de sus conductas con incidencia en la esfera subjetiva de otras personas, en áreas tales como prestación de servicios de salud, educación, finanzas, seguros, energía eléctrica, agua potable, etc.

En cualquiera de estos casos, sin coacción arbitraria, el particular estará actuando en ámbitos o situaciones en los que se justifica, o bien la exclusión de un importante conjunto de posibles conductas por sus negativos efectos sociales y la existencia de relaciones de sujeción respecto de una autoridad administrativa, o bien la definición a través de mandatos de los pasos a seguir y fines a perseguir en aras de la seguridad, el orden, la paz social, certeza, etc., y no puedan preferencias privadas alterarlos o modificarlos.

De este modo, cuando el particular entra en relación directa con la Administración del Estado se justifica que esté obligado a seguir ciertos mandatos «externos» que fijen las etapas y el objeto de procedimientos y, al igual que la autoridad, deba cumplir ciertos requisitos, plazos, etc., pues ello es más consecuencia del principio de legalidad que rige a la Administración, así como del valor seguridad jurídica que se debe garantizar en dichas relaciones, que de la intención de las autoridades en dirigir la conducta de los individuos, o protegerlos de alguna mala decisión.

También, cuando el particular usa algún bien bajo dominio público que es gerenciado por la propia Administración del Estado o un concesionario, como autopistas, carreteras, avenidas, aeropuertos, puertos, el espectro radioeléctrico, parques, ferrocarriles, metros, etc., o aprovecha algún bien natural reservado o bajo régimen especial de protección, se justifica que se apliquen mandatos externos a su conducta, y que no dependa de su libre elección el cómo se usarán esos bienes.

Igualmente, cuando el particular actúa en lugar de la Administración del Estado, por ejemplo, bajo régimen de concesiones, o como productor de «actos de autoridad», es razonable que la regulación 
le aplique mandatos, e incluso en este único caso, mandatos tanto externos como internos, es decir, de configuración u ordenación interna de la actividad, pues (i) la titular de esa actividad es la Administración del Estado al estar reservada la misma, (ii) el particular ejerce potestades administrativas en lugar de la Administración del Estado, (iii) los fines están previstos en la ley o en un contrato administrativo o público según el caso, así como los medios para alcanzarlos, no cabe autonomía de la voluntad respecto de ello, y (iv) más allá de que siempre se busca un fin de interés privado, el particular, en este supuesto, sí actúa como colaborador, casi como extensión, de la Administración del Estado, no integra su organización en sentido formal, pero sí es instrumento para realizar los fines públicos que aquélla, pues no actúa en ejercicio derechos inherentes a sí, sino derivados de una legislación compuesta de mandatos y bajo relación de sujeción.

Por último, cabe aplicar ciertos mandatos externos al particular que elige realizar una actividad calificada por ley como de interés público, siendo este sin duda el supuesto en que más complejo resulta equilibrar la relación ley-libertad con mandato-organización que siempre debe la regulación procurar armonizar ${ }^{22}$.

En efecto, en áreas tales como educación, medicamentos de consumo humano, alimentos, servicios de salud, telecomunicaciones, servicios financieros y de seguros, servicios de energía eléctrica o agua potable, etc., es decir, en todos los sectores que la Constitución o que el Parlamento en tanto órgano democrático haya declarado por ley como de interés general (declaratoria que siempre debe debatirse y estar abierta a revisión según sus costos y beneficios) cabe exigir a los particulares que cumplan con ciertas condiciones que acrediten su capacidad, experticia, solvencia, transparencia, etc., a fin de fortalecer en el sector la competencia, garantizar, preventivamente, antes de que surjan crisis o controversias jurídicas de compleja solución ante los tribunales, el respeto a los derechos de todos los agentes económicos y la existencia de métodos alternativos de resolución de conflictos que no se puedan prevenir.

22 Arancibia Mattar (2017) 2 y ss. 
Pero en ningún caso, como sí se acepta y ocurre bajo el predominio de la concepción neutral o de la concepción paternalista, con apoyo en tópicos como el «servicio público», el «débil jurídico», la «función social», la «cláusula del Estado social»o el «interés público», bajo la concepción evolutiva pueden aplicarse mandatos internos en los casos de actividades de interés general, es decir, mandatos de configuración o sustitutivos de la autonomía privada, que permitan al Gobierno ejercer potestades discrecionales ilimitadas, o asumir directamente los atributos de la libre empresa y de la propiedad privada en lugar de los titulares de esos derechos según la Constitución, que es por ejemplo lo que ocurría en Venezuela en una vasta generalidad de casos, desde antes de 1999, y se convirtió en regla general a partir de 2007 aproximadamente.

Estimamos compatible con la concepción evolutiva de la regulación aplicar mandatos externos a los particulares en cualquiera de los casos indicados (e internos solo en el supuesto 3), dado que en ellos no se aprecia coacción externa arbitraria contraria a los contenidos de un orden público económico constitucional garante de una economía basada en el mercado, como ocurre en el caso chileno, pues en ellos el particular actúa en ámbitos o situaciones en los que se justifica la fijación de pasos para conseguir un fin o usar un bien público, o bien la exclusión de un conjunto de conductas por sus negativos efectos sociales, la ordenación de relaciones de sujeción, o la protección jurídica al mercado, a la competencia y a los derechos y libertades de las personas que actúan en aquel.

Ahora bien, todas las regulaciones contentivas de mandatos aplicables a particulares que estén fuera de los supuestos antes examinados, tanto desde el punto de vista jurídico como del económico -por sus costos nocivos para la sociedad-, sí serían incompatibles con la concepción evolutiva de la regulación e incompatibles con la libertad económica y la propiedad privada, y salvo en situaciones de emergencia declaradas mediante formal Decreto de Estado de Excepción, y por muy breve tiempo, no se pueden aplicar para ni para restringir, menos aún para funcionalizar, la actividad de los particulares.

Ejemplos de este tipo de regulaciones hoy día vigentes en Venezuela son, entre otras tantas que cabría mencionar, el régimen de control cambiario mediante convenios del Banco Central con 
el Ejecutivo Nacional, los controles de precios que aplica la Superintendencia para la Defensa de los Derechos Socioeconómicos, los controles de movilización y almacenamiento de bienes -alimentos y medicamentos, por ejemplo- aplicados por los Ministerios de esos ramos y sus órganos subalternos, todas las declaratorias y autorizaciones que crean monopolios para la importación, distribución y exportación, los decretos sublegales de fijación de los arriendo de viviendas, de inamovilidad laboral, de fijación de matrículas y mensualidad de escuelas y colegios, las licencias que restringen la oferta de servicios, etc.

Esos mandatos internos, contrarios a derechos fundamentales e ineficientes en lo económico, que la doctrina y la jurisprudencia de países como Venezuela han tolerado y justificado con pésimos argumentos, pero que gracias al principio de subsidiariedad ${ }^{23}$-entre otros contenidos constitucionales- no han sido aceptados en Chile, no son «límites» al ejercicio de esos derechos, sino derogatorias explícitas de los atributos esenciales de todos esos derechos, es decir, liquidan las libertades económicas, además de que no resisten el más mínimo análisis económico del derecho, de costos beneficios, elección pública o compatibilidad con el orden espontáneo de la función empresarial, pues el fracaso de las regulaciones dominadas por normas de organización a particulares en lugar de por normas de conducta está demostrado por la historia reciente de diferentes sociedades, incluso en las más desarrolladas ${ }^{24}$.

Congruente con la concepción evolutiva de la regulación, la Administración del Estado no puede olvidar, y deber ser forzada jurídicamente a cumplir con ello, que: «...la política regulatoria tiene como objetivo único y exclusivo la defensa y buena ordenación del sistema de prestaciones de que se trate en las mejores condiciones posibles de seguridad, calidad y precios; con la mayor eficiencia que el estado del arte lo permita, tanto para hoy como para mañana» ${ }^{25}$, lo que solo es posible si los agentes económicos disponen de la mayor libertad para el desarrollo de la función empresarial, no sujeta a plan previo sino atenta a las demandas de consumidores y usuarios.

23 Soto KLoss, (2012) 109 y ss.

24 Rojas (20I4) y BenEgas (2013).

25 Ariño Ortiz (2006) 32 y 34. 
Para que se logre ese objetivo, deben darse unas condiciones: «... la regulación económica es una tarea compleja. Sólo una adecuada mezcla de ingeniería, análisis económico y buen derecho público permitirá hacer una buena regulación para la competencia en sectores estratégicos. Asimismo, para adoptar decisiones correctas, el regulador, que goza siempre de una gran discrecionalidad técnica, debe seguir determinados procedimientos formales (convenios, audiencias públicas, llamamiento a los interesados, solución de reclamaciones) con los cuales va estableciendo los equilibrios necesarios. Además, debe explicar en foros, organismos consultivos o publicaciones de diversos tipos, la razón económica y técnica de la decisión que se pretende adoptar» ${ }^{26}$. Y junto a lo anterior, es fundamental que el regulador disponga tanto de una metateoría de la regulación económica, así como de un conocimiento adecuado sobre la acción humana y la función empresarial, de modo que no haya excesos ni vulneración de derechos fundamentales al establecer el contenido de la regulación.

Acerca del conocimiento al que se alude, que no es apreciado ni por la concepción neutral ni por la concepción paternalista, pero sí por la concepción evolutiva, valga como reflexión final la siguiente declaración de dos reconocidos académicos de la economía contemporánea: «claro que la libertad es más que la economía y el mercado, pero requiere el mercado y sus instituciones fundamentales, como la propiedad privada y los contratos voluntarios (...) En las democracias intervenidas de nuestro tiempo, se observa también este paralelismo porque los mismos Estados que recortan la libertad en los mercados hacen lo propio en numerosos ámbitos de la vida social, comunitaria y familiar. Y esta intromisión es lo que está mal, no la libertad. Lo que no es justo, ni recto, ni debido es la coacción y la intimidación del poder y su constante empeño en recortar los derechos de los ciudadanos, alegando que él si sabe lo que mejor conviene a sus súbditos. Esa soberbia de las autoridades, esa prepotencia de los poderosos, esa pasión por controlar, dividir, enfrentar, moralizar, asustar, imponer, organizar, prohibir, vigilar, multar, recaudar, eso es pecado» ${ }^{27}$.

26 ARIÑO (2006) 32 y 34.

27 Rodríguez Braun y Rallo (2011) 298 y 299. 


\section{BibliografíA}

Arancibia MatTAR, Jaime (2017): «La relación jurídica público-privada: iter conceptual, atributos y criterios», en Sото Kloss, Eduardo (coord.), El Derecho Administrativo y la Protección de las Personas: Libro Homenaje a 30 años de docencia del profesor Ramiro Mendoza en la PUC (Santiago, Pontificia Universidad Católica de Chile).

AriÑo Ortiz, Gaspar (2006): «Fallos y logros de los sistemas regulatorios», en AA/VV, Regulación, Desregulación, Liberalización y Competencia (Madrid, Fundación Rafael del Pino y Círculo de Empresarios).

Ariño Ortiz, Gaspar (2005): «La liberalización de los servicios públicos en Europa. Hacia un nuevo modelo de regulación para la competencia», en Cassagne, Juan Carlos, y Ariño Ortiz, Gaspar (coord..), Servicios Públicos, Regulación y Renegociación (Buenos Aires, Editorial LexisNexis Abeledo Perrot).

Benegas Lynch (H), Alberto (2013): Estados Unidos contra Estados Unidos (Madrid: Unión Editorial).

Boulin, Ignacio y CADENAs, Enrique (2018): Innovar el Derecho Administrativo. Bases para la mejora del sistema regulatorio y la calidad de las políticas públicas en Argentina. (Buenos Aires, Universidad Austral).

Cano Campos, Tomás (2009): "Lección 1. El marco general de la intervención pública en la economía y sus técnicas de intervención», en Cano Campos, Joaquín (Coord.). Lecciones y Materiales para el Estudio del Derecho Administrativo. Tomo VIII. Volumen I. Los sectores regulados (Madrid, Editorial Iustel).

Fermandois, Arturo (2011): Derecho Constitucional Económico. Tomo I. (Santiago, Ediciones de la Pontificia Universidad Católica de Chile).

Hayek, Friedrich von (2014): Derecho, Legislación y Libertad. Una nueva formulación de los principios liberales de la justicia y de la economía política (Madrid, Unión Editorial).

Hernández González, José Ignacio (2006): Derecho Administrativo y Regulación Económica (Caracas, Editorial Jurídica Venezolana).

Herrera Orellana, Luis Alfonso (2013): «Leyes, mandatos y regulación administrativa", en Herrera Orellana, Luis Alfonso (coord.), Enfoques sobre Derecho y Libertad en Venezuela (Caracas, Academia de Ciencias Políticas y Sociales).

InFANTINo, Lorenzo (2001): El Orden sin Plan. Las razones del individualismo metodológico (Madrid, Unión Editorial). 
LARA Arroyo, José Luis (2011): «La regulación administrativa en materia económica y sus nuevas manifestaciones: la irrupción del denominado soft law», en Ars Boni et Aequi No. 2, agosto (Santiago de Chile, Instituto de Ciencias Sociales y de la Comunicación, Universidad Bernardo O'Higgins).

Martínez Meseguer, César, (2009): César, La Teoría Evolutiva de las Instituciones. La perspectiva austríaca. 2 da edición (Madrid, Unión Editorial).

Mises, Ludwig von (2018): La Acción Humana. Tratado de economía (Madrid, Unión Editorial).

Navarro Beltrán, Enrique (2016): La Constitución Económica Chilena ante los Tribunales de Justicia (Santiago, Universidad Fines Terrae).

Rallo, Juan Ramón (2018): «El origen de la riqueza», en La Libertad Digital, disponible en la siguiente dirección: https://goo.gl/ZJPnxp, [Fecha de consulta: 23 de noviembre de 2018].

Rodríguez Braun, Carlos, y Rallo, Juan Ramón (2011): El Liberalismo no es Pecado. La economía en cinco lecciones (Barcelona, Editorial Deusto).

Rojas, Mauricio (2014): Suecia, el otro modelo (Santiago: Fundación para el Progreso).

Sото KLoss, Eduardo (2012): Derecho Administrativo. Temas fundamentales (Santiago, Thompson Reuters).

Sunstein, Cass R. y Thaler, Richard H. (2006): «El paternalismo libertario no es un oximorón», en Revista Derecho y Sociedad No. 27 (Lima, Pontificia Universidad Católica del Perú).

Sunstein, Cass (2014): (más) Simple. El futuro del gobierno. (Madrid, Editorial Marcial Pons).

Sunstein, Cass (2017): Paternalismo libertario. ¿Por qué un empujoncito? (Madrid, Editorial Herder).

Zavala Morales, Joaquín, y Morales, José Luis (2009): Derecho Económico (Santiago, Editorial Thomson Reuters). 



\title{
LAS CONCENTRACIONES MEDIÁTICAS EN CHILE Y EL PRINCIPIO DEL PLURALISMO INFORMATIVO
}

\section{The Media CONCENTRATIONS IN CHILE AND THE PRINCIPLE OF INFORMATIVE PLURALISM}

\author{
Alexander Espinoza ${ }^{1}$ \\ Jhenny Rivas Alberti ${ }^{2}$
}

Resumen. El presente trabajo analiza la concentración de medios de comunicación social, desde diversas perspectivas: de la concentración de audiencias, la de la inversión publicitaria en los medios; la concentración de la propiedad y reparto del capital social de las sociedades mercantiles propietarias de empresas de información, y la incidencia de la tecnología en las expectativas de concentración mediática frente a las exigencias que se desprenden del principio del

1 Doctor iuris (Universität Passau, Alemania). Docente (Universidad Autónoma de Chile, Sede Talca). E-mail: alexander.espinoza@uautonoma.cl.

2 Doctora en Derecho (Universidad de Zaragoza, España). Docente (Universidad Autónoma de Chile, Sede Talca).E-mail: jhenny.rivas@uautonoma.cl. 
pluralismo informativo y la protección del proceso de formación de la opinión pública.

PAlabras Clave: concentración de medios, principio de pluralismo informativo

AвsTRACT. The present work analyzes the concentration of social media, from different perspectives: the concentration of audiences, the advertising investment in the media; the concentration of the ownership and distribution of the social capital of the mercantile companies that own information companies, and the impact of technology on the expectations of media concentration in the face of the demands arising from the principle of pluralism of information and the protection of the process of formation of public opinion

KEYWORDS: media concentrations, principle of informative pluralism

Sumario. 1.Introducción. 2. Pluralismo informativo: 2.1. Regulaciones audiovisuales y principio del pluralismo Informativo en Chile. 2.2. Pluralismo Corte Interamericana de Derechos Humanos. 3. Concentración mediática: 3.1. Medidas anticoncentración en Chile; 3.2. Medidas para fomentar el pluralismo informativo. 4. Conclusiones. 5. Bibliografía.

\section{INTRODUCCIÓN}

Los medios de comunicación juegan un papel definitivo en el progreso y desarrollo de la sociedad hacia nuevas formas de organización, ya que la difusión de la información tiene implicaciones en la educación, los modos de pensamiento, la cultura y los estilos de vida. El desarrollo de los medios de comunicación de masas está asociado a las innovaciones técnicas que hicieron posible la ampliación de las potencialidades presentes en medios como la prensa. El impacto y proyección de la radio y la televisión en la sociedad los colocan en el sitial de honor dentro de los medios de comunicación social.

Para que pueda formarse la opinión pública es necesario que existan al menos tres condiciones: (i) Que exista un régimen general de libertad de expresión, entendida esta en un sentido amplio, es decir, que incluya todas las libertades civiles y políticas vinculadas a la libre 
expresión de ideas y opiniones. Desde la libertad de pensamiento, hasta la libertad de prensa, pasando por el derecho al sufragio y el derecho de reunión y manifestación; (ii) que estas libertades se desarrollen en una sociedad abierta, en un marco de publicidad, de espacio público político, que exista suficiente transparencia, no solo de la acción del poder, sino también más ampliamente, de todo el proceso de formación de la opinión y de la voluntad política en el ámbito de la sociedad civil; (iii) que la opinión se cree sin perjuicios, que sea el resultado de la pública y libre deliberación de los ciudadanos. ${ }^{3}$

La democracia requiere que el público tenga toda la información relevante y que sea consciente de los puntos de vista opuestos o en conflicto sobre todas las cuestiones. Una prensa libre debería hacer realidad este supuesto. Ha señalado el Tribunal Constitucional español que el proceso de formación de la opinión pública, en tanto que actividad previa al ejercicio del derecho al sufragio, ha de considerarse, como "uno de los pilares de la sociedad libre». ${ }^{4}$

El pluralismo informativo resulta una de las condiciones fundamentales para que esa opinión pública pueda formarse en forma idónea. Razones históricas permiten explicar las exigencias de pluralismo informativo en la radiotelevisión.

\section{Plunalismo informativo}

El pluralismo es uno de los objetivos que justifican la intervención del Poder Público sobre los medios de comunicación. En tanto que reconocimiento de la multiplicidad de opciones, puntos de vista o doctrinas, el pluralismo afecta tanto los contenidos (libertad de expresión, representatividad política, cultural o social, diversidad de géneros, etc.) como la estructura del sector (propiedad empresarial, libertad de acceso al mercado, libre competencia, acceso a la audiencia, etc.). ${ }^{5}$ La aplicación de normas sobre competencia a las concentraciones mediáticas representa una serie de desafíos guiados por la concreción del llamado principio del pluralismo informativo. Si partimos de la idea fundamental conforme a la cual el pluralismo

RODRíguez (1999) 18.

STC $159 / 1986$

FISS (1997) 183 
informativo se relaciona con la diversidad y proliferación de medios de comunicación; mientras más fuentes de información existen, mayor es la capacidad de elección de los ciudadanos puesto que los medios de comunicación constituyen un soporte informativo básico por el cual una significativa cantidad de público forma su criterio y opinión. Sin embargo, la complejidad del mercado de las empresas de comunicación obliga a replantearse las medidas que legislativa y administrativamente deben tomarse para proteger el principio del pluralismo informativo al tiempo que permitir el desarrollo del sector.

De esta forma, la comunicación pública fundamenta la democracia, dota al ciudadano de competencia para la circulación de sentidos, para que la sociedad reconozca y tramite su agenda pública. El Tribunal Constitucional de Chile ha reconocido la relación directa entre libertad de expresión y democracia. En la Sentencia N $^{\circ}$ 567/2010 en su considerando jurídico 32 expresó: "Que la libertad de expresión, por su parte, desempeña un papel fundamental en la sociedad democrática, pues permite el debate de ideas, el intercambio de puntos de vista, emitir y recibir mensajes, la libre crítica, la investigación científica y el debate especulativo, la creación artística, el diálogo sin restricción, censura ni temor, y la existencia de una opinión pública informada.» Lo anterior es clave por cuanto la democracia, libertad de expresión se vinculan a un valor clave en los Estados constitucionales moderno: el valor del pluralismo, el cual permite la libre circulación de todas las ideas, aunque éstas sean antagónicas entre sí e incluso con la institucionalidad constitucional. ${ }^{6}$

La democracia y libertad de expresión están vinculadas por el valor del pluralismo. Este no es solo político, como lo dispone el artículo 19, $\mathrm{N}^{\circ}$ 15, inciso sexto ( «La Constitución garantiza el pluralismo político»), sino de toda índole (ideológico, religioso, social etc...). De esta forma, la democracia, pluralismo y libertad de expresión están íntimamente vinculados, por cuanto es un elemento nuclear en las sociedades democráticas, donde todos los actores sociales en razón de la procedencia pluralista, pueden expresar todo tipo de opiniones o dar a conocer todo tipo de informaciones, teniendo como límite

$6 \quad$ STC Rol N 567/2010 
la comisión de delitos o el abuso del ejercicio del derecho (inciso primero del artículo $\left.19, \mathrm{~N}^{\circ} 12\right){ }^{7}$

El pluralismo es uno de los objetivos que justifican la intervención del Poder Público sobre los medios de comunicación. En tanto que reconocimiento de la multiplicidad de opciones, puntos de vista o doctrinas, el pluralismo afecta tanto los contenidos (libertad de expresión, representatividad política, cultural o social, diversidad de géneros, etc.) como la estructura del sector (propiedad empresarial, libertad de acceso al mercado, libre competencia, acceso a la audiencia, etc.). ${ }^{8}$

En una aproximación a la noción de pluralismo informativo el Tribunal Constitucional de Chile se ha referido en lo siguientes términos: «Este comprende respeto a la diversidad social, cultural, étnica, política, religiosa, de género, de orientación sexual e identidad de género" . ${ }^{9}$ Con ocasión de la revisión constitucional del Proyecto de Ley de Televisión Digital Terrestre el cual será nuevamente abordado.

El pluralismo informativo, en su esencia, muestra la existencia de intereses sociales contrapuestos y con ideas divergentes, y como democrático, propone límites a la divergencia y al conflicto que pueden nacer de la visión diferente que tenga del hombre y la sociedad, y de los intereses parciales. ${ }^{10}$

El pluralismo, es un principio de reconocimiento del sujeto y de los grupos que aspiran a su delimitación por referencia a subjetividades externas al Estado. También incluye, las etnias, las razas, las edades, los sexos, así como el acceso a los medios tanto de las mayorías como de las minorías. ${ }^{11}$ Son los poderes públicos quienes deben preservar la igualdad de oportunidades, la libre constitución de la sociedad, el derecho a la disidencia y a la identidad de las minorías. ${ }^{12}$

Es así como el pluralismo aplicado a los medios de comunicación audiovisual se manifiesta en la posibilidad de todo ciudadano por acceder de manera equitativa al máximo de opiniones, ideas e informaciones; el pluralismo es un valor que asegura a los ciudadanos

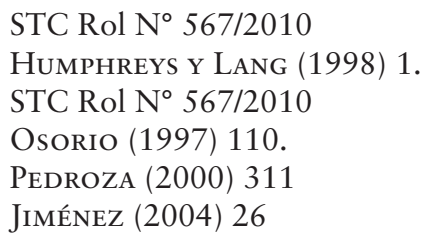


la diversidad informativa. Esta no se refiere exclusivamente a las informaciones políticas sino a todo tipo de programas y contenidos, ya que son todos estos, en su conjunto, los que construyen la imagen de la sociedad que los medios devuelven a sus ciudadanos, imagen que les permitirá forjarse una opinión y asimilar determinados valores. La calidad de la democracia se mide por la pluralidad y libertad en que se desarrolle este proceso. ${ }^{13}$

En este mismo sentido, encontramos que el pluralismo informativo consiste, de un lado, en la posibilidad de concurrencia de opiniones e informaciones, lo que redunda en un proceso de libre formación de la opinión pública. De otro lado, en la posibilidad de que esa concurrencia llegue al mayor número posible de personas. ${ }^{14}$

En un Estado democrático de derecho, todos los ciudadanos deben estar en condiciones de poder recibir la información puesta en el mercado. El derecho a recibir información adquiere una entidad propia, bien como derecho subjetivo, bien en su dimensión objetiva de contenido sustancial del pluralismo. ${ }^{15}$

En cuanto a la forma de garantizar el pluralismo en la radiodifusión la doctrina ha desarrollado las nociones de pluralismo interno y pluralismo externo. El pluralismo interno se refiere al pluralismo en la organización de las instituciones públicas de televisión. ${ }^{16}$ Mientras que el pluralismo externo garantiza la diversidad de canales de televisión y la regulación en cuanto a las normas de competencia y funcionamiento. ${ }^{17}$

En este sentido, es necesario garantizar el pluralismo interno a través de la programación diversa, protegiendo las distintas tendencias. ${ }^{18}$ Esta concepción de garantizar la diversidad por medio de la representación de los grupos sociales más significativos en la programación fue plasmada por el $B$ VerfG en su decisión de 9 de febrero de $1982 .{ }^{19}$

En cuanto al ámbito de protección de la libertad de televisión, elaborar la programación es la principal actividad protegida y

\footnotetext{
Olalla (2004) 1

BASTIDA (2001) 274

BASTIDA (2001) 274

BVerfGE 74, 297 (324)

Niepalla (1990) 127

SCHUSTER (1990) 96

BVerfGE 60, 53
} 
constituye, por tanto, el núcleo del ámbito protegido por el derecho. Se trata de garantizar la libertad en la elección, contenido y desarrollo de la programación, con la única obligación de respetar ciertos principios o criterios establecidos por el legislador, entre los más importantes el «pluralismo y equilibrio en la programación». ${ }^{20}$

Ahora bien, por lo que respecta al pluralismo externo, a partir de la sentencia del 16 de junio de 1981 el $B$ VerfG empezó a utilizar la expresión "pluralismo externo». De acuerdo con esta decisión el pluralismo en la televisión privada podía ser alcanzado mediante el pluralismo interno como ocurría con la televisión pública o a través de otra forma de organización. A pesar de la posibilidad de elección entre un modelo u otro, los medios privados también debían garantizar en todo caso el pluralismo informativo. ${ }^{21}$ Es así como en el marco de protección al principio del pluralismo informativo externo se van desarrollando progresivamente una serie de principios que deben ser incorporados en las legislaciones para proteger el pluralismo externo y evitar las concentraciones mediáticas. Entre otros mencionamos los siguientes: (i) los índices de audiencia, de manera de establecer un criterio cierto para estudiar la influencia del medio de comunicación en la formación de la opinión pública, (ii) porcentaje en el mercado conseguida por la empresa líder o las dos primeras de cada rama de la comunicación,

\subsection{Regulaciones audiovisuales y principio del pluralismo informativo en Chile}

En cuanto al estatuto jurídico que rige a la radiodifusión chilena, encontramos que ella se basa en un esquema de funcionamiento y financiación bajo criterios de mercado al que se aplican derechos como los asegurados en los numerales $16^{\circ}, 21^{\circ}$ y $22^{\circ}$ del artículo 19 de la Constitución Política, pero con ciertas particularidades que tienen que ver con la titularidad de los medios televisivos, con una estructura de multipropiedad y con una regulación particularmente compleja. Esta regulación se contiene, básicamente, en la Ley que rige

20 BVerfGE 59, 231 (260) 257

21 SChuster (1990) 182 
al Consejo Nacional de Televisión y también en la normativa referida a las libertades de opinión e información -Ley $\mathrm{N}^{\circ}$ 19.733- que procura fomentar la libre competencia en esta materia, impidiendo, al mismo tiempo, la concentración de mercado. Se agrega la Ley General de Telecomunicaciones No. 18.168 y el Decreto Supremo ${ }^{\circ}$ 127, de 2006, del Ministerio de Transportes y Telecomunicaciones, que aprobó el Plan General de Uso del Espectro Radioeléctrico y sus modificaciones, así como el Decreto Ley 211 que fija normas sobre defensa de la libre competencia.

La perspectiva constitucional busca la concurrencia de la pluralidad de medios, para lo cual se prohíbe al legislador «establecer monopolio estatal sobre los medios de comunicación social.» (Artículo $19 \mathrm{~N}^{\mathrm{o}} 12^{\circ}$, inciso segundo, de la Constitución). Esta norma, unida a la libertad para desarrollar actividades económicas, a que se refiere el numeral $21^{\circ}$ del artículo 19 de la misma Carta Fundamental, establece una batería normativa de apertura a la pluralidad o multiplicidad del dominio sobre los medios de radiodifusión televisiva.

En materia de titularidad activa de este derecho se reduce solamente a las personas jurídicas. Si bien el legislador, mediante las leyes $\mathrm{N}^{\circ} 18.562$ y 18.838 estableció la posibilidad de la televisión privada con titularidad de personas naturales, fue la Ley $\mathrm{N}^{\circ} 19.131$ la que reservó la condición de concesionario de servicios de televisión exclusivamente a personas jurídicas. En cuanto a la titularidad extranjera o nacional. Aquí la regla general es que los concesionarios deben ser personas jurídicas de derecho público o privado nacionales, «constituidas en Chile y con domicilio en el país» (artículo 18 de la Ley $N^{\circ} 18.838$ sobre Consejo Nacional de Televisión

Por otra parte, los canales de televisión propiamente estatales están sometidos a un régimen específico muy complejo dentro de la estructura de mercado que rige la televisión chilena. Televisión Nacional de Chile es un "canal público", sometido a las reglas del artículo $8^{\circ}$ de la Constitución relativas al acceso a la información pública, y con deberes relativos a ciertos controles parlamentarios.

Por tanto, si bien hay mercado, la estructura del mismo es doblemente reducida en materia de titularidad, sin personas naturales y sin personas jurídicas extranjeras, con una estructura de multipropiedad y con una obligación a la regulación más compleja del sector. 
Respecto al rol del Estado, es cada vez más claro que este se encuentra ausente en la generación de espacios y condiciones necesarias para garantizar la participación en los medios de todos los sectores; por lo que la intervención del Estado chileno en este sentido no se ha hecho presente ni de forma directa, con la creación de medios estatales ni de forma indirecta, con aportes de dineros en inversión o subvención de medios. Ejemplo de esto es que la inversión estatal de publicidad en prensa, es decir, de los avisos que las instituciones del Estado publican en los diarios, un 50\% está dirigido al grupo comunicacional Edwards, un 30\% a COPESA y el 20\% restante se distribuyen en todos los demás grupos económicos dueños de algunos medios. En este sentido, el Estado no ha desarrollado adecuados mecanismos que impidan la concentración de la propiedad de los medios de comunicación social. ${ }^{22}$

En cuanto a las normas para garantizar la diversidad en los medios y evitar la concentración en el sector, la Relatoría Especial para la Libertad de Expresión señala que la Ley de Prensa, mediante una modificación legal introducida en el año 2009, dispone en su artículo 38 que «cualquier hecho o acto relevante, relativo a la modificación o cambio en la propiedad de un medio de comunicación social, deberá ser informado a la Fiscalía Nacional Económica, dentro de treinta días de ejecutado». Se trata de un ejemplo de medida que debería proteger el pluralismo externo. En esta misma línea se inscribe, las medidas respecto de los medios de comunicación social sujetos al sistema de concesión otorgada por el Estado, el hecho o acto relevante deberá contar, previo a su perfeccionamiento, con informe de la Fiscalía Nacional Económica referido a su efecto sobre la competencia. Las dificultades se presentan en que la limitación solo contraviene actos de concentración mediática exclusivamente en los medios de comunicación que requieran uso del espacio radioeléctrico, siendo que estas disposiciones serían inútiles respecto de concentraciones en prensa, medios que utilicen tecnología satelital u otras concentraciones cruzadas de propiedad por fusiones o adquisiciones.

Por su parte, el artículo 13 de la Ley General de Telecomunicaciones establece una limitación a la acumulación de frecuencias

22 URIBE (1999) 30 
por parte de una misma empresa o grupo económico para una misma localidad. Esta norma dispone que «una misma empresa y sus empresas filiales, coligadas o relacionadas no podrán presentar más de una solicitud para una misma localidad, en un mismo concurso. De hacerlo, ninguna de las solicitudes será considerada en el concurso». ${ }^{23}$ El artículo 15 de la Ley No. 18.838 del Consejo Nacional de Televisión dispone, además, que «no podrán otorgarse nuevas concesiones con medios propios a aquellas personas jurídicas que ya sean titulares de una concesión de la misma naturaleza, o bien controlen o administren a otras concesionarias de servicios de radiodifusión televisiva de libre recepción, que hayan sido otorgadas por concurso público, en la misma zona de servicio [...]. Las limitaciones que establecen los incisos precedentes afectarán también al grupo empresarial respectivo, conforme al artículo 96 de la ley $\mathrm{N}^{\mathrm{o}} 18.045$ ». ${ }^{24}$

La regulación no impide que se repartan proporciones de acciones menores entre muchas personas naturales y jurídicas para cumplir con la norma para cumplir con la norma, mientras que un solo grupo o persona natural o jurídica conserva un porcentaje de acciones que lo mantengan en control efectivo de la empresa.

La Ley de Televisión Digital dispuso que, una vez que se asignen las frecuencias necesarias para que la televisión pueda hacer la transición a señal digital, el $40 \%$ del total de las concesiones restantes para este sector, serán destinadas a señales de radiodifusión televisiva digital regionales, locales y locales comunitarias, o para señales culturales o educativas. No obstante, es posible que el espacio disponible para medios comerciales sea captado por los actores que tienen actualmente posiciones dominantes en la industria televisiva o en otras empresas de radiodifusión. Por ello es necesario que el Estado fortalezca las medidas de fomento para garantizar el acceso de nuevos actores al espectro, como la producción y transmisión de contenidos a través de fondos concursables.

23 Biblioteca del Congreso Nacional de Chile (2019): Ley General de Telecomunicaciones No. 18.168.

24 Biblioteca del Congreso Nacional de Chile (2019): Ley No. 18.838 que crea el Consejo Nacional de Televisión. 
Resulta interesante destacar modelos como el empleado en el Reino Unido donde se regulan los controles de fusiones y adquisiciones de una forma muy distinta a la de otros países. Al igual que en la mayoría de países del mundo, mediante el control de fusiones $\mathrm{y}$ adquisiciones, se busca recolectar data de las empresas fiscalizadas y analizarlas para determinar si una fusión o adquisición es lesiva al mercado o a los consumidores, sujetándose a estrictos criterios de mercado que giran en torno a la protección de la libre competencia. Sin embargo, hay control de fusiones especial, al que se llama public interest interventions. Estos casos representan supuestos excepcionales en los que no se aplican las normas convencionales vinculadas a la protección de la libre competencia, sino que permite la intervención estatal en materias vinculadas a seguridad nacional y pública, fusiones de empresas de prensa escrita y otros medios de comunicación, en todo caso esta intervención no puede ser arbitraria, se realiza en base a un test de pluralidad. El referido test es un estudio técnico que mide la afectación que tendría la fusión o la adquisición al pluralismo informativo y considerará, entre otras cosas, el porcentaje de información que controlaría la empresa concentradora, las cuotas de mercado que controlaría el concentrador -considerando propiedad cruzada de medios de comunicación- y el control que el grupo económico mantiene sobre la o las empresas vinculadas.

En Chile podemos encontrar varios hitos importantes en cuanto a la discusión del tema del pluralismo informativo en primer lugar en encontramos la Ley de Prensa de 1995, instrumento respecto del cual el Tribunal Constitucional tuvo ocasión de pronunciarse en virtud de requerimiento de constitucionalidad, siendo uno de los puntos a destacar de este pronunciamiento del Tribunal Constitucional la imposibilidad por parte del Estado de equilibrar el flujo noticioso « a fin de pretender una pluralidad ideológica o cultural» y de imponer obligaciones a los medios de comunicación social en este sentido. Otro hito importante es la Ley de la Televisión Digital Terrestre. ${ }^{25}$ En dicha sentencia el Tribunal entre otros aspectos afirma que el deber asignado a los concesionarios y permisionarios de servicios de televisión en orden a excluir de los contenidos entregados aquellos

25 STC Rol No 2509, 24/09/2013 
que atenten contra ciertos principios que define el legislador, «importa una evidente mutilación al pleno ejercicio de la libertad de emitir opinión y de informar, representando una forma de censura previa. Las ideas, juicios o noticias que el emisor desea difundir no quedan entregados a su libre albedrío, sino que son juzgados por un poder externo", afectando el derecho en su esencia (considerando $\left.7^{\circ}\right) .{ }^{26}$ Existen otros fallos de menor importancia en donde el tema del pluralismo informativo también resulta relevante. ${ }^{27}$

\subsection{Pluralismo de la Corte Interamericana de Derechos Humanos}

En el ámbito interamericano destaca la Opinión Consultiva OC 5/85, del 13 de noviembre de 1985, sobre la Colegiación Obligatoria de Periodistas, donde se señaló que:

Así, si en principio la libertad de expresión requiere que los medios de comunicación social estén virtualmente abiertos a todos sin discriminación, o, más exactamente, que no haya individuos o grupos que, a priori, estén excluidos del acceso a tales medios, exige igualmente ciertas condiciones respecto de éstos, de manera que, en la práctica, sean verdaderos instrumentos de esa libertad y no vehículos para restringirla. Son los medios de comunicación social los que sirven para materializar el ejercicio de la libertad de expresión, de tal modo que sus condiciones de funcionamiento deben adecuarse a los requerimientos de esa libertad. Para ello es indispensable, inter alia, la pluralidad de medios, la prohibición de todo monopolio respecto de ellos, cualquiera sea la forma que pretenda adoptar, y la garantía de protección a la libertad e independencia de los periodistas. ${ }^{28}$

26 STC Rol No 2358, 9/01/2013

27 STC Rol No 2509, 24/09/2013

28 Opinión Consultiva OC 5/85, del 13 de noviembre de 1985 
En cuanto a la pluralidad como parte de la libertad de expresión en el caso Ivcher Bronstein vs. Perú ${ }^{29}$, la Corte Interamericana de Derechos Humanos determinó que:

Con respecto a la segunda dimensión del derecho consagrado en el articulo 13 de la Convención, la social, es menester señalar que la libertad es un medio para el intercambio de ideas e informaciones entre las personas; comprende su derecho a tratar de comunicar a otras sus puntos de vista, pero implica también el derecho de todos a conocer opiniones, relatos y noticias.

Asimismo, en el caso Herrera Ulloa v. Costa Rica, la Corte destacó que: «existe entonces una coincidencia en los diferentes sistemas regionales de protección de los derechos humanos y en el universal, en cuanto al papel esencial que juega la libertad de expresión en la consolidación y dinámica de una sociedad democrática, Sin una efectiva libertad de expresión, materializada en todos sus términos, la democracia se desvanece, el pluralismo y la tolerancia empiezan a quebrantarse, los mecanismos de control y denuncia ciudadana se empiezan a tornar inoperantes y, en definitiva, se empieza a crear el campo fértil para que sistemas autoritarios se arraiguen en la sociedad». ${ }^{30}$

En ese orden de ideas, la Corte IDH ha destacado que el pluralismo de medios «constituye una efectiva garantía de la libertad de expresión» que es «un deber del Estado [...] proteger y garantizar[...] por medio, tanto de la minimización de restricciones a la información, como por medio de propender por el equilibrio en la participación, al permitir que los medios estén abiertos a todos sin discriminación, puesto que se busca que 'no haya individuos o grupos que, a priori, estén excluidos'», en virtud del artículo 1.1 de la Convención, por medio, tanto de la minimización de restricciones a la información, como por medio de propender por el equilibrio en la participación. ${ }^{31}$

\footnotetext{
CIDH (2001), Caso Ivcher Bronstein vs. Perú.

CIDH (2004), Caso Herrera Ulloa Vs. Costa Rica

CIDH (2015), Caso Granier y otros (Radio Caracas Televisión) Vs. Venezuela. Serie C No. 293. Párr. 142
} 


\section{Concentración mediática}

La concentración de medios se puede analizar desde diversas perspectivas: de la concentración de audiencias, la de la inversión publicitaria en los medios; la concentración de la propiedad y reparto del capital social de las sociedades mercantiles propietarias de empresas de información, y la incidencia de la tecnología en las expectativas de concentración mediática. Estos puntos de vistas son en todo caso complementarios. ${ }^{32}$

Los procesos de concentración pueden producirse por muy diversos motivos entre los cuales pueden destacarse: coyunturas económicas, deseos expansionistas, producción a gran escala, cambios sociales, cambios de mercado. ${ }^{33}$

La concentración de medios de comunicación puede ser determinada mediante: (i) el número de productos disponibles en cada mercado y (ii) la participación porcentual en el mercado conseguida por la empresa líder o las dos primeras de cada rama de la comunicación. En principio, con estos criterios podríamos medir la variedad de información disponible para los consumidores y la posibilidad de competencia desleal como consecuencia del posible abuso de posiciones dominantes en determinados mercados. ${ }^{34}$

En el primer supuesto medimos la concentración atendiendo a los usuarios desde la perspectiva de las empresas. En el segundo caso es posible incluso realizar un análisis mucho más pormenorizado y diferenciar entre la perspectiva de la empresa y el punto de vista del mercado, pues desde el punto de vista del mercado la concentración aumenta cuando se fortalece la posición de dominio o de influencia de las principales compañías, cuando disminuye la capacidad de elección de los ciudadanos, cuando desaparecen algunas «voces independientes». Desde la perspectiva empresarial, la concentración implica crecimiento industrial de los grupos de comunicación. ${ }^{35}$ Por otra parte, la concentración del mercado puede no ser consecuencia del crecimiento de una compañía: en muchas ciudades de Europa y,

\footnotetext{
MÖNCKeBERG (2009) 423

MÖNCKEBERg (2009) 423

AlCALÁ (2013) 67

AlCALÁ (2013) 67
} 
sobre todo, de Estados Unidos, el cierre de diarios ha originado que sus competidores se conviertan en monopolios locales. ${ }^{36}$

Se pueden señalar como causas de concentración de medios de comunicación las fusiones y adquisiciones en el sector audiovisual. Estas técnicas permiten veloces crecimientos pero también reducen el nivel de elección de medios; pueden fortalecer la posición de una empresa en un mercado, favoreciendo la consolidación de oligopolios. Por otro lado, las adquisiciones no provocan la desaparición de medios de comunicación, pero causan reducción en el número de fuentes de información independientes, permiten un crecimiento rápido si la empresa compradora ya opera en el mercado, incrementan el volumen de ventas de la empresa y los libera de un competidor. ${ }^{37}$

La uniformidad de contenidos y el efecto de la publicidad de los medios son algunos de los impactos que sufre la sociedad en general al tener pocos medios de comunicación. No obstante, debe existir también pluralidad dentro de los medios, pues muchos competidores ofrecen el mismo tipo de programas lo que no representa ningún beneficio para la sociedad. En este sentido, si la elaboración de la agenda pública es una de las mayores influencias de los medios de comunicación sobre el público, la concentración y el control editorial de unas cuantas grandes empresas puede suponer un daño potencial para el proceso democrático. ${ }^{38}$

La reducción de empresas tiene un efecto negativo sobre la diversidad de opciones y la pluralidad de contenido. La calidad del flujo comunicativo depende de la cantidad de medios disponibles, de la variedad de estos y de cómo satisfacen las necesidades del consumidor. Es posible deducir que con la autorización de canales privados hay un aumento en la variedad de productos, pero la aparición de nuevos medios implica que estos dispongan de menos presupuesto, generando que las audiencias y los ingresos publicitarios se fragmenten; aumenten las repeticiones porque los programas de producción propia no están bien financiados, no mejora el nivel de innovación

\footnotetext{
SÁNCHEZ-TABERNERo (2002) 134

AlCalá (2013) 68

AlCAlá (2013) 68
} 
y la adquisición de programas de entretenimiento aumenta porque poseen mejor relación entre precio-audiencia. ${ }^{39}$

En este sentido, la Comisión Interamericana de Derechos Humanos señala que las libertades de información pueden verse restringidas sin intervención directa del Estado, por la existencia de monopolios u oligopolios en la propiedad de medios de comunicación, pues establecen en la práctica medidas que impiden la comunicación y la circulación de ideas. ${ }^{40}$

Existe un consenso generalizado acerca de la necesidad de evitar posiciones excesivamente dominantes, que impliquen un riesgo razonable para la libre competencia. La aplicación práctica de normas que protejan la libre competencia, que eviten el abuso de las concentraciones mediáticas plantea una serie de cuestionamientos que deben ser resueltos en primer lugar por el legislador: cuotas de mercado razonables, cuotas máximas diferenciadas dependiendo del tipo de medio de comunicación social de que se trate, cómo supervisar otras formas de posición de dominio que no impliquen porcentajes de mercado.

Para evitar estas casuísticas, los organismos reguladores y de control tienden a concentrar su actividad en los procesos externos de crecimiento: examinan si las fusiones o adquisiciones de empresas originan situaciones en las que exista riesgo de abuso de posición dominante. En cambio, suelen poner menos énfasis en el análisis de los procesos internos de crecimiento (lanzamiento de nuevos medios) y en otros factores que favorecen la concentración del mercado (como la desaparición de competidores).

\subsection{Medidas anticoncentración en Chile}

El artículo 38 de la Ley 19.733 contempla un mecanismo de información de cualquier «hecho o acto relevante relativo a la

39 SÁnCHEZ-TABERnero (2002) 135

40 Véase OEA (2009): Relatoría Especial para la Libertad de Expresión, Marco jurídico interamericano sobre el derecho a la libertad de expresión número OEA/Ser.L/V/II CIDH/RELE/INF. 2/09 del 30 de diciembre de 2009, párr. 8, publicado en: http://www.cidh.org/pdf\%20files/Marco\%20Juridico\%20Interamericano $\% 20$ estandares.pdf 
modificación o cambio en la propiedad o control de un medio» a la Fiscalía Nacional Económica (FNE). Es así como en el caso de medios de comunicación social sujetos a sistemas de concesión se requiere además la aprobación de la Fiscalía Nacional Económica. Si se considera que existe vulneración a la libre competencia con el cambio de propiedad, se remitirá el asunto al Tribunal de Defensa de la Libre Competencia. Se trata de un análisis basado en estructura del mercado.

Analicemos algunos casos resueltos por el Tribunal de Defensa de la Libre Competencia (TDLC): en el caso de la compra por parte de RadioDifusión SpA -firma vinculada a Canal 13 del grupo Luksic, el Tribunal dio su aprobación para adquirir las concesiones de radiodifusión de las radios Horizonte y Oasis, no obstante resulta interesante destacar que la operación se consideraba válida (no infringiendo las normas contenidas en el Decreto Ley $\mathrm{N}^{\circ} 211$ ) siempre que se diera cumplimiento a las siguientes condiciones, en cumplimiento del artículo 100 de la Ley de Mercado de Valores. Condiciones: (i) la primera de las condiciones está referida a la protección de la publicidad en tanto que se le prohíbe a RadioDifusión SpA obligar a las agencias de medios o avisadores a publicitar tanto en televisión como en una o más radios, permitiendo que tanto agencias como avisadores tengan libertad para publicitar separadamente de la forma que estimen conveniente. Se trata de una típica medida estructural de protección del mercado; (ii) Se prohíbe toda forma de subsidio cruzado, entiéndase por subsidio cruzado, como una estrategia que consiste en elevar el precio de un producto o servicio a un grupo de clientes. De esa forma, la empresa genera un excedente que le permite reducir la tarifa del mismo bien para otro segmento económico. Con esta medida se prohíben las discriminaciones arbitrarias contrarias a la libre competencia ${ }^{41}$; (iii) Una de las medidas más interesantes tomadas por el TDLC, es la separación de los negocios de radio y televisión, por lo que se impuso mantener los negocios de radiodifusión sonora y televisiva en empresas legalmente independientes y separadas, aún cuando se encuentren relacionadas.

41 Véase: https://economipedia.com/definiciones/subsidio-cruzado.html 
Es de hacer notar que el informe de la Fiscalía Económica se presentó con ocasión de la aplicación del artículo 38 inciso $2^{\circ}$ de la Ley $\mathrm{N}^{\circ} 19.733$ sobre libertades de opinión e información y ejercicio del periodismo, aplicable a los medios de comunicación social sujetos al sistema de concesión otorgada por el Estado, dicho informe es previo al perfeccionamiento de la operación en relación con los efectos sobre la competencia de la misma, y el caso bajo estudio siendo que el informe resultó desfavorable la Fiscalía lo comunicó al TDLC. Destaca en dicho informe que para la Fiscalía era una posibilidad cierta que Canal 13, como eje de un conglomerado de medios de comunicación social y valiéndose de su posición significativa en el mercado de avisaje televisivo, trasladara el poder con el que cuenta en dicho mercado al avisaje radial, entre otras posibilidades a través de ofertas conjuntas o "paquetes publicitarios».

Una de las consecuencias de la concentración de medios de comunicación social es el evidente control de la publicidad afectando una de las principales fuentes de ingreso, provocando incluso que desaparezcan los competidores y con ellos la posibilidad de otros mensajes y contenidos. ${ }^{42}$ En este sentido también se pronunció la Fiscalía Nacional Económica al señalar que con esta operación económica podrían verse comprometidos la calidad y variedad del servicio, así como la pluralidad y diversidad del mismo debido a que «la operación podría conllevar a la eventual desaparición de radios de nicho y de menor tamaño, como lo son las radio Horizonte y Oasis». ${ }^{43}$

En otro caso la sociedad de CorpGroup, perteneciente al grupo Saieh, adquirió el 20\% de VTR.». En consideración a que VTR es propietario de medios de comunicación social, como por ejemplo CNN Chile, la Fiscalía Nacional Económica (FNE) abrió una investigación sobre los alcances y efectos de esta adquisición, en aplicación del artículo 38 ejusdem. Sobre el particular es importante señalar que dicha operación no se trataba de una operación de concentración horizontal o vertical, por el contrario, podía ser identificada como una fusión de conglomerados y siendo que los conglomerados tienen

42 Informe Fiscalía Nacional Económica 05/04/2012(https://www.fne.gob.cl/wpcontent/uploads/2012/04/requ_tdlc_88_2012.pdf)

43 Informe Fiscalía Nacional Económica 05/04/2012 (https://www.fne.gob.cl/ wp-content/uploads/2012/04/requ_tdlc_88_2012.pdf) 
presencia en diversos mercados era importante poder establecer los efectos de esta operación en el multimercado. Por los riesgos que los conglomerados pueden acarrear en relación con los competidores estableciendo barreras u obstáculos importantes mediante ventas atadas. También era importante analizar en esta operación los riesgos en cuanto a influencias indebidas en el mercado de grillas de televisión pagada, por ejemplo, ante la negativa a terceros de incluir una determinada señal de televisión en su grilla con las respectivas consecuencias en el mercado de avisaje. Sin embargo, el análisis que realizó en su momento la Fiscalía Nacional Económica negó efectos contrarios a la libre competencia en dicha operación y por lo tanto descartó la necesidad de ante el TDLC. ${ }^{44}$

En el caso de la transferencia de la concesión de radiodifusión sonora de frecuencia modulada de la localidad de Laguna de Acúleo, Región Metropolitana y como adquiriente Radiodifusora y televisión San Manuel, la Fiscalía Nacional Económica estimó que la operación no generaba efectos adversos al proceso de libre competencia en el mercado relevante, en virtud de no alterar la cantidad de participantes en dicho mercado, tampoco se estimó una modificación significativa en la participación de las radios locales en el área geográfica relevante definida, ni alteraría las condiciones de competencia existes en ella. ${ }^{45}$

En los casos de Transferencia de acciones de UCVTV SpA a GCO Televisión SpA, Transco S.A. a Sociedad de Radio y Televisión Carivisión Ltda., FM, Señales XQC-401, XQC-470, Operación de concentración por Servicios de Televisión Canal del Fútbol Limitada, las resoluciones de la FNE han sido similares.

Por su parte, en el caso de la solicitud de transferencia de la concesión de televisión XRD-103 de la Ciudad de Temuco Región de la Araucanía al Centro de Alabanza y Adoración Jehová Nisi, la FNE analizó el mercado relevante y estimó que no existía amenaza a la libre competencia. El análisis hecho por la FNE de carácter meramente cuantitativo puede ser alimentado con algunas

44 Informe Fiscalía Nacional Económica 19/06/2012, Resolución 1644-10 (http:// www.fne.cl/transparencia/libro/archivos/archivo/informe_1644-10.pdf)

45 Informe Fiscalía Nacional Económica 18/04/2017, Resolución 017/2017-602 (https://www.fne.gob.cl/wp-content/uploads/2017/04/ilpr_017_2017-602-17.pdf) 
consideraciones referidas a la protección del pluralismo informativo; así si bien es cierto que el pluralismo informativo en la televisión privada se garantiza, fundamentalmente, según el modelo del pluralismo externo. Sin embargo, en países como Alemania se establecen algunas obligaciones para la televisión nacional privada, destinadas a favorecer un cierto nivel de pluralismo interno fundamentalmente a través del respeto a la diversidad de opiniones de los grupos políticos, ideológicos y sociales significativos. También deben ser respetadas las opiniones de la minoría, ello no resulta incompatible con la posibilidad de ofrecer canales temáticos. ${ }^{46}$

No puede dejar de mencionarse la sentencia de la tercera sala de la Corte Suprema que rechazó los recursos de reclamación interpuestos por la Fiscalía Nacional Económica (FNE) y la Sociedad Finis Terrae Radiodifusora (propietaria de Radio Universo de Santiago y su red nacional, a su vez, propiedad de la Compañía Chilena de Radiodifusión, dueña de la cadena Cooperativa) en contra de la sentencia que autorizó con restricciones la compra del grupo Consorcio Radial GLR Chile de las radios propiedad de Iberoamerican Radio Chile S. A. ${ }^{47}$

El grupo Prisa consultó a través de GLR a la FNE, la Fiscalía aplicó el índice Herfindahl-Hirschman (HHI), un indicador internacional utilizado para medir concentración de mercado y llegó a contundentes resultados. Según este índice el estado de competencia perfecta sería cero y el de monopolio diez mil. ${ }^{48}$ En el caso de marras la Fiscalía determinó que la compra de Prisa aumentaría la concentración del mercado radial chileno desde 2099 a 2420, insertándose en un rango de elevada concentración.

Se advirtió que dicha fusión podría propiciar situaciones de abuso unilateral y coordinación de precios. ${ }^{49}$ Adicionalmente, se exponía que de realizarse esta operación «la sobre inversión en el espectro

46 Pieroth/Schlink (2006) 142

47 Corte Suprema, 22 de noviembre de 2007, Resolución 30642

48 Informe Fiscalía Nacional Económica, 28/05/2008 compra del grupo Consorcio Radial GLR Chile de las radios propiedad de Iberoamerican Radio Chile S.A. (https://www.fne.gob.cl/wp-content/uploads/2011/03/ilpr_0032_2008.pdf)

49 Informe Fiscalía Nacional Económica, 28/05/2008 compra del grupo Consorcio Radial GLR Chile de las radios propiedad de Iberoamerican Radio Chile S.A. (https://www.fne.gob.cl/wp-content/uploads/2011/03/ilpr_0032_2008.pdf) 
radioeléctrico que obtiene la empresa fusionada aumenta su capacidad de minutos de avisaje al aire, a un nivel tal que resulta imposible de contestar por los demás actores. ${ }^{50}$ Adicionalmente, es de hacer notar que al estar los avisadores dispuestos a pagar más, las emisoras que quedan fueran de la fusión estarían en completa desventaja frente al imponente competidor radial en que prisa se convirtió.

En cuanto a los límites establecidos por el Tribunal de Defensa de la Libre Competencia podemos destacar: (i) que el grupo Latino de Radio Limitada estaría obligado a consultar previamente a esa instancia cualquier renovación de alguna de sus concesiones, igual camino deberían seguir las futuras operaciones que les permitieran adquirir la propiedad o control de otras concesiones no incluidas en la consulta (ii) respecto de las que ya tenía en sus manos, debería enajenar, renunciar o poner término a una de las que tenía en Iquique, La Serena, Tongoy, Cartagena, Quilpue, Talcahuano, Los Ángeles, Temuco, Nueva Imperial y Valdivia; y a dos en cada una de las ciudades de Concepción, Villarrica, Osorno y Puerto Montt. ${ }^{51}$

En el fallo de la Corte Suprema se pondera el derecho de propiedad primando sobre el derecho a la información. El fallo del máximo tribunal determina que las condiciones establecidas por el fallo del TDLC son suficientes para salvaguardar la libre competencia, garantizando la pluralidad de medios y la libertad de expresión.

Es de hacer notar que, de acuerdo con la encuesta de la Asociación de Radiodifusores de Chile (ARCHI) 2001-2002 se establece que los chilenos consumen 4,5 horas diarias de radio, en diferentes actitudes de escucha. Lo anterior no es extraño, dado que en el país existen casi 2.000 concesiones de radio. ${ }^{52}$ Es así como la operación mencionada produjo una importante concentración de medios de comunicación social, en particular por lo que respecta a la radio y en el análisis del tema se desestimó por parte de los llamados a resolver la controversia el principio del pluralismo informativo y

50 Informe Fiscalía Nacional Económica, 28/05/2008 compra del grupo Consorcio Radial GLR Chile de las radios propiedad de Iberoamerican Radio Chile S. A (https://www.fne.gob.cl/wp-content/uploads/2011/03/ilpr_0032_2008.pdf)

51 TDLC 27/07/2007, Resolución 20/207

52 Incluye las emisoras de Onda Corta y de Mínima Cobertura. Ver detalles en la página de la subsecretaria de telecomunicaciones, del Ministerio de Transportes y Telecomunicaciones en: www.subtel.cl (diciembre 07). 
su importancia en un proceso como la formación de la opinión pública el cual debe caracterizarse por ser libre y plural, siendo la concentración un tema en principio de carácter cuantitativo con importantes consecuencias en lo cualitativo.

De acuerdo con información publicada por medios ligados al mundo publicitario, 31 emisoras de la Región Metropolitana (Santiago de Chile), concentran el 98\% de la inversión publicitaria en radio. ${ }^{53}$ Las tres emisoras principales son Romántica (Grupo Bezanilla, que ha encabezado las reclamaciones legales en contra de la fusión), Cooperativa (primera sintonía noticiosa) e Infinita (del mismo grupo Bezanilla). Las mismas cifras otorgan un $15 \%$ de participación en la torta publicitaria de las emisoras insignias del Grupo Iberoamerican (Pudahuel y FmDos), las que absorbidas ahora por CRC aumentarían al menos en 12 puntos tal participación. Las tres emisoras principales son Romántica (Grupo Bezanilla, que encabezaron las reclamaciones legales en contra de la fusión), Cooperativa (primera sintonía noticiosa) e Infinita (del mismo grupo Bezanilla). Las mismas cifras otorgan un 15\% de participación en la torta publicitaria de las emisoras insignias del Grupo Iberoamerican (Pudahuel y FmDos), las que absorbidas ahora por CRC aumentaron al menos en 12 puntos tal participación. Esta concentración pone en grave riesgo el pluralismo y el debate constante de ideas que debe caracterizar a una sociedad democrática. ${ }^{54}$

\subsection{Medidas para fomentar el pluralismo informativo}

Jurídicamente resulta complejo establecer una ley, regulación o control que permita contrarrestar idóneamente todos los actos de concentración mediática. Así pues, los países latinoamericanos se han enfocado en regular cuotas máximas permisibles respecto de las concesiones del espectro radioeléctrico en radio y televisión, dejando de lado las concentraciones en prensa escrita, medios que no dependen

53 Digiradio de MegaTime (2007) 32-33

54 Digiradio de MegaTime (2007) 32-33 
del espacio radioeléctrico y, la más peligrosa de todas las concentraciones: la propiedad cruzada de medios de comunicación. ${ }^{55}$

Además de las regulaciones que limitan la concentración de medios de comunicación, los Estados europeos han puesto en práctica medidas para fomentar el pluralismo, entre ellas, las subvenciones a los medios o las ayudas para productores independientes. Los países preocupados por el debate público y cultural aplican políticas que establecen diferentes tipos de ayudas. Un ejemplo es Estados Unidos, que fomenta la pluralidad de títulos y la existencia de diarios alternativos; o Suecia, que adopta un sistema de subvenciones, recogiendo un fondo nacional por medio de impuestos a todas las formas de publicidad. Una junta de apoyo a la prensa distribuye el dinero en efectivo a los diarios que no alcanzan al $40 \%$ de las familias de su mercado y, por otra parte, recompensa a las publicaciones cuyo contenido no está en un principio ajustado a las preferencias de lectores potenciales, como es el caso de los diarios que están afiliados a partidos políticos. Podrían ofrecerse ayudas directas e indirectas a los medios; las primeras implicarían la concesión monetaria de subvenciones, siendo selectiva y concediéndose solo a empresas que cumplan con ciertos requisitos; las subvenciones directas podrían ser por consumo o distribución nacional o internacional, por reconversión tecnológica, por ingresos publicitarios limitados, por ayuda para colaboración, por formación profesional para periodistas, para atenuar costes de transporte y distribución, para compensar la competencia de medios audiovisuales, para la promoción de la lengua y la cultura, para la calidad y cantidad de páginas, concesiones para el desarrollo de producción o creación y concesiones para la colaboración o distribución de proyectos conjuntos. Las indirectas podrían aplicarse a través de exención de impuestos, créditos o tarifas preferentes, concesiones sobre IVA, tarifas postales, de telecomunicaciones o ferroviarias especiales, reducción de costes de transporte para periodistas, exención de aranceles, exoneración de impuesto profesional y subvenciones a empresas editoriales. ${ }^{56}$

Para fomentar el pluralismo se puede aumentar la transparencia de la industria de la comunicación, garantizando un acceso a la

55 SÁNCHEZ-TABERnERo (2002) 134

56 SÁNCHEZ-TABERNERo (2002) 134 
información sobre la propiedad e influencia de las empresas. Fortaleciéndose la efectividad de los instrumentos de control existentes, las medidas anticoncentración y la defensa de la competencia, pues la regulación estatal debe garantizar que la concentración de medios no amenace el proceso democrático de formación de opinión, que se mantenga la pluralidad periodística y que se garantice el acceso de nuevos actores al mercado. Otra medida puede efectuarse mediante la responsabilidad editorial de los propietarios y titulares de medios; responsabilidad para la audiencia del medio que sintoniza con la línea editorial, así como para los profesionales del propio medio, lo que garantizará la independencia en el desempeño de su función profesional, permitiendo que éste solicite la rescisión de su relación jurídica, cuando se produzca un cambio sustancial en la línea ideológica u orientación informativa del medio, cuando la empresa traslade al trabajador de un medio a otro que represente ruptura con la orientación profesional y cuando se le exijan informaciones contrarias a los principios éticos de la comunicación.

Se pueden resaltar además como medidas para fomentar el pluralismo los principios de la comunicación audiovisual, los cuales implican el respeto a la dignidad de la persona humana y a los derechos fundamentales ajenos, el acatamiento de la verdad y fidelidad, la promoción de la cultura, el respeto de la autoría audiovisual y al interés público en la programación, la independencia del operador de televisión en relación con patrocinadores de sus emisiones, confidencialidad y conserva de información, así como la objetividad, transparencia e igualdad en el tratamiento de propaganda electoral. ${ }^{57}$

En este sentido, la Comisión Interamericana de Derechos Humanos señala que las libertades de información pueden verse restringidas sin intervención directa del Estado, por la existencia de monopolios u oligopolios en la propiedad de medios de comunicación, pues establecen en la práctica medidas que impiden la comunicación y la circulación de ideas; además puede limitarse con actos de agresión de particulares, puesto que no solo se viola el derecho

57 Delgado (2016) 38 
cuando se imponen restricciones por el Estado, sino también cuando se permite el establecimiento de controles de particulares. ${ }^{58}$

Además de las regulaciones que limitan la concentración de medios de comunicación, en el caso de los Estados europeos han puesto en práctica medidas para fomentar el pluralismo, entre ellas: (i) las subvenciones a los medios, (ii) las ayudas para productores independientes, (ii) el nombramiento de un Consejo Asesor de Programación. Se le imponen al operador privado de obligaciones propias del pluralismo interno. ${ }^{59}$

Para fomentar el pluralismo se puede aumentar la transparencia de la industria de la comunicación, garantizando un acceso a la información sobre la propiedad e influencia de las empresas. Fortaleciéndose la efectividad de los instrumentos de control existentes, las medidas anticoncentración y la defensa de la competencia, pues la regulación estatal debe garantizar que la concentración de medios no amenace el proceso democrático de formación de la opinión, que se mantenga la pluralidad periodística y que se garantice el acceso de nuevos actores al mercado.

En el caso de Alemania cuando se demuestra que una empresa privada de televisión ejerce influencia determinante sobre la opinión pública, se puede exigir de acuerdo con la ley respectiva que el órgano regulador de la radiodifusión designe un Consejo Asesor de Programación, encargado de velar por la garantía de pluralismo interno dentro de la cadena de televisión. ${ }^{60}$

El Consejo asesora a los responsables de la cadena de televisión, gestores, accionistas, programadores acerca de la ordenación de la programación con el fin de favorecer el pluralismo informativo, en todo caso se debe garantizar que los principales grupos sociales se hallen representados en su seno. El Consejo Asesor ejerce funciones de supervisión y control, es por ello que debe ser informado de los

58 Véase Relatoría Especial para la Libertad de Expresión, Marco jurídico interamericano sobre el derecho a la libertad de expresión número OEA/Ser.L/V/ II CIDH/RELE/INF. 2/09 del 30 de diciembre de 2009, párr. 8, publicado en: http://www.cidh.org/pdf\%20files/Marco \%20Juridico\%20Interamericano \%20 estandares.pdf

59 Hess (1997) 682

60 Hess (1997) 682 
cambios que afecten la estructura del canal de televisión, modificaciones en el contenido de la programación y horarios. ${ }^{61}$

En el caso particular de Chile uno de los fondos concursables de que dispone la Ley de Prensa es el referido al desarrollo de medios regionales lo cual puede constituirse en una medida que promueva el pluralismo. Podemos mencionar como otra medida de protección del pluralismo el uso de la libre competencia, elemento particularmente destacado en este trabajo, como una forma de limitar la existencia de un poder de mercado de parte de quien pueda generar un poder de dominio abusivo en lo económico, incidiendo en los contenidos. Sin embargo, la base del control estructural es entender que defendiendo la libre competencia, el mensaje se verá protegido sin necesidad de intervenir directamente en este.

\section{Conclusiones}

En diversos países de la región latinoamericana se están debatiendo los problemas derivados de la concentración indebida de los medios de comunicación social, en algunos pocos se han realizado esfuerzos al dictar legislaciones para limitar la concentración de medios y desconcentrar lo ya altamente concentrado de algunos mercados. Sin embargo, estos procesos se han dado de manera desigual, a veces con distorsiones que no hacen efectivas las medidas anticoncentración. A todo evento se requieren medidas que protejan el pluralismo informativo al tiempo que permitan el desarrollo de un mercado con alto potencial de expansión y crecimiento como lo es el de los medios de comunicación social, garantizando la protección del proceso de formación de la opinión pública de manera libre y plural. Tales medidas deben implicar el cumplimiento de estrictos requisitos de transparencia sobre la propiedad de los medios de comunicación a todos los niveles y el monitoreo activo de operaciones que puedan suponer concentración indebida de la propiedad.

61 Hess (1997) 682 


\section{Bibliografía}

\section{a) Doctrina:}

AlcalÁ, Myriam (2013): «Impacto de las concentraciones mediáticas en el pluralismo informativo", Revista Internacional Online de Derecho de la Comunicación No. 15, Nueva Época. Septiembre-Noviembre, pp. 64-76

Bastida, Francisco Javier (2001): Concentración de Medios y Pluralismo, Acordes y Desacuerdos entre Pluralismo y Mercado, Responsa Iurisperitorum, Ediciones Universidad de Salamanca, Vol. II.

Biblioteca del Congreso Nacional de Chile (2019): Ley General de Telecomunicaciones No. 18.168. Octubre de 1982. Última versión de 20 de agosto de 2016. Artículo 13. Disponible en: https://www. leychile.cl/Navegar?idNorma $=29591$

Biblioteca del Congreso Nacional de Chile (2019): Ley No. 18.838 que crea el Consejo Nacional de Televisión. 29 de septiembre de 1989. Última modificación de 21 de enero de 2016. Disponible en: http:// www.bcn.cl/

Delgado, Bruno (2016): «La concentración de los medios de comunicación y el derecho humano a la libertad de expresión», Revista Instituto de Derechos Humanos, $\mathrm{N}^{\circ} 63$.

Digiradio de MegaTime (2007): «La Radio informa», Revista Publimark, No 214, octubre, pp. 32-33

Humphreys P., Lang M. (1998): Digital television between the economy and pluralism,

Changing channels: The prospects for television in a digital world, J. STEEMERS (ed.), Luton.

Fiscalía Nacional Económica (2008): Informe 28/05/2008 compra del grupo Consorcio Radial GLR Chile de las radios propiedad de Iberoamerican Radio Chile S. A (https://www.fne.gob.cl/wp-content/ uploads/2011/03/ilpr_0032_2008.pdf)

Fiscalía Nacional Económica (2017): Informe 18/04/2017, Resolución 017/2017-602 (https://www.fne.gob.cl/wp-content/uploads/2017/04/ ilpr_017_2017-602-17.pdf)

Fiscalía Nacional Económica (2012): Informe 19/06/2012, Resolución 1644-10 (http://www.fne.cl/transparencia/libro/archivos/archivo/ informe_1644-10.pdf)

Fiscalía Nacional EConómica (2012): Informe 05/04/2012 (https://www. fne.gob.cl/wp-content/uploads/2012/04/requ_tdlc_88_2012.pdf)

Fiss, Owen (1997): La Construcción de una Prensa Libre, Libertad de Expresión y Estructura Social (Ciudad de México, Fontamara). 
HEss, W. (1997): «Medienkonzentrationsrecht nach dem neuen Runddfunkvertrag», Archiv fürPresserecht, Dusseldorf.

Jiménez, José J (2004): «La Opinión Pública», Revista Electrónica de la Asociación Andaluza de Filosofía, Granada.

Mönckeberg, María Olivia (2009): Los Magnates de la prensa (Santiago, Editorial Random House Mondadori).

NiePalla, Peter (1990): Die Grundversorgung durch die öffentlich-rechtlichen Rundfunkanstalten, C.H Beck, München.

OEA (2009): Relatoría Especial para la Libertad de Expresión, Marco jurídico interamericano sobre el derecho a la libertad de expresión número OEA/Ser.L/V/II CIDH/RELE/INF. 2/09 del 30 de diciembre de 2009, párr. 8, publicado en: http://www.cidh.org/pdf\%20files/Marco\%20 Juridico \%20Interamericano\%20estandares.pdf

Olalla, Tomás (2004): «Revisión Crítica de las Relaciones entre Pluralismo y Mercado en los Medios Audiovisuales», Revista de Estudios de la Comunicación, País Vasco.

Osorio, Hugo (1997): Políticas de Información y Derecho (Santiago, Konrad Adenauer).

Pedroza, Susana (2000): «Concentración de Medios y Pluralismo, el Marco Jurídico del Canal de Televisión Mexicano", Serie Doctrina Jurídica No 37, Universidad Nacional Autónoma de México.

Pieroth/Schlink (2006): Grundrechte Staatsrecht II, C.F Müller, Heidelberg

Rodríguez. José Manuel (1999): Opinión Pública. Conceptos y Modelos Históricos (Barcelona, Marcial Pons).

SÁnCHEZ-TABERnERo, Alfonso Miguel (2002): «Concentración de empresas de comunicación en Europa: nuevos datos contradicen los viejos mitos", Comunicación y sociedad, vol. XV, núm.1, pp. 129-162

SCHUSTER, Detlev (1990): Meinungsvielfalt in der dualen Rundfunkordnung (Belin, Duncker \& Humblot).

URIBE, Hernán (1999): La invisible mordaza, el mercado contra la prensa (Santiago, Ed. Cuarto Propio).

\section{b) Jurisprudencia:}

BVerfGE 74, 297 (324)

BVerfGE 59, 231, (260) 257

BVerfGE 60,53

Corte Suprema, 22 de noviembre de 2007, Resolución 30642

CIDH (2001), Caso Ivcher Bronstein vs. Perú.

CIDH (2004), Caso Herrera Ulloa Vs. Costa Rica

CIDH (2015). Caso Granier y otros (Radio Caracas Televisión) Vs. Venezuela.

Serie C No. 293. Párr. 142

STC 159 /1986 - Tribunal Constitucional de España 
STC Rol No 2541, 18/11/2013

STC Rol No 2358, 9/01/2013

STC Rol No 2509, 24/09/2013

STC Rol N² 2487, 21/06/2013

\section{c) Normativa:}

Ley $N^{\circ} 18.838,03 / 11 / 2017$ que crea el Consejo Nacional de Televisión Ley $\mathrm{N}^{\circ} 19.733,18 / 05 / 2001$ sobre las Libertades de Opinión e Información y Ejercicio del Periodismo

Ley No. 18.168, 06/11/2018 General de Telecomunicaciones

Decreto Supremo No $127,06 / 03 / 2007$, del Ministerio de Transportes y Telecomunicaciones, que aprobó el Plan General de Uso del Espectro Radioeléctrico y sus modificaciones.

Decreto Ley $\mathrm{N}^{\circ} 211,18 / 10 / 2004$ que fija normas sobre defensa de la libre competencia. 



\title{
REGULACIÓN AMBIENTAL Y FINANCIERA DE LA MINERÍA EN LOS SUELOS Y SUBSUELOS MARINOS, LA ZONA
}

\author{
ENVIRONMENTAL AND FinANCIAL \\ REGULATION OF THE MINING \\ IN THE DEEP SEABED, THE AREA
}

\author{
Patricio Masbernat ${ }^{1}$ \\ Gloria Ramos-Fuentes ${ }^{2}$
}

RESUMEN. Este artículo tiene por objeto mostrar algunos aspectos generales de la regulación y tributación de la actividad de explotación minera en la Zona (the Area), la que está constituida por los fondos marinos y el subsuelo oceánico más allá de los límites de las jurisdicciones nacionales. Para ello, efectúa una breve exposición acerca del modo de regular estos asuntos por la CONVEMAR, sus

1 Profesor (Universidad Autónoma de Chile). Miembro de la Academia Brasileira de Direito Tributário - ABDT, São Paulo. E-mail: patricio.masbernat@ uautonoma.cl ORCID Id.: http://orcid.org/0000-0001-7137-9474.

2 Doctora (c) en Derecho por la Universidad Autónoma de Chile. Abogada del Ministerio de Relaciones Exteriores del Gobierno de Chile. Profesora de Derecho Internacional Público. E-mail: gloramos76@gmail.com ORCID Id.: https:// orcid.org/0000-0002-8697-2649. 
principios y conceptos básicos. Luego, explica el modo en que el Proyecto de Reglamento sobre la Explotación de los Recursos Minerales en la Zona de Julio de 2018, trata estos asuntos, esto es, los principios y conceptos, y las regulaciones ambientales y los aspectos tributarias de la explotación de la minería en dichos territorios. Finalmente, reflexiona brevemente sobre algunas interrogantes esenciales en los asuntos estudiados, que dicen relación con lo siguiente: si la Zona debe o no debe ser explotada; acerca de cómo se distribuyen los poderes de gestión de la Zona, como se toman decisiones al interior de la Autoridad Internacional de los Fondos Marinos, y cuáles son los derechos de los Estados y de los contratistas; cómo resolver el dilema entre obtener dinero o proteger el ecosistema; cómo resolver el problema de la gobernanza en la Zona; cómo resolver el modo de compartir beneficios a través de mecanismos fiscales globales.

Palabras clave: CONVEMAR; la Zona; minería oceánica; tributación global.

AвSTRACT. The purpose of this paper is to show some general aspects of the regulation and taxation of the mining activity in the Area, which is constituted by the seabed and oceanic subsoil, beyond the limits of national jurisdiction. To do so, the authors give a brief exposition about how the CONVEMAR regulates these matters through, its principles and basic concepts. Then, they explain how the Draft Regulations on the Exploitation of Mineral Resources in the Area, of July 2018, deals with these issues, that is, the principles and concepts, and the environmental regulations and the tax aspects of the exploitation of mining in the area. Finally, they reflect briefly on some essential questions in the matters studied, which relate to the following: whether the Area should or should not be exploited; about how the management powers of the area are distributed, how decisions are made within the International Seabed Authority, and what are the rights of States and contractors; how to solve the dilemma between obtaining money or protecting the ecosystem; how to solve the problem of governance in the Area; how to solve the way of sharing benefits through global tax.

KEYwORDS: UNaCLOS; the Area; ocean mining; global taxation.

Sumario: Introducción. 1. El marco general del Proyecto de Código de Explotación de Recursos Minerales en la Zona: la 
Convención de las Naciones Unidas sobre el Derecho del Mar. 2. Proyecto de Código de Explotación de Recursos Minerales en la Zona. 3. Una visión general del «Proyecto de Código de Explotación de Recursos Minerales en la Zona» y sus principios fundamentales: 3.1. Regalías y tarifas ¿Impuestos globales y distribución de beneficios en la perspectiva global?; 3.2. Las regulaciones ambientales. 4. Algunas reflexiones y palabras finales: (a) ¿Deben o no explotarse los fondos marinos?; (b) ¿A quién pertenecen los recursos de la Zona? Y a partir de esa respuesta, ¿Cómo distribuir los poderes de las organizaciones internacionales y los diferentes tipos de derechos y facultades?; (c) ¿Cómo resolver el dilema entre obtener dinero o proteger el ecosistema?; (d) Si los recursos de la Zona pertenecen a toda la humanidad, ¿Cómo resolver el problema de la gobernanza territorial, ambiental y fiscal?; (e) Si los recursos de la Zona pertenecen a toda la humanidad, ¿Cómo resolver el problema de compartir beneficios a través de mecanismos fiscales globales? La Tributación Global. 5. Bibliografía.

\section{INTRODUCCIÓN}

En este artículo, analizaremos brevemente las medidas fiscales y ambientales del «Proyecto de Reglamento sobre la Explotación de los Recursos Minerales en la Zona» ( "Draft Regulations on Exploitation of Mineral Resources in the Area», versión publicada en julio de 2018, ${ }^{3}$ en adelante DR), preparado por la Comisión Jurídica y Técnica de la Autoridad Internacional de los Fondos Marinos (International Seabed Authority, en adelante, la Autoridad o ISA), en el marco de la Convención de las Naciones Unidas sobre el Derecho del Mar (CONVEMAR).

Para hacer esto, abordaremos algunos aspectos de la CONVEMAR de manera general, el Proyecto de Código de Explotación de Recursos Minerales en la Zona (los principios fundamentales, las regalías y las tarifas, las regulaciones ambientales) y, finalmente, expondremos algunas reflexiones. En particular, estos tres aspectos (los

A la fecha de publicación de este artículo, habrá una nueva versión de la Propuesta o Draft Regulations on Exploitation of Mineral Resources in the Area, en el primer semestre de 2019, el cual esperamos analizar en una próxima publicación. 
principios fundamentales, las regalías y las tarifas, las regulaciones ambientales) deben responder a los requisitos y fundamentos del Derecho del Mar y del Derecho Internacional del Medio Ambiente. Esta evaluación es la que debe llevarse a cabo, y en estas líneas intentamos avanzar algunos juicios. ${ }^{4}$

\section{El marco general del Proyecto de Código de Explotación de Recursos Minerales en la Zona: La CONVENCIÓN DE las Naciones UNidAs SOBRE EL DERECHO DEL MAR.}

La CONVEMAR regula la alta mar, según lo dispuesto en el artículo 86. Esta corresponde a todas las partes del mar que no están incluidas en la zona económica exclusiva, en las aguas territoriales o internas de un Estado, o en las aguas archipelágicas de un archipiélago Estado. La CONVEMAR reconoce una serie de libertades para los Estados en alta mar, que serán ejercidos por los Estados teniendo en cuenta los intereses de otros Estados en su ejercicio de la libertad de alta mar, y también con el respeto mutuo de los derechos consagrados por dicho Convenio con respecto a las actividades en la Zona. Según su artículo 1(3), las actividades en la Zona aluden a «todas las actividades de exploración y explotación de los recursos de la Zona».

Según el artículo 1.(1) de la CONVEMAR, la Zona hace referencia al lecho marino, el fondo oceánico y el subsuelo, más allá de los límites de la jurisdicción nacional. Ahora, según lo prescrito en el artículo 2, la soberanía de un estado costero se extiende, más allá de su territorio terrestre y aguas interiores, y en el caso de un estado archipiélago, sus aguas archipelágicas, a un cinturón de mar adyacente, descrito como el mar territorial, el espacio aéreo sobre el territorial y su lecho y subsuelo. Sin embargo, el ejercicio de dicha soberanía está sujeto a la CONVEMAR y a otras normas de Derecho Internacional.

Para los fines de la Parte XI (Zona) de la CONVEMAR, el artículo 133 prescribe que el término «recursos» dice relación con todos

4 Los expertos se han preocupado de la explotación minera en el océano, desde hace décadas. KINDT (1984) 1-55. 
los recursos minerales sólidos, líquidos o gaseosos in situ en la Zona, en o debajo del lecho marino, incluidos los nódulos polimetálicos, y los minerales que se recuperan de la Zona.

Aunque esa parte se ha modificado, se ha mantenido el estatus de la Zona como un patrimonio común de la humanidad. Por otro lado, es necesario determinar cuál es el contenido mínimo sobre el cual hay un consenso general y qué normas tienen una naturaleza imperativa ${ }^{5}$. La CONVEMAR se basa en algunos pilares, uno de los cuales es el principio del patrimonio común de la humanidad como norma del ius cogens internacional (incluido en el artículo 136), es decir, este principio tiene una naturaleza imperativa.

Las cuestiones ambientales son muy importantes para la CONVEMAR, y las disposiciones sobre protección y preservación del medio marino se detallan en la Parte XII, tales como: la cooperación mundial y regional, la asistencia técnica, el monitoreo y la evaluación ambiental; las normas internacionales y la legislación nacional para prevenir, reducir y controlar la contaminación del medio marino; la contaminación por actividades de los fondos marinos sujetos a la jurisdicción nacional; la contaminación por actividades en la Zona; la aplicación con respecto a la contaminación de origen terrestre o con respecto a la contaminación de las actividades de los fondos marinos.

El artículo 1(4) de la CONVEMAR, define la contaminación del medio marino como «la introducción por el hombre, directa o indirectamente, de sustancias o de energía en el medio marino incluidos los estuarios, que produzca o pueda producir efectos nocivos tales como daños a los recursos vivos y a la vida marina, peligros para la salud humana, obstaculización de las actividades marítimas, incluidos la pesca y otros usos legítimos del mar, deterioro de la calidad del agua del mar para su utilización y menoscabo de los lugares de esparcimiento».

La Parte XI de la CONVEMAR contiene principios y objetivos que gobiernan e inspiran la utilización de los recursos de la Zona y guían el ejercicio de las funciones de la Autoridad. ${ }^{6}$ La Parte XI, Sección 2 de la CONVEMAR, establece los principios que rigen la Zona, entre ellos, la condición jurídica de la Zona y sus recursos, que la Zona y sus recursos son patrimonio común de la humanidad

5 Salamancas (2003).

6 Salamancas (2003). 
en beneficio de la humanidad, acerca del desarrollo de actividades en la Zona y en el medio marino, la protección del medio marino, la protección de la vida humana, la responsabilidad de garantizar el cumplimiento y la responsabilidad por daños, la conducta general de los Estados en relación con la Zona, la participación de los Estados en desarrollo en actividades en la Zona, los derechos e intereses legítimos de los Estados ribereños.

La Autoridad Internacional de los Fondos Marinos es una de las tres instituciones establecidas por la CONVEMAR en 1982. Los otros dos son la Comisión de Límites de la Plataforma Continental y el Tribunal Internacional del Derecho del Mar.

La Autoridad Internacional de los Fondos Marinos (International Seabed Authority) se define, en el Acuerdo relacionado con la implementación de la Parte XI de la Convención de las Naciones Unidas sobre el Derecho del Mar de 10 de diciembre de 19827, como la organización mediante la cual los Estados Partes de la CONVEMAR, organizarán y controlarán las actividades en la Zona, particularmente con miras a administrar sus recursos. Los poderes y funciones de la Autoridad serán aquellos expresamente conferidos por la Convención. La ISA tendrá tales poderes expresados de conformidad con la Convención, como aquellos implícitos en y necesarios para el ejercicio de esos poderes y funciones con respecto a las actividades en la Zona.

La Sección 3 regula el desarrollo de los recursos de la Zona, las políticas relacionadas con las actividades en dichos territorios, las políticas de producción, los poderes y las funciones de la Autoridad, el sistema de exploración y explotación.

El artículo 153 detalla que las actividades en la Zona serán organizadas, llevadas a cabo y controladas por la Autoridad en nombre de la humanidad en su conjunto de acuerdo con la Convención, sus Anexos, y las normas, reglamentos y procedimientos de la ISA. Dichas actividades en la Zona serán llevadas a cabo directamente por la Empresa, o en asociación con la Autoridad por los Estados Partes, o por empresas estatales o por personas físicas o jurídicas que posean la nacionalidad de los Estados Partes o que estén efectivamente

7 Ver web de la ONU [http://www.un.org/Depts/los/convention_agreements/ convention_overview_part_xi.htm] 
controladas por ellos o sus nacionales, cuando estén patrocinados por dichos Estados, o cualquier grupo de los anteriores que cumpla con los requisitos previstos en la CONVEMAR.

La prospección, exploración y explotación puede ser realizada directamente por la Empresa o la Autoridad puede firmar un contrato con compañías (contratistas) patrocinadas por los Estados. Para ello, el Proyecto de Código de Explotación de Recursos Minerales en la Zona considera un Registro Minero de Fondos Marinos (DR 90).

Conforme a la Convención, estas actividades se llevarán a cabo de acuerdo con un plan de trabajo escrito formal aprobado por el Consejo después de ser revisado por la Comisión Jurídica y Técnica. La Autoridad ejercerá el control sobre las actividades en la Zona según sea necesario para garantizar el cumplimiento de las disposiciones pertinentes del Convenio, así como las reglas, reglamentos y procedimientos provenientes de ella, y los planes de trabajo aprobados. Los Estados Partes asistirán a la ISA tomando todas las medidas necesarias para garantizar su cumplimiento. La Autoridad tendrá derecho a tomar en cualquier momento las medidas previstas en el Convención para garantizar el cumplimiento de sus disposiciones y el ejercicio de las funciones de control. y reglamentación que se le asigne en virtud del mismo o bajo cualquier contrato. La Autoridad tendrá el derecho de inspeccionar todas las instalaciones en la Zona utilizadas en relación con las actividades que en ella se desarrollen. En el caso de las actividades llevadas a cabo por contratistas en la Zona, el plan de trabajo tomará la forma de un contrato, y esto debe ser respetado en la medida en que las partes cumplan con todas las reglas mencionadas.

En la Subsección E, titulada «La Empresa», el artículo 170 la define y regula sus funciones, indicando que este se trata del órgano de la Autoridad que directamente llevará a cabo actividades en la Zona, entre ellas, el transporte, procesamiento y comercialización de los minerales recuperados. Ella estará bajo el marco de la personalidad jurídica internacional de la Autoridad, y actuará de conformidad con esta Convención y las normas, reglamentos y procedimientos de la Autoridad, las políticas generales establecidas por la Asamblea, y estará sujeto a las directivas y al control del Consejo. 
El Anexo IV establece el Estatuto de la Empresa y, de acuerdo con el artículo 12 («Operaciones»), ella debe proponer proyectos al Consejo para llevar a cabo actividades mineras, incluido un plan de trabajo formal por escrito. Una vez que se apruebe el plan de trabajo, la Empresa lo desarrollará. En materia de minería hay dos reglas básicas: la Empresa debe tener títulos de todos los minerales y sustancias procesadas producidas por ella; la Empresa venderá sus productos de forma no discriminatoria y no otorgará descuentos sin fundamento comercial.

En relación con sus tareas, el Anexo 1 Sección 2 (La Empresa) $\mathrm{N}^{\circ} 5$ del Convenio, se establece que entre su entrada en vigor y la aprobación del primer plan de trabajo para la explotación, la Autoridad se concentrará en diferentes acciones correspondientes a tres áreas relevantes para nuestro análisis: exploración y explotación, regulación y protección del medio ambiente marino: (a) Monitoreo y revisión de tendencias y desarrollos relacionados con las actividades mineras de los fondos marinos profundos; (b) Estudio del impacto potencial de la producción de minerales de la Zona en las economías de los países con producción minera de superficie y los minerales que probablemente se vean más gravemente afectados, con el fin de minimizar sus dificultades y ayudarles en su ajuste económico; (c) Evaluación de los datos disponibles relacionados con la prospección y exploración; (d) Evaluación de los resultados de la investigación científica marina con respecto a las actividades en la Zona; (e) Promoción y fomento de la realización de investigaciones científicas marinas con respecto a las actividades en la Zona y la recopilación y difusión de los resultados de esas investigaciones y análisis; (f) Adquisición de conocimiento científico y monitoreo del desarrollo de tecnología marina relevante para las actividades en la Zona; (g) Elaboración oportuna de normas, reglamentos y procedimientos de explotación; (h) Adopción de las normas, reglamentos y procedimientos necesarios para llevar a cabo las actividades en la Zona a medida que avanzan; (i) Adopción de normas, reglamentos y procedimientos que incorporen las normas aplicables para la protección y preservación del medio ambiente marino.

Con respecto a las obligaciones financieras, el Anexo III (artículo 13) incorpora las condiciones básicas de prospección, exploración y 
explotación, y un gravamen para el solicitante por el costo administrativo de procesar una solicitud de aprobación de un plan de trabajo en forma de contrato por un monto de \$US500.000 por solicitud, y se establece para el contratista una tarifa fija anual de \$US1 millón a partir de la fecha de entrada en vigencia del contrato.

De acuerdo con el artículo 13.4, el contratista debe pagar una contribución financiera alternativa desde un año desde el inicio de la producción comercial, entre las siguientes opciones:

(a) La contribución financiera mediante el pago de un cargo por producción, se establecerá en un porcentaje del valor de mercado de los metales procesados obtenidos de los nódulos polimetálicos extraídos del área cubierta por el contrato, según la siguiente escala: años 1-10, $5 \%$; años 11 y más, $12 \%$. El valor de mercado será el precio promedio de esos metales durante el período contable correspondiente.

(b) Contribución financiera como una combinación de un cargo por producción y una parte de los ingresos netos, dichos pagos se determinarán de la siguiente manera:

(b.1.) El cargo de producción se fijará en un porcentaje del valor de mercado: el primer período de producción comercial, $2 \%$; el segundo periodo de producción comercial, $4 \%$.

(b.2) La participación de la Autoridad en los ingresos netos se tomará de esa parte de los ingresos netos del contratista que sea atribuible a la extracción de los recursos del área cubierta por el contrato, referidos como ingresos netos atribuibles. La participación de la Autoridad en los ingresos netos atribuibles se determinará de acuerdo con el programa incremental de la parte que representa el rendimiento de la inversión. El «retorno de la inversión» en cualquier año contable significa la relación entre los ingresos netos atribuibles en ese año y los costos de desarrollo del sector minero. El cronograma incremental es el siguiente: (i) La porción que representa un retorno de la inversión mayor de $0 \%$, pero menor de 10\%: 35\% (primer período) y $40 \%$ (segundo período); ii) La porción que representa un retorno de la inversión del $10 \%$ o mayor, pero inferior al $20 \%$ : $42,5 \%$ (primer período) y $50 \%$ (segundo período); (iii) La porción que representa un retorno de la inversión del 20\% o más: $50 \%$ (primer período) y $70 \%$ (segundo período). 
Según la Convención, por «ingresos netos atribuibles» se expresa el producto de los ingresos netos del contratista y la relación entre los costos de desarrollo en el sector minero y los costos de desarrollo del contratista.

El primer período de producción comercial comenzará en el primer año contable de la producción comercial y finalizará en el año contable en el cual los costos de desarrollo del contratista, más intereses sobre la parte no recuperada de los mismos, se recuperen completamente con su superávit de efectivo, de acuerdo con una serie de reglas. El segundo período de producción comercial comenzará en el año contable posterior a la terminación del primer período de producción comercial y continuará hasta el final del contrato.

\section{Proyecto de Código de Explotación de Recursos Minerales EN LA ZoNA}

Hoy en día, la Autoridad está analizando un «Proyecto de Código de Explotación de Recursos Minerales en la Zona» ( Draft Regulations on Exploitation of Mineral Resources in the Area»), preparado por su Comisión Jurídica y Técnica.

Esta propuesta forma parte del "Código de Minería», que la ISA define como el conjunto completo de normas, reglamentos y procedimientos emitidos por ella misma, con el objeto de regular la prospección, exploración y explotación de minerales marinos en el ámbito internacional de los fondos marinos o Zona (que denomina al lecho marino y al subsuelo más allá de los límites de la jurisdicción nacional $)^{8}$. El marco legal general del «Código de Minería» del Mar fue establecido por la CONVEMAR (1982) y su Acuerdo de Implementación de 1994 relacionado con la minería de los fondos marinos.

En primer lugar, típicamente, hay diferentes tipos de depósitos minerales explotables:

(a) Los depósitos de sulfuro masivo (SMS) del fondo marino son áreas de sustrato duro con un alto contenido de sulfuros y metales

8 Ver página web de la International Seabed Authority [www: https://www.isa. org.jm/mining-code] 
básicos que se forman a través de la circulación hidrotérmica y se encuentran comúnmente en los sitios de ventilación hidrotérmica. ${ }^{9}$

(b) La corteza de ferromanganeso, rica en cobalto, son capas metálicas duras como rocas que se forman en los flancos de los volcanes submarinos, llamados montes submarinos.

(c) Los nódulos polimetálicos, también llamados nódulos de manganeso, son concreciones de roca formadas por capas concéntricas de hidróxidos de hierro y manganeso alrededor de un núcleo. ${ }^{10}$ Presenta un tipo de régimen jurídico diferente ${ }^{11}$ a los dos anteriores. ${ }^{12}$

Al día de hoy, las normas aprobadas son las siguientes: Reglamento de Prospección y Exploración de Nódulos Polimetálicos en la Zona (13 de julio de 2000, actualizado el 25 de julio de 2013); Reglamento sobre prospección y exploración de sulfuros polimetálicos en la zona (7 de mayo de 2010) y Reglamento sobre prospección y exploración de cortezas ricas en cobalto (adoptado el 27 de julio de 2012). La ISA explica que «el conjunto completo de estas

9 Boschen (2013) 55

10 Salamancas explica que, en relacion a la localización en la Zona, hay tres áreas consideradas primariamente: a) The Clarion-Clipperton area; b) Southwestern Pacific Basin; c) Central basin of the Indian Ocean. Salamancas (2003).

11 NANDAN explica: "the system of regulations for the exploration and exploitation of polymetallic nodules is established in Part XI of the Convention and the Agreement is the so-called 'parallel' system, elaborated in article 153 of the Convention. The essential elements of the parallel system include assured access for States Parties and their nationals to seabed mineral resources along with a system of site-banking, whereby reserved areas are to be set aside for the conduct of activities by the Authority through the Enterprise either by itself or in association with developing States, or in joint-venture with a contractor who provided the particular reserved site. This is to avoid the monopolization of seabed mining industry and to ensure that viable mine sites would be available for those who come later. This requires an applicant to propose two sites of equal commercial value one to be designated a reserved site and the other to be allocated to the applicant.» NANDAN (2005) 14.

12 NANDAN explica: «respect with the regulations for Polymetallic Sulphides and Cobalt-Rich Crusts, the basic formal elements of the regulations would be the same as that for polymetallic nodules. However, because of the localized nature of the deposits there will be differences relating inter alia to the size of the area allocated for exploration under the contract, the size of the eventual exploitation area and the system for participation by the Authority either through the application of the parallel system which may not always be practical in this case, or other form of participation, such as equity participation, as well as the environmental regulations appropriate to the unique environment in which these deposits are found.» NANDAN (2005) 19. 
regulaciones formará parte del Código de Minería junto con las recomendaciones de la Comisión Jurídica y Técnica de la Autoridad para la orientación de los contratistas en la evaluación de los impactos ambientales de la exploración de nódulos polimetálicos». ${ }^{13}$

El análisis sobre el régimen de explotación proviene de 2014. El documento producido como resultado de estas discusiones se denominó «Aprovechar al máximo los recursos minerales de los fondos marinos profundos para desarrollar términos financieros para la explotación minera en los profundos mares» ( «Making the Most of Deep Seabed Mineral Resources Developing Financial Terms for Deep Sea Mining Exploitation») ${ }^{14}$, el cual muestra mucho interés en el régimen fiscal y describe los regímenes tributarios mineros de los países mineros con grandes costos, y aborda los fundamentos técnicos y los posibles instrumentos de un sistema impositivo ideal.

En 2015, la ISA llevó a cabo un proceso de consulta y emitió dos documentos, el Informe «Desarrollo de un Marco Regulatorio para la Explotación de Minerales en la Zona» («Developing a Regulatory Framework for Mineral Exploitation in the Area» $)^{15}$ y el Documento de Discusión «Desarrollo de un Marco reglamentario para la Explotación de Minerales en la Zona» ( Developing a Regulatory Framework for Mineral Exploitation in the Area» $)^{16}$.

Más adelante, la ISA publicó el «Primer borrador de trabajo de las regulaciones y términos contractuales estándar sobre la explotación de recursos minerales en la Zona» ("First Working Draft of the Regulations and Standard Contract Terms on Exploitation for Mineral Resources in the Area», 2016); el "Documento de debate sobre el desarrollo y la elaboración de reglamentos sobre la explotación de recursos minerales en la Zona-asuntos ambientales» ( "Discussion Paper on the Development and drafting of Regulations on exploitation for mineral resources in the Area-Environmental

13 Ver webpage de la International Seabed Authority [www: https://www.isa.org. $\mathrm{jm} / \mathrm{mining}$-code]

14 Ver webpage de la ISA [www: https://www.isa.org.jm/files/documents/EN/Regs/ FinTerms2014.pdf]

15 Ver webpage de la ISA [See www: https://www.isa.org.jm/files/documents/EN/ Survey/Report-2015.pdf]

16 Ver webpage de la ISA [www: https://www.isa.org.jm/files/documents/EN/ WorkingPapers/DiscussionPaper-FinMech.pdf] 
matters», 2017); Proyecto de Reglamento sobre la Explotación de los Recursos Minerales en la Zona ( $D$ Daft Regulations on Exploitation of Mineral Resources in the Area», 2017); Proyecto revisado de Reglamento sobre la explotación de los recursos minerales en la zona ( Revised Draft Regulations on Exploitation of Mineral Resources in the Area, 2018»). ${ }^{17}$

\section{UnA Visión general del «Proyecto de Código DE Explotación de Recursos Minerales en la Zona» Y SUS PRINCIPIOS FUNDAMENTALES ${ }^{18}$}

El Proyecto de Código de Explotación tiene 105 artículos (Draft Regulations, DR en lo sucesivo). De todas estas reglas, nos centraremos en cuatro aspectos: principios fundamentales; impuestos globales y distribución de beneficios; medioambiente; responsabilidad y derechos de los Estados costeros (especialmente en materia ambiental).

El Proyecto de Código de Explotación, en el Anexo 1 (Schedule 1), «Uso de Términos y Alcance», incorpora definiciones oficiales de recursos (como todos los recursos minerales sólidos, líquidos o gaseosos in situ en la Zona en o debajo del lecho marino), explorar y exploración ${ }^{19}$, regulaciones de exploración ( «Significa el Reglamento sobre Prospección y Exploración de Nódulos Polimetálicos, Sulfuros Polimetálicos en la Zona y Cortezas de Ferromanganeso Ricas en Cobalto en la Zona»), explotar y explotación.

17 A la fecha de publicación de este artículo, habrá una nueva versión de la Propuesta o Draft Regulations on Exploitation of Mineral Resources in the Area, de 2019, el cual esperamos analizar en una próxima publicación.

18 ISA (2018), Legal and Technical Commission, International Seabed Authority, Draft Regulations on Exploitation of Mineral Resources in the Area. Twenty-fourth session. Legal and Technical Commission session, part II, Kingston, 2-13 July 2018, Item 10 of the agenda. Consideration and adoption of the draft regulations on the exploitation of mineral resources in the Area. 9 July 2018, Kingston, Jamaica.

19 De acuerdo al Proyecto de Código de Explotación, por «explorar» y «exploración», según el caso, «se entiende la búsqueda de recursos en la Zona en virtud de derechos exclusivos, el análisis de esos recursos, la utilización y el ensayo de sistemas y equipo de extracción, instalaciones de tratamiento y sistemas de transporte y la realización de estudios de los factores ambientales, técnicos, económicos y comerciales y otros factores apropiados que haya que tener en cuenta en la explotación.» 
De este modo, según el Proyecto de Código de Explotación, «explotar»y «explotación» aluden a la «recuperación con fines comerciales de los recursos en la Zona con derechos exclusivos y la extracción de minerales de los mismos, incluida la construcción y operación de los sistemas de minería, procesamiento y transporte en la Zona, para la producción y comercialización de metales, así como el desmantelamiento y cierre de operaciones mineras».

Uno de los temas más importantes es el Registro de minería de los fondos marinos, en el que se publicarán todos los asuntos relevantes de la explotación minera, incluidos los Contratistas y los términos de los contratos de explotación (DR 90).

El DR 2 describe los principios fundamentales y, por supuesto, uno de los temas que deben verificarse es la alineación de estos con los principios consagrados por el Derecho del Mar, en general. En materia minera, estos son los principios fundamentales básicos: sobre la propiedad de la riqueza minera (la humanidad en su conjunto): el fomento del desarrollo saludable de la economía mundial y el crecimiento equilibrado del comercio internacional; la promoción de la cooperación internacional para el desarrollo general de todos los países, especialmente los países en vías de desarrollo ${ }^{20}$; buenas prácticas industriales en la explotación y las actividades comerciales; protección de la vida humana; protección efectiva del medio marino frente a los efectos nocivos que pueden surgir de la explotación ${ }^{21}$ : la incorporación de la mejor evidencia científica disponible en procesos de toma de decisiones; la gestión y regulación efectivas de la Zona y sus recursos de manera que promueva el desarrollo del patrimonio

20 En particular: "The orderly, safe and rational management of the Resources of the Area, including the efficient conduct of activities in the Area and, in accordance with sound principles of conservation, the avoidance of unnecessary waste», "The participation in revenues by the Authority and the transfer of technology to the Enterprise and developing States", "The protection of developing countries from serious adverse effects on their economies or on their export earnings resulting from a reduction in the price of an affected Mineral or in the volume of exports of that Mineral, to the extent that such reduction is caused by activities in the Area".

21 Basado en los siguientes principios: protección y conservación del medioambiente marino, incluyendo la diversidad biológica y la integridad ecológica; la aplicación del enfoque sustentado en el principio precautorio y el enfoque ecosistémico; acceso a los datos y a la información. 
común de la humanidad; la interpretación de los Reglamentos de manera compatible con estos principios fundamentales.

\subsection{Regalias y tarifas ¿Impuestos globales y distribución de beneficios en la perspectiva global?}

En esta sección, el objetivo es mostrar la propuesta de una estructura impositiva global para la explotación de un patrimonio universal y evaluar si dicho pago es suficiente como compensación por los sacrificios y pérdidas de los países costeros y como una carga impositiva para el beneficio de las naciones del mundo.

Otra discusión en el Derecho Comparado es acerca de si las regalías constituyen impuestos. Se ha argumentado que las regalías representan pagos al propietario por la explotación de los recursos naturales ${ }^{22}$. Básicamente, las regalías son compensaciones.

Este asunto es tratado en la Parte VII, en relación con los «Términos financieros de un contrato de explotación». En la Sección 1, el DR 60 establece una regla de igualdad de trato, que prescribe que «El Consejo, de acuerdo con las recomendaciones de la Comisión, aplicará las disposiciones de esta Parte de manera uniforme y no discriminatoria, y garantizará la igualdad de trato financiero y obligaciones financieras comparables para los Contratistas».

El DR 61, prescribe la posibilidad de ofrecer incentivos a los Contratistas de manera no discriminatoria, a través de una decisión del Consejo, para promover las actividades de prospección, exploración, explotación y transmisión de tecnología. No hay duda de que ante la explotación de los recursos naturales, las regalías deben establecerse y pagarse. Y esto está regulado por la CONVEMAR. En nuestra opinión, son impuestos. Por otro lado, los gravámenes o tarifas deben pagarse a la ISA por la prestación de servicios a las empresas mineras. Estos derechos, creemos, también constituyen una clase de tributos (tasas). Ambos obedecen a distintos fundamentos.

La respuesta a las preguntas esenciales es diferente con respecto a las regalías que respecto de los gravámenes (tarifas, en el Proyecto de Código de Explotación,). La pregunta esencial es si pagarán suficientes

22 KorineK (2013) 22. 
impuestos (según el tipo de impuestos en cuestión y su finalidad) y si su recaudación se entregará a los que deberían beneficiarse.

En relación con los gravámenes (aranceles o tarifas), ellos deben responder al costo de administración de la ISA, y los beneficios deben pertenecer a dicha Autoridad para orientarse a la mantención de su equilibrio financiero y su operación.

En relación con las regalías (compensaciones por explotación de recursos naturales), se deben recaudar cantidades suficientes que constituyan una compensación por la pérdida del patrimonio de los dueños. Los resultados de la recaudación de regalías deben entregarse a los propietarios del patrimonio común, es decir, a todos los Estados. Con respecto a la regla de distribución, entre los diferentes países, este es otro asunto, que (también) debe incorporarse claramente entre las reglas para explotar los recursos naturales del mar.

Pero otros puntos siguen pendientes, como los impuestos directos (ganancias, ingresos o ingresos) y los impuestos indirectos (IVA, especialmente), y los impuestos sobre las rentas económicas o las rentas mineras. Una solución no satisfactoria es que ellos se cobren en los países de residencia de las empresas mineras. Pero no se puede afirmar de manera solvente que estos impuestos pertenecen a las jurisdicciones donde residen las empresas mineras, ya que la riqueza extraída no es solo de ellos, sino solo en una cantidad muy pequeña.

Por otro lado, el argumento contrario a la validez de los impuestos globales sobre la base de que los impuestos no se pagan por la extracción de otros recursos naturales del patrimonio universal no es suficiente, ya que esto constituye un déficit del sistema internacional y no un principio legal. Este es un tema controvertido desde el punto de vista de los intereses económicos de los países ricos en oposición a los países pobres. ${ }^{23}$

23 KLEIN sostiene que: "There are so many antagonisms between the industrialised and the third world that it would be a miracle if a communis opinio on the distribution of the natural resources of the deep sea should be reached. There is indeed a declaration of intent: 'such exploitation should be carried out for the benefit of mankind as a whole, taking into account the special interests and needs of the developing countries', as is already stated in the resolution of 21 December 1968", KLEIN (1976) 138. 
Esto abre el camino hacia el concepto de impuestos globales, en un sentido genuino. ${ }^{24}$

El problema de la administración tributaria puede resolverse, en principio, de la misma manera que la administración de regalías. Pero también ellos pueden recolectarse por las jurisdicciones de las empresas mineras (cuyas administraciones conocen mejor a dichas empresas, solventando el problema de la asimetría de información) y derivarse a la ISA, descontándose un gasto estandarizado de administración.

A partir de aquí, mostramos algunos detalles de la regulación propuesta por el Proyecto de Código de Explotación, con respecto a regalías y tarifas. Este documento propone estas reglas en los DR 60 a 82; y los gravámenes o tarifas, en los DR 83 a 86.

Con respecto a las regalías, se dispone que «un Contratista, a partir de la fecha de inicio de la Producción Comercial, pagará una regalía por el mineral vendido o retirado sin venta de la Zona de Contrato según se determina en el apéndice IV de este Reglamento» (DR 62). El Secretario General puede emitir Pautas con respecto al cálculo y pago de regalías (DR 63). De vez en cuando y bajo ciertas condiciones, el Consejo de la Autoridad puede revisar el sistema de pagos (DR 79) y una revisión de las tasas de pagos (DR 80) de las regalías. El Apéndice IV del Proyecto de Código de Explotación, establece la metodología para el cálculo de una regalía.

La presentación de declaración de regalías se hará en la forma prescrita por la Guía, ante el Secretario General, firmada por el funcionario designado por el Contratista, y se hará en cada período de medio año, de enero a junio y de julio a diciembre. La presentación de declaración de regalías deberá efectuarse para cada área minera concesionada a más tardar noventa días después del final del período correspondiente coincidente con la fecha de inicio de la Producción Comercial, y posteriormente a más tardar noventa días del periodo de declaración durante el proceso de ejecución del contrato de explotación; acompañando información complementaria sobre las cantidades de minerales extraídos y su valor, detalles de todos los contratos y acuerdos para la venta o intercambio de minerales, y un cálculo de

24 Bonta (2002) 15 et seq., "Two suggested examples are the Tobin Tax and the Carbon Tax». 
la determinación de regalías (DR 64-66). Cada año, debe presentar una declaración de un auditor o contador independiente (DR 69).

Si existe un acuerdo de empresa conjunta o un consorcio de Contratistas, se deberá presentar una declaración de regalías. La regalía se pagará el día en que se deba presentar la declaración de regalías, a la Autoridad, en dólares de Estados Unidos u otra moneda extranjera de libre convertibilidad, y estará exenta de deducciones, tarifas de transmisión, gravámenes u otros cargos (DF 68).

Acerca de los registros, inspección y auditoría, el DR 72 regula que «[un] Contratista mantendrá... registros completos y precisos relacionados con los Minerales recuperados para verificar y respaldar todas las devoluciones o cualquier otro informe contable o financiero requerido por el Autoridad en relación con la explotación». Estos registros se prepararán de conformidad con los principios de contabilidad aceptados internacionalmente, que verifican, en relación con cada área de minería concesionada, entre otros: "detalles de la cantidad y la ley de los minerales recuperados de cada Área de Minería; detalles de ventas, envios, transferencias, intercambios y otras disposiciones de minerales de la Zona de Minería, incluidos el tiempo, el destino, el valor y la base de la valoración y la cantidad y la ley de cada venta, envío, transferencia, cambio u otra disposición; detalles de todos los gastos y pasivos de capital elegibles por categoría de gastos y pasivos incurridos en cada Área de Minería; y detalles de todos los ingresos y costos operativos».

El contratista mantendrá estos registros y siempre los presentará cuando lo solicite la Autoridad para la inspección y auditoría de los documentos y las instalaciones, de acuerdo con el proceso dictaminado por el DR 73 en relación con la Parte XI del Proyecto de Código de Explotación, por varias razones legales incluyendo la responsabilidad por pago de regalías (de la misma manera a cualquier inspección de obligaciones fiscales), e intercambio de información relevante a las obligaciones de un Contratista de los Estados patrocinadores.

Si como resultado de la auditoría, y si la declaración de regalías del contratista no es correcta y precisa, la Autoridad (a través del Secretario General) puede determinar el monto de las regalías (DR 74). Del mismo modo, el Proyecto de Código de Explotación, 
establece una regla general contra la elusión (DR 75, en relación con la responsabilidad por el pago de una regalía) y una regla de ajustes de la competencia ( «rule of arm's-length adjustments», DR 76 , en relación con los contratos y transacciones, costos, precios e ingresos), intereses sobre regalías impagas y multas monetarias (DR 74 a DR 78).

Los pagos del Contratista a la Autoridad tienen dos reglas básicas: se considerarán no confidenciales; se registrará en el Registro de Minería de los Fondos Marinos (DR 81).

Además de las regalías, la Autoridad recibe de un Contratista, gravámenes administrativos y otros gravámenes aplicables: una tarifa de informe anual pagadera a la Autoridad en el momento de la presentación del informe anual del Contratista bajo el DR 40 (DR 82); una tarifa fija anual desde la fecha de inicio de la Producción Comercial en un Área de Contrato, cuyo monto está relacionado con el tamaño de la concesión minera (DR 83); una tarifa de solicitud para la aprobación de un Plan de trabajo y otras tarifas por costos administrativos incurridos por la Autoridad al procesar una solicitud (DR 84); otros gravámenes con respecto a cualquier asunto especificado en el apéndice II, y de acuerdo con la regulación aplicable (DR 85). Conforme al DR 86, el Consejo «revisará y determinará periódicamente el monto de cada uno de las tarifas administrativas anuales, de procesamiento y de otro tipo que se especifican en el apéndice II para garantizar que cubran los costos administrativos esperados de la Autoridad por el servicio prestado.»

\subsection{Las regulaciones ambientales}

El asunto más importante en este tema es determinar si la regulación ambiental de la explotación minera en los fondos marinos es suficiente para abordar los enormes daños potenciales de esta actividad en el medio ambiente y en la vida de los habitantes de los estados costeros en particular y de todos los países del mundo en general. ${ }^{25}$

25 JaeCKel afirma que los actuales desafíos del impacto ambiental de la minería submarina tienen varios elementos: «eight potential components of an environmental management strategy: regional and ecosystem based management; marine protected areas; precautionary approach and best environmental practices; 
La Convemar dedica muchas reglas para regular aspectos de la protección ambiental y del ecosistema, y los diferentes borradores de Proyecto de Código de Explotación, tienen normas integradas progresivamente en esta materia, que constituyen limitaciones a las actividades de explotación de minerales en el suelo y subsuelo marinos.

Probablemente, en este campo, las definiciones más importantes incorporadas en Proyecto de Código de Explotación, son las de Medio Ambiente Marino (Programa 1, Uso de términos y alcance); Efecto Ambiental de las actividades de explotación (DR 76); Daño grave por actividades en la Zona sobre el Medio Marino (Lista 1, Uso de términos y alcance); Mitigar y Mitigación (Lista 1, Uso de términos y alcance). Las secciones del Proyecto de Código de Explotación, dedicadas a las cuestiones ambientales son la Parte IV (Protección y preservación del medio ambiente marino), la Parte VI (Planes de cierre), el Anexo IV (Declaración de impacto ambiental), el Anexo VII (Gestión ambiental y Plan de monitoreo), el Anexo VII (Plan de Monitoreo y Gestión Ambiental), y otros artículos específicos. ${ }^{26}$

El Proyecto de Código de Explotación, indica que «se complementará con las Normas y Directrices, así como otras normas, reglamentos y procedimientos de la Autoridad, en particular sobre la protección y preservación del medio ambiente marino». Las otras reglas importantes son los principios fundamentales contenidos en el deber de cooperar e intercambiar información, y el deber de los contratistas de tomar todas las medidas necesarias para garantizar que sus actividades se realicen para no causar daños graves al medio ambiente marino, y esta es una condición para aprobar el Plan de

cumulative environmental impacts; resource use conflicts; cooperation by contractors on environmental studies; marine scientific research; and compliance, monitoring, and enforcement.» JAECKEL (2015) 102.

26 Conforme al documento, estas son las regulaciones principals: DR 2 -Fundamental principles-; DR 3 -Duty to cooperate and exchange of information-; DR 4 -Rights of coastal States-; DR 7 -Form of applications and information to accompany a Plan of Work-; DR 11 -Publication and review of the Environmental Plans-; DR 14 -Publication and review of the Environmental Plans-; DR 26 -Documents to be submitted prior to production-; DR 27 -Environmental Performance Guarantee-; DR 30 -Reduction or suspension in production due to market conditions-; DR 33 -Reasonable regard for other activities in the Marine Environment-; DR 58-59 -Closure Plan; DR 92 -Adoption of Standards-; DR 97 -Inspectors' power to issue instructions-; etc. 
trabajo, ya que los solicitantes incluyen una Declaración de impacto ambiental y un Plan de Monitoreo y Gestión Ambiental, un Plan de Cierre y un monitoreo posterior al cierre. La evaluación de los solicitantes es un proceso muy complejo que incluye la evaluación si el solicitante tiene capacidad financiera para enfrentar los costos estimados de la implementación del Plan de Monitoreo y Gestión Ambiental y el Plan de Cierre, y la capacidad técnica para llevarlos a cabo, y debe presentar una garantía financiera para afianzar las obligaciones generales y específicas relativas al medio marino, en varios Anexos del Proyecto de Código de Explotación, (IV, VII, X, etc.).

\section{Algunas reflexiones y palabras finales.}

Muchos temas abordados por el Proyecto de Código de Explotación atraen la atención, pero para nosotros cinco asuntos son particularmente relevantes, acerca de: si los fondos marinos deben ser explotados o no; los derechos de propiedad y explotación; el gobierno, la distribución de competencias y la resolución de disputas; el medio ambiente; los impuestos.

\section{(a) ¿Deben o no explotarse los fondos marinos?}

Este no es un tema cuyo debate haya sido cerrado. Los diferentes actores (países, empresas, y otros) tienen objetivos diferentes e intereses distantes e incluso opuestos, y prácticamente no hay propuestas adecuadas para ninguno de los problemas esenciales que surgen de la explotación de minerales en la Zona, considerando que es un bien que constituye un patrimonio común. de la humanidad y debe beneficiarla en su conjunto. ${ }^{27}$ Las variables que deben considerarse son diversas, como la capacidad de gobernar los asuntos involucrados, la capacidad de la tecnología para llevar a cabo la tarea en condiciones adecuadas para la protección del medio ambiente y el ecosistema (ya sea en la producción como en las etapas de postproducción y reciclaje), etc. ${ }^{28}$

27 Kim (2017) 134-137

28 Bolong (2016) 127-146. 
Por ejemplo, se prevé que los impactos negativos en todos los entornos marinos se produzcan en el lecho marino ${ }^{29}$ y en el subsuelo marino ${ }^{30}$, y se extiendan desde el sitio donde se ubica la explotación hasta alcanzar una escala regional durante períodos cortos y prolongados.

\section{(b) ¿A quién pertenecen los recursos de la Zona? Y a partir de esa respuesta, ¿Cómo distribuir los poderes de las organizaciones internacionales y los diferentes tipos de derechos y facultades?}

Este asunto está relacionado con el problema de la definición de propiedad minera por parte de la humanidad, las potestades de la ISA, los derechos y poderes legales de los Estados y los derechos privados. ${ }^{31}$ Para Hennicke, en las circunstancias actuales, la minería de los fondos marinos profundos plantea cuestiones legales controvertidas con respecto a sus condiciones, su alcance y control, de modo que para responder a estas preguntas es necesario determinar los derechos de propiedad de los fondos oceánicos. ${ }^{32}$

Normativamente, los recursos de la Zona pertenecen a la humanidad, en propiedad inalienable, y los minerales solo pueden ser transferidos después de ser extraídos (artículo 137 de la Convemar). Los contratos entre la autoridad y los contratistas establecerán los derechos (artículo 153.6 de la Convemar) derivados de autorizaciones de producción (Anexo III, artículo 7), de autorizaciones exclusivas de exploración y explotación (Anexo III, artículo 3.4.c), y los beneficios se distribuirán de manera equitativa entre los países del mundo (artículo 140 de la Convemar). ${ }^{33}$

29 Boschen (2013) 60.

30 Escobar (2004) 68.

31 HeINNICKE sostiene que «the ISA has certain controlling and administrative powers and should be the solution for an optimal management of marine resources, however, its members are states which have their own interests, powers and also political influences». HeINNICKE (2014) 211.

32 Heinnicke (2014) 209.

33 "Artículo 140. Beneficio de la humanidad. 1. Las actividades en la Zona se realizarán, según se dispone expresamente en esta Parte, en beneficio de toda la humanidad, independientemente de la ubicación geográfica de los Estados, ya sean ribereños o sin litoral, y prestando consideración especial a los intereses y necesidades de los Estados en desarrollo y de los pueblos que no hayan logrado 
Henley muestra que la noción de «patrimonio común de la humanidad» ha tenido una introducción lenta y quizás incompleta en las reglas del derecho internacional ${ }^{34}$, y es un concepto controvertido $^{35}$. Sin embargo, añade, que «se reconoce cada vez más como una noción legal importante, si no fundamental, que facilita la actividad humana útil y sostenible en áreas y con respecto a los recursos que trascienden las fronteras nacionales», y que «el patrimonio común de la humanidad, junto con la preocupación común de la humanidad en la prevención de la contaminación marina es una noción capaz de actuar como la base legal de un régimen legal complejo en el que las normas relacionadas con el desarrollo económico y la protección del medio ambiente pueden ser equilibradas de manera efectiva y racional». ${ }^{36}$

Por otra parte, la distribución de beneficios es un elemento integral del patrimonio común de la humanidad, pero aún no se ha determinado qué medidas específicas tomarán la ISA y sus Estados parte para poner en práctica esta obligación. JAECKEL, GJERDE \& ARDRON $^{37}$ consideran un enfoque que incluye: la distribución de beneficios financieros; la equidad y transparencia; procedimientos para abordar posibles conflictos de intereses; suficiencia del sistema de pago; eficiencia del sistema de pagos; la capacidad de ISA de compartir los beneficios financieros de la minería de los fondos marinos (v.g., los riesgos asociados con un sistema de regalías, o con impuestos progresivos y empresas conjuntas vinculadas a la rentabilidad); la eficiencia de la empresa; cambios en el «sistema

la plena independencia u otro régimen de autonomía reconocido por las Naciones Unidas de conformidad con la resolución 1514 (XV) y otras resoluciones pertinentes de la Asamblea General. 2. La Autoridad dispondrá la distribución equitativa de los beneficios financieros y otros beneficios económicos derivados de las actividades en la Zona mediante un mecanismo apropiado, sobre una base no discriminatoria, de conformidad con el inciso i) del apartado f) del párrafo 2 del artículo 160.»

34 Henley (2011) 377.

35 Henley (2011) 378.

36 Henley (2011) 394.

37 JAECKEL (2017) 150-157. 
paralelo» (the parallel system), tal vez reservando áreas mineras para los Estados en desarrollo. ${ }^{38}$

La conclusión de HenNicke no es optimista, piensa que «la minería en alta mar es una espada de doble filo», que "ofrece muchas oportunidades de explotación, que pueden permitir un mayor crecimiento económico, así como el apoyo necesario para el aumento de la población humana». Añade que "aunque la Unclos estaba destinada a proteger a los estados en desarrollo, prácticamente no tienen ninguna posibilidad de involucrarse en la minería y beneficiarse de ella». ${ }^{39}$

(c) ¿Cómo resolver el dilema entre obtener dinero o proteger el ecosistema?

Este es un tema difícil, en el que compiten dos clases de intereses: el interés en obtener riqueza financiera de las empresas mineras y de algunos países que pueden beneficiarse y, por otro lado, el daño para otros países que desarrollan una minería menos perjudicial desde un punto de vista ambiental. Los científicos han estado preocupados por la minería en el suelo y subsuelo marinos, tanto por sus consecuencias físicas como biológicas, en el ecosistema. ${ }^{40}$

JAECKEL explica que «el enfoque de precaución es una herramienta clave para abordar los desafíos de protección ambiental planteados por la minería de los fondos marinos, tanto a nivel regulatorio como a nivel de gestión», que «requiere una protección ambiental adecuada mediante la adopción de medidas tempranas en respuesta a los riesgos de daños ambientales, incluso en el contexto de la incertidumbre científica». ${ }^{41}$ Para este especialista, el enfoque preventivo tiene tres aspectos: la dimensión procesal o el proceso de toma de decisiones sobre actividades potencialmente dañinas, como la minería de los fondos marinos profundos; la necesidad de

38 "The parallel system requires an application for an exploration contract to include information for two sites of estimated equal economic value, capable of permitting two mining operations.» JAECKEL (2017).

39 HeinNiCKe (2014) 212.

40 VAn Dover (2017) 464-465; Amon (2016).

41 JAECKEL (2017) 1. 
capacidad y competencias institucionales para prever la toma de decisiones precautorias, facilitar la evaluación de riesgos y la gestión de riesgos, adoptar medidas de protección y garantizar su supervisión y cumplimiento; las medidas de protección. ${ }^{42}$

\section{(d) Si los recursos de la Zona pertenecen a toda}

la bumanidad, ¿Cómo resolver el problema de la gobernanza territorial, ambiental y fiscal?

La gobernanza sostenible de los océanos es un tema muy complejo, con regulaciones dispersas en regímenes, instituciones, procesos y políticas a nivel nacional, regional e internacional. ${ }^{43}$ BRÄUNINGER \& KöNIG resaltan la complejidad de la toma de decisiones por parte del gobierno de los problemas comunes relacionados con la explotación de la riqueza que se encuentra en la Zona, ya que no solo es un asunto relacionado con los órganos rectores de la IsA, sino también con la voluntad de los estados partes de la Convemar. ${ }^{44}$

Por otro lado, la explotación minera en la Zona no solo implica el desarrollo del régimen de explotación de IsA, sino también del Derecho Internacional tanto existente como emergente relacionado con los fondos marinos, el Derecho Ambiental Internacional y el Derecho Público Internacional general (dados los intereses de todos los Estados) y el Derecho general del Mar, debido a los posibles conflictos de las operaciones mineras con otros usos oceánicos. Para Till \& Pradeep, la Isa debe desarrollar un régimen de transparencia, proporcionar un foro internacional para asuntos futuros relacionados con la minería de los fondos marinos, garantizar el respeto del principio del patrimonio común de la humanidad y la protección del medio ambiente ${ }^{45}$.

En un sentido similar, Ardron, Ruhl \& Jone defienden que, en el gobierno de los recursos naturales, la transparencia se ha relacionado con una mejor rendición de cuentas, así como con la

\footnotetext{
JAECKEL (2017) 2-4.

RoMero (2018) 131-158.

BRÄUNINGER \& KÖNIG (2000) 604-629.

Till \& Pradeep (2016) 361
} 
exigibilidad, el cumplimiento, la sostenibilidad y, en última instancia, con resultados más equitativos. ${ }^{46}$

(e) Si los recursos de la Zona pertenecen a toda la humanidad, ¿Cómo resolver el problema de compartir beneficios a través de mecanismos fiscales globales? La Tributación Global

Como explica Garnaut, en esta materia están presentes las categorías de tributación de los recursos naturales y recursos de propiedad común, tales como rentas de recursos naturales ${ }^{47}$ Como en el caso de los tributos sobre los recursos naturales, podría haber impuestos sobre la renta, impuestos especiales (regalías) e impuestos ambientales, en un contexto general de tributos globales (además de las tasas y tarifas ya comentadas). ${ }^{48}$

BIRD se pregunta acerca de «si pueden o deben existir verdaderos impuestos globales y, de ser así, cómo podrían estructurarse, administrarse y distribuirse sus ganancias». Para él, «tal vez sea útil comenzar señalando tanto la importante diferencia entre la tributación internacional y los impuestos globales como la similitud igualmente importante entre ellos». Refleja que «la tributación internacional se relaciona con la interacción de los sistemas tributarios nacionales», mientras que los «impuestos globales son tributos que no son exigidos por una nación, sino por un grupo de naciones a nivel regional o incluso mundial». En cualquier caso, «todos los países involucrados deben estar preparados para renunciar a un cierto grado de soberanía fiscal». ${ }^{49}$

En este lugar, nosotros no nos referimos ni a los tributos internacionales ni a los tributos globales en el sentido explicado por BIRD (en la medida en que requieren la renuncia a la soberanía), ya que fuera de la jurisdicción no existe la soberanía de un Estado, sino del grupo de Estados, y la única forma de establecer y administrar impuestos es a través de fórmulas conjuntas entre todos los países. Y si la

\footnotetext{
ARDron (2018) 58-66

47 Garnaut (1982) 256 y ss.

48 Paul \& Wahlberg (2002).

49 BIRD (2015) 6.
} 
gestión de la Zona corresponde a la IsA, ella misma podría constituir la administración de los impuestos globales que corresponden a la explotación de la Zona. Con todo, la colaboración de los Estados y sus administraciones tributarias otorgaría una mejor solución frente a las empresas mineras residentes en ellos, por las razones y bajo las condiciones que anteriormente han sido mencionadas.

\section{Bibliografía}

\section{a) Doctrina}

Amon, Diva J. et all (2016): «Insights into the abundance and diversity of abyssal megafauna in a polymetallic-nodule region in the eastern Clarion-Clipperton Zone», Scientific Reports, Vol. 6, Article Nº 30492 (2016). Disponible en: https://www.nature.com/articles/srep30492.

Ardron, Jeff A., Ruhl, Henry A., Jone, Daniel O.B. (2018): «Incorporating transparency into the governance of deep-seabed mining in the Area beyond national jurisdiction», Marine Policy, V. 89, February 2018, pp. 58-66

BIRD, Richard M. (2015): "Global taxes and international taxation: Mirage and reality», ICTD Working Paper 28, First published by the Institute of Development Studies in January 2015, Brighton, UK.

Bolong, Luz (2016): «Into The Abyss: Rationalizing Commercial Deep Seabed Mining Through Pragmatism and International Law», Journal of International \& Comparative Law, V. 2016, Tulane, pp. 127-146.

Bonta, Steve (2002), "New push for global taxes», The New American; Apr 22; 18, 8; Research Library.

Boschen, R.E., Rowden, A.A., Clark, M.R. \& Gardner, J.P.A. (2013), «Mining of deep-sea seafloor massive sulfides: A review of the deposits, their benthic communities, impacts from mining, regulatory frameworks and management strategies», Ocean \& Coastal Management 84, pp. 54-67.

BRÄUNINGER, T., \& KöNIG, T. (2000): «Making Rules for Governing Global Commons: The Case of Deep-Sea Mining», The Journal of Conflict Resolution, 44(5), pp. 604-629.

Escobar, Jairo (2004): «El impacto producido por la actividad minera en los fondos profundos oceánicos sobre los recursos genéticos y el Reglamento para la prospección y exploración de nódulos polimetálicos en la Zona» (Santiago, CEPAL ECLAC) 6 Diciembre 2004. 
Garnaut, Ross (1982): «Fiscal Policies and Resource Rents in the Extraterritorial Oceans», EN H.E. English \& Anthony Scott, Editors, Renewable Resources in the Pacific, Proceedings of the 12th Pacific Trade and Development Conference, held in Vancouver, Canada, 7-11 September 1981 (Otawa, International Development Research Centre).

Henley, Peter Holcombe (2011): «Case Note, Minerals and Mechanisms: The legal significance of the notion of the 'Common Heritage of Mankind' in the Advisory Opinion of the Seabed Disputes Chamber», Melbourne Journal of International Law. Vol. 12, pp. 374-395. Hennicke, Larissa (2014): «Property Issues Relating to Deep-Seabed Mining in the Light of the United Convention on the Sea of 1982», Adam Mickiewicz University Law Review, V. 4, pp. 207-212.

ISA (2018): Legal and Technical Commission, International Seabed Authority, Draft Regulations on Exploitation of Mineral Resources in the Area. Twenty-fourth session. Legal and Technical Commission session, part II, Kingston, Jamaica, 2-13 July 2018

Jaeckel, Aline (2015): «An Environmental Management Strategy for the International Seabed Authority? The Legal Basis», The International Journal of Marine and Coastal Law, 30, 2015, pp. 93-119.

JAECKEL, Aline (2017): «The Implementation of the Precautionary Approach by the International Seabed Authority». International Seabed Authority, Discussion Paper, $\mathrm{N}^{\circ}$ 5, March 2017, Jamaica,

Jaeckel, Aline; GJerde, Kristina M. \&. Ardron, Jeff A. (2017): "Conserving the common heritage of humankind - Options for the deep-seabed mining regime», Marine Policy, Vol. 78, April 2017, pp. 150-157

KIM, Rakhyun E. (2017): «Should deep seabed mining be allowed?», Marine Policy 82, pp. 134-137

KINDT, John Warren (1984,) «Deep Seabed Exploitation», UCLA Journal of Environmental Law and Policy, V. 4 (1), 1984, pp. 1-55.

KLEIN Wassink, H. I. W. (1976): «Imposition of Taxes and Levies in International Waters», Intertax 1976, 14, pp. 137-143.

Korinek, J. (2013): «Mineral Resource Trade in Chile: Contribution to Development and Policy Implications", OECD Trade Policy Papers, $\mathrm{N}^{\circ} 145$ (Paris, OECD Publishing).

Nandan, Satya N. (2005): «Keynote Speaker, Secretary-General, International Seabed Authority 'Administering the mineral resources'», The British Institute of International and Comparative Law of the deep seabed, Law of the Sea Symposium, London - 22 \& 23 March 200.

PAUl, J \& WAHLBERG, K. (2002): Global taxes for global priorities - Global Policy Forum the World Economy, Ecology and Development Association (WEED) and the Heinrich Böll Foundation, 2002 - umich.edu 
Romero, María Carolina (2018): "Algunas consideraciones en torno a las deficiencias de la Convención de las Naciones Unidas sobre el Derecho del Mar para contribuir a la gobernanza sostenible de los océanos», Vol. 11 (Bogotá, ACDI), pp. 131-158.

SALAMANCAS, Esther (2003): La zona internacional de los fondos marinos (Dikynson, Madrid).

Till, Markus \& Pradeer, Singh (2016): «Promoting Consistency in the Deep Seabed: Addressing Regulatory Dimensions in Designing the International Seabed Authority's Exploitation Code», Review of European Community \& International Environmental Law, RECIEL 25 (3) 2016, pp. 347-362.

VAN Dover, C.L. et all. (2017), «Biodiversity loss from deep-sea mining», Nature Geoscience, volume 10, pp.464-465. 

CONSUlTA INDÍGENA Y CENTRALES

DE GENERACIÓN HIDROELÉCTRICA

DE MENOS DE 3 MW: DESREGULACIÓN

RIESGOSA, A LA LUZ DEL DERECHO

FUNDAMENTAL A LA IDENTIDAD CULTURAL

DE LOS PUEBLOS INDÍGENAS

\author{
INDIGENOUS CONSULTATION \\ AND HYDROPOWER GENERATION PLANTS \\ OF LESS THAN 3 MW: RISKY DEREGULATION, \\ IN LIGHT OF THE FUNDAMENTAL RIGHT \\ TO THE CULTURAL IDENTITY \\ OF INDIGENOUS PEOPLES
}

Juan Jorge Faundes Peñafiel ${ }^{1}$

Resumen. Sostenemos que el derecho fundamental a la identidad cultural de los pueblos indígenas, reconocido por la Corte Interamericana de Derechos Humanos, se ha recepcionado en el ordenamiento jurídico chileno. Frente a ello se deben consultar los

1 Profesor (Universidad Autónoma de Chile, Sede Temuco). E-mail: juanjorgef@ gmail.com 
proyectos de centrales de generación hidroeléctrica de menos de $3 \mathrm{MW}$, aunque estén exentas legalmente de someterse al SEIA, porque la afectación o susceptibilidad de afectación de valores culturales «intangibles» indígenas es de naturaleza diferente a los efectos o impactos ambientales contemplados en la legislación ambiental y, por tanto, no son asimilables.

Palabras clave: Derecho fundamental a la identidad cultural; consulta indígena; centrales hidroeléctricas pasada.

АвSTRACт. We argue that the fundamental right to cultural identity of indigenous peoples, recognized by the IACHR, has been received in the Chilean legal system. Faced with this, projects of hydroelectric power plants of less than $3 \mathrm{MW}$ should be consulted, even though they are legally exempt from environmental assessment, because the affectation or susceptibility to affect indigenous «intangible» cultural values is different in nature from the effects or impacts environmental laws and, therefore, are not assimilable.

KEYWORDS: Fundamental right to cultural identity; indigenous peoples; indigenous consultation; run-of-the-river hydroelectric power plants.

Sumario. 1.El derecho fundamental a la identidad cultural de los pueblos indígenas en el Derecho Internacional de los Derechos Humanos: 1.1. Alcances del DFIC; 1.2. Estándares sobre el DFICPI desarrollados por la jurisprudencia de la Cte.IDH. 2.Recepción en Chile del DFICPI: 2.1. Reconocimiento del DFICPI en Chile. 3. Marco regulatorio en materia de consulta indígena aplicable las CHm3MW: 3.1. Regulación general de la consulta indígena; 3.2. Estándares internacionales de la consulta indígena; 3.3. Estándares internacionales de la consulta indígena; 3.4. La medida administrativa consultada en las $\mathrm{CHm} 3 \mathrm{MW}$ y el órgano responsable de la consulta; 3.5. Los presupuestos de afectación directa y susceptibilidad de afectación previstos en el Convenio N¹69 de la OIT. 4. Jurisprudencia: 4.1. Casos de consultas municipales no sometidos al SEIA: a) Caso del Cerro Colo-Colo; b) Caso de la Comunidad Indígena Entuco. 4.2 Consulta y casos de «carácter ambiental» excluidos del SEIA: a) Concesiones de explotación y exploración geotérmica; b) El caso de la Minicentral Hidroeléctrica Las Flores. 5. A modo de conclusión, propuesta de una correcta comprensión del 
marco regulatorio para los proyectos de $\mathrm{CHm} 3 \mathrm{MW}$ en territorios indígenas. 6. Bibliografía.

\section{CONSULTA INDÍGENA Y CENTRALES DE GENERACIÓN HIDROELÉCTRICA DE MENOS DE 3 MW: DESREGULACIÓN RIESGOSA, A LA LUZ DEL DERECHO FUNDAMENTAL A LA IDENTIDAD CULTURAL DE LOS PUEBLOS INDÍGENAS}

La regulación chilena de las centrales hidroeléctricas «de pasada» considera un régimen que exige el ingreso de los proyectos al Sistema de Evaluación de Impacto Ambiental (SEIA) solo a partir de una potencia de generación eléctrica de más de $3 \mathrm{MW}$. Este criterio enlaza los impactos ambientales con la capacidad generadora. Paralelamente, los proyectos sometidos al SEIA consideran un proceso especial de consulta indígena dentro de dicho sistema. En consecuencia, en la práctica, se podría entender que un proyecto excluido de evaluación ambiental no tendría la obligación de consultar a los pueblos indígenas conforme el Convenio $\mathrm{N}^{\circ} 169$ de la OIT (Convenio N¹69 o Convenio 169). Sin embargo, como demostraremos, dicho razonamiento es erróneo, porque, primero, la capacidad de generación eléctrica no tiene necesaria relación con la potencial producción de efectos que, en especial, dañen valores intangibles de naturaleza cultural amparados por el derecho fundamental a la identidad cultural de los pueblos indígenas (DFICPI) -coincidan o no con factores ambientales-; segundo, porque existe un marco regulatorio vinculante para los casos de consulta indígena que opera, supletoria e imperativamente, en los casos no cubiertos por la legislación ambiental.

En este contexto, la Corte Interamericana de Derechos Humanos (Cte.IDH) sostiene que el derecho a la identidad cultural es un derecho fundamental y de naturaleza colectiva cuya titularidad corresponde a las comunidades y pueblos indígenas, que debe ser respetado en una sociedad multicultural, pluralista y democrática ${ }^{2}$. A su vez, el desarrollo progresivo del DFICPI en el ámbito internacional y su paralela recepción en el ámbito interno, plantea importantes desafíos para los Estados, en especial respecto del control de convencionalidad de los

2 Pueblo Indígena Sarayaku Vs. Ecuador (2012) 
jueces a la luz de la Convención Americana de Derechos Humanos (CADH) y del Convenio $\mathrm{N}^{\circ} 169$, ambos tratados de derechos humanos ratificados y vinculantes para Chile, interpretados bajo la doctrina del bloque de constitucionalidad, articulados con la Declaración de $\mathrm{Na}$ ciones Unidas de Derechos de los Pueblos Indígenas y la Declaración Americana de Derechos de los Pueblos Indígenas . Dicha recepción del DFICPI, lo instala como un derecho implícito ${ }^{3}$ en la Constitución de la República de Chile y tiene impactos en diversos ámbitos de derechos de los pueblos indígenas, tales como derechos territoriales, a los recursos naturales y a la consulta indígena, entre otros. En consecuencia, como demostraremos, la obligación de consultar a los pueblos indígenas (artículo 6 del Convenio $\mathrm{N}^{\circ} 169$ ) hoy excede los estrictos límites del SEIA, dentro de la cual se la tiende a restringir.

Luego, en este trabajo sostenemos que la recepción del DFICPI en el ordenamiento jurídico chileno hace exigible la obligación de consultar a las comunidades y pueblos indígenas en el caso de las centrales de generación hidroeléctrica de menos de 3MW (CHm3MW), aunque estén exentas legalmente de someterse al SEIA conforme el artículo 10, letra c) de la Ley 19.300, porque la afectación o susceptibilidad de afectación de valores culturales intangibles indígenas es de naturaleza diferente a los efectos o impactos ambientales contemplados en la legislación ambiental y, por tanto, unos y otros no son asimilables (más allá que en diversos casos puedan coincidir). En este sentido, por sobre la normativa interna ambiental y la aparente desregulación de la consulta en los casos de CHm3MW, las obligaciones contraídas por el Estado de Chile, conforme la CADH y el Convenio N¹69, en armonía con el Decreto Supremo Nº 66 de 2013, Reglamento sobre Consulta Indígena (Decreto 66) ${ }^{4}$ que reglamenta la consulta de manera general, constituyen un marco regulatorio suficiente (supletorio e imperativo) para los casos de proyectos de inversión de $\mathrm{CHm} 3 \mathrm{MW}$ en territorios indígenas.

En con el fin de sustentar esta tesis: i) presentamos el DFICPI conforme las fuentes que recogen en el Derecho Internacional de los Derechos Humanos, revisamos la jurisprudencia de la Cte.IDH y desarrollamos la recepción en Chile de este derecho en relación

Bidart Campos (2000) 103-113.

4 Decreto Supremo No 66 de 2013. 
con la obligación de consultar del Convenio $\mathrm{N}^{\circ} 169$ de la OIT; ii) estudiamos críticamente el marco reglamentario y jurisprudencial en materia de consulta indígena en Chile, aplicable a las CHm3MW, en especial, con una revisión de los conceptos de afectación directa y susceptibilidad de afectación, como presupuestos de la consulta indígena a la luz del DFICPI; iii) realizamos una breve revisión de jurisprudencia administrativa y judicial atingente a nuestra tesis, iv) conclusivamente, proponemos la que estimamos es una correcta comprensión del marco regulatorio para los proyectos de $\mathrm{CHm} 3 \mathrm{MW}$ en territorios indígenas bajo el amparo del DFICPI.

\section{I.- EL DERECHO FUNDAMENTAL A LA IDENTIDAD CULTURAL DE LOS PUEBLOS INDÍGENAS EN EL DERECHO INTERNACIONAL DE LOS DERECHOS HuMANOS}

\subsection{Alcances}

EL DFICPI comprende dos dimensiones, una individual y otra colectiva: una como derecho individual o indirecta que protege al individuo y su identidad en la comunidad; y una dimensión directa que resguarda a la comunidad como sujeto de derecho ${ }^{5}$. La segunda es la central para el aseguramiento de los derechos de los pueblos indígenas, teniendo en cuenta especialmente que la Cte.I.D.H reconoció expresamente la naturaleza colectiva y de derecho fundamental del derecho a la identidad cultural, cuando su ejercicio corresponde a los pueblos indígenas ${ }^{6}$.

Asimismo, este derecho tutela dos bienes jurídicos, identidad y cultura, que se integran, a su vez, en dos derechos conexos: el derecho a la identidad y el derecho a la cultura. El derecho a la identidad refiere al resguardo del sentido de pertenencia que un individuo tiene

\footnotetext{
Corte Constitucional de Colombia, Sentencia T-778/05. RuIz (2006) 43-69; Del Real (2014).

6 Un desarrollo más extenso y crítico de los alcances y debates en torno a la perspectiva individual y la colectiva del derecho a la identidad cultural véase en Del ReAl (2014).
} 
respecto de una determinada cultura ${ }^{7}$, mientras el derecho a la cultura tutela la cultura a la que pertenece el sujeto, como valor en sí ${ }^{8}$.

Los principales instrumentos internacionales de derechos humanos que sostienen este derecho son la Declaración Universal de Derechos Humanos que dispone que «Toda persona, como miembro de la sociedad, tiene derecho a obtener... la satisfacción de los derechos económicos, sociales y culturales, indispensables a su dignidad y al libre desarrollo de su personalidad» (art. 22) y que toda persona «tiene derecho de participar libremente en la vida cultural de la comunidad...» (art.27.1); el PIDESC que en su artículo 1 señala que: «Todos los pueblos tienen el derecho de libredeterminación. En virtud de este derecho establecen libremente su condición política y proveen asimismo a su desarrollo económico, social y cultural», lo cual se articula con el artículo 27 del PIDCP que dispone que «En los Estados en que existan minorías étnicas, religiosas o lingüísticas, no se negará a las personas que pertenezcan a dichas minorías el derecho que les corresponde, en común con los demás miembros de su grupo, a disfrutar de su propia cultura, a profesar y practicar su propia religión y a emplear su propio idioma». ${ }^{9}$

También, dentro de los instrumentos específicos referentes a los pueblos indígenas que aseguran el derecho fundamental a la identidad cultural de los pueblos indígenas encontramos la Declaración de las Naciones Unidas sobre los Derechos de los Pueblos Indígenas (DNUDPI), el Convenio No 169 OIT y la Declaración Americana sobre los derechos de los pueblos indígenas (DADPI) de 2016, que considera el derecho a la identidad cultural como un valor transversal ${ }^{10}$.

Por su parte, la CADH permite fundamentar el DFICPI, evolutivamente y conforme el principio pro persona, a partir de sus artículos 1.1, 4, 11, 21, 24, 29.b.

\section{Grimson (2009) 63-79.}

Declaración Universal de la Unesco (2001).

9 En el mismo sentido la Convención para la salvaguardia del patrimonio cultural inmaterial (Paris, 2003), art.1. a. b. y 2 c. d.

10 Artículo 13: "Los pueblos indígenas tienen derecho a su propia identidad e integridad cultural y a su patrimonio cultural, tangible e intangible...». 


\subsection{Estándares sobre el DFICPI desarrollados por la jurisprudencia de la Cte.IDH}

La jurisprudencia de la Cte.IDH, evolutivamente, en armonía con las observaciones y recomendaciones de la Organización Internacional del Trabajo (OIT) y otros organismos especializados de Naciones Unidas, ha logrado sostener un corpus juris de derechos humanos en materia de derechos de los pueblos indígenas, de hard law y soft law, que integra hermenéuticamente los estándares recogidos de otros instrumentos de diversa naturaleza, como la DNUDPI, las observaciones de la CEACR y los Manuales de la OIT relativos al Convenio $\mathrm{N}^{\circ} 169^{11}$ y las recomendaciones los relatores de $\mathrm{Na}$ ciones Unidas sobre las libertades y derechos fundamentales de los indígenas, entre otros ${ }^{12}$.

En el año 2001 la sentencia del Caso de la Comunidad Magna (Sumo) AwasTign» (2001), se pronuncia sobre los derechos territoriales de los pueblos indígenas, su autonomía conceptual sobre la concepción de la propiedad registral predominante en los ordenamientos jurídicos internos nacionales y destaca la necesidad del amparo de la propiedad indígena ancestral, dada su íntima relación con la sobrevivencia misma de estos pueblos. Con este fallo la Cte. IDH asume un rol activo de control de convencionalidad en favor de los derechos de los pueblos indígenas, bajo una inseparable relación entre la propiedad indígena, el derecho a la vida (en sentido amplio) y la identidad e integridad cultural. Paralelamente, la Corte irá desarrollando los derechos y estándares en materia de consulta indígena, como derecho cautelar de la sobrevivencia indígena inclusiva de su identidad cultural. Luego, en el caso de la Comunidad Moiwana Vs. Suriname (2005) la Corte Interamericana profundiza en la conexión normativa existente entre el derecho fundamental a la identidad cultural y la libertad de conciencia y religiosa, que ya se venía reconociendo de manera emergente en los casos Caso Bámaca Velásquez Vs. Guatemala (2000) y de la Comunidad Plan Sánchez (2004). En general la Corte reafirmará la dimensión colectiva de

11 OIT $(2003 ; 2011)$.

12 Aguilar (2010) 18-20; Aylwin, Meza-Lopehandía, Yañez (2013); Calderón (2016) 343-344; FAundes (2013.c) 571-579. 
la identidad cultural, en especial a partir del reconocimiento de un daño de carácter inmaterial - «daño espiritual»- de «proyección intergeneracional» como forma especial y «agravada de daño moral». La Corte reconoce los daños inmateriales en estrecha relación con la identidad cultural, valorando, por sobre la dimensión subjetiva individual, el daño colectivo comunitario respecto de los valores religiosos, particularmente respecto del valor de la relación con los muertos y ancestros y la normatividad de las tradiciones territorializadas vinculadas a ellos ${ }^{13}$.

En el caso de la Comunidad Indígena Yakye Axa Vs. Paraguay (2005) la Cte.IDH expresó que, para garantizar efectivamente los derechos a las comunidades indígenas, «los Estados deben tomar en consideración las características propias que diferencian a los miembros de los pueblos indígenas de la población en general y que conforman su identidad cultural» ${ }^{14} \mathrm{y}$ «la significación especial de la propiedad comunal de las tierras ancestrales para los pueblos indígenas... para preservar su identidad cultural y trasmitirla a las generaciones futuras» ${ }^{15}$ por lo que al vulnerarse derechos territoriales se puede afectar el derecho a la identidad cultural y la propia supervivencia de las comunidades indígenas y sus miembros ${ }^{16}$. Agregó la Corte que, incluso, puede resultar necesaria una restricción al derecho a la propiedad privada de particulares «para lograr el objetivo colectivo de preservar las identidades culturales en una sociedad democrática y pluralista en el sentido de la Convención Americana ${ }^{17}$. Este alcance resultará clave al momento de establecer el marco regulatorio interno porque ofrece y exige medios de acción y tutela al Estado, dentro del Estado de Derecho, pero ampliando la comprensión de los alcances de la consulta indígena.

Cançado Trindade aborda el entendimiento normativo del derecho fundamental a la identidad cultural en relación con el derecho a la vida en el caso Sawhoyamaxa Vs. Paraguay (2006). En este sentido, destaca la importancia de la identidad cultural «como componente o

\footnotetext{
Comunidad Moiwana Vs. Suriname (2005), Cons. 13.

Comunidad Indígena Yakye Axa Vs. Paraguay (2005), Cons. 51.

Comunidad Indígena Yakye Axa Vs. Paraguay (2006), Cons. 124, supra párr. 51.

Comunidad Indigena Yakye Axa Vs. Paraguay (2006), 79, Cons. 147.

Comunidad Indígena Yakye Axa Vs. Paraguay (2006), p. 82. Cons. 148.b.
} 
agregado del propio derecho fundamental a la vida» y el valor de las tierras ancestrales para los miembros de las comunidades indígenas para la preservación de «su propia identidad cultural y, en última instancia, su derecho fundamental a la vida lato sensu'» ${ }^{18}$. Señala que el derecho a la vida posee una «vinculación estrecha e ineludible con la identidad cultural», porque la identidad cultural «se forma con el pasar del tiempo, con la trayectoria histórica de la vida en comunidad. Ante lo cual -agrega- «el Estado no puede eximirse del deber de debida diligencia para salvaguardar el derecho de vivir.» ${ }^{19}$. En este sentido, se impone al Estado una obligación de acción diligente, un deber de impulsar medidas y actos efectivos para salvaguardar el derecho fundamental a la identidad cultural, lo que integra inalienablemente la protección de sus territorios y recursos naturales, en una comprensión amplia del derecho a la vida, en la perspectiva colectiva de los pueblos indígenas, sus comunidades e integrantes.

Finalmente, en los casos más recientes de «Sarayaku Vs. Ecuador» $(2012)^{20}$ y «Sukuro Vs. Brasil» $(2018)^{21}$ destacará el reconocimiento expreso del DFICPI por parte de la Cte.IDH. Señala la sentencia del caso Sarayaku:

... el derecho a la identidad cultural es un derecho fundamental y de naturaleza colectiva de las comunidades indígenas, que debe ser respetado en una sociedad multicultural, pluralista y democrática» [y que es] "vía de interpretación transversal para concebir, respetar y garantizar el goce y ejercicio de los derechos humanos de los pueblos y comunidades indígenas protegidos por la Convención y por los ordenamientos jurídicos internos ${ }^{22}$.

\footnotetext{
18 Comunidad Indigena Sawhoyamaxa Vs. Paraguay (2006) pp. 127-128, Cons. 4,7.

19 Comunidad Indígena Sawhoyamaxa Vs. Paraguay (2006) p. 137, Cons. 33.

20 Pueblo Indígena Sarayaku Vs. Ecuador (2012).

21 Pueblo indígena Xucuru y sus miembros Vs. Brasil (2018), Cons. 188.

22 Pueblo Indígena Sarayaku Vs. Ecuador (2012).
} 


\section{ReCEPCión EN CHILE DEL DFICPI}

\subsection{Reconocimiento del DFICPI en Chile}

Para encuadrar la recepción en Chile del DFICPI solo dejaremos planteado que estamos de acuerdo con quienes sostienen que existe una tendencia latinoamericana compartida a la apertura constitucional al Derecho Internacional de los Derechos Humanos ${ }^{23}$, un bloque de constitucionalidad», se trata de entendimiento regional de un sentido integrador y evolutivo de los derechos fundamentales, asegurados tanto en el Derecho Internacional de los Derechos Humanos, como en las constituciones nacionales que ha ido conformando progresivamente un «derecho común internacional» de naturaleza constitucional, en el sentido material e imperativo de su contenido común, dinámico y en ampliación evolutiva a partir de las sentencias de la Cte.IDH, conforme la $\mathrm{CADH}^{24}$. Se trata de la idea compartida y cada vez más relevante, de un nuevo corpus jurídico de derechos humanos limitante para la actuación de los estados conforme el principio pro persona. Esta comprensión de un nuevo Derecho que avanza incluso por sobre las propias fuentes en su dimensión formal, bajo un estándar internacional de derechos humanos, que opera como «una concepción unitaria de las instancias normativas internacionales y nacionales de derechos humanos que dan un contenido material a principios constitucionales e internacionales respecto de estos derechos para resolver los casos en el fuero nacional» ${ }^{25}$.

Así, para el caso chileno, sin entrar en los latos debates de la doctrina sobre el artículo 5 inciso $2^{\circ}$ de la Constitución, entendemos que este mandato constitucional impone una aplicación preferente de las normas internacionales de derechos humanos que se incorporan al derecho interno, bajo una necesaria interpretación evolutiva de los derechos humanos, como expresión del principio pro persona y bajo control de convencionalidad de las obligaciones internacionales

\footnotetext{
GÓNGORA-MERA (2017) 302-305.

Von Bogdandy, Fix-Fierro, Morales-Antoniazzi (2014) 19-20.

25 Morales-AnzionatTi (2014) 265-299; NASH (2008) 73, 245-246; MartíneZ Bullé (2013); Aguilar (2010).
} 
de derechos humanos ${ }^{26}$. Estos alcances del artículo 5 inciso $2^{\circ}$ de la Constitución se han refrendado por la jurisprudencia nacional y consideran la aplicación preferente de las disposiciones de derechos humanos como un auténtico límite para el ejercicio de la soberanía por parte de los organismos del Estado, conformando un bloque de constitucionalidad como marco normativo inexcusable ${ }^{27}$.

En la forma antes descrita, el DFICPI, por una parte, se incorpora normativa y materialmente al bloque constitucional de derechos fundamentales. Por otra, como consecuencia del carácter de derecho fundamental ${ }^{28}$, reconocido por la Cte.I.D.H, constituye una norma imperativa para el Estado que opera como un límite para el ejercicio de la soberanía por parte de éste, fundado en el Convenio 169 y la $\mathrm{CADH}$, como tratados de derechos humanos y o que integra el bloque de constitucionalidad, según lo ha resulto sistemáticamente la jurisprudencia nacional e internacional ${ }^{29}$. Asimismo, el Estado

26 Corte Apelaciones Rancagua, Rol N 103-2011 (2013) en cumplimiento de lo resuelto por la Cte.IDH en el caso Almonacid Arellano Vs. Chile (2006).

27 Medina (1994); Precht (1997); Nogueira (1997); Nogueira (2007). Nash (2009) desarrolla la idea de «estándares normativos» y Aldunate (2010) plantea la cuestión del límite para los órganos del Estado conforme el Principio de Legalidad Constitucional.

28 Arango (2014) 27-29; Faundes (2013.d) 233-234; Medina (1994) 44-46.

29 Ej.: Recurso de hecho deducido por el actor en la causa Pilquiman, Crecencio cl Instituto Autárquico de Colonización y Fomento Rural s/ acción de amparo", 7 octubre 2014, P. 811. XLIV, cons. 6º . Tribunal Constitucional del Perú, Exp. N. ${ }^{\circ}$ 05427-2009-PC/TC, "Asociación Interétnica de Desarrollo de la Selva» (2010), cons. 9, 23, 26; Corte Constitucional de Colombia, Sentencia C-882/11, «Reforma constitucional introducida al Artículo 49 de la Constitución Política»; Corte Constitucional de Colombia. Sentencia. T-116/11, «Comunidades indígenas como sujetos de especial protección constitucional y titulares de derechos fundamentales», cons.8; Corte de Constitucionalidad, Guatemala, Apelación de sentencia de amparo, Exps. acum. 156-2013 y 159-2013, Sent. 25.03.2015; Corte de Constitucionalidad, Guatemala, Apelación de sentencia de amparo, Exps. acum. 90-2017, 91-2017 y 92-2017, Sent. 26.05.2017. cons. VI; Corte de Constitucionalidad, Guatemala, Apelación de sentencia de amparo, Expediente 2906-2017, Sent. 21.09.2017, cons. IV; Corte de Constitucionalidad, Guatemala, Apelación de sentencia de amparo, expediente 4785-2017, Sent. 3.09.2018; STF (Brasil), Pleno, ADI 3239, Red. p/ o acórdão Min. Rosa Weber, DJe, 01.02.2019. En Chile, entre otros: Francisca Linconao con Forestal Palermo (2010); Alejandro Papic Domínguez con Comunidad Indígena Aymara Chusmiza y Usmagama (2009); Condore Vilca y comuneros de la Quebrada de Tarapacá cl COREMA de la I Región de Tarapacá, (caso "Paguanta») (2012); Requerimiento de inaplicabilidad por inconstitucionalidad presentado por 
no puede excusarse de cumplir la norma del referido Convenio 169 invocando la legislación nacional, conforme el artículo 27 de la Convención de Viena de Derecho de los Tratados.

En consecuencia, se gatilla una transformación en la comprensión del Derecho bajo la cual el poder del Estado solo puede ejercerse armónicamente articulado con el derecho fundamental a la identidad cultural de los pueblos indígenas. En este sentido, emerge el deber de una lectura de los derechos humanos que recoja los contextos históricos, culturales y cosmogónicos de los pueblos indígenas, que considere las condiciones necesarias para su sobrevivencia como pueblos. Entre ellas, claramente se encuentra la recomprensión y ampliación del sentido de la propiedad (art. $21 \mathrm{CADH}$ ) que introduce el concepto de territorios indígenas, con el resguardo de sus recursos naturales y una concepción extensiva de la consulta indígena, como mecanismo de tutela de dichos derechos, entendidos como inescindibles del DFICPI.

\section{Marco Regulatorio en MATERia De CONSUlta INDÍGENA APLICABLE LAS CHM3 MW}

\subsection{Regulación general de la consulta indígena}

La Ley 19.300 regula el SEIA, implementado mediante el Decreto Supremo N$^{\circ} 40$ de 2012, Reglamento del Sistema de Evaluación de Impacto Ambiental (Decreto 40). El artículo $9^{\circ}$ de esta ley dispone que todo titular de un proyecto o actividad que contemple un impacto ambiental de conformidad al artículo 10 de la misma Ley deberá presentar una Declaración de Impacto Ambiental (DIA) o elaborar un Estudio de Impacto Ambiental (EIA). A su vez, el referido artículo 10 de la Ley 19.300 señala diecinueve actividades o tipos de proyectos de inversión «susceptibles de causar impacto ambiental, en cualesquiera de sus fases» que deben someterse al SEIA. Y, luego de dicho listado taxativo del artículo 10, el artículo 11 describe los supuestos en que dichos proyectos requieren un EIA, por estimar la

Inversiones Tama S.A. respecto de los artículos 54, 55, 56 y 58 de la Ley $N^{\circ}$ 19.253 (2015); Comunidad indigena Yakye Axa Vs. Paraguay (2005); Pueblo Indígena Kichwa de Sarayaku Vs. Ecuador (2012). 
Ley -«objetivamente»- que ocasionan impacto ambiental, especificando los efectos, características o circunstancias precisas suponen la necesidad del EIA.

Paralelamente, el 8 artículo del Decreto 66 dispone que las actividades que ingresan al SEIA conforme el artículo 10 de la ley $\mathrm{N}^{\circ} 19.300$ y que requieran un proceso de consulta indígena, se consultarán de acuerdo a la normativa del SEIA. Y el artículo 85 del referido Decreto 40 regula en concreto la consulta indígena de los proyectos de inversión sometidos al SEIA que requieren EIA mediante un procedimiento a cargo del (Servicio de Evaluación Ambiental (SEA).

Por su parte, el artículo 10, letra c) de la Ley 19.300 describe las distintas actividades subordinadas al proceso ambiental, incluyendo solo las «Centrales generadoras de energía mayores a $3 \mathrm{MW».} \mathrm{En}$ consecuencia, tan solo las centrales hidroeléctricas de generación superior a $3 \mathrm{MW}$ se someten al SEIA, ergo, aquellos proyectos hidroeléctricos de una capacidad de generación inferior a $3 \mathrm{MW}$ se excepcionan de evaluación ambiental (DIA o EIA) y, de conformidad al artículo 8 del Decreto 66, estos proyectos quedan excluidos de la consulta indígena inserta en el SEIA regulada por el artículo 85 del Decreto 40.

Entonces, desde la perspectiva regulatoria ambiental, el supuesto del artículo 10 letra c) de la Ley 19.300 que excluye los proyectos de $\mathrm{CHm} 3 \mathrm{MW}$-entendemos- asume que dichos proyectos no son susceptibles de causar impacto ambiental. Sin embargo, corresponderá revisar la situación de los proyectos implementados en territorios indígenas, desde la perspectiva de la potencial afectación de valores culturales intangibles tutelados a la luz del DFICPI que no necesariamente son asimilables a impactos ambientales.

De esta forma, para abordar el problema, debe considerarse que el marco regulatorio en Chile para la consulta indígena contempla dos escenarios: uno taxativo y especial, para la consulta dentro del SEIA; y otro, general, supletorio e imperativo, que incluye los casos de consulta indígena excluidos del SEIA. Por lo tanto, si bien opera la exclusión de la consulta indígena especial regulada por el artículo 85 del Decreto 40, de conformidad al artículo 10 letra c), no es correcto suponer que esos proyectos están eximidos de consulta 
indígena, porque siguen estando regulados por el Decreto 66 que regula los presupuestos de la consulta Indígena, en la medida que se produzcan los efectos del artículo 6 del Convenio 169 bajo los parámetros del artículo 7 del mismo Decreto 66. Y, como veremos, el marco regulatorio del artículo 7 del Decreto 66 debe ser interpretado a la luz del DFICPI.

\subsection{Estándares internacionales de la consulta indígena}

La fuente normativa vinculante principal de la consulta indígena es el Convenio $\mathrm{N}^{\circ} 169$ de la OIT que establece que:

Los Estados deberán consultar a los pueblos Indígenas «mediante procedimientos apropiados y en particular a través de sus instituciones representativas, cada vez que se prevean medidas legislativas o administrativas susceptibles de afectarles directamente» (art. 6.1.a).

«Las consultas llevadas a cabo... deberán efectuarse de buena fe y de una manera apropiada a las circunstancias, con la finalidad de llegar a un acuerdo o lograr el consentimiento acerca de las medidas propuestas» (art. 6.2). ${ }^{30}$

De la disposición citada se han abstraído los conocidos estándares internacionales de la consulta indígena que, en resumen, prescriben que los gobiernos deben consultar a los pueblos interesados en forma libre, informada, de buena fe, flexible y adecuada, mediante procedimientos apropiados culturalmente, considerando sus procedimientos tradicionales para la toma de decisiones y sus formas de representación tradicional, dirigida a obtener el consenso ${ }^{31}$.

30 Además, en materia de consulta indígena, debe relacionarse sistemáticamente con los artículos 7, 15.2, 16, 13 y 14 del mismo Convenio 169 y con el artículo 19 DNUPI.

31 Conforme han sido sistematizados por la relatoría de Naciones Unidas sobre pueblos indígenas, como "Los Principios Internacionales Aplicables a la Consulta», AnAya (2009.a), la Corte Interamericana de Derechos Humanos: Caso Comunidad Indígena Yakye Axa vs. Paraguay (2005); Pueblo Indígena Kichwa de Sarayaku Vs. Ecuador (2012) y los órganos de seguimiento de OIT (ICACR, 2010, 2011, 2012; OIT, 2003; 2009). 
De esta forma, para cumplir con el mandato internacional de adecuación normativa de la legislación nacional, no bastará la sola enunciación en las leyes o reglamentos internos (como en el caso chileno está previsto en el artículo 4 de la Ley 19.300 y en el artículo 85 del Reglamento del SEIA), sino que se requiere, primero, que las consultas efectivamente se realicen en la medida que se presenten los presupuestos de la consulta conforme el artículo 6 del Convenio 169; y, segundo, que en la ejecución material de los procesos específicos de consulta se cumpla con los respectivos estándares internacionales.

En este sentido, el DFICPI en armonía con la consulta indígena, exige un actuar de buena fe por parte del Estado en materia de consulta indígena que recoja los propósitos mismos de la consulta. Se trata de la necesaria concatenación y razonabilidad que debe existir en el actuar continuo en el tiempo del Estado y de sus órganos. En ese sentido, visto desde el punto de vista de la consulta indígena, constatada la susceptibilidad de afectación de un proyecto o medida para un pueblo indígena o sus comunidades, no es posible negar la procedencia de la consulta, sin vulnerar el principio de buena fe. Este razonamiento configura lo que podríamos enunciar como un principio precautorio de presunción de procedencia de la consulta indígena. Conforme con este postulado, la regulación nacional de la consulta indígena (Ley 19.300 y su Decreto 40 que regula la consulta indígena) no puede conducir a un estándar más bajo que el establecido internacionalmente, porque ello vulneraría la aplicación de buena fe del Convenio 169 conforme el «Principio de Aplicación Integral» contenido en el artículo 35 del mismo ${ }^{32}$.

Paralelamente, el principio de flexibilidad del artículo 34 del Convenio 169, ofrece la posibilidad de cumplir con sus obligaciones de diversas formas, acorde a la realidad de cada Estado, pero en caso alguno habilita a dejar de cumplir este tratado, porque ello, a su vez, vulneraría el principio del «efecto útil» del Derecho Internacional y el mismo principio de la buena fe ya enunciado ${ }^{33}$. Tampoco podemos dejar de considerar el carácter autoejecutable de la consulta indígena del Convenio $\mathrm{N}^{\circ} 169$, que permite al Estado desarrollar procesos de consulta, directamente, de conformidad al estándar internacional,

32 Faundes (2013c) 574-575.

33 Faundes (2013c) 574-575. 
incluso prescindiendo de la legislación y la reglamentación interna cuando ellas arrojen un estándar inferior. En general, así se desprende del control jurisdiccional de convencionalidad ejercido por la Corte Suprema en los fallos del Plano Regulador de San Pedro de Ataca$\mathrm{ma}^{34}$, Parque Eólico de Chiloé ${ }^{35}$ y Paguanta ${ }^{36}$, cuando señaló que la consulta realizada en el marco del SEIA conforme la Ley 19.300, «deberá realizarse cumpliendo los estándares internacionales conforme el Convenio 169 de la OIT» ${ }^{37}$.

En consecuencia, resulta esencial desde el punto de vista del diálogo de buena fe que la consulta indígena se realice y concluya, en base a los estándares internacionales, con las organizaciones indígenas que pueden ser afectadas. Por el contrario, con la exclusión de la consulta basada en una interpretación regulatoria estrecha, se vulnera el principio de buena fe, al impedir que la consulta cumpla con sus fines. A su vez, una interpretación regulatoria que excluya la consulta indígena del Convenio $\mathrm{N}^{\circ} 169$, existiendo susceptibilidad de afectación directa, vulnera con toda evidencia el objeto y fin del Convenio 169 al obtener el objetivo opuesto al buscado por la norma internacional.

\subsection{La medida administrativa consultada en las $\mathrm{CHm3MW}$ y el órgano responsable de la consulta}

Señala el Convenio 169 que deberá consultarse «cada vez que se prevean medidas legislativas o administrativas susceptibles de afectarles directamente» (art. 6.1.a). A su vez, como explicamos, el Decreto 66 especifica que, reglamentariamente, existiría una «medida administrativa» cuando "tales medidas sean causa directa de un impacto significativo y específico sobre los pueblos indígenas en su calidad de tales, afectando el ejercicio de sus tradiciones y costumbres

34 Asociacion indigena Consejo de Pueblos Atacameños contra Corema Region Antofagasta (2011).

35 Comunidad indigena antu lafquen de buentetique cl Comisión Regional del Medio Ambiente Región de los Lagos (2011).

36 Condore Vilca y comuneros de la Quebrada de Tarapacá cl COREMA de la I Región de Tarapacá (2012).

37 Condore Vilca y comuneros de la Quebrada de Tarapacá cl COREMA de la I Región de Tarapacá (2012). 
ancestrales, prácticas religiosas, culturales o espirituales, o la relación con sus tierras indígenas» (art. 7 inc. $2^{\circ}$ ). Además, indica el mismo Reglamento que dicha medida administrativa debe consistir en un acto formal «cuya propia naturaleza no reglada» permita a los órganos del Estado «el ejercicio de un margen de discrecionalidad que los habilite para llegar a acuerdos u obtener el consentimiento de los pueblos indígenas» $\left(\text { art. } 7 \text { inc. } 3^{\circ}\right)^{38}$.

En este contexto regulatorio, sostendremos en el caso de las $\mathrm{CHm} 3 \mathrm{MW}$ que la medida administrativa susceptible de afectar a los pueblos indígenas conforme el artículo 6 del Convenio 169 y el artículo 7 del Decreto 66 es el Decreto de Concesión Eléctrica que otorga la Concesión Eléctrica Definitiva que dicta el Ministerio de Energía, previo Decreto de Concesión provisorio de la Superintendencia de Electricidad y Combustibles (SEC), ello, conforme a lo dispuesto en los artículos el artículo 11, 19 y 25 de la Ley Eléctrica $^{39}$. Consecuentemente, el órgano de la administración del Estado responsable de la consulta en los casos de CHM3MW sería el Ministerio de Energía (mismo caso de la consulta de la concesión de explotación geotérmica $)^{40}$.

\subsection{Los presupuestos de afectación directa y susceptibilidad de afectación previstos en el Convenio $N^{\circ} 169$ de la OIT}

El Concepto de afectación directa se ha planteado como requisito de aplicabilidad de la consulta, fundado en los artículos 6 y 7 del Convenio 169 que disponen:

38 Por extensión no podemos abordar las críticas a esta restricción reglamentaria. FueNZALIDA (2017) 17-26, realiza una acuciosa revisión crítica del artículo 7 del Decreto 66, en especial la noción de actos reglados que esta disposición contempla incumpliendo los estándares del Convenio 169.

39 D.F.L. Nº 1 de Minería de 1982, Ley 20.018, de 2018.

40 Con todo, estimamos que el asunto no está resuelto categóricamente, como lo evidencia el caso de la Central Añihuerraqui en que se discutió administrativa y judicialmente la consulta del Decreto de Concesión eléctrica provisorio de la SEC y el Decreto de Concesión eléctrica definitiva del Ministerio de Energía. Finalmente, la Corte negó ambos supuestos (Coñuequir Curilaf Alejandro con Ministerio de Energía, 2018). 
«Los Estados deberán consultar a los pueblos Indígenas... cada vez que se prevean medidas legislativas o administrativas susceptibles de afectarles directamente» (art. 6.1.a).

«Los pueblos interesados deberán tener el derecho de decidir sus propias prioridades en lo que atañe al proceso de desarrollo, en la medida en que éste afecte a sus vidas, creencias, instituciones y bienestar espiritual y a las tierras que ocupan o utilizan de alguna manera...» (7.1).

En este sentido explica Anaya que, caso a caso, los estados deben implementar y evaluar las medidas legislativas o administrativas que se propongan, en especial las relativas a extracción de recursos naturales cuando afectan los intereses de los pueblos indígenas para determinar la necesidad de iniciar procesos de consultas previamente a que se adopten tales medidas ${ }^{41}$. En Chile el artículo 7 (inc. $1^{\circ}$ y $2^{\circ}$ ) del Decreto 66 restringe los alcances de la referida susceptibilidad de afectación del Convenio 169 cuando prescribe que:

Los órganos de la Administración del Estado... deberán consultar a los pueblos indígenas... cada vez que se prevean medidas administrativas o legislativas susceptibles de afectarles directamente...

Son medidas legislativas susceptibles de afectar directamente a los pueblos indígenas... cuando sean causa directa de un impacto significativo y específico sobre los pueblos indígenas en su calidad de tales...

Criticando los alcances dados regulatoriamente a la susceptibilidad de afectación y afectación directa, señalan López y Mohr que «que el artículo 6 del Convenio 169 no se refiere solo a la afectación directa, sino que a la susceptibilidad de ella» ${ }^{42}$. Al respecto, explican que la susceptibilidad refiere a la "cualidad de susceptible» de una persona o cosa, la que a su vez significa "capaz de recibir modificación o impresión», luego que serán titulares de la consulta indígena, como «pueblos interesados», "aquellos capaces de ser afectados

\footnotetext{
41 Anaya (2009a) 23.

42 Énfasis nuestro.
} 
directamente por una medida que se prevea dictar, no aquellos que necesariamente vayan a ser afectados» ${ }^{43}$. Entonces, en pro de la mejor y más adecuada protección de los derechos fundamentales de los pueblos indígenas y sus miembros, en relación a la consulta como derecho en sí y a la misma consulta como mecanismo que permite mostrar la eventual afectación de otros derechos, el enunciado principio precautorio de presunción de procedencia de la consulta indigena nos indica que:

... ante la duda acerca de si procede o no realizar la consulta previa, si la medida es susceptible de afectar a los pueblos indígenas... deberá gatillarse tal procedimiento. ${ }^{44}$

Consecuentemente, enlazada a la susceptibilidad de afectación se encuentra la flexibilización probatoria como criterio que debe operar siempre en favor de los indígenas y no, como lo ha resuelto parte de la jurisprudencia nacional, una mayor carga para los indígenas que puedan verse afectados ${ }^{45}$. Como señalan López y Mohr, «el estándar de procedencia favorece necesariamente a los pueblos indígenas sin que sea admisible que se requieran certeras acreditaciones al respecto por parte de ellos» ${ }^{46}$. Luego, en un ejercicio de control de convencionalidad, se debiera dar lugar a la consulta indígena sobre la base del concepto de susceptibilidad de afectación y no exigir la comprobación de afectos directos ${ }^{47}$. Y ello es un imperativo de impulso procesal que indica que, no siendo procedente el procedimiento

43 López y Mohr (2014) 112.

44 LÓPez y MoHr (2014) 113.

45 Comunidad indígena Chiloé de huentetique contra Comisión Regional del Medio Ambiente Región de los Lagos (2011) (primera instancia); Asociación indígena tragun mapu maile allipen contra Comisión Evaluadora ambiental, Región de la Araucanía (2012). Sentencias sobre casos de concesiones de exploración geotérmica (sin aplicación del SEIA): Comunidad Indígena Huenchullán contra Ministro de Energía Jorge Bunster (2012: CA. Santiago Rol 12.533-2012, confirmada CS, Rol 9527-2012; CA Santiago, Rol 9431-2012, confirmada CS, Rol 9526-2012.

46 López y MoHr (2014) 113.

47 Condore Vilca y comuneros de la Quebrada de Tarapacá cl COREMA de la I Región de Tarapacá, C.S. Rol 10.090-2011 (2da. Instancia revocatoria); Asociacion indigena Consejo de Pueblos Atacameños contra Corema Region Antofagasta (2011). 
reglamentado para la consulta en materia ambiental, -siempre- queda a salvo el procedimiento de consulta general, fundado en el artículo 6 del Convenio 169, regulado internamente en el Decreto 66 y ajustada la consulta, necesariamente, a los estándares del Convenio 169.

Ahora bien, en nuestra opinión, este principio precautorio no es solo un mero enunciado o una afirmación relativista que absolutice la consulta, sino que establece un marco de razonamiento causal que debe verificarse bajo sus propios estándares especiales dados por la especificidad que determina el DFICPI. En consecuencia, sostendremos que este principio hace procedente la consulta conforme dos presupuestos fundamentales que deben verificarse: uno objetivo territorial imprescindible; y otro, subjetivo cultural, más amplio y flexible (de estándar probatorio más bajo), pero que solo operará una vez satisfecho el primer presupuesto objetivo. Respecto del entendimiento específico de los estándares que permiten normar las dimensiones indicadas a continuación veremos sintéticamente, algunos criterios.

Respecto del factor objetivo territorial, -como explica Carmona- «el objeto de protección de la norma... justifica un test menos intenso respecto de la afectación, que se cumple con la sola proximidad del proyecto a las comunidades indígenas ${ }^{48}$. En consecuencia, el antecedente necesario y suficiente para activar la consulta es la posibilidad de verse afectado por un proyecto, bajo un estándar de causalidad mínimo, coherentemente con ello. No es necesario que de forma anticipada se demuestre la ocurrencia de un efecto o que deba ocurrir inevitablemente, solamente debieran indicarse los presupuestos fácticos conforme los cuales se estima existe la susceptibilidad o posibilidad de afectación. Se trata de un efecto potencial, sostenido en un proyecto o medida en concreto que implica un riesgo en concreto, sobre valores materiales o intangibles, que el Convenio 169 acoge haciendo procedente la consulta indígena. Bajo este razonamiento para que proceda la consulta solo bastará la presencia de algunos factores mínimos que permitan «suponer la existencia de un territorio indígena en las cercanías del proyecto ${ }^{49}$. En especial, esta menor carga probatoria, derivada de la sola susceptibilidad de afectación,

48 CARMONA (2013) 78.

49 Carmona (2013) 72. 
opera cuando se enfrentan proyectos de inversión localizados en tierras indígenas, Áreas de Desarrollo Indígena o territorios indígenas, a la luz del Convenio $\mathrm{N}^{\circ} 169$. En estos casos debe realizarse la consulta indígena previa solo «en atención a la susceptibilidad de afectación» dada por este factor territorial ${ }^{50}$.

Entonces, el factor objetivo de determinación de la susceptibilidad de afectación supone la instalación de un proyecto de inversión dentro de un territorio indígena, en un espacio continuo a este o aledaño a él (su «área de influencia»). Al respecto es necesario despejar de qué forma opera este vínculo normativo entre la consulta indígena y los derechos territoriales. El concepto de territorio indígena, conforme el artículo 13 del Convenio $\mathrm{N}^{\circ} 169$ de la OIT ${ }^{51}$, corresponde a una concepción más amplia que el de las tierras indígenas (según están definidas en el artículo 12 de la Ley 19.253). Con todo, existen diversos fallos en que se ha buscado reducir la afección directa o la susceptibilidad de afectación a la propiedad particular, especialmente al referido caso en que existe «tierra indígena» (en el sentido del artículo 12 de la Ley 19.253) y no se hace extensiva al concepto de territorio ${ }^{52}$. Sin embargo, ambos conceptos («tierra»y «territorio») no son excluyentes, pero requieren de un esfuerzo hermenéutico evolutivo en pro de los pueblos indígenas, de tal manera de que, sin perder la protección que las tierras indígenas tienen como tales en su sentido legal estricto conforme la Ley Indígena 19.253 (art. 13), al mismo tiempo gocen del estatus normativo como territorios indígenas a las que pertenecen (geográfica-cultural-étnicamente), como se ha manifestado jurisprudencialmente en otros $\operatorname{casos}^{53}$. En este sentido, compartimos la jurisprudencia que para efectos tutelares

50 López y Mohr (2014) 121-122.

51 Los derechos territoriales en favor de los pueblos indígenas se contemplan en los artículos 13, 14, 15, 16 y 18 del Convenio $\mathrm{N}^{\circ} 169$. Por exceder las pretensiones de este trabajo, solo referiremos aquí a algunas cuestiones mínimas de este elemento objetivo territorial. Sus estándares pueden revisarse en $\mathrm{CIDH}$ (2010) y Faundes Peñafiel (2015).

52 Reyes Alcaman y otros Con Ministerio de Obras Públicas (2011), Millaray Virginia Huichalaf Pradines y otros con Juan Heriberto Ortiz Ortiz (2012).

53 Entre otros: Codelco Chile División Chuquicamata con Dirección Regional y Nacional de Aguas (2014), CA Antofagasta, Rol 235-2013, confirmada CS, Rol 14.003-13; CS, Alejandro Papic Domínguez con Comunidad Indigena Aymara Chusmiza y Usmagama (2009); Faundes PeÑafiel (2015). 
ha entendido que «tierras» o «terrenos» equivalen a territorios, en el sentido del artículo 13 del Convenio $169^{54}$.

Para definir el segundo presupuesto, subjetivo cultural, el razonamiento precautorio propuesto para la consulta indica que los propios pueblos afectados deben determinar de qué forma han sido o pueden verse afectados. Esto es, los pueblos indígenas o sus organizaciones representativas indicarán:
a. Si son afectados o hay susceptibilidad de afectación;
b. Cómo son afectados o cuál es la naturaleza de esa afectación; y
c. En qué medida o magnitud son afectados. ${ }^{55}$

$\mathrm{Al}$ respecto, los proyectos de inversión pueden generar efectos ambientales que, desde la perspectiva técnica ambiental, pueden ser medidos mediante variables objetivas, cuantificables, modelables y mitigables. Pero esta forma de razonamiento no resulta pertinente necesariamente respecto de otros efectos sobre el ecosistema comprendido en la lógica del hábitat, como «impactos de carácter sociocultural, los que tienen un carácter subjetivo, y en el caso de los pueblos indígenas, depende de su cosmovisión y de su relación espiritual con sus tierras y territorios» ${ }^{56}$. Por ejemplo, la revisión de potenciales efectos sobre sitios de significación cultural mapuche, como los menoko y su ngen o entidad espiritual que cuida el agua; o con espíritus tutelares, como el Ngen Kintuante de los Huilliche; y el borde costero, lafken mapu, para los Lafkenche. Por ello, -siguiendo a Anaya- nos preguntamos ¿cuál es el régimen normativo especial aplicable a los que se ha denominado efectos no perceptibles por quienes no pertenecen a los pueblos indígenas? ${ }^{57}$.

Una medida legislativa o administrativa puede no afectar a una persona o grupo de una determinada cultura, pero sí puede afectar «a una persona o grupo que provenga de una cultura distinta y

\footnotetext{
54 Alejandro Papic Domínguez con Comunidad Indígena Aymara Chusmiza y Usmagama (2009).

55 Faundes (2013d) 209.

56 Carmona (2013) 83. En el mismo sentido: Matta, M., en Contesse (2012) 114; Aylwin, Meza-Lopehandía; Yañez (2013) 397-398; López y Mohr (2014).

57 Anaya (2009b) 23.
} 
viceversa, debido a que presentan diferentes referentes cognitivos» ${ }^{58}$. Por su parte, los agentes del Estado deben resolver desde su propio marco cultural. En este contexto, la consulta indígena se torna en instrumento esencial para permitir que las decisiones que se adopten en torno a dichos proyectos puedan, efectivamente, incluir la perspectiva de los propios afectados (que no es necesariamente perceptible para el organismo estatal responsable de hacer la consulta y o el titular del proyecto de inversión), ni para los jueces llamados a resolver el conflicto en torno a la realización de la consulta. Por ello, como hemos venido sosteniendo, no debieran ser terceros, como organismos sectoriales y jueces, que no forman parte de estos pueblos y que «por lo tanto no pueden percibir las afectaciones de la misma manera» que los pueblos indígenas, quienes decidan de forma exclusiva cuando hay afectación y o susceptibilidad de afectación $n^{59}$. Entonces, no es posible prescindir de la consulta sobre la base de la opinión previa y unilateral del propio Estado o de quien éste indica debe llevar a cabo la consulta, porque, en el ámbito sociocultural, no podrá comprender «los efectos positivos o negativos que la medida tendría sobre esos pueblos ${ }^{60}$. En este sentido, falló la Corte Suprema que una consulta debe considerar efectivamente que los pueblos indígenas tengan "posibilidades reales de influir en la gestión y forma de desarrollo... en consideración a la necesidad de protección de los derechos de esos pueblos y garantizar su integridad» ${ }^{61}$.

Entonces, si se asume que el tenor y el estándar seguido por el Convenio 169 supone, a lo menos, la susceptibilidad de afectación directa sobre el medio humano indígena y no, necesariamente, la acreditación previa de la afectación directa, la obligación de consultar se activará, primero, por ciertos elementos objetivos, que se evidencian en el propio proyecto. Por ejemplo, por la sola presencia de población indígena, sitios ceremoniales, tierras indígenas, los cuales hacen presumir que existe un territorio o hábitat indígena ${ }^{62}$. Ese sería el caso de una correcta interpretación del concepto de «área

\footnotetext{
Explican López y MoHr (2014).

CARMONA (2013) 84.

CARMONA (2013) 84.

61 Condore Vilca y comuneros de la Quebrada de Tarapacá c/ COREMA de la I Región de Tarapacá (2012).

62 Carmona (2013) 85.
} 
de influencia» de un proyecto que se planteó en el caso del «Parque Eólico de Chiloé» ${ }^{63}$. Segundo, estos antecedentes objetivos, serán suficientes para estimar, a continuación, en una dimensión subjetiva, conforme lo manifiesten autodeterminadamente los propios indígenas afectados o potencialmente afectados y desde su percepción cosmogónica o cultural, que existe, a lo menos, dicha susceptibilidad de afectación.

En conclusión, como el derecho a la identidad cultural es un derecho fundamental ${ }^{64}$, por su propia relevancia normativa, es exigible al Estado una mayor apertura y flexibilidad en la constatación de esta susceptibilidad de afectación «cultural», lo que supone acoger la posibilidad de afectación en la forma y medida que los propios indígenas indican. Luego, en el supuesto en estudio de las $\mathrm{CHm} 3 \mathrm{MW}$, el razonamiento basado en una doble constatación, objetivo territorial y subjetiva cultural, a su vez, hace exigible normativamente el proceso de consulta indígena bajo los estándares del Convenio N¹69 de la OIT que debe desarrollarse conforme el Decreto 66, porque, como hemos dicho, la Ley 19.300 descarta el procedimiento del artículo 85 del Decreto 40.

\section{4.- JURISPRUDENCIA}

4.1. Casos de consultas municipales no sometidos al SEIA ${ }^{65}$ :

\section{a. Caso del Cerro Colo-Colo}

En el año 2010 la Comunidad Indígena Chilcoco recurrió de protección constitucional en contra de la Municipalidad de Arauco por actos de daño en el Monumento Histórico Cerro Colo Colo. Se trata de un sitio de alta relevancia cultural para el desarrollo de

63 Comunidad indigena antu lafquen de huentetique contra Comision Regional del Medio Ambiente Región de los Lagos (2011).

64 Pueblo Indígena Sarayaku Vs. Ecuador (2012), opinan en el sentido de exigir un mayor estándar probatorio "proporcional» a la limitación que implicaría la consulta para el titular del proyecto.

65 Presentamos dos casos ejemplares de la procedencia de la consulta en estos casos. Un excelente reporte de todas las consultas municipales desarrolladas hasta 2014 se puede revisar en FuENZALIDA (2014). 
las tradiciones y ceremonias religiosas propias de la cosmovisión indígena mapuche. El cerro había sido intervenido (con maquinaria pesada) inconsultamente por razones de seguridad pública tras el terremoto que afectó la zona en febrero de 2010.

El fallo invocó textualmente el artículo 13 del Convenio $\mathrm{N}^{\circ}$ 169 y dispuso que al aplicar sus disposiciones los gobiernos deben respetar la importancia especial que para las culturas y valores espirituales de los pueblos interesados reviste su relación con las tierras y territorios que ocupan o utilizan de alguna otra manera. En especial la sentencia aclaró que en el caso no se ha discutido la pertinencia técnica ni las razones de seguridad tenidas en cuenta para la intervención de este espacio sagrado para el Pueblo Mapuche, sino que no se consultó a los pueblos indígenas afectados «no obstante la certeza de la importancia que el lugar representa para su cultura y que amerita el máximo respeto a sus tradiciones y sentir propio de las mismas» ${ }^{66}$.

\section{b. Caso de la Comunidad Indígena Entuco}

En este caso, en 2015, la Comunidad Indígena Entuco ubicada en la Comuna de Padre Las Casas, recurrió de protección contra la Municipalidad local porque ésta dispuso, sin consulta previa, la construcción de una medialuna, en un terreno colindante a la Comunidad Entuco que era reivindicado históricamente por ella.

La sentencia de la Corte Suprema acogió el Recurso de Protección constitucional interpuesto por la falta de consulta en el caso. Señaló la Corte:

Sexto: Que el emplazamiento de la media luna tiene por objeto la difusión de costumbres y la realización de un rodeo anual. Éstas no son costumbres indígenas. Esto no significa que ellas no puedan manifestarse, pero una finalidad del Convenio $\mathrm{N}^{\circ} 169$... es precisamente dar lugar a un proceso de consulta con la finalidad de alcanzar un acuerdo con las comunidades afectadas... Así se evita que la cultura dominante se imponga sin siquiera considerar los intereses culturales afectados. [...]

66 Comunidad Indígena Chilcoco con Ilustre Municipalidad de Arauco, "Cerro Colo Colo» (2010). 
Octavo: Que... el hecho de que el predio en que se emplazaría la media luna es relativamente pequeño y es vecino del predio que habita la comunidad recurrente, sí es suficiente para estimar que la medida puede tener un impacto significativo sobre sus tradiciones y costumbres ancestrales, sobre todo si se trata de canalizar una actividad deportiva de la herencia cultural antagónica a la mapuche. ${ }^{67}$

En el caso la sentencia visualiza plenamente las dimensiones objetiva territorial ("predio vecino») y subjetiva cultural ( la medida puede tener un impacto significativo sobre sus tradiciones y costumbres ancestrales») de la consulta, ejerciendo el control de convencionalidad del Convenio $\mathrm{N}^{\circ} 169$ en Chile, tutelando el DFICPI -según vimos-.

\subsection{Consulta y casos de "carácter ambiental» excluidos del SEIA:}

\section{a. Concesiones de explotación y exploración geotérmica ${ }^{68}$}

El Ministerio de Energía por medio de la Resolución Exenta No 28 de 2014, de fecha 7 de julio de 2014, decretó procedente la consulta indígena, de manera previa al otorgamiento de las concesiones de explotación de energía geotérmica Pampa Lirima 1, Pampa Lirima 2 y Pampa Lirima 3, conforme lo dispone el Decreto 66. Esta resolución del Ministerio de Energía utilizó como marco normativo general el artículo del 6 del Convenio 169, dando cumplimiento al artículo 7 del Decreto 66 -que ya revisamos-69. En especial, dejó

67 Comunidad Indígena Entuco (2016).

68 En este acápite se agradecen al profesor Carmona los invaluables diálogos y disensos académicos, su oportuno y generoso rastreo de jurisprudencia que nos han permitido profundizar en el estudio de este tema.

69 Estos decretos, a su vez, se ampararon en el informe, conforme el artículo 13 del Decreto 66, que remitió la Subsecretaría de Servicios Sociales del Ministerio de Planificación social, que declaraba procedente la consulta, Subsecretaría de Asuntos Sociales, Of. Ord. 3303 de 2 de julio de 2014. Incluso, se sostuvo una opinión en contrario al Dictamen N 70292 de Contraloría General de la República de fecha 17 de diciembre de 2009 que señaló que las concesiones no eran consultables. 
establecido que procede la consulta en el caso de los decretos supremos de otorgamiento de concesión de explotación geotérmica del Ministerio de Energía ${ }^{70}$.

La procedencia de la consulta ordenada administrativamente en estos casos, en gran medida, tuvo como antecedente la jurisprudencia judicial de los años previos que negó la procedencia de la consulta de las concesiones de exploración geotérmica. En su fundamentación, el Ministerio de Energía adoptó los argumentos de la Corte de Apelaciones de Santiago -confirmada por la Corte Suprema en enero del 2013-, que rechazó la impugnación de comunidades atacameñas interpuesta mediante recursos de protección por diversas concesiones de exploración de energía geotérmica ${ }^{71}$. La Corte, por una parte, estimó improcedente la realización de consulta indígena para las concesiones de exploración geotérmica, pero dejo asentado que al momento del «otorgamiento de concesiones de explotación de energía geotérmica sobre territorio donde habiten comunidades originarias, se deberá dar estricto cumplimiento a lo dispuesto en los artículos 6, 7 y 8 del Convenio 169 sobre Pueblos Indígenas y Tribales, especialmente a lo referido a la participación de estas comunidades en la toma de decisiones que afecten los territorios» ${ }^{72}$.

Así, en el caso nos interesa relevar que en esta materia, a falta de un procedimiento especial de carácter ambiental para las concesiones de explotación geotérmica (misma razón que debiese darse para las concesiones de exploración geotérmica, contrariamente a la tendencia jurisprudencial ${ }^{73}$ ), la jurisprudencia administrativa y judicial ha

70 Art. 20 de la Ley 19.657, sobre Concesiones de Energía Geotérmica.

71 Sentencia Corte de Apelaciones de Santiago, de 16 de noviembre de 2012, en causa rol 12.533-2012, caratulados «Cruz Plaza Antonio Y Otros / Ministerio De Energía», confirmada por la Corte Suprema con fecha 17 de enero de 2013, rol de ingreso a Corte 9527-2012, Considerando $9^{\circ}$.

72 Consejo de pueblos atacameños con Ministro Energía Jorge Bunster (2012) confirmada por la Corte Suprema con fecha 17 de enero de 2013, rol de ingreso a Corte $9527-2012$, cons. $10^{\circ}$. Énfasis nuestro.

73 Compartimos las críticas de Carmona a esta jurisprudencia administrativa y judicial que estima improcedente la consulta en las concesiones de exploración geotérmica y solo la obligación para la concesión de explotación geotérmica, porque no se ha evidenciado una razón jurídica ni material para la diferenciación, existiendo más bien razones en común. Sin embargo, no es nuestro objetivo atender dicho problema que, por lo demás, ya ha sido evidenciado extraordinariamente por el referido profesor Carmona Caldera (2014). CARMONA (2014). 
estimado procedente la consulta conforme el procedimiento general, supletorio e imperativo del Decreto 66. Como expresa Carmona, lo relevante es que «esas actividades pueden significar una intervención directa y de magnitud considerable en territorio indígena... como la misma Ley 19.657 describe, entre las operaciones que comprende este tipo de concesión, se incluye 'la perforación y medición de pozos de gradiente y los pozos exploratorios profundos' (art. 6). Estas actividades no son inocuas ${ }^{74}$.

\section{b. El caso de la Minicentral Hidroeléctrica Las Flores}

El caso del proyecto "Ampliación Minicentral Hidroeléctrica Las Flores» del titular, Hidroeléctrica Las Flores S.A (en adelante "Minicentral Hidroeléctrica Las Flores), actualmente en revisión por el Tribunal Ambiental de Valdivia ${ }^{75}$ nos permite mostrar los alcances de la tesis sostenida en este trabajo. El proyecto Minicentral Hidroeléctrica Las Flores se sometió al SEIA el 18 de julio de 2016, mediante una DIA, conforme el presupuesto de la letra c) del artículo 3 del Decreto 40 de 2012, en relación a «Centrales generadoras de energía mayores a $3 \mathrm{MW».} \mathrm{Se} \mathrm{emplazó} \mathrm{en} \mathrm{el} \mathrm{sector} \mathrm{de} \mathrm{Pumol,}$ en la ribera del río Quimán, donde ya se encontraba construida y en operación la Minicentral Hidroeléctrica Las Flores. El proyecto específico sometido a evaluación ambiental corresponde a una ampliación de la Minicentral Hidroeléctrica las Flores que para el Servicio de Evaluación Ambiental (SEA) de los Ríos se denomina como: «el proyecto original» o la «MCHF».

La MCHF no se sometió al SEIA de forma previa a su construcción porque no se trataba de un Proyecto que superase los $3 \mathrm{MW}$ de generación eléctrica. La MCHF se construyó el año 2013 y se puso en operación en el año 2015, con una potencia de 2,0 MW (caudal de $0,9 \mathrm{~m}^{3} / \mathrm{s}$ ). Luego, el proyecto «Minicentral Hidroeléctrica Las Flores» (2016-2019) amplía la potencia instalada a 4,2 MW (caudal de diseño de $1,95 \mathrm{~m}^{3} / \mathrm{s}$ ), utilizando los derechos de aprovechamiento de agua que posee el titular sobre el caudal del río Quimán. Entonces, de

74 Carmona (2014).

75 Comunidad Indígena Saturnino Leal Neiman y otros c/ Comisión de Evaluación Ambiental los Ríos (2018). 
conformidad al artículo 2 literal g) del Decreto 40 (Reglamento del SEIA), conforme, a su vez, al artículo 10 letra c) de la Ley 19.300, la modificación del Proyecto debía ingresar al SEIA, ya que aumentará la potencia autorizada de 2,0 MW a 4,2 $\mathrm{MW}^{76}$.

Frente a este proyecto, con fecha 19 de noviembre de 2018 un conjunto de comunidades indígenas interpuso una reclamación judicial, ante el Tribunal Ambiental de Valdivia, en contra de la Comisión de Evaluación Ambiental de los Ríos («COEVA de Los Ríos»), requiriendo la anulación de la resolución de Calificación Ambiental (RCA) $)^{77}$. En lo pertinente a nuestro trabajo, se argumentó la vulneración de los estándares de la consulta indígena conforme el Convenio $\mathrm{N}^{\circ} 169$ de la OIT y, en lo concreto, entre otros, se fundó en la «fragmentación del proyecto a fin de eludir la obligación de consultar del artículo 85 del Decreto 40. Alegan los reclamantes, entre otras cuestiones clave, que:

... lejos de funcionar como una central de pasada, MHF cuenta con una barrera o represa que está construida en el sector de bocatoma, sobre el Trawunco, la cual se extiende de ribera a ribera interviniendo todo el ancho del cauce del río Quimán, impidiendo el libre desplazamiento de peces y especies nativas que habitan dicho ecosistema y fragmentando el hábitat de los recursos hidrobiológicos, generando la desecación de 2,4 kilómetros lineales del río (entre el sector de la bocatoma y el punto de restitución). Esto ha significado la reducción de nuestras áreas de recolección de hierbas en los ecosistemas ribereños del río Quimán, lo que ha generado impactos que nunca han sido evaluados y que, durante la evaluación ambiental del proyecto de modificación de la MHF, fueron subvalorados, ya que solo se consideraron las restricciones al acceso a nuestras áreas de recolección y no las restricciones

76 "Comunidad indígena Saturnino Leal Neiman y otros/Dirección ejecutiva, Servicio de Evaluación Ambiental (Res. Exenta $N^{\circ} 035$ / 2018)»: 1-2.

77 Reclamación contra la Resolución Exenta N 035 (8 de octubre de 2018), que rechazó la solicitud de invalidación de fecha 24 de noviembre de 2017, deducida contra la Resolución Exenta N 60, de 13 de octubre de 2017, que calificó ambientalmente de manera favorable) la DIA del proyecto «Ampliación Minicentral Hidroeléctrica Las Flores», de la COEVA Región de Los Ríos, RCA $\mathrm{N}^{\circ} 60 / 2017$, de conformidad al artículo $17 \mathrm{~N}^{\circ} 8$ de la Ley $\mathrm{N}^{\circ} 20.600$, que crea los Tribunales Ambientales. 
derivadas de la pérdida de los ecosistemas ribereños (trawunco y menoko) de los cuales depende la supervivencia de las prácticas tradicionales de recolección, producto de la captación de las aguas por el embalse en la bocatoma [...]

No se puede desconocer el uso extendido que realizamos del territorio, que supera con creces las propiedades particulares que le corresponden a cada familia o comunidad. Este es el caso de las actividades de recolección de lawen en la ribera del río Quimán, que se realiza a lo largo de toda la extensión del río, de forma rotativa, dependiendo de la disponibilidad de las yerbas, las estaciones, así como de otros factores culturales que dicen relación con nuestra cosmovisión... ${ }^{78}$.

Dentro de los argumentos para desestimar administrativamente la reclamación impugnada (y para desestimar la consulta) fue que la distancia de las comunidades reclamantes (en el caso de dos de ellas), era de 2 a 4 kilómetros del río Quimán ${ }^{79}$.

Para nosotros, en este caso, sin perjuicio de compartir los argumentos del actual reclamo en sede jurisdicción ambiental, estimamos que era procedente, inicialmente, el recurso de protección constitucional, por haberse omitido la obligación de consultar conforme lo dispuesto en el artículo 6 del Convenio $\mathrm{N}^{\circ} 169$ en relación al artículo 7 del Decreto 66, respecto del Decreto de Concesión Eléctrica bajo los mismos argumentos de fondo, en lo constitucional y en lo material, que se han presentado ante el Tribunal Ambiental de Valdivia. Primero, respecto a la procedencia del recurso de protección, sin extendernos aquí, por una parte la Corte Suprema ya se ha pronunciado anulando una RCA por vulneración de derechos fundamentales, incluso existiendo un proyecto presentado al SEIA, al dar por terminada unilateralmente una consulta, en el caso del Proyecto «Octopus» de Penco Lirquén ${ }^{80}$. Y, en particular, en los casos de la consulta general, supletoria e imperativa del Decreto 66, la jurisprudencia se encuentra conteste en la procedencia del recurso

78 Comunidad Indígena Saturnino Leal Neiman y otros con Comisión de Evaluación Ambiental de los Ríos (2018).

79 Reclamación judicial: 17.

80 Asociación Indígena Koñintu Lafken Mapu Penco y otros con Comisión de Evaluación Ambiental de la Región del Bío Bío y otro (2016) (Revocada), Corte Suprema (2017). 
de protección como medio de amparo constitucional por falta de consulta conforme el Convenio 169, según ya revisamos.

En lo reglamentario, conforme el artículo 7 del Decreto 66 y conforme las alegaciones de los reclamantes, el proyecto se construyó sin consulta previa y dentro del territorio (espacio de influencia) de las comunidades reclamantes (a lo menos respecto de dos de ellas). En el caso existe afectación (por que el proyecto se construyó) y a la fecha en que se debió consultar existía susceptibilidad de afectación respecto del conjunto de espacios de significación cultural que las reclamantes con detalle describen en relación a su forma de vida asociada al río Quiman, íntimamente ligada a la propia sobrevivencia de estas comunidades indígenas.

Sin embargo, en la primera etapa el titular del proyecto, planteando una capacidad generadora eléctrica menor a $3 \mathrm{MW}$ eludió el SEIA y derechamente omitió (ilícitamente a nuestro entender) la obligación de consultar conforme el artículo 7 del Decreto 66, en relación al artículo 6 del Convenio $\mathrm{N}^{\circ} 169$ de la OIT, no obstante, se daban los presupuestos de la consulta, conforme el principio precautorio que establecimos a la luz del DFICPI.

\section{A MOdO DE CONCLUSIÓN, PROPUESTA DE UNA CORRECTA COMPRENSIÓN DEL MARCO REGULATORIO PARA \\ LOS PROYECTOS DE CHM3 MW EN TERRITORIOS INDÍGENAS}

Hemos dejado establecido que para la Cte.IDH, en el caso de los pueblos indígenas, el derecho a la vida se enlaza con el derecho a la identidad cultural, como derecho a la sobrevivencia de los pueblos indígenas. De esta forma, en relación con los pueblos indígenas, el derecho fundamental a la identidad cultural es inalienable del derecho a la vida en sentido amplio. Esto es, el derecho a la vida lato sensu, como derecho a la sobrevivencia de los pueblos indígenas, solo puede concebirse si se le entiende comprensivo del derecho fundamental a la identidad cultural como presupuesto de los restantes derechos de los pueblos indígenas.

En relación con su contenido, el derecho fundamental a la identidad cultural, enlazado con el derecho a la vida en sentido amplio, comprende el derecho de los miembros de los pueblos indígenas a 
tener una identidad y una cosmogonía propias y ella, a su vez, se sustenta en el ejercicio efectivo de los derechos territoriales y sus recursos naturales.

Los estándares planteados por la Cte.IDHH sobre el DFICPI contienen obligaciones específicas de aseguramiento efectivo del derecho fundamental a la identidad cultural por parte del Estado. Por ello, para garantizar en concreto los derechos a las comunidades y pueblos indígenas, los estados deben tomar en consideración sus características propias, asegurando aquellas cuestiones que diferencian a sus miembros del resto de la población y que conforman el centro de su identidad cultural. Asimismo, el Estado tiene una obligación de acción diligente ${ }^{81}$. Esto es, tiene un deber de impulsar medidas y actos efectivos para salvaguardar el derecho fundamental a la identidad cultural, lo que integra inalienablemente la protección de sus territorios y recursos naturales, en una comprensión amplia del derecho a la vida que se concreta con la obligación de consultar a los pueblos indígenas. Ello implicará -en nuestro caso- considerar para la consulta indígena un alcance que, efectivamente, permita a este mecanismo amparar la identidad cultural de los pueblos indígenas y no -como se viene sosteniendo en Chile- suponer el efecto inverso de excluir cierto tipo de proyectos energéticos de la consulta indígena.

El DFICPI se vincula estrechamente con el derecho a la consulta indígena, bajo los presupuestos de afectación directa y de susceptibilidad de afectación sobre pueblos indígenas, requeridos para su exigibilidad que han recibido muy diversas lecturas desde la legislación interna y doctrina chilena, especialmente la ambiental. En especial, el problema se presenta con los llamados efectos intangibles o aquellos no perceptibles por quienes no son miembros de los pueblos indígenas $^{82}$. En esta materia, el DFICPI implica un cambio de paradigma en Chile en relación a la exigencia jurisprudencial mayoritaria de evidenciar grados de afectación directa y de forma previa a la ocurrencia de un proceso de consulta ${ }^{83}$.

31 Faundes (2019).

82 Anaya (2012) 18.

83 Entre otros, Comunidad Indígena Huenchullán contra Ministro de Energía Jorge Bunster (2012). 
Mientras, a la luz del DFICPI, bajo una perspectiva eminentemente cautelar de la consulta, el correcto sentido es el de la susceptibilidad de afectación (como afectación potencial) se requiere un mínimo estándar probatorio en las etapas preliminares. En este sentido, para nosotros, conforme el DFICPI, si la medida es susceptible de afectar a los pueblos indígenas, deberá gatillarse tal procedimiento de consulta y ello ocurre, también, con la afectación o potencial afectación de valores intangibles de orden cultural amparados por los artículos 6 y 7 del Convenio 169.

En síntesis, bajo un enfoque precautorio del DFICPI, la susceptibilidad de afectación, como criterio mínimo de procedencia de la consulta indígena, supone la verificación preliminar de dos elementos: uno objetivo territorial y otro subjetivo colectivo cultural. Así, constatada, a lo menos, la susceptibilidad de afectación, bajo estos parámetros -territoriales y culturales-: i) procederá la consulta indígena en los casos de CHm3MW; ii) dichas consultas deberán llevarse a cabo de acuerdo al procedimiento general, supletorio e imperativo de la consulta contemplado en el Decreto 66, siguiendo el Convenio 169 ; iii) en el caso de no realizarse la consulta de los decretos de concesión eléctrica para las $\mathrm{CHm} 3 \mathrm{MW}$, corresponderá un examen de naturaleza cautelar constitucional de derechos fundamentales, por la vía del recurso de protección (art. 20 de la Constitución) y en lo probatorio, considerando un examen de menor intensidad o flexible a la luz del principio precautorio de la consulta indígena enunciado.

\section{BibliogRAfía}

\section{a) Doctrina:}

Aguilar, Gonzalo (2010): «Emergencia de un derecho constitucional común en materia de pueblos indígenas», en: Von Bogdandy, Armin; Ferrer Mac-Gregor, Eduardo, Morales-Anzionatti, Mariela (coordinadores): La justicia constitucional y su internacionalización. ¿Hacia un Ius Constitucionale Commune en América Latina? Tomo II. (México, UNAM, MPI, IIADC), pp. 3-84.

Aldunate, Eduardo (2010): «La posición de los trata dos internacionales en el sistema de fuentes del ordenamiento jurídico positivo", Revista Ius et Praxis, Año 16, No 2, 2010, pp. 185-210, $\mathrm{N}^{\circ} 16$ vol. 2, pp. 185-210. 
AnAya, James (2012): Informe del Relator Especial sobre los derechos de los pueblos indígenas al Consejo de Derechos Humanos de la AG de Naciones Unidad, 21 período de sesiones.

Anaya, James (2009a): Principios Internacionales Aplicables a la Consulta en Relación con la Reforma Constitucional en materia de Derechos de los Pueblos Indígenas en Chile. Relator Especial de N.U.para los Derechos Humanos de los Indígenas.

AnAYA, James (2009b): Informe del Relator Especial sobre la situación de los derechos humanos y las libertades fundamentales de los indígenas. Disponible en: https://www.acnur.org/fileadmin/Documentos/ BDL/2010/8057.pdf [Fecha de consulta: 23 de junio de 2019].

Arango, Rodolfo, (2014), «Fundamentos del IUS CONSTITUCIONALE COMMUNE En América Latina: derechos fundamentales, democracia y justicia constitucional», en: Amin von Bogdandy, Héctor Fix-Fierro, Mariela Morales-Antoniazzi (Edts.), IUS Constitucionale Commune en América latina. Rasgos, potencialidades y desafíos (México: UNAM - MPI), pp. 25-36

Aylwin, José; MeZa-Lopehandía, M.; YaÑez, N. (2013): Los pueblos indígenas y el derecho. (Santiago: LOM Ediciones-Observatorio Ciudadano).

Bidart CAMpos, Germán, (2002). «Los derechos no enumerados en su relación con el derecho constitucional y el derecho internacional», en: Méndez Silva (Ed.): Derecho internacional de los derechos humanos: memoria del VII Congreso iberoamericano de derecho constitucional». (Buenos Aires: Instituto de Investigaciones Jurídicas), pp. 103-113.

CALDERón, Jorge (2016): «Avances, aproximaciones y desafíos emergentes en el reconocimiento de los derechos colectivos de los pueblos indígenas y tribales en la jurisprudencia de la Corte interamericana de Derechos Humano", en: Armin Von Bogdandy, Mariela MoralesAntoniazzi, Eduardo Ferrer Mac-Gregor, Eduardo (Edts.), Construcción de un ius constitucionale commune en América Latina. (México: UNAM - MPI - Corte IDH), pp. 341-344.

CARmona, Cristobal (2014): «¿Deben ser consultadas las concesiones de exploración de energía geotérmica? susceptibilidad de afectación y territorio?» (inédito, en arbitraje), versión editada de la ponencia "Concesiones de exploración de energía geotérmica y derecho a consulta», Primer Congreso Internacional de Derecho Indígena. (U. de Tarapacá, Derecho, sede Iquique, noviembre de 2014). 
CARmona, Cristobal (2013): «La aplicación del derecho a consulta del Convenio 169 de la OIT en Chile: hacia una definición de su contenido sustantivo: afectación e instituciones representativas». En, Ricardo Miranda y Cristobal Carmona, Tesis de maestría sobre Pueblos Indígenas, Vol.III, Colección Tesis de Maestría U. Nacional San Martín de Buenos Aires (Buenos Aires: U. Nacional de San Martín, CIEP).

Comisión Interamericana de Derechos Humanos (CIDH) (2010): Derechos de los pueblos indigenas y tribales a sus tierras ancestrales y recursos naturales. Normas y jurisprudencia del Sistema Interamericano de Derechos Humanos.

CONTESSE, Jorge (2012): El convenio 169 de la OIT y el Derecho chileno. (Santiago de Chile, Ed. UDP).

Del Real, Alberto (2014): El derecho a la identidad cultural. (Pamplona, Editorial Aranzadi S.A.).

Faundes Peñafiel, Juan Jorge (2019.a): «Derecho fundamental a la identidad cultural de los pueblos indígenas: un nuevo paradigma en la defensa penal indígena en Chile frente al Estado de Derecho hegemónico", Revista Izquierdas (Scopus). № 45, febrero 2019, pp. 51-78.

Faundes PeÑafiel, Juan Jorge (2019.b). «El derecho fundamental a la identidad cultural de los pueblos indígenas: un derecho matriz y filtro hermenéutico para las constituciones de América Latina: la justificación». Revista Brasileira Políticas Públicas. Vol. 2 N² 2, agosto 2019. pp. 513-535".

Faundes Peñafiel, Juan Jorge (2015): «Convenio N¹69 de la OIT en la Jurisprudencia de la Excelentísima Corte Suprema en Chile. Tendencias y debates en materia de propiedad y derecho al Territorio». Colecciones Jurídicas de la Corte Suprema. Disponible en: http://decs. pjud.cl/index.php/informes/informes-academicos/62-informes-academicos-indigena/379-tendencias-y-debates-en-materia-de-propiedad-yderecho-al-territorio [Fecha de consulta: 31 de diciembre de 2018].

Faundes Peñafiel, Juan Jorge (2013.a): «Interpretación evolutiva de los derechos humanos", en: Mario Álvarez y Roberto CipPITANi (coords.), Diccionario Analítico de Derechos Humanos e Integración Jurídica. (Roma-Perugia-México, Istituto per gli Studi Economici e Giuridici), pp. 325-332.

Faundes Peñafiel, Juan Jorge (2013.b): «Corpus iuris internacional de derechos humanos», en: Mario Álvarez y Roberto Cippitani (coords.): Diccionario Analítico de Derechos Humanos e Integración Jurídica. (Roma-Perugia-México, Istituto per gli Studi Economici e Giuridici), pp. 93-95. 
Faundes Peñafiel, Juan Jorge (2013.c): «Pueblos indígenas como titulares de derechos humanos». Mario Álvarez y Roberto Cippitani (coords.): Diccionario Analítico de Derechos Humanos e Integración Jurídica. (Roma-Perugia-México, Istituto per gli Studi Economici e Giuridici), pp. 571-579.

Faundes Peñafiel, Juan Jorge (2013.d): «La Jurisprudencia, su impacto y debates en torno a la aplicación en Chile del Convenio $\mathrm{N}^{\circ} 169$ de la OIT y el Deber de Consulta", Revista de Derecho Universidad de Concepción, $\mathrm{N}^{\circ}$ LXXXI, V. enero-junio y julio-diciembre, pp. 233-234.

Faundes Peñafiel, Juan Jorge (2010): «Primera sentencia que aplica el Convenio $N^{\circ} 169$ de la OIT en Chile. Comentario de Jurisprudencia, «Linconao Francisca con Forestal Palermo»», Revista Chilena de Derecho y Ciencia Política. Temuco, año 2010, nº1, pp. 97- 113.

FuENZALIDA, Sergio (2017): «La función administrativa discrecional y la consulta indígena", Revista de Derecho Universidad Católica del Norte. Sección: Estudios Año 24 - No 2, 2017 pp. 181-210.

FuENZALIDA, Sergio (2014): «Análisis sobre la implementación del derecho de consulta indígena a nivel municipal». Proyecto interno Universidad Central. Proyecto Código CIR 1446.

Góngora-Mera, Manuel Eduardo (2017): «Judicialización de la discriminación estructural contra pueblos indígenas y afrodescendientes en América Latina: Conceptualización y tipología de un diálogo interamericano». En Von Bogdandy, Armin; Morales, Mariela; Ferrer MaC-Gregor, Eduardo (Coords), 2017. Ius Constitutionale Commune en América Latina Textos básicos para su comprensión. Querétaro (México) Max Planck Institute for Comparative Public Law and International Law; Instituto de Estudios Constitucionales del Estado de Querétaro Poder Ejecutivo del Estado de Querétaro, pp. 323-337.

GRIMSON, Alejandro (2009): «Culture and identity: two different notions», Revista Social Identities, vol. 16 n¹, January 2010, pp 63-79.

HitTers, Juan (2009): «Control de constitucionalidad y control de convencionalidad. Comparación (Criterios fijados por la Corte Interamericana de Derechos Humanos)», en: Estudios Constitucionales, Año $7, \mathrm{~N}^{\circ} 2$, Centro de Estudios Constitucionales de Chile, Universidad de Talca, pp. 109-128.

López, Ricardo y Mohr, Tania (2014): «Susceptibilidad de afectación directa en la consulta previa del Convenio 169. Análisis de Normas Previstas y de su trato en la Jurisprudencia. ¿Una cuestión de derecho?», Revista de Derecho (Valdivia), Vol. XXVII-N¹-Julio 2014. pp. 105-126. 
Martínez Bullé, V. (2013). «Estándares internacionales de derechos humanos». En, Mario Álvarez y Roberto Cippitani (coords.): Diccionario Analítico de Derechos Humanos e Integración Jurídica. (Roma-Perugia-México, Istituto per gli Studi Economici e Giuridici), pp. 243-247.

Medina, Cecilia (1994): Constitución, Tratados y derechos esenciales (Santiago: CNVR).

Morales Antoniazzi, Mariela (2014): «El Estado Abierto como objetivo del Ius Constitucionales Commune. Aproximación desde el impacto de la Corte Interamericana de Derechos Humanos», en: Amin von Bogdandy, Héctor Fix-Fierro, Mariela Morales-Antoniazzi (Edts.), «IUS Constitucionale Commune en América latina. Rasgos, potencialidades y desafíos (México: UNAM - MPI), pp. 265-299.

Nash, Claudio (2008): La Concepción de Derechos Fundamentales en Latinoamérica. Tendencias jurisprudenciales. Tesis doctoral, Universidad de Chile.

Nash, Claudio (2009): El sistema interamericano de derechos humanos en acción. Aciertos y desafíos (México, Editorial Porrúa S.A.)

Nogueira, Humberto (1997): Dogmática Constitucional (Santiago, Universidad de Talca).

NogueIRA, Humberto (2007): «Reforma constitucional del 2005 y control de constitucionalidad de tratados internacionales», Revista Estudios Constitucionales, año 5, No 1, pp. 59-88.

OrganizaCión InTERNACiONAL del Trabajo (2003): Convenio No 169 de la OIT, un Manual. Disponible en: http://www.ilo.org/indigenous/ Resources/Guidelinesandmanuals/WCMS_100764/lang--es/index. htm [fecha de consulta: 13 de enero de 2019].

Organización Internacional del Trabajo (2011): Informe de la Comisión de Expertos en Aplicación de Convenios y Recomendaciones 2011. Disponible en: http://www.ilo.org/global/standards/WCMS_ 151493/ [fecha de consulta: 20 diciembre de 2018].

Organización Internacional del Trabajo (2011): Observación General sobre pueblos indígenas y tribales, reunión de la OIT $\mathrm{N}^{\circ} 100$, Ginebra 2011.

Precht, J. (1997): «Vino nuevo en odres viejos. Derecho internacional convencional y derecho interno chileno», Revista Ius et Praxis, 2(2), pp. 121-154.

Ruiz Chiriboga, Oswaldo (2006): «El derecho a la identidad cultural de los pueblos indígenas y las minorías nacionales: una mirada desde el sistema interamericano", Revista Internacional de Derechos $\mathrm{Hu}$ manos 3(5), pp. 43-69. 
Von Bogdandy, Armin; Fix-Fierro, Héctor; Morales Antoniazzi, Mariela (2014): Ius constitucionale comune en América Latina. Rasgos, potencialidades y desafíos. (México, UNAM, MPI, IIDC).

\section{b) Jurisprudencia:}

Alejandro Papic Domínguez con Comunidad Indígena Aymara Chusmiza y Usmagama (2009): Corte Suprema, 25 noviembre 2009. Rol 28402008 (Recurso de casación forma y fondo).

Asociación indígena tragun mapu maile allipen contra Comisión Evaluadora ambiental, Región de la Araucanía («Línea de transmisión Melipeuco-Freire») (2012): Corte Suprema, 8 junio de 2012. Rol 1602-2012 (Recurso de protección).

Asociación Indígena Koñintu Lafken Mapu Penco y otros con Comisión de Evaluación Ambiental de la Región del Bío Bío y otro (2016): Corte Apelaciones de Concepción, 27 de agosto de 2016, Recurso de protección Rol 17.128-2016; Revocada, Corte Suprema 30 enero 2017, Rol No 65.349-2016.

Asociacion indigena Consejo de Pueblos Atacameños contra Corema Region Antofagasta (2011): Corte Suprema, 13 julio 2011, Rol 258-2011 (Recurso de protección).

Comunidad indigena antu lafquen de huentetique contra Comision Regional del Medio Ambiente Región de los Lagos (caso Parque Eólico Chiloé) (2011): Corte Apelaciones Puerto Montt. 11 de octubre 2011. Rol 239-2011 (recurso de protección); Corte Suprema Rol 10.090-2011 (2da. Instancia revocatoria).

Caso Almonacid Arellano y otros Vs. Chile (2013): Corte Apelaciones Rancagua. 14 de enero de 2013.Rol 103-2011.

Caso Almonacid Arellano y otros Vs. Chile (2006): Corte Interamericana de Derechos Humanos, sentencia de 26 de septiembre de 2006.

Caso Bámaca Velásquez Vs. Guatemala (2000): Sentencia de 25 de noviembre de 2000 (Fondo).

Caso Masacre Plan de Sánchez Vs. Guatemala (Reparaciones), 19 de noviembre de 2004.

Comunidad Indigena Sawhoyamaxa Vs. Paraguay (2006): Corte Interamericana de Derechos Humanos, 29 de marzo de 2006 (Fondo, Reparaciones y Costas).

Comunidad Moiwana vs Suriname (2005): Corte Interamericana de Derechos Humanos. 15 de junio de 2005 (fondo, reparaciones y costas).

Comunidad Indigena Yakye Axa Vs. Paraguay (2005): Cte.IDH 17 de junio 2005 (Fondo, Rep. y Costas). 
Comunidad Mayagna (Sumo) Awas Tingni Vs. Nicaragua (2001): Cte. IDH Humanos. 31 agosto de 2001 (Fondo, Reparaciones y Costas). Comunidad Indígena Saturnino Leal Neiman y otros con Comisión de Evaluación Ambiental de los Ríos (2018): Tercer Tribunal Ambiental de Chile, Valdivia, Rol: 78-2018.

Codelco Chile División Chuquicamata cl Dir.Regional y Nacional de Aguas (2014): Corte de Apelaciones de Antofagasta, Rol 235-2013, 28 agosto 2013; Corte Suprema, Rol 14.003-13, 15 mayo 2014.

Compañía Minera Cerro Colorado Ltda. en contra del Fisco de Chile (2016): Corte Suprema, 4 de mayo de 2016 (casación, sentencia de reemplazo). Rol No 6.628-2015.

Coñuequir Curilaf Alejandro con Ministerio de Energía (Central Añibuerraqui): Corte de Apelaciones de Santiago, Rol 23143-2018, 10 de agosto 2018; Corte Suprema Rol 23.024-2018 y Rol No 22.0342018, 22 enero 2019.

Comunidad Indigena Entuco Contra Municipalidad De Padres Las Casas (2016): Corte Suprema, 4 de abril 2016. Rol 36728 - 2015 (apelación a la protección).

Comunidad Indígena Huenchullán contra Ministro de Energía Jorge Bunster (2012): Corte de Apelaciones de Santiago, 16 noviembre 2012, Rol 9431-2012.

Comunidad Indígena Huenchullán contra Ministro de Energía Jorge Bunster (2012): Corte Suprema, 17 enero 2013, Rol 9526-2012.

Comunidad Indígena Chilcoco con Ilustre Municipalidad de Arauco, "Cerro Colo Colo» (2010): Corte Apelaciones Concepción, 10 agosto 2010. Rol 289-2010 (Recurso de protección).

Comunidad Indígena Saturnino Leal Neiman y otros con Comisión de Evaluación Ambiental de los Ríos», Tercer Tribunal Ambiental de Chile, Valdivia, Rol: R-78-2018.

Comunidad indigena Xákmok Kásek Vs. Paraguay (2010): Cte.IDH. 24 agosto 2010 (fondo, reparaciones y costas).

Condore Vilca y comuneros de la Quebrada de Tarapacá contra la COREMA de la I Región de Tarapacá, (caso «Paguanta») (2012): Corte Suprema 30 marzo 2012, Rol 10.090-2011.

Consejo de pueblos atacameños con Ministro Energía Jorge Bunster (2012): Corte de Apelaciones de Santiago, 16 noviembre 2012, Rol 12.533-2012

Corte Constitucional de Colombia, Sentencia C-882/11, «Reforma constitucional introducida al Artículo 49 de la Constitución Política».

Corte Constitucional de Colombia. Sentencia. T-116/11, "Comunidades indígenas como sujetos de especial protección constitucional y titulares de derechos fundamentales». 
Corte de Constitucionalidad, Guatemala, Apelación de sentencia de amparo, Exps. acum. 156-2013 y 159-2013, Sent. 25 marzo 2015.

Corte de Constitucionalidad, Guatemala, Apelación de sentencia de amparo, Exps. acum. 90-2017, 91-2017 y 92-2017, Sent. 26 mayo 2017.

Corte de Constitucionalidad, Guatemala, Apelación de sentencia de amparo, Expediente 2906-2017, Sent. 21 septiembre 2017.

Corte de Constitucionalidad, Guatemala, Apelación de sentencia de amparo, expediente 4785-2017, Sent. 3 septiembre 2018.

Cruz Plaza Antonio y otros cl M. de Energía (2012): Corte Suprema, 17 enero 2013, Rol 9527-2012.

Francisca Linconao con Forestal Palermo (2010): Corte de Apelaciones de Temuco, 16 septiembre 2009. Rol 7287-2009 (Recurso de protección). Millaray Virginia Huichalaf Pradines y otros con Juan Heriberto Ortiz Ortiz (caso «Represa Pilmaiken») (2012): Corte de Apelaciones de Valdivia, sentencia 4 mayo 2012. Rol No 501 - 2011; Corte suprema, 21 septiembre 2012. Rol No 3.863-2012

Pueblo Indigena Kichwa de Sarayaku Vs. Ecuador (2012): Cte.IDH. 27 junio 2012.

Pueblo indígena Xucuru y sus miembros Vs. Brasil (2018): Cte.IDH, 5 febrero 2018 (Excepciones Preliminares, Fondo, Reparaciones y Costas). Recurso de hecho deducido por el actor en la causa Pilquiman, Crecencio cl Instituto Autárquico de Colonización y Fomento Rural s/ acción de amparo", 7 octubre 2014, P. 811. XLIV.

Requerimiento de inaplicabilidad por inconstitucionalidad presentado por Inversiones Tama S.A. respecto de los artículos 54, 55, 56 y 58 de la Ley $N^{\circ} 19.253$ (2015): Tribunal constitucional, 24 diciembre 2015. Rol 2552-2013.

Reyes Alcaman y otros Con Ministerio de Obras Públicas (2011): Corte Suprema, 6 mayo 2011. Rol 1608-2011 (apelación recurso de protección).

Pueblo Saramaka vs. Surinam (2007): Corte Interamericana de Derechos Humanos. 28 noviembre 2007 (Excepciones Preliminares, Fondo, Reparaciones y Costas).

Sentencia T-778/05 (2005): Corte Constitucional de Colombia. 27 julio 2005. Supremo Tribunal Federal de Brasil, STF, Pleno, ADI 3239, Red. p/ o acórdão Min. Rosa Weber, DJe, 01-02-2019.

Tribunal Constitucional del Perú, Exp. N. . 05427-2009-PC/TC, «Asociación Interétnica de Desarrollo de la Selva» (2010). 
c) Normativa:

Decreto Supremo No 66 (15/09/2013; 4/03/2014), Ministerio de Desarrollo Social, «Reglamento que regula el procedimiento de consulta indígena en virtud del artículo $6 \mathrm{~N}^{\circ} 1$ letra a) y $\mathrm{N}^{\circ} 2$ del Convenio $\mathrm{N}^{\circ} 169$ de la Organización Internacional Del Trabajo y deroga normativa que indica».

Decreto Supremo No40 (30/10/2012; 30/08/2013), Ministerio del Medio Ambiente, «Aprueba Reglamento del Sistema de Evaluación de Impacto Ambiental».

D.F.L. $N^{\circ}$ 4, Ley 20.018 que fija el texto Refundido, Coordinado y Sistematizado del D.F.L. $N^{\circ} 1$ de Minería de 1982, «Ley General de Servicios Eléctricos, en materia de energía eléctrica», 5 febrero 2007.

La Ley 19.300, 1994 que «Aprueba Ley Sobre Bases Generales Del Medio Ambiente».

Declaración Universal de la Unesco (2001). UNESCO, «Conferencia Mundial sobre las Políticas Culturales» México, 1982.

Convenio 169 de la Organización Internacional del Trabajo sobre Pueblos Indígenas y Tribales en Países Independientes, 1989.

Declaración Americana sobre los derechos de los pueblos indígenas, OEA, 14 de junio de 2016. 



\title{
LA REGULACIÓN DE LA EDUCACIÓN EN EL ESTADO GARANTE
}

\author{
THE REgulation OF EDUCATION \\ IN THE GUARANTEED STATE
}

\section{Pablo Nuevo López ${ }^{1}$}

Resumen. El presente trabajo aborda la regulación de los derechos educativos desde la perspectiva del Estado garante, como modelo que permite construir un sistema de derechos sociales en clave de subsidiariedad, para alcanzar la justicia social en un orden de libertad. Palabras clave: derecho a la educación, Estado garante, libertad, subsidiariedad.

AвSTRACт. The present paper deals with the regulation of educational rights from the perspective of the guarantor State, as a model that allows the construction of a system of social rights in the key of subsidiarity, to achieve social justice in an order of freedom.

KEYwORDs: right to education, Guarantor State, freedom, subsidiarity.

1 Profesor de Derecho constitucional (Universidad Abat Oliba CEU, España). E-mail: pnuevo@uao.es 
SumARIO: 1. Introducción. 2. Estado social y derecho a la educación. 3. Estado regulador y derechos educativos: 3.1. Programación de centros docentes y derecho de elección del tipo de educación; 3.2. La garantía del derecho de elección de centro docente. 4. Conclusiones. 5. Bibliografía.

\section{INTRODUCCIÓN}

Nuestro modelo de Estado constitucional basado en la dignidad humana y el libre desarrollo de la personalidad se corresponde con lo que la doctrina denomina una "sociedad de derecho privado", es decir, una sociedad en la que no corresponde al Estado decidir por el individuo, sino que es este, en tanto que sujeto autónomo, libre y responsable, quien debe perseguir sus propios fines. Para ello, y ante la imposibilidad de proveerse por sí mismo de todos los bienes necesarios para dicho desarrollo personal, debe cooperar con el resto de los miembros de la sociedad. Por tanto, el Estado constitucional se funda en la cooperación voluntaria entre las personas que integran la sociedad.

Ello no implica que el Estado renuncie a cualquier tipo de intervención sobre la sociedad, limitándose a dejar espacio a la autonomía de la voluntad de los individuos. De entrada, corresponde al poder público poner los medios (también jurídicos) que permitan dicha cooperación, así como remover los obstáculos que la dificulten o imposibiliten. Pero, en virtud de la cláusula de Estado social, el Estado asume fines de carácter material, dirigidos a lograr la conformación del orden social con arreglo a valores de justicia e igualdad, lo que se traduce en deberes jurídicos para el poder público de actuar positivamente sobre la sociedad ${ }^{2}$.

Ahora bien, como ha puesto de manifiesto la doctrina las transformaciones del Estado en los últimos decenios han conducido a un cambio de paradigma en la articulación del Estado social. Si se mantiene como algo irrenunciable la asunción por el Estado de determinados fines conducentes a intervenir activamente en la sociedad, para hacer posible la libertad real y efectiva de todos los

2 Santamaría Pastor (1988) 227. Cfr. También Díez Moreno (2004). 
ciudadanos, ha dejado de ser pacífica la asunción por el Estado de la responsabilidad de proporcionar directamente las prestaciones derivadas de esos fines estatales ${ }^{3}$.

En el presente trabajo se abordará la cuestión del papel del Estado para garantizar el acceso universal a la educación, como parte de los fines irrenunciables de un Estado social orientado al bien común, así como el modo en que esto puede ser realizado desde la perspectiva del Estado garante, "al que corresponde preservar, garantizar, la realización de ese bien común» ${ }^{4}$.

Ahora bien, a la hora de concretar la regulación de la educación en el contexto del Estado garante debe partirse del principio de unidad de la Constitución. Al ser la Constitución un todo, en el que no puede afirmarse un derecho o principio en detrimento de los demás, la regulación educativa debe contemplar la totalidad de los factores implicados: universalidad del derecho a la educación, derechos de los padres, libertad de cátedra de los docentes y, en un Estado descentralizado como el español, las competencias de los diferentes entes públicos de base territorial. Esto se proyecta sobre los ámbitos de la regulación: régimen jurídico de los centros docentes, definición de los currículos escolares, posiciones iusfundamentales de todos los agentes que participan en la educación (alumnos, docentes, padres, titulares de centros docentes de iniciativa social...), normativa sobre plurilingüismo en la enseñanza reglada, modo y grado de presencia del hecho religioso, etc. ${ }^{5}$

No obstante, en el presente trabajo abordaremos la cuestión regulatoria en materia educativa centrándonos en lo que podríamos llamar la base material de la educación: la programación de la red escolar y la asignación de plaza escolar a los alumnos, tanto por limitaciones de espacio como por ser la temática en la que se puede observar, con mayor nitidez, el modelo de Estado regulador como expresión del Estado garante. Para ello, previamente analizaremos la relación entre Estado social y derecho a la educación, precisamente desde la perspectiva del Estado garante, pues sólo con esa

Cfr. Esteve Pardo (2013).

Esteve Pardo (2013) 175.

Un análisis de las diferentes posiciones iusfundamentales materia educativa en el Derecho constitucional español puede encontrarse en Nuevo López (2009). 
aproximación conceptual podrá captarse lo fecundo del Derecho regulatorio aplicado a los derechos sociales.

\section{ESTADO SOCIAL Y DERECHO A LA EDUCACIÓN}

Una sociedad respetuosa con la dignidad de la persona debe asegurar que todos los miembros de la misma tengan acceso a la educación. Si la dignidad implica considerar a la persona como sujeto, y nunca como objeto para satisfacer fines o intereses de terceros, es indudable que el acceso a la educación juega un papel determinante, pues la educación hace posible que el individuo tome las riendas de su propia vida.

De ahí que el Estado social, que como se ha dicho ordena la sociedad para hacer posible la libertad, asume como fin crear «el escenario adecuado para que las potencialidades de los individuos puedan desarrollarse, lo que incluye no sólo medidas destinadas a satisfacer sus necesidades vitales, sino también las educativas, culturales y de ocio ${ }^{6}$. Por tanto, debe prestar una atención especial a la educación.

En efecto, como señala Fernández-Miranda, la constitucionalización del derecho a la educación es «la manifestación más concreta y con mayor densidad jurídica de la cláusula constitucional del Estado social» ${ }^{7}$, si bien es cierto que al mismo tiempo subraya con énfasis la dimensión de libertad presente en la educación. Considera FernándezMiranda que el art. 27 integra dialécticamente la libertad de enseñanza y el derecho a la educación, de forma que éste «como instrumento de igualdad y justicia, ha de realizarse en un sistema educativo presidido por los principios de libertad y pluralismo» ${ }^{8}$. Ahora bien, ello no obsta para que entienda el derecho a la educación como un derecho social de prestación, derecho público subjetivo de prestación ${ }^{9}$.

A la luz de estas consideraciones podemos entender el derecho a la educación como derecho a una acción positiva del Estado; es decir, presenta un contenido conforme al cual no es suficiente con

\footnotetext{
Correas Sosa (2006) 342.

Fernández-Miranda Campoamor (2003) 162.

FernándeZ-Miranda Campoamor (1981) 125.

Fernández-Miranda Campoamor (1988) 37 y ss.
} 
que el Estado se abstenga de interferir en el ámbito protegido por el derecho (derecho fundamental como prohibición de injerencia estatal), sino que para no conculcarlo «el Estado debe hacer algo ${ }^{10}$.

Siguiendo el modelo de derechos fundamentales de Robert Alexy, podemos considerar que el derecho a la educación presenta -al menos en parte- la estructura propia de un derecho prestacional en sentido estricto. A este respecto, podemos señalar como punto de partida que «los derechos prestacionales en sentido estricto son derechos del individuo frente al Estado a algo que -si el individuo tuviera los medios financieros suficientes, y si encontrase en el mercado una oferta suficiente- podría obtener también de los particulares» ${ }^{11}$.

La dimensión prestacional del derecho a la educación hace necesaria la regulación en este ámbito, pues precisamente porque el Estado debe conseguir que todos los niños - verdaderos sujetos del derecho a la educación- tengan un puesto escolar es preciso concretar el modo en que es posible asignarles plaza en un centro educativo. Al hacerlo la regulación adquiere un carácter configurador del derecho, al dotarle de «contenido material» y fijar «la forma de ejercicio» del mismo ${ }^{12}$.

Ahora bien, precisamente porque la educación nunca puede ser completamente neutral, coincido con lo sostenido por Rubio Llorente, para quien «el derecho a la educación aparece más como un derecho de libertad que de prestación» ${ }^{13}$; es decir, presenta una naturaleza en cierto modo híbrida ${ }^{14}$, pues es a la vez un derecho de libertad y un derecho «económico-social, un derecho a recibir del Estado una prestación determinada» ${ }^{15}$.

Las argumentaciones precedentes se ven reforzadas por la doctrina del Tribunal Constitucional. En efecto, el Alto Tribunal, en su Sentencia 86/1985, de 10 de julio, señaló (FJ 3) que:

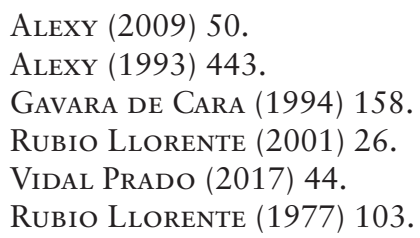


El derecho de todos a la educación (...) incorpora así, sin duda, junto a su contenido primario de derecho de libertad, una dimensión prestacional, en cuya virtud los poderes públicos habrán de procurar la efectividad de tal derecho y hacerlo, para los niveles básicos de la enseñanza, en las condiciones de obligatoriedad y gratuidad.

Alexy se plantea cómo un derecho de libertad puede a su vez fundamentar un derecho prestacional. A este respecto, considera que esta fundamentación únicamente puede realizarse si la prestación es un presupuesto necesario para la realización del derecho de libertad, ya que «la libertad que los derechos fundamentales deben asegurar incluye la libertad fáctica», por lo que «son normaciones no sólo del poder hacer jurídico, sino también del poder actuar realmente» ${ }^{16}$. Es decir, la fundamentación es correcta si la prestación (o mejor, aquello que se consigue con la misma) constituye una garantía para alcanzar o incrementar una porción de libertad fáctica. Haciendo suya una afirmación del Tribunal Constitucional Federal alemán, considera Alexy que «el derecho de libertad carecería de valor sin el presupuesto real de poder recurrir a él» ${ }^{17}$.

Esta dimensión de derecho de libertad se proyecta sobre la regulación de la educación ya que «lo que el modelo constitucional vigente exige del Estado es que establezca los cauces para que la oferta educativa sea lo más amplia posible y que, en todo caso, todos tengan acceso a la educación ${ }^{18}$, de forma que el papel del poder público en este ámbito presenta un carácter garantizador más que necesariamente de prestación directa de servicios educativos.

Este papel garantizador cobra especial relevancia, por la dificultad de deslindar, en el ámbito educativo, la transmisión de conocimientos de la transmisión de valores, ya que «es casi imposible transmitir conocimientos sin comunicar a la vez opiniones o convicciones» ${ }^{19}$, pues «en toda enseñanza hay una concepción del mundo $»^{20}$. Ello implica que la familia tenga un papel determinante

\footnotetext{
Alexy (1993) 447, 488-489.

BVerfGE 33, 303 (331).

Vidal Prado (2017) 45.

Vidal Prado (2001) 137.

20 SÁnchez Agesta (1977) 177.
} 
en la educación, pues «si los padres dan el ser a sus hijos, deben llevar a ese ser a una perfección suficiente para vivir según cumple a la persona humana ${ }^{21}$. Precisamente por ello la vertiente prestacional del derecho a la educación debe plantearse desde el equilibrio de su dimensión de derecho de libertad, pues la prestación que debe proporcionar el Estado debe ajustarse lo más posible a lo que quieran los padres de los alumnos, para que la transmisión de valores presente en todo proceso educativo no tenga lugar en oposición a las convicciones de los padres.

A este respecto, debe ponerse de manifiesto que la acción del Estado dirigida a hacer posible diversos modelos educativos (en sintonía con las preferencias de los padres) no solo sirve a respetar la dimensión de libertad del derecho a la educación, sino que es necesario para que pueda haber auténtica educación en un contexto de neutralidad estatal. Como señala Isensee, "prestaciones derivadas de la autonomía de los derechos fundamentales están acuñadas desde un punto de vista religioso y fundamentadas desde una visión ideológica, y no pueden ser sustituidas por el Estado neutral. En todo caso podría desarrollar sucedáneos» ${ }^{22}$.

Y es que, como señala Ortiz Díaz, «la Constitución no consagra el derecho a recibir educación en un servicio público ni estatal o de otro titular, sino el derecho a recibir educación», con la consecuencia de que "por la Constitución, el Estado no asume para sí mismo y con exclusividad una función educativa prestadora. Sobre los poderes públicos pesa una función garantizadora de que las prestaciones educativas van a quedar cubiertas en régimen de servicio público o privado ${ }^{23}$.

\section{Estado REgUlAdor y DERECHOS EDUCATIVOS}

Como se ha indicado anteriormente, corresponde al Estado la regulación de la base material de la educación. Aun cuando la educación reglada pueda tener lugar en centros de iniciativa social, es una exigencia del interés general que todas las personas

21 Díez Moreno (1988) 2421-2422.

22 ISENSEe (2001) 501.

23 Ortiz Díaz (1980) 244. 
tengan acceso a dicha educación reglada, así como que se facilite a todas las personas, con independencia de su condición social, el acceso a educación reglada en centros distintos de los creados por los poderes públicos, para que sea real y efectiva la libertad de las familias de elegir el tipo de educación que quieren para sus hijos. Ello se traducirá, en primer lugar, en un concreto modo de regular la programación de centros docentes (y el acceso de los mismos a los fondos públicos), y en segundo término en el establecimiento de criterios para la adjudicación de plazas en el supuesto de que no coincidencia de la demanda y la oferta educativa.

\subsection{Programación de centros docentes y derecho de elección del tipo de educación}

El derecho de acceso a la enseñanza es, en mi opinión, un derecho a una acción positiva fáctica. Los derechos a acciones positivas fácticas se caracterizan por imponer al Estado una obligación de resultado: el acceso generalizado a la mencionada enseñanza. Acción positiva fáctica que, a mi entender, tiene la estructura de regla. De acuerdo con Alexy, las reglas "contienen determinaciones en el ámbito de lo fáctica y jurídicamente posible» y «solo pueden ser cumplidas o no» ${ }^{24}$.

Al mismo tiempo, en el derecho a la financiación pública de la educación podemos encontrar tanto un derecho a una acción positiva fáctica, cuyo resultado ha de ser dotar a los centros docentes de los medios necesarios para ofrecer la enseñanza (de manera que puedan, así, hacer efectivo el derecho a la educación), como un derecho a una acción positiva normativa (el establecimiento de las normas en que -sin discriminación- los centros privados pueden acceder a esa financiación). Este contenido doble viene determinado porque, según me parece, el derecho a la financiación pública de la educación incluiría el derecho a la subvención a los centros privados. Ahora bien, a diferencia del derecho de acceso a la enseñanza básica, este derecho adopta en el art. 27 la forma de principio, de modo que constituye

24 Alexy (1993) 87. 
un mandato de optimización ${ }^{25}$, esto es, exige que esa financiación pública sea realizada en la mayor medida posible.

En relación con este asunto, el Tribunal Constitucional ha resaltado que «la financiación pública de los centros privados sirve al contenido prestacional $»^{26}$ del derecho a la educación, si bien no es posible entender el derecho a la financiación pública de la educación como un derecho ilimitado cuya consecuencia sea que los fondos públicos acudan donde vayan las preferencias privadas ${ }^{27}$. La optimización de la financiación pública de la enseñanza básica debe ser, en primer lugar y con respecto a todos los centros docentes (con independencia de su titularidad, estatal o de iniciativa social), compatible con las posibilidades presupuestarias del Estado, y en lo que se refiere a la optimización de las preferencias de los padres por un determinado tipo de educación, tanto con la oferta existente como con la competencia atribuida a los poderes públicos para realizar una programación general de la enseñanza (competencia que, ex art. 27.5 CE, tiene por finalidad garantizar el acceso de todos a la educación).

De lo anterior se desprende que la programación no puede consistir únicamente en una cuantificación de los puestos escolares necesarios, previendo tan solo la demanda a satisfacer, sino que debe tener en cuenta asimismo las preferencias de los padres, el modelo de enseñanza o el tipo de centros por los que esa demanda se ha decantado ${ }^{28}$.

A esto responde la regulación vigente en España. Por lo que se refiere a la regulación de la oferta educativa para garantizar el derecho al puesto escolar, en el caso español debemos atender a lo dispuesto en tanto en la Ley orgánica 8/1985, de 3 de julio, reguladora del derecho a la educación (en adelante, LODE) como en la Ley orgánica 2/2006, de 3 de mayo, de educación (en adelante, LOE).

De conformidad con el art. 27.1 LODE, «Los Poderes públicos garantizarán el ejercicio efectivo del derecho a la educación mediante una programación general de la enseñanza, con la participación efectiva de todos los sectores afectados, que atienda adecuadamente las

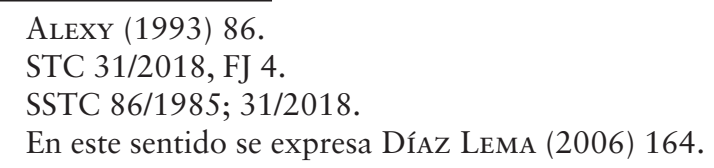


necesidades educativas y la creación de centros docentes», precisando el segundo párrafo del apartado 3 de este mismo precepto que «La programación específica de puestos escolares de nueva creación en los niveles gratuitos deberá tener en cuenta, en todo caso, la oferta existente de centros públicos y concertados» ${ }^{29}$.

Por su parte, el art. 109 LOE dispone al respecto lo siguiente:

1. En la programación de la oferta de plazas, las Administraciones educativas armonizarán las exigencias derivadas de la obligación que tienen los poderes públicos de garantizar el derecho de todos a la educación y los derechos individuales de alumnos y alumnas, padres, madres y tutores legales.

2. Las Administraciones educativas programarán la oferta educativa de las enseñanzas que en esta Ley se declaran gratuitas, teniendo en cuenta la programación general de la enseñanza, las consignaciones presupuestarias existentes y el principio de economía y eficiencia en el uso de los recursos públicos y, como garantía de la calidad de la enseñanza, una adecuada y equilibrada escolarización de los alumnos y alumnas con necesidad específica de apoyo educativo, tomando en consideración la oferta existente de centros públicos y privados concertados y la demanda social. Asimismo, las Administraciones educativas garantizarán la existencia de plazas suficientes.

Como puede apreciarse, la tarea de regulación dirigida a garantizar que todos los titulares del derecho a la educación tengan su correspondiente plaza escolar debe hacerse armonizando la competencia pública con el derecho de los padres a elegir el tipo de educación que quieren para sus hijos, y teniendo en cuenta tanto

29 Como señala el Tribunal Constitucional «El concierto es el modelo adoptado por el legislador para dar cumplimiento a la obligación contemplada en el artículo 27.9 CE, aunque también cabrían otras fórmulas de ayuda distintas. De este modo, los conciertos educativos están enmarcados en el ámbito prestacional del más genérico derecho a la educación.» (STC 31/2018, FJ 4). La regulación básica de los conciertos educativos se encuentra en el Real Decreto 2377/1985, de 18 de diciembre, por el que se aprueba el Reglamento de Normas Básicas sobre conciertos educativos. En todo caso, excede del ámbito del presente trabajo un estudio sobre la naturaleza jurídica de los conciertos educativos. 
los centros existentes (público y privados concertados) como la demanda social.

Lógicamente los poderes públicos tienen que crear centros docentes, de modo que algunos de los titulares del derecho a la educación recibirán la prestación en que consiste el derecho directamente de los poderes públicos, pero cuando haya demanda social de enseñanza proporcionada por sujetos privados los poderes públicos deberán acomodar su programación a la misma.

Ello determinará en primer lugar que si en una determinada zona existen centros docentes privados sostenidos con fondos públicos que cubren la demanda social, no puedan las Administraciones crear centros docentes de titularidad pública que entren en contacto con ellos. En segundo término, si hay centros docentes de titularidad privada que quieren acceder al régimen de conciertos (y cumplen con la normativa aplicable) los poderes públicos deberán suscribir los correspondientes conciertos educativos. Y, por último, si no hay centros privados disponibles, pero sí demanda para ese tipo de educación, los poderes públicos tienen competencia para fomentar el desarrollo de centros de iniciativa social ${ }^{30}$.

\subsection{La garantía del derecho de elección de centro docente}

Un segundo ámbito en el que cobra importancia la regulación a fin de garantizar el acceso a una plaza escolar en un centro que ofrezca el tipo de educación que desean los padres es el de la asignación de plazas en centros sostenidos con fondos públicos en casos en que hay un desajuste entre oferta y demanda ${ }^{31}$. Como hemos señalado, con objeto de hacer posible que de manera efectiva los padres puedan elegir el tipo de educación que quieren para sus hijos los poderes públicos sostienen centros docentes de iniciativa social, para garantizar la gratuidad de la educación. Ahora bien, precisamente porque dichos centros reciben fondos públicos la admisión de alumnos-que son los verdaderos sujetos del derecho a la educación,

30 Cfr. Guardia Hernández y Manent Alonso (2015) 174-190.

31 Sobre el derecho de elección de centro docente, vid. De los Mozos Touya (1995) 159 y ss. 
y por tanto los beneficiarios de la gratuidad de la enseñanza- no puede quedar completamente condicionada a la voluntad subjetiva de los titulares de los centros.

En primer término, como ha señalado el Tribunal Constitucional la «gratuidad garantizada constitucionalmente no puede referirse exclusivamente a la escuela pública, negándola a todos los centros privados, ya que ello implicaría la obligatoriedad de tal enseñanza pública, al menos en el nivel básico, impidiendo la posibilidad real de elegir la enseñanza básica en cualquier centro privado", lo cual «cercenaría de raíz, no solo el derecho de los padres a elegir centro docente, sino también el derecho de creación de centros docentes» ${ }^{32}$.

Por tanto, la gratuidad debe estar garantizada también respecto de centros docentes de iniciativa social, que deben ser accesibles para todas las personas. A esto es a lo que se refiere el Tribunal Constitucional cuando afirma que el derecho a la educación conlleva «el reconocimiento prima facie de una libertad de los padres para elegir centro docente» ${ }^{33}$, si bien el acceso efectivo al concreto centro elegido «dependerá de si se satisfacen o no los requisitos establecidos en el procedimiento de admisión de alumnos» ${ }^{34}$.

Por lo que respecta a esta libertad prima facie el Tribunal Supremo considera que «en líneas generales puede aceptarse que el derecho de los padres o tutores a elegir centro de enseñanza para sus hijos o pupilos constituye un ingrediente «habitual» del derecho fundamental a la educación, pero cuando choca con las conveniencias didácticas el ejercicio de ese derecho solo puede ser satisfecho como manifestación de preferencia que debe ser satisfecha siempre que sea posible» ${ }^{35}$.

Es decir, el Tribunal Supremo considera que hay que optimizar la posibilidad de elección de los padres, esto es, satisfacer la preferencia indicada para el acceso a un centro, siempre que sea posible. Así formulado, el derecho de los padres es un derecho prima facie, que necesita de la intervención normativa de los poderes públicos que haga compatible (eso sí, maximizando la elección de los padres)

\footnotetext{
STC 31/2018, FJ 4.

STC 10/2014, FJ 3.

STC 74/2018, FJ 4; ATC 382/1996, FJ 4.

Sentencia del Tribunal Supremo de 29 de marzo de 1993.
} 
la armonización de dicha elección con las obvias razones materiales y presupuestarias.

De ahí que de acuerdo con la jurisprudencia «el derecho de elección de centro docente forma parte del derecho a la educación y de la libertad de enseñanza, aunque no constituya un derecho de carácter absoluto que excluya la adopción de razonables criterios de selección» ${ }^{36}$.

Con otras palabras, a mi juicio lo que se desprende de la Jurisprudencia del Tribunal Supremo es que es la norma la encargada de transformar el derecho prima facie a la elección de centro en derecho definitivo, tarea en la cual la propia norma debe adoptar «razonables criterios de selección».

Como pone de manifiesto Cotino, «ante la limitación de las plazas existentes en la enseñanza sostenida con fondos públicos, los poderes públicos están legitimados para establecer una serie de criterios que sirvan para seleccionar entre quienes pretenden ocupar plazas en centros concretos. Los criterios objetivos de selección del alumnado vienen a reforzar el derecho de elegir un centro, evitando una selección arbitraria por parte de los centros públicos y concertados ${ }^{37}$.

Para Fernández-Miranda, de la Constitución se desprende la prohibición tanto de un sistema de zonificación que tenga casi únicamente en cuenta la cercanía del domicilio al centro, que eliminaría el derecho de elección de centro, como un mecanismo que ajuste oferta y demanda educativa que permita a los centros seleccionar a los alumnos, "porque vulneraría el derecho a la igualdad y convertiría el derecho a la elección en una prerrogativa de quien no es su titular». Más allá de esto, considera que el legislador dispone de margen para establecer dichos criterios, en función de los principios políticos que le animen, siempre y cuando al hacerlo respete la «igualdad, razonabilidad, adecuación y proporcionalidad ${ }^{38}$.

Ahora bien, a mi entender, para que estos criterios de selección sean realmente razonables han de tener en cuenta el carácter relacional de la educación, con lo que implica en cuanto a confianza

36 Sentencia del Tribunal Supremo de 29 de 13 de mayo de 1996.

37 Cotino Hueso (2000) 225.

38 FernándeZ-Miranda Campoamor (2006) 52. 
entre los padres que delegan parte de la educación de sus hijos en un centro determinado.

La jurisprudencia del Tribunal Supremo de España ha considerado equivalentes criterios razonables a criterios objetivos e igualitarios, como son la proximidad domiciliaria, la distribución conforme a la tendencia numérica ideal expresada por el legislador, etc $^{39}$. En este sentido, considera el Tribunal Constitucional en la Sentencia 77/1985 que:

La selección de acuerdo con los criterios previstos se produce en un momento distinto y forzosamente posterior al momento en que padres y tutores, en virtud de sus preferencias, han procedido a la elección de Centro. Los recurrentes no niegan la competencia del legislador para establecer criterios ordenadores, ni aducen que los criterios establecidos para seleccionar, de entre todas las solicitudes de admisión presentadas en función de las preferencias educativas de padres y tutores, aquellas que puedan ser atendidas resulten arbitrarias. Únicamente señalan, sin mayor fundamentación, que «el criterio de proximidad geográfico no sería enteramente el más racional». Si se indica que, como consecuencia de la aplicación de esos criterios, cabe la posibilidad de que algún alumno, que prefiera un Centro determinado en razón de su ideario, se vea desplazado por otro que quizás tenga un interés menor por el mismo; pero de la eventual intensidad, mayor o menor, de las preferencias (sic) no puede deducirse, o debe instrumentarse jurídicamente, un derecho constitucionalmente reconocido a ocupar preferentemente una plaza en un Centro docente (FJ 5).

Continúa el Tribunal considerando que:

De las disposiciones impugnadas no resulta traba alguna para la elección inicial de Centro, ni, caso de insuficiencia de plazas, se prescinde de la voluntad expresada por padres o tutores al respecto, ya que la adjudicación de plazas se lleva a cabo entre aquellos que ya han manifestado su preferencia y realizado su elección por un Centro determinado. Por ello,

39 Como ejemplo, se pueden citar las Sentencias de 10 de mayo de 1985, 23 y 29 de marzo de 1993, 13 de mayo de 1996 o 5 de octubre de 1999. 
y sin necesidad de entrar en el análisis del contenido del derecho indicado a la elección de Centro, más bien podría decirse que tal derecho se ve reforzado por las disposiciones impugnadas, al establecer criterios objetivos que impiden, caso de insuficiencia de plazas, una selección arbitraria por parte de los Centros públicos y concertados.

Esto ha sido precisado por el TC en su Auto 328/1992, de 18 de diciembre, que en su FJ 4 establece que:

En principio, ciertamente, no hay dificultad alguna en admitir que el derecho de todos a la educación, en cuanto derecho de libertad (STC 86/1985, fundamento jurídico 3.), comprende la facultad de elegir el centro docente, incluyendo prima facie la de escoger un centro distinto de los creados por los poderes públicos. Y ello no sólo porque así lo prevea el art. 4 b) de la Ley Orgánica 8/1985, reguladora del Derecho a la Educación (en adelante L.O.D.E.), sino porque el Tribunal Europeo de Derechos Humanos, al interpretar el alcance del primer inciso del art. 2 del Protocolo núm. 1 ( «A nadie se le puede negar el derecho a la instrucción»), ha reconocido taxativamente que este derecho se garantiza igualmente tanto a los alumnos de las escuelas públicas como a los de las privadas, sin establecer distinción alguna entre ellos (Sentencia Castello-Roberts c. el Reino Unido, de 25 de marzo de 1993, núm. 27). Protocolo que, de acuerdo con el art. 10.2 C.E., al haber sido ratificado por España, puede servir de fuente interpretativa para delimitar el contenido constitucionalmente protegido de los derechos que se pretenden tutelar en amparo (por todas, STC 64/1991, fundamento jurídico 4.). Así, pues, bajo el ámbito de cobertura del art. 27.1 C.E., cabe ubicar la capacidad de optar entre los diversos centros existentes, sean públicos o privados, aunque, naturalmente, el acceso efectivo al elegido dependerá de si se satisfacen o no los requisitos establecidos en el procedimiento de admisión de alumnos (...). Por lo demás, este Tribunal ya ha revelado la relación estrecha que media entre la facultad de escoger centro docente y el derecho consagrado en el art. 27.3 C.E., puesto que el ejercicio de aquélla constituye «un modo de elegir una determinada formación religiosa y moral» (STC 5/1981, fundamento jurídico 8). 
De manera coherente con esta doctrina constitucional, el art. 84.2 LOE establece que:

Cuando no existan plazas suficientes, el proceso de admisión se regirá por los criterios prioritarios de existencia de hermanos matriculados en el centro, padres, madres o tutores legales que trabajen en el mismo, proximidad del domicilio o del lugar de trabajo de alguno de sus padres, madres o tutores legales, renta per cápita de la unidad familiar y condición legal de familia numerosa, situación de acogimiento familiar del alumno o la alumna, y concurrencia de discapacidad en el alumno o alumna o en alguno de sus padres, madres o hermanos, sin que ninguno de ellos tenga carácter excluyente y sin perjuicio de lo establecido en el apartado 7 de este artículo.

Tanto una regulación de los criterios de selección que tenga en cuenta únicamente elementos objetivos (renta familiar, cercanía del domicilio familiar o laboral al centro, hermanos escolarizados en el mismo, etc.) como una regulación que a estos criterios añada alguno de orden subjetivo ${ }^{40}$ (coincidencia en el ideario educativo, por ejemplo) son, a priori, aptas para conjugar las elecciones de los padres con las obvias razones materiales y presupuestarias que impiden atender, de manera incondicionada, las preferencias de los padres en los casos de carencia de plazas, y, por tanto, hacen inevitable la selección.

Ahora bien, siendo ambos modelos de regulación idóneos para garantizar la racionalidad del sistema educativo y la programación general de la enseñanza, no se nos presentan igualmente necesarios.

El fin público de programación de la enseñanza y de igualdad en la elección del centro ${ }^{41}$ se logra con cualquiera de los modelos propuestos. Podemos convenir, entonces, que, para la realización del interés general, ambas regulaciones de los criterios de selección son igualmente idóneas. En cambio, la regulación que únicamente

40 Se hace difícil pensar en una regulación que únicamente atendiera a criterios subjetivos.

41 La introducción de criterios objetivos (renta familiar, hermanos en el centro, distancia del domicilio al centro elegido, etc.) garantizan esta igualdad a la hora de ejercer el derecho a la elección de centro cuando hay más solicitudes que plazas. 
contempla criterios objetivos incide, más intensamente, sobre el derecho de los padres a elegir el tipo de educación que quieren para sus hijos, en la medida en que la no satisfacción de su preferencia sobre el tipo de educación es mayor que la regulación que tenga en cuenta los criterios subjetivos.

Este supuesto es equivalente al siguiente ejemplo planteado por Alexy, en el que $F$ o $P 1$ es el fin público de programación de la enseñanza y de igualdad en la elección del centro, $M 1$ es la regulación según criterios objetivos, M2 la regulación que además tiene en cuenta criterios subjetivos (la identificación con el ideario del centro), y $P 2$ el derecho de los padres a elegir el centro que quieren para sus hijos.

Como señala Alexy,

Existen, por lo menos, dos medios, M1 y M2, que son igualmente adecuados para lograr o promover F. M2 afecta menos intensamente que M1, o no afecta en absoluto, la realización de aquello que exige una norma iusfundamental con carácter de principio, P2. Bajo estos presupuestos, para P1 es igual que se elija M1 o M2. P1 no exige que se elija M1 en lugar de M2 o M2 en lugar de M1. Para P2, no es igual el que se elija M1 o M2. En tanto principio, P2 impone una optimización tanto por lo que respecta a las posibilidades fácticas como jurídicas. Con respecto a las posibilidades fácticas, P2 puede ser realizado en una medida mayor si se elige M2 y no M1. Desde el punto de vista de la optimización con respecto a las posibilidades fácticas, bajo el presupuesto de la validez tanto de P1 como de P2, solo M2 está permitido y M1 está prohibido. Lo dicho vale para cualesquiera principios, fines y medios. Por lo tanto, la máxima de la necesidad que el Tribunal Constitucional Federal entre otros ha formulado como mandato afirmando que 'el fin no puede ser logrado de otra manera que afecte menos al individuo' se infiere del carácter de principio de las normas de derecho fundamental ${ }^{42}$.

Esta inclusión de criterios subjetivos en la norma que ha de regular los procesos de admisión en los centros docentes en los casos en que la demanda sea superior a la oferta, a mi entender, es compatible

42 Alexy (1997) 113-114. 
con la doctrina constitucional relativa a la admisión de alumnos en los centros sostenidos con fondos públicos, en el sentido de que «en todo caso, al aplicar dichos criterios prioritarios, en la selección de solicitudes se evitará cualquier tipo de discriminación por razones ideológicas, religiosas, morales, sociales, de raza o nacimiento».

En efecto, lo que está vedado es la discriminación, esto es, la diferencia de trato no justificada que convierte la desigualdad en injusta. Como ha señalado en repetidas ocasiones el Tribunal Constitucional, «el principio de igualdad ante la ley consagrado en el art. 14 de la CE consiste en que, ante supuestos de hecho iguales, las consecuencias jurídicas que se extraigan deben ser asimismo iguales, y que han de considerarse iguales dos supuestos de hecho cuando la introducción en uno de ellos de un elemento o factor que permita diferenciarlo del otro se encuentre carente de fundamento racional y sea, por tanto, arbitraria porque tal factor diferencial no resulte necesario para la protección de bienes y derechos buscada por el legislador ${ }^{43}$.

La principal consecuencia es que un tratamiento legislativo diferente es legítimo cuando existe una justificación objetiva y razonable que persiga una finalidad legítima y que respete una adecuada proporcionalidad entre los medios empleados y la finalidad perseguida. Es decir, tiene que haber un interés público legítimo que justifique el trato diferenciado, y además, debe existir una proporción razonable entre las diferentes consecuencias jurídicas.

A mi modo de ver, hay un fundamento racional para establecer -en la norma que regule la admisión de alumnos- un criterio dirigido a contrastar la adecuación entre las convicciones y preferencias de los padres y el proyecto educativo del colegio (incluyendo el ideario). Este criterio que conduce a una mejor protección de los derechos y fines públicos en juego. La introducción en la norma de un criterio de esta naturaleza permite a los padres, precisamente, conseguir la escolarización de sus hijos en el Centro docente cuyo ideario mejor se ajuste a sus preferencias.

En la medida en que este factor diferencial es necesario para proteger el derecho de los padres (su ausencia condicionaría la

43 STC 68/1990. 
elección del padre no a criterios subjetivos de coincidencia de sistema educativo, sino a elementos objetivos), su inclusión no se antoja arbitraria. Por otro lado, mientras que dicha norma introduzca criterios objetivos junto a los subjetivos (criterios objetivos que hemos señalado expresamente garantizan la igualdad), no parece que sea irrazonable o desproporcionada la diferenciación en función de la coincidencia con el ideario o carácter propio del centro. Es más, como hemos señalado, parece que el derecho de los padres exige esta diferenciación.

En sentido contrario se expresa Fernández-Miranda, para quien «no es admisible -aparte las dificultades intrínsecas debidas a las exigencias del derecho a la libertad de conciencia- medir la intensidad de la comunión con el ideario; debe bastar con la manifestación de la voluntad de recibir tal orientación educativa ${ }^{44}$.

Para responder a las objeciones planteadas por FernándezMiranda debe señalarse con carácter previo que, dado que el ideario o proyecto educativo de los centros de iniciativa social no está limitado a las cuestiones religiosas, sino que se extiende también a asuntos como las preferencias pedagógicas o el modo de entender la enseñanza, la inclusión de criterios subjetivos no tiene por qué afectar al derecho a la libertad de conciencia.

Para salvar los problemas derivados de que la norma tenga que establecer criterios destinados a «medir la intensidad de comunión con el ideario», una manera a través de la cual se podrían introducir los criterios subjetivos sería la posible autorización a los titulares de los centros para añadir criterios complementarios a los criterios prioritarios establecidos por la correspondiente Administración educativa. Criterios complementarios entre los cuales el titular del centro podría incluir la necesidad de realizar una entrevista con alguna persona de la dirección del centro, con objeto de verificar la aceptación o no del ideario del centro.

En un Estado social de Derecho no puede entenderse el interés público como contrapuesto a los derechos fundamentales. Es más, como señaló tempranamente el Tribunal Constitucional en su Sentencia 25/1981 (FJ 5), los derechos fundamentales, si bien continúan

44 Fernández-Miranda Campoamor (2006) 52. 
concibiéndose primordialmente como derechos subjetivos de defensa frente al Estado, presentan además una dimensión objetiva, en virtud de la cual operan como componentes estructurales básicos que han de informar el entero ordenamiento jurídico.

A este respecto, considera el TC, en su Auto 382/1996 que:

Como consecuencia de este «doble carácter» de los derechos fundamentales, pende sobre los poderes públicos una vinculación también dual: en su tradicional dimensión subjetiva, les impone la obligación negativa de no lesionar la esfera de libertad por ellos citada; en su vertiente jurídico-objetiva, reclama genéricamente de ellos que, en el ámbito de sus respectivas funciones, coadyuven a fin de que la implantación y disfrute de los derechos fundamentales sean reales y efectivos, sea cual fuere el sector del ordenamiento en el que los mismos resulten concernidos (SSTC 53/1985, fundamento jurídico 4, y 129/1989, fundamento jurídico 3.). Tal es, ciertamente, la comprensión de los derechos fundamentales que se infiere de un texto constitucional que, tras proclamar el Estado social y democrático de Derecho (art. 1.1 CE), y, por ende, comprometer a los poderes públicos en la promoción de la libertad y la igualdad el individuo (art. 9.2 CE), eleva el libre desarrollo de la personalidad y el respeto a los derechos de los demás a la condición de fundamento del orden político y de la paz social (art. 10.1 CE).

Así pues, el «instrumento normativo adecuado» que debe establecer los criterios para la admisión de alumnos en los centros, haciendo así posible el derecho de los padres a elegir la educación que quieren para sus hijos, tiene que tener en cuenta este derecho al establecer los mencionados criterios, lo que determina la necesidad de incorporar criterios de naturaleza subjetiva. Esta es la interpretación más correcta del art. $27 \mathrm{CE}$, que permite armonizar el derecho de los padres con el fin público de la programación general de la enseñanza y la garantía de la igualdad en el acceso a la educación, al tiempo que refuerza el principio de unidad de la Constitución. 


\section{Conclusiones}

No puede haber Estado constitucional sin garantía de un acceso universal a la educación. Ahora bien, ello no debe conducir a la estatalización de la enseñanza (con el riesgo inherente de dirigismo cultural), pero tampoco parece que pueda dejarse ese ámbito al juego exclusivo de las fuerzas del mercado o a un marco de relaciones privadas de carácter estrictamente bilateral.

De los apartados precedentes puede concluirse, en mi opinión, que el modelo de derecho regulatorio propio del Estado garante se manifiesta particularmente apto para incorporar la perspectiva del interés general en ámbitos sociales como el de la educación, en los que es conveniente que los servicios sean prestados -al menos en parte- por sujetos privados.

Esta variante del Estado social, que pone el foco más en el logro del bien común que en la intervención directa del Estado, permite construir un modelo de derechos sociales en clave de subsidiariedad, en el que las obligaciones de justicia social se alcancen en un marco de libertad, para hacer realidad las cláusulas constitucionales que prescriben que el orden político está al servicio de la persona humana.

\section{Bibliografía}

\section{a) Doctrina:}

Alexy, Robert (1993): Teoría de los derechos fundamentales (trad. Ernesto GaRCón VAldÉs), $1^{a}$ ed. (Madrid, Centro de Estudios Constitucionales). Alexy, Robert (2009): «Sobre los derechos constitucionales a protección», en: Ricardo García MANRiQue (coord.), Derechos sociales y ponderación (Madrid, Fundación Coloquio Jurídico Europeo), pp. 45-84. CORREAS Sosa, Irene (2006): «Reflexiones en torno al Estado social. Aproximación al contenido, fines y valoración crítica de la vigencia del concepto", Corts. Anuario de Derecho Parlamentario, núm. 117, pp. 333-370.

Cotino Hueso, Lorenzo (2000): «La libertad del estudiante: derechos, libertades, deberes y responsabilidades del alumnado", en Derechos, deberes y responsabilidades en la enseñanza: análisis jurídico-práctico a la luz de las exigencias constitucionales, (Valencia, Publicaciones de la Generalitat Valenciana), pp. 99-154.

De los Mozos Touya, Isabel (1995): Educación en libertad y concierto escolar (Madrid, Montecorvo). 
DíAz Lema, José Manuel (2006): «La reforma de los conciertos educativos en el contexto constitucional (1985-2005)", en Mercedes de Esteban (coord.), Escolarización del alumnado en el sistema educativo español: cuestiones jurídicas, (Madrid, Fundación Europea Sociedad y Educación), pp. 143-174.

Díez Moreno, Fernando (1988): «El derecho fundamental a la educación y la libertad de enseñanza", en Introducción a los derechos fundamentales, Volumen III (Madrid, Ministerio de Justicia).

Díez Moreno, Fernando (2004): El Estado social (Madrid, Centro de Estudios Políticos y Constitucionales).

Esteve Pardo, José (2010): «La recepción en la Europa continental del derecho de la regulación de la economía", Revista de Administración Pública, núm. 183, pp. 295-307.

Esteve Pardo, José (2007): «La regulación de la economía desde el Estado garante», La Autonomía municipal, administración y regulación económica, títulos académicos y profesionales (Madrid, Thomson Reuters Aranzadi), pp. 79-126.

Esteve Pardo, José (2013): La nueva relación entre Estado y sociedad. Aproximación al trasfondo de la crisis (Madrid, Marcial Pons).

Fernández-Miranda Campoamor, Alfonso (1981): «Artículo 27. Educación», en Óscar Alzaga, (dir.), Comentarios a la Constitución, (Madrid, Edersa), pp. 117-199.

Fernández-Miranda Campoamor, Alfonso (1988): De la libertad de enseñanza al derecho a la educación. Los derechos educativos en la Constitución Española (Madrid, CEURA).

Fernández-Miranda Campoamor, Alfonso (2003): «El Estado social», Revista Española de Derecho Constitucional, núm. 69, pp. 139-180. Fernández-Miranda Campoamor, Alfonso (2006). «El derecho a la educación y la libertad de enseñanza en el mercado educativo", en Escolarización del alumnado en el sistema educativo español: cuestiones jurídicas, Madrid, Fundación Europea Educación y Sociedad), pp. 37-68.

Gavara de CARA, Juan Carlos (1994): Derechos fundamentales y desarrollo legislativo. La garantía del contenido esencial de los derechos fundamentales en la Ley Fundamental de Bonn (Madrid, Centro de Estudios Constitucionales).

Guardia Hernández, Juan José y Manent Alonso, Luis (2015): «La cesión de suelo público dotacional para la apertura de centros docentes concertados: una nueva manifestación del Estado garante», Revista Catalana de Dret Públic, núm. 51, pp. 174-190.

IsENSEE, Josef (2001): «El dilema de la libertad en el Estado de Derecho», Anuario de Derechos Humanos (nueva época), volumen 2, pp.481-522. 
Nuevo López, Pablo (2009): La Constitución educativa del pluralismo. Una aproximación desde la teoría de los derechos fundamentales (La Coruña, Netbiblo-UNED).

Nuevo López, Pablo (2014): «La reforma de la LOMCE. Mejora de la calidad educativa y política de derechos fundamentales», Cuadernos de Pensamiento Político, núm. 43, pp. 155-169.

Ortiz Díaz, José (1980): La libertad de enseñanza (Málaga, Publicaciones de la Universidad de Málaga).

Rubio Llorente, Francisco (1977): «Constitución y Educación», en L. SÁnchez-Agesta, ed., Constitución y economía. La ordenación del sistema económico en las constituciones occidentales (Madrid, Centro de Estudios y Comunicación Económica).

Rubio Llorente, Francisco (2001): «Deberes constitucionales», Revista Española de Derecho Constitucional, núm. 62, pp. 11-56.

SÁNCHez Agesta, Luis (1977): «La socialización de la enseñanza», Razón y Fe, núm. 944-945, pp. 177.

Santamaría Pastor, Juan Alfonso (1988): Fundamentos de Derecho Administrativo, (Madrid, Editorial Centro de Estudios Ramón Areces).

Vidal Prado, Carlos (2017): El derecho a la educación en España. Bases constitucionales para el acuerdo y cuestiones controvertidas (Madrid, Marcial Pons).

Vidal Prado, Carlos (2001): La libertad de cátedra: un estudio comparado (Madrid, Centro de Estudios Políticos y Constitucionales).

\section{b) Jurisprudencia:}

\section{Tribunal Constitucional de España}

Sentencia 25/1981, de 14 de julio.

Sentencia 77/1985, de 27 de junio.

Sentencia 86/1985, de 10 de julio.

Sentencia 68/1990, de 5 de abril.

Sentencia 10/2014, de 27 de enero.

Sentencia 31/2018, de 10 de abril.

Sentencia 74/2018, de 5 de julio.

Auto 382/1996, de 18 de diciembre.

Auto 328/1992, de 26 de octubre.

\section{Tribunal Supremo de España}

Sentencia de la Sala III (Contencioso-Administrativo) de 10 de mayo de 1985 Sentencia de la Sala III (Contencioso-Administrativo) de 23 de marzo de 1993. 
Sentencia de la Sala III (Contencioso-Administrativo) de 29 de marzo de 1993. Sentencia de la Sala III (Contencioso-Administrativo) de 13 de mayo de 1996. Sentencia de la Sala III (Contencioso-Administrativo) de 5 de octubre de 1999. 


\title{
VENTAJAS Y DESVENTAJAS DE LA MULTA COMO SANCIÓN PENAL PARA PERSONAS JURÍDICAS
}

\author{
AdVANTAgES AND DISADVANTAGES \\ OF THE FINE AS A CRIMINAL \\ SANCTION AGAINST LEGAL PERSONS
}

\section{Patricia Faraldo Cabana ${ }^{1}$}

RESUMEN. La multa es la sanción penal más usada contra personas jurídicas. La preferencia por la multa es evidente en la normativa comunitaria europea y en los Ordenamientos jurídicos que prevén la responsabilidad penal de las personas jurídicas. Sin embargo, desde hace años se discute si, en efecto, se trata de una sanción que tiene efectos preventivo-generales y especiales sobre la persona jurídica. En este trabajo se exponen los argumentos utilizados a favor y en contra, llegando a la conclusión de que otras sanciones, sobre todo las que inciden en la estructura societaria de la persona jurídica, podrían ser más eficaces para prevenir la delincuencia de estos entes.

1 Catedrática de Derecho Penal (Universidade da Coruña, A Coruña, España) y Adjunct Professor (Queensland University of Technology, Brisbane, Australia). E-mail: patricia.faraldo@udc.es 
PALABRAS CLAVE: responsabilidad penal de las personas jurídicas, multa, análisis económico del Derecho

Aвstract. The fine is the most widely used criminal sanction against corporations and other legal persons. The preference for the fine is evident in European Union legislation and in the legal systems that provide for the criminal liability of corporations. However, for years there has been a debate as to whether, in effect, it is a sanction that has preventive-general and special effects on the legal person. This paper presents the arguments used in favour of and against the fine, reaching the conclusion that other sanctions, especially those that have an impact on the corporate structure of the legal person, could be more effective in preventing the criminal activity of these entities.

KEYWORDS: corporate penal responsibility, penal fine, economic analysis of law

Sumario. 1. Introducción. 2. El catálogo de penas para personas jurídicas. 3. ¿Es la multa la pena adecuada para las personas jurídicas? 4. Conclusiones. 5. Bibliografía.

\section{INTRODUCCIÓN}

En el panorama internacional, la multa se ha convertido en la pena por excelencia para personas jurídicas ${ }^{2}$. Esta preeminencia de la pena pecuniaria se justifica generalmente sobre la base de que un ente colectivo no puede ser condenado a pena de prisión, al carecer de un cuerpo físico que pueda sufrir la privación de libertad ${ }^{3}$, pero lo cierto es que sus limitaciones han incentivado la creatividad legislativa permitiendo alumbrar en las últimas décadas un catálogo de penas bastante amplio. Aún así, los instrumentos europeos que

2 En este artículo parto de la admisión de la responsabilidad penal de las personas jurídicas por parte del legislador chileno y español. Ello no significa que esté de acuerdo con ella, pues creo que debilita la exigencia de responsabilidad penal a la persona física en último término responsable. En mi opinión, el único mérito de esta forma de responsabilidad de entes colectivos es que incentiva a las empresas a la hora de adoptar programas de prevención de delitos. Al respecto, Faraldo Cabana (2013) 77-113. Similar, Ransiek (2016).

3 Es famosa la cita atribuida al primer Barón Thurlow (1731-1806), quien habría preguntado «Did you ever expect a corporation to have a conscience, when it has no soul to be damned, and no body to be kicked?». El autor que más ha contribuido a popularizarla es CoffeE (1981) 386-459. 
prevén la imposición de sanciones a las personas jurídicas por parte de los Estados miembros indican habitualmente que se incluirá en todo caso la multa, sin predeterminar su naturaleza penal o administrativa, pudiéndose incluir a mayores otras sanciones ${ }^{4}$.

También en los ordenamientos europeos la multa se ha convertido en la sanción central para personas jurídicas, siendo de aplicación obligatoria en muchos de ellos 5 . Como veremos, no faltan razones para ello. No obstante, esta preferencia resulta llamativa desde un doble punto de vista: por un lado, las críticas que un sector doctrinal ha formulado en contra de la multa, en particular en referencia a la ausencia de efectos preventivos, al no resultar una sanción intimidatoria por diversas razones a las que haré referencia más adelante; por otro, el hecho de que tradicionalmente el nivel de la multa penal se haya mantenido en niveles bastante bajos, lo que reduce todavía más sus potenciales efectos preventivos.

\section{El catálogo de penas para personas Jurídicas}

En el ordenamiento jurídico chileno, como en el español, se contempla la multa como pena para personas jurídicas. Analizaremos su idoneidad en el apartado siguiente. Constituye la única pena pecuniaria que cabe imponer a las personas jurídicas ${ }^{6}$. También se recoge la pena capital para personas jurídicas, la disolución, a la que siguen una serie de prohibiciones, medidas e inhabilitaciones que cabe considerar penas privativas y restrictivas de derechos.

Faltan en este catálogo otras posibles penas, como la publici$\mathrm{dad}^{7}$ (por ejemplo, a través de la publicación de la sentencia en

$4 \quad$ Tales como la exclusión del disfrute de ventajas o ayudas públicas, la prohibición temporal o permanente del desempeño de actividades comerciales, el sometimiento a vigilancia judicial; y la medida judicial de liquidación.

5 Vid. el excelente resumen de la situación comparada que facilita la obra de Pieth e Ivory (2011).

6 El decomiso se configura en España como una consecuencia accesoria, no como una pena. En Chile, la única pena pecuniaria es la multa.

7 En relación con el efecto de esta pena sobre las personas jurídicas sigue siendo de interés la obra de Fisse y Braithwaite (1983). Vid. también ANDrix (2007) 1857 1890; CoHAn (1992) 2387-2420. Con carácter más general, vid. JüNGEL (2011). 
los medios de comunicación ${ }^{8}$, la prohibición de hacer publicidad sobre mercancías o servicios, pero también de la llamada publicidad denigratoria ${ }^{9}$ ), la imposición de prestaciones de servicios a la comunidad $^{10}$, la reparación ${ }^{11}$, la fianza ${ }^{12} \ldots$... Todas estas eventuales sanciones, sin suponer un riesgo para la viabilidad de la entidad, pueden tener efectos preventivos no desdeñables, como demuestra en algunos casos la perspectiva comparada ${ }^{13}$. Sin embargo, ni el legislador español ni el chileno las han tenido en cuenta.

8 La publicación de la sentencia en los periódicos oficiales y, si lo solicitara el perjudicado, en cualquier otro medio informativo, a costa del condenado, se suele considerar un instrumento válido de prevención especial, al reforzar los efectos de la inhabilitación y servir de apoyo a la lealtad en el orden económico, puesto que pone en evidencia a los no leales. Ya hace años ponía de relieve Tiedemann (1985) 166, que «muchas veces los inculpados están dispuestos a toda suerte de concesiones si se renuncia a publicar sus nombres». Afecta, en fin, a la estimación social del sujeto y restringe su capacidad criminal en el tráfico económico. Algunos instrumentos europeos apuntan en esta dirección, con el fin de aprovechar el temor de las empresas al daño que pueda causar en su reputación comercial que se dé a conocer al público la imposición de sanciones administrativas o penales. Por ejemplo, la Directiva 2003/6/CE del Parlamento europeo y del Consejo, de 28 de enero de 2003, sobre las operaciones con información privilegiada y la manipulación del mercado, dispone que «los Estados miembros establecerán que la autoridad competente pueda revelar al público las medidas o sanciones que se impongan por el incumplimiento de las medidas adoptadas de conformidad con la presente Directiva, salvo que la revelación comprometiera seriamente a los mercados financieros o causara un daño desproporcionado a las partes implicadas» (art. 14.4). Obsérvese, sin embargo, que no está clara la naturaleza de esta medida. Sobre su posible eficacia, vid. ENGELEN (2003) 253-263.

9 Vid. al respecto, entre otros, GUERRINI (2006) 181-182.

10 Sobre las ventajas de esta pena para personas jurídicas sigue siendo fundamental FISSE (1981) 970-1017. Vid. también GRUNER (1993) 292-295.

11 Sobre las posibilidades de la reparación como sanción penal para las corporaciones, vid. GrunER (1993) 267 ss. Sobre las modalidades que puede adoptar la reparación, vid. brevemente Nieto Martín (2008) 310-313.

12 Vid. Heine (1999) 241. Se trata de una de las sanciones propuestas por la Recomendación $N^{\circ}$. R (88) 18, del Comité de Ministros del Consejo de Europa a los Estados miembros, relativa a la responsabilidad de las empresas con personalidad jurídica por las infracciones cometidas en el ejercicio de sus actividades.

13 Vid. la panorámica ofrecida por de Maglie (2002) pássim. 


\section{3. ¿ES LA MULTA LA PENA ADECUADA PARA LAS PERSONAS JURÍDICAS?}

La preferencia legal por la pena de multa, unida a los menores costes estatales que conlleva la ejecución de la pena de multa y a la presunción de que tiene un gran potencial disuasorio, desde la perspectiva de que la persona jurídica, al igual que la física, hace elecciones racionales sobre la base de un cálculo de costes y benefi$\operatorname{cios}^{14}$, permite afirmar que la multa es la pena por excelencia para personas jurídicas. No sin obstáculos, pues en el panorama comparado se han vertido fuertes críticas contra la multa para personas jurídicas, en buena medida empleando argumentos muy razonables. Vayamos por partes.

Los principales valedores de la pena de multa, para personas físicas, pero también, muy especialmente, para las jurídicas, se encuadran en la escuela de Chicago. Desde la perspectiva del análisis económico del Derecho, se parte de un modelo en el que las personas toman decisiones racionales en la medida en que hacen elecciones que tienden a maximizar sus beneficios y minimizar sus costes. Ciertamente, el enfoque de la elección racional en ningún momento sostiene que todas las personas sean racionales, ni que el modelo que propone sea una descripción de la realidad. Parte, eso sí, de que los supuestos conductuales de la economía son útiles para construir modelos de comportamiento en el mercado, y también en el mercado de la pena ${ }^{15}$, lo que permite afrontar el estudio de una realidad compleja mediante la abstracción de sus elementos no esenciales ${ }^{16}$.

Aplicada al Derecho Penal, esta teoría predice que se cometerá un delito cuando los beneficios percibidos de tal infracción superen sus costes percibidos ${ }^{17}$. La teoría de la elección racional permite determinar cuál es la pena óptima y con qué grado de intensidad

14 Es un lugar común en la doctrina. Vid. por todos Chambliss (1967) 705-719; Braithwaite y Geis (1982) 302; Miller (1993) 203 ss.; Paternoster y Simpson (1993) pássim; Ulen (1997) 119-141. En contra de esta presunción de que la persona jurídica se comporta como la física, resultan de interés ERMANN y RABe (1997) pássim; Laufer (1994) 647-730; Metzger y Schwenk (1990) 323-377.

15 Cfr. North (1990) 17.

16 Vid. Ortiz de Urbina Gimeno (2006) 324-325.

17 Cfr. Grasmick y Burskik (1990) 837-861; Piliavin et al. (1986) 101-119. 
ha de imponerse. Tal y como expuso originalmente Gary Becker en $1968^{18}$, la pena de multa es la pena óptima, por cuanto ahorra a la sociedad el coste de la prisión y permite que el condenado siga trabajando. En su estudio afirma que si algunos delincuentes pueden pagar la multa y otros no, los primeros deben ser castigados con multa y para los segundos se han de buscar otras penas ${ }^{19}$. La primera consecuencia de esta propuesta es que la selección de penas debe realizarse no sobre la base de la gravedad del delito, sino de la posibilidad del delincuente de hacer frente a la multa. La segunda es que un delincuente solvente no debería ir a prisión siempre que sea capaz de pagar la pena de multa. A la misma conclusión llegan otros conocidos representantes del análisis económico del Derecho, que aconsejan la sanción pecuniaria siempre que sea posible, mientras que la pena privativa de libertad solo se aplicaría subsidiariamente para suplementar a la multa, una vez que ésta se haya fijado en su máximo nivel posible y, aun así, no se pudieran alcanzar los fines que la pena tiene atribuidos en el sistema penal en relación con el concreto delito cometido ${ }^{20}$.

Becker no se refirió en su estudio al delincuente corporativo. Sí lo hizo Richard Posner ${ }^{21}$. Para este autor, el fin que ha de perseguir la multa en el ámbito de la delincuencia corporativa es motivar a la empresa (en realidad a los socios) para organizarse de forma que pueda prevenir la comisión de delitos. Se parte, pues, de que los delitos que cometen las personas jurídicas responden a motivaciones racionales, por lo que si se amenaza con una sanción cuyo coste de aplicación (expected punishment cost) ${ }^{22}$ equivalga como mínimo al beneficio que se espera obtener con la comisión del delito la empresa se abstendrá de cometerlo, aplicando un sencillo cálculo de costes y beneficios. Posner pone de manifiesto que, dado que la sanción corporativa por excelencia es la pecuniaria, no está claro por qué ha de tener naturaleza criminal, puesto que los costes que impone

18 Aquí citado a través de Becker (1974) 1-54. Vid. también Becker (1976).

19 Cfr. Becker (1974) 31-32.

20 Polinsky y Shavell (1982) 89-99.

21 Posner (1980) 409-418; (2002) 437-439.

22 Sobre este concepto, Coffee (1981) 389 y Coffee (1980) 7-8. Este coste se calcula a partir de dos factores: el importe de la pena pecuniaria y la probabilidad de su aplicación. 
la tutela de las garantías propias del procedimiento penal solo tienen sentido económico cuando la pena criminal impone costes más pesados que la mera transferencia de dinero del criminal al Estado. La conclusión es que es preferible sancionar al infractor corporativo con sanciones pecuniarias no penales.

Pese a la claridad teórica de esta propuesta hay al menos dos aspectos que resultan criticables. En primer lugar, supone asumir un doble rasero penal que no compensa las desigualdades sociales, sino que las perpetúa. En efecto, en lo que respecta a la multa como pena óptima para las personas físicas, la conclusión es que los condenados capaces de pagar la multa impuesta, por elevada que sea, se verán liberados de una condena de prisión y de las consecuencias que ésta supone no solo en términos de privación de libertad, sino también de la estigmatización posterior a su cumplimiento, esto es, de lo que puede llamarse un efecto «reputacional» 23 .

Además, puesto que se argumenta sobre la base del efecto posterior que la pena tiene sobre los ingresos del sancionado y en la medida en que el coste esperado del delito para un delincuente rico y uno pobre debe ser el mismo, se concluye que es necesario establecer una probabilidad inferior de condena en el primer caso que en el segundo. Es decir, el sistema penal tenderá a sancionar menos al delincuente que antes de cometer el delito cuente con mayores ingresos que al que tenga menos, considerando que el coste esperado de la pena debe incluir también los ingresos perdidos como consecuencia de la estigmatización a la que se verá sometido el condenado tras cumplir la pena, y que serán mayores para el primero que para el segundo.

Como apunta Lott ${ }^{24}$, «si los delincuentes pudientes sufren una mayor reducción en los ingresos y unos mayores costes de oportunidad perdidos como consecuencia de la pena de prisión, la teoría de la pena óptima predice que se enfrentarán a una probabilidad de sanción menor». Esta formulación impersonal es engañosa, puesto que lo que se quiere decir es que el sistema penal debe sancionar en

23 Incluso los estudios realizados por partidarios del análisis económico del Derecho apuntan a la existencia de un efecto persistente de la condena a pena de prisión sobre los ingresos y el empleo: el condenado tiene menores posibilidades de encontrar un trabajo tras la condena, siendo este, cuando lo consigue, de peor calidad y remuneración que el que tenía antes. Cfr. WALDFogel (1994) 103-119. 24 LotT (1992) 585. 
menor medida a los ricos que a los pobres, si se quiere obtener un sistema óptimo de penas. Solo los individuos incapaces de pagar la multa han de ser condenados a pena privativa de libertad ${ }^{25}$. Este planteamiento no hace más que perpetuar el círculo vicioso de la delincuencia: son siempre los mismos los que sufren el estigma de la prisión, los pobres, mientras que quienes pueden permitírselo serán sancionados con multas no estigmatizantes, cuya imposición no tiene los mismos efectos que la prisión.

Una crítica más general es la relativa a que la perspectiva adoptada desde el análisis económico del Derecho prescinde de que el Derecho Penal es de por sí antieconómico. Como apuntó en su día Frank von Liszt (1882), la pena es «un arma de doble filo; tutela derechos por medio de la lesión de derechos». La aplicación de la pena impone a la colectividad costes elevados, no para producir beneficios, sino para producir ulteriores daños al reo, a su familia y a la propia colectividad, sin indemnizar el daño originalmente causado a la víctima o a la colectividad. El Derecho Penal juridifica fenómenos y comportamientos sociales per se irracionales, en cuanto contrarios al paradigma del bien social, y sus reglas, al contrario de lo que ocurre en otros sectores del Ordenamiento, no están concebidas para compensar el colosal desequilibrio económico del sistema, completamente volcado del lado de los costes. Ninguna elección, ni individual ni institucional, en el contexto del Derecho Penal se puede explicar por completo acudiendo únicamente a términos económicos, con un análisis de coste-beneficio, dado el profundo sentido ético que lo informa, por una parte (la orientación a valores es fundamental) ${ }^{26}$, y las necesidades psicosociales de pena ${ }^{27}$, por otra.

A ello se añade que la aplicación especular invertida de la ley de la oferta y la demanda al Derecho Penal no es sostenible. Como señala Paliero ${ }^{28}$, esta ley pretende explicar la distribución en el mercado de bienes que suponen una ventaja para los actores en el mercado -para todos, tanto para el productor como para los consumidores-.

25 Posner (2002) 363; Posner (1980) 413.

26 Como apuntan Lewin y Trumbull (1990) 271-284, el elemento normativo del Derecho Penal debe ser siempre tenido en consideración. Vid. también DAUSCHMIDT (1990)1-38.

27 Sobre la necesidad social de pena, Garland (1990).

28 PALIERo (2005) 1372. 
Presupone además un modelo de comportamiento dirigido a incentivar las decisiones relativas a los bienes, no a desincentivarlas.

Por el contrario, la lógica que subyace al «mercado de la pena» es justamente la inversa: en este mercado se distribuye un bien negativo -la pena-, que supone costes para todos y no aporta ningún beneficio, ni público ni privado. Es un mercado cuya lógica se orienta a deprimir, no a desarrollar sus propias dinámicas, y sobre todo a desincentivar tanto la demanda de pena -por parte del reo a través de su comportamiento criminal- como la oferta de pena -por parte del Estado-. Cierto es que en este mercado hay un beneficio final, representando por el mantenimiento del orden social gracias a la prevención de los delitos, pero este beneficio no es cuantificable, ergo no es apreciable en términos económicos. Para terminar, tanto el comportamiento del actor institucional como de los actores individuales en este mercado es, al menos en parte, y en algún caso completamente, inelástico, es decir, insensible a modificaciones en la cantidad y precio del bien ofrecido por el «mercado de la pena». Dicho brevemente, buena parte del comportamiento criminal no responde a los parámetros de una "elección racional», como nos indican los estudios criminológicos dedicados al estudio de la tipología criminal.

No solo existen crímenes pasionales, sino también subculturas criminales que no responden a una racionalidad económica. En ocasiones, incluso los delincuentes racionales por excelencia, las personas jurídicas, actúan de forma irracional. Así ocurre cuando la infracción surge de la ignorancia, o de la falta de capacidad técnica u organizativa de cumplimiento de la norma, con independencia del nivel de la multa. A ello se suma que hay indicios de que la maximización del beneficio puede no ser una explicación adecuada del comportamiento corporativo en absoluto, pues, por ej., el deseo de ascender de los gestores de nivel medio y alto y las luchas de poder entre grupos de accionistas en empresas cotizadas son motivaciones importantes ${ }^{29}$.

En segundo lugar, sigue siendo difícil determinar el nivel óptimo de la pena de multa. La mayoría de los delitos imputables a personas jurídicas son delitos socioeconómicos en sentido amplio, con una

29 Cfr. Levin (1983) 641. 
tasa muy baja de descubrimiento, y todavía menor de persecución y condena. La percepción de la amenaza que supone la imposición de la sanción refleja la probabilidad de que esta no se imponga. Hay que conocer y tener en cuenta este dato a la hora de determinar el importe idóneo de la multa, lo que explica que siga existiendo una amplia controversia al respecto ${ }^{30}$. En cualquier caso, existe bastante coincidencia en que el importe ha de ser considerable, dados los bajos niveles de descubrimiento y persecución de los delitos generalmente atribuidos a personas jurídicas ${ }^{31}$. Pero la previsión de multas suficientemente altas como para tener un efecto disuasivo puede impedir la supervivencia de las empresas a las que efectivamente se les aplique ${ }^{32}$ : se produce la llamada deterrence trap, esto es, la trampa de la disuasión ${ }^{33}$. Los efectos preventivos de la multa de nada sirven cuando la persona jurídica es incapaz de hacer frente a la pena.

Por otra parte, dado que la persona jurídica es distinta de las personas físicas que la dirigen, tampoco está claro si una multa elevada, pero de la que es destinataria la persona jurídica, tiene efectos disuasivos tanto sobre los representantes legales y administradores, que son los que más pueden verse directamente afectados en su carrera profesional por el estigma inherente al delito ${ }^{34}$, como

30 Cfr. Gruner (1997) 147-148; Heine (1999) 242 ss. En España son muy interesantes las propuestas de lege ferenda de Baucells Lladós (2013) 196 ss.

31 Cfr. Miller (1993) 204.

32 Cfr. Gruner (1997) 148.

33 Al respecto, es imprescindible Coffee (1981) 389 ss. Se trata de un efecto que se ha considerado únicamente predicable de la pena pecuniaria aplicable a la persona jurídica, puesto que en lo que respecta a la persona física siempre aparece la posibilidad de imponer una responsabilidad personal subsidiaria que implique la privación de libertad, lo que al afectar a la libertad personal añade un nuevo contenido con efectos preventivos. Cfr. de MAglie (2002) 162. En mi opinión, la imposición de la supervisión judicial durante el plazo que se otorgue a la persona jurídica para el pago de la multa puede tener en las personas jurídicas un efecto similar a la responsabilidad personal subsidiaria en las físicas.

34 En la doctrina se ha ido abandonando la posición que defendía que solo la persona física es capaz de advertir el efecto estigmatizante de la condena, que una estructura inanimada como la persona jurídica no puede percibir. Por ejemplo, Coffee (1981) 389. Hoy se sabe que la imagen es muy importante para las empresas cotizadas, que invierten ingentes cantidades de dinero en campañas publicitarias dirigidas a mejorarla. Vid. entre otros FISSE (1983) 1153. 
sobre los mandos intermedios, más preocupados por conseguir un ascenso a toda costa ${ }^{35}$.

Además, se ha indicado que la previsión de multas sobredimensionadas puede producir otros efectos indeseados, conocidos como overspill ${ }^{36}$, que pesan sobre terceros inocentes: fundamentalmente, acreedores, trabajadores y clientes o consumidores ${ }^{37}$.

La multa reduce el patrimonio de la entidad, y por tanto la garantía de cobro de los acreedores sociales ${ }^{38}$. Al disminuir su capacidad productiva, puede obligar a la persona jurídica a modificar su estrategia empresarial, reduciendo personal ${ }^{39}$. Por último, la multa se puede considerar un coste empresarial más ${ }^{40}$, que la persona jurídica puede trasladar a sus clientes y consumidores a través del aumento de los precios de sus productos y servicios.

Estas son críticas habituales, repetidas hasta la saciedad por los comentaristas. Sin embargo, en mercados muy competitivos no resulta fácil para las empresas aumentar los precios sin perder competitividad. Además, ¿no es razonable pensar que si la empresa hubiera podido aumentar los precios sin perder competitividad lo habría hecho antes, sin necesidad de esperar a la imposición de una

35 Cfr. Heine (1999) 244. Aunque los partidarios del análisis económico del Derecho suelen asumir que los factores individuales y organizativos interactúan, afectando el proceso de decisión, hay pocos estudios empíricos al respecto. Resulta excepcional a este respecto el trabajo de Vaughan (1996). Por su parte, PATERnOSTER y Simpson (1996) 549 ss., descubrieron que las consideraciones morales constituyen para administradores y directores una fuente importante de control social, hasta el punto de condicionar los efectos de factores más racionales. Solo en áreas en que se debilita la inhibición moral predominan las consideraciones de tipo instrumental.

36 «Cuando la persona jurídica se resfría, estornuda otro». CoffeE (1981) 401.

37 Cfr. Rush (1986) 455. No incluyo entre estos terceros inocentes a los socios y obligacionistas, pues tal y como se configura el modelo de imputación de responsabilidad penal a la persona jurídica en España son responsables, aunque no se les imponga directamente una sanción penal, de no haber ejercido el debido control sobre los representantes legales y administradores de hecho o de derecho de la entidad. Vid. sin embargo Coffee (1980) 6. Entiende que la multa no hace más que privar a los accionistas del enriquecimiento injusto que experimentaron con el delito, McAdams (1977) 994-995. A ello apuntan también Kreiner Ramírez (2005) 991 ss; de Maglie (2002) 347-348.

38 Cfr. Kennedy (1985) 455.

39 Coffee (1981) 401-402.

40 Al respecto, vid. ya Coffee (1981) 401-402; Levin (1983) 639; Orland (1980) 516. 
multa ${ }^{41}$ Por lo que respecta al efecto sobre los acreedores y trabajadores, conviene tener en cuenta que no hay pena que no imponga costes a terceros inocentes, y los apuntados no parecen desproporcionados, sobre todo porque cuando lo sean el Juez o Tribunal está obligado a considerarlos en el proceso de decidir la aplicación de las penas que corresponde imponer a la persona jurídica. Más preocupante me parece la constatación llevada a cabo en otros países de que los Jueces y Tribunales son reluctantes a imponer penas de multa de cuantía elevada a las personas jurídicas, precisamente para evitar esa supuesta afectación a terceros inocentes, lo que se conoce como nullification ${ }^{42}$.

\section{Conclusiones}

Al igual que en el caso de las penas imponibles a las personas físicas, existe un amplio debate doctrinal sobre los fines que han de cumplir las penas para personas jurídicas ${ }^{43}$. Además de su función preventivo-general, las penas para personas jurídicas tienen una clara vocación preventivo-especial, pues pretenden controlar o inocuizar, de forma temporal o definitiva, a una persona jurídica que ha revelado una especial peligrosidad a través de la comisión de delitos por sus dirigentes.

Esa peligrosidad de la persona jurídica se relaciona directamente con su incapacidad para organizarse de forma que sus administradores, representantes y empleados no cometan delitos, de manera que incentivar a la persona jurídica a adoptar medidas preventivas es uno de los objetivos fundamentales que ha de perseguir el sistema penal. Como hemos visto, ello lleva a los partidarios del análisis económico del Derecho a defender la multa como la sanción óptima para personas jurídicas, dado que estas tienden a actuar de forma racional, calculando costes y beneficios, de forma que una multa suficientemente elevada como para igualar el daño infligido a las víctimas, más los costes de la detección del delito y la condena habrá de tener necesariamente efectos preventivos.

41 Cfr. ya Cooter (1984) 1523 ss.

42 Cfr. Miller (1993) 207.

43 Vid. ampliamente Baucells Lladós (2013) 176 ss. 
Esta posición se basa, como se ha podido comprobar, en dos pilares fundamentales: la concepción de la persona jurídica de tipo empresarial como un ser racional y la convicción de que es posible calcular multas suficientemente disuasorias, que pueden ser pagadas por el destinario de la sanción sin afectar excesivamente a terceros inocentes. Ambos aspectos han sido objeto de críticas razonables.

A ello se suma que la multa por sí sola no motiva a la empresa a cambiar su organización interna en el sentido de implementar medidas eficaces para prevenir y descubrir los delitos que en el futuro pudieran cometerse con sus medios o bajo su cobertura ${ }^{44}$. De ahí la importancia de otras sanciones no pecuniarias que incidan sobre la organización interna de la persona jurídica. Es conveniente que la multa esté acompañada de sanciones no pecuniarias que eliminen la peligrosidad instrumental del ente y le incentiven u obliguen a reorganizarse de forma que pueda prevenir la comisión de delitos en el futuro.

A este respecto, la intervención se revela como una de las medidas con mayores posibilidades, siempre que en el reglamento pendiente de aprobación y en su aplicación práctica se configure como una suerte de probation corporativa que permita desde la remoción de administradores y directores a la imposición de nuevas estructuras organizativas orientadas a la prevención de delitos dentro de la empresa. Lo que desde luego no me parece adecuado centrar toda la atención en la existencia de programas de prevención de delitos. Algunos estudios apuntan a que estos programas se dirigen fundamentalmente a atenuar la responsabilidad penal, más que a conseguir una verdadera modificación de la conducta corporativa en orden a garantizar el cumplimiento de la ley en el futuro ${ }^{45}$.

En segundo lugar, hay que tener en cuenta, también, que la sola imposición de una multa a personas jurídicas no traslada a la sociedad la idea de que la conducta criminal es socialmente intolerable, sino que

44 Cfr. ya Stone (1975) 57. No faltan opiniones en contra, que sostienen que la multa es más apta que otras medidas, como la probation, para cumplir los fines de la pena. Así, Wray (1992) 2031 ss.

45 Por ejemplo, KRAWIeC (2003) 510 ss., quien destaca que la evidencia empírica sugiere que ni los códigos éticos ni los programas de cumplimiento son mecanismos efectivos para impedir "conductas socialmente indeseables dentro de las organizaciones»; McKendall (2002) 376-379. 
da la impresión de que el delito es aceptable siempre que la empresa pague el precio ${ }^{46}$, lo que disminuye la confianza de la comunidad.

Para terminar, debería evitarse la utilización de la multa como instrumento para privar a la persona jurídica delincuente de las ganancias obtenidas o que hubiera podido obtener. La multa no debería tener eso como objetivo principal. Hay otros instrumentos más apropiados para ello, como el decomiso penal, que ha evolucionado en los últimos años con el objetivo de «aligerar» la carga de la prueba con presunciones en contra del propietario y admitir el comiso por equivalencia, incluyendo reglas especiales en caso de delincuencia organizada. Cierto es que las dificultades todavía vinculadas a la naturaleza penal del decomiso han limitado su eficacia a la hora de reducir las ganancias provenientes del crimen. Tanto el número total de decomisos ejecutados como las sumas recuperadas se mantienen en niveles modestos ${ }^{47}$. Ello ha llevado a que también se esté probando en algunos países la vía civil ${ }^{48}$, siguiendo la Reco-

46 Cfr. Fisse (1990) 220; Kahan y Posner (1999) 380.

47 Así se afirma, entre otros documentos, en la Comunicación de la Comisión al Parlamento Europeo y al Consejo sobre «Productos de la delincuencia organizada. Garantizar que «el delito no resulte provechoso» », COM (2008) 766 final, Bruselas, 20.11.2008, p. 4.

48 En lo que respecta a la normativa internacional, la primera alusión directa a la posibilidad de que los Estados permitan la confiscación sin condena penal se encuentra en el art. 54 de la Convención de las Naciones Unidas contra la Corrupción (aprobada en Mérida en diciembre de 2003 y que entró en vigor el 14 de diciembre de 2005), según el cual «1. Cada Estado Parte, a fin de prestar asistencia judicial recíproca conforme a lo dispuesto en el artículo 55 de la presente Convención con respecto a bienes adquiridos mediante la comisión de un delito tipificado con arreglo a la presente Convención o relacionados con ese delito, de conformidad con su derecho interno: ... c) Considerará la posibilidad de adoptar las medidas que sean necesarias para permitir el decomiso de esos bienes sin que medie una condena, en casos en que el delincuente no pueda ser enjuiciado por motivo de fallecimiento, fuga o ausencia, o en otros casos apropiados». También se incluye una referencia en el art. 3.4 de la Decisión Marco 2005/212/JAI del Consejo, de 24 de febrero de 2005, relativa al decomiso de los productos, instrumentos y bienes relacionados con el delito, según el cual «los Estados miembros podrán recurrir a procedimientos distintos de los de carácter penal para privar al autor de la infracción de los bienes de que se trate». Con anterioridad otros textos internacionales ya abrían las puertas a la posibilidad de establecer mecanismos no penales de exigencia de responsabilidad. Vid., por ejemplo, el art. 10.2 de la Convención de Naciones Unidas contra la Delincuencia Organizada Transnacional, que señala que «con sujeción a los principios jurídicos del Estado Parte, la responsabilidad de las personas 
mendación 4 del Grupo de Acción Financiera Internacional (GAFI ${ }^{49}$. Figuras como la extinción del dominio ya no son infrecuentes en el panorama comparado ${ }^{50}$. Estos instrumentos deben ser suficientes, sin necesidad de que la multa se configure como un instrumento confiscatorio.

\section{Bibliografía}

\section{a) Doctrina}

ANDRIX, J. (2007): «Negotiated Shame: An Inquiry into the Efficacy of Settlement in Imposing Publicity Sanctions on Corporations», Cardozo Law Review, vol. 28, ํ 4: pp. 1857-1890.

BAucells Lladós, J. (2013): «Las penas previstas para la persona jurídica en la reforma penal de 2010. Un análisis crítico», Estudios Penales y Criminológicos, Vol. XXXIII: pp. 175-218.

Becker, G. (1974): «Crime and Punishment: An economic approach», en Becker, G. y Landes, W. (eds.): Essays in the Economics of Crime and Punishment (New York, Columbia University Press), pp. 1-54. Becker, G. (1976) The Economic Approach to Human Behavior (ChicagoLondon, University of Chicago Press).

Braithwaite, J. y Geis, G. (1982): «On Theory and Action for Corporate Crime Control», Crime and Delinquency, vol. 28: pp. 292-314.

Chambliss, W. J. (1967): «Types of Deviance and the Effectiveness of Legal Sanctions", Wisconsin Law Review, pp. 705-719.

Coffee, J. C. Jr. (1980): «Making the Punishment fit the Corporation: The Problem of Finding an Optimal Corporation Criminal Sanction", Northern Illinois University Law Review: pp. 3-36.

jurídicas [por participación en delitos graves en que esté involucrado un grupo delictivo organizado, así como por los delitos tipificados con arreglo a los arts. 5, 6, 8 y 23 de la Convención] podrá ser de índole penal, civil o administrativa».

49 La numeración se corresponde con el texto revisado en febrero de 2012, ya que anteriormente esta sugerencia se encontraba en la Recomendación 3. De acuerdo con el texto actual, «los países deben considerar la adopción de medidas que permitan que tales productos o instrumentos sean decomisados sin necesidad de condena penal (comiso no basado en una condena) o requieran a un delincuente para que demuestre el origen lícito de los activos eventualmente sujetos a comiso, en la medida en que tal requisito sea consistente con los principios de su derecho interno».

50 Vid. una amplia panorámica de la situación internacional en Young (2009) pássim. 
Coffee, J. C. Jr. (1981) « «No soul to damn: No body to kick»: An unscandalized inquiry into the problem of corporate punishment», Michigan Law Review, vol. 79, $\mathrm{N}^{\circ}$ 3: pp. 386-459.

Cohan, A. (1992): «Scarlet letters for the corporation? Punishment by publicity under the new sentencing guidelines", Southern California Law Review, vol. 65: pp. 2387-2420.

Cooter, R. (1984): «Prices and Sanctions», Columbia Law Review, vol. 84, $\mathrm{N}^{\circ}$ 6: pp. 1523-1560.

DAu-Schmidt, K. G. (1990): «An Economic Analysis of the Criminal Law as Preference Shaping Police», Duke Law Journal, $\mathrm{N}^{\circ}$ 1: pp. 1-38.

ENGelen, P.-J. (2003): «Can Reputational Damage Restrict Illegal Insider Trading?", European Journal of Crime, Criminal Law and Criminal Justice, vol. 11, $\mathrm{N}^{\circ}$ 3: pp. 253-263.

Ermann, M. D. y Rabe, G. A. (1997): «Organizational Processes (not rational choices) Produce most Corporate Crimes», en LofQuist, W., Cohen, M. y Rabe, G. (eds.): Debating Corporate Crime (Cincinnati, Anderson Publishing), pp. 53-67.

Faraldo Cabana, P. (2013): «¿Es la multa una pena apropiada para las personas jurídicas?», en Cuesta Arzamendi, J. L. de la y Pérez Machío, A. I. (Dirs.): Armonización penal en Europa (San Sebastián: IVAP), pp. 77-113.

Fisse, W. B. y BRAithwaite, J. (1983): The Impact of Publicity on Corporate Offenders (Albany, State University of New York Press).

FIsSE, W. B. (1981): «Community Service as a Sanction against Corporations», Wisconsin Law Review: pp. 970-1017.

Fisse, W. B. (1983): «Reconstructing Corporate Criminal Law: Deterrence, Retribution, Fault, and Sanctions", Southern California Law Review, vol. 56, $\mathrm{N}^{\circ}$ 6: pp. 1141-1246.

Fisse, W. B. (1990) «Sentencing options against corporations», Criminal Law Forum, vol. 1, N² 2, 1990: pp. 211-258.

Garland, D. (1990): Punishment and Modern Society (Oxford, Oxford University Press).

Grasmick, H. G. y Bursik, R. J. (1990): «Conscience, Significant Others, and Rational Choice: Extending the Deterrence Model», Law and Society Review, vol. 24, $\mathrm{N}^{\circ}$ 3: pp. 837-861.

GRUNER, R. (1997): «Structural sanctions: corporate sentences beyond fines», en Lofquist, W., Cohen, M. y Rabe, G. (eds.): Debating Corporate Crime (Cincinnati, Anderson Publishing), pp. 143-167.

Guerrini, R. (2006): La responsabilità da reato degli enti. Sanzioni e loro natura, (Milano, Giuffrè). 
HeInE, G. (1999): "Sanctions in the field of corporate criminal liability", en Eser, A. (ed.): Criminal responsibility of Legal and Collective Entities (Freiburg, Max-Planck-Institut für Ausländisches und Internationales Strafrecht) pp. 237-254.

Jüngel, M. (2011): Shame Sanctions - Wiedergeburt der Schandstrafe? Generalpräventive Publizität und materieller Strafbegriff (Langenfeld, Banana Wissensverlag).

Kahan, D. M. y Posner, E. A. (1999): «Shaming White-Collar Criminals: A Proposal for Reform of the Federal Sentencing Guidelines», Journal of Law \& Economics, vol. 41, No 2: pp. 365-391.

Kennedy, C. (1985): «Criminal Sentences for Corporations: Alternative Fining Mechanisms", California Law Review, vol. 73, $\mathrm{N}^{\circ}$ 2: pp. 443-482.

Krawiec, K. D. (2003): "Cosmetic Compliance and the Failure of Negotiated Governance», Washington University Law Quarterly, vol. 81, $\mathrm{N}^{\circ} 2$ : pp. 487-544.

Kreiner Ramirez, M. (2005): «The Science Fiction of Corporate Criminal Liability: Containing the Machine through the Corporate Death Penalty», Arizona Law Review, vol. 47: pp. 933-1002.

LAufer, W. S. (1994): «Corporate Bodies and Guilty Minds», Emory Law Journal, vol. 43: pp. 647-730.

Levin, M. H. (1983): "Corporate probation conditions: Judicial creativity or abuse of discretion?", Fordham Law Review, vol. 52, No 4: pp. 637-656.

Lewin, J. L. y Trumbull, W. N. (1990): «The Social Value of Crime?», International Review of Law and Economics, vol. 10, $\mathrm{N}^{\circ}$ 3: pp. 271-284.

LotT, J. R. Jr. (1992): «Do We Punish High Income Criminals Too Heavily?», Economic Inquiry, vol. 30, No 4: pp. 583-608.

Maglie, C. de (2002): L'etica e il mercato. La responsabilità penale delle società, (Milano, Giuffrè).

Maglie, C. de (2011) «Societas Delinquere Potest? The Italian Solution», en Pieth, M. e Ivory, R. (eds.): Corporate Criminal Liability. Emergence, Convergence, and Risk (Dordrecht, Springer) pp. 255-270.

Mapelli Caffarena, B. (2011): Las consecuencias jurídicas del delito, 5 ed. (Cizur Menor, Civitas).

McAdams, J. B. (1977): «The Appropriate Sanctions for Corporate Criminal Liability: An Eclectic Alternative», University of Cincinnati Law Review, vol. 46: pp. 989-1002.

McKendall, M., DeMarr, B. y Jones-Rikkers, C.: «Ethical Compliance Programs and Corporate Illegality: Testing the Assumptions of the Corporate Sentencing Guidelines", Journal of Business Ethics, vol. $37, \mathrm{~N}^{\circ} 4,2002$, pp. 367-383. 
Metzger, M. B. y Schwenk, C. R.: «Decision Making Models, Devil's Advocacy, and the Control of Corporate Crime», American Business Law Journal, vol. 28, $\mathrm{N}^{\circ}$ 3: pp. 323-377.

MilLER, E. H. (1993): «Federal Sentencing Guidelines for Organizational Defendants», Vanderbilt Law Review, vol. 46: pp. 197-234.

Nieto Martín, A. (2008): La responsabilidad penal de las personas jurídicas: un modelo legislativo, Madrid, iustel.

North, D. C. (1990): Institutions, Institutional Change and Economic Performance, Cambridge, Cambridge University Press.

Orland, L. (1980): «Reflections on Corporate Crime: Law in Search of Theory and Scholarship", American Criminal Law Review, vol. 17, $\mathrm{N}^{\circ}$ 3: pp. 501-520.

Ortiz de Urbina Gimeno, I. (2006): «El análisis económico del Derecho: ¿método útil, o ideología nefasta?», en CourTis, C. (coord.): Observar la ley (Madrid, Trotta), pp. 321-348.

Paliero, C. E. (2005): «L'economia della pena», Rivista Italiana di Diritto e Procedura Penale: pp. 1336-1401.

Paternoster, R. y Simpson, S. (1993): «A Rational Choice Theory of Corporate Crime», en Clarke, R. V. y Felson, M. (eds.): Routine Activities and Rational Choice: Advances in Criminological Theory. Volume 5 (New Brunswick: Transaction Publishers) pp. 37-58.

Paternoster, R. y Simpson, S. (1996) «Sanction Threats and Appeals to Morality: Testing a Rational Choice Model of Corporate Crime», Law and Society Review, vol. 30, $\mathrm{N}^{\circ}$ 3: pp. 549-584.

Pieth, M. e Ivory, R. (eds.): Corporate Criminal Liability: Emergence, Convergence, and Risks (Dordrecht, Springer).

Piliavin, I., Gartner, R., Thornton, C. y Matsueda, R.: «Crime, Deterrence, and Rational Choice", American Sociological Review, vol. 51, $\mathrm{N}^{\mathrm{o}}$ 1: pp. 101-119.

Polinsky, A. M. y Shavell, S. (1982): «The optimal use of fines and imprisonment», Journal of Public Economics, vol. 24, $\mathrm{N}^{\circ}$ 1: pp. 89-99.

Posner, R. A. (1980): «Optimal Sentences for White-Collar Criminals», American Criminal Law Review, vol. 17: pp. 409-418. Disponible en la página web https://chicagounbound.uchicago.edu/cgi/viewcontent. cgi? referer=https://www.google.de/\&httpsredir=1\&article=2842\&c ontext=journal_articles

Posner, R. A. (2002) Economic Analysis of Law, 6 ed. (New York, Aspen Publishers).

Ransiek, A. (2016): "Criminal Sanctions Against Corporations», en PAHA, J. (Ed.): Competition Law Compliance Programmes. An Interdisciplinary Approach (Cham, Springer), pp. 123-134 
Rush, F. L. (1986): "Corporate Probation: Invasive Techniques for Restructuring Institutional Behavior», Suffolk University Law Review, vol. 21, $\mathrm{N}^{\circ}$ 1: pp. 33-90.

Simpson, S. (2002): Corporate Crime, Law and Social Control, (Cambridge: Cambridge University Press).

Stone, C. D. (1975): Where the Law Ends. The Social Control of Corporate Behavior (New York, Harper \& Row).

Tiedemann, K.: Poder económico y delito (Barcelona, Ariel).

Ulen, T. S. (1997): «The Economic Case for Corporate Criminal Sanctioning», en Lofquist, W., Cohen, M. y Rabe, G. (eds.): Debating Corporate Crime (Cincinnati, Anderson Publishing) pp. 119-141.

Vaughan, D. (1996): The Challenger Launch Decision (Chicago, University of Chicago Press).

Waldvogel, J. (1994): «Does Conviction Have a Persistent Effect on Income and Employment?", International Review of Law and Economics, vol. 14, $\mathrm{N}^{\circ}$ 1: pp. 103-119.

Wray, C.A. (1992): "Corporate Probation under the New Organizational Sentencing Guidelines», The Yale Law Journal, vol. 101, No 8: pp. 2017-2042.

Young, N. M. (ed.) (2009): Civil Forfeiture of Criminal Property. Legal Measures for Targeting the Proceeds of Crime (Cheltenham, Edward Elgar). 


Este libro se terminó de imprimir en Santiago de Chile, marzo de 2020

Teléfono: 222238100 / ril@ rileditores.com

Se utilizó tecnología de última generación que reduce el impacto medioambiental, pues ocupa estrictamente el papel necesario para su producción, y se aplicaron
altos estándares para la gestión y reciclaje de desechos altos estándares para la gestión y reciclaje de
en toda la cadena de producción. 
ste libro contiene los valiosos aportes de profesionales y académicos, nacionales y extranjeros, presentados en el evento que, con el mismo nombre, organizó el Centro de Regulación y Consumo y el Instituto de Investigaciones en Derecho de la Universidad Autónoma de Chile el pasado 6 de diciembre de 2018.

La primera parte contiene artículos del Derecho de Consumo y, en particular, se desarrollan temas como la atribución de competencias del Sernac; el análisis de las cláusulas del no-show, la responsabilidad por productos sanitarios defectuosos; el estudio del impacto del etiquetado de alimentos; sharing economy, prosumer y derecho del consumidor; el ombudsman sectorial en el consumo en general y en los servicios básicos en particular; el rol de la carga de la prueba en el procedimiento de los Juzgados de Policía Local; la cosa juzgada y la insuficiencia de pruebas en procesos colectivos; la protección del consumidor de crédito inmobiliario europeo; las consideraciones desde el Derecho civil sobre el Derecho de Consumo y las acciones colectivas indemnizatorias, así como los avances del Derecho del Consumidor en Brasil.

La segunda parte muestra trabajos referidos al Derecho Regulatorio tales como las reflexiones sobre la regulación económica desde la teoría evolutiva de las instituciones; las concentraciones mediáticas en Chile y el pluralismo informativo; la regulación ambiental y financiera de la minería en los suelos y subsuelos marinos; la consulta indígena y centrales de generación hidroeléctrica de menos de $3 \mathrm{Mw}$; la regulación de la educación en el Estado garante y las ventajas y desventajas de la multa como sanción penal para personas jurídicas. 